Universidade de São Paulo

Escola de Engenharia de São Carlos

\title{
Avaliação de Camadas de Proteção para Geomembranas de PVC e PEAD
}

\author{
Karla Maria Wingler Rebelo
}

Tese apresentada à Escola de Engenharia de São Carlos da Universidade de São Paulo, como parte dos requisitos para obtenção do título de Doutor em Geotecnia.

ORIENTADOR: Prof. Dr. Orencio Monje Vilar.

São Carlos

2009 
Dedico esta tese à minha família, em especial a o meu estima do pai e minha adorável mãe. 
À Fundação de Amparo e Pesquisa do Estado de São Paulo (FAPESP), pelo auxílio que viabilizou todo o andamento da pesquisa.

À Coordenação de Aperfeiçoamento de Pessoal de Nível Superior (CAPES), pela concessão da bolsa de estudos.

À Empresa Ober, pela doação dos geotêxteis indispensáveis ao andamento da pesquisa. Em especial ao Engenheiro Carlos Vinicius por toda a atenção prestada.

À Empresa Sansuy, pela cooperação no fornecimento das geomembranas de PVC, indispensáveis ao andamento da pesquisa.

À empresa Etclass do Brasil, pelo empréstimo do aparelho de detecção de descontinuidade (Spark Test) e pelo treinamento de sua utilização.

Ao Departamento de Transportes, pela estrutura física na realização de ensaios de laboratório, em especial, ao Professor Dr. Glauco.

À Prefeitura do Campus da Escola de Engenharia de São Carlos, pela concessão da área utilizada na construção do aterro experimental.

Ao Departamento de Geotecnia e ao Laboratório de Geossintéticos da Escola de Engenharia de São Carlos, pela estrutura física necessária durante o andamento da pesquisa.

A todos os professores do Departamento de Geotecnia, pela contribuição pessoal e profissional.

A todos os funcionários do Departamento de Geotecnia, pelo apoio técnico e pela boa convivência. Em especial aos técnicos Oscar, José Luis, Clever, Dito e Antônio, e aos 
funcionários Maristela, Álvaro, Neiva e Herivelto pelo auxílio em todos as etapas do doutorado, pela presteza e pelo companheirismo.

A todos os colegas do Departamento de Geotecnia, pela boa convivência durante todos estes anos.

Aos infindáveis amigos que fiz aqui em São Carlos, agradeço pelo apoio incondicional. Não poderia deixar de citar meus queridos amigos: Neiva, Juliana / Marieli, Jeferson, Giulliana, Karina (Ká), Rodrigo (Rô), Ivan, Eduardo Amaral, Oscar, Maristela. "Fácil é ser colega, fazer companhia a alguém, dizer o que ele deseja ouvir. Difícil é ser amigo para todas as horas e dizer sempre a verdade quando for preciso. E com confiança no que diz." (C. Drummond de Andrade).

Ao professor Edmundo Esquivel, pela presteza e amizade durante os anos de convivência.

Ao professor Cintra, pela apreciável amizade que se estende desde os tempos de mestrado.

Ao meu orientador, mestre e amigo, Orencio Monje Vilar, pela orientação do trabalho, pelos ensinamentos, pela amizade, pelo companheirismo e pela compreensão em todos os momentos.

Aos meus irmãos, Wagner, Viniccius e Victor, pelo amor e apoio à distância. Aos meus pais, Marizéa e Vagner (eternamente presente na minha vida), pelo incentivo, pelo amor incondicional, pelos esforços e, principalmente, pelo exemplo de caráter. 
"Sonhe com aquilo que você quiser. Seja o que você querser, porque você possui apenas uma vida e nela só se tem uma chance de fazer aquilo que se quer. Tenha felicidade bastante para fazê-la doce.

Dificuldades para fazê-la forte.

Tristeza para fazê-la humana

Eesperança suficiente para fazê-la feliz. As pessoas ma is felizes não têm as melhores coisas. Elas sa bem fazer o melhor das oportunida des que a parecem em seus ca minhos. A felicidade aparece para aquelesque choram.

Para aquelesque se machucam.

Para aqueles que buscam e tentam sempre E para aqueles que reconhecem a importância daspessoas que passam porsuas vidas. O futuro mais brilhante é baseado num passado intensamente vivido. Você só terá sucesso na vida quando perdoarosemos e as decepções do passado. A vida é curta, mas as emoções que podemos deixar duram uma etemidade... "

(C. Lispector) 



\section{SUMÁRIO}

LISTA DE FIGURAS ___ $i$

LISTA DE TABELAS __ vii

LISTA DE SIGLAS E ABREVIATURAS ___ ix

LISTA DE SÍMBOLOS___ $\mathrm{x}$

RESUMO _ $x i$

ABSTRACT__ Xii

CAPÍTULO 1 INTRODUÇÃO____ 1

CAPÍTULO 2. REVISÃO BIBLIOGRÁFICA _ 5

2.1. Introdução: Resíduos Sólidos, Aspectos Gerais e Formas de Disposição ___ 5

2.2. Geomembranas _ 10

2.2.1. Aspectos Gerais — 10

2.2.2. Polímeros 14

2.3. Geotêxteis —_ 27

2.4. Proteção de Geomembranas___ 30

2.4.1. Danos Mecânicos em Geomembranas__ 30

2.4.2. Desempenho de Camadas de Proteção __ 39

2.4.3. Ensaios de Danos Mecânicos em Geomembranas ___ 65

2.5. Considerações Finais __ 72

CAPÍTULO 3. MATERIAIS E MÉTODOS___ 75

3.1. Descrição dos Materiais___ 75

3.1.1. Geossintéticos —— 75

3.1.2. Solos e Agregados___ 76

3.2. Ensaios de Laboratório para Avaliação das Camadas de Proteção ___ 77

3.2.1. Ensaios Índices __ 78

3.2.2. Ensaios de Desempenho - Dano de Instalação ___ 82

3.3. Ensaios de Danos de Instalação em Grande Escala - Ensaio de Campo ___ 83

3.3.1. Procedimento de Campo ___ 84

3.3.2. Ensaios Não Destrutivos para Detecção de Furos em Geomembranas ___ 97

3.3.3. Critério para Estimar o Desempenho de Camadas de Proteção para Geomembranas ___ 99

3.4. Ensaios Pós-Danos Realizados nas Geomembranas para Avaliação das Camadas de Desempenho 101

3.4.1. Ensaios Mecânicos __ 102

3.4.2. Ensaio de Fissuramento sob Tração (Stress cracking) _ـ_ 107

3.4.3. Ensaio Hidráulico - Permeabilidade por Transmissividade ao Vapor d'Água ___ 110

CAPÍTULO 4. APRESENTAÇÃO E ANÁLISE DOS RESULTADOS__ 111

4.1. Ensaios de Caracterização dos Materiais ___ 111

4.1.1. Geossintéticos _ 111 
4.2. Ensaios de Laboratório___ 116

4.1.1. Ensaios Índices __ 116

4.1.2. Ensaios de Desempenho: Danos de Instalação ___ 138

4.2. Ensaios de Campo___ 157

4.2.1. Geomembranas de PEAD__ 157

4.2.2. Geomembranas de PVC__ 196

4.3. Avaliação do Desempenho dos Materiais de Proteção para Ensaios de Campo segundo o CFG (2001) _ 219

4.4. Comparação entre os Resultados dos Ensaios de Laboratório e de Campo ___ 222

4.4.1. Ensaios de Campo versus Ensaios Índice___ 222

4.4.2. Ensaios de Campo versus Ensaios Cíclicos___ 223

4.5. Comparação dos Resultados de Campo com os Dados e Métodos da Literatura___ 226

4.5.1. Análise dos Danos de Instalação: Comparação com Reddy et al. (1996) ___ 226

4.5.2. Metodologia proposta por Badu et al.(1998) ___ 229

4.5.3. Metodologia proposta baseada no desempenho a curto prazo (Narejo et al, 1996) __ 230

CAPÍTULO 5. CONCLUSÃo__ 235

5.1. Sugestão para Futuras Pesquisas___ 239

Referências Bibliográficas____ 241 


\section{LISTA DE FIGURAS}

Figura 1. Percentual da geração de resíduos sólidos por região brasileira (PNSB, 2000). 6

Figura 2. Evolução do destino final dos resíduos brasileiros.

Figura 3. Configurações típicas de barreiras impermeáveis (KOERNER, 1998). __ 9

Figura 4. Monômeros dos polímeros mais comuns (AGNELLI, 2000). __ 14

Figura 5. Ilustração da estrutura linear.__ 17

Figura 6. Ilustração da estrutura ramificada. _ـ 18

Figura 7. Ilustração da estrutura reticulada. 19

Figura 8. Estrutura lamelar do PEAD (HSUAN, 2000). __ 22

Figura 9. Stress cracking: (a) na borda de uma emenda (HSUAN, 2000); (b) propagação rápida (PEGGS, 1988). 23

Figura 10. Detalhes da ranhura feito nos CP's utilizados no ensaio NCLT: (a) dimensões da ranhura; (b) foto microscópica da ranhura. _ 24

Figura 11. Curvas obtidas através do método de ensaio NCLT (HSUAN AND KOERNER, 1998).__ 25

Figura 12. Tipos de fibras: geotêxteis tecidos: (a) monofilamentos; (b) multifilamentos; (c) laminetes; (d) fibrilas (BHATIA \& SMITH, 1996). _ 28 Figura 13. Exemplos de geotêxteis tecidos (BHATIA \& SMITH, 1996).___ 28

Figura 14. Exemplos de estruturas de geotêxteis não tecidos (BHATIA \& SMITH, 1996). ___ 29

Figura 15. Ilustração do ensaio do jato ou poça d'água (CFG, 2003; LOPES, 2006).__ 35

Figura 16. Ilustração do ensaio da Faísca (CFG, 2003; LOPES, 2006). ___ 36

Figura 17. Ilustração do ensaio com sistema fixo de deteç̧ão e localização de furos (CFG, 2003; LOPES, 2006). 37

Figura 18. Ilustração do ensaio da geomembrana condutora (CFG, 2003; LOPES, 2006). __ 38

Figura 19. Ilustração do ensaio da sonda móvel (CFG, 2003; LOPES, 2006). 39

Figura 20. Geometria utilizada na análise de punção em geomembranas (WILSON-FAHMY ET AL., 1996). __ 42

Figura 21. Forma deformada da geomembrana sob aumento de pressão (WILSON-FAHMY ET AL., 1996). _ 45

Figura 22. Mecanismo de carregamento (a) estágio de compressão inicial do geotêxtil; (b) Deformação da geomembrana e compressão do geotêxtil (JONES ET AL. 2000).

Figura 23. Área com ausência de geotêxtil (SNOW ET AL., 1999).__ 64

Figura 24. Perfurações observadas nas geomembranas (SNOW ET AL., 1999). ___ 64

Figura 25. Ensaio de punção hidrostática com cones truncados (GEROTO, 2003).__ 68

Figura 26. Esquema do ensaio do cilindro (GALLAGHER ET AL., 1999). _ 70

Figura 27. Ensaio de punção estática: (a) arranjo do corpo de prova; (b) vista geral. ___ 78

Figura 28. Ensaio de punção estática: introdução de base de solo compactado. __ 79

Figura 29. Ensaio de punção dinâmica: (a) arranjo do corpo de prova; (b) vista geral.

Figura 30. Ensaio de dano de instalação: (a) vista geral do equipamento; (b) detalhe da caixa.___ 83

Figura 31. Escavação da área. __ 85

Figura 32. Preparação da base. ___ 86

Figura 33 (Continua). Detalhes do processo de compactação da base. ___ 87

Figura 34. Controle de compactação no campo - método do cilindro de cravação.___ 89

Figura 35. Instalação das geomembranas. __ 92

Figura 36. Identificação das geomembranas. ___ 93

Figura 37. Instalação das camadas de proteção. ___ 94

Figura 38 (Continua). Construção da camada de drenagem. ___ 95

Figura 39. Retirada da brita. _ـ 96

Figura 40. Esquema do princípio do ensaio de Spark Test. ___ 98

Figura 41. Realização do Spark Test em campo. ___ 99

Figura 42. Detalhes do equipamento do Spark Test. ___ 99

Figura 43. Ensaio do ensaio de tração: (a) normal; (b) faixa larga. 103

Figura 44. Ilustração do ensaio de rasgo em geomembrana de PEAD. 103 
Figura 45. Ilustração do ensaio de tração multiaxial. 105

Figura 46. Vista do equipamento de FST: (a) vista frontal; (b) vista lateral do ensaio em andamento. ___ 108 Figura 47. Ensaio de fissuramento sob tração (stress cracking): (a) detalhes da ranhura; (b) moldes para corte do corpo de prova. 108 Figura 48. Ilustração de algumas configurações com corpo de prova sem ranhura. 109 Figura 49. Ensaio de transmissividade ao vapor em geomembranas. ___ 110 Figura 50. Curva granulométrica do solo. 114 Figura 51. Resultado do ensaio de índice de forma: (a) brita 1; (b) brita 3. Figura 52. Curva granulométrica dos agregados. _ 116 Figura 53. Curvas de punção - geomembrana de PVC, 1,Omm - GT/GM, GT PET. __ 117 Figura 54. Curvas de punção - geomembrana de PVC, 1,0mm - GT/GM, GT PP. __ 117 Figura 55. Curvas de punção - geomembrana de PEAD, 1,5 mm - GT/GM, GT PET. ___ 117 Figura 56. Curvas de punção - geomembrana de PEAD, 1,5 mm - GT/GM, GT PP. — 118 Figura 57. Curvas de punção - geomembrana de PELMD, 1,25 mm - GT/GM, GT PET.___ 118 Figura 58. Curvas de punção - geomembrana de PELMD, 1,25 mm - GT/GM, GT PET. __ 118 Figura 59. Efeito da gramatura na resistência à punção - GT sobre GM. — 121 Figura 60. Efeito da gramatura na resistência à punção - GM sobre GT. — 121 Figura 61. Efeito da gramatura na resistência à punção $-G T / G M / G T$. _ـ 122 Figura 62. Influência das características do geotêxtil. ___ 123 Figura 63. Influência das características de tração da geomembrana e do geotêxtil no aumento na força de punção. 124 Figura 64. Influência da espessura - sistema GT/GM, GT PET $300 \mathrm{~g} / \mathrm{m}^{2}$. 125

Figura 65. Influência da espessura - sistema GT/GM, GT PET $300 \mathrm{~g} / \mathrm{m}^{2}$. 127

Figura 66. Efeito da disposição dos geotêxteis na resistência à punção do sistema.__ 128

Figura 67. Análise do efeito da introdução de base de solo compactado: GMs de PVC. 129 Figura 68. Análise do efeito da introdução de base de solo compactado: GMs de PEAD. __ 129 Figura 69. Análise do efeito da introdução de base de solo compactado: GMs de PELMD. Figura 70. Resultados obtidos no ensaio de punção dinâmica - geomembrana de PVC, 1, $0 \mathrm{~mm}$ - GT/GM. _ 131 Figura 71. Resultados obtidos no ensaio de punção dinâmica - geomembrana de PEAD, 1,5 mm - GT/GM. _ 131 Figura 72. Resultados obtidos no ensaio de punção dinâmica - geomembrana de PELMD, 1,25 mm - GT/GM. 132 Figura 73. Efeito do polímero nas geomembranas de PVC (1,0mm) e PEAD (1,5mm). __ 133 Figura 74. Análise dos ensaios realizados com geomembrana de PVC, 1,0mm: efeito da disposição. ___ 134 Figura 75. Análise dos ensaios realizados com geomembrana de PEAD, 1,5mm: efeito da disposição. __ 135 Figura 76. Análise dos ensaios realizados com geomembrana de PELMD, 1,25mm: efeito da disposição.__ 136 Figura 77. Influência da camada de solo compactado - GT PET 300g/m². 137 Figura 78. Vista da superfície da geomembrana de PEAD $(1,5 \mathrm{~mm})$. ___ 138 Figura 79. Curvas obtidas nos ensaios de punção para geomembrana de PEAD - carga de $200 \mathrm{kPa}$ ___ 139 Figura 80. Curvas obtidas nos ensaios de punção para geomembrana de PEAD - carga de $400 \mathrm{kPa}$. ___ 140 Figura 81. Curvas obtidas nos ensaios de rasgo para geomembrana de PEAD - carga de $200 \mathrm{kPa}$.___ 140 Figura 82. Curvas obtidas nos ensaios de rasgo para geomembrana de PEAD - carga de $400 \mathrm{kPa}$.___ 141 Figura 83. Curvas obtidas nos ensaios de tração para geomembrana de PEAD - carga de $200 \mathrm{kPa}$.___ 141 Figura 84. Curvas obtidas nos ensaios de tração para geomembrana de PEAD - carga de $400 \mathrm{kPa}$. ___ 142 Figura 85. Resultados dos ensaios de punção realizados nas geomembranas de PEAD com proteção: ensaios cíclicos.

Figura 86. Resultados dos ensaios de rasgo realizados nas geomembranas de PEAD com proteção: ensaios cíclicos. 144 Figura 87. Resultados dos ensaios de tração realizados nas geomembranas de PEAD com proteção: ensaios cíclicos / valores no escoamento. 145 Figura 88. Resultados dos ensaios de tração realizados nas geomembranas de PEAD com proteção: ensaios cíclicos / valores na ruptura. 145 Figura 89. Curvas obtidas no ensaio de stress cracking: GM de PEAD 1,5 mm. _ 146 Figura 90. Vista da superfície da geomembrana de PVC $(1,0 \mathrm{~mm})$. __ 148 Figura 91. Curvas obtidas nos ensaios de punção para geomembrana de PVC - $200 \mathrm{kPa}$.__ 149 Figura 92. Curvas obtidas nos ensaios de punção para geomembrana de PVC $-400 \mathrm{kPa}$ —_ 150 Figura 93. Curvas obtidas nos ensaios de rasgo para geomembrana de PVC - $200 \mathrm{kPa}$.___ 150 Figura 94. Curvas obtidas nos ensaios de rasgo para geomembrana de PVC $-400 \mathrm{kPa}$.__ 151 Figura 95. Curvas obtidas nos ensaios de tração para geomembrana de PVC - $200 \mathrm{kPa}$ __ 151 
Figura 96. Curvas obtidas nos ensaios de tração para geomembrana de PVC - 400 kPa.

Figura 97. Resultados dos ensaios de punção realizados nas geomembranas de PVC: ensaios cíclicos.

Figura 98. Resultados dos ensaios de rasgo realizados nas geomembranas de PVC: ensaios cíclicos.

Figura 99. Resultados dos ensaios de tração realizados nas geomembranas de PVC: ensaios cíclicos.

Figura 100. Resultados dos ensaios de transmissividade ao vapor (permeabilidade) em geomembranas de PVC.

Figura 101. Danos visuais: GM de PEAD de 1,5 $\mathrm{mm}$ sem proteção e brita 3.

Figura 102. Danos visuais: GM de PEAD de $1,5 \mathrm{~mm}$ com GT PET $300 \mathrm{~g} / \mathrm{m}^{2}$ e brita 3 .

Figura 103. Danos visuais: GM de PEAD de $1,5 \mathrm{~mm}$ com GT PET $600 \mathrm{~g} / \mathrm{m}^{2}$ e brita 3 .

Figura 104. Danos visuais: GM de PEAD de $1,5 \mathrm{~mm}$ com GT PP $600 \mathrm{~g} / \mathrm{m}^{2}$ e brita 3.

Figura 105. Danos visuais: GM de PEAD de $1,5 \mathrm{~mm}$ com GT PET $1200 \mathrm{~g} / \mathrm{m}^{2}$ e brita 3 .

Figura 106. Danos visuais: GM de PEAD de 1,5 mm com camadas naturais e brita 3: (a) areia; (b) solo. ___ 160

Figura 107. Danos visuais: GM de PEAD de 2,0 mm sem proteção e brita 3.

Figura 108. Danos visuais: GM de PEAD de 1,5 mm sem proteção e brita 1.

Figura 109. Danos visuais: GM de PEAD de $1,5 \mathrm{~mm}$ com GT PET $300 \mathrm{~g} / \mathrm{m}^{2}$ e brita 1.

Figura 110. Danos visuais: GM de PEAD de $1,5 \mathrm{~mm}$ com GT PET $600 \mathrm{~g} / \mathrm{m}^{2}$ e brita 1 .

Figura 111. Danos visuais: GM de PEAD de $1,5 \mathrm{~mm}$ com GT PET $1200 \mathrm{~g} / \mathrm{m}^{2}$ e brita 1.

Figura 112. Danos visuais: GM de PEAD de 1,5 mm com camadas naturais e brita 1: (a) areia; (b) solo. ___ 162

Figura 113. Resultados dos ensaios de tração em faixa larga: GM de PEAD de 1,5 mm sem proteção / brita 3.

Figura 114. Resultados dos ensaios de tração em faixa larga - GM de PEAD e GTPET $300 \mathrm{~g} / \mathrm{m}^{2} / \mathrm{brita} 3$.

Figura 115. Resultados dos ensaios de tração em faixa larga - GM de PEAD e GT PET $600 \mathrm{~g} / \mathrm{m}^{2} /$ brita 3.

Figura 116. Resultados dos ensaios de tração em faixa larga - GM de PEAD e GTPP $600 \mathrm{~g} / \mathrm{m}^{2} / \mathrm{brita} 3$. _ 165

Figura 117. Resultados dos ensaios de tração em faixa larga - GM de PEAD e GT PET $1200 \mathrm{~g} / \mathrm{m}^{2} / \mathrm{brita} 3$. _ 166

Figura 118. Resultados dos ensaios de tração em faixa larga - GM de PEAD e areia / brita 3. ___ 166

Figura 119. Resultados dos ensaios de tração em faixa larga - GM de PEAD e solo / brita 3.____ 167

Figura 120. Resultados dos ensaios de tração em faixa larga - GM de PEAD de 2,0 mm sem proteção / brita 3.

167

Figura 121. Resultados dos ensaios de tração em faixa larga - GM de PEAD de 1,5 mm sem proteção / brita 1.

168

Figura 122. Resultados dos ensaios de tração em faixa larga - GM de PEAD e GT PET $300 \mathrm{~g} / \mathrm{m}^{2} / \mathrm{brita} 1$.__ 168

Figura 123. Resultados dos ensaios de tração em faixa larga - GM de PEAD e GT PET $600 \mathrm{~g} / \mathrm{m}^{2} / \mathrm{brita} 1$. _ 169

Figura 124. Resultados dos ensaios de tração em faixa larga - GM de PEAD e GT PET $1200 \mathrm{~g} / \mathrm{m}^{2} / \mathrm{brita} 1$. _ 169

Figura 125. Resultados dos ensaios de tração em faixa larga - GM de PEAD e areia / brita 1 . ___ _ _ 170

Figura 126. Resultados dos ensaios de tração em faixa larga - GM de PEAD e solo / brita 1. ___ 170

Figura 127 (Continua). Mecanismo de ruptura nos ensaios de tração em faixa larga - GM de PEAD. ___ 171

Figura 128. Resultados de tração em faixa larga - GM de PEAD e brita 3: (a) escoamento; (b) ruptura. __ 174

Figura 129. Resultados de tração em faixa larga - GM de PEAD e brita 1: (a) escoamento; (b) ruptura. __ 175

Figura 130. Resultados dos ensaios de tração multiaxial - GM de PEAD de 1,5 mm virgem.____ 178

Figura 131. Resultados dos ensaios de tração multiaxial - GM de PEAD de 1,5 mm sem proteção / brita 3 . _ 179

Figura 132. Resultados dos ensaios de tração multiaxial - GM de PEAD de $1,5 \mathrm{~mm}$ e GT PET $300 \mathrm{~g} / \mathrm{m}^{2} / \overline{b r i t a} 3$.

179

Figura 133. Resultados dos ensaios de tração multiaxial - GM de PEAD de $1,5 \mathrm{~mm}$ e GT PET $600 \mathrm{~g} / \mathrm{m}^{2} / \mathrm{brita} 3$. 180

Figura 134. Resultados dos ensaios de tração multiaxial - GM de PEAD de $1,5 \mathrm{~mm}$ e GT PET $1200 \mathrm{~g} / \mathrm{m}^{2} / \mathrm{brita}^{2}$. 180

Figura 135. Resultados dos ensaios de tração multiaxial - GM de PEAD de 1,5 mm e camada de areia/ brita 3.

Figura 136. Resultados dos ensaios de tração multiaxial - GM de PEAD de 1,5 mm e camada de solo/ brita 3.

Figura 137. Resultados dos ensaios de tração multiaxial - GM de PEAD de 1,5 mm sem proteção / brita 1 . _ 182 Figura 138. Resultados dos ensaios de tração multiaxial - GM de PEAD de $1,5 \mathrm{~mm}$ e GT PET $300 \mathrm{~g} / \mathrm{m}^{2} / \overline{b r i t a} 1$.

Figura 139. Resultados dos ensaios de tração multiaxial - GM de PEAD de $1,5 \mathrm{~mm}$ e GT PET $600 \mathrm{~g} / \mathrm{m}^{2} / \mathrm{brita} 1$.

Figura 140. Resultados dos ensaios de tração multiaxial - GM de PEAD de $1,5 \mathrm{~mm}$ e GT PET $1200 \mathrm{~g} / \mathrm{m}^{2} / \mathrm{brita} 1$. 
Figura 141. Resultados dos ensaios de tração multiaxial - GM de PEAD de 1,5 mm e camada de areia / brita 1. 184

Figura 142. Resultados dos ensaios de tração multiaxial - GM de PEAD de 1,5 mm e camada de solo / brita 1. 184

Figura 143. Resultados de tração multiaxial - GM de PEAD 1,5 $\mathrm{mm}$. 185

Figura 144. Modo de ruptura nos ensaios de tração multiaxial: GM PEAD 1,5 mm / brita3. 187

Figura 145. Modo de ruptura nos ensaios de tração multiaxial: GM PEAD 1,5 mm / brita1.___ 188

Figura 146. Resultados do ensaio de stress cracking: (a) CPs com ranhura; (b) CPs sem ranhura. ___ 190

Figura 147. Resultados dos ensaios de tração em faixa larga em função do diâmetro dos agregados: GM de PEAD. 193 Figura 148. Resultados dos ensaios de tração multiaxial em função do diâmetro dos agregados: GM de PEAD. 194

Figura 149. Resultados dos ensaios de stress cracking em geomembranas de PEAD em função do diâmetro dos agregados: $C P^{\prime}$ s sem ranhura. 195

Figura 150. Danos visuais: GM de PVC de 1,0 mm sem proteção e brita 3. 197

Figura 151. Danos visuais: GM de PVC de 1,0 mm com GT PET $300 \mathrm{~g} / \mathrm{m}^{2}$ e brita 3. 197 Figura 152. Danos visuais: GM de PVC de $1,0 \mathrm{~mm}$ com GT PET $600 \mathrm{~g} / \mathrm{m}^{2}$ e brita 3 . Figura 153. Danos visuais: GM de PVC de $1,0 \mathrm{~mm}$ com GT PP $600 \mathrm{~g} / \mathrm{m}^{2}$ e brita 3. 198 Figura 154. Danos visuais: GM de PVC de $1,0 \mathrm{~mm}$ com GT PET $1200 \mathrm{~g} / \mathrm{m}^{2}$ e brita 3.199 Figura 155. Danos visuais: GM de PVC de 1,0 mm com camadas naturais e brita 3.__ 199 Figura 156. Danos visuais: GM de PVC de 2,0 mm sem proteção e brita 3 . ___ 199 Figura 157. Danos visuais: GM de PVC de 1,0 mm sem proteção e brita 1. Figura 158. Danos visuais: GM de PVC de 1,0 mm com GT PET $600 \mathrm{~g} / \mathrm{m}^{2}$ e brita 1. Figura 159. Danos visuais: GM de PVC de 1,0 mm com camadas naturais e brita 1: (a) areia; (b) solo.___ 200 Figura 160. Danos visuais: GM de PVC de 1,0 mm com geocomposto. __ 201 Figura 161. Resultados dos ensaios de tração em faixa larga: GM de PVC de 1,0 mm sem proteção / brita 3.203 Figura 162. Resultados dos ensaios de tração em faixa larga - GM de PVC de 1,0 mm e GT PET $300 \mathrm{~g} / \mathrm{m}^{2} / \mathrm{brita}$ 3. 203 Figura 163. Resultados dos ensaios de tração em faixa larga - GM de PVC de 1,0 mm e GT PET $600 \mathrm{~g} / \mathrm{m}^{2} / \mathrm{brita}$ 3.__ 204 Figura 164. Resultados dos ensaios de tração em faixa larga-GM de PVC de 1,0 mm e GT PP $600 \mathrm{~g} / \mathrm{m}^{2} / \mathrm{brita} 3$. 204 Figura 165. Resultados dos ensaios de tração em faixa larga-GM de PVC de 1,0 mm e GT PET $1200 \mathrm{~g} / \mathrm{m}^{2} / \mathrm{brita}$ 3. 205

Figura 166. Resultados dos ensaios de tração em faixa larga - GM de PVC de 1,0 mm e camada de areia / brita 3. 205

Figura 167. Resultados dos ensaios de tração em faixa larga-GM de PVC de 1,0 mm e camada de solo / brita 3. 206

Figura 168. Resultados dos ensaios de tração em faixa larga: GM de PVC de 2,0 mm sem proteção / brita 3. 206 Figura 169. Resultados dos ensaios de tração em faixa larga - GM de PVC de 1,0 mm sem proteção/ brita 1. 207 Figura 170. Resultados dos ensaios de tração em faixa larga - GM de PVC de 1,0 mm e GT PET $600 \mathrm{~g} / \mathrm{m}^{2} / \mathrm{brita}$ 1.

Figura 171. Resultados dos ensaios de tração em faixa larga - GM de PVC de 1,0 mm e areia / brita 1.__ 208

Figura 172. Resultados dos ensaios de tração em faixa larga - GM de PVC de 1,0 mm e solo / brita 1.__ 208

Figura 173. Mecanismo de ruptura nos ensaios de tração em faixa larga - GM de PVC. __ 209

Figura 174. Resultados de tração em faixa larga - GM de PVC: (a) brita 3. __ 211

Figura 175. Resultados dos ensaios de tração multiaxial - GM de PVC de 1,0 mm sem proteção / brita 3. Figura 176. Resultados dos ensaios de tração multiaxial - GM de PVC de 1,0 mm e GT PET $300 \mathrm{~g} / \mathrm{m}^{2} / \overline{\mathrm{brita}} 3$.

212

Figura 177. Resultados dos ensaios de tração multiaxial - GM de PVC de 1,0 mm e GT PET $600 \mathrm{~g} / \mathrm{m}^{2} / \mathrm{brita} 3$. 213 Figura 178. Resultados dos ensaios de tração multiaxial - GM de PVC de 1,0 mm e GT PET $1200 \mathrm{~g} / \mathrm{m}^{2} / \mathrm{brita} 3$. 213 Figura 179. Resultados dos ensaios de tração multiaxial - GM de PVC de 1,0 mm e camada de areia / brita 3. 214

Figura 180. Resultados dos ensaios de tração multiaxial - GM de PVC de 1,0 mm e camada de solo / brita 3. 214 Figura 181. Análise ensaio de tração multiaxial - GM de PVC e brita 3. 215 
Figura 182. Modo de ruptura nos ensaios de tração multiaxial: GM PVC 1,0 mm / brita3.

Figura 183. Resultados dos ensaios de tração em faixa larga de GM de PVC $(1,0 \mathrm{~mm})$ em função do diâmetro e formato dos agregados.

Figura 184. Estimativa da pressão disponível para geomembranas sem proteção (NAREJO et al, 1996). 

Tabela 1. Tipos de geomembranas: principais componentes e propriedades (adaptado de DANIEL e KOERNER, 1995).

Tabela 2. Ensaios realizados em geomembranas (modificado de Bueno e Vilar, 2004).

Tabela 3. Ensaios realizados em geotêxteis (modificado de BUENO e VILAR, 2004).

Tabela 4. Normas de ensaio para avaliação da resistência de emendas para vários tipos de geomembranas (DANIEL \& KOERNER, 1995).

Tabela 5. Métodos de ensaios não destrutivos conforme os tipos de emendas e de geomembranas (DANIEL \& KOERNER, 1995).

Tabela 6. Métodos de ensaios de verificação da estanqueidade da geomembrana após a sua colocação $e$ ligação dos painéis (adaptado de CFGG 2003).

Tabela 7. Propriedades físicas e mecânicas dos geossintéticos utilizados.

Tabela 8. Pressão de ruptura obtida a partir de ensaios de punção para diferentes espessuras de geomembrana de PEAD.

Tabela 9. Pressão de ruptura obtida a partir de ensaios de punção usando cones truncados para uma geomembrana de PEAD de 1,5 mm de espessura com vários tipos de materiais de proteção. __ 48 Tabela 10. Pressão no escoamento para camada de pedregulhos.

Tabela 11. Pressão de ruptura obtida a partir dos ensaios geostáticos com geomembrana de PEAD e vários geotêxteis não tecidos agulhados.

Tabela 12. Fatores modificados de forma.

Tabela 13. Fatores parciais de segurança para fluência.

Tabela 14. Valores sugeridos de fatores de segurança global contra ruptura no uso das equações de projeto._52

Tabela 15. Propriedades físicas das camadas geossintéticas de proteção.

Tabela 16. Comparação dos resultados a partir dos ensaios em modelo de grande escala e ensaio de laboratório de desempenho para proteção.

Tabela 17. Sumário dos ensaios realizados em modelo de grande escala.

Tabela 18. Sumário das deformações obtidas a partir das medidas locais detalhadas. 61 Tabela 19. Ensaios de laboratório utilizados para verificação do desempenho de materiais de proteção para geomembranas.

Tabela 20. Aumento de carga para várias condições de ensaio.

Tabela 21. Ensaios de caracterização das geomembranas. 76

Tabela 22. Ensaios de caracterização dos geotêxteis. ___ 76

Tabela 23. Ensaios de caracterização dos solos e agregados.___ 77

Tabela 24. Configurações dos ensaios índice realizados.____ 81

Tabela 25. Especificações técnicas dos equipamentos de terraplenagem utilizados.___ 84

Tabela 26. Condições de compactação no campo pelo método do cilindro de cravação. ___ 90

Tabela 27. Configuração dos ensaios de campo. ___ 91

Tabela 28. Ensaios pós-danos realizados nas amostras de geomembranas danificadas. 101

Tabela 29. Resultados dos ensaios de caracterização das geomembranas. __ 112

Tabela 30. Resultados dos ensaios de caracterização dos geotêxteis. ___ 113

Tabela 31. Características dos solos utilizados. 114

Tabela 32. Características dos agregados. 115

Tabela 33. Resumo dos resultados dos ensaios índice. 119

Tabela 34. Resultados dos ensaios mecânicos pós-dano - GM PEAD (1,5 mm) sem proteção. ___ 142

Tabela 35. Resultados dos ensaios mecânicos pós-dano - GM PEAD (1,5 mm) sem proteção. __ 142 
Tabela 36. Sumário dos resultados - stress cracking: geomembranas de PEAD, 1,5 mm de espessura. 146 Tabela 37. Resultados dos ensaios mecânicos pós-dano - GM PVC $(1,0 \mathrm{~mm})$ sem proteção.

Tabela 38. Valores de permeabilidade recomendados.

Tabela 39. Danos visuais observados nas geomembranas de PEAD.

Tabela 40. Resultados dos ensaios de tração faixa larga realizados nas geomembranas de PEAD.

Tabela 41. Resultados dos ensaios de tração multiaxial realizados nas geomembranas de PEAD.

Tabela 42. Síntese dos resultados de stress cracking em geomembranas de PEAD. ___ 191

Tabela 43. Danos visuais observados nas geomembranas de PVC.

Tabela 44. Resultados dos ensaios de tração faixa larga realizados nas geomembranas de PVC.

Tabela 45. Resultados dos ensaios de tração multiaxial realizados nas geomembranas de PVC.

Tabela 46. Desempenho dos elementos de proteção utilizados nas geomembranas de PEAD.

Tabela 47. Desempenho dos elementos de proteção utilizados nas geomembranas de PVC.

Tabela 48. Comparação dos danos visuais observados nas geomembranas de PEAD.

Tabela 49. Comparação dos danos visuais observados nas geomembranas de PVC.

Tabela 50. Comparação dos Ensaios de Tração Multiaxial.

Tabela 51. Comparação dos Ensaios de Tração Faixa Larga.

Tabela 52. Fatores de correlação utilizados para as condições do ensaio de campo.

Tabela 53. Cálculo da pressão admissível segundo a metodologia proposta por Narejo et al (1996). 
ABNT

AASHO

ASTM

BAM

CFG

EA

FS

FST

GB

GC

GM

GRI

Gr

GT

NBR

NCLT

NW

NP

PA

PEAD

PEBD

PEC

PECS

PELMD

PET

PP

PVC

SCDF

SP - NCLT
Associação Brasileira de Normas Técnicas

American Association of State Highway Transportation Officials

American Society for Testing and Materials

Bundesanstalt für Materialforschung Undprüfung

Comité Français dês Geosynthétiques

Environmental Agency

Fator global de segurança

Fissuramento sob Tensão

Geocomposto bentonítico

Grau de compactação

Geomembrana

Geosynthetic Research Institute

Gramatura

Geotêxtil

Norma Brasileira

Notched Constant Tensile Load Test

Não tecido

Agulhado

Poliamida

Polietileno de alta densidade

Polietileno de baixa densidade

Polietileno clorado

Polietileno clorosulfonado

Polietileno linear de média densidade

Poliéster

Polipropileno

Policloreto de vinila

Sistemas de captação e desvio de fluxo

Single Point-Notched Constant Tensile Load Test 
$\Delta \mathrm{Fp} \quad$ Acréscimo de resistência à punção

$\mathbf{F}_{\mathbf{p}} \quad$ Força à punção

$\mathbf{F}_{\mathbf{y G M}}$ Tensão de tração da geomembrana

$\mathbf{F}_{\mathbf{y G T}}$ Tensão de tração do geotêxtil

$\rho_{\mathbf{d}} \quad$ Massa específica seca

$\rho_{\delta} \quad$ Massa específica dos sólidos

$\phi_{\mathbf{p}}$ Diâmetro de perfuração

$\omega$ ótima Umidade ótima

k Permeabilidade

$\sigma \quad$ Tensão de tração

$\varepsilon \quad$ Deformação

$\delta$ Relação entre a resistência à tração da geomembrana e a resistência à tração do geotêxtil

$\mathbf{r}_{\mathbf{0}} \quad$ Raio da ponta protuberante

H Altura da protuberância

$\mathbf{p}_{\mathbf{i}} \quad$ Pressão hidrostática

$\mathbf{F}_{\mathbf{i}} \quad$ Força total da geomembrana na posição instantânea $\mathbf{i}$

$\mathbf{d}_{\psi} \quad$ Variação do ângulo tangente ao talude

$\mathbf{d}_{\mathbf{s}} \quad$ Comprimento de corda do elemento

i Posição instantânea da geomembrana

$\left(\mathbf{R}_{\mathbf{i}-\mathbf{x}}\right)$ Raio a partir do centro da protuberância para um elemento infinitesimal da geomembrana.

$1_{i} \quad$ Comprimento da geomembrana em contato com a ponta protuberante num instante $\mathbf{i}$.

$\Delta \mathrm{l}_{\mathrm{i}} \quad$ Incremento de alongamento da geomembrana

$\Delta \mathrm{F}_{\mathrm{i}} \quad$ Incremento da força de tração da geomembrana

$\mathrm{J}_{\mathrm{GM}}$ módulo carga - deformação da geomembrana 
RESUMO

REBELO, K.M.W. (2008). Avaliação de Camadas de Proteção para Geomembranas de PVC e PEAD, Tese de Doutorado, Escola de Engenharia de São Carlos (EESC/USP), 247 páginas.

O presente trabalho investiga o desempenho de geotêxteis e de solos como elementos de proteção para geomembranas de Polivinil Clorado (PVC) e de Polietileno de Alta Densidade (PEAD). Foram utilizadas geomembranas de PVC com espessuras de 1,0 e 2,0 mm e de PEAD com espessuras de 1,5 e 2,0 mm. Como camadas de proteção utilizaram-se geotêxteis não tecidos de poliéster (PET), com gramaturas de 130, 300, 400 e $600 \mathrm{~g} / \mathrm{m}^{2}$, e de polipropileno (PP), com gramatura de 400 e $600 \mathrm{~g} / \mathrm{m}^{2}$, além de uma areia de granulometria fina a média e uma areia argilosa típica da Região Centro-Oeste do Estado de São Paulo. O estudo foi conduzido através da construção de um aterro experimental para simulação dos danos de instalação em campo e da realização de ensaios índice e de desempenho em laboratório. A eficiência dos materiais de proteção foi avaliada através da análise qualitativa e quantitativa das amostras de geomembranas danificadas. Os resultados dos ensaios de laboratório índice mostraram que a introdução do geotêxtil aumenta a resistência à punção da geomembrana, e que o acréscimo de resistência é função das características de resistência à tração do geotêxtil e da geomembrana. O maior incremento de resistência à punção foi observado na geomembrana com menor resistência à tração. Os resultados dos ensaios de campo mostraram que a introdução do elemento de proteção reduz os danos mecânicos apesar da alteração de algumas das propriedades físicas e de desempenho nas geomembranas. Da análise dos resultados, verificou-se que a eficiência dos geotêxteis no campo não é função de suas características de tração, conforme constatado nos ensaios índices. A análise também sugere que os danos mecânicos no campo foram mais intensos do que nos ensaios de desempenho em laboratório.

Palavras-chave: geomembranas; danos mecânicos; camadas de proteção; geotêxteis; ensaios de laboratório; ensaios de campo. 
REBELO, K.M.W. (2008). Assessment of the Performance of Protective Layers for PVC and HDPE Geomembranes, Thesis (Doctorate), Escola de Engenharia de São Carlos (EESC /USP), $247 \mathrm{p}$.

The performance of non-woven geotextiles and soils as protection elements of Polyvinyl Chloride (PVC) and High Density Polyethylene (HDPE) geomembranes is studied. The materials used comprised PVC geomembranes of 1,0 and 2,0 $\mathrm{mm}$ thickness and HDPE geomembranes of 1,5 and 2,0 $\mathrm{mm}$ thickness while the protective layers were of non-woven polyester (PET) geotextiles with mass per unit area of 130, 300, 400 e $600 \mathrm{~g} / \mathrm{m}^{2}$ and polypropylene (PP) with mass per unit area of 400 e $600 \mathrm{~g} / \mathrm{m}^{2}$. It was also used protective layers made of a fine to medium sand and a typical clayey sand of central area of the State of São Paulo. The study was based on an experimental landfill built to simulate the damage associated to construction procedures and on index and performance laboratory tests. Through qualitative and quantitative analysis of damaged geomembranes, the behavior of each protective element was evaluated. Index laboratory test results have shown that the geotextile is able to increase the geomembrane puncture strength and that the strength increase is related to the tensile strength of geotextile and geomembrane. For similar geotextiles, the larger increase in puncture strength was observed for the geomembrane that presented the lower tensile strength. Visual observation of field tests has shown that the introduction of protective layers reduces the mechanical damage; however some physical and performance properties of geomembrane have changed. It was also observed that the performance of geotextiles in the experimental landfill does not depend on the tensile strength, as observed in laboratory index tests. Test results also suggest that field damage associated to the landfill construction are more intense than that observed in laboratory tests such as the dynamic puncture test.

Keywords: geomembranes, mechanical damage, protective layers; geotextiles; laboratory tests; field tests. 


\section{CAPÍTULO 1 INTRODUÇÃO}

Tem-se tornado crescente a utilização de técnicas de gerenciamento que visam reduzir, reciclar e reaproveitar os resíduos produzidos pelas diferentes atividades humanas. Nestas estratégias de gerenciamento, sempre restam materiais que necessitam ser dispostos no meio físico. Uma das alternativas mais utilizadas para esse propósito consiste na disposição em aterros sanitários e industriais e em lagoas de efluentes.

Nestas técnicas de disposição devem ser previstos um sistema de barreiras de controle e desvio de fluxo na fundação, cuja finalidade é evitar a contaminação do solo e águas subjacentes, e na cobertura, cuja função é diminuir a taxa de formação de percolados e proteger as células de resíduos. Além destas funções, essas barreiras contribuem para evitar a migração indesejável de gases para o entorno, sejam os solos de fundação ou a atmosfera.

As geomembranas são elementos presentes em grande parte das barreiras de controle e desvio de fluxo. Dependendo da configuração das barreiras, podem se apresentar em contato direto com diferentes materiais formados pelo solo da fundação, resíduos e materiais granulares provenientes do sistema de drenagem. Um dos problemas associados a barreiras de controle e desvio de fluxo consiste no efeito que estes materiais podem exercer sobre a geomembrana como, por exemplo, perfurações e deformações indesejáveis. Durante a fase de instalação, por exemplo, a geomembrana pode ser puncionada e perfurada por ferramentas, 
maquinários, agregados ou protuberâncias no solo de fundação. Por outro lado, durante a vida útil do aterro (fase de operação), a geomembrana pode ser puncionada por recalque gradual devido à ação do peso dos resíduos, possibilitando também o aparecimento de furos ou provocando deformações excessivas.

Para minimizar estes problemas, tem-se recorrido ao uso de uma camada de proteção sobre a geomembrana, de forma a garantir a integridade do sistema durante as fases de instalação (construção) e vida útil (operação) do aterro. Dentre as alternativas comumente adotadas para camadas de proteção destacam-se os geotêxteis e, em algumas situações, os geocompostos.

Atualmente, duas alternativas têm sido utilizadas para o dimensionamento de uma camada de proteção. Uma delas é baseada na prevenção de danos a curto prazo, de modo a garantir que o alongamento não ultrapasse o ponto do escoamento (membranas de polietileno de alta densidade - PEAD), sem que ocorram perfurações na geomembrana. No entanto, existem vários questionamentos sobre este método porque além de não considerar o efeito de deformações locais nas geomembranas ao longo do tempo, as quais podem ocasionar rupturas por stress cracking, parte do princípio da seleção do geotêxtil baseada em sua gramatura. Assim, outros fatores como tipo e qualidade da fibra, métodos de fabricação de geotêxteis, resistência à tração e outras propriedades mecânicas, os quais podem estar relacionados ao desempenho, não são considerados nesta proposta. Além disto, o método é baseado em observações visuais, sem quantificação do dano.

A segunda alternativa consiste no critério adotado para avaliar o desempenho das camadas de proteção a longo prazo, de forma a evitar que deformações locais ocasionem rupturas por stress cracking na geomembrana. Este critério é baseado em regulamentações técnicas do Bundesanstalt für Materialforschung Undprüfung - BAM (Instituto Federal para Ensaio e Pesquisa de Materiais), e consiste na limitação de deformações para um valor 
aceitável de $0,25 \%$. Entretanto, existem muitas questões sobre a credibilidade e precisão deste valor de deformação limite adotado. Primeiro, pelo fato dos dados existentes na literatura indicarem que os materiais de proteção mais utilizados não são capazes de evitar deformações menores que o valor adotado pelo BAM. Segundo, por não considerarem alguns fatores que são imprescindíveis para uma análise de desempenho a longo prazo como envelhecimento do geotêxtil devido à degradação química e biológica, ação da temperatura e presença de soldas ou emendas, as quais compreendem um ponto crítico para o aparecimento de fissuras por stress cracking.

Em ambas as metodologias também não são consideradas os danos que ocorrem durante a fase de instalação (construção) dos SCDF, que correspondem aos danos mais recorrentes em geomembranas.

Neste contexto, nota-se uma escassez de informações e divergências de opiniões em nível mundial acerca da eficiência de camadas de proteção e que os conhecimentos sobre o assunto ainda não foram devidamente consolidados.

Diante deste cenário, pretende-se, neste trabalho, investigar o desempenho de algumas alternativas de elementos de proteção para geomembranas de PVC e de PEAD através da realização e interpretação de ensaios de laboratório e de campo, simulando as fases de instalação (construção) de barreiras impermeabilizantes. Serão investigadas as propriedades destas alternativas que sejam relevantes para projeto e correlacionados o comportamento de laboratório e de campo.

Cabe destacar que esta tese está associada a um projeto de pesquisa mais amplo que é complementado pela Dissertação de Mestrado de Geroto (2008), onde são apresentados e discutidos resultados que procuram retratar aspectos adicionais de danos de operação, representados por ensaios de punção hidrostática com cones isolados e camadas de pedregulhos naturais, dentre outros. 
O objetivo geral deste projeto é investigar o desempenho de camadas de proteção para geomembranas de PEAD e PVC através de ensaios de laboratório e de campo. 


\subsection{Introdução: Resíduos Sólidos, Aspectos Gerais e Formas de Disposição}

Os resíduos sólidos são definidos como "resíduos nos estados sólido e semi-sólido, que resultam de atividades de origem industrial, doméstica, hospitalar, comercial, agrícola, de serviços e de varrição. Ficam incluídos nesta definição os lodos provenientes de sistemas de tratamento de água, aqueles gerados em equipamentos e instalações de controle de poluição, bem como determinados líquidos cujas particularidades tornem inviável o seu lançamento na rede pública de esgotos ou corpos de água, ou exijam para isso soluções técnicas e economicamente inviáveis em face à melhor tecnologia disponível” (NBR 10.004).

Em função da sua natureza são diversos os problemas causados pela disposição inadequada como, por exemplo, os impactos ambientais gerados à atmosfera, ao lençol freático e ao ecossistema, além dos problemas econômicos gerados pela restrição e ocupação do local e arredores.

Segundo a Pesquisa Nacional de Saneamento Básico (PNSB, 2000), são coletadas aproximadamente 229.000 toneladas diárias de resíduos. Deste valor, 126.000 toneladas referem-se aos resíduos domiciliares. A Figura 1 ilustra o percentual de resíduos sólidos 
gerados no Brasil por região. Observa-se que a Região Sudeste apresenta a maior produção de resíduos.

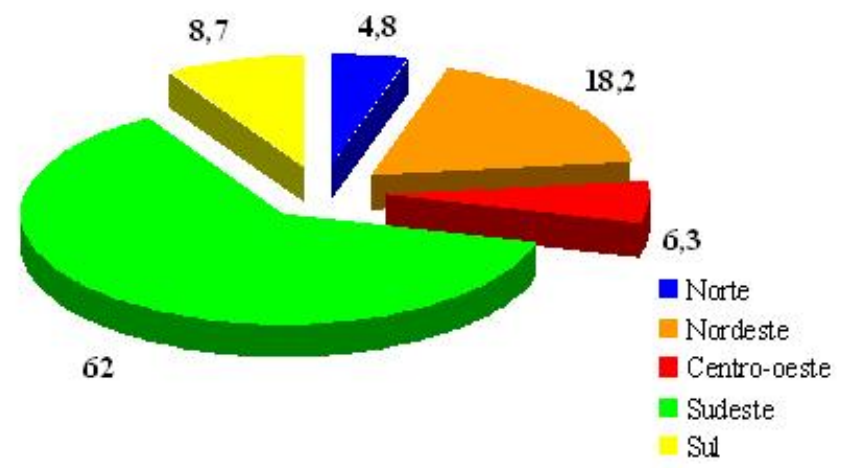

Figura 1. Percentual da geração de resíduos sólidos por região brasileira (PNSB, 2000).

Dados da pesquisa também indicam um aumento considerável na quantidade de resíduos gerados a partir da década de 1990 motivado pela redução nos índices inflacionários e pelo aumento do consumo por parte da população. No entanto, ao se analisar os cuidados referentes ao tratamento e destinação final dos resíduos, constata-se uma redução da quantidade de resíduos depositados em lixões e um aumento de aterros controlados e sanitários, além de um pequeno crescimento de outros tipos de tratamento, como reciclagem e compostagem.

A Figura 2 ilustra o destino final dos resíduos segundo os dados publicados pela Pesquisa Nacional de Saneamento Básico (2000). Observa-se uma situação totalmente favorável no que se refere à destinação adequada de resíduos, principalmente na forma de aterros sanitários. 


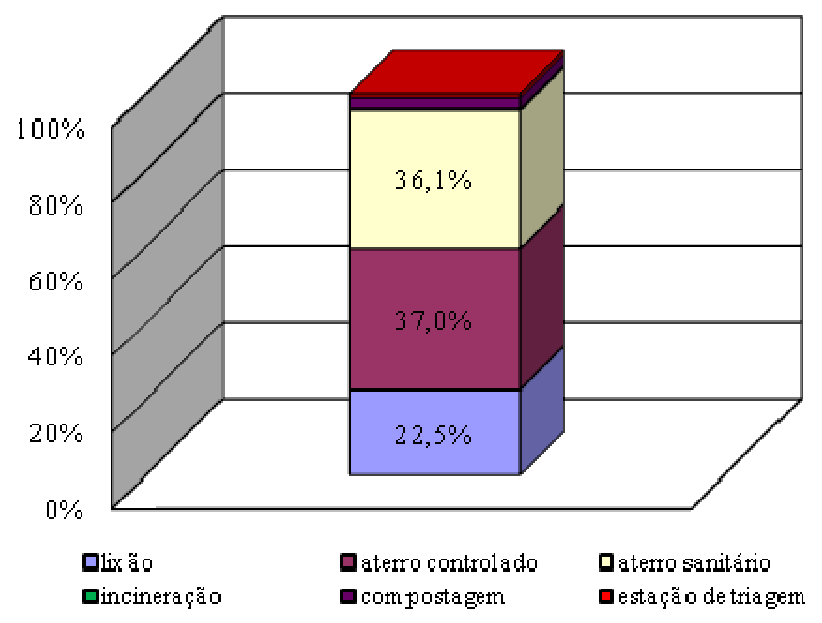

Figura 2. Evolução do destino final dos resíduos brasileiros.

Em algumas destas aplicações de Engenharia, como em aterros sanitários e industriais, além dos canais e lagoas de contenção de efluentes, devem ser previsto um sistema de barreiras impermeabilizantes. Atualmente, as barreiras impermeabilizantes são denominadas de sistemas de captação e desvio de fluxo (SCDF).

Os SCDF são empregados no sistema de confinamento basal, com a função de prevenir a migração de líquidos percolados junto ao solo e água subterrânea e superficial e, no sistema de cobertura, com a função de controlar a infiltração das águas superficiais e de evitar a migração não controlada de gases.

Os sistemas de impermeabilização antigos consistiam basicamente de solo local compactado. Atualmente, tais sistemas podem apresentar em sua constituição materiais poliméricos, como os geossintéticos, e camadas de argilas compactadas. A escolha dos materiais utilizados é influenciada pelo uso a que se destina, pelo meio ambiente físico, pela química da solução percoladora e da água subterrânea, pela vida útil do projeto, taxa de infiltração e restrições físicas.

As barreiras naturais compreendem os solos argilosos naturais de baixa condutividade hidráulica, variando entre $10^{-6}$ a $10^{-7} \mathrm{~cm} / \mathrm{s}$ (DANIEL, 1993). Na grande maioria dos casos, as 
barreiras naturais são utilizadas como complemento, mas podem ser apresentadas em sua forma simples.

As barreiras de argila compactada são constituídas essencialmente por solos compactados, podendo conter bentonita. Este tipo de material apresenta condutividade hidráulica adequada, são resistentes em longo prazo com relação às influências químicas dos percolados e podem apresentar alto potencial de retenção do contaminante (DANIEL, 1993).

As barreiras sintéticas são compostas de materiais poliméricos (geomembranas) que apresentam condutividade hidráulica extremamente baixa e elevada resistência química e física. Geralmente as geomembranas não são utilizadas sozinhas em função dos possíveis defeitos que podem apresentar e resultar em grandes fluxos de percolação (BOUAZZA et al, 2002). Acrescentam-se a este grupo os geocompostos bentoníticos (GB) ou geosynthetic clay liners (GCL). Os geocompostos bentoníticos são barreiras com condutividade hidráulica entre $10^{-10}$ e $10^{-8} \mathrm{~cm} / \mathrm{s}$, constituídas por uma camada de bentonita não hidratada aderida mecanicamente ou quimicamente a um geotêxtil ou geomembrana.

Os SCDF podem se apresentar na forma simples, quando constituídos por único material, ou na forma composta, quando são constituídos por uma combinação de diferentes materiais. E ainda podem ser duplos, quando apresentam uma camada dupla de revestimento, sendo esta configuração mais utilizada para disposição de rejeitos perigosos.

A Figura 3 apresenta algumas configurações típicas de barreiras de SCDF. 


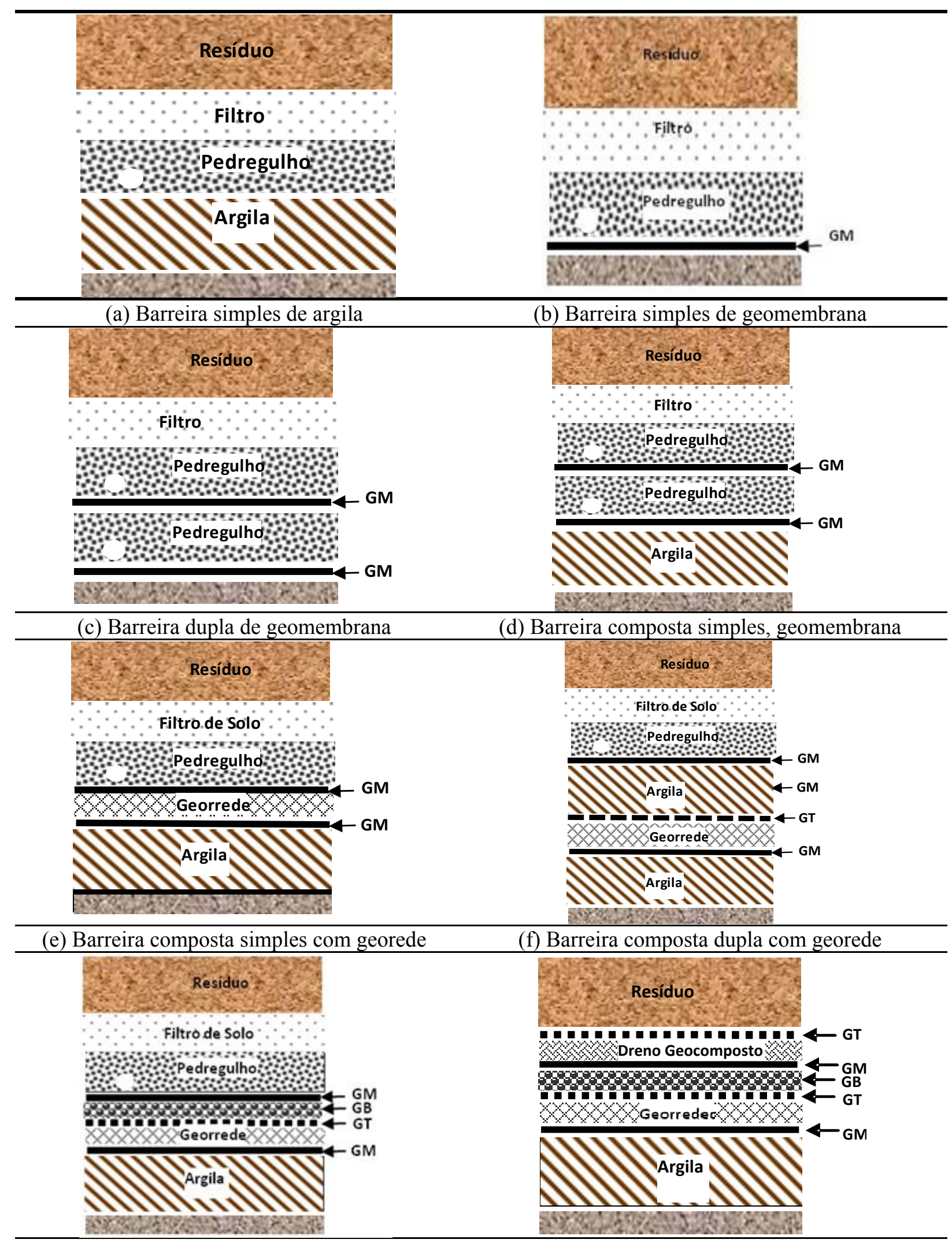

(g) Barreira composta dupla com GB e GR

(h) Barreira composta dupla com GB, GR e GC

Figura 3. Configurações típicas de barreiras impermeáveis (KOERNER, 1998). 
A camada de pedregulho tem como finalidade promover a drenagem e captação dos líquidos percolados. A ASSHO recomenda as seguintes faixas de granulometria dos materiais: 9 a $13 \mathrm{~mm}, 25$ a $38 \mathrm{~mm}$ ou 50 a $64 \mathrm{~mm}$. Também é recomendada a espessura mínima de 30 cm. O Instituto Federal para Ensaio e Pesquisa de Materiais - Bundesanstalt für Materialforschung Undprüfung - (BAM) recomenda a faixa de variação da curva granulométrica entre 16 e $32 \mathrm{~mm}$.

Os produtos geossintéticos de drenagem são estruturas extrudadas de plástico manufaturadas de forma a promover a drenagem de percolados e gases. Compreendem as georredes (GR) e os drenos geocompostos. As georredes consistem de grupos de estruturas sintéticas planares paralelamente conectadas sobrepostos transversalmente (ou em outros ângulos) a grupos similares. Os drenos geocompostos consistem em uma composição de georredes e geotêxteis. São usados para prevenir a extrusão de solos ou outros materiais adjacentes.

Os geotêxteis (GT) são materiais sintéticos permeáveis, geralmente compostos por polímeros de poliéster (PET) e polipropileno (PP). Dentre as funções que podem exercer, citam-se a função de filtração e separação, como pode ser observado na figura anterior, e a função de proteção. Informações adicionais sobre os diferentes tipos de geossintéticos, suas funções e aplicações podem ser encontradas em Koerner (1998) e Vertematti (2004).

\subsection{Geomembranas}

\subsubsection{Aspectos Gerais}

As geomembranas são materiais poliméricos, de baixa condutividade hidráulica (da ordem de $10^{-12} \mathrm{~cm} / \mathrm{s}$ ) e de pequena espessura. Possuem como função primária controlar a percolação e o fluxo de líquidos e, em alguns casos, de gases. 
As geomembranas surgiram como alternativa a materiais tradicionais devido à regulamentação de atividades ambientais e à maior distribuição de dados e informações sobre suas propriedades e eficácia.

Sua introdução no mercado só se tornou possível com a produção do PVC (polivinil clorado) no início de 1930, sendo apenas utilizado no início do ano de 1940 com aplicações na agricultura, na impermeabilização de canais, e somente utilizado como contenção de resíduos a partir de 1965 (LENGEN \& SIEBKEN, 1996).

As geomembranas de polietileno (PE) tiveram sua produção no ano de 1943 na Alemanha, e o seu uso como geomembrana não foi desenvolvido até os anos 60 (LENGEN \& SIEBKEN, 1996).

Atualmente, as geomembranas são aplicadas na impermeabilização de diversas obras, tais como: lagoas ornamentais e para piscicultura; lagoas de tratamento de efluentes; tanques e silos de armazenamento; reservatórios de água; base e cobertura de aterros sanitários e industriais; barreiras separadoras de barreiras; revestimento de túneis e barragens, dentre outras.

Especificamente em aterros de resíduos, as geomembranas de PEAD são as mais utilizadas nos SCDF devido à sua resistência química, mecânica e durabilidade, além de permitirem soldas resistentes do ponto de vista mecânico e hidráulico (LOPES, 2006).

No mercado brasileiro tem-se utilizado geomembranas de PVC e PEAD nos SCDF de bases de aterros e lagoas e, de PELMD (polietileno de baixa densidade) nos sistemas de coberturas de aterros.

As geomembranas são constituídas essencialmente por polímeros e, em menor escala, por aditivos. Os aditivos podem ser incorporados no processo de fabricação dos geossintéticos visando à melhoria de suas propriedades, reduzir o custo, facilitar o processamento, colorir, dentre outros aspectos. 
Os plastificantes, por exemplo, são utilizados para aumentar a flexibilidade. Os fillers, que são pequenas partículas minerais (ex.: carbonato de cálcio), são utilizados para aumentar a rigidez. O negro de fumo aumenta a rigidez e retarda a degradação pelos raios ultravioletas (UV). Os aditivos como os fungicidas evitam o ataque de fungos e bactérias. E por último, os antioxidantes, que têm como função evitar a degradação por oxidação (DANIEL \& KOERNER, 1995).

A Tabela 1 apresenta os tipos de geomembranas mais utilizadas em aterros de resíduos com seus principais componentes e propriedades.

Tabela 1. Tipos de geomembranas: principais componentes e propriedades (adaptado de DANIEL e KOERNER, 1995).

\begin{tabular}{|c|c|c|c|c|c|c|}
\hline \multirow[b]{2}{*}{ GM } & \multicolumn{5}{|c|}{ Componentes (\% em peso) } & \multirow[b]{2}{*}{ Propriedades } \\
\hline & Resina & Plastificante & Fillers & $\begin{array}{c}\text { Negro de } \\
\text { fumo }\end{array}$ & Aditivos & \\
\hline PEAD & $95-98$ & 0 & & $2-3$ & $0,25-1$ & $\begin{array}{l}\text { - mais alta resistência à tração } \\
\text { - boa resistência química aos UV } \\
\text { e temperatura } \\
\text { - satisfatória a boa resistência à } \\
\text { punção }\end{array}$ \\
\hline PEBD & $94-96$ & 0 & 0 & $2-3$ & $1-4$ & $\begin{array}{l}\text { - boa resistência química } \\
\text { - boa resistência à punção e } \\
\text { tração } \\
\text { - boa resistência aos UV } \\
\text { - boa flexibilidade }\end{array}$ \\
\hline PVC & $50-70$ & $25-35$ & $0-10$ & $2-5$ & $2-5$ & $\begin{array}{l}\text { - boa resistência química } \\
\text { - fraca resistência aos UV } \\
\text { - muito boa resistência à punção } \\
\text { - excelente flexibilidade } \\
\text { - mais fácil de instalar } \\
\end{array}$ \\
\hline PECS & $40-60$ & 0 & $40-50$ & $5-40$ & $5-15$ & $\begin{array}{l}\text { - boa resistência química } \\
\text { - boa resistência química aos UV } \\
\text { e temperatura } \\
\text { - satisfatória a boa resistência à } \\
\text { punção e ao rasgo }\end{array}$ \\
\hline
\end{tabular}

Os ensaios em geomembranas são regulamentados por normas americanas (ASTM) e européias (ISO). Destacam-se, no contexto nacional, a regulamentação de algumas normas 
brasileiras $(\mathrm{ABNT})$. Os principais ensaios e suas respectivas normas são apresentados na Tabela 2.

Tabela 2. Ensaios realizados em geomembranas (modificado de Bueno e Vilar, 2004).

\begin{tabular}{|c|c|c|}
\hline Propriedades & Norma & Observação \\
\hline \multicolumn{3}{|l|}{ Físicas } \\
\hline & ASTM D $751 \mathrm{e}$ & \\
\hline Espessura nominal & $\begin{array}{c}5199 \\
\text { ASTM } 5994 \\
\end{array}$ & Geomembrana texturizada \\
\hline \multirow{4}{*}{ Densidade } & ASTM D 792 & Método do deslocamento \\
\hline & ASTM D 1505 & Método do gradiente de densidade \\
\hline & ASTM D 297 & Método do picnômetro \\
\hline & ISO 1183 & - \\
\hline Dureza & $\begin{array}{l}\text { ASTM D } 2240, \\
\text { ISO } 868\end{array}$ & - \\
\hline Estabilidade dimensional & ASTM D 1204 & - \\
\hline \multicolumn{3}{|l|}{ Mecânicas } \\
\hline \multirow{5}{*}{ Resistência à tração } & NBR 12824 & faixa larga \\
\hline & ASTM D 4885 & \\
\hline & ASTM D4632 & \\
\hline & ASTM D638 & halteres \\
\hline & ASTM D 882 & tiras, espessura da $\mathrm{GM}<1,0 \mathrm{~mm}$ \\
\hline & NBR 13359 & Pistão CBR \\
\hline $\begin{array}{l}\text { Resistencia ao puncionamento } \\
\text { estático }\end{array}$ & $\begin{array}{l}\text { ASTM } 4833 \\
\text { ISO } 12236\end{array}$ & $\begin{array}{l}\text { Pistão: } 8 \text { mm de diâmetro; corpo de prova: } 45 \\
\text { mm de diâmetro }\end{array}$ \\
\hline $\begin{array}{l}\text { Resistência ao puncionamento } \\
\text { dinâmico }\end{array}$ & NBR 14971 & Cone de $500 \mathrm{~g}$, altura de queda de $500 \mathrm{~mm}$ \\
\hline Resistência a rasgo & $\begin{array}{l}\text { ASTM D } 1004 \\
\text { ISO } 4674\end{array}$ & $\begin{array}{c}\text { Forma geométrica particular } \\
\text { Formas variadas }\end{array}$ \\
\hline \multicolumn{3}{|l|}{ Hidráulicas } \\
\hline $\begin{array}{l}\text { Permeabilidade ao vapor de } \\
\text { água }\end{array}$ & ASTM E 96 & - \\
\hline \multicolumn{3}{|l|}{ Desempenho } \\
\hline $\begin{array}{l}\text { Resistência a radiação } \\
\text { ultravioleta }\end{array}$ & $\begin{array}{l}\text { ASTM G 26, ISO } \\
4892\end{array}$ & Ciclos de luz ultravioleta e vapor \\
\hline Resistência química & $\begin{array}{l}\text { ENV ISO } 12960, \\
\text { ENV ISO } 12225\end{array}$ & $\begin{array}{l}\text { Incubação de amostras em contato com meio } \\
\text { agressivo em temperaturas de } 23 \text { e } 50^{\circ} \mathrm{C}\end{array}$ \\
\hline $\begin{array}{l}\text { Resistência a degradação } \\
\text { biológica }\end{array}$ & PR EN ISO 13430 & $\begin{array}{l}\text { Incubação de amostras em contato com solo } \\
\text { contendo microorganismos agressivos }\end{array}$ \\
\hline $\begin{array}{l}\text { Resistência a degradação } \\
\text { térmica }\end{array}$ & ASTM D 794 & $\begin{array}{l}\text { Incubação de amostras em estufa sob } \\
\text { elevadas temperaturas e circulação de ar }\end{array}$ \\
\hline Resistência das soldas & ASTM D 4545 & Cisalhamento e descolamento \\
\hline \multirow{3}{*}{$\begin{array}{l}\text { Resistência contra fissuração } \\
\text { sob tensão (stress cracking) }\end{array}$} & ASTM D 1693 & Realizadas em tubos de ensaio \\
\hline & ISO 4599 & \\
\hline & $\begin{array}{l}\text { ASTM } 5397 \\
\text { ISO } 6252 \\
\end{array}$ & Realizada sob carga de tração \\
\hline Atrito de interface & ASTM D 5321 & Cisalhamento direto ou plano inclinado \\
\hline
\end{tabular}




\subsubsection{Polímeros}

Para uma melhor compreensão das propriedades dos geossintéticos, faz-se necessário o conhecimento dos fundamentos relacionados aos polímeros, os quais são sintetizados a seguir.

Um polímero é uma macromolécula formada pela união ou encadeamento de pequenas e simples unidades químicas (monômeros) constituindo um padrão repetitivo. Já os monômeros são moléculas ou compostos químicos de massa molecular relativamente baixa que reagem entre elas ou com outros compostos similares para formar polímeros. Os monômeros possuem ligações covalentes duplas ou triplas, geralmente ligando átomos de carbono. A Figura 4 ilustra alguns dos monômeros mais comuns.
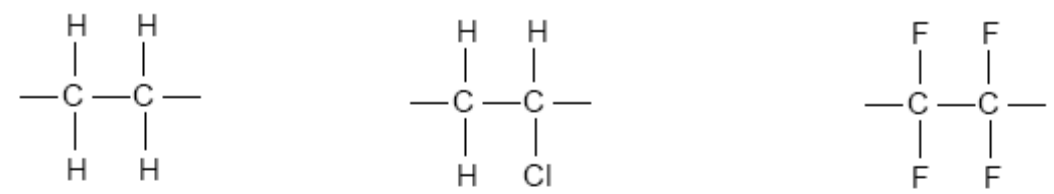

PE - Polietileno

PVC - Poli (cloreto de vinila)

PTFE - Poli (tetrafluoretino)
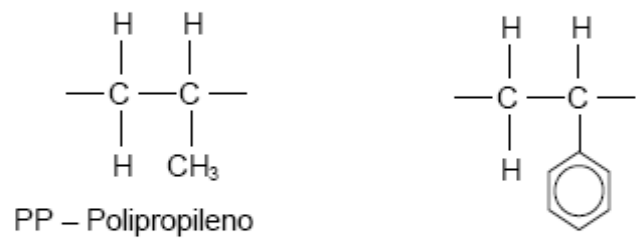

PS - Poliestireno

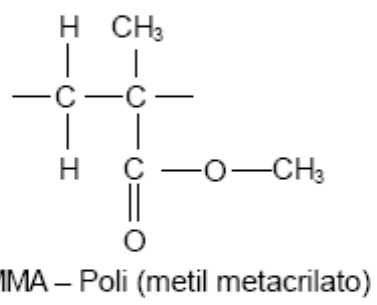

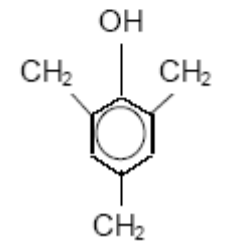

Fenol formaldeido

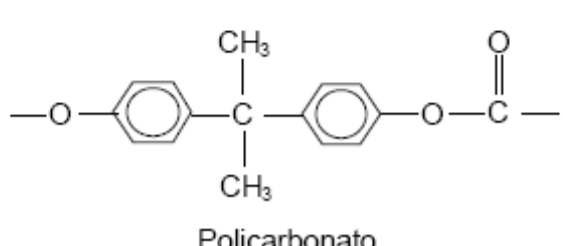

Policarbonato

Figura 4. Monômeros dos polímeros mais comuns (AGNELLI, 2000). 
As principais fontes de matéria-prima para os polímeros podem ser divididas em três grupos: produtos naturais, hulha (carvão mineral) e petróleo.

No grupo dos produtos naturais encontra-se a celulose, a borracha natural, o óleo de mamona e o óleo de soja. A hulha após destilação seca produz gás de hulha, de onde é possível separar o etileno e metano. Do coque do alcatrão de hulha obtém-se acetileno (via reação $\mathrm{CaO}$ ) que com água, por hidrogenação, produz etileno, ou por reação com ácido clorídrico $(\mathrm{HCl})$, produz cloreto de vinila para a produção do Poli (Cloreto de Vinila). O petróleo aparece como a fonte mais importante de todos os produtos minerais. Após a destilação fracionada do petróleo, a fração que interessa para os polímeros é a nafta. Essa fração irá gerar várias frações contendo moléculas saturadas e insaturadas após sofrer um processo de craqueamento térmico apropriado. As moléculas insaturadas (etileno, propileno, butadieno, buteno, isobutileno, aromáticos, etc.) são separadas e aproveitadas para a síntese dos respectivos polímeros (AGNELLI, 2000; LODI, 2003).

A polimerização consiste na reação química através da qual os monômeros se transformam no polímero. Corresponde ao processo de união dos monômeros transformandoos em meros, que será a unidade repetitiva que aparecerá na macromolécula. Tal reação é extremamente importante na definição das características mecânicas dos polímeros, e é controlada por parâmetros processo industrial tais como temperatura, pressão no reator e presença de canalizadores.

Existem dois principais processos de polimerização, o primeiro formado pela adição de meros iguais, e o segundo formado pela condensação através da reação de mais de um monômero, gerando sempre um subproduto.

Os polímeros podem ser termoplásticos, termofixos ou elastômeros. Os polímeros termoplásticos podem ser amolecidos ou liquefeitos por aquecimento e endurecidos por resfriamento, repetidas vezes, sem perder as suas propriedades. As ligações entre as cadeias 
dos termoplásticos são predominantemente secundárias. Assim, quando aquecidos, as ligações secundárias são enfraquecidas pela vibração das moléculas, tornando os materiais plásticos, podendo ser remoldados. Como exemplos, citam-se o polietileno, o poliestireno, o PVC, o nylon, etc. A estrutura molecular deste tipo de polímero é linear ou ramificada.

Os polímeros termofixos possuem ligações covalentes entre as cadeias. A energia necessária para o rompimento destas ligações é muito alta e os polímeros são "queimados" antes de se transformarem em materiais moldáveis, portanto não podem ser reciclados. O aquecimento é usado para dar formato a uma peça apenas uma vez, visto que, o mesmo não pode mais amolecer. Ao serem aquecidos, os termofixos formam as ligações cruzadas entre as cadeias lineares, criando uma estrutura de cadeia tridimensional estável que impede um novo deslocamento das moléculas do polímero. Com o aquecimento e pressão, somente haverá o rompimento da cadeia, resultando em degradação das propriedades. Como exemplos, citam-se as resinas fenólicas, melamínicas (revestimento) e alquídicas.

Por último, têm-se os elastômeros que são polímeros intermediários. Os elastômeros apresentam certo número de ligações cruzadas. Apresentam uma grande capacidade de deformação elástica em temperatura ambiente. Possuem cadeias predominantes lineares com alguma reticulação. A grande capacidade de deformação dos elastômeros está associada à configuração espiralada de suas cadeias poliméricas. Alguns exemplos de elastômeros são os silicones usados como selantes na construção civil e o policloropreno (neoprene) utilizado em pinturas, aparelhos de apoio e em impermeabilizações.

Dependendo da natureza química dos monômeros e da técnica empregada para a polimerização, os polímeros podem exibir diferentes tipos de estruturas. Os mais comuns são os de estrutura linear, ramificada ou em rede.

Nos polímeros lineares a seqüência de monômeros é contínua, seguindo em direção reta (linear), ou seja, a cadeia polimérica cresce em uma única dimensão. Estes polímeros são 
obtidos tanto por polimerização em cadeia como por polimerização em etapas. A Figura 5 ilustra o polietileno de alta densidade (PEAD), uma molécula de cadeia longa e linear, feita pela polimerização do etileno.

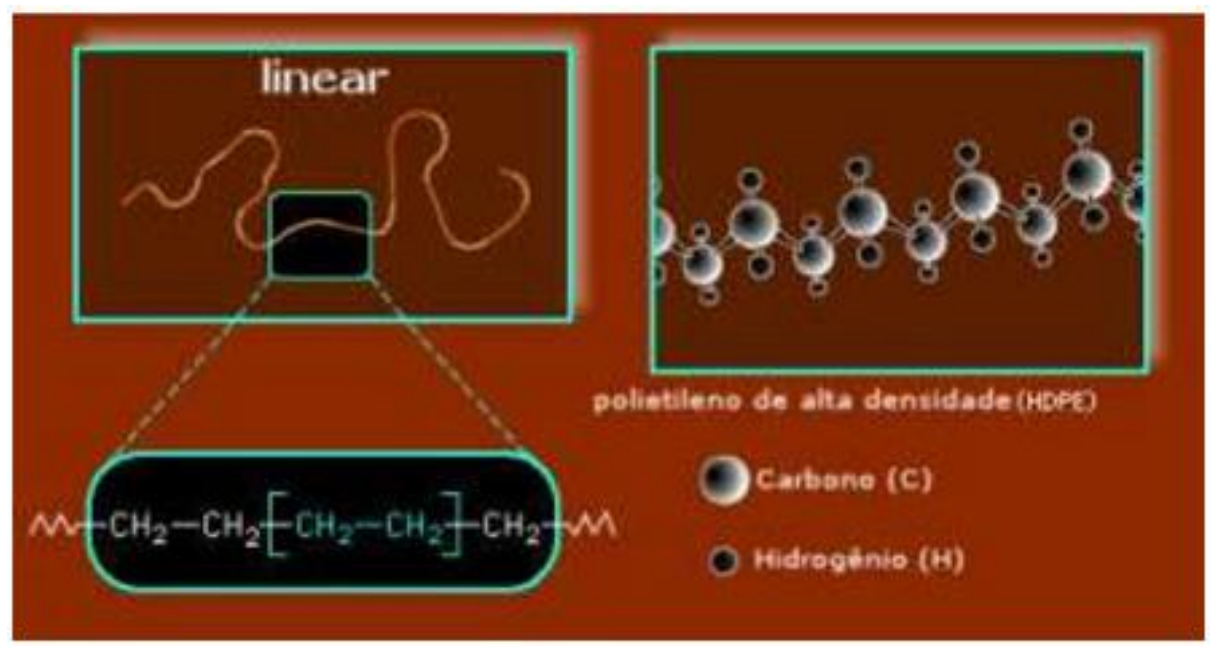

$\begin{array}{llllll}\text { Figura } & \text { 5. Ilustração } & \text { da } & \text { estrutura linear }\end{array}$ www.quimica.matrix.com.br/artigos/polimeros.html, acesso em 08/05/2002).

Os polímeros ramificados são aqueles que apresentam ramificações partindo da sua cadeia principal, formando uma configuração de "galhos de árvores". Os polímeros ramificados não se agrupam em retículos cristalinos, como os lineares, e têm sua cristalinidade diminuída pela ramificação. Também podem ser obtidos por polimerização em cadeia e por etapas (Figura 6). 


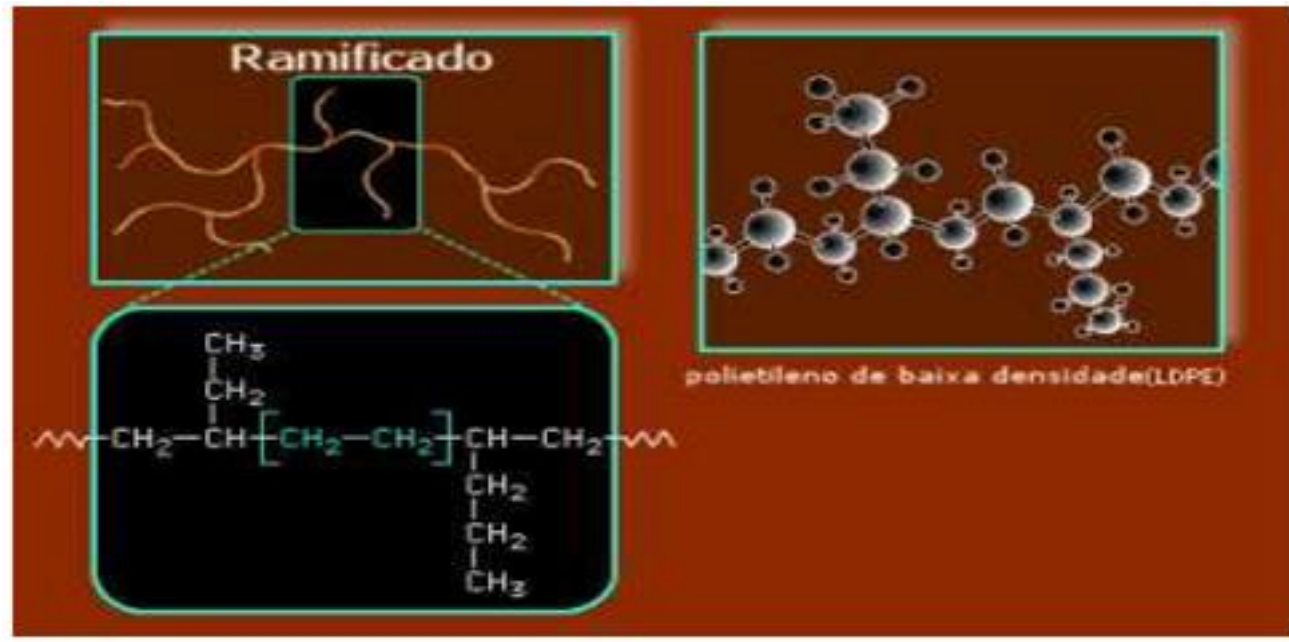

$\begin{array}{llllll}\text { Figura } & \text { 6. Ilustração } & \mathrm{da} & \text { estrutura } & \text { ramificada } & \text { (http:// }\end{array}$ www.quimica.matrix.com.br/artigos/polimeros.html, acesso em 08/05/2002).

Os polímeros reticulados são estruturas tridimensionais que têm sua origem na ligação covalente das moléculas lineares, em pontos que não são os seus extremos. $\mathrm{O}$ agente de ligação usado entre as cadeias e o método de reticulação pode fazer com que elas variem em número e em comprimento. Os polímeros também são chamados de reticulados quando o número de ligações cruzadas entre as moléculas é suficientemente alto. Nesses polímeros, as ligações covalentes se desenvolvem nas três direções do espaço e, como resultado, tornam-se altamente insolúveis e infusíveis. A Figura 7 ilustra uma estrutura molecular do tipo reticulada. 


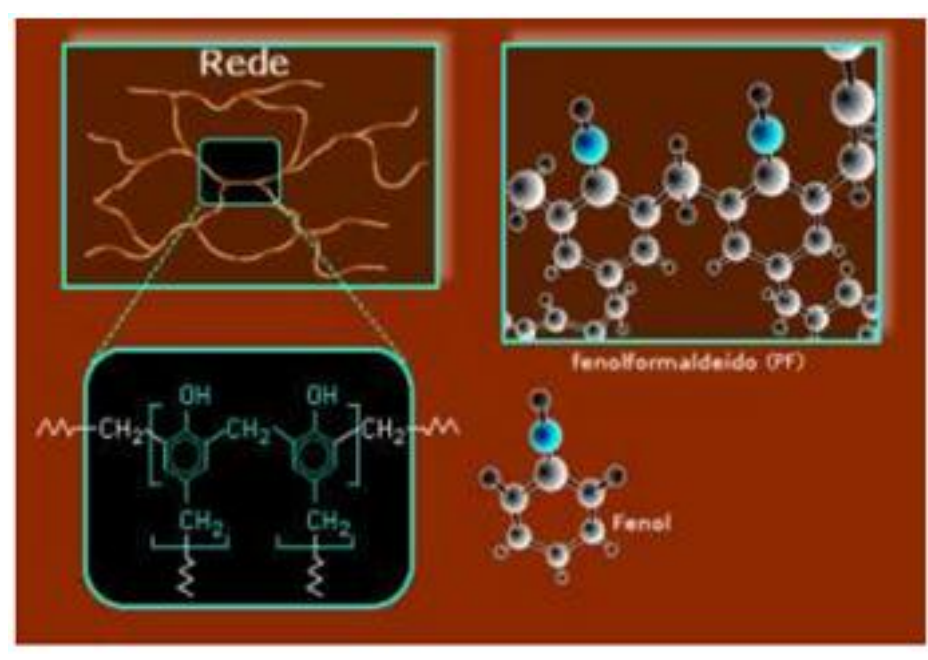

$\begin{array}{llllll}\text { Figura } & \text { Ilustração } & \text { da } & \text { estrutura } & \text { reticulada }\end{array}$ www.quimica.matrix.com.br/artigos/polimeros.html, acesso em 08/05/2002).

Os polímeros no estado amorfo são caracterizados pela disposição desordenada das moléculas, de formato irregular, não possuindo ordem estrutural em suas cadeias. Esse comportamento lembra visualmente uma "porção de espaguete cozido", em razão das ondulações e da irregularidade.

Outro conceito importante relacionado a polímeros consiste na cristalinidade. Segundo Agnelli (2000), a cristalinidade em polímeros consiste no alinhamento de segmentos de cadeias em um arranjo tridimensional perfeito. No caso de polímeros termoplásticos, tal propriedade nunca é total, podendo ser amorfos ou apresentar cristalinidade parcial (termoplásticos semicristalinos).

Algumas propriedades físicas e mecânicas relacionam-se diretamente com o grau de cristalinidade do polímero e da morfologia de suas regiões cristalinas. Quanto mais cristalinos os polímeros, maiores serão estas propriedades, como a rigidez, resistência química, densidade, estabilidade dimensional, resistência à abrasão, temperatura de fusão (Tm) e de transição vítrea $(\mathrm{Tg})$, etc. 
Entretanto, a cristalinidade causa a diminuição de outras propriedades como resistência ao impacto, alongamento na ruptura, claridade ótica e resistência ao fenômeno do stress-cracking (FST - fissuramento sob tensão).

Vários fatores favorecem a cristalinidade dos polímeros como a linearidade, taticidade e aditivos. O PEAD, por exemplo, com suas cadeias lineares apresenta um elevado grau de cristalinidade, em torno de 90\%. Já o PEBD, que apresenta cadeiras ramificadas, a cristalinidade se situa em $40 \%$.

A taticidade é caracterizada por uma ordem na disposição do grupo lateral (regularidade) conferindo, portanto, cristalinidade ao polímero.

Outro aspecto importante consiste nos aditivos. Os aditivos aparecem como substâncias estranhas ao polímero alojando-se entre suas cadeias, dificultando o empacotamento e, portanto, sua cristalinidade. Quando se adicionam plastificantes ao PVC, sua cristalinidade nominal reduz de $10 \%$ para zero.

Conforme mencionado acima, polímeros altamente cristalinos podem desencadear a ruptura da geomembrana por stress cracking. Segundo a ASTM D883, o fenômeno de stress cracking é definido pela como "uma ruptura interna ou externa em um plástico causada por tensões de tração menores que sua resistência mecânica num curto espaço de tempo”.

As tensões que causam o stress cracking podem estar presentes internamente ou externamente ou ainda ser uma combinação dessas tensões. O desenvolvimento de tais fissuras é freqüentemente acelerado pelo meio ambiente ao qual o plástico é exposto.

A alta cristalinidade que confere ao PEAD excelente resistência química e características de resistência é também responsável pela susceptibilidade ao stress cracking (HSUAN, 2000).

O FST pode ser explicado através da Figura 8. A microestrutura cristalina de uma geomembrana de PEAD é composta por uma série de lamelas com moléculas dobradas e 
ramificações laterais que oscilam para fora da lamela e, freqüentemente, se entrelaçam na lamela adjacente (Figura 8.a).

Quando se aplica uma tensão elevada a essa estrutura (Figura 8.b), as cadeias mantêmse unidas às lamelas adjacentes e as quebram em fragmentos que causam o escoamento e alongamento característicos de um ensaio de tração uniaxial (Figura 8.c). Contudo, quando baixas tensões são aplicadas (Figura 8.d), as ligações entre as cadeias têm tempo suficiente para lentamente se soltarem, provocando a separação das lamelas e gerando uma ruptura frágil (Figura 8.e) em comparação ao escoamento/alongamento previstos na quebra dúctil (HSUAN, 2000). 


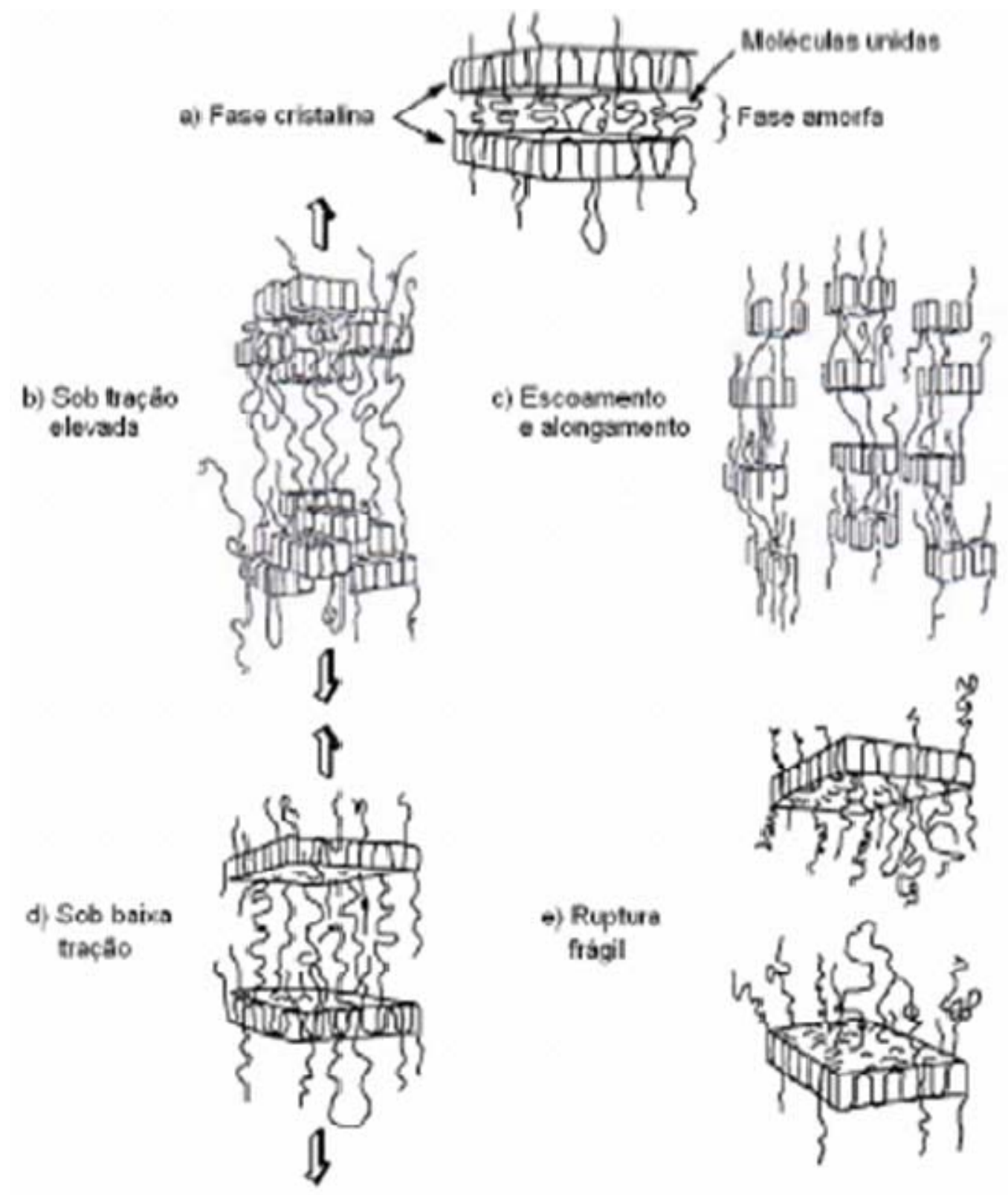

Figura 8. Estrutura lamelar do PEAD (HSUAN, 2000).

Os polímeros utilizados na fabricação de geossintéticos, como o polietileno (PE), o poliéster (PET) e o PVC (polivinil clorado) estão sujeitos ao fenômeno de stress cracking. No entanto, os polímeros de PVC e o PET apresentam menor susceptibilidade ao FST do que o polímero de PE e o PP.

Segundo Reddy \& Butul (1999), existem dois diferentes modos de ruptura por stress cracking: propagação rápida de fissuras ou propagação lenta de fissuras. A propagação rápida 
logicamente está associada a velocidades muito altas (acima de $300 \mathrm{~m} / \mathrm{s}$ ), e pode se espalhar em centenas de metros de comprimento. A propagação lenta de fissuras apresenta velocidades menores que $0,1 \mathrm{~m} / \mathrm{s}$, e ocorre numa proporção específica durante a vida útil da geomembrana. A velocidade de propagação é função do material polimérico, tensão aplicada, e temperatura.

A Figura 9 mostra alguns exemplos do fenômeno de stress cracking.
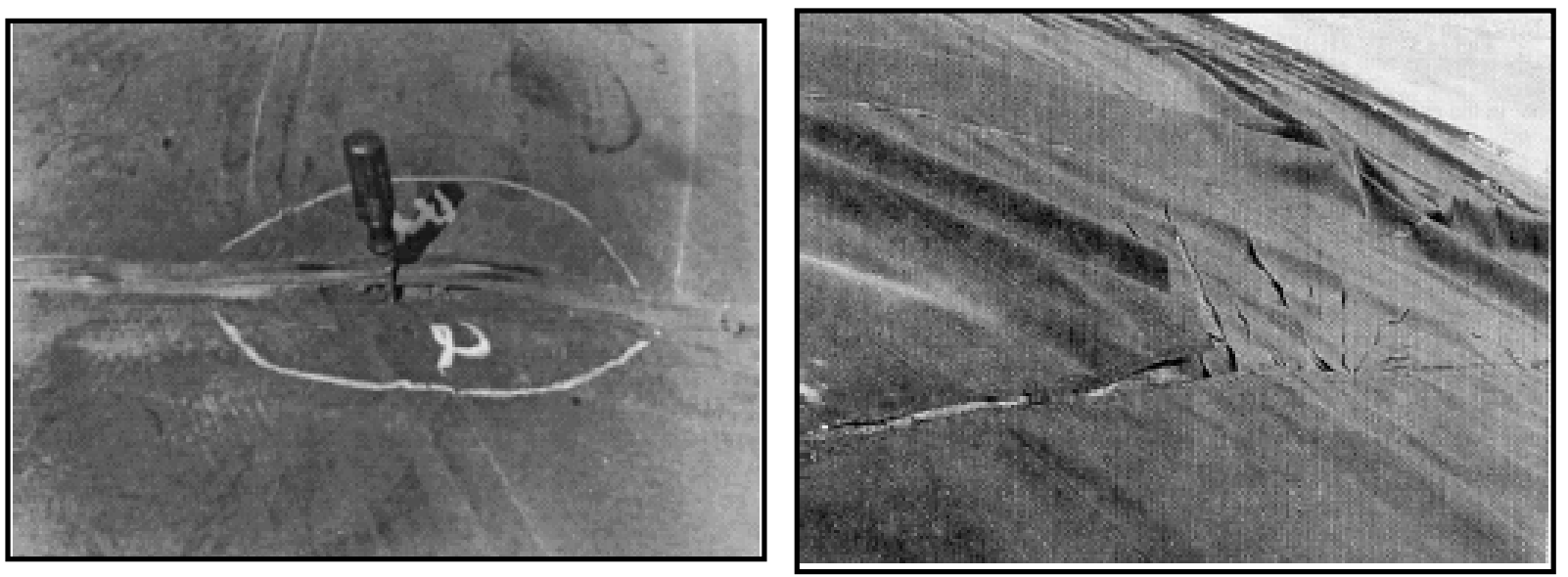

Figura 9. Stress cracking: (a) na borda de uma emenda (HSUAN, 2000); (b) propagação rápida (PEGGS, 1988).

Existem vários aspectos que afetam o comportamento do FST. Um deles consiste na temperatura. Com a aceleração da temperatura ocorre uma diminuição da resistência ao FST, evidenciada pela diminuição do tempo de ruptura. Além disto, a combinação do aumento da temperatura com agentes químicos pode reduzir ainda mais o tempo de ruptura de plásticos susceptíveis ao FST.

O fenômeno de FST pode ser avaliado através de ensaios de laboratório em geomembranas submetidas a solicitações mecânicas e em contato com fluidos agressivos. Um tipo de ensaio bastante utilizado para avaliação do FST consiste no ensaio de fluência. Este método é o mais recomendado, pois envolve a aplicação de tensões de tração, o 
monitoramento do tempo de ruptura, juntamente a sua imersão no fluido agressivo. Como exemplos de ensaio de fluência citam-se o método NCLT e SP - NCLT.

O método NCLT (Notched Constant Tensile Load Test - ASTM D5397) consiste em aplicar vários estágios de carga (de 20\% a 65\% da carga de escoamento da geomembrana) em corpos de prova padrão, imersos numa solução de Igepal CO 630 com concentração de $10 \%$ em volume e $90 \%$ de água, sob temperatura constante de $50^{\circ}$.

Os corpos de prova apresentam uma ranhura na região central, a qual corresponde a $20 \%$ da espessura da geomembrana. A Figura 10 mostra detalhes da ranhura realizados nos corpos de prova e uma foto microscópica da ranhura na geomembrana.

(a)

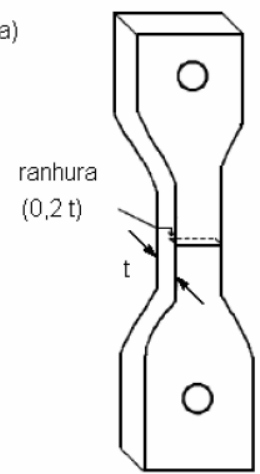

(b)

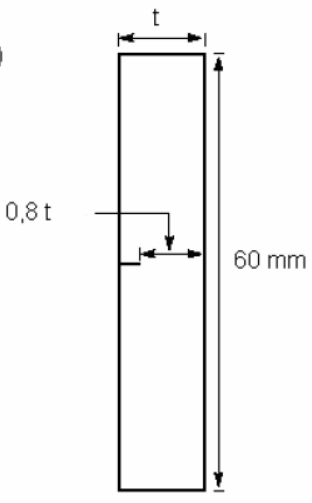

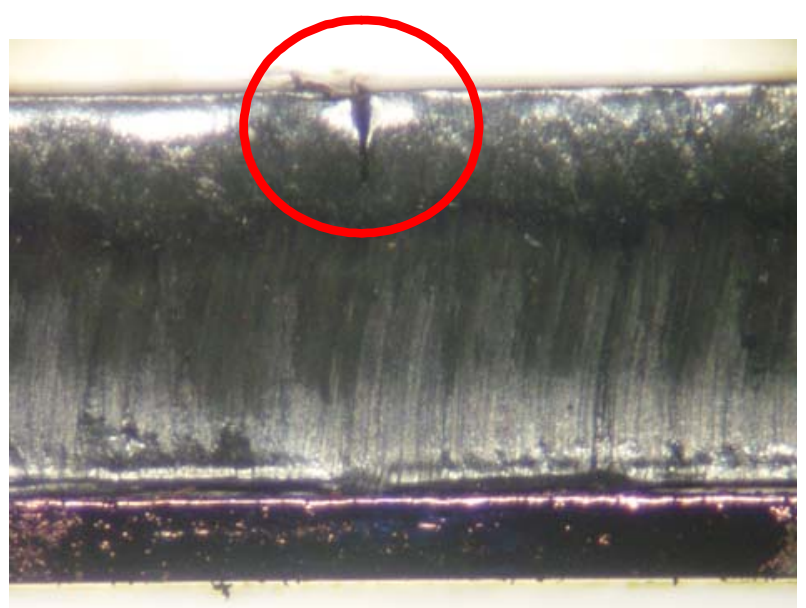

(b)

(a)

Figura 10. Detalhes da ranhura feito nos CP's utilizados no ensaio NCLT: (a) dimensões da ranhura; (b) foto microscópica da ranhura.

O resultado do ensaio consiste numa curva das tensões aplicadas versus seus respectivos tempos de ruptura. As curvas são divididas em duas partes. A primeira, de comportamento dúctil, apresenta um suave declive; enquanto a segunda, de comportamento frágil, apresenta um declive acentuado. A transição entre as duas partes das curvas pode ser do tipo degrau, joelho ou nariz (Figura 11). 
Uma informação importante desta curva é o tempo de transição $\left(T_{t}\right)$. O ponto de transição $\left(T_{t}\right)$ pode ser identificado como o ponto inicial da região frágil da curva. Quanto maior o tempo de transição $\left(\mathrm{T}_{\mathrm{t}}\right)$, menor a susceptibilidade de ocorrência do stress cracking na geomembrana. Koerner et al. (1993) recomendam um valor do tempo de transição mínimo de 100 horas.

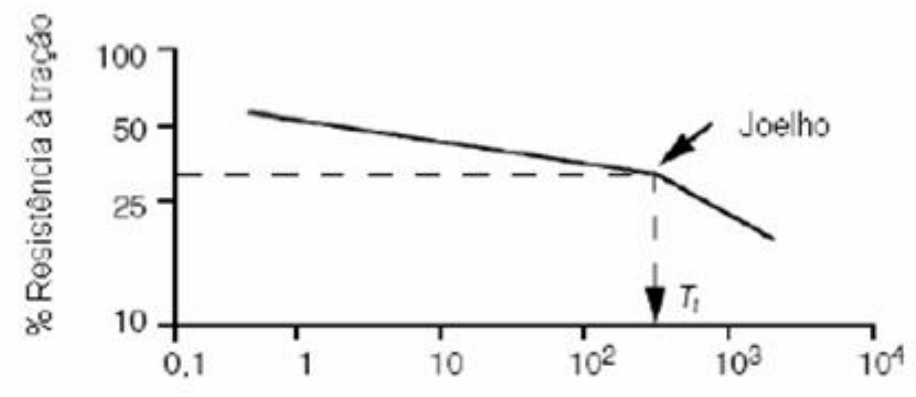

Tempo de ruptura (h)
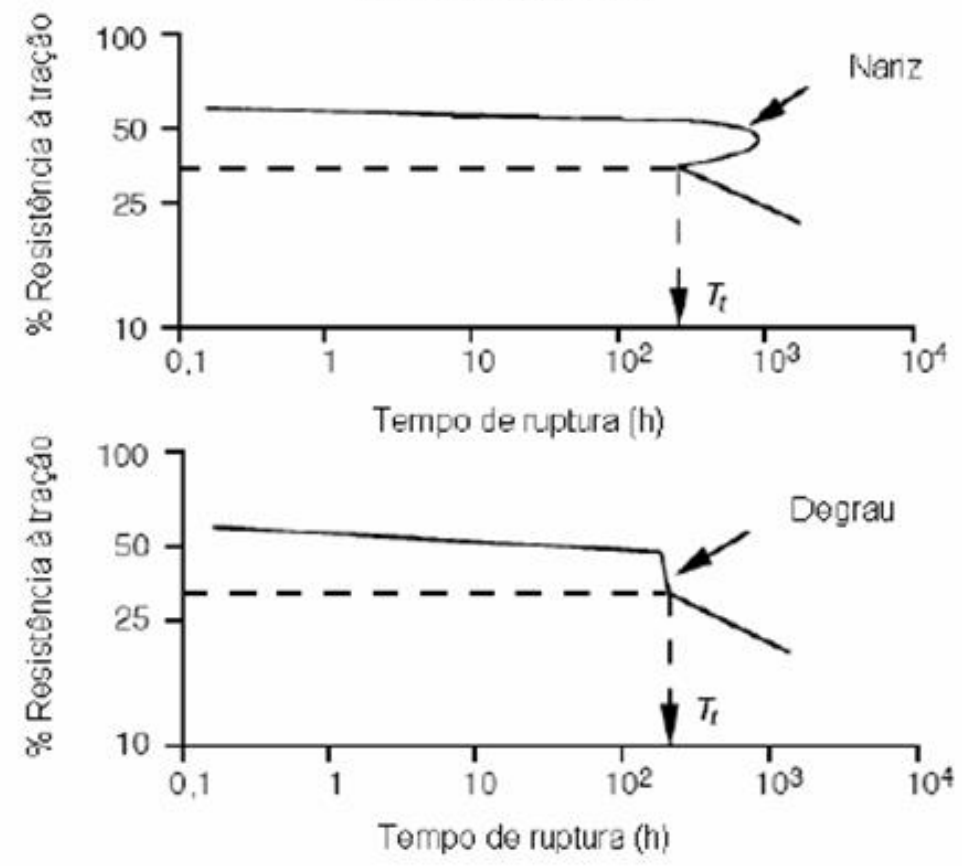

Figura 11. Curvas obtidas através do método de ensaio NCLT (HSUAN AND KOERNER, 1998).

Devido ao tempo total requerido neste método de ensaio, uma alternativa proposta prescrita pela norma ASTM D 5397 consiste no método SP - NCLT (Single Point-Notched 
Constant Tensile Load Test). Neste método é utilizado apenas um estágio de carga $(30 \%$ da resistência a tração no escoamento da geomembrana). São utilizados cinco corpos de prova e o tempo mínimo de ruptura deve ser de 200 horas. O valor da carga foi estabelecido a partir de um estudo de Hsuan \& Koerner (1995), onde se verificou que tal estágio de carga se apresentava na parte frágil da curva obtida pelo ensaio.

O Instituto de Pesquisa de Geossintéticos (GRI - Geosynthetic Research Institute) especifica a norma GM 10 (2003) para a avaliação do fenômeno do FST. O critério para aceitação ou recusa de uma amostra é baseado em ciclos de ensaios. No primeiro ciclo (ciclo A) são ensaiados cinco corpos de prova e o critério de aceitação estabelece que pelo menos quatro corpos de prova apresentem um tempo de ruptura $\left(\mathrm{T}_{\mathrm{r}}\right)$ mínimo de 300 horas. Caso ocorra o descumprimento do critério, as amostras são re-ensaiadas (ciclo B). Em último caso, utiliza-se o ciclo C, que corresponde ao ensaio NCLT, sendo que o tempo de transição $\left(T_{t}\right)$ deva ser superior a 100 horas.

Lavoie (2006) realizou um amplo estudo do fenômeno do FST em geomembranas virgens e degradadas sob diferentes condições. Neste trabalho, as geomembranas foram degradadas pela exposição à radiação ultravioleta, por envelhecimento térmico em estufa e pela compatibilidade química com soda cáustica e vinhaça. Os resultados dos ensaios NCLT mostraram que os processos de degradação a que as geomembranas foram submetidas são considerados catalisadores do fenômeno FST, pois ocorreram reduções da ordem de 50 a $60 \%$ no tempo de ruptura. Outra informação importante foi que os ensaios SP - NCLT mostraram o mesmo comportamento observado nos ensaios NCLT.

Vilar (2003) e Azambuja (2003) enfatizam que a presença de ranhuras e arranhões, deformações localizadas e a superposição de soldas por extrusão também podem ser a causa da ruptura por stress cracking. 


\subsection{Geotêxteis}

Geotêxteis são "produtos têxteis permeáveis utilizados com fundação, solo, rocha, ou qualquer outro material relacionado à engenharia geotécnica, como parte integrante de um projeto, estrutura ou sistema feito artificialmente" (ABNT 12.553).

Atualmente, os geotêxteis apresentam diversas funções em obras geotécnicas como separação, proteção, filtração, drenagem e reforço. Cita-se também a função de impermeabilização quando são impregnados por betume.

A maior parte dos geotêxteis é feito de polímeros de poliéster (PET) e polipropileno (PP). Em menor grau, são feitos de polímeros de polietileno (PE) e poliamida (PA).

Os geotêxteis são agrupados em função do arranjo estrutural de suas fibras: geotêxteis tecidos e não-tecidos.

Os geotêxteis tecidos são constituídos por materiais obtidos através do entrelaçamento de fios, filamentos ou outros componentes, segundo direções preferenciais, denominadas trama e urdume. A trama corresponde aos fios dispostos transversalmente à direção de fabricação do geotêxtil, enquanto urdume corresponde aos fios dispostos longitudinalmente.

Nesta categoria são utilizados quatro tipos principais de fibra: monofilamento, multifilamento, laminete e fibrilas. Os monofilamentos podem atingir centenas ou milhares de metros e constituem fibras individuais fabricadas com seção transversal circular ou oval. Por outro lado, os multifilamentos são formados pela associação de diversos filamentos (Figura 12b). Quando o produto extrusado apresenta-se lamelar, pode-se cortá-lo em fitas estreitas, originando os laminetes, ou cortá-los em pequenos elementos que, quando unidos, constituem as fibrilas. 

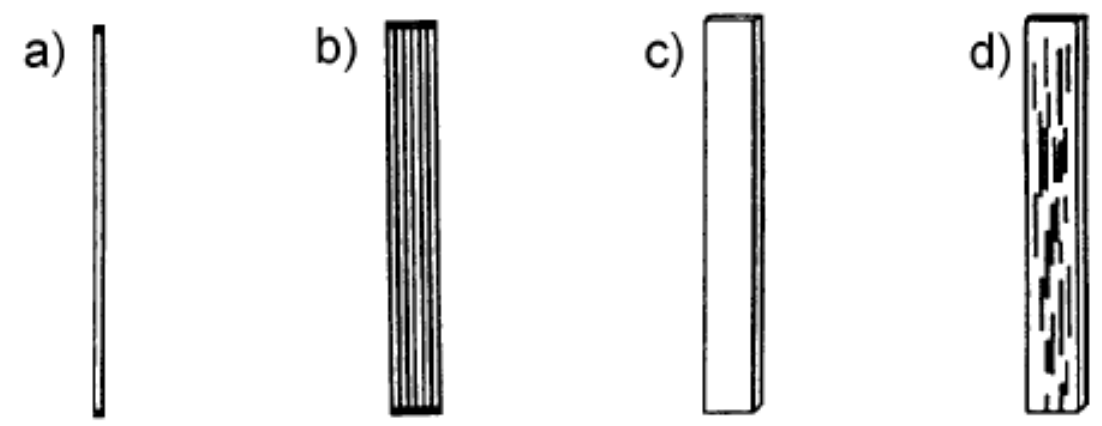

Figura 12. Tipos de fibras: geotêxteis tecidos: (a) monofilamentos; (b) multifilamentos; (c) laminetes; (d) fibrilas (BHATIA \& SMITH, 1996).

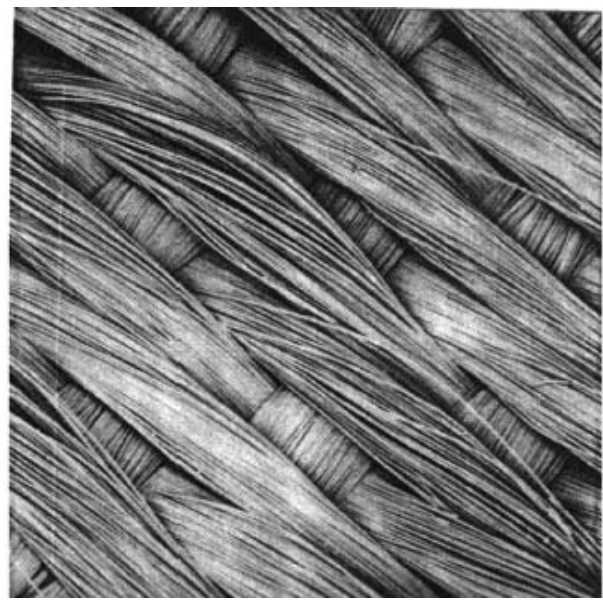

Multifilamento

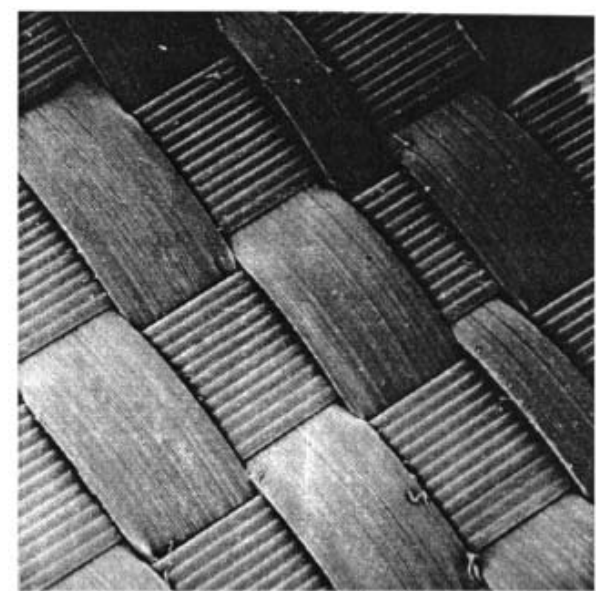

Laminete

Figura 13. Exemplos de geotêxteis tecidos (BHATIA \& SMITH, 1996).

Os geotêxteis não tecidos são compostos por fibras ou filamentos distribuídos aleatoriamente e interligados por processos mecânicos, térmicos e/ou químicos. Nesta categoria são utilizados dois tipos de fibras: as cortadas e os filamentos contínuos, ambas com seção transversal triangular. Os filamentos contínuos possuem grande extensão, enquanto as fibras apresentam comprimento reduzido.

O processo de fabricação dos geotêxteis não tecidos é denominado "spumbonding", que abrange desde a produção das fibras até a obtenção do produto final (mantas). 
Conforme o tipo de ligação das fibras, os geotêxteis podem ser do tipo agulhado, termoligado e resinado. No processo de agulhagem, as fibras dispostas na esteira rolante passam sob uma prancha constituída por uma série de agulhas dentadas. A ligação acontece mediante a penetração de agulhas, repetidas vezes, em toda a profundidade do material a fim de provocar entrelaçamento das fibras. Nos geotêxteis termoligados, a ligação acontece através da fusão parcial das fibras. E, nos geotêxteis resinados, a ligação ocorre através de alguma substancia química como, por exemplo, resina acrílica aplicada por imersão ou pulverização. A Figura 14 ilustra algumas estruturas de geotêxteis não tecidos.

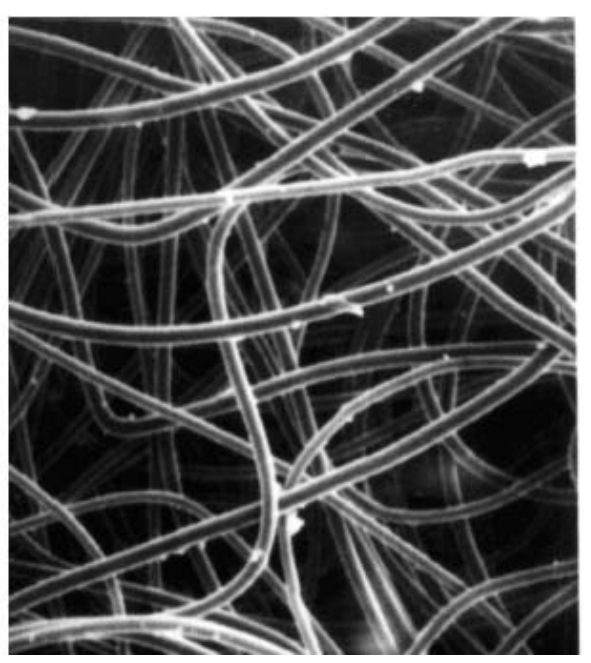

Agulhado

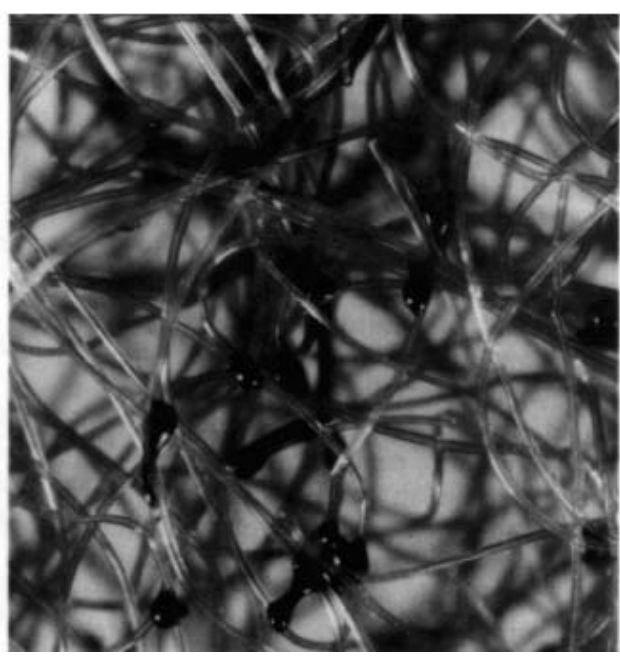

Termoligado

Figura 14. Exemplos de estruturas de geotêxteis não tecidos (BHATIA \& SMITH, 1996).

Os ensaios em geotêxteis também são regulamentados por normas americanas (ASTM), européias (ISO) e, por normas brasileiras (ABNT). Os principais ensaios em geotêxteis são apresentados na Tabela 3. 
Tabela 3. Ensaios realizados em geotêxteis (modificado de BUENO e VILAR, 2004).

\begin{tabular}{|c|c|}
\hline Propriedades & Norma \\
\hline \multicolumn{2}{|l|}{$\begin{array}{l}\text { Físicas } \\
\end{array}$} \\
\hline Massa por unidade de área (Gramatura) & NBR 12568, ISO 9864, ASTM D 3776 \\
\hline Espessura nominal & NBR 12569, ISO 9863, ASTM D 964 \\
\hline Porosidade & - \\
\hline \multicolumn{2}{|l|}{ Mecânicas } \\
\hline Compressibilidade & - \\
\hline \multicolumn{2}{|l|}{ Resistência à tração } \\
\hline - faixa larga & NBR 12824, ASTM D 4595, ISO 10319 \\
\hline - faixa restrita ou grab & ASTM D 4632 \\
\hline - multidirecional & ASTM D 5716 \\
\hline Resistência ao puncionamento & - \\
\hline - estático (CBR) & NBR 13359, ISO 12236 \\
\hline - dinâmico (queda do cone) & NBR 13359, ISO 12236 \\
\hline Resistência a propagação de rasgo & ASTM D 4533 \\
\hline Resistência a estouro & ASTM D 3786 \\
\hline Fluência & NBR 15226, ISO 13431, ASTM D 5262 \\
\hline \multicolumn{2}{|l|}{ Hidráulicas } \\
\hline Permissividade & ISO 11058 \\
\hline Transmissividade & ISSO 12958 \\
\hline \multicolumn{2}{|l|}{ Filtração } \\
\hline - abertura de filtração & NBR 15226, ISO 12956 \\
\hline - abertura aparente & ASTM D 4751 \\
\hline \multicolumn{2}{|l|}{ Desempenho } \\
\hline Resistência à tração confinada & - \\
\hline Fluência confinada & - \\
\hline \multicolumn{2}{|l|}{ Resistência de interface: } \\
\hline \multicolumn{2}{|l|}{ - arrancamento } \\
\hline - cisalhamento direto & ISO 13427 e ASTM D 5321 \\
\hline \multicolumn{2}{|l|}{ - plano inclinado } \\
\hline Resistência a abrasão & ISSO 13427 \\
\hline Filtração de longa duração & ASTM D 5101 \\
\hline Danos de Instalação & ISO 10722, ASTM D 5818 \\
\hline
\end{tabular}

\subsection{Proteção de Geomembranas}

\subsubsection{Danos Mecânicos em Geomembranas}

Os danos ou defeitos existentes na geomembrana podem ocorrer por deficiente fabricação ou pelas atividades de construção (instalação) e operação do aterro.

Os danos ou defeitos de fabricação correspondem a pequenos orifícios, variação de espessura e baixa resistência ao stress cracking. 
As atividades de construção compreendem o transporte, armazenamento, instalação, soldagem e colocação da camada drenante sobrejacente a geomembrana. Comumente, os danos decorrentes da construção se manifestam na forma de sulcos, cortes, rasgos, orifícios, furos, descolagens, tensões e ruptura da geomembrana.

Os danos de operação se devem ao contato de pedras ou pedregulhos com a geomembrana sob tensões normais estáticas provenientes do carregamento dos resíduos. Os tipos de danos que podem ocorrer nesta fase são orifícios, rasgos, sulcos e rupturas.

Segundo os primeiros estudos sobre danos em geomembranas apresentados por Nosko et al. (1996) apud Lopes (2006), 25\% dos danos ocorrem durante a instalação da geomembrana, $73 \%$ durante a fase de colocação da camada drenante e $2 \%$ durante a fase de operação do aterro.

Dos danos que ocorrem durante a instalação das geomembranas, os pesquisadores atribuem $61 \%$ a extrusões deficientes, $18 \%$ a fusões deficientes por sobreaquecimento, $17 \%$ a punção devido a pedras existentes no solo subjacente e 4\% a cortes decorrentes das operações de colocação e ensaios.

Dos danos ocorridos durante a fase de colocação da camada drenante, $68 \%$ são devidos a pedras angulosas, a inaceitáveis dimensões das partículas constituintes da camada drenante ou ao deficiente dimensionamento do geotêxtil de proteção; $16 \%$ devido ao equipamento pesado usado para espalhar a camada drenante, e $16 \%$ devido à incorreta utilização do utensílio utilizado para verificar a espessura da camada drenante.

Desta forma, para que a geomembrana garanta um bom desempenho ao longo da vida útil do aterro, torna-se necessário verificar a sua integridade e conformidade durante as fases de construção e de operação do aterro. 
Os ensaios de conformidade asseguram que as características da geomembrana fornecida se encontram em conformidade com as especificações técnicas dos fabricantes, e também para verificar possíveis defeitos de fabricação.

Os ensaios de verificação de integridade asseguram que a integridade da geomembrana não será afetada durante a construção dos aterros. São divididos em dois grupos: o primeiro usado para detecção de defeitos durante a instalação e ligação dos painéis das geomembranas, e o segundo usado após a colocação e ligação dos painéis de geomembranas (para detectar defeitos decorrentes da colocação da camada drenante sobrejacente à geomembrana).

Segundo Lopes (2006), depois de efetuado o controle de qualidade de fabricação não há razões para ocorrerem defeitos nos painéis das geomembranas, a não serem os ocorridos durante o transporte e colocação. Portanto, os ensaios de verificação da integridade da geomembrana durante a colocação e ligação dos painéis de geomembrana referem-se principalmente a integridade das emendas.

Os ensaios para verificação da resistência das emendas (ensaios destrutivos) dependem do tipo de geomembrana, que pode condicionar o tipo de emenda. Tais ensaios são realizados em emendas efetuadas por extrusão e termofusão, sobre amostras cortadas nas emendas existentes. Tem como objetivo avaliar a resistência ao cisalhamento e ao arrancamento das emendas. Na Tabela 4 são apresentadas as normas de ensaios mais utilizadas para avaliação destas propriedades.

Tabela 4. Normas de ensaio para avaliação da resistência de emendas para vários tipos de geomembranas (DANIEL \& KOERNER, 1995).

\begin{tabular}{ccc}
\hline Tipo de geomembrana & $\begin{array}{c}\text { Ensaio de resistência ao } \\
\text { cisalhamento }\end{array}$ & $\begin{array}{c}\text { Ensaio de resistência ao } \\
\text { arrancamento }\end{array}$ \\
\hline PEAD & ASTM D 4437 & ASTM D 4437 \\
PEBD & ASTM D 6392 & ASTM D 6392 \\
\hline CSPE & ASTM D 751 & ASTM D 413 \\
\hline \multirow{2}{*}{ PVC } & ASTM D 3083 & ASTM D 413 \\
& ASTM D 6392 & ASTM D 6392 \\
\hline
\end{tabular}


Os ensaios de verificação da continuidade das emendas também dependem do tipo de geomembrana e do tipo de emenda e, são realizados ao longo de todo o comprimento das emendas e em todos os tipos de emendas. A Tabela 5 apresenta os tipos de ensaio de acordo com os tipos de emendas e geomembranas.

Tabela 5. Métodos de ensaios não destrutivos conforme os tipos de emendas e de geomembranas (DANIEL \& KOERNER, 1995).

\begin{tabular}{|c|c|c|}
\hline Métodos de ensaios mais comuns & Tipo de emenda & Tipo de geomembrana \\
\hline Jato de ar & Química colagem & Todas exceto PEAD \\
\hline Haste metálica & Todas & Todas \\
\hline Pressão de ar & Termofusão dupla & Todas \\
\hline Vácuo & Todas & Todas \\
\hline Arame elétrico & Todas & Todas \\
\hline Vibração & $\begin{array}{l}\text { Química } \\
\text { Colagem } \\
\text { Termofusão }\end{array}$ & PEAD, PEBD, PVC \\
\hline Impedância plana & $\begin{array}{c}\text { Química } \\
\text { Colagem } \\
\text { Termofusão }\end{array}$ & PEAD, PEBD, PVC \\
\hline Sombra & $\begin{array}{l}\text { Termofusão } \\
\text { Extrusão }\end{array}$ & PEAD, PEBD \\
\hline
\end{tabular}

Os ensaios realizados após a colocação e ligação dos painéis de geomembranas destinam-se a detectar somente os defeitos resultantes das operações de construção que implicam na fuga de fluidos. Os métodos são divididos em dois grupos conforme a geomembrana se encontra coberta ou não pelas camadas sobrejacentes.

A Tabela 6 apresenta uma síntese dos métodos de ensaios mais comuns. Descrevem-se a seguir o mecanismo de funcionamento destes métodos. 
Tabela 6. Métodos de ensaios de verificação da estanqueidade da geomembrana após a sua colocação e ligação dos painéis (adaptado de CFGG 2003).

\begin{tabular}{|c|c|c|c|}
\hline Métodos de ensaio & $\begin{array}{c}\text { Geomembrana } \\
\text { não coberta }\end{array}$ & $\begin{array}{c}\text { Geomembrana } \\
\text { coberta }\end{array}$ & Observações \\
\hline $\begin{array}{c}\text { Jato ou poça de } \\
\text { água }\end{array}$ & $\operatorname{sim}$ & não & $\begin{array}{l}\text { - só para GMs não condutoras } \\
\text { - materiais em contato com a } \\
\text { superfície inferior da GM têm de } \\
\text { ser condutores } \\
\text { - } 200 \text { a } 300 \mathrm{~m}^{2} / \mathrm{h} / \text { operador } \\
\text { - defeitos da ordem de milímetros }\end{array}$ \\
\hline Faísca Elétrica & $\operatorname{sim}$ & não & $\begin{array}{l}\text { - só para GMs não condutoras } \\
\text { - materiais em contato com a } \\
\text { superfície inferior da GM têm de } \\
\text { ser condutores } \\
\text { - } 5000 \text { a } 8000 \mathrm{~m}^{2} / \mathrm{h} / \text { operador } \\
\text { - defeitos da ordem de milímetros }\end{array}$ \\
\hline $\begin{array}{l}\text { Sistema fixo de } \\
\text { detecção e } \\
\text { localização de } \\
\text { orifícios }\end{array}$ & $\operatorname{sim}$ & $\operatorname{sim}$ & $\begin{array}{l}\text { - colocação prévia de sensores no } \\
\text { solo de suporte } \\
\text { - só para GMs não condutoras } \\
\text { - materiais em contato com a } \\
\text { superfície inferior e superior da } \\
\text { GM têm de ser condutores } \\
\text { - } 5 \text { a } 12 \text { minutos (área máxima de } \\
\text { prospecção } 10000 \mathrm{~m}^{2} \text { ) }\end{array}$ \\
\hline $\begin{array}{l}\text { Geomembrana } \\
\text { condutora }\end{array}$ & $\operatorname{sim}$ & $\operatorname{sim} *$ & $\begin{array}{l}\text { - necessidade de GMs condutoras } \\
\text { - GM deve estar seca } \\
\text { - } 6000 \text { a } 8000 \mathrm{~m}^{2} / \text { dia/máq./ } 2 \\
\text { operadores } \\
\text { - defeitos da ordem de milímetros }\end{array}$ \\
\hline $\begin{array}{l}\text { Sonda elétrica } \\
\text { móvel }\end{array}$ & não & $\operatorname{sim} *$ & $\begin{array}{l}\text { - só para GMs não condutoras } \\
\text { - materiais em contato com a } \\
\text { superfície inferior e superior da } \\
\text { GM têm de ser condutores } \\
\text { - } 150 \text { a } 250 \mathrm{~m}^{2} / \mathrm{h} / \text { operador } \\
\text { - defeitos da ordem de milímetros }\end{array}$ \\
\hline
\end{tabular}

\section{Ensaio do Jato ou Poça de Áqua}

Este método de ensaio utiliza dois eletrodos, um passivo ligado ao subsolo e outro ativo ligado a um jato d'água ou a uma ferramenta utilizada para espalhar a água, sendo que ambos os eletrodos estão ligados a um gerador de corrente contínua. Se houver um orifício sobre a geomembrana, a água entra em contato com o solo carregado negativamente e o 
circuito se fecha. Um sinal sonoro avisa ao operador da existência do defeito. A Figura 15 ilustra o método do jato ou poça d'água.

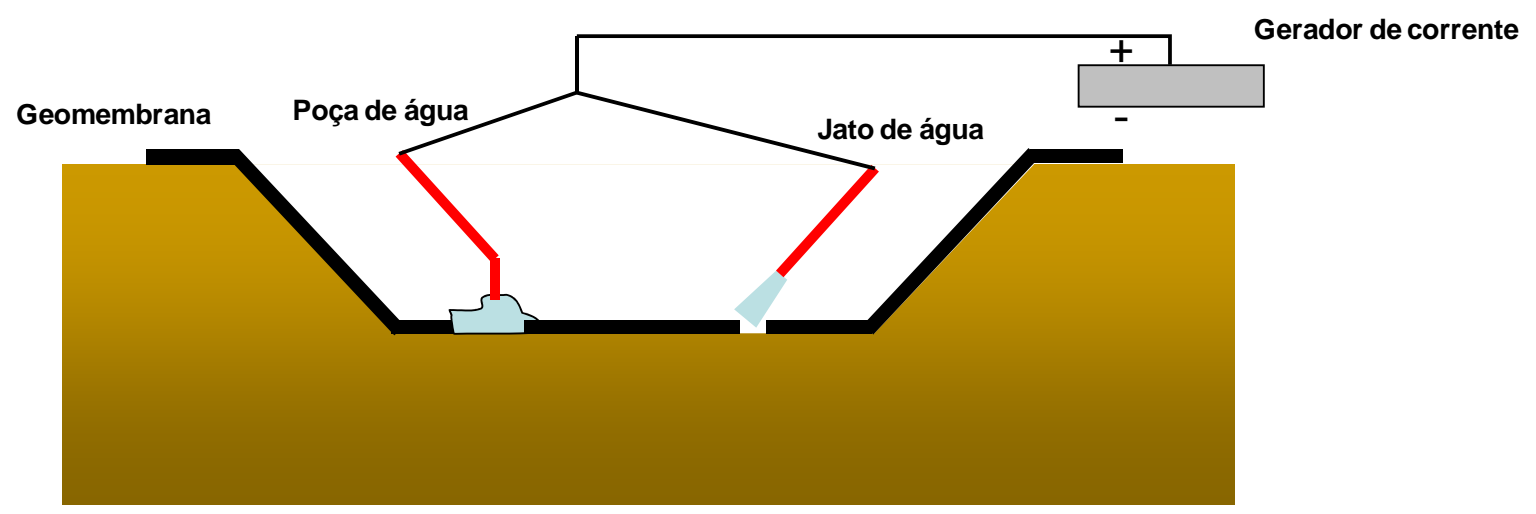

Figura 15. Ilustração do ensaio do jato ou poça d'água (CFG, 2003; LOPES, 2006).

\section{$\underline{\text { Ensaio da Faísca Elétrica }}$}

Este método de ensaio também se utiliza um gerador de baixa corrente elétrica e elevada tensão ligados a dois eletrodos. Um eletrodo (passivo) é ligado ao subsolo e o outro (ativo) é ligado a uma haste com escova ou barra metálica na ponta, que é passada lentamente sobre a superfície superior da geomembrana.

A geomembrana (não condutora) funciona como um isolante. Assim, se houver um orifício sobre a geomembrana, o circuito se fecha e uma faísca é emitida, acompanhada de um sinal sonoro. 


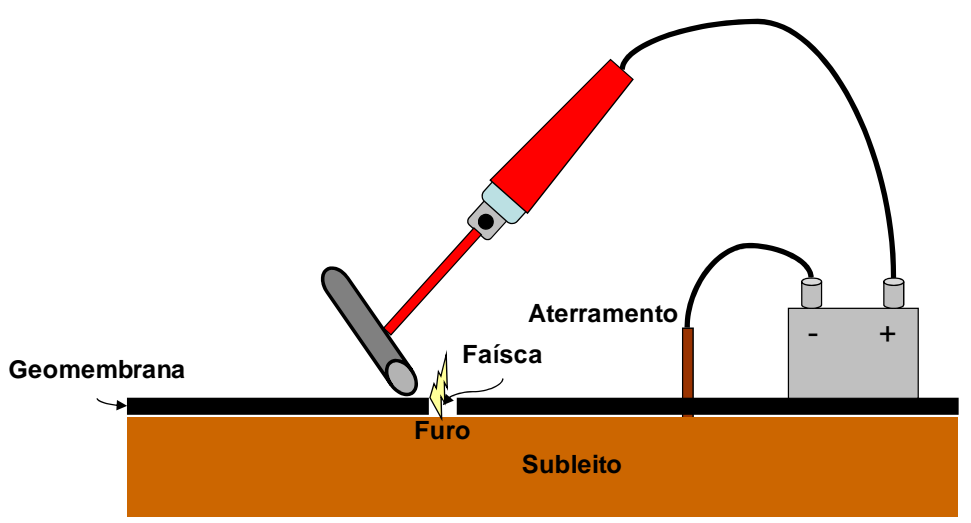

Figura 16. Ilustração do ensaio da Faísca (CFG, 2003; LOPES, 2006).

\section{Ensaio com Sistema Fixo de Detecção e Localização de Furos}

Ao contrário dos ensaios descritos acima, o ensaio com sistema fixo de detecção e localização de furos permite a verificação de furos após a cobertura da geomembrana.

Neste ensaio, faz-se necessário, antes da colocação da geomembrana, a introdução de uma rede de sensores no solo segundo uma malha pré-definida. Cada sensor é ligado através de um cabo elétrico a um aparelho de aquisição de dados. Após a colocação da geomembrana, ou também da camada de proteção e da camada drenante, instala-se um gerador de corrente elétrica ligado a dois eletrodos. Um eletrodo é colocado acima da geomembrana e o outro é ligado ao solo de fundação. Aplicando-se uma corrente elétrica, pode-se medir a densidade da corrente sob a geomembrana através dos diversos sensores. Qualquer perfuração da geomembrana provoca uma anomalia na distribuição da densidade da corrente elétrica. Este método permite localizar os orifícios da geomembrana com bastante precisão (Figura 17). 


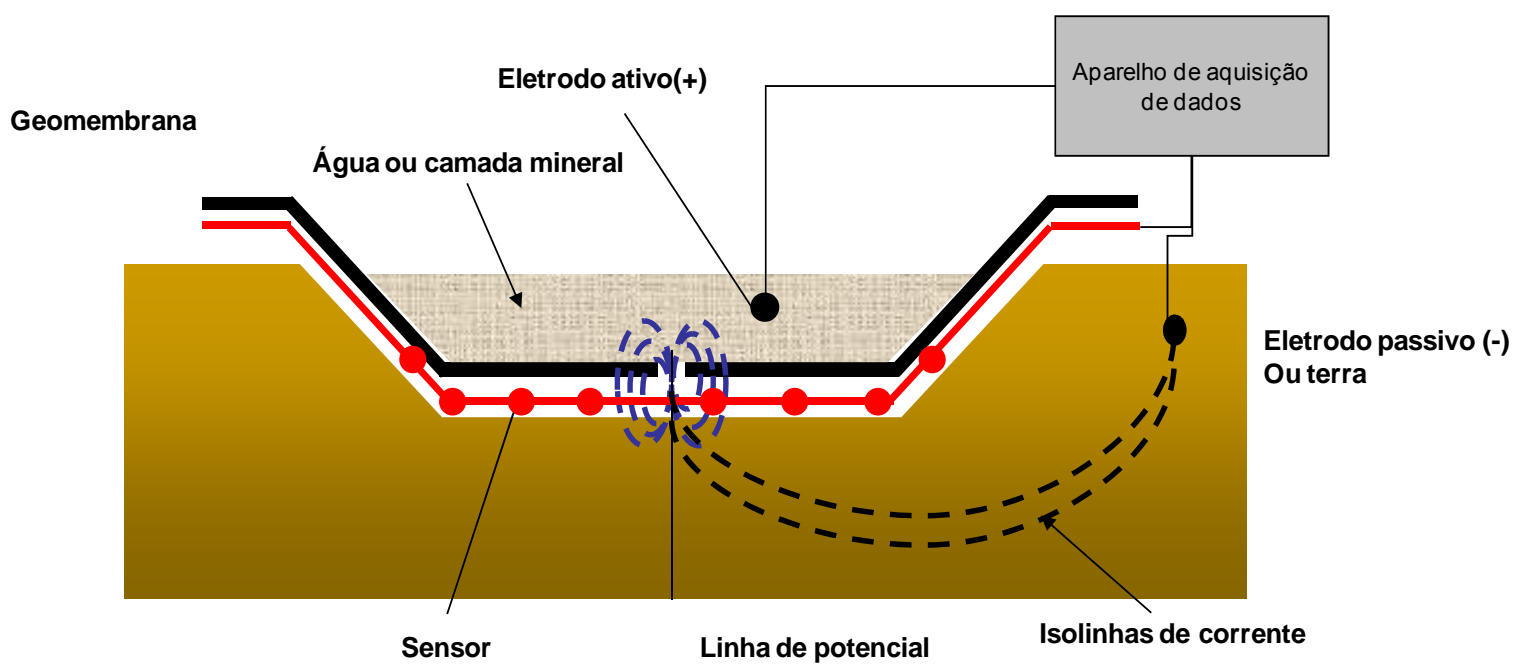

Figura 17. Ilustração do ensaio com sistema fixo de detecção e localização de furos (CFG, 2003; LOPES, 2006).

\section{$\underline{\text { Ensaio com Geomembrana Condutora }}$}

O ensaio da geomembrana condutora utiliza uma camada condutora fina $(0,1 \mathrm{~mm})$ abaixo da geomembrana. Começa-se por carregar uma placa condutora de neoprene, colocada sobre a superfície superior da geomembrana, com uma tensão variando de 15 a $30 \mathrm{kV}$. Esta tensão é transmitida para a camada condutora através do efeito capacitivo. Em seguida, com ao auxílio de uma vassoura elétrica, faz-se a prospecção da superfície superior não condutora da geomembrana. Se houver um orifício, estabelece-se uma corrente, gerando uma faísca e/ou sinal sonoro (Figura 18). 


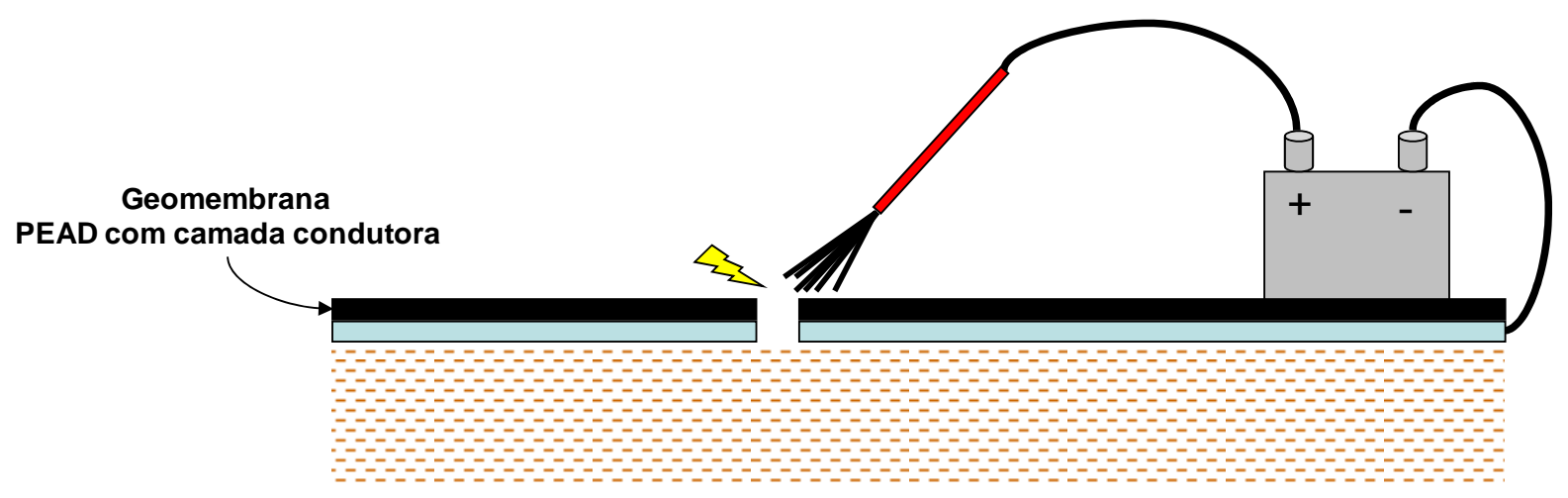

Figura 18. Ilustração do ensaio da geomembrana condutora (CFG, 2003; LOPES, 2006).

\section{Ensaio da Sonda Elétrica Móvel}

O ensaio da sonda elétrica móvel só pode ser utilizado em geomembranas cobertas. Este ensaio também utiliza dois eletrodos ligados a um gerador de corrente contínua. Um eletrodo é colocado no solo da fundação e outro, é colocado no material que cobre a superfície superior da geomembrana, estabelecendo-se uma diferença de potencial entre o solo exterior e o meio interior.

Com a ajuda de uma sonda elétrica móvel são efetuadas medidas de potencial elétrico, segundo uma densidade pré-determinada. Uma mudança de sinal nos valores medidos pode indicar a presença de um orifício. Como o campo de potencial diminui à medida que a sonda se afasta do eletrodo, se verificar um aumento de potencial, significa que a sonda está próxima de um orifício. 


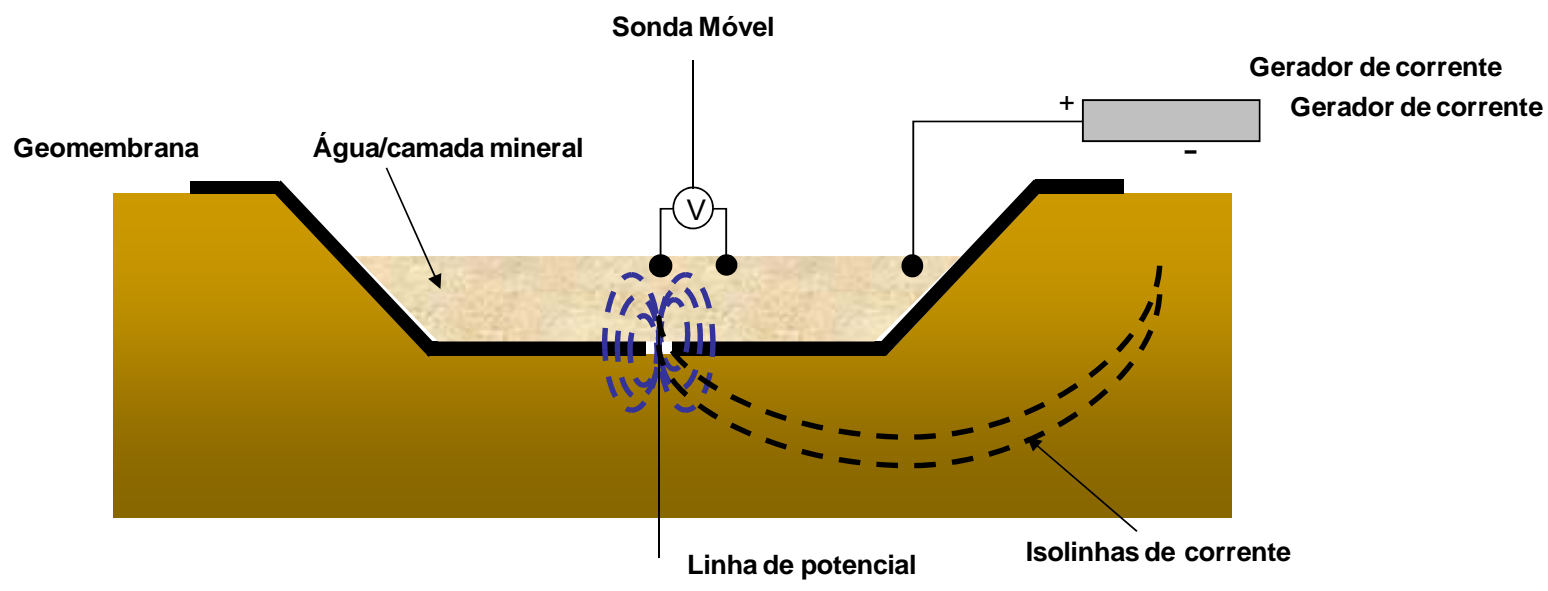

Figura 19. Ilustração do ensaio da sonda móvel (CFG, 2003; LOPES, 2006).

\subsubsection{Desempenho de Camadas de Proteção}

Frente às diferentes solicitações durante as fases de instalação e operação de aterros, vários autores como Tognon et al. (2000), Bouazza et al. (2002) e Seeger \& Müller (1996), dentre outros, sugerem a introdução de uma camada de proteção de forma a prevenir danos mecânicos e também minimizar as tensões e deformações induzidas na geomembrana.

Vários produtos geossintéticos são comumente utilizados como camadas de proteção de geomembranas. As especificações variam de país para país dependendo da filosofia de projeto adotada. Nos Estados Unidos, por exemplo, são freqüentemente utilizados geotêxteis não tecidos com baixa gramatura $\left(200 \mathrm{~g} / \mathrm{m}^{2}\right.$ a $\left.600 \mathrm{~g} / \mathrm{m}^{2}\right)$. Ao contrário, em países da Europa, na Alemanha em particular, geotêxteis não tecidos com elevada gramatura $\left(>2000 \mathrm{~g} / \mathrm{m}^{2}\right)$ são geralmente utilizados em casos de aterros de pequenos tamanhos, onde há situação de baixo carregamento. Para aterros de elevada altura (situação de carregamento pesado) são utilizados materiais alternativos como camadas de geotêxteis preenchidas com areia e produtos geossintéticos de amortecimento sem material de preenchimento (BOUAZZA et al. 2002; TOGNON, 1999). 
Narejo (1995) também sugere como materiais de proteção para geomembranas tapetes pneumáticos, geocompostos bentoníticos, georedes, tapetes domésticos ou industriais, e composição dos materiais acima.

No entanto, para avaliar o desempenho destas camadas de proteção, torna-se necessário o estabelecimento de um estado limite aceitável para as deformações que ocorrem na geomembrana. A seleção deste valor tem sido discutida recentemente por alguns pesquisadores, apresentando distintas opiniões com relação ao modo como estas deformações devem ser limitadas.

Segundo Bouazza et al. (2002) duas metodologias têm sido utilizadas, uma baseada na prevenção de punção na geomembrana a curto prazo e a outra para garantir o desempenho da geomembrana a longo prazo. $\mathrm{O}$ aspecto a curto prazo corresponde à prevenção de danos como rasgos profundos, alongamento além do ponto de escoamento ou perfurações na geomembrana durante os processos de fabricação, transporte e instalação. Esta aproximação é bastante utilizada e comanda, na maior parte, os casos de aprovação das camadas de proteção, principalmente nos Estados Unidos. O método de projeto se baseia na seleção de uma camada de proteção de geotêxtil com gramatura (massa por unidade de área) suficiente para fornecer um fator de segurança global contra o escoamento da geomembrana.

A longo prazo, o critério para estimativa do desempenho das camadas de proteção consiste na limitação de deformações locais na geomembranas para um valor aceitável, de forma que não ocorra o fenômeno de stress cracking (aparecimento de fissuras sob tensão). Segundo as regulamentações técnicas para certificação das camadas de proteção do Instituto Federal para Ensaio e Pesquisa de Materiais - Bundesanstalt für Materialforschung Undprüfung - (BAM), o valor limite para deformações em geomembranas é 0,25\% (SEEGER \& MÜLLER, 1996; GALAGHER ET AL., 1998; ZANZINGER, 1999; ROWE, 1998). 


\subsubsection{Método baseado no desempenho a curto prazo}

Segundo Reddy \& Saichek (1998), os estudos iniciais sobre proteção de geomembranas é baseado na introdução de geotêxteis de diferentes gramaturas (massa por unidade de área) sobre ou abaixo da geomembrana em ensaios de impacto e punção, constatando-se o aumento da resistência à punção e ao impacto devido à introdução do geotêxtil.

Por sua vez, Koerner e seus co-pesquisadores da University of Drexel desenvolveram uma aproximação teórica, um extensivo programa experimental de laboratório e um procedimento de projeto simplificado para estimar o desempenho de uma camada de proteção para geomembranas. Este desenvolvimento foi publicado numa série de três artigos divididos em análise teórica (WILSON-FAHMY ET AL., 1996), parte experimental (NAREJO ET AL., 1996) e exemplos de projeto (KOERNER ET AL., 1996).

A análise teórica apresentada por Wilson-Fahmy et al. (1996) é baseada na teoria de uma geomembrana tracionada, sobreposta a uma protuberância isolada e elevada sobre um subleito rígido. O objeto de punção é caracterizado pela sua forma e altura acima da superfície do subleito. O comportamento da geomembrana é considerado em termos de seu comportamento carga-alongamento, e o material de proteção é caracterizado pela sua espessura (gramatura) e o comportamento carga-alongamento.

A geometria utilizada na análise é apresentada na Figura 20, onde $\mathbf{r}_{\mathbf{0}}$ é o raio da ponta da protuberância esférica; $\mathbf{H}$ é a altura da protuberância; $\mathbf{p}_{\mathbf{i}}$ é pressão hidrostática submetida à geomembrana; $\mathbf{F}_{\mathbf{i}}$ é a força total na geomembrana; $\mathbf{d}_{\psi}$ é a variação do ângulo tangente ao talude; $\mathbf{d}_{\mathbf{s}}$ é o comprimento de corda do elemento; $\mathbf{i}$ se refere à posição instantânea da geomembrana e $\left(\mathbf{R}_{\mathbf{i - x}}\right)$ corresponde ao raio a partir do centro da protuberância para um elemento infinitesimal da geomembrana. 


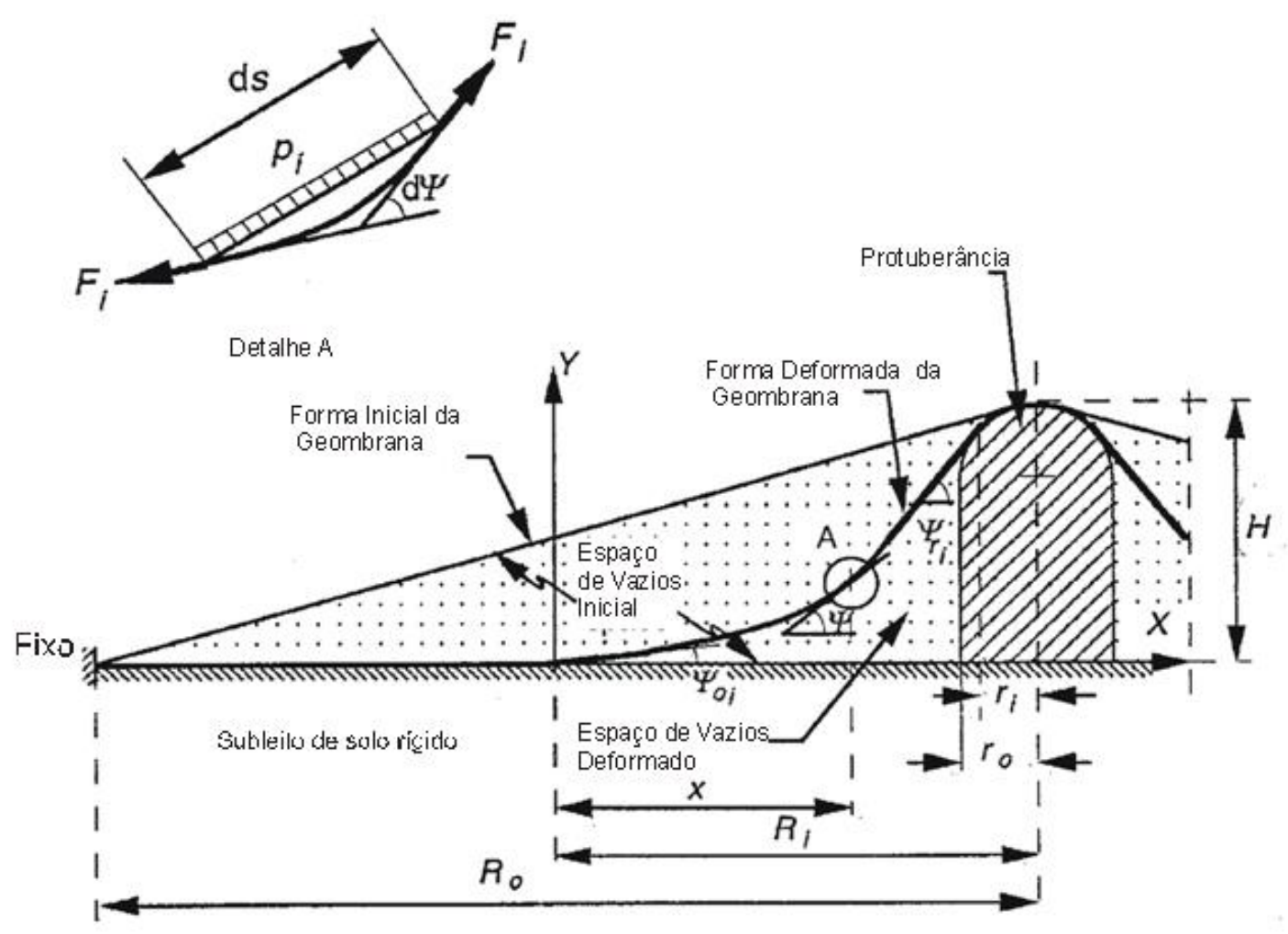

Figura 20. Geometria utilizada na análise de punção em geomembranas (WILSON-FAHMY ET AL., 1996).

Inicialmente, a geomembrana assume a forma cônica a partir de uma posição fixa no subleito sobre o espaço vazio, conforme mostrado na figura. Apenas no topo a geomembrana assume a forma esférica da ponta protuberante. A extremidade externa da geomembrana é considerada estar restrita pela carga normal aplicada.

Esta teoria admite que o carregamento da geomembrana seja hidrostático. Com o aumento da pressão, a geomembrana se deforma reduzindo o espaço vazio, ao mesmo tempo em que sua superfície muda de forma cônica para uma forma assimétrica. A deformação aumenta com o aumento da pressão até a geomembrana encontrar a tensão de escoamento ou de ruptura ou até se adaptar completamente ao objeto protuberante e ao subleito adjacente.

Para simplificar a análise, Wilson-Fahmy et al. (1996) assumem as seguintes hipóteses: 
- A geomembrana não possui rigidez à flexão.

- O comportamento carga - alongamento da geomembrana é elástico linear.

- A parte da geomembrana em contato com a ponta protuberante é assumida estar num estado de tensões isotrópicas por analogia a teoria da membrana sujeita a carregamento hidrostático.

- O contato entre a geomembrana e a ponta protuberante não possui atrito.

- As deformações por tração deixam de acontecer após a geomembrana adaptarse ao subleito.

- A parte suspensa da geomembrana está num estado de tensões isotrópicas.

- O efeito do coeficiente de Poisson é negligenciado.

Assim, a equação abaixo é derivada a partir da força de equilíbrio de um elemento infinitesimal de uma geomembrana, assumindo a forma de um arco de círculo e submetido à pressão hidrostática $\mathbf{p}_{\mathbf{i}}$ :

$$
2 \cdot \pi \cdot\left(R_{i}-x\right) \cdot p_{i} \cdot d s=2 \cdot F_{i} \cdot \sin \left(\frac{d \varphi}{2}\right)
$$

Onde:

- $\left(\mathrm{R}_{\mathrm{i}}-\mathrm{x}\right) \rightarrow$ raio a partir do centro do objeto protuberante para um elemento infinitesimal da geomembrana;

- $\quad$ ds $\rightarrow$ comprimento de corda do elemento;

- $\mathrm{F}_{\mathrm{i}} \rightarrow$ força total na geomembrana num instante $\mathbf{i}$;

- $\mathrm{d} \psi \rightarrow$ variação do ângulo tangente da inclinação.

Como d $\psi$ é um ângulo pequeno, assume-se que $\sin (d \varphi / 2)$ é igual a $d \varphi / 2$. Assim, a Equação 1 se reduz para: 


$$
\left(\frac{d \varphi}{d s}\right)=\frac{2 \cdot \pi \cdot\left(R_{i}-x\right) \cdot p_{i}}{F_{i}}
$$

E,

$$
\left(\frac{d \varphi}{d s}\right)=\left(\frac{d \varphi}{d x}\right) \cdot\left(\frac{d x}{d s}\right)=\cos \varphi \cdot\left(\frac{d \varphi}{d x}\right)
$$

Combinando as Equações 2 e 3, tem-se que

$$
\frac{\pi \cdot p_{i} \cdot\left(2 R_{i}-x^{2}\right)}{F_{i}}=\sin \varphi+C
$$

Sendo C uma constante.

As condições de contorno da geometria são definidas da seguinte maneira: na posição $\mathrm{x}=0, \varphi=\varphi_{o}$; e na posição $\mathrm{x}=\mathrm{R}_{\mathrm{i}}-\mathrm{r}_{\mathrm{i}}, \varphi=\varphi_{r_{i}}$. Assumindo-se $\varphi_{o_{i}}=0$ e introduzindo-se as condições de contorno, a Equação 4 assume a forma:

$$
\sin \varphi=\frac{x \cdot\left(2 R_{i}-x\right) \cdot \sin \varphi_{r_{i}}}{\left(R_{i}^{2}-r_{i}^{2}\right)}
$$

Desta forma, a inclinação tangente da forma curva da geomembrana deformada $(\varphi)$ em qualquer distância x pode ser expressa pela Equação 6 .

$$
\frac{d y}{d x}=\tan \varphi=\frac{1}{\sqrt{\frac{\left(R_{i}^{2}-r_{i}^{2}\right)^{2}}{\left[x \cdot\left(2 R_{i}-x\right) \cdot \sin \varphi_{r_{i}}\right]^{2}}-1}}
$$


A Figura 21 ilustra a forma curva da geomembrana deformada sob aumento de pressão.

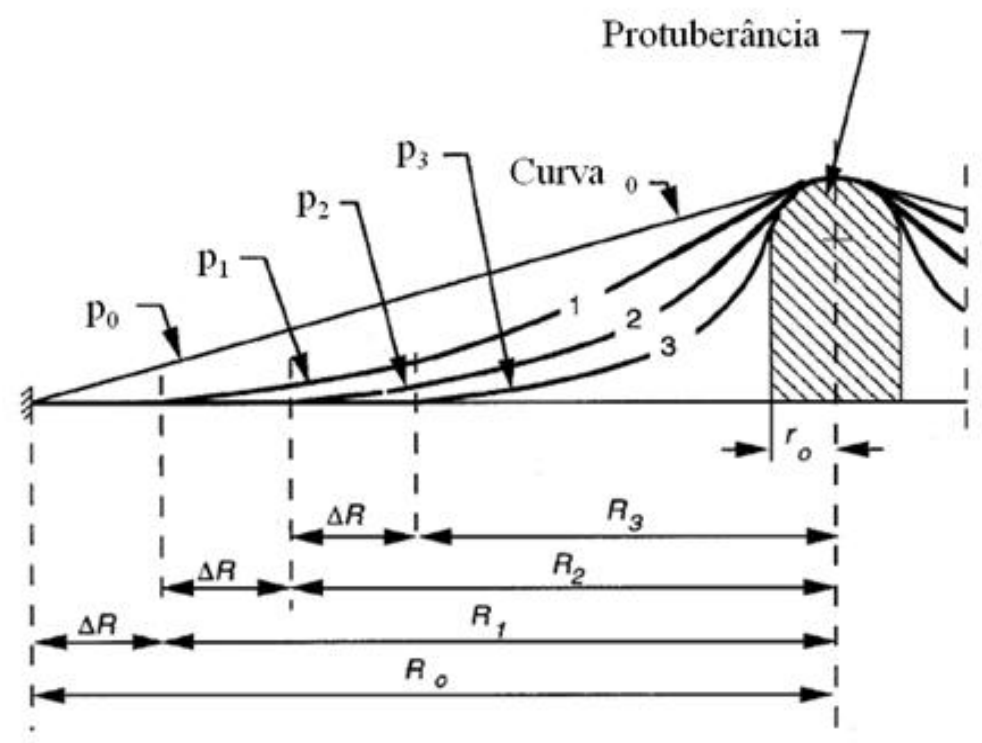

Figura 21. Forma deformada da geomembrana sob aumento de pressão (WILSON-FAHMY ET AL., 1996).

$\mathrm{O}$ incremento do alongamento da geomembrana corresponde à diferença de comprimento entre duas curvas consecutivas e, o incremento da força de tração que faz com que a geomembrana tome a forma da curva subseqüente é dado pela Equação 7.

$$
\Delta L_{i}=\frac{\Delta F_{i}}{2 \pi J_{G M}} \cdot\left[\left(\sum_{N} \frac{\Delta l}{\left(R_{i}-x\right)}\right)+\left(\frac{l_{i}}{r_{i}}\right)\right]
$$

Onde:

- $\Delta \mathrm{l}_{\mathrm{i}} \rightarrow$ incremento de alongamento da geomembrana;

- $\Delta \mathrm{F}_{\mathrm{i}} \rightarrow$ incremento da força de tração da geomembrana;

- $\mathrm{N} \rightarrow$ número de elementos da geomembrana a partir do ponto tangente com o subleito ao ponto tangente com a ponta da protuberância; 
- $\Delta \mathrm{l} \rightarrow$ comprimento do elemento da geomembrana;

- $\mathrm{J}_{\mathrm{GM}} \rightarrow$ módulo carga - deformação da geomembrana;

- $\mathrm{l}_{\mathrm{i}} \rightarrow$ comprimento instantâneo da geomembrana em contato com a ponta da protuberância.

Assim, conhecendo a relação $p_{i} / F_{i}$ e o incremento de força de tração $\Delta \mathrm{F}_{\mathrm{i}}$, pode-se obter a força de tensão total e pressão correspondente para qualquer raio $R_{i}$. Desta forma, variando o raio com acréscimos de incrementos, pode-se estabelecer a relação entre a pressão aplicada e força de tração. Para qualquer força de tração, $F_{i}$, a tensão máxima na geomembrana pode ser determinada para qualquer pressão aplicada.

Com base nesta geometria e nas equações derivadas, Wilson-Fahmy et al. (1996) desenvolveram dois procedimentos de solução teórica para geomembranas: o primeiro para geomembranas sem proteção, e o segundo para geomembranas com proteção. Estas análises teóricas implicaram nas seguintes observações:

- A geometria da protuberância tem um efeito significante na resistência à punção da geomembrana, sendo que tal resistência aumenta com:

o Aumento da espessura da geomembrana;

o Aumento do raio do objeto protuberante, $\mathrm{r}_{\mathrm{o}}$;

o Diminuição da altura do objeto protuberante, $\mathrm{H}$;

o Redução do comprimento não ancorado da geomembrana, $\mathrm{R}_{0}$;

- A resistência a punção da geomembrana pode ser melhorada com as seguintes condições:

o Aumento da espessura da geomembrana;

o Utilização de um elemento de proteção;

o Aumento da espessura (gramatura) do material de proteção;

o Aumento da resistência à tração do material de proteção. 
No entanto, esta análise teórica é baseada em configurações idealizadas do objeto protuberante, da geomembrana e do material de proteção. Assim, a correlação com condições de campo seria primariamente difícil devido à natureza aleatória dos objetos protuberantes com relação à forma, tamanho e arranjo das partículas. Por isto, como continuidade desta análise, os mesmos pesquisadores desenvolveram uma aproximação experimental publicada na parte II desta série de papers (NAREJO et al.,1996).

A aproximação experimental consistiu em estimar a resistência à punção de geomembranas de PEAD com e sem geotêxteis não tecidos agulhados como materiais de proteção. Para isto, foram realizados os seguintes ensaios:

- Ensaios de punção hidrostática usando cones truncados (ASTM D 5514);

- Ensaios similares de punção usando pedregulhos isolados ao invés de cones;

- Ensaios hidrostáticos com camadas de pedregulhos;

- Ensaios geostáticos.

As características das geomembranas e dos geossintéticos utilizados são apresentadas na Tabela 7. Na Tabela 8 são apresentados os resultados dos ensaios de punção envolvendo apenas geomembranas; enquanto na Tabela 9 são apresentados os resultados dos ensaios envolvendo diferentes camadas de proteção. A Tabela 10 apresenta os resultados dos ensaios utilizando uma camada de pedregulhos ao invés de pedras isoladas ou de cones truncados. E, por último, a Tabela 11 mostra os resultados dos ensaios realizados em condição geostática. 
Tabela 7. Propriedades físicas e mecânicas dos geossintéticos utilizados.

\begin{tabular}{|c|c|c|c|c|c|c|}
\hline \multirow{2}{*}{$\begin{array}{c}\text { Geomembrana } \\
\text { GM } 1\end{array}$} & Espessura (mm) & \multicolumn{2}{|c|}{$\begin{array}{c}\text { Carga de } \\
\text { escoamento }(\mathrm{kN} / \mathrm{m})\end{array}$} & \multicolumn{2}{|c|}{$\begin{array}{c}\text { Deformação no } \\
\text { escoamento } \\
(\%)\end{array}$} & $\begin{array}{c}\text { Força de } \\
\text { punção } \\
(\mathbf{k N})\end{array}$ \\
\hline & 2.0 & & 30 & 18 & & 63 \\
\hline GM 2 & 1.5 & & 23 & 18 & & 44 \\
\hline GM 3 & 1.0 & & 14 & 18 & & 28 \\
\hline $\begin{array}{l}\text { Material de } \\
\text { proteção }\end{array}$ & $\begin{array}{l}\text { Gramatura } \\
\qquad\left(\mathrm{g} / \mathrm{m}^{2}\right)\end{array}$ & $\begin{array}{l}\text { Espessura } \\
\quad(\mathrm{mm})\end{array}$ & $\begin{array}{c}\text { Resistência } \\
\text { (kN/m) }\end{array}$ & $\begin{array}{l}\text { Módulo } \\
(\mathbf{k N} / \mathbf{m})\end{array}$ & $\begin{array}{c}\text { Deformação } \\
(\%)\end{array}$ & $\begin{array}{c}\text { Força } \\
\text { de } \\
\text { Punção } \\
\text { (kN) }\end{array}$ \\
\hline NW-NP-PET-1 & 130 & 1.3 & 10 & 37 & 60 & 0.2 \\
\hline NW-NP-PET-2 & 270 & 2.5 & 19 & 61 & 60 & 0.4 \\
\hline NW-NP-PET-3 & 550 & 4.8 & 41 & 69 & 60 & 0.8 \\
\hline NW-NP-PET-4 & 1080 & 9.6 & 75 & 142 & 70 & 1.5 \\
\hline NW-NP-PP- 1 & 300 & 3.0 & 28 & 42 & 40 & 0.5 \\
\hline NW-NP-PP- 2 & 680 & 5.6 & 51 & 78 & 40 & 1.1 \\
\hline NW-NP-PP- 3 & 1350 & 11.0 & 96 & 137 & 40 & 2.3 \\
\hline
\end{tabular}

Legenda: $\mathrm{NW}=$ não tecido; $\mathrm{NP}=$ agulhado PET = poliéster; $\mathrm{PP}=$ polipropileno.

Tabela 8. Pressão de ruptura obtida a partir de ensaios de punção para diferentes espessuras de geomembrana de PEAD.

\begin{tabular}{ccccc}
\hline \multirow{2}{*}{$\begin{array}{c}\text { Espessura da } \\
\text { geomembrana }\end{array}$} & \multicolumn{4}{c}{ Pressão de Ruptura (kPa) } \\
\cline { 2 - 5 }$(\mathbf{m m})$ & \multicolumn{4}{c}{ Altura do cone (mm) } \\
\hline 1.0 & $\mathbf{5 0}$ & $\mathbf{3 8}$ & $\mathbf{2 5}$ & $\mathbf{1 2}$ \\
\hline 1.5 & 21 & 28 & 28 & 110 \\
\hline 2.0 & 34 & 55 & 69 & 140 \\
\hline Fonte: Narejo et al. (1996). & 48 & 62 & 100 & 310 \\
\hline
\end{tabular}

Tabela 9. Pressão de ruptura obtida a partir de ensaios de punção usando cones truncados para uma geomembrana de PEAD de 1,5 mm de espessura com vários tipos de materiais de proteção.

\begin{tabular}{ccccc}
\hline \multirow{2}{*}{$\begin{array}{c}\text { Condição de } \\
\text { Ensaio }\end{array}$} & \multicolumn{4}{c}{ Pressão de ruptura (kPa) } \\
\cline { 2 - 5 } & 50 & 38 & 25 & 12 \\
\cline { 2 - 5 } & 34 & 55 & 69 & 140 \\
\hline GM & 69 & 83 & 100 & 410 \\
\hline NW-NP-PET-1 & 69 & 83 & 320 & 830 \\
\hline NW-NP-PET-2 & 83 & 103 & 450 & $>1100$ \\
\hline NW-NP-PET-3 & 150 & 365 & 610 & $>1100$ \\
\hline NW-NP-PET-4 & 76 & 210 & 320 & 990 \\
\hline NW-NP-PP- 1 & 120 & 280 & 500 & $>1100$ \\
\hline NW-NP-PP- 2 & 290 & 470 & $>1100$ & $>1100$ \\
\hline NW-NP-PP- 3 & & &
\end{tabular}


Tabela 10. Pressão no escoamento para camada de pedregulhos.

\begin{tabular}{ccccc}
\hline $\begin{array}{c}\text { Número das } \\
\text { pedras } \\
\text { AASHTO }\end{array}$ & $\begin{array}{c}\text { Tamanho } \\
\text { máximo } \\
\mathbf{( m m )}\end{array}$ & $\begin{array}{c}\mathbf{d}_{\mathbf{5 0}} \\
\mathbf{( m m )}\end{array}$ & $\begin{array}{c}\text { Pressão no } \\
\text { escoamento } \\
\mathbf{( k P a )}\end{array}$ & $\begin{array}{c}\text { Pressão de } \\
\text { ruptura } \\
\mathbf{( k P a )}\end{array}$ \\
\hline 3 & $50-64$ & 38 & 70 & $>1100$ \\
\hline 57 & $25-38$ & 12 & 170 & $>1100$ \\
\hline 8 & $9-13$ & 10 & 690 & $>1100$ \\
\hline Fonte: modificado de Narejo et al. (1996).
\end{tabular}

Tabela 11. Pressão de ruptura obtida a partir dos ensaios geostáticos com geomembrana de PEAD e vários geotêxteis não tecidos agulhados.

\begin{tabular}{lcccc}
\hline \multirow{2}{*}{$\begin{array}{c}\text { Condição do } \\
\text { Ensaio }\end{array}$} & \multicolumn{4}{c}{ Pressão de ruptura (kPa) } \\
\cline { 2 - 5 } & $\mathbf{5 0}$ & $\mathbf{3 8}$ & $\mathbf{2 5}$ & $\mathbf{1 2}$ \\
\cline { 2 - 5 } & 240 & 310 & 450 & 700 \\
\hline GM sem proteção do cone (mm) & 510 & $>700$ & $>700$ \\
\hline NW-NP-PET-2 & 380 & $>700$ & $>700$ & $>700$ \\
\hline NW-NP-PET-3 & 580 & $>700$ & $>700$ & $>700$ \\
\hline NW-NP-PET-4 & $>700$ & &
\end{tabular}

Os resultados dos ensaios de laboratório realizados mostram que a resistência à punção da geomembrana aumenta com o acréscimo da massa por unidade de área (gramatura) do geotêxtil. Além disto, a resistência à punção da geomembrana utilizando pedregulhos angulares é semelhante à resistência à punção utilizando cones truncados. Os resultados também mostram que a resistência à punção da geomembrana nos ensaios utilizando pedregulhos de forma arredondada ou sub-arredondada foi maior do que nos ensaios com pedregulhos de forma angular. Quanto menor a altura dos cones, maior a resistência da geomembrana. Constatou-se também que a resistência à punção é maior nas configurações utilizando camada de pedregulhos e nas configurações com carregamento geostático. 
Esta pesquisa, principalmente no que diz respeito aos dados experimentais, permitiu o desenvolvimento de um método de projeto para seleção de geotêxteis como camada de proteção, e verificação do fator global de segurança em situações onde a resistência à punção deve ser verificada. Este método se concentra na seleção de um geotêxtil não tecido com gramatura suficiente para fornecer um fator global de segurança contra o escoamento da geomembrana.

Primeiro, a ruptura a curto prazo do sistema é determinada através de ensaios de punção hidrostática (ensaio do cone), e fatores são então aplicados para correlacionar estes dados às condições de campo. Tais fatores estão associados ao formato e arranjo dos grãos, e a processos como fluência, degradação química e biológica.

A equação básica do projeto apresenta a seguinte forma:

$$
p^{\prime}=p_{\text {disponível }}\left(\frac{1}{M F_{S} \times M F_{P D} \times M F_{R}}\right) \cdot\left(\frac{1}{F S_{C R} \times F S_{C B D}}\right)
$$

Onde:

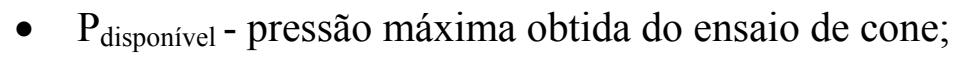

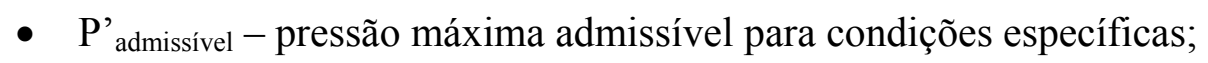

- $\mathrm{MF}_{\mathrm{S}}$ - fator modificado para o formato dos grãos;

- $\mathrm{MF}_{\mathrm{PD}}$ - fator modificado para a densidade;

- $\mathrm{MF}_{\mathrm{R}}$ - fator modificado para o arqueamento do solo;

- $\quad \mathrm{FS}_{\mathrm{CR}}$ - fator parcial de fluência;

- $\mathrm{FS}_{\mathrm{CBD}}$ - fator parcial de degradação biológica e química.

Na Tabela 12 são apresentados os valores dos fatores modificadores de forma; enquanto na Tabela 13 são apresentados os fatores parciais de segurança para fluência. 
Quanto aos fatores de degradação química/ biológica, Narejo et al. (1996) sugerem valores entre 1,0 e 2,0, com um valor médio de 1,5.

Tabela 12. Fatores modificados de forma.

\begin{tabular}{|c|c|c|c|c|c|}
\hline \multicolumn{2}{|c|}{$\begin{array}{l}\text { Forma das protuberâncias } \\
\qquad\left(\mathrm{MF}_{\mathrm{S}}\right)\end{array}$} & \multicolumn{2}{|c|}{$\begin{array}{c}\text { Disposição das protuberâncias } \\
\left.\text { (MF }{ }_{\mathrm{PD}}\right)\end{array}$} & \multicolumn{2}{|c|}{$\begin{array}{l}\text { Arqueamento do solc } \\
\qquad\left(\mathrm{MF}_{\mathrm{A}}\right)\end{array}$} \\
\hline Angular & 1.0 & Isoladas & 1.0 & Nenhum & 1.0 \\
\hline Subarredondada & 0.50 & Acondicionadas & 0.50 & Moderado & 0.75 \\
\hline Arredondada & 0.25 & - & - & Máximo & 0.25 \\
\hline
\end{tabular}

Tabela 13. Fatores parciais de segurança para fluência.

\begin{tabular}{ccccc}
\hline $\begin{array}{c}\text { Gramatura do geotêxtil } \\
\left(\mathrm{g} / \mathrm{m}^{2}\right)\end{array}$ & \multicolumn{4}{c}{ Fatores parciais de segurança para fluência (FScr) } \\
\cline { 2 - 5 } & 38 & \multicolumn{3}{c}{ Altura da Protuberância (mm) } \\
\cline { 2 - 5 } & $\mathrm{N} / \mathrm{R}$ & $\mathrm{N} / \mathrm{R}$ & $\mathrm{N} / \mathrm{R}$ & \multicolumn{1}{c}{25} \\
\hline Sem geotêxtil & $\mathrm{N} / \mathrm{R}$ & $\mathrm{N} / \mathrm{R}$ & $>1.5$ & 1.5 \\
\hline 270 & $\mathrm{~N} / \mathrm{R}$ & 1.5 & 1.3 & 1.2 \\
\hline 550 & 1.3 & 1.2 & 1.1 & 1.0 \\
\hline 1100 & $\sim 1.2$ & $\sim 1.1$ & $\sim 1.0$ & 1.0 \\
\hline$>1100$ & & &
\end{tabular}

Legenda: $\mathrm{N} / \mathrm{R}=$ não recomendado.

Adotado um fator de segurança de projeto e os fatores de correlação, determina-se a gramatura adequada para o geotêxtil, segundo a Equação 9.

$$
p_{\text {disponivel }}=450 \cdot \frac{M}{H^{2}}
$$

Onde: 
- $\mathrm{M}$ - massa por unidade de área ou gramatura $\left(\mathrm{g} / \mathrm{m}^{2}\right)$;

- $\quad \mathrm{H}$ - altura de penetração dos grãos (mm).

O fator global de segurança é definido como:

$$
F S=\frac{p_{\text {disponível }}^{\prime}}{p_{\text {requerida }}}
$$

Sendo $\mathrm{p}_{\text {req }}$ a pressão máxima atuante no sistema.

Este fator de segurança global é introduzido para reduzir incertezas quanto às situações de campo. Koerner et al. (1996) sugerem alguns valores de segurança global contra ruptura, sendo este fator superior a 3,0, os quais são apresentados na Tabela 14 .

Tabela 14. Valores sugeridos de fatores de segurança global contra ruptura no uso das equações de projeto.

\begin{tabular}{ccc}
\hline Arranjo das Pedras & $\begin{array}{c}\text { Altura efetiva da protuberância } \\
(\mathbf{m m})\end{array}$ & $\begin{array}{c}\text { Fator global de } \\
\text { segurança }\end{array}$ \\
\hline \multirow{3}{*}{ Pedras isoladas } & 6 & 3.0 \\
\cline { 2 - 3 } & 12 & 4.5 \\
\cline { 2 - 3 } & 25 & 7.0 \\
\hline Pedras acondicionadas & 38 & 10.0 \\
\hline Fonte: Narejo et al. (1996) & 38 ou menor & 3.0 \\
\hline
\end{tabular}

No entanto, Reddy \& Saichek (1998) fazem algumas críticas à metodologia proposta por Narejo et al. (1996). Os autores afirmam que os danos observados nos ensaios somente são observados visualmente, faltando uma quantificação das mudanças físicas ocorridas na 
geomembrana para diferentes tipos de agregados. Além disto, o procedimento de projeto é considerado conservador porque são baseados em ensaios com cones ou pedras isoladas, sendo atribuídos fatores de modificação e fatores parciais de segurança.

Outro aspecto citado por Reddy \& Saichek (1998) e Reddy et al. (1996) é que os efeitos do carregamento devido à construção da barreira impermeabilizante (danos de instalação) não são retratados na metodologia proposta por Narejo et al. (1996).

Jones et al. (2000) também questionam a influência de outros aspectos no desempenho de camadas de proteção como, por exemplo, o tipo e a qualidade das fibras e os processos de fabricação dos geotêxteis. Para validar tal teoria, realizaram uma investigação experimental através de ensaios índice e de desempenho com geotêxteis de mesma gramatura, mas de diferentes materiais. Os resultados dos ensaios revelaram que os geotêxteis com mesma gramatura apresentaram comportamentos distintos.

Desta forma, Jones et al. (2002) propõem a teoria de que o desempenho de um geotêxtil não tecido está fortemente relacionado ao atrito entre fibras, dividindo o mecanismo de carregamento do sistema em dois estágios, apresentados na Figura 22.

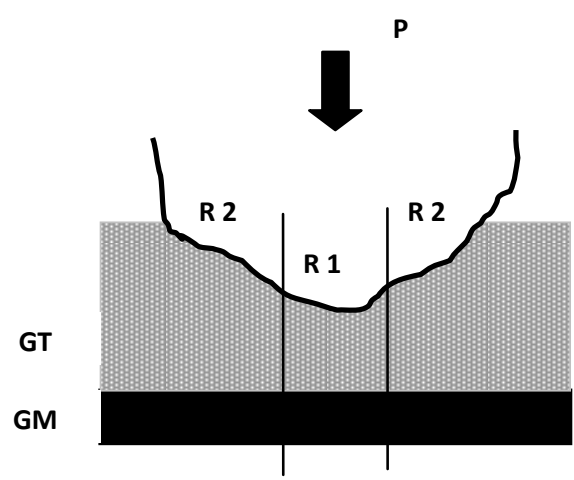

(a)

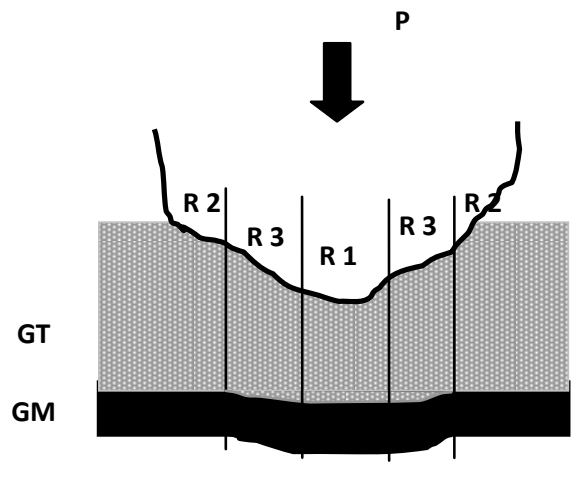

(b)

Figura 22. Mecanismo de carregamento (a) estágio de compressão inicial do geotêxtil; (b) Deformação da geomembrana e compressão do geotêxtil (JONES ET AL. 2000). 
O primeiro estágio compreende a fase de compressão inicial do geotêxtil, onde duas regiões de influência são desenvolvidas. Na região 1, apesar de se verificar uma compressão do geotêxtil, as fibras permanecem com o mesmo arranjo. Entretanto, na região 2, ocorre o desenvolvimento de duas componentes do carregamento atuando na direção normal e paralela à interface do grão/geotêxtil. Estas componentes geram forças de cisalhamento que são transmitidas ao geotêxtil como uma combinação de forças de tração em torno das fibras e de forças de atrito entre fibras.

O segundo estágio compreende um mecanismo combinado de deformação da geomembrana e subseqüente compressão do geotêxtil. Neste estágio, ocorre a deformação da geomembrana e forças adicionais de atrito são geradas na interface GM/GT. Dependendo da estrutura do geotêxtil, tem-se uma matriz rígida junto a esta interface. Assim, o carregamento aplicado é distribuído para as fibras do geotêxtil e a magnitude das deformações na geomembrana pode ser reduzida.

Assim, a capacidade de um geotêxtil em gerar forças de tração ao longo das fibras e elevado atrito entre fibras depende do tipo e qualidade das fibras utilizadas junto ao processo de fabricação. Esta teoria da interação da fibra é considerada por alguns pesquisadores essencial para o desempenho das camadas de proteção.

\subsubsection{Método baseado no desempenho da geomembrana a longo prazo}

Neste método, o desempenho dos elementos de proteção é verificado através do ensaio do cilindro, o qual consiste em submeter uma geomembrana a condições de carregamento e verificar as deformações induzidas na geomembrana. Se as deformações induzidas forem menores que $0,25 \%$, então a camada de proteção é adequada para prevenir fissuras na geomembrana devido ao stress cracking (SEEGER \& MÜLLER, 1996). 
Este limite de deformação foi determinado através de ensaios de fluência conduzidos pelo grupo Quo Vadis Schutzlagen (Alemanha) em geomembranas de PEAD, de acordo com as regulamentações técnicas do BAM (Bundesanstalt für Materialforschung und - puefung).

A partir das curvas de tensão versus deformação obtidas em diferentes velocidades de deformação verificou-se, para a menor velocidade $(0,1 \% /$ hora $)$ e para uma tensão de 10 $\mathrm{N} / \mathrm{mm}^{2}$, um alongamento de $6 \%$ na geomembrana. Esta deformação foi descrita como a deformação limite. Aplicando-se um fator de segurança de 2, foi obtida uma deformação máxima de 3\%. Também foi estimado um valor de deformação devido ao recalque do subsolo em $2,75 \%$, conduzindo para $0,25 \%$ o máximo de deformação local que pode ocorrer na geomembrana (GALLAGHER et al., 1999).

No entanto, esta relação entre a deformação crítica de geomembranas cristalinas como o PEAD, geralmente adotada como $6 \%$, e o critério de ruptura de $0,25 \%$ usado no ensaio de cilindro não tem sido comprovada. Apesar disto, este critério tem sido utilizado até hoje, e também foi estendido aos projetos de aterros na Inglaterra.

Segundo Gallagher et al. (1999), desde 1997 os pesquisadores britânicos têm adquirido mais experiência com o ensaio do cilindro, criando um novo protocolo (ENVIRONMENTAL AGENCY, 1998) para metodologia do ensaio.

Através das pesquisas conduzidas pela EA (ENVIRONMENTAL AGENCY, 1998), verificou-se que os resultados dos ensaios são sensíveis a diversos fatores, tais como tipo de subleito; rigidez/espessura da placa de metal utilizada para gravar as deformações; método de tomada de medidas; definição da extensão das deformações individuais, e método do cálculo de deformações locais, e que estes fatores podem influenciar a confiabilidade dos resultados (GALLAGHER et al., 1999).

Uma das questões levantadas neste método consiste nos métodos usados para calcular as deformações locais. Tal aspecto foi retratado por Tognon et al. (1999; 2000), que além de 
questionar o limite de deformação proposto pelo BAM, também questiona a complexidade das medidas de tais deformações.

Segundo o BAM, o cálculo da deformação máxima na geomembrana é obtido admitindo-se um segmento circular crítico para representar a indentação do pedregulho com curvatura homogênea ao longo do perfil deformado. No entanto, esta simplificação pode não representar adequadamente as deformações porque não consideram o efeito de deformações localizadas em cada ponto da geomembrana.

Tognon (2000) propõe uma alternativa para interpretar as deformações induzidas nas geomembranas considerando o efeito da ação combinada membrana / flexão. A proposta desta alternativa é considerar as deformações localizadas em cada ponto da geomembrana, considerando que a geomembrana atua como um elemento de viga. Para validar esta teoria, os mesmo autores realizaram ensaios de punção de grande escala com diferentes camadas de proteção, utilizando-se as duas formulações (método do arco e método da ação combinada membrana / flexão.

Os resultados desta investigação mostraram que o método do alongamento do arco somente providencia uma magnitude aproximada das deformações que ocorrem na geomembrana, além de não representar adequadamente a distribuição de deformação ou deformações de pico.

Por sua vez, o método considerando a deformação da membrana / flexão apresenta uma estimativa mais apropriada da distribuição de tensões e das deformações de pico. Os resultados dos ensaios mostraram que as tensões e deformações localizadas foram significantemente maiores do que as calculadas pelo método do alongamento do arco. Estes resultados apontam a importância e a complexidade das medidas de deformações induzidas em geomembranas. 
Zanzinger (1990) sugere que o método do alongamento do arco é mais adequado nos ensaios índices, como CBR, Rod Plunger Test, onde as deformações são impostas por um corpo de prova isolado e com corpo de prova de pequenas dimensões, de forma que não a amostra não consegue atuar como um elemento de viga (flexão). Diferente destes, nos ensaios em grande escala, onde a geomembrana pode ser comportar como um elemento de viga, torna-se mais apropriado usar o método da ação combinada membrana/flexão.

Em suma, Gallagher et al. (1999) e Zanzinger (1999) afirmam que o ensaio de cilindro compreende uma ferramenta de projeto para seleção de um geoprotetor adequado em situações particulares.

Zanzinger (1999) também propõe ensaios com modelo em grande escala para verificação do desempenho de camadas de proteção, e com objetivo de simular uma condição mais próxima ao comportamento in situ.

Em função disto, conduziram ensaios em modelo de grande escala e de desempenho (ensaio do cilindro) com diferentes camadas de proteção. Os ensaios em grande escala foram realizados durante um período de nove meses, com treze fases de carregamento até atingir 800 $\mathrm{kPa}$. No final da compressão, aplicou-se um carregamento de $1.000 \mathrm{kPa}$ durante duas semanas. Já no ensaio do cilindro, aplicou-se um carregamento de $1.350 \mathrm{kPa}$, correspondente a $60 \mathrm{~m}$ de coluna de resíduos, e considerando um fator de segurança igual a 1,5. O tempo de duração do ensaio foi de 100 horas.

Os materiais utilizados como elementos de proteção são apresentados na Tabela 15 e os resultados são apresentados na Tabela 16. 
Tabela 15. Propriedades físicas das camadas geossintéticas de proteção.

\begin{tabular}{|c|c|c|c|c|}
\hline $\begin{array}{l}\text { Sistema de } \\
\text { Proteção }\end{array}$ & Descrição & Matéria prima & $\begin{array}{c}\text { Gramatura } \\
\left(\mathbf{g} / \mathbf{m}^{2}\right)\end{array}$ & $\begin{array}{c}\text { Espessura } \\
\text { sob } 2 \text { kPa } \\
\quad(\mathrm{mm})\end{array}$ \\
\hline 1 & $\begin{array}{c}\text { Geocomposto } \\
\text { (geotêxtil/geomat/borracha) }\end{array}$ & PET/PA/borracha & 6.650 & 12,2 \\
\hline 2 & $\begin{array}{c}\text { Geocomposto * } \\
\text { (geotêxtil/geodreno/geotêxtil) }\end{array}$ & PEAD e PP & $2.030^{*}$ & $12,9 *$ \\
\hline 3 & $\begin{array}{l}\text { Geocontainer } * * \\
\text { (geotêxtil tecido conectado com fios } \\
\text { espaçadores preenchidos com areia) }\end{array}$ & PEAD/areia & 70.000 & 50 \\
\hline 4 & $\begin{array}{l}\text { Geocontainer } * * \\
\text { (geotêxtil tecido conectado com fios } \\
\text { espaçadores preenchidos com areia) }\end{array}$ & PEAD/areia & 56.000 & 40 \\
\hline 5 & $\begin{array}{c}\text { Geotêxtil* } \\
\text { (não tecido, agulhado) }\end{array}$ & PP & $4.270^{*}$ & $26,8^{*}$ \\
\hline 6 & $\begin{array}{c}\text { Geotêxtil } \\
\text { (não tecido, agulhado) }\end{array}$ & PP & 2.140 & 13,4 \\
\hline 7 e 8 & $\begin{array}{c}\text { Geocomposto ** } \\
\text { (geotêxtil/tapete sintético/areia/ } \\
\text { geotêxtil tecido e não tecido) }\end{array}$ & $\mathrm{PP} /$ areia/PEAD & 48.000 & 26 \\
\hline
\end{tabular}

Fonte: Zanzinger (1999).

* 2 duas camadas combinadas

** preenchido com areia local 
Tabela 16. Comparação dos resultados a partir dos ensaios em modelo de grande escala e ensaio de laboratório de desempenho para proteção.

\begin{tabular}{|c|c|c|c|c|}
\hline \multirow[t]{2}{*}{ Camada de Proteção } & \multicolumn{2}{|c|}{$\begin{array}{c}\text { Ensaio em Modelo de Grande } \\
\text { Escala }\end{array}$} & \multicolumn{2}{|c|}{$\begin{array}{c}\text { Ensaio de Desempenho de } \\
\text { Proteção (cilindro) }\end{array}$} \\
\hline & $\begin{array}{c}\text { Deformação } \\
\text { média } \\
(\%)\end{array}$ & $\begin{array}{c}\text { Deformação } \\
\text { máxima, } \varepsilon \\
(\%)\end{array}$ & $\begin{array}{c}\text { Deformação } \\
\text { média } \\
(\%)\end{array}$ & $\begin{array}{c}\text { Deformação } \\
\text { máxima, } \varepsilon \\
(\%)\end{array}$ \\
\hline 1 & 0,08 & 0,41 & 0,04 & 0,21 \\
\hline 2 & 0,08 & 0,66 & 0,02 & 0,07 \\
\hline 3 & 0,11 & 0,75 & 0,34 & 0,99 \\
\hline 4 & 0,05 & 0,46 & 0,02 & 0,19 \\
\hline 5 & 0,09 & 0,58 & 0,06 & 0,17 \\
\hline 6 & 0,10 & 0,92 & 0,09 & 0,26 \\
\hline 7 & 0,07 & 0,79 & 0,07 & 0,62 \\
\hline 8 & 0,05 & 0,78 & - & - \\
\hline
\end{tabular}

Os resultados dos ensaios indicaram, em geral, que as deformações obtidas nos ensaios de desempenho em cilindro foram menores que $0,25 \%$. Contudo, nos ensaios em grande escala, as deformações máximas foram maiores que $0,25 \%$.

Zanzinger (1999) e Zanzinger \& Gartung (1998) atribuem este comportamento às características de tensão / relaxação dos geossintéticos com o tempo. Enquanto o ensaio de cilindro foi realizado durante um período de 100 (cem) horas; o ensaio em grande escala foi realizado durante um período de nove meses. Outra justificativa consiste nas diferenças de configurações entre os ensaios como, por exemplo, a utilização de placas elásticas nos ensaios de desempenho em cilindro e camadas de argilas compactadas nos ensaios de grande escala.

Apesar das diferenças constatadas entre ambos os ensaios, os resultados indicam que as deformações foram menores que $1 \%$, abaixo da deformação de escoamento típica em 
geomembranas de PEAD, e que os materiais apresentaram desempenho satisfatório, sem danos, rasgos e/ou perfurações na geomembrana.

Tognon (1999) também conduziu ensaios em grande escala para verificar o desempenho de diferentes materiais de proteção. Além da escolha da deformação limite, estes autores questionam outros aspectos como os métodos de cálculo para deformações e as formas geométricas utilizadas nos demais ensaios, uma vez que tendem a simplificar a sua execução. Deste modo, questionam a correlação entre o comportamento de tensão e deformação de laboratório com o comportamento de campo. O sumário dos ensaios realizados é apresentado na Tabela 17, e os resultados são apresentados na Tabela 18.

Tabela 17. Sumário dos ensaios realizados em modelo de grande escala.

\begin{tabular}{|c|c|c|c|c|c|c|}
\hline Ensaio & $\begin{array}{c}\text { Camada de } \\
\text { proteção }\end{array}$ & Descrição & $\begin{array}{c}\text { Massa total } \\
\text { por unidade } \\
\text { de área } \\
\left(\mathrm{g} / \mathrm{m}^{2}\right) \\
\end{array}$ & $\begin{array}{c}\text { Espessura } \\
\text { total } \\
(\mathbf{m m})\end{array}$ & $\begin{array}{c}\text { Pressão } \\
\text { (kPa) }\end{array}$ & $\begin{array}{l}\text { Duração } \\
\text { do ensaio } \\
\text { (min) }\end{array}$ \\
\hline A & GT1 & NW, NP & 435 & 2 & 250 & 200 \\
\hline $\mathrm{B}$ & GT1 & NW, NP & 435 & 2 & 250 & 200 \\
\hline $\mathrm{C}$ & $\begin{array}{l}\text { GT2 (duas } \\
\text { camadas de } \\
\left.600 \mathrm{~g} / \mathrm{m}^{2}\right)\end{array}$ & NW, NP & 1200 & $4,4^{b}$ & 900 & 720 \\
\hline $\mathrm{D}$ & $\begin{array}{l}\text { Geocushion } \\
\text { preenchido } \\
\text { com areia }\end{array}$ & $\begin{array}{l}\text { Camada GT (NW, NP), } \\
\text { preenchimento de areia } \\
\text { com fios de polímeros, e } \\
\text { GT }(\mathrm{NW}, \mathrm{NP})\end{array}$ & 70.000 & 25 & 650 & 520 \\
\hline $\mathrm{E}$ & $\begin{array}{l}\text { Geocushion } \\
\text { preenchido } \\
\text { com areia }\end{array}$ & $\begin{array}{c}\text { Camada GT (NW, NP), } \\
\text { preenchimento de areia } \\
\text { com fios de polímeros, e } \\
\text { GT }(\mathrm{NW}, \mathrm{NP})\end{array}$ & 70.000 & 25 & 900 & 720 \\
\hline F & $\begin{array}{c}\text { Tapete } \\
\text { sintético de } \\
\text { borracha } 1 \\
\end{array}$ & $\begin{array}{c}\text { Camada GT }(\mathrm{NW}, \mathrm{NP}) \text {, } \\
\text { matriz de borracha, e GT } \\
(\mathrm{NW}, \mathrm{NP})\end{array}$ & 6.000 & 10 & 600 & 480 \\
\hline 7 e 8 & $\begin{array}{c}\text { Tapete } \\
\text { sintético de } \\
\text { borracha } 2\end{array}$ & $\begin{array}{c}\text { Camada GT (NW, NP), } \\
\text { matriz de borracha, e } \\
\text { grelha de poliéster }\end{array}$ & 6.000 & 10 & 600 & 480 \\
\hline
\end{tabular}


Tabela 18. Sumário das deformações obtidas a partir das medidas locais detalhadas.

\begin{tabular}{|c|c|c|c|c|c|c|}
\hline \multirow[b]{2}{*}{ Ensaio } & \multirow[b]{2}{*}{$\begin{array}{c}\text { Pressão } \\
\text { (kPa) }\end{array}$} & \multirow{2}{*}{$\begin{array}{c}M_{A} \\
\left(g / m^{2}\right)\end{array}$} & \multicolumn{2}{|c|}{$\begin{array}{c}\text { Tamanho do embricamento } \\
\text { médio }\end{array}$} & \multicolumn{2}{|c|}{$\begin{array}{c}\text { Tamanho de embricamento } \\
\text { máximo }\end{array}$} \\
\hline & & & $\begin{array}{c}\text { Alongamento } \\
\text { do arco* } \\
(\%) \\
\end{array}$ & $\begin{array}{c}\text { Deformação } \\
\text { de pico** } \\
(\%) \\
\end{array}$ & $\begin{array}{c}\text { Alongamento } \\
\text { do arco* } \\
(\%) \\
\end{array}$ & $\begin{array}{c}\text { Deformação } \\
\text { de pico** } \\
(\%) \\
\end{array}$ \\
\hline A-B & 250 & 435 & 1,9 & 4 & 3,8 & 8 \\
\hline $\mathrm{C}$ & 900 & 1.200 & 1 & 5 & 10 & 13 \\
\hline $\mathrm{D}$ & 650 & 70.000 & 0,5 & 0,52 & 0,29 & 0,8 \\
\hline $\mathrm{E}$ & 900 & 70.000 & 0,19 & 0,52 & 1,4 & 0,9 \\
\hline $\mathrm{F}$ & 600 & 6.000 & 1 & 3,6 & 3,6 & 7,5 \\
\hline $\mathrm{G}$ & 600 & 6.000 & 0,12 & 1,1 & 0,16 & 1,5 \\
\hline
\end{tabular}

Observa-se que nenhuma das camadas de proteção pôde limitar a deformação máxima para menos que $0,25 \%$. Além disto, constatou-se que o pior desempenho foi observado nas camadas de geotêxteis selecionados segundo o critério de Narejo et al. (1996). Verificou-se também que os materiais mais rígidos apresentaram melhor desempenho, o que sugere que a característica de rigidez pode ser tão importante quanto o efeito da massa por unidade de área (gramatura).

Além destes questionamentos, os autores ainda sugerem alguns fatores adicionais que afetam a deformação a longo prazo, como vida útil, temperatura, exposição ambiental, presença de emendas e tempo de execução do ensaio, no estudo do desempenho de camadas de proteção.

2.4.2.3. Critério proposto por Badu - Tweneboah et al. (1998).

Seguindo a mesma filosofia de proteção da geomembrana a curto prazo, BaduTweneboah et al. (1998) propõem uma aproximação baseada no uso de ensaios de tração multiaxial (ensaio de estouro). O objetivo é estabelecer um critério para estimar danos mecânicos na geomembrana dentro de um limite aceitável. 
Se forem observados danos na geomembrana após um estágio de exposição qualquer, então a geomembrana não funcionará como barreira hidráulica efetiva. Neste caso, o nível de danos é inaceitável e não é necessário avaliar as propriedades da geomembrana através do ensaio multiaxial.

Entretanto, outros tipos de danos podem diminuir a habilidade da geomembrana para resistir à ruptura quando sujeitas a cargas de trabalhos e deformações desenvolvidas durante a sua vida útil. Neste caso, é necessário avaliar os danos existentes na geomembrana através do ensaio multiaxial.

Este raciocínio conduz a seguinte definição de nível aceitável para danos: as características de deformação à tração da geomembrana não precisam ser significativamente afetadas. Contudo, o modo de ruptura é a característica mais importante. Segundo os autores, a geomembrana precisa romper no topo da abóbada (centro da amostra) porque este é o local onde as tensões são maiores. Se a geomembrana não rompe na abóbada, isto indica que a amostra foi previamente enfraquecida no local onde a ruptura ocorreu.

Desta forma, surge o critério proposto por Badu-Tweneboah et al. (1998): o dano mecânico submetido à geomembrana é denominado inaceitável se a amostra de geomembrana testada por ensaios de tensão multiaxial de grande diâmetro exibir ruptura em local diferente do centro da abóbada e se a localização de danos é visível.

Para validar este critério, os autores realizaram ensaios de compressão estática e de tração multiaxial em geomembranas de PEAD submetidas ao contato com diferentes solos. Os ensaios de compressão estática foram realizados com materiais granulares de diferentes granulometrias. Realizou-se o mesmo procedimento em cada configuração, compactando-se uma base de solo argiloso, seguido da colocação da geomembrana e do material granular. Em seguida, aplicou-se uma carga de $860 \mathrm{kPa}$ durante um período de 72 horas. Após a realização 
dos ensaios, as amostras de geomembranas foram inspecionadas visualmente e submetidas aos ensaios de tração multiaxial.

Os resultados dos ensaios indicam que as propriedades obtidas pelo ensaio não forneceram informações precisas para correlacioná-las com os danos visíveis nas geomembranas, principalmente em termos de tensão de tração na ruptura. Contudo, o modo de ruptura forneceu o melhor indicativo de danos na geomembrana, sem a necessidade de atribuir valores aceitáveis para as propriedades das geomembranas. Na configuração com geomembrana mais danificada, a ruptura ocorreu exatamente nos pontos danificados. Ao contrário, na configuração com poucos sinais de danos, a ruptura foi semelhante à geomembrana virgem, localizada no centro da amostra.

\subsubsection{Desempenho de geotêxteis sob Carregamento de Construção}

Todos os critérios utilizados para seleção de camadas de proteção apresentados anteriormente são baseados em ensaios estáticos, ou seja, simulam a fase de operação do aterro. No entanto, existem poucos estudos sobre o desempenho de geotêxteis durante a fase de instalação, a qual envolve a colocação da geomembrana, da camada drenante e o carregamento de maquinários pesados.

Segundo Snow et al. (1999), a dimensão dos danos de construção superam os danos provenientes por outras causas. Neste trabalho, retratam um aterro sanitário localizado na Califórnia, onde foi verificado um vazamento da ordem de 400 litros por dia, provocado por danos existentes na geomembrana. Após a detecção do vazamento, realizou-se a escavação da área, verificando-se a ausência do geotêxtil de proteção devido ao seu deslocamento durante a construção. Foram encontrados treze perfurações na geomembrana e outros tipos de danos como ranhuras, todos atribuídos a operação dos maquinários juntamente sobre uma camada de 
solo de proteção fina ou inexistente. As Figuras abaixo ilustram os danos observados após a escavação da área.

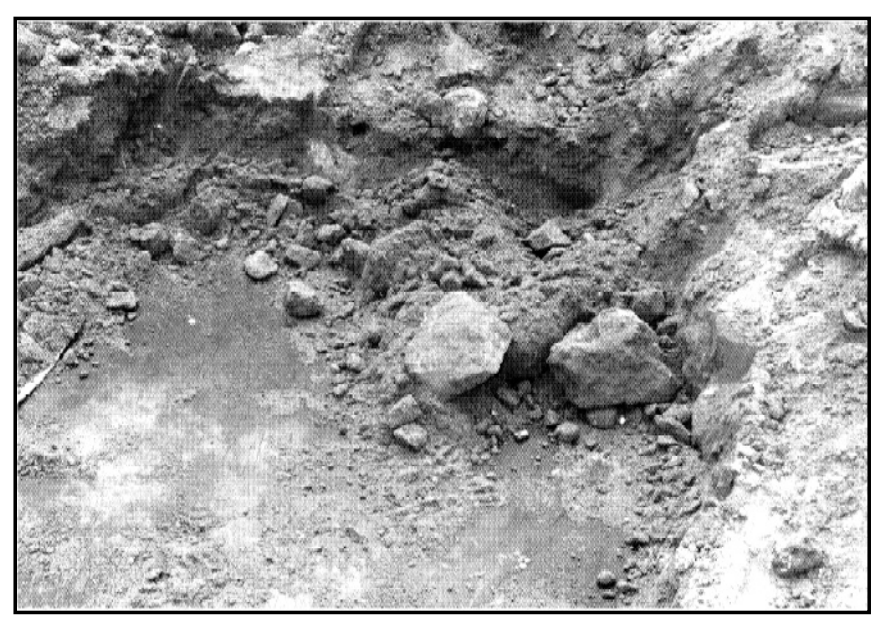

Figura 23. Área com ausência de geotêxtil (SNOW ET AL., 1999).
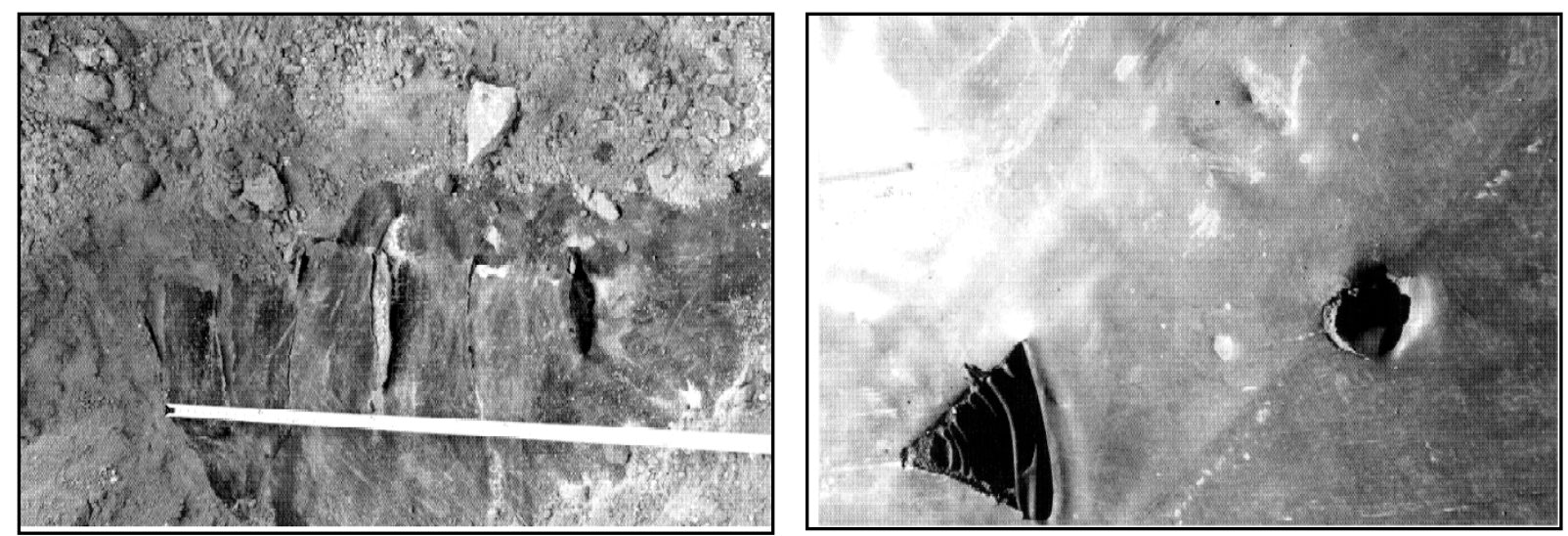

Figura 24. Perfurações observadas nas geomembranas (SNOW ET AL., 1999).

Conforme já mencionado, Lopes (2006) relatam que a maior porcentagem de danos ocorre durante a fase de colocação da camada drenante em função da dimensão das partículas da camada drenante, do deficiente dimensionamento do geotêxtil e do equipamento pesado usado para espalhar a camada drenante. 
Para quantificar este tipo de dano em laboratório, cita-se o ensaio de dano de instalação sob carregamento cíclico ISO 10. 722. Entretanto, ressalta-se que não existem estudos utilizando este tipo de ensaio para simular o carregamento de maquinários em aterros.

Reddy et al. (1996) desenvolveram um estudo experimental de campo para estudar o desempenho de camadas de proteção sob carregamento de construção para geomembranas de PEAD de 1,5 mm. Neste estudo foram variadas a granulometria dos agregados, a carga dos tratores e a introdução do elemento de proteção.

Após a aplicação de repetitivos carregamentos de construção, amostras de geomembranas foram exumadas, observadas visualmente e ensaiadas em laboratório. Os ensaios de laboratório foram empregados com o objetivo de se quantificar as mudanças físicas nas propriedades das geomembranas. Foram realizados ensaios de tração faixa larga, tensão multiaxial e transmissividade ao vapor.

Os resultados dos ensaios mostraram que as principais mudanças nas propriedades físicas das geomembranas foram em termos de alongamento no estouro a partir dos ensaios de tração multiaxial e, tensão e deformação na ruptura a partir dos ensaios de tração faixa larga. Além disto, para as condições utilizadas nos ensaios, verificou-se que um geotêxtil não tecido agulhado de $270 \mathrm{~g} / \mathrm{m}^{2}$ fornece proteção suficiente para a geomembrana sob ação de carregamento de construção.

\subsubsection{Ensaios de Danos Mecânicos em Geomembranas}

Os ensaios de danos mecânicos em geomembranas correspondem a ensaios de compressão estáticos ou dinâmicos, sob a forma de um mecanismo de punção.

Os métodos utilizados para determinação da resistência à punção em geossintéticos se dividem em ensaios índice e ensaios de desempenho. 
Os ensaios índice são geralmente de pequena escala e são utilizados principalmente durante o processo de fabricação dos materiais para controle de qualidade. São ensaios rápidos e de fácil execução. Entretanto, não são utilizados na previsão da capacidade do geossintético resistir a tensões de instalação e condições de serviço.

Os ensaios de desempenho procuram simular no laboratório as condições e tensões que um geossintético experimentará em obra. Estes ensaios, ao contrário dos ensaios índice, podem ser lentos e, algumas vezes, difíceis de serem executados. Não obstante, são necessários para prever precisamente o desempenho de campo e são freqüentemente utilizados nos projetos (FROBEL \& RIGO, 1991).

A Tabela 19 apresenta os tipos de ensaios de laboratório utilizados para determinar a resistência de camadas de proteção para geomembranas.

Tabela 19. Ensaios de laboratório utilizados para verificação do desempenho de materiais de proteção para geomembranas.

\begin{tabular}{ll}
\hline Ensaios & Norma \\
\hline Índice & \\
\hline Punção estática - Rod Plunger Test & ASTM D 4833 \\
\hline Punção estática - CBR & ISO 12236 / NBR 13359 \\
\hline Punção estática com pirâmide & ASTM D 5494 \\
\hline Punção dinâmica queda do cone & ISO 13433 / NBR 14971 \\
\hline Desempenho & \\
\hline $\begin{array}{l}\text { Punção hidrostática em grande escala (ensaio dos cones } \\
\text { truncados) }\end{array}$ & ASTM D 5514 \\
\hline Ensaio do cilindro & BAM \\
\hline Ensaio de danos durante a instalação & ISO 10722 \\
\hline
\end{tabular}

Como a maior parte dos ensaios será descrita em capítulo a parte (Capítulo 3 Materiais e Métodos), somente serão descritos aqui o ensaio de punção hidrostática e o ensaio do cilindro. 


\subsubsection{Ensaio de punção hidrostática em grande escala}

O ensaio de punção hidrostática em grande escala, também denominado ensaio dos cones truncados, é conduzido de acordo com a norma americana ASTM D 5514. Este ensaio estima as propriedades de tensão / deformação de geossintéticos usando uma pressão hidrostática para comprimir o geossintético sobre uma base natural ou sintética constituídas de pirâmides / cones manufaturados, pedras, solos ou vazios.

Existem dois procedimentos de ensaios. No primeiro, a base do equipamento é constituída de pirâmides ou cones, assemelhando-se a um ensaio de semi-desempenho. Também são conduzidos para comparar dados de laboratório e, podem ser usados como um guia geral para ensaios de rotina de vários materiais.

Segundo Narejo et al. (1996), apesar de este ensaio apresentar formas geométricas idealizadas, o modo de ruptura é similar às condições de campo nas quais a geomembrana é colocada sobre ou abaixo de possíveis protuberâncias. O dispositivo de ensaio é apresentado na Figura 25. 

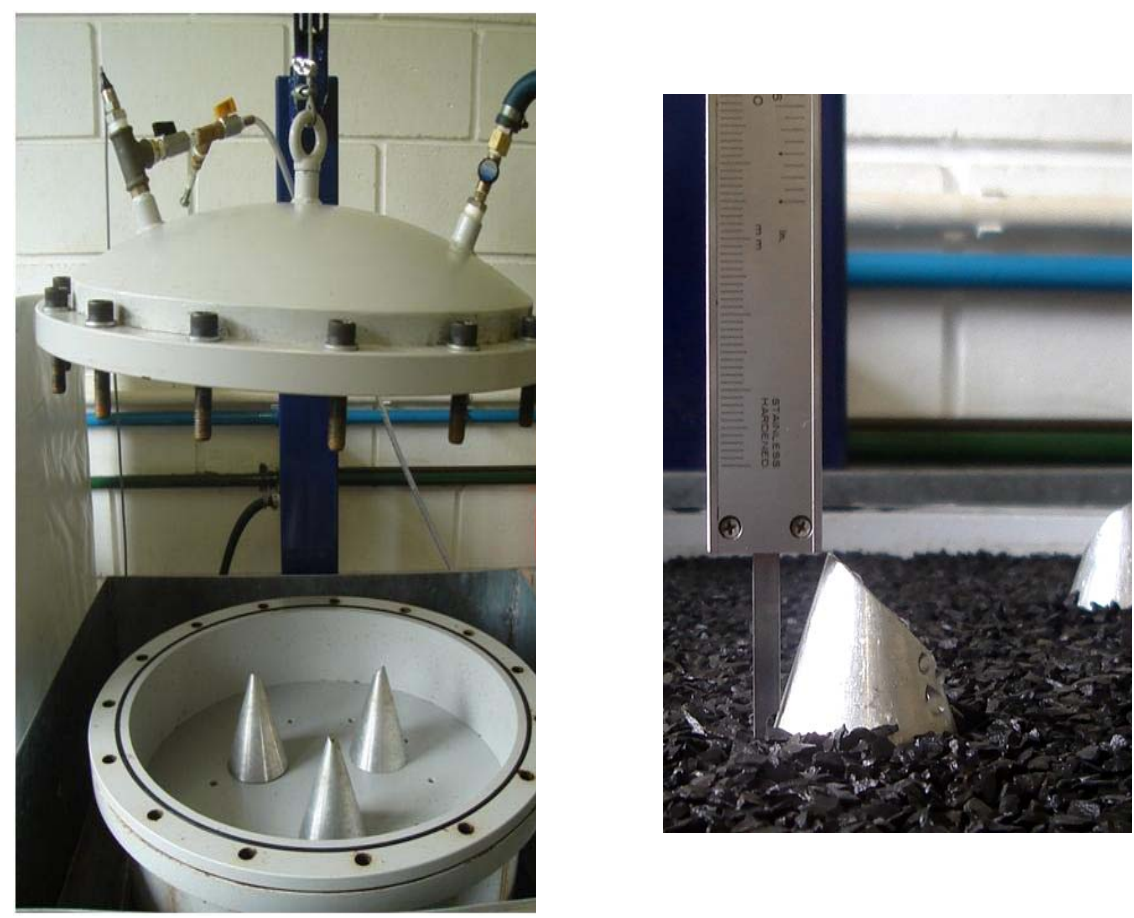

Figura 25. Ensaio de punção hidrostática com cones truncados (GEROTO, 2003).

Os cones são montados sobre uma plataforma rígida em disposição triangular. O material de proteção é colocado sobre os cones e, por sua vez, a geomembrana é colocada sobre o material de proteção. A tampa superior é colocada sobre a geomembrana. Introduz-se água ou ar a partir do topo e a pressão é aumentada no recipiente numa velocidade de aproximadamente $7 \mathrm{kPa} / \mathrm{min}$, até que ocorra a ruptura da geomembrana. A ruptura da geomembrana pode ser detectada através de sensores elétricos presentes nos cones. Um cronômetro também é utilizado para medir o tempo de ruptura da geomembrana. Os cones apresentam alturas de 12, 25, 38 e $50 \mathrm{~mm}$. Esta gama de variações permite investigar o efeito da altura da protuberância sobre a resistência à punção.

No segundo procedimento é permitida a utilização de pedregulhos isolados ao invés de cones; como também de camadas de pedregulhos de diâmetros variados. Este ensaio consiste num ensaio de desempenho, com procedimento similar ao ensaio com cones. No entanto, apresentam a vantagem de se conformarem mais adequadamente às condições de campo, com 
solos e subleitos específicos. Uma desvantagem deste tipo de ensaio é que a repetibilidade pode ser pobre, uma vez que a resistência à punção da geomembrana parecer ser sensível à orientação e a densidade do objeto protuberante (NAREJO ET AL., 1996).

\subsubsection{Ensaio do Cilindro (Cylinder Test)}

O ensaio do cilindro, também conhecido como ensaio sobre placa ou ensaios de placa para deformações a longo prazo, consiste num ensaio de desempenho utilizado para determinar a eficiência de geossintéticos como proteção para geomembranas de PEAD.

Tal equipamento foi desenvolvido pela Sociedade Geotécnica Alemã (Deutsche Gesellschaft für Geotechnik, DGGT) por volta de 1990 como um modo de se quantificar o grau para o qual uma geomembrana de PEAD, em conjunto com uma camada particular de proteção e um pedregulho para drenagem específico, numa temperatura e carregamento comparáveis com a base do aterro, pode estar sujeita a condições ambientais de stress cracking a longo prazo.

Segundo Gallagher et al. (1999), o método de ensaio foi primeiro aprovado pelo German Quo Vadis Schutzlagen e regulamentado pelo Instituto Federal para Ensaio e Pesquisa de Materiais (Bundesanstalt für Materialforschung Undprüfung - BAM).

De acordo com as regulamentações do BAM, neste ensaio uma camada de geomembrana é colocada sobre uma placa flexível de espessura entre 0,5-1,0 mm contida num recipiente cilíndrico de diâmetro entre 30 e $50 \mathrm{~cm}$. Esta placa por sua vez é colocada sobre outra placa, porém mais rígida, com espessura aproximadamente igual a $2 \mathrm{~cm}$. Uma amostra da camada de proteção é colocada sobre a geomembrana e coberta com uma camada de pedregulho para drenagem, uma camada de separação de geotêxtil não tecido e, finalmente, uma camada de areia para distribuição da carga. A carga especificada é exercida por meio de uma placa de carga e monitorada através de células de carga. 
Para exprimir as condições de carregamento do aterro junto aos parâmetros experimentais, tem sido aplicada uma carga de ensaio equivalente a 1,5 vezes a máxima sobrecarga esperada no aterro, para uma temperatura de $40^{\circ} \mathrm{C}$ e durante um período de 1.000 horas. As deformações são examinadas após 10, 100 e 1.000 horas. Após um período de carregamento de 1.000 horas, a placa é removida e os embricamentos são estimados. Um mínimo de três ensaios é exigido para determinar a dispersão devido ao efeito da variação dos grãos na camada de pedregulhos. A Figura 26 apresenta o esquema do ensaio de cilindro.

\section{Carregamento aplicado}

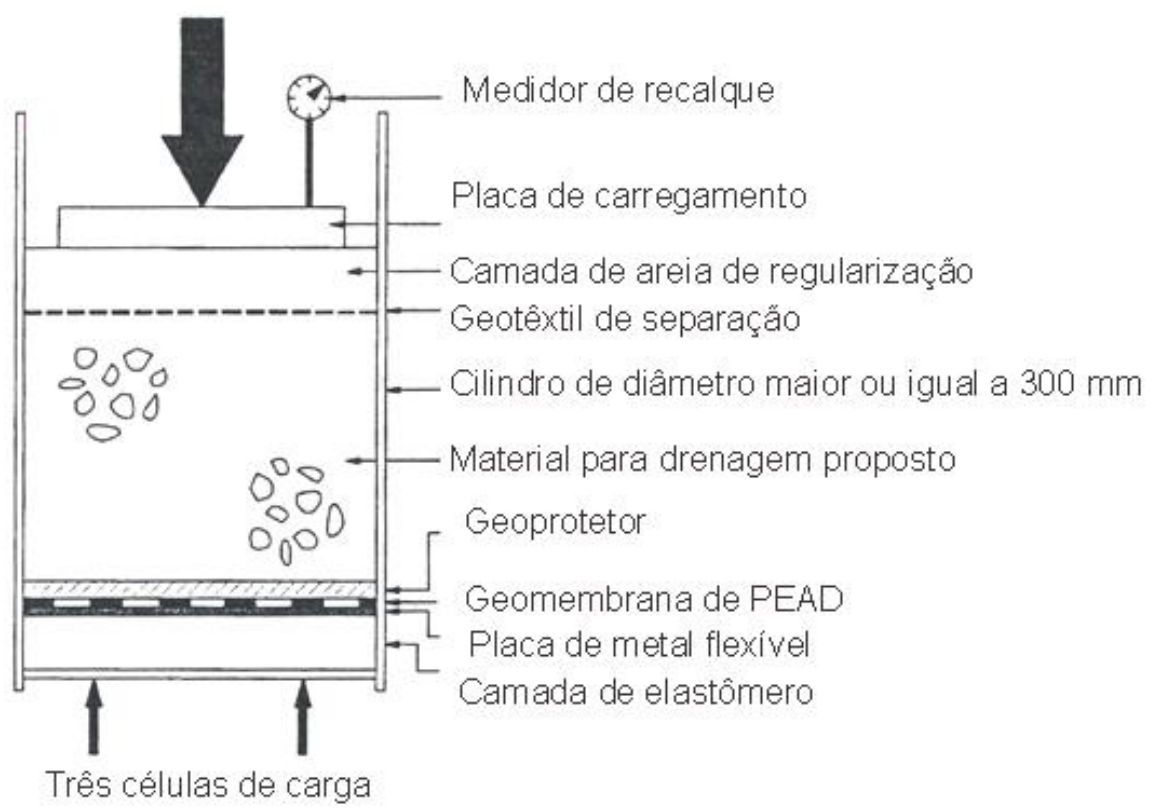

Figura 26. Esquema do ensaio do cilindro (GALLAGHER ET AL., 1999).

O critério para estimativa do desempenho da camada de proteção é baseado na geomembrana, sendo estabelecidas as seguintes condições para um nível aceitável: nenhum dano à superfície superior em forma de fissuras; nenhuma forma de deformação angular, e uma deformação local máxima permitida de $0,25 \%$.

$\mathrm{Na}$ Alemanha, geralmente é utilizada uma camada de drenagem de $200 \mathrm{~mm}$ de espessura, com diâmetro do pedregulho variando de 16 a $32 \mathrm{~mm}$, e uma geomembrana de 
PEAD de 1,5 mm de espessura. O peso específico do resíduo é tomado com regra e equivale a $15 \mathrm{kN} / \mathrm{m}^{3}$. Na Inglaterra, adota-se geomembranas de PEAD com 2,0 mm de espessura e, o peso específico do resíduo é tomado como $10 \mathrm{kN} / \mathrm{m}^{3}$.

Nesta metodologia do desempenho de camadas de proteção a longo prazo, admite-se que tanto a temperatura quanto o aumento do carregamento contribuem para acelerar as condições experimentais através de um fator de correção de carga.

A Tabela 20 apresenta os fatores de correção de carga para a temperatura e o tempo de ensaio. No entanto, cabe ressaltar que o fator de carregamento e de temperatura aqui mencionado não reflete o comportamento de fluência dos geossintéticos durante a vida útil do aterro.

Tabela 20. Aumento de carga para várias condições de ensaio.

\begin{tabular}{cc}
\hline Condições de ensaio & Fator de correção de carga \\
\hline $1.000 \mathrm{~h}, 40^{\circ} \mathrm{C}$ & 1,5 \\
\hline $1.000 \mathrm{~h}, 23^{\circ} \mathrm{C}$ & 2,25 \\
\hline $100 \mathrm{~h}, 23^{\circ} \mathrm{C}$ & 2,5 \\
\hline
\end{tabular}

Uma das propostas para verificar o comportamento de materiais de proteção para geomembranas submetidas a danos de instalação e de operação consiste nos ensaios de grande escala e de campo.

Como exemplo de ensaios em grande escala, citam-se os trabalhos de Zanzinger (1999); Zanzinger \& Gartung (1998) e Tognon (1999), cujos objetivos consistiram em simular danos devido ao carregamento do resíduo (fase de operação), e o trabalho de Reddy et al. (1996), voltado para avaliação dos danos mecânicos em geomembranas devido ao carregamento da construção. 


\subsection{Considerações Finais}

Uma das questões relevantes na utilização de geomembrana em sistemas de captação e desvio de fluxo (SCDF) consiste na seleção e desempenho de camadas de proteção mecânica contra danos à sua integridade.

No entanto, as informações relatadas na literatura se mostram escassas e divergentes quanto aos métodos de projeto e ao modo como a avaliação dos elementos deve ser conduzida.

$\mathrm{Na}$ filosofia proposta por Koerner et al. (1996), por exemplo, a seleção do geotêxtil como elemento de proteção é baseada somente na sua gramatura. No entanto, outras propriedades mecânicas como resistência à tração e à punção não são consideradas. Tais propriedades estão relacionadas à composição polimérica, ao tipo e qualidade da fibra, e aos métodos de fabricação que, por sua vez, podem estar relacionados ao desempenho de geotêxteis como elemento de proteção.

Outra consideração acerca desta filosofia de projeto consiste nos fatores de redução aplicados para correlacionar os dados de laboratório com as condições de campo, os quais podem não corresponder às condições específicas de campo.

$\mathrm{Na}$ filosofia baseada no desempenho a longo prazo, o valor limite admitido para deformações nas geomembranas é discutível. Além do questionamento do critério de derivação de tal limite, resultados de ensaios de grande escala realizados por Tognon et al. (2000) mostram que nenhum dos tipos de proteção mais utilizados foi capaz de apresentar deformações locais inferiores a $0,25 \%$, apesar das geomembranas não apresentarem danos visíveis. Além disto, alguns autores relatam que os danos mais recorrentes em geomembranas ocorrem durante a fase de instalação (construção), o que não minimiza a relevância dos danos que podem ocorrer durantes a fase de operação de aterros. No entanto, a fase de instalação 
não é simulada em nenhuma das filosofias citadas acima. Assim, as formulações aplicadas à fase de operação do aterro são estendidas para a fase de instalação, podendo não se adequar a este tipo de solicitação.

Para simular os danos de instalação, tem-se o método de ensaio proposto pela norma européia ISO 10.722. O princípio do ensaio consiste em submeter um geossintético a carregamentos cíclicos para posterior avaliação de suas propriedades. Neste ensaio pode ser variado o carregamento e o número de ciclos. Apesar de este ensaio simular a condição de fadiga na geomembrana, apresenta a limitação de não simular os movimentos operacionais de maquinários durante a construção da camada de drenagem.

A literatura também mostra que existem vários ensaios para avaliar o desempenho de geotêxteis como camada de proteção, divididos em ensaios índices, de desempenho e de campo ou em grande escala. Os estudos já realizados mostram que as diferenças de configurações interferem na avaliação do elemento de proteção e, que os critérios usualmente utilizados podem não ser representativos do comportamento em campo.

As geomembranas de PEAD possuem elevada resistência à punção e podem apresentar danos principalmente sob a forma de arranhões e entalhes. Conforme já mencionado, tais danos podem acelerar o mecanismo de stress cracking. O critério proposto pelo BAM se baseia na limitação de deformações para que tal mecanismo não seja desencadeado. No entanto, faltam dados de ensaios de stress cracking em geomembranas danificadas para quantificar a influência dos danos de instalação e de operação no mecanismo de stress cracking.

Em face às suas características, vários trabalhos na literatura relatam um bom desempenho de geomembranas de PVC em obras geotécnicas ambientais. Contudo, percebese que todos os trabalhos se referem apenas às geomembranas de PEAD e, que faltam 
informações sobre o comportamento de geotêxteis como proteção para geomembranas de PVC.

Enquanto nas geomembranas de PEAD os danos se manifestam principalmente sob a forma de arranhões e entalhes, nas geomembranas de PVC se manifestam na forma de deformações ou furos. Percebe-se que cada geomembrana se comporta de maneira diferente e, que maiores estudos devem ser realizados antes de estender as considerações do PEAD para as geomembranas de PVC. 
CAPÍTULO 3. MATERIAIS E MÉTODOS

\subsection{Descrição dos Materiais}

\subsubsection{Geossintéticos}

Foram empregadas geomembranas de PVC (polivinil clorado) de 1,0 e 2,0 mm de espessura, PEAD (polietileno de alta densidade) com espessuras de 1,5 mm e 2,0 $\mathrm{mm}$ e, PELMD (polietileno linear de baixa densidade) com espessura de 1,25 mm.

Como camadas de proteção foram utilizados geotêxteis não tecidos de poliéster (PET) com gramaturas de 130, 300, 400 e $600 \mathrm{~g} / \mathrm{m}^{2}$, e de polipropileno (PP) com gramatura de 400 e $600 \mathrm{~g} / \mathrm{m}^{2}$

Foram utilizados dois lotes de fabricação para todos os materiais assim divididos: lote A (materiais empregados em campo) e lote B (materiais empregados em laboratório).

Os ensaios de caracterização realizados nos geossintéticos são apresentados na Tabela 21 e na Tabela 22. 
Tabela 21. Ensaios de caracterização das geomembranas.

\begin{tabular}{cc}
\hline Ensaio & Norma \\
\hline Espessura nominal & ASTM 5199 \\
\hline Massa específica (densidade) & ASTM D 792 \\
\hline Tração & ASTM D 882 / D 6693 \\
\hline Rasgo & ASTM D 1004 \\
\hline Punção estática & NBR 13359 / ASTM D 4833 \\
\hline Permeabilidade a vapor d'água & ASTM E 96
\end{tabular}

Tabela 22. Ensaios de caracterização dos geotêxteis.

\begin{tabular}{cc}
\hline Ensaio & Norma \\
\hline Espessura & ABNT NBR 12569 \\
\hline Massa por unidade de área (gramatura) & ABNT NBR 12568 \\
\hline Tração Faixa Larga & ABNT NBR 12824 \\
\hline Rasgo & ASTM D 4533 \\
\hline Punção estática & ABNT NBR 13359 / ASTM D 4833
\end{tabular}

\subsubsection{Solos e Agregados}

Foram utilizadas uma areia argilosa como base de solo compactado nos ensaios de campo e de laboratório, e uma areia bem graduada como elemento de proteção nos ensaios de campo. Como camada de drenagem foram utilizados dois tipos de agregados, com diferentes granulometrias. Os ensaios de caracterização dos solos e agregados são apresentados na Tabela 23. 
Tabela 23. Ensaios de caracterização dos solos e agregados.

\begin{tabular}{ll}
\hline \multicolumn{1}{c}{ Ensaio } & Norma \\
\hline Solos & \\
\hline Análise Granulométrica & NBR 7181 \\
\hline Massa específica dos sólidos & NBR 6508 \\
\hline Ensaio de compactação & NBR 7182 \\
\hline Limite de plasticidade & NBR 7180 \\
\hline Limite de liquidez & NBR 6459 \\
\hline Agregados & NBR 7181 \\
\hline Análise Granulométrica & NBR 6458 \\
\hline Massa específica dos sólidos & NBR 12051 \\
\hline Índice de vazios mínimo & NBR 12004 \\
\hline Índice de vazios máximo &
\end{tabular}

\subsection{Ensaios de Laboratório para Avaliação das Camadas de Proteção}

Os ensaios de laboratório realizados foram divididos em ensaios índices e de desempenho. Nos ensaios índices foram realizados ensaios de punção estática (ASTM D4833) e de punção dinâmica (ABNT NBR 14.971 - queda do cone). Nesta etapa foram variados o polímero e espessura da geomembrana; polímero, gramatura e disposição do geotêxtil, bem como se procurou verificar o efeito da introdução de uma base de solo compactado.

O ensaio de desempenho realizado foi o de dano de instalação, segundo a norma ISO 10.722-1. Este ensaio tem como objetivo simular danos cíclicos em geossintéticos em contato com agregados. Nesta etapa foram avaliados os danos sobre a geomembrana submetida a carregamento cíclico sem elemento de proteção sob diferentes cargas e número de ciclos. Também foram avaliados os danos sobre a geomembrana submetida a carregamento com proteção de geotêxtil. Após a realização do ensaio, amostras das geomembranas danificadas foram submetidas a ensaios mecânicos, hidráulicos e de degradação para quantificação do dano através da mudança de suas propriedades. 


\subsubsection{Ensaios Índices}

O princípio do ensaio de punção estática consiste em submeter uma amostra, colocada num molde cilindro vazado de $45 \mathrm{~mm}$ de diâmetro, a um ensaio de compressão. A amostra é solicitada por uma haste biselada de $8 \mathrm{~mm}$ de diâmetro com uma velocidade de $300 \mathrm{~mm} / \mathrm{min}$. A resistência ao puncionamento é tomada como a carga máxima registrada durante o ensaio. A Figura 27 ilustra o equipamento utilizado para realização do ensaio. Na Figura 28 são apresentados detalhes do ensaio onde se introduziu uma base de solo argiloso compactado.

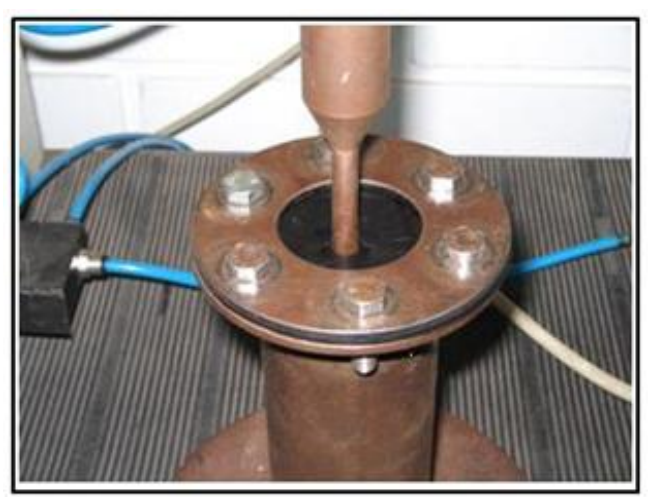

(a)

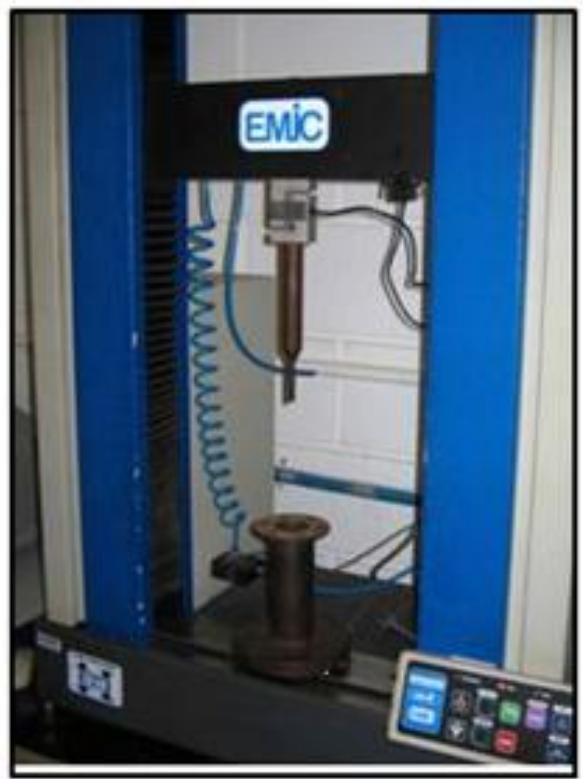

(b)

Figura 27. Ensaio de punção estática: (a) arranjo do corpo de prova; (b) vista geral. 


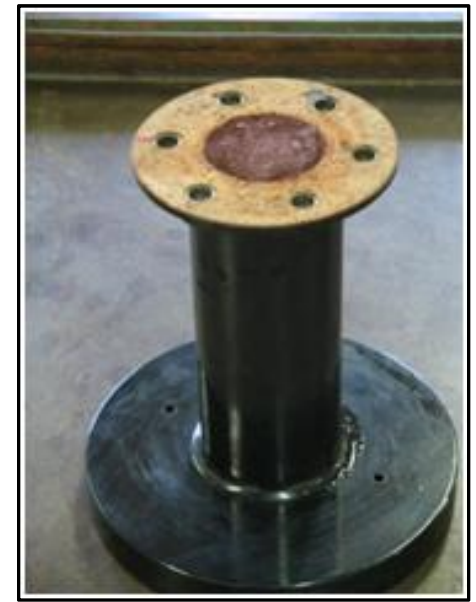

Base antes do ensaio

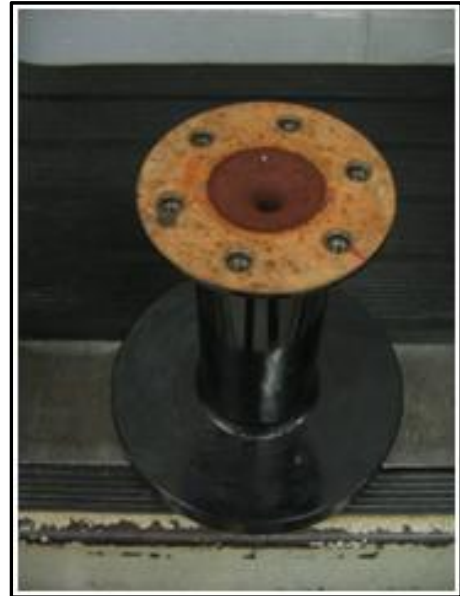

Base puncionada

Figura 28. Ensaio de punção estática: introdução de base de solo compactado.

No ensaio de punção dinâmica, um cone de aço de 500 g com ângulo e forma definidos é desprendido a partir de uma altura de $500 \mathrm{~mm}$ acima da amostra. O diâmetro do furo criado é medido por meio de outro cone de alumínio de peso definido (500g) e menor ângulo, com escala medida em milímetros. A Figura 29 apresenta o esquema ilustrativo do ensaio. 

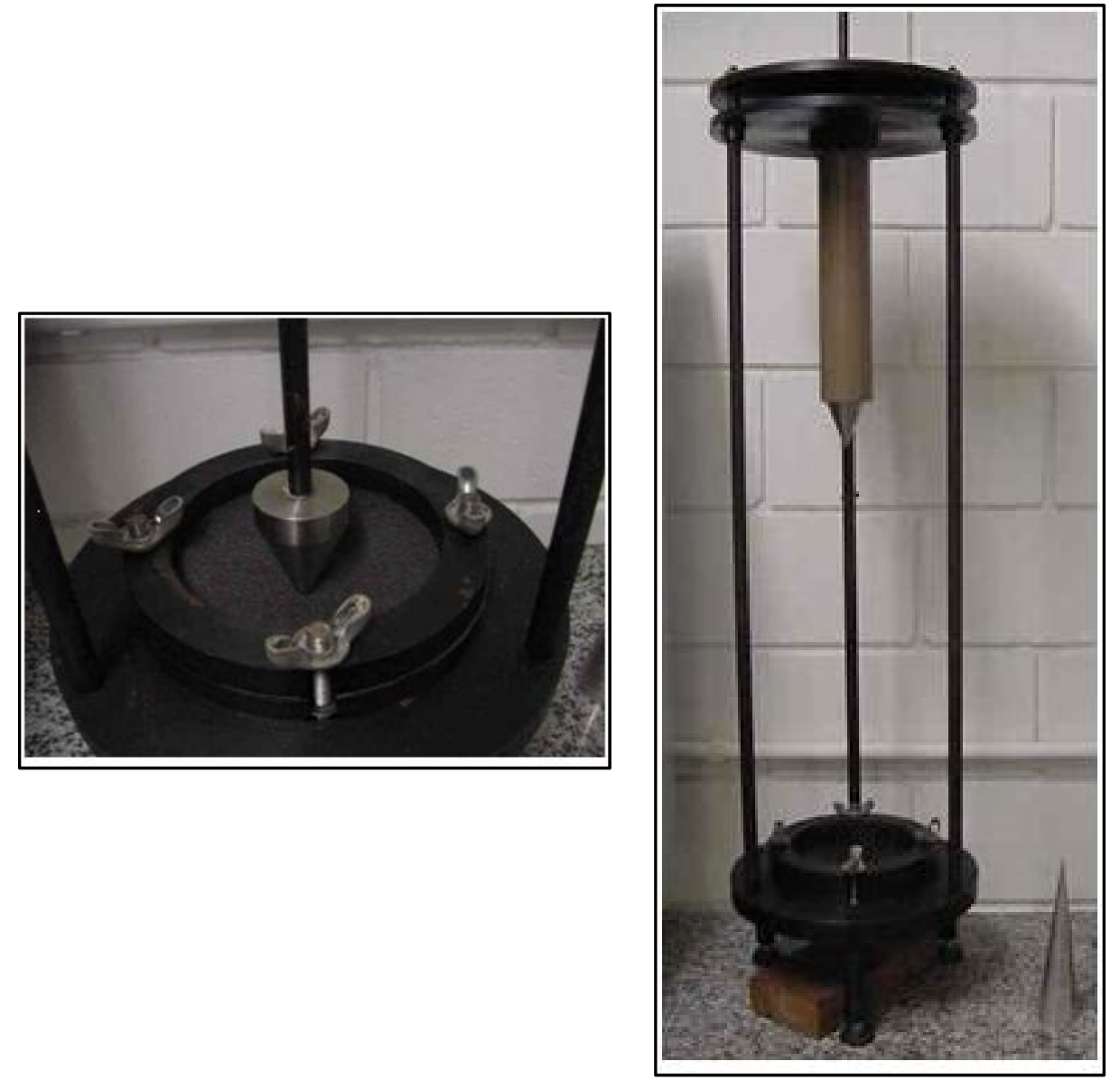

(a)

(b)

Figura 29. Ensaio de punção dinâmica: (a) arranjo do corpo de prova; (b) vista geral.

A Tabela 24 apresenta a configuração de todos os ensaios índice realizados. 
Tabela 24. Configurações dos ensaios índice realizados.

\begin{tabular}{|c|c|c|c|c|c|}
\hline \multirow[t]{3}{*}{ Geomembrana } & \multirow{3}{*}{$\begin{array}{c}\text { Disposição do } \\
\text { GT }\end{array}$} & \multicolumn{4}{|c|}{ Configuração dos ensaios } \\
\hline & & \multicolumn{2}{|c|}{ Sem base de solo compactado } & \multicolumn{2}{|c|}{ Com base de solo compactado } \\
\hline & & $\begin{array}{l}\text { Punção } \\
\text { Estática } \\
\end{array}$ & $\begin{array}{c}\text { Punção } \\
\text { Dinâmica }\end{array}$ & $\begin{array}{l}\text { Punção } \\
\text { Estática } \\
\end{array}$ & $\begin{array}{c}\text { Punção } \\
\text { Dinâmica }\end{array}$ \\
\hline \multirow[t]{17}{*}{ PVC } & \multirow[t]{7}{*}{ GT /GM } & sem proteção & sem proteção & sem proteção & sem proteção \\
\hline & & PET $130 \mathrm{~g} / \mathrm{m}^{2}$ & PET $130 \mathrm{~g} / \mathrm{m}^{2}$ & - & - \\
\hline & & PET $300 \mathrm{~g} / \mathrm{m}^{2}$ & PET $300 \mathrm{~g} / \mathrm{m}^{2}$ & PET $300 \mathrm{~g} / \mathrm{m}^{2}$ & PET $300 \mathrm{~g} / \mathrm{m}^{2}$ \\
\hline & & PET $400 \mathrm{~g} / \mathrm{m}^{2}$ & PET $400 \mathrm{~g} / \mathrm{m}^{2}$ & - & - \\
\hline & & PET $600 \mathrm{~g} / \mathrm{m}^{2}$ & PET $600 \mathrm{~g} / \mathrm{m}^{2}$ & - & - \\
\hline & & $\mathrm{PP} 400 \mathrm{~g} / \mathrm{m}^{2}$ & $\mathrm{PP} 400 \mathrm{~g} / \mathrm{m}^{2}$ & - & - \\
\hline & & PP $600 \mathrm{~g} / \mathrm{m}^{2}$ & PP $600 \mathrm{~g} / \mathrm{m}^{2}$ & - & - \\
\hline & \multirow[t]{5}{*}{ GM / GT } & PET $130 \mathrm{~g} / \mathrm{m}^{2}$ & PET $130 \mathrm{~g} / \mathrm{m}^{2}$ & - & - \\
\hline & & PET $300 \mathrm{~g} / \mathrm{m}^{2}$ & PET $300 \mathrm{~g} / \mathrm{m}^{2}$ & PET $300 \mathrm{~g} / \mathrm{m}^{2}$ & PET $300 \mathrm{~g} / \mathrm{m}^{2}$ \\
\hline & & PET $600 \mathrm{~g} / \mathrm{m}^{2}$ & PET $600 \mathrm{~g} / \mathrm{m}^{2}$ & - & - \\
\hline & & PP $400 \mathrm{~g} / \mathrm{m}^{2}$ & PP $400 \mathrm{~g} / \mathrm{m}^{2}$ & - & - \\
\hline & & PP $600 \mathrm{~g} / \mathrm{m}^{2}$ & PP $600 \mathrm{~g} / \mathrm{m}^{2}$ & - & - \\
\hline & \multirow[t]{5}{*}{ GT / GM / GT } & PET $130 \mathrm{~g} / \mathrm{m}^{2}$ & PET $130 \mathrm{~g} / \mathrm{m}^{2}$ & - & - \\
\hline & & PET $300 \mathrm{~g} / \mathrm{m}^{2}$ & PET $300 \mathrm{~g} / \mathrm{m}^{2}$ & PET $300 \mathrm{~g} / \mathrm{m}^{2}$ & PET $300 \mathrm{~g} / \mathrm{m}^{2}$ \\
\hline & & PET $600 \mathrm{~g} / \mathrm{m}^{2}$ & PET $600 \mathrm{~g} / \mathrm{m}^{2}$ & - & - \\
\hline & & PP $400 \mathrm{~g} / \mathrm{m}^{2}$ & PP $400 \mathrm{~g} / \mathrm{m}^{2}$ & - & - \\
\hline & & PP $600 \mathrm{~g} / \mathrm{m}^{2}$ & PP $600 \mathrm{~g} / \mathrm{m}^{2}$ & - & - \\
\hline \multirow[t]{17}{*}{ PEAD } & \multirow[t]{7}{*}{ GT /GM } & sem proteção & sem proteção & sem proteção & sem proteção \\
\hline & & PET $130 \mathrm{~g} / \mathrm{m}^{2}$ & PET $130 \mathrm{~g} / \mathrm{m}^{2}$ & - & - \\
\hline & & PET $300 \mathrm{~g} / \mathrm{m}^{2}$ & PET $300 \mathrm{~g} / \mathrm{m}^{2}$ & PET $300 \mathrm{~g} / \mathrm{m}^{2}$ & PET $300 \mathrm{~g} / \mathrm{m}^{2}$ \\
\hline & & PET $400 \mathrm{~g} / \mathrm{m}^{2}$ & PET $400 \mathrm{~g} / \mathrm{m}^{2}$ & - & - \\
\hline & & PET $600 \mathrm{~g} / \mathrm{m}^{2}$ & PET $600 \mathrm{~g} / \mathrm{m}^{2}$ & - & - \\
\hline & & PP $400 \mathrm{~g} / \mathrm{m}^{2}$ & PP $400 \mathrm{~g} / \mathrm{m}^{2}$ & - & - \\
\hline & & PP $600 \mathrm{~g} / \mathrm{m}^{2}$ & PP $600 \mathrm{~g} / \mathrm{m}^{2}$ & - & - \\
\hline & \multirow[t]{5}{*}{$\mathrm{GM} / \mathrm{GT}$} & PET $130 \mathrm{~g} / \mathrm{m}^{2}$ & PET $130 \mathrm{~g} / \mathrm{m}^{2}$ & - & - \\
\hline & & PET $300 \mathrm{~g} / \mathrm{m}^{2}$ & PET $300 \mathrm{~g} / \mathrm{m}^{2}$ & PET $300 \mathrm{~g} / \mathrm{m}^{2}$ & PET $300 \mathrm{~g} / \mathrm{m}^{2}$ \\
\hline & & PET $600 \mathrm{~g} / \mathrm{m}^{2}$ & PET $600 \mathrm{~g} / \mathrm{m}^{2}$ & - & - \\
\hline & & PP $400 \mathrm{~g} / \mathrm{m}^{2}$ & PP $400 \mathrm{~g} / \mathrm{m}^{2}$ & - & - \\
\hline & & PP $600 \mathrm{~g} / \mathrm{m}^{2}$ & PP $600 \mathrm{~g} / \mathrm{m}^{2}$ & - & - \\
\hline & \multirow[t]{5}{*}{ GT / GM / GT } & PET $130 \mathrm{~g} / \mathrm{m}^{2}$ & PET $130 \mathrm{~g} / \mathrm{m}^{2}$ & - & - \\
\hline & & PET $300 \mathrm{~g} / \mathrm{m}^{2}$ & PET $300 \mathrm{~g} / \mathrm{m}^{2}$ & PET $300 \mathrm{~g} / \mathrm{m}^{2}$ & \\
\hline & & PET $600 \mathrm{~g} / \mathrm{m}^{2}$ & PET $600 \mathrm{~g} / \mathrm{m}^{2}$ & - & - \\
\hline & & PP $400 \mathrm{~g} / \mathrm{m}^{2}$ & PP $400 \mathrm{~g} / \mathrm{m}^{2}$ & - & - \\
\hline & & - & PP $600 \mathrm{~g} / \mathrm{m}^{2}$ & - & - \\
\hline \multirow[t]{17}{*}{ PELMD } & \multirow[t]{7}{*}{ GT /GM } & sem proteção & sem proteção & sem proteção & sem proteção \\
\hline & & PET $130 \mathrm{~g} / \mathrm{m}^{2}$ & PET $130 \mathrm{~g} / \mathrm{m}^{2}$ & - & - \\
\hline & & PET $300 \mathrm{~g} / \mathrm{m}^{2}$ & PET $300 \mathrm{~g} / \mathrm{m}^{2}$ & PET $300 \mathrm{~g} / \mathrm{m}^{2}$ & PET $300 \mathrm{~g} / \mathrm{m}^{2}$ \\
\hline & & PET $400 \mathrm{~g} / \mathrm{m}^{2}$ & PET $400 \mathrm{~g} / \mathrm{m}^{2}$ & - & - \\
\hline & & PET $600 \mathrm{~g} / \mathrm{m}^{2}$ & PET $600 \mathrm{~g} / \mathrm{m}^{2}$ & - & - \\
\hline & & PP $400 \mathrm{~g} / \mathrm{m}^{2}$ & PP $400 \mathrm{~g} / \mathrm{m}^{2}$ & - & - \\
\hline & & PP $600 \mathrm{~g} / \mathrm{m}^{2}$ & PP $600 \mathrm{~g} / \mathrm{m}^{2}$ & - & - \\
\hline & \multirow[t]{5}{*}{ GM / GT } & PET $130 \mathrm{~g} / \mathrm{m}^{2}$ & PET $130 \mathrm{~g} / \mathrm{m}^{2}$ & - & - \\
\hline & & PET $300 \mathrm{~g} / \mathrm{m}^{2}$ & PET $300 \mathrm{~g} / \mathrm{m}^{2}$ & PET $300 \mathrm{~g} / \mathrm{m}^{2}$ & PET $300 \mathrm{~g} / \mathrm{m}^{2}$ \\
\hline & & PET $600 \mathrm{~g} / \mathrm{m}^{2}$ & PET $600 \mathrm{~g} / \mathrm{m}^{2}$ & - & - \\
\hline & & PP $400 \mathrm{~g} / \mathrm{m}^{2}$ & PP $400 \mathrm{~g} / \mathrm{m}^{2}$ & - & - \\
\hline & & PP $600 \mathrm{~g} / \mathrm{m}^{2}$ & PP $600 \mathrm{~g} / \mathrm{m}^{2}$ & - & - \\
\hline & \multirow[t]{5}{*}{ GT / GM / GT } & PET $130 \mathrm{~g} / \mathrm{m}^{2}$ & PET $130 \mathrm{~g} / \mathrm{m}^{2}$ & - & - \\
\hline & & PET $300 \mathrm{~g} / \mathrm{m}^{2}$ & PET $300 \mathrm{~g} / \mathrm{m}^{2}$ & PET $300 \mathrm{~g} / \mathrm{m}^{2}$ & PET $300 \mathrm{~g} / \mathrm{m}^{2}$ \\
\hline & & PET $600 \mathrm{~g} / \mathrm{m}^{2}$ & PET $600 \mathrm{~g} / \mathrm{m}^{2}$ & - & - \\
\hline & & PP $400 \mathrm{~g} / \mathrm{m}^{2}$ & - & - & - \\
\hline & & PP $600 \mathrm{~g} / \mathrm{m}^{2}$ & PP $600 \mathrm{~g} / \mathrm{m}^{2}$ & - & - \\
\hline
\end{tabular}




\subsubsection{Ensaios de Desempenho - Dano de Instalação}

O ensaio foi realizado no Laboratório de Mecânica dos Solos do Departamento de Geotecnia, utilizando-se uma Prensa Servo - Controlada.

O equipamento consiste em duas caixas bipartidas de dimensões de $30 \times 30 \times 7,5 \mathrm{~cm}$, cada uma, onde são colocados os materiais a serem ensaiados.

A norma ISO 10.722 (Procedimento para simulação de danos de instalação - Parte 1: Instalação em materiais granulares) prevê a colocação de agregado nas caixas inferior e superior. No entanto, algumas modificações foram realizadas durante o ensaio com o intuito de simular um comportamento mais próximo da situação de campo.

Assim, na caixa inferior foi compactada uma camada de solo argiloso sob condições pré-estabelecidas $\left(\mathrm{w}_{\text {ótima }}=14,5 \%\right.$ e $\left.\mathrm{GC}=98\right)$. Sobre a camada de solo foi colocada a geomembrana e, posteriormente, fixou-se a caixa superior, preenchendo-a com a brita. Após a colocação de todo o material, instalou-se a placa de carregamento. Uma carga inicial de 200 $\mathrm{kPa}$ foi aplicada para acomodação da brita. Após, o carregamento cíclico foi aplicado através de uma pressão sinusoidal de 200 e $400 \mathrm{kPa}$, ambas na freqüência de $1 \mathrm{~Hz}$ (um carregamento por segundo). O número de ciclos foi variado, sendo aplicados 200 (recomendado pela norma), 500 e 1000 ciclos.

Após o ensaio, as geomembranas danificadas foram avaliadas por meio de inspeção visual e de ensaios mecânicos, hidráulicos e de stress cracking. Na inspeção visual foi verificada a existência de furos, marcas profundas ou rasgos. A Figura 30 mostra uma visão geral do equipamento. 


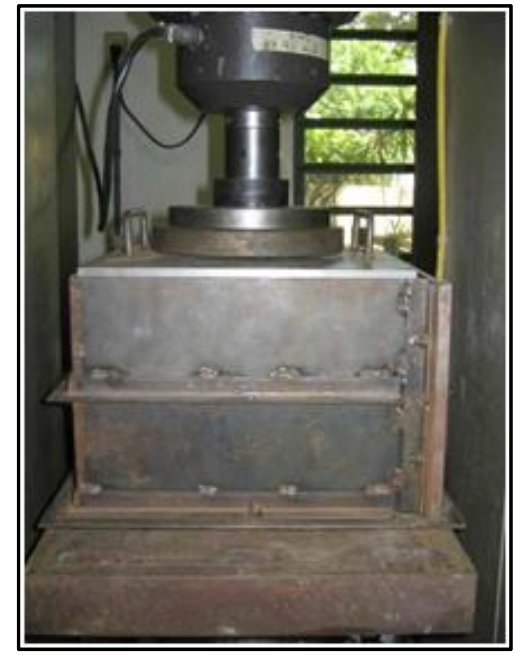

(a)

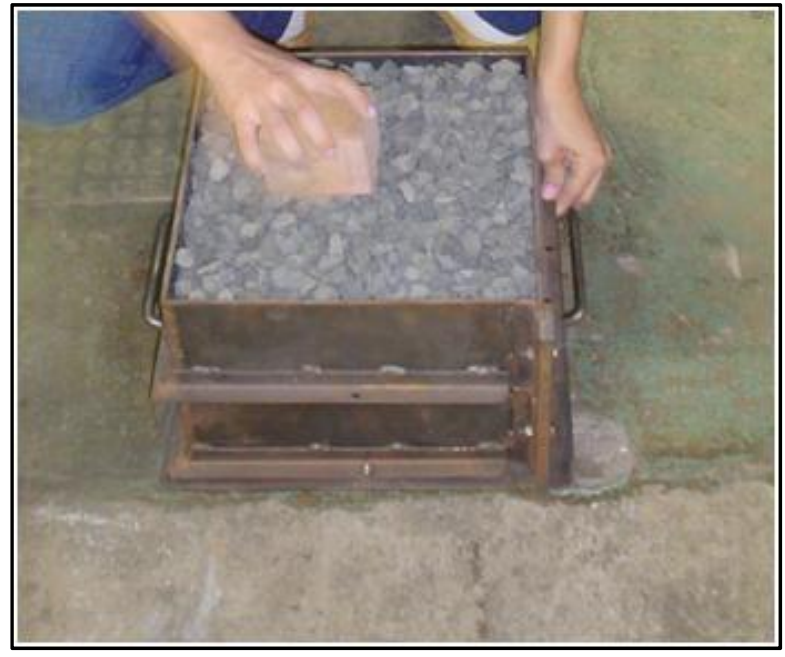

(b)

Figura 30. Ensaio de dano de instalação: (a) vista geral do equipamento; (b) detalhe da caixa.

\subsection{Ensaios de Danos de Instalação em Grande Escala - Ensaio de Campo}

Esta etapa teve como objetivo simular os danos mecânicos que podem ocorrer na geomembrana durante a fase de instalação e construção da camada de drenagem sobre a geomembrana. Para isto, foi construído um aterro experimental em jazida localizada no campus II da USP de São Carlos.

Inicialmente, executou-se a preparação da base escavando e compactando-se o solo em condições pré-estabelecidas. Após esta etapa, geomembranas de diferentes polímeros foram instaladas, seguido das camadas de proteção e, finalmente, da camada de drenagem.

A partir dos resultados obtidos em campo, pôde-se avaliar de forma qualitativa e quantitativa o desempenho dos materiais de proteção utilizados. Em primeiro momento, foram registrados os tipos de danos existentes na geomembrana segundo o guia proposto pelo Comitê Francês de Geossintéticos (CFG, 2001) - Guia para a realização de placas de testes de danos em geossintéticos. Após, as amostras das geomembranas foram submetidas a ensaios de laboratório (ensaios pós-danos) para quantificação da mudança de suas propriedades mecânicas. 


\subsubsection{Procedimento de Campo}

Para realização dos serviços de terraplenagem e construção da camada de drenagem foram utilizados os seguintes maquinários, cujas principais especificações técnicas são apresentadas na Tabela 25 .

- Motoniveladora (patrol) modelo 135 H Caterpillar;

- Pá carregadeira modelo 924 G Caterpillar;

- Rolo vibratório pé de careiro modelo CS 431C Caterpillar.

Tabela 25. Especificações técnicas dos equipamentos de terraplenagem utilizados.

\begin{tabular}{cccc}
\hline $\begin{array}{c}\text { Propriedades dos } \\
\text { equipamentos }\end{array}$ & $\begin{array}{c}\text { Motoniveladora } \\
\text { (patrol) } \\
(\mathbf{1 3 5} \mathbf{~ H})\end{array}$ & $\begin{array}{c}\text { Pá } \\
\text { carregadeira } \\
\mathbf{( 9 2 4} \mathbf{G})\end{array}$ & $\begin{array}{c}\text { Rolo vibratório pé de } \\
\text { carneiro } \\
\text { (CS 431C) }\end{array}$ \\
\hline Massa total $(\mathrm{kg})$ & 13.080 & 10.968 & 20.755 \\
\hline $\begin{array}{c}\text { Comprimento das } \\
\text { rodas/esteira (m) }\end{array}$ & 1,20 & 1,50 & - \\
\hline Largura das rodas/esteira (m) & 0,40 & 0,60 & - \\
\hline Largura da lâmina & 3,60 & 3,60 & - \\
\hline Diâmetro tambor $(\mathrm{m})$ & - & - & 1,03 \\
\hline Diâmetro externo $(\mathrm{m})$ & - & - & 60 \\
\hline Pontas por roda & - & - & - \\
\hline $\begin{array}{c}\text { Tensão de contato com o solo } \\
(\mathrm{kPa})\end{array}$ & $\cong 50$ & $\cong 30$ & 1,42 \\
\hline
\end{tabular}

A escavação do solo local foi realizada com a retro-escavadeira hidráulica, numa área de $20 \times 55 \mathrm{~m}^{2}$ com $80 \mathrm{~cm}$ de profundidade. A Figura 31 mostra os detalhes executivos do processo de escavação.

Após a escavação, o solo foi destorroado com a patrol (motoniveladora) e a base foi nivelada para o lançamento das camadas a serem compactadas (Figura 32). 


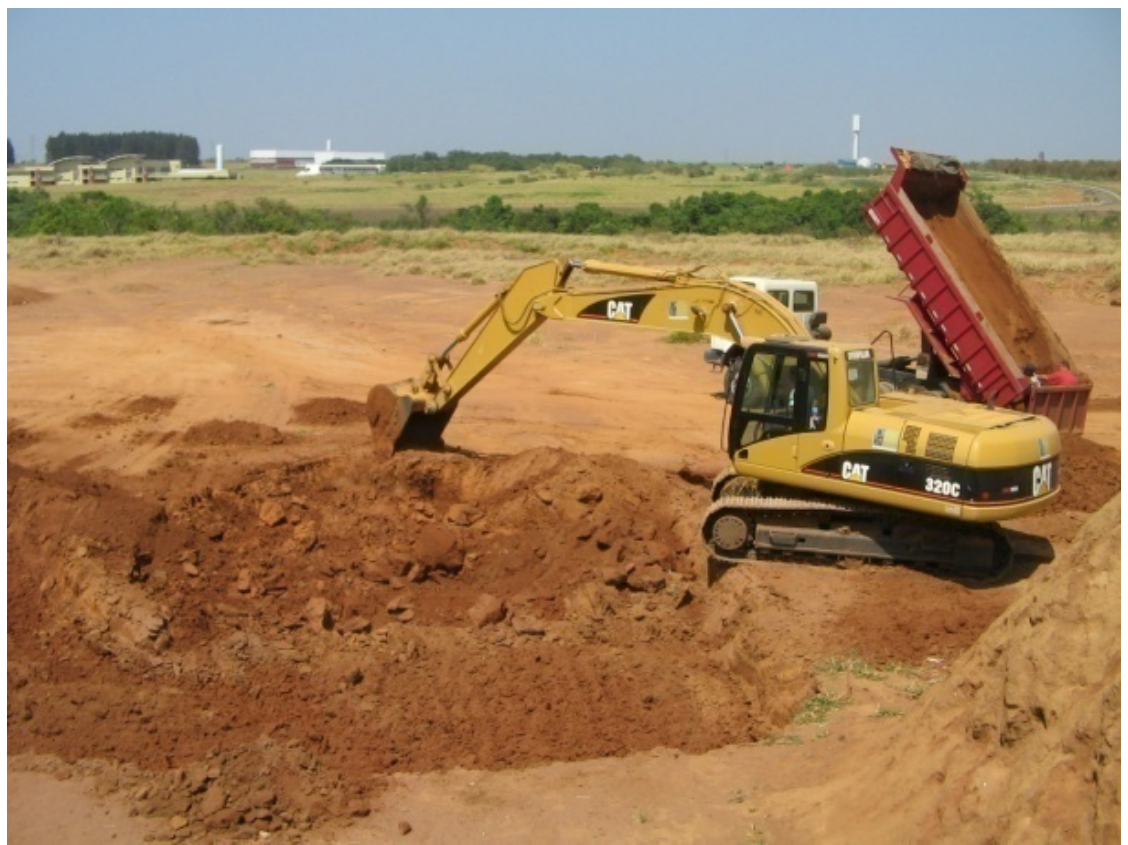

início da escavação

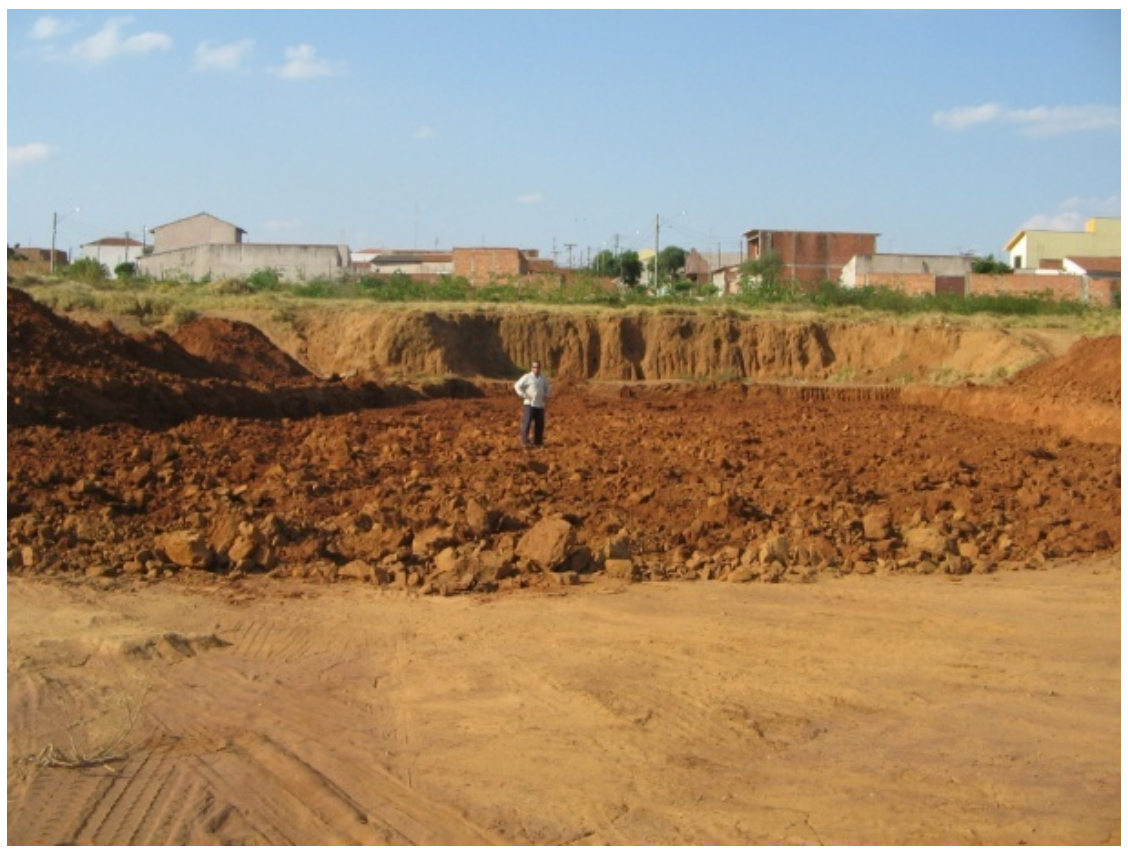

escavação total

Figura 31. Escavação da área. 


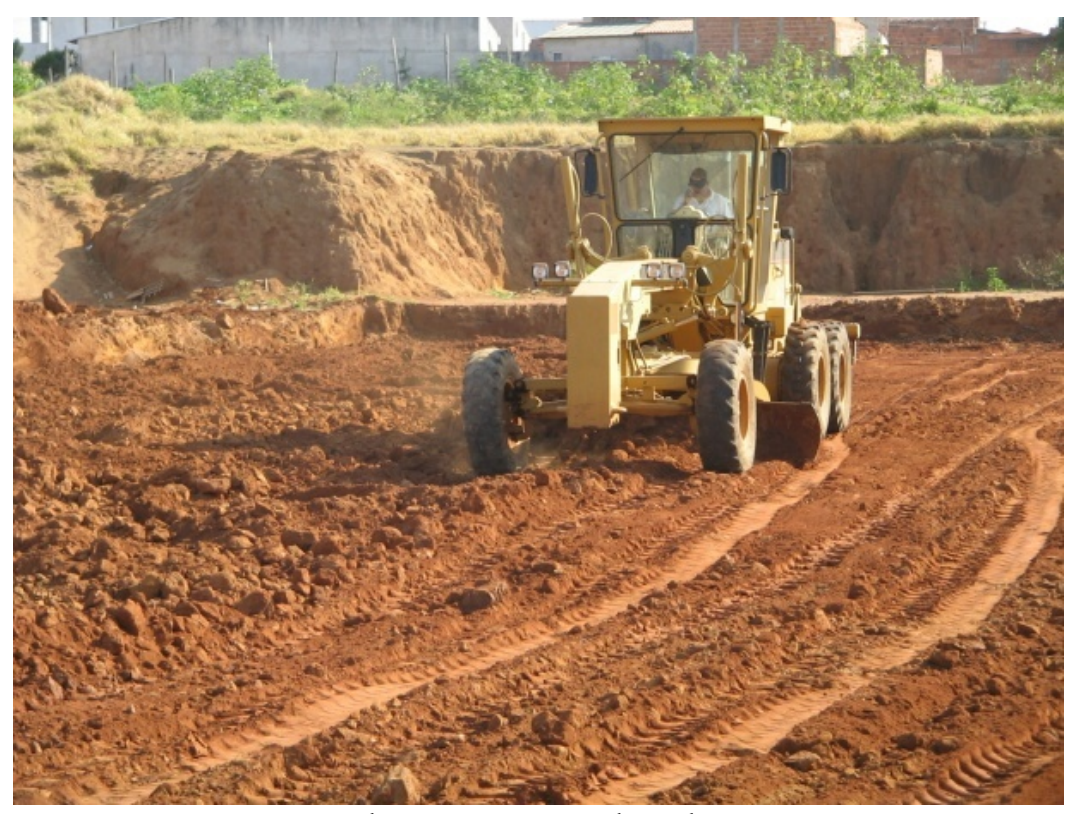

destorroamento do solo

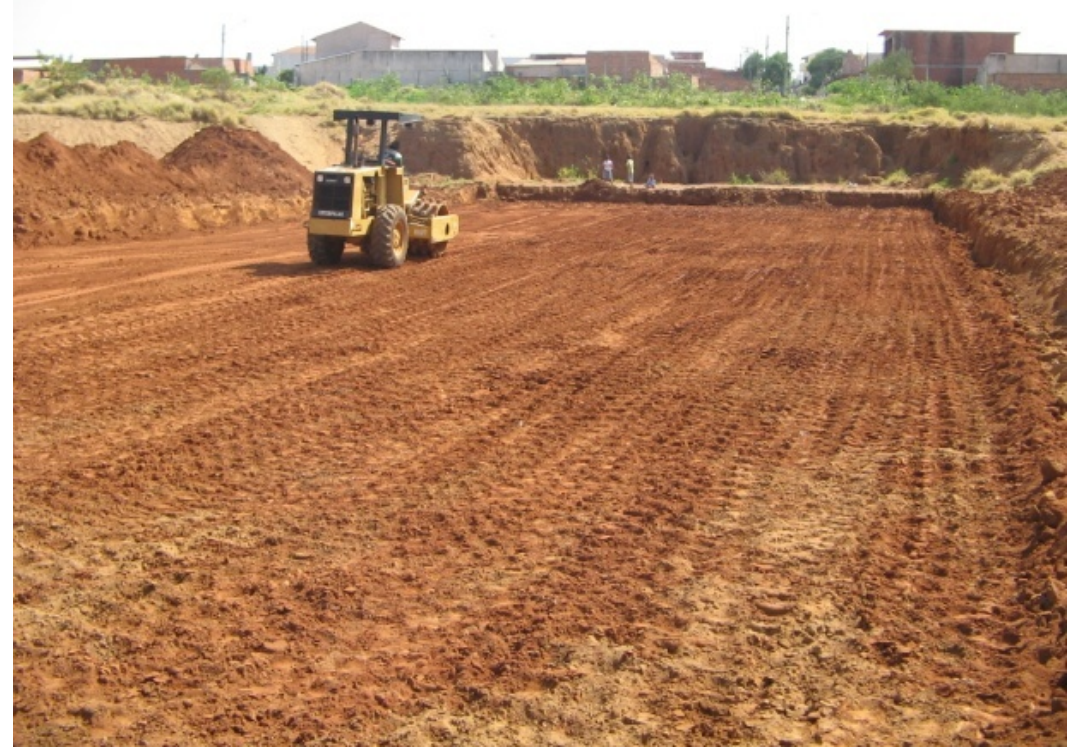

compactação do solo

Figura 32. Preparação da base.

O solo retirado foi revolvido e compactado em três camadas de $20 \mathrm{~cm}$ cada uma, totalizando uma profundidade de $60 \mathrm{~cm}$. As camadas foram compactadas com $\mathrm{GC}$ de $95 \% \mathrm{e}$ umidade de $15 \%(\Delta \mathrm{w}= \pm 2 \%)$. 


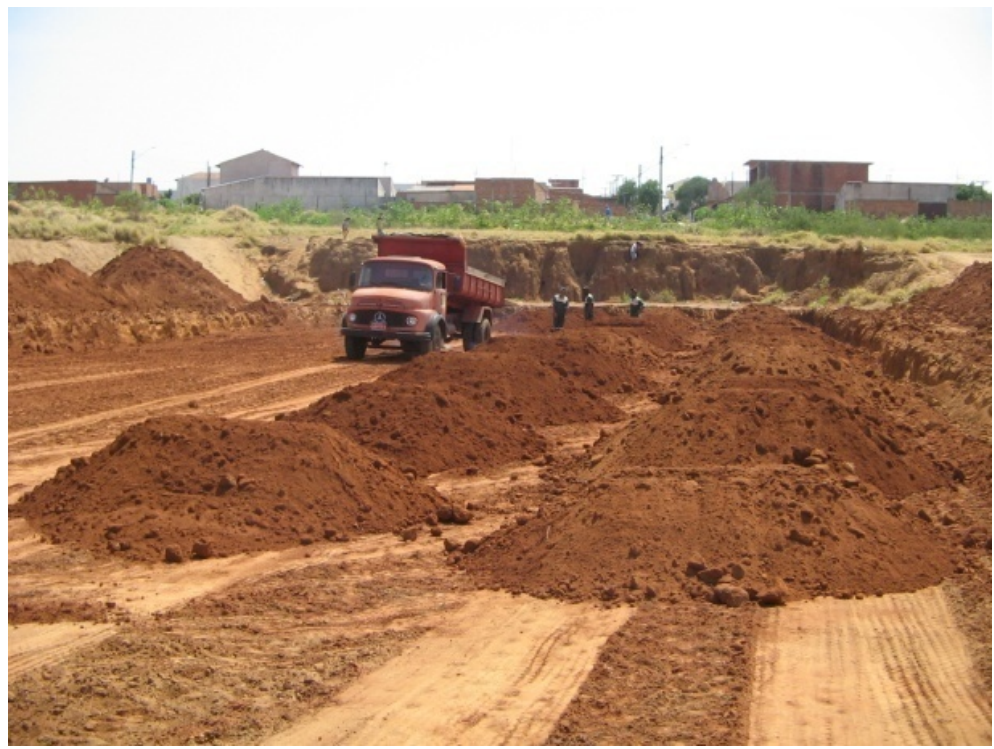

Lançamento do solo

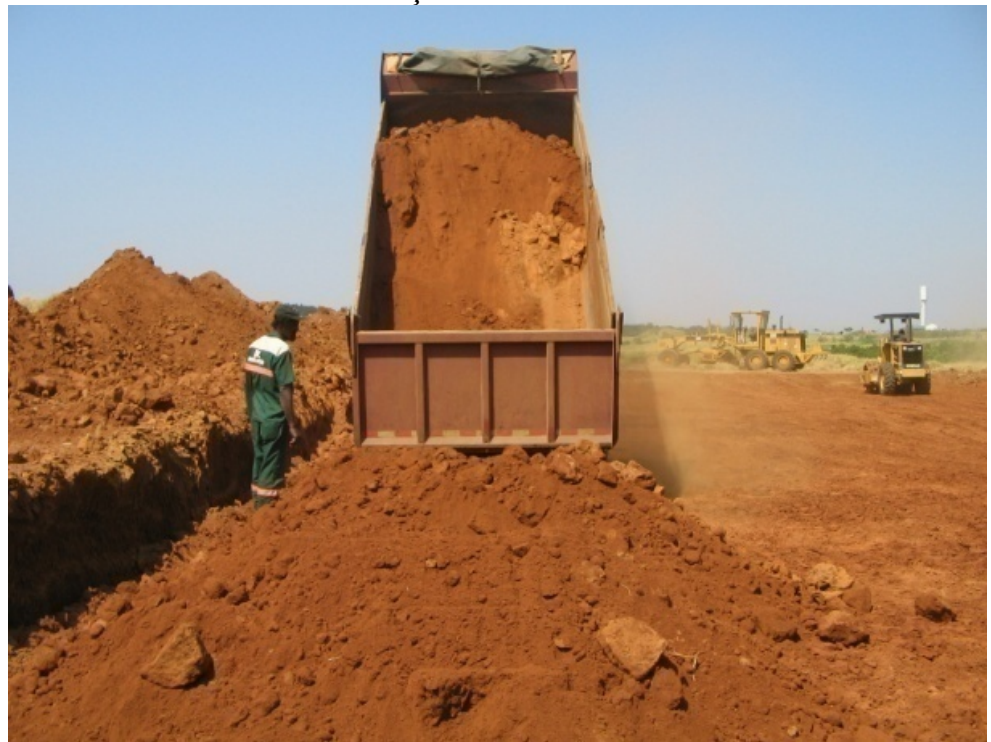

Lançamento do solo

Figura 33 (Continua). Detalhes do processo de compactação da base. 


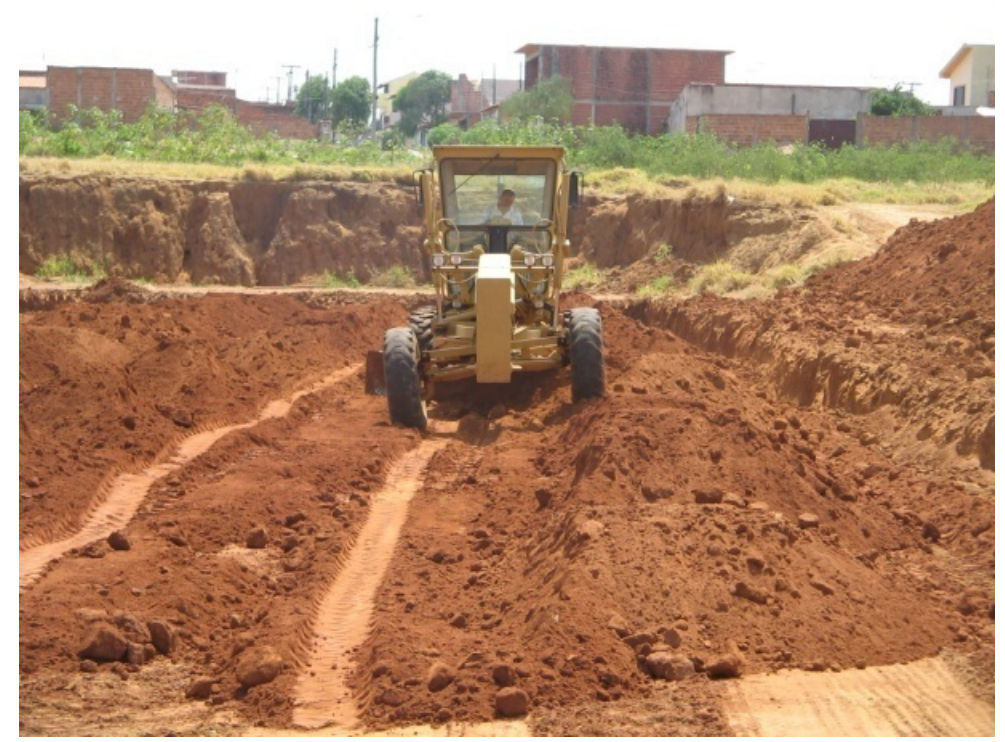

Espalhamento do solo

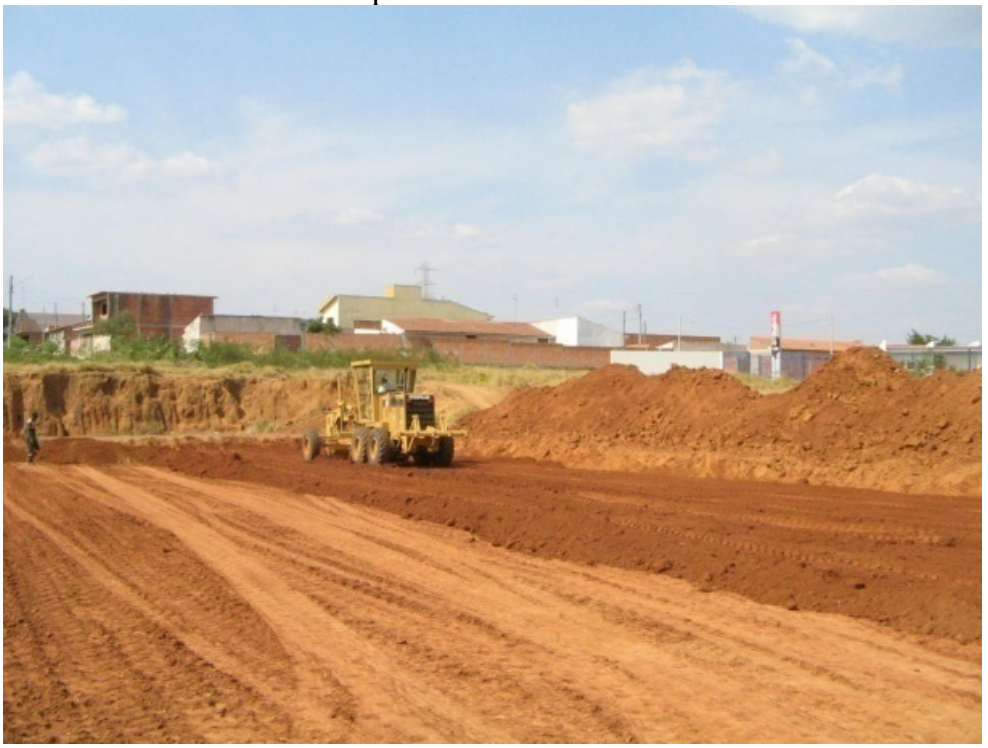

Espalhamento do solo

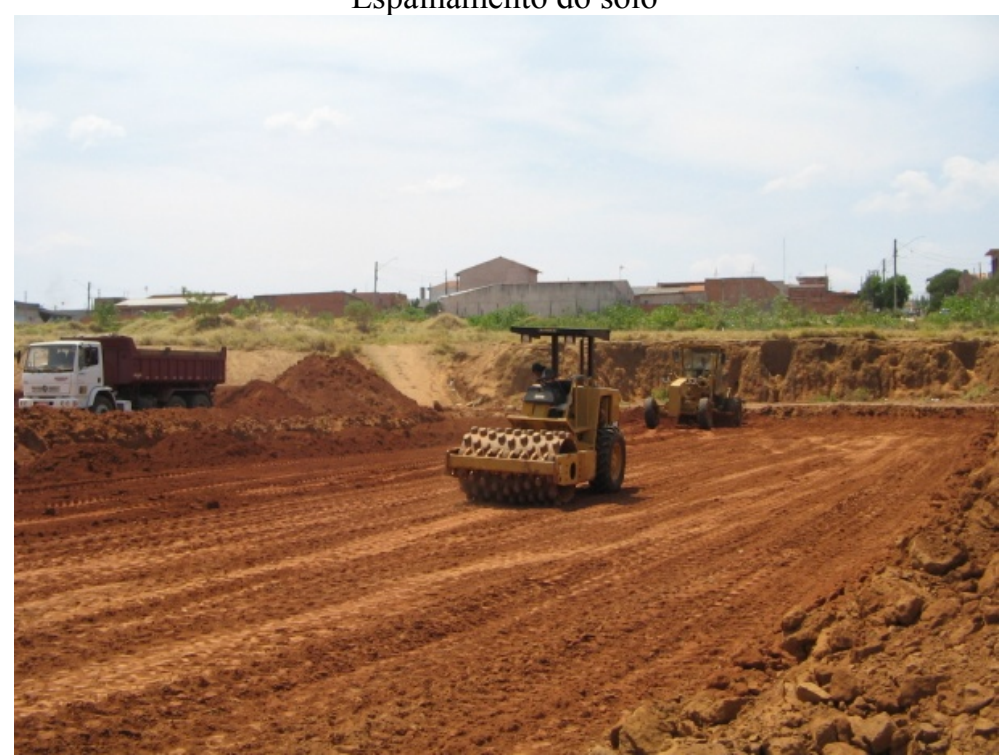

Compactação do solo

Figura 33 (Continuação). Detalhes do processo de compactação da base. 


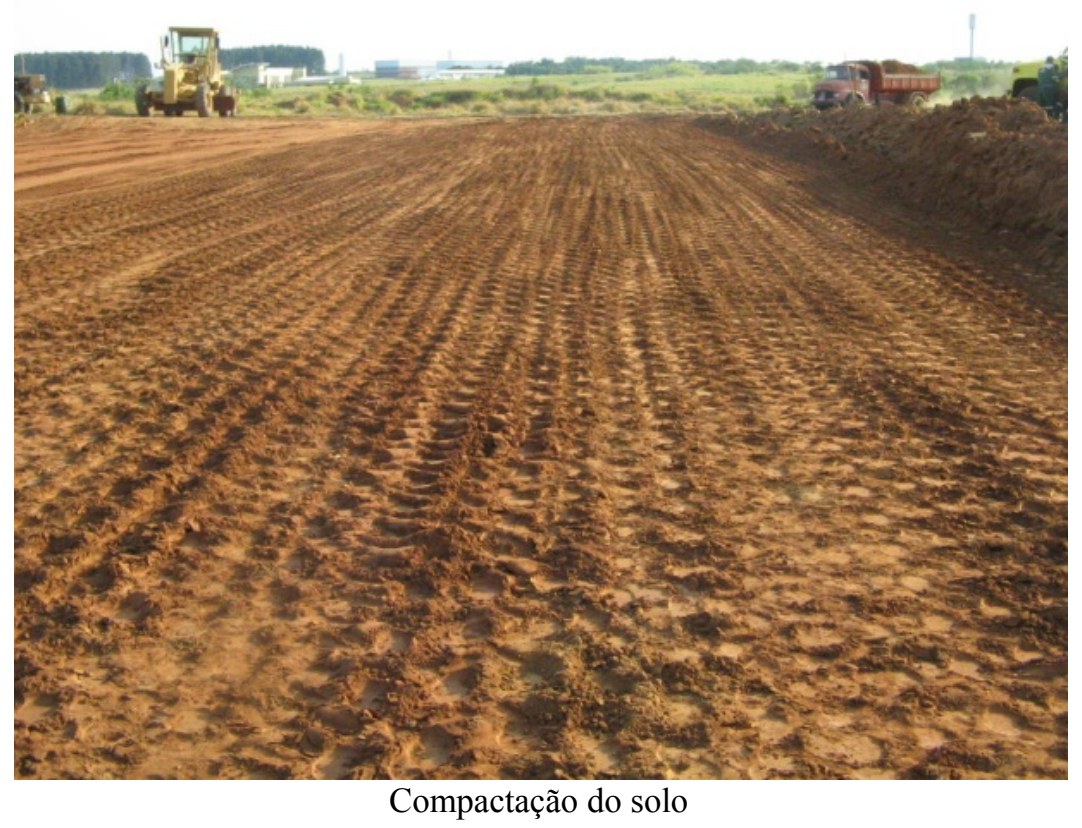

Figura 33 (Final). Detalhes do processo de compactação da base.

Em cada camada foram verificadas as condições de compactação com o método do cilindro de cravação. Foram realizados quatro ensaios em cada camada. Os resultados finais são apresentados na Tabela 26.

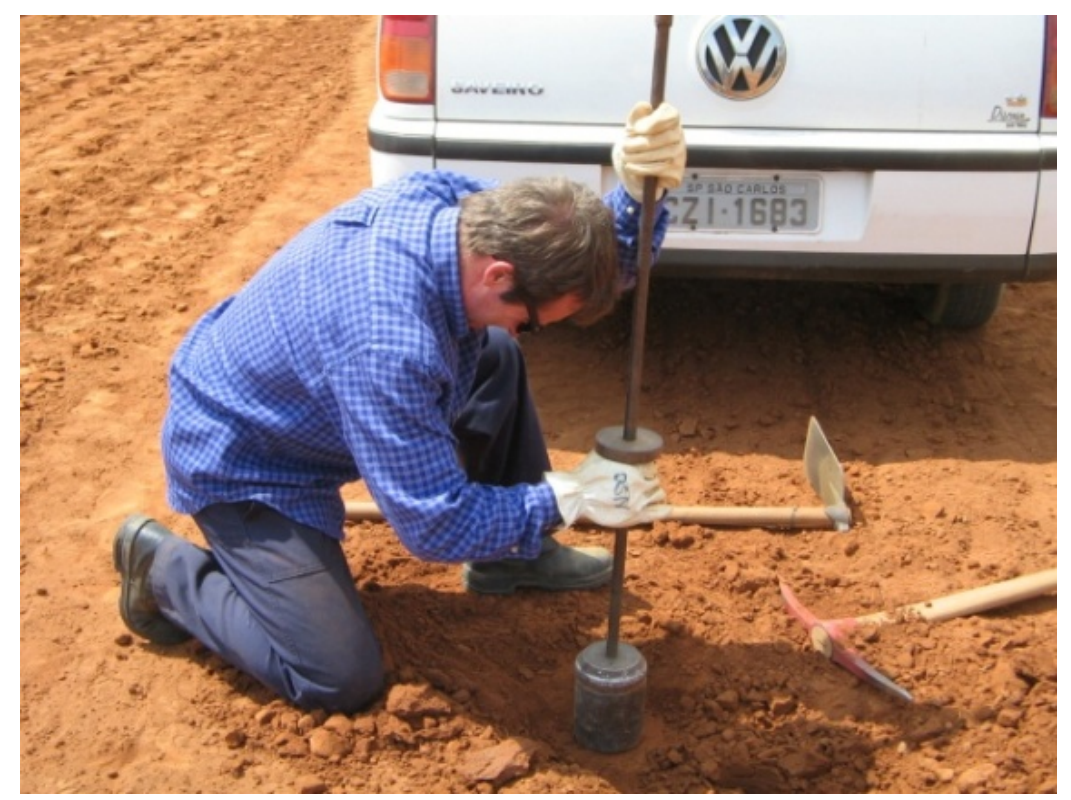

Figura 34. Controle de compactação no campo - método do cilindro de cravação. 
Tabela 26. Condições de compactação no campo pelo método do cilindro de cravação.

\begin{tabular}{ccc}
\hline Camada & GC (\%) & $\Delta \mathbf{w}(\mathbf{\%})$ \\
\hline $1^{\text {a camada }}$ & 90 & $+3,9$ \\
\hline $2^{\text {a camada }}$ & 91 & $+1,9$ \\
\hline $3^{\text {a camada }}$ & 95 & $+1,4$ \\
\hline
\end{tabular}

Após a fase de terraplenagem, iniciou-se a construção da barreira de impermeabilização (barreira de captação e desvio de fluxo). Esta etapa compreendeu a instalação da geomembrana, a instalação da camada de proteção e a construção da camada de drenagem.

Os materiais utilizados (geomembranas e camadas de proteção) foram dispostos conforme se especifica na Tabela 27. A camada com proteção de colchão de areia foi formada utilizando-se uma areia de granulometria fina a média, lançada sobre a geomembrana até atingir uma altura de $15 \mathrm{~cm}$ (2x diâmetro da brita). O colchão de solo foi constituído por uma camada do solo local (mesmo solo da fundação), também com altura de $15 \mathrm{~cm}$. 
Tabela 27. Configuração dos ensaios de campo.

\begin{tabular}{|c|c|c|c|}
\hline \multirow{2}{*}{ Identificação da baia } & \multicolumn{3}{|c|}{ Configuração } \\
\hline & Geomembrana & Camada de Proteção & Brita \\
\hline 1 & PEAD $1,5 \mathrm{~mm}$ & Sem proteção & \multirow{17}{*}{3} \\
\hline 2 & PEAD $1,5 \mathrm{~mm}$ & GET PET 300 & \\
\hline 3 & PEAD $1,5 \mathrm{~mm}$ & GET PET 600 & \\
\hline 4 & PEAD $1,5 \mathrm{~mm}$ & GET PP 600 & \\
\hline 5 & PEAD $1,5 \mathrm{~mm}$ & GET PET $2 \times 600$ & \\
\hline $6 \mathrm{~A}$ & PEAD $1,5 \mathrm{~mm}$ & Colchão de areia & \\
\hline $6 \mathrm{~B}$ & PEAD $1,5 \mathrm{~mm}$ & Colchão de solo & \\
\hline 7 & PEAD 2,0 mm & Sem proteção & \\
\hline 8 & PVC 1,0 mm & Sem proteção & \\
\hline 9 & PVC 1,0 mm & GET PET 300 & \\
\hline 10 & PVC $1,0 \mathrm{~mm}$ & GET PET 600 & \\
\hline 11 & PVC $1,0 \mathrm{~mm}$ & GET PP 600 & \\
\hline 12 & PVC $1,0 \mathrm{~mm}$ & GET PET $2 \times 600$ & \\
\hline $13 \mathrm{~A}$ & PVC $1,0 \mathrm{~mm}$ & Colchão de areia & \\
\hline $13 \mathrm{~B}$ & PVC 1,0 mm & Colchão de solo & \\
\hline 14 & PVC 2,0mm & Sem proteção & \\
\hline 15 & GC PVC/GT & - & \\
\hline 16 & PEAD $1,5 \mathrm{~mm}$ & Sem proteção & \multirow{10}{*}{1} \\
\hline 17 & PEAD $1,5 \mathrm{~mm}$ & GET PET 300 & \\
\hline 18 & PEAD $1,5 \mathrm{~mm}$ & GET PET 600 & \\
\hline 19 & PEAD $1,5 \mathrm{~mm}$ & GET PET $2 \times 600$ & \\
\hline 20 & PEAD $1,5 \mathrm{~mm}$ & Colchão de areia & \\
\hline 21 & PEAD $1,5 \mathrm{~mm}$ & Colchão de solo & \\
\hline 22 & PVC $1,0 \mathrm{~mm}$ & Sem proteção & \\
\hline 23 & $\mathrm{PVC} 1,0 \mathrm{~mm}$ & GET PET 600 & \\
\hline 24 & PVC $1,0 \mathrm{~mm}$ & Colchão de areia & \\
\hline 25 & PVC $1,0 \mathrm{~mm}$ & Colchão de solo & \\
\hline
\end{tabular}

As geomembranas foram instaladas em fileiras e mantidas esticadas, sem apresentar qualquer tipo de rugas ou ondulações. Sacos de solo foram colocados nas extremidades das geomembranas para mantê-las esticadas e evitar o descolamento das placas sob a ação do vento (Figura 35). 

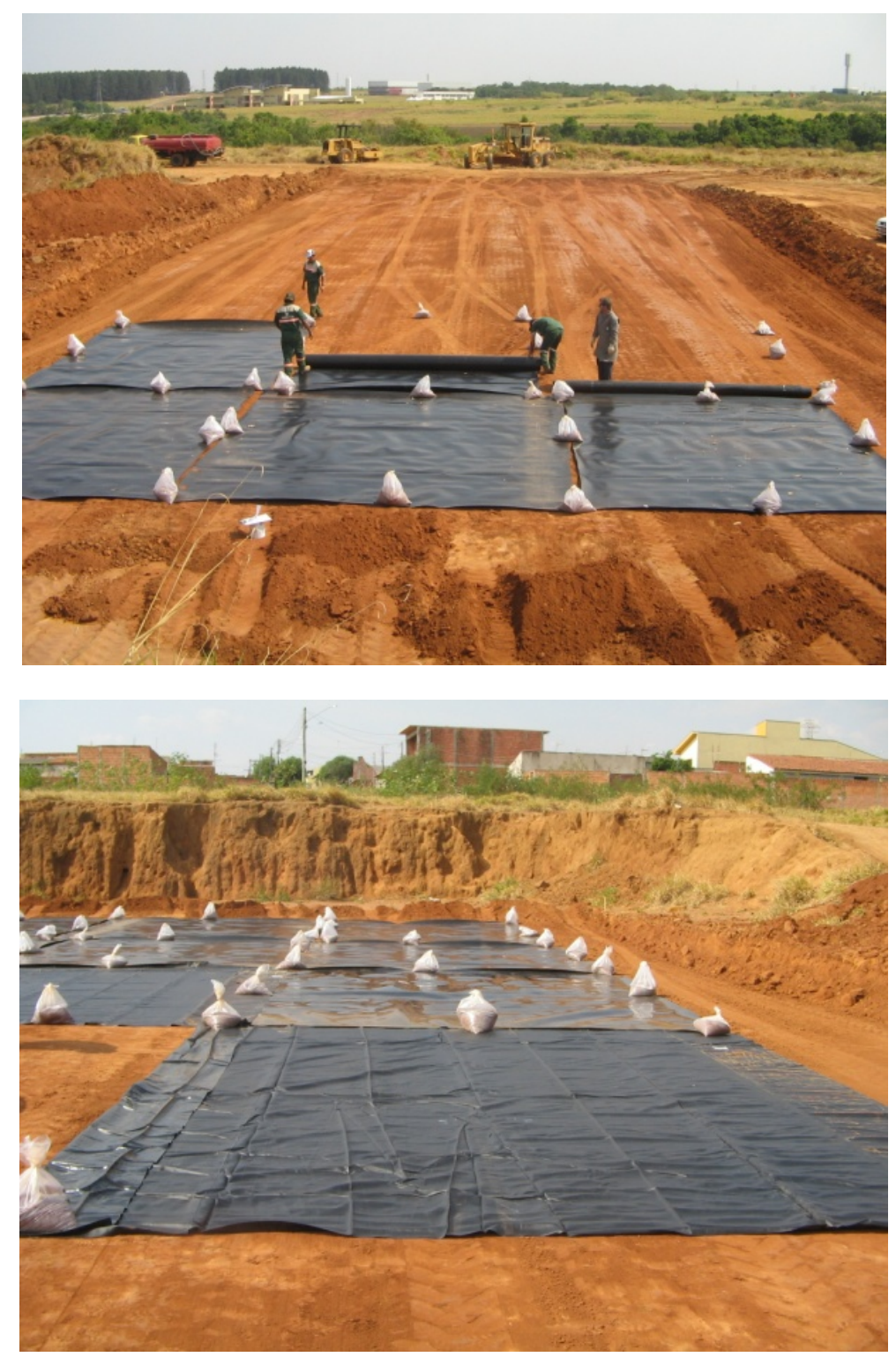

Figura 35. Instalação das geomembranas.

Após a instalação, as geomembranas foram devidamente identificadas conforme a tabela de configuração dos ensaios apresentada anteriormente (Tabela 27). 

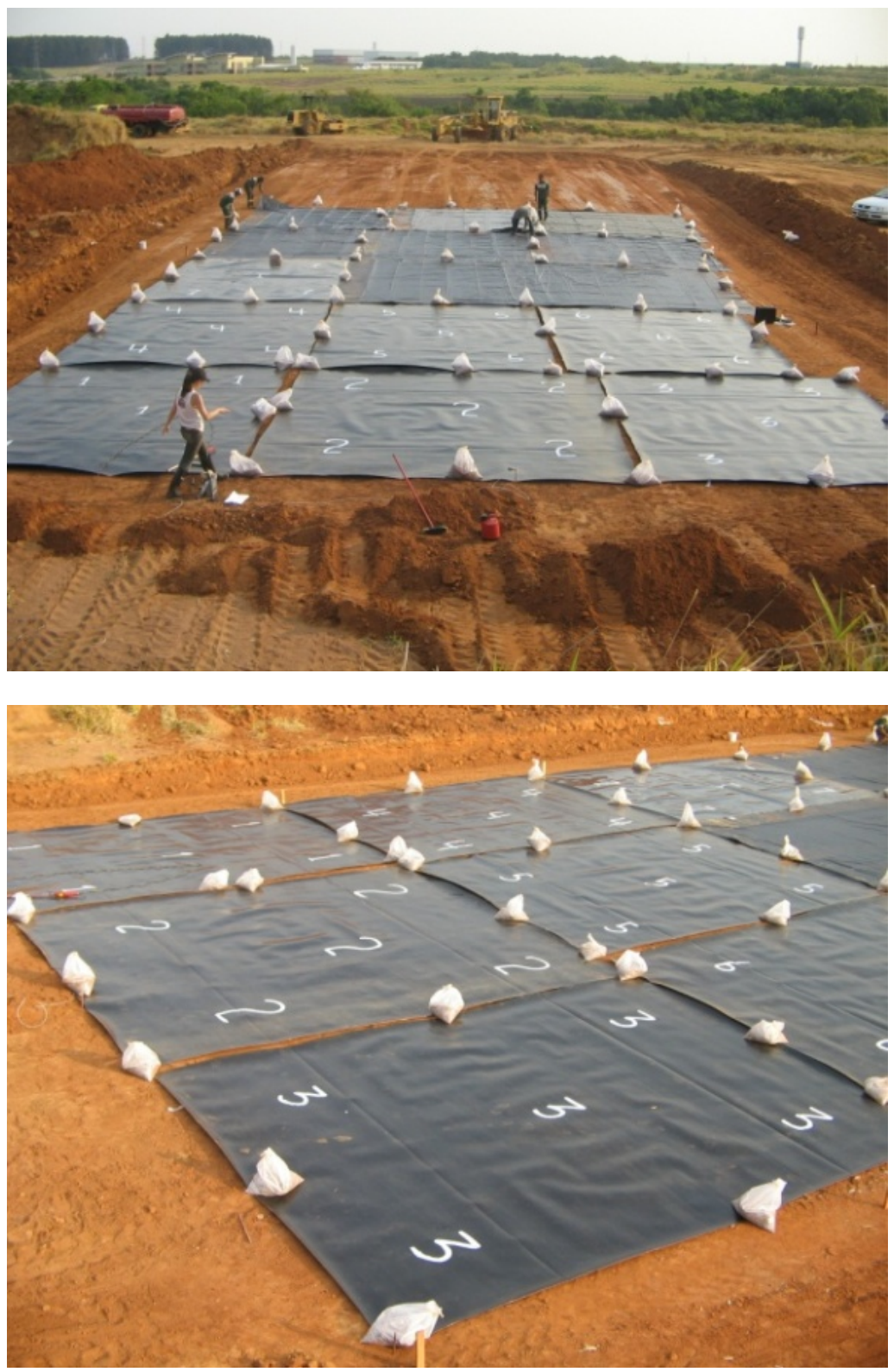

Figura 36. Identificação das geomembranas.

Ensaios de detecção de furo (Spark Test) foram realizados em cada de placa de manta. O objetivo deste ensaio foi o de verificar a existência de algum furo devido aos processos de fabricação e transporte da geomembrana. As camadas de proteção somente foram colocadas após a liberação deste ensaio. A disposição das camadas de proteção também obedeceu à seqüência apresentada na Tabela 27. 


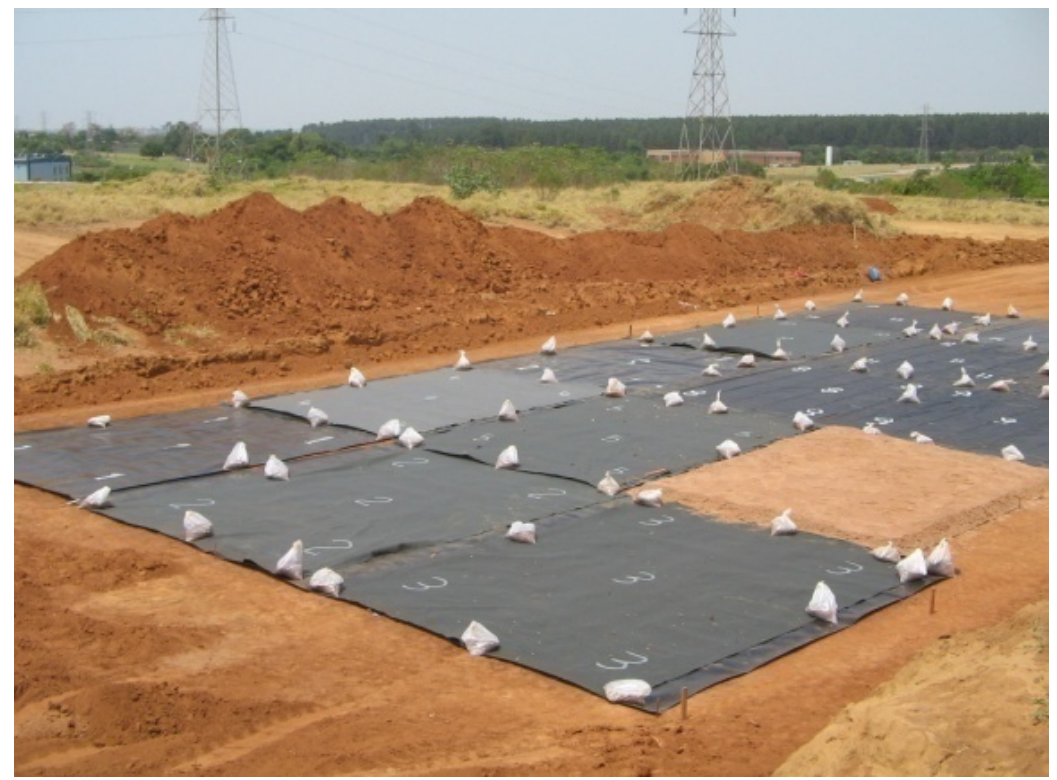

vista geral

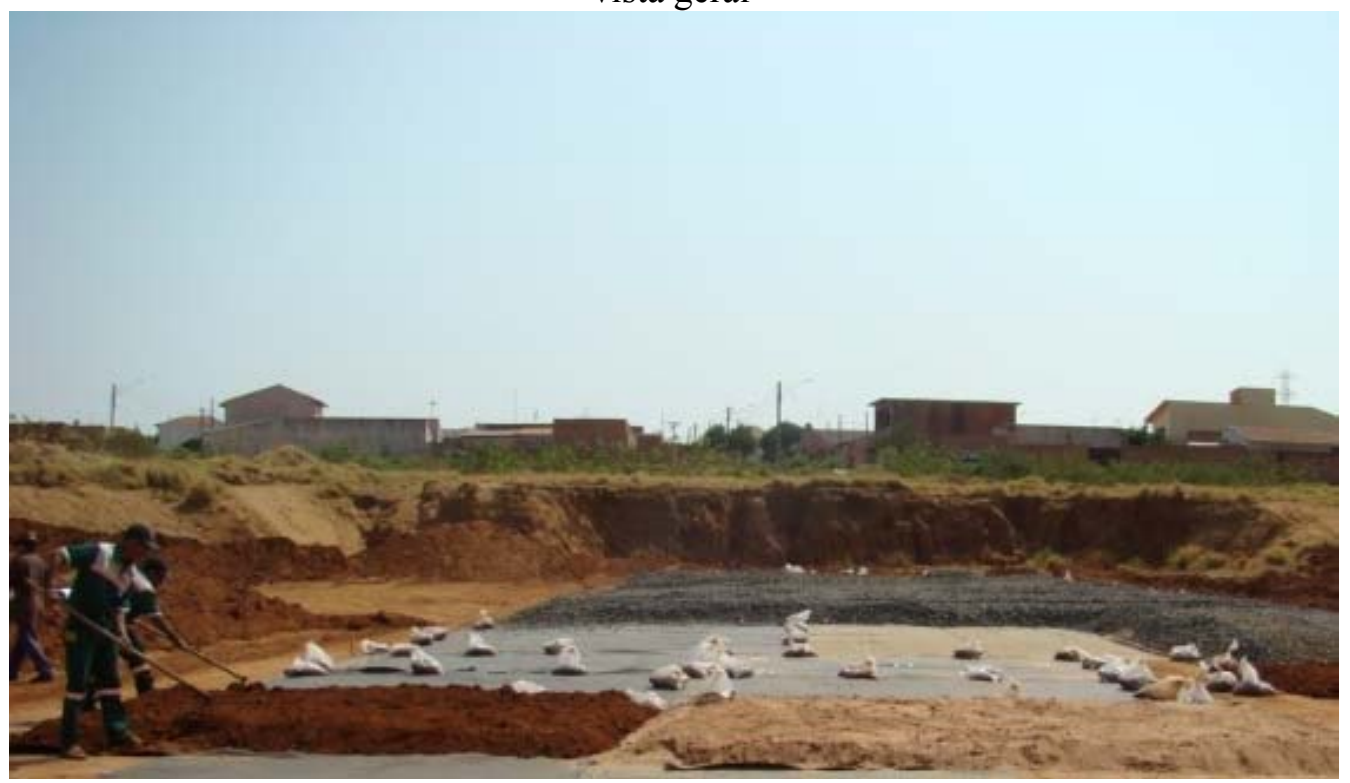

camadas com solos naturais

Figura 37. Instalação das camadas de proteção.

A camada de drenagem foi construída com o auxílio da pá-carregadeira. Os agregados foram inicialmente amontoados ao pé das baias, e depois espalhados ao longo das mantas até atingir a altura de $30 \mathrm{~cm}$. Ao final da construção da camada de drenagem, foram realizadas 10 passadas em cada sentido (avançando e recuando) também com a pá-carregadeira (Figura 38). 


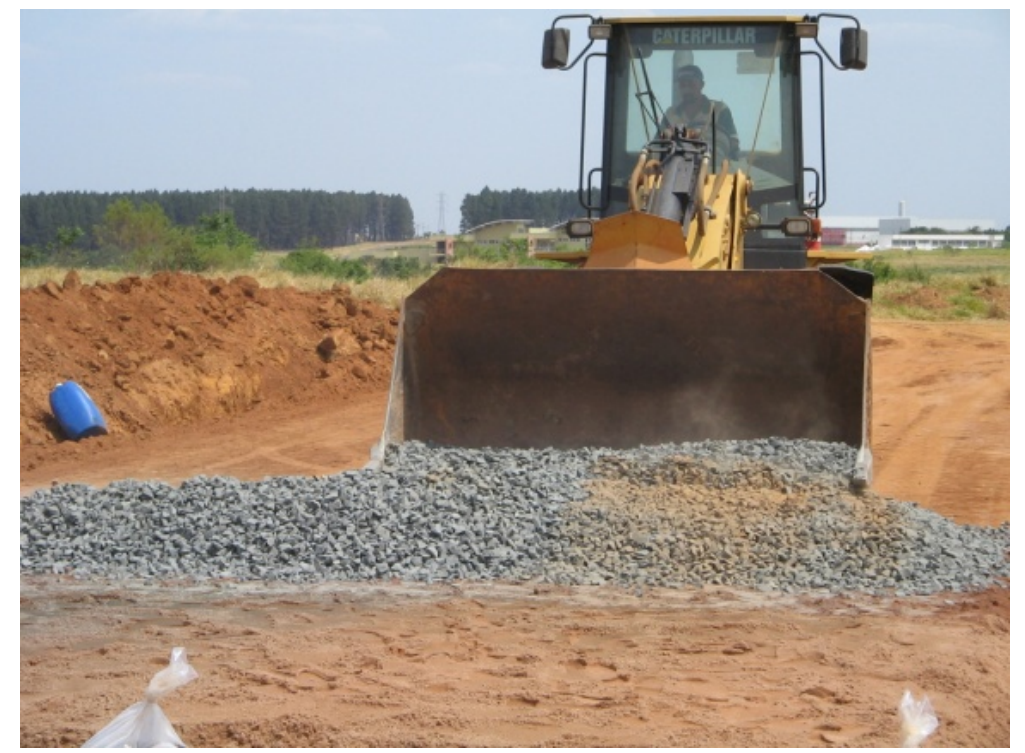

Início da construção da camada

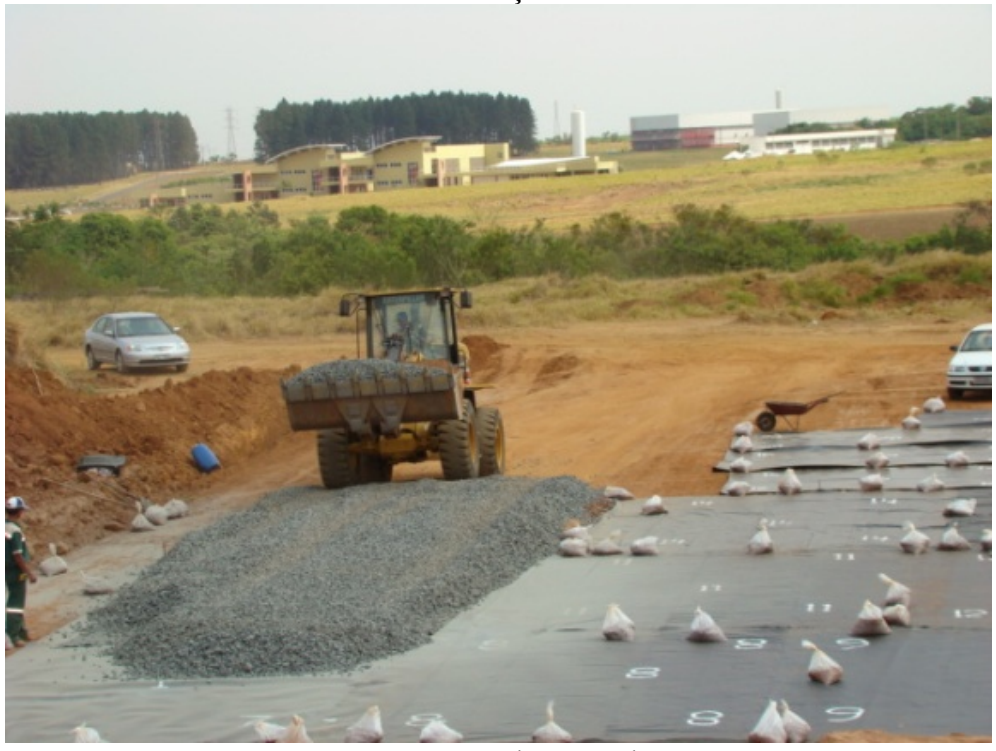

Construção da camada

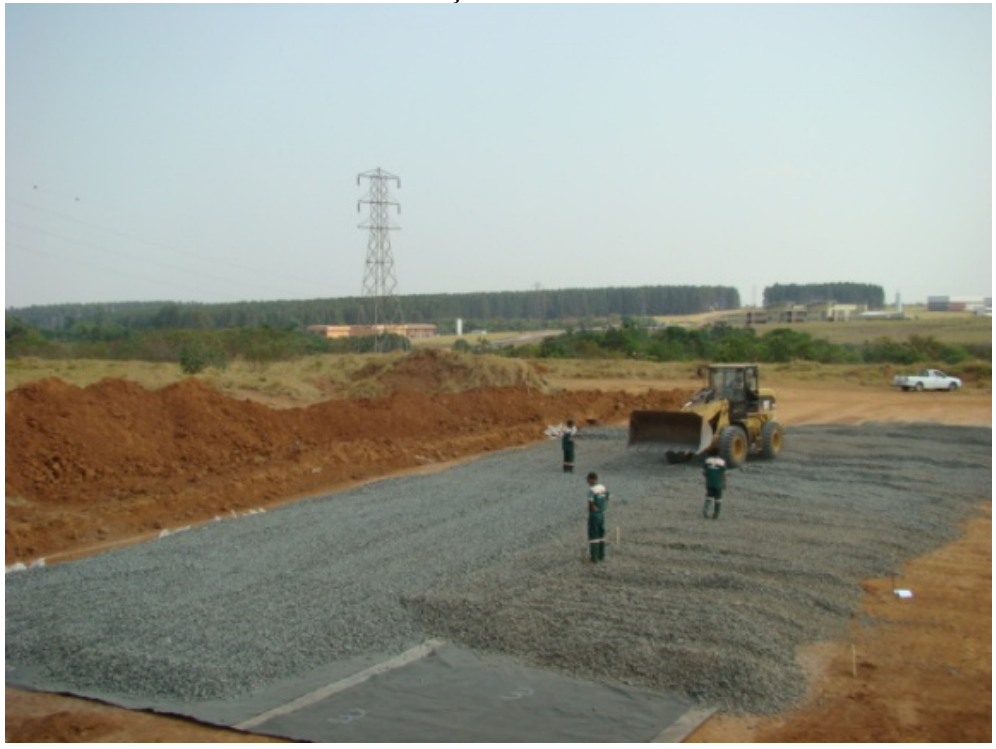

Fechamento da camada

Figura 38 (Continua). Construção da camada de drenagem. 


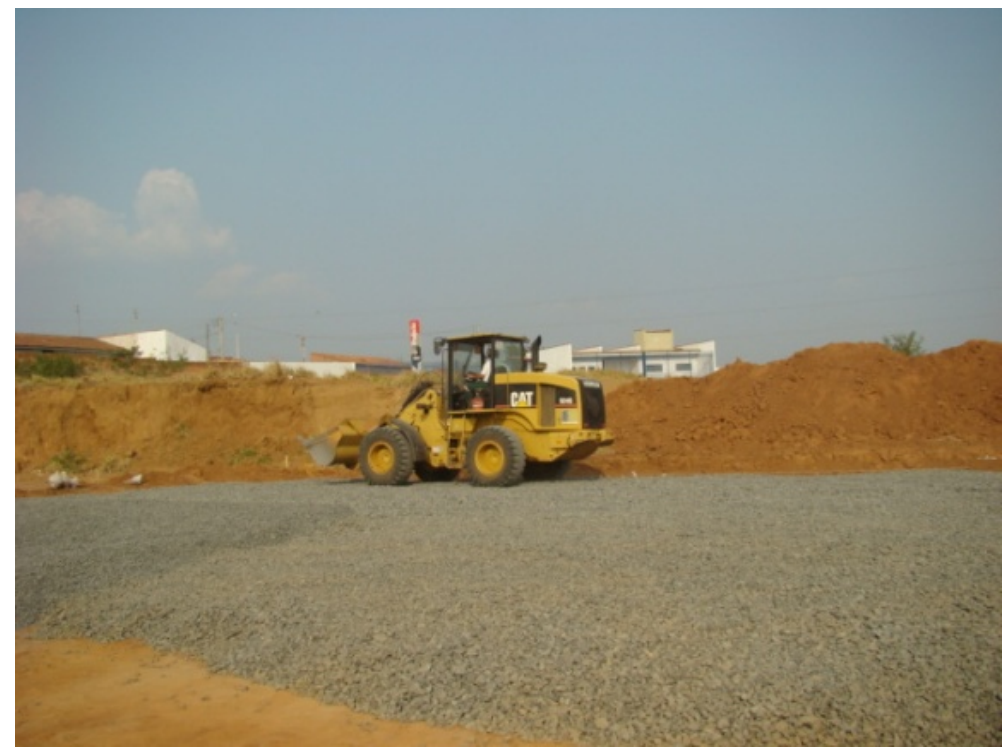

Compactação da camada

Figura 38 (Final). Construção da camada de drenagem.

Finalizada a compactação da camada de drenagem, removeu-se toda a brita sendo que os vinte primeiros centímetros foram retirados com o auxílio da pá-carregadeira. Os centímetros finais foram retirados manualmente com o auxílio de pás e enxadas (Figura 39).
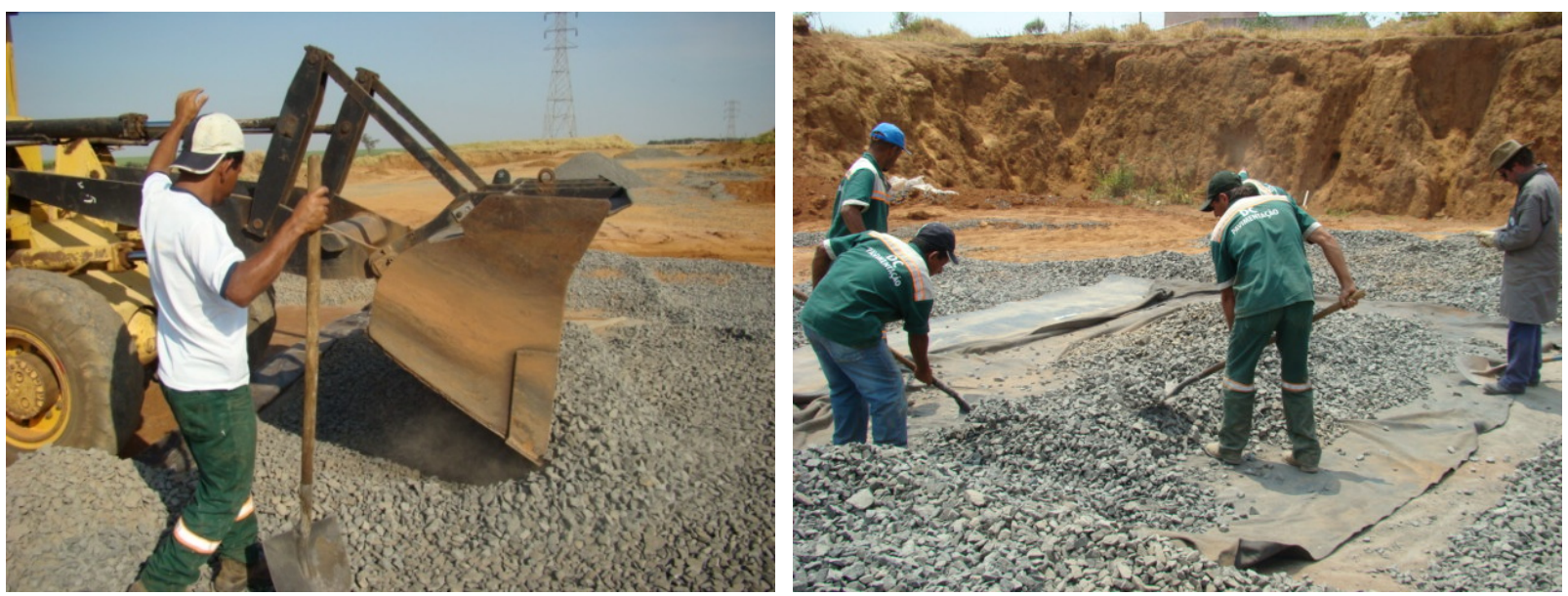

Figura 39. Retirada da brita.

Ao término da retirada da brita, os materiais geossintéticos, em especial as geomembranas, foram avaliados visualmente. Para isto, realizou-se novamente o ensaio de detecção de furos em geomembranas (Spark Test) em todas as geomembranas. Dados como 
furos, rasgos, deformações e outros tipos de danos foram documentados em planilha de campo. As geomembranas foram amostradas e identificadas seguindo a nomenclatura apresentada na Tabela 27. Ao final de todo o ensaio de campo, os materiais foram transportados em placas (mantas de PEAD) e rolos (mantas de PVC) para o laboratório com caminhão basculante.

\subsubsection{Ensaios Não Destrutivos para Deteç̧ão de Furos em Geomembranas}

Para verificação da existência de furos, rasgos, fissuras ou danos similares nas geomembranas utilizou-se o método da faísca elétrica (Spark Test), gentilmente cedido pela Empresa Etclass do Brasil, e seguindo as recomendações da norma americana ASTM D 6747.

O princípio básico das técnicas elétricas consiste em aplicar um potencial elétrico sobre a geomembrana, e então localizar áreas onde a corrente elétrica passa devido à presença de descontinuidades na geomembrana.

No caso do método da faísca elétrica, existe um gerador de alta tensão e baixa corrente elétrica. Este gerador é acoplado a dois eletrodos, um passivo ligado ao solo, e outro ligado a uma haste com uma escova ou barra metálica na ponta. Esta haste é passada lentamente pela superfície superior da geomembrana. Quando existe uma descontinuidade na manta, o circuito se fecha e uma faísca é produzida, conforme esquematizado na Figura 40. Para facilitar a localização da descontinuidade, o equipamento inclui um alarme sonoro. 


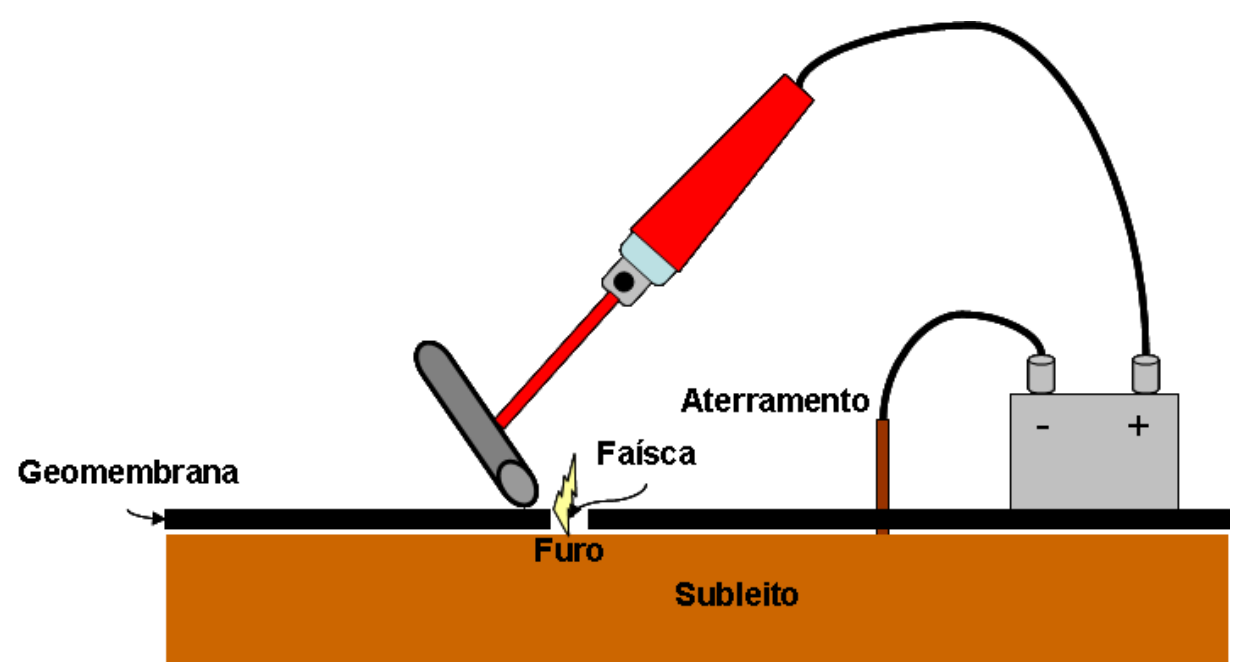

Figura 40. Esquema do princípio do ensaio de Spark Test.

A voltagem do equipamento se situa entre $20 \mathrm{kV}$ e $100 \mathrm{kV}$. No entanto, a ASTM D6747 não faz referência à voltagem que deve ser emitida. Na ausência de uma regulamentação específica, foram seguidas as sugestões do fabricante do equipamento para materiais aplicados à construção civil (10 kV para cada milímetro de espessura do material).

O equipamento foi calibrado para os dois tipos de geomembranas, obtendo-se como resultado final uma voltagem de $15 \mathrm{kV}$ para as geomembranas de PVC (de 1,0 a 2,0 mm de espessura), e $30 \mathrm{kV}$ para as geomembranas de PEAD (de 1,5 a 2,0 mm de espessura).

A Figura 41 e a Figura 42 mostram a execução do ensaio em campo e detalhes do equipamento. 


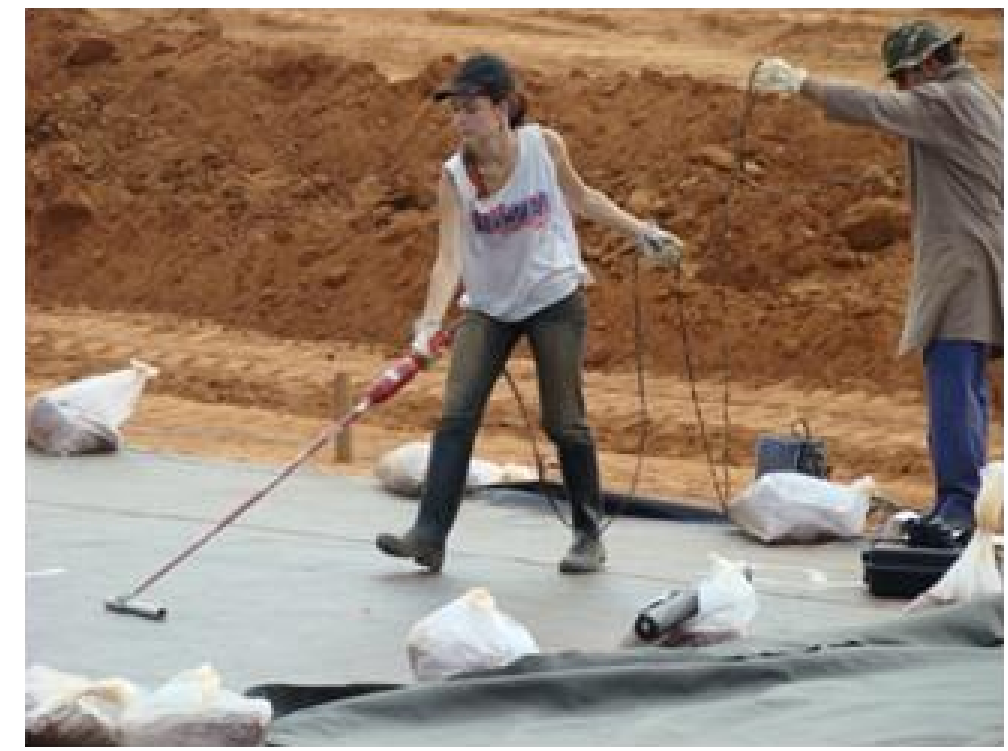

Figura 41. Realização do Spark Test em campo.

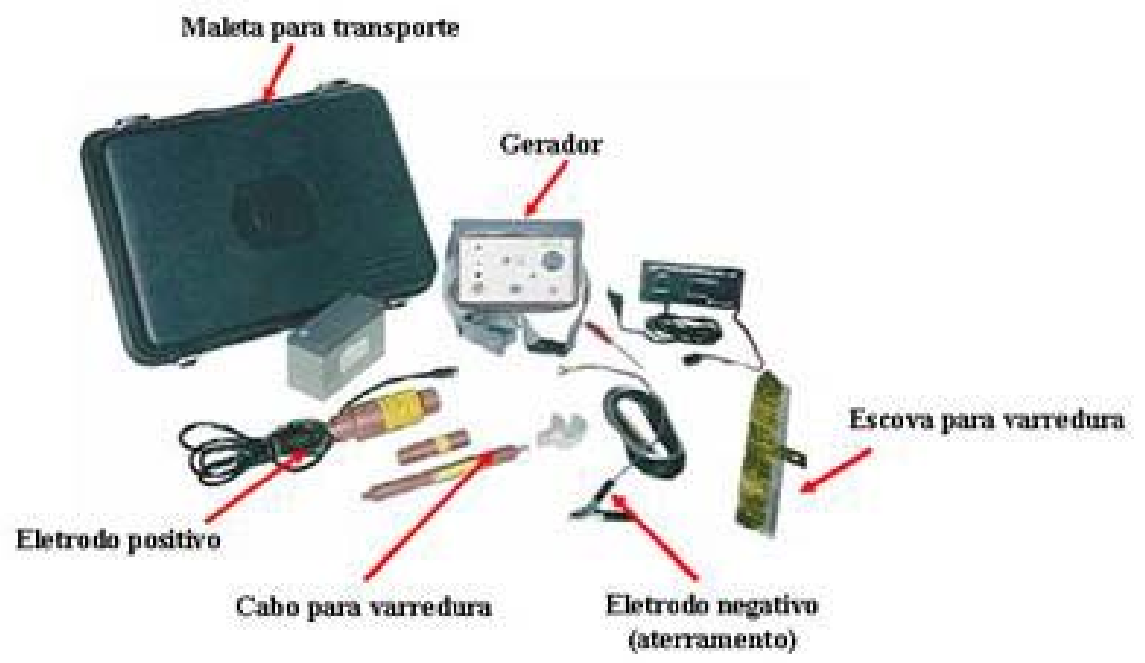

Figura 42. Detalhes do equipamento do Spark Test.

\subsubsection{Critério para Estimar o Desempenho de Camadas de Proteção para}

\section{Geomembranas}

Para avaliar o desempenho dos elementos utilizados como camada de proteção seguiram-se as recomendações propostas pelo Comitê Francês de Geossintéticos - Comité Français dês Geosynthétiques (2001). 
Primeiramente, os danos observados visualmente nas amostras de geomembranas foram classificados em cinco categorias de danos:

- Arranhão $\rightarrow$ ranhura superficial;

- Entalhe $\rightarrow$ arranhão mais profundo, sem perfuração da geomembrana;

- Indentação $\rightarrow$ punção pontual profunda remanescente e sem perfuração da geomembrana, com um importante decréscimo de espessura (marca do pedregulho);

- Furo $\rightarrow$ furo ou rasgo da geomembrana;

- Deformação $\rightarrow$ deformação da geomembrana devido à irregularidade da superfície ou devido à proeminência de um elemento graúdo, remanescente ou não, e sem redução visível de espessura.

O guia ainda recomenda a classificação das geomembranas em função dos tipos de danos identificados, dividindo-os em três níveis:

- Nível I: A geomembrana apresenta furos (1 ou vários).

- Nível II: A geomembrana apresenta um ou várias indentações, entalhes, deformações ou arranhões.

- Nível III: A geomembrana não apresenta nenhum tipo de dano.

Os níveis podem ainda ser refinados e subclassificados em função do nome e dimensão dos danos observados, e seguindo uma numeração por dano decrescente.

As geomembranas enquadradas no nível I podem ser subdivididas conforme o número de furos existentes. Por exemplo, a classificação I-1 seria atribuída à manta com maior número de furos. O nível I é considerado totalmente inaceitável pelo CFG e, em geral, não necessita ensaios complementares, nem sobre a geomembrana como nem sobre os outros geossintéticos. 
Os níveis II e III dependem de resultados de ensaios de laboratório. Nestes níveis, as modificações de propriedades importantes são consideradas. O guia sugere um mínimo de $25 \%$ de decréscimo nas propriedades analisadas para que a geomembrana seja considerada danificada. O nível II analisa as mudanças nas propriedades das geomembranas; enquanto o nível III sugere que sejam analisadas as características residuais dos geotêxteis (elementos de proteção).

\subsection{Ensaios Pós-Danos Realizados nas Geomembranas para Avaliação das Camadas de Desempenho}

A Tabela 28 apresenta os tipos de ensaios pós-danos realizados nas amostras de geomembranas danificadas em campo e em laboratório.

Tabela 28. Ensaios pós-danos realizados nas amostras de geomembranas danificadas.

\begin{tabular}{lcccc}
\hline \multicolumn{1}{c}{ Tipo de Ensaio } & \multicolumn{2}{c}{ PVC } & \multicolumn{2}{c}{ PEAD } \\
& $\begin{array}{c}\text { Amostras de } \\
\text { Campo }\end{array}$ & $\begin{array}{c}\text { Amostras de } \\
\text { Laboratório }\end{array}$ & $\begin{array}{c}\text { Amostras de } \\
\text { Campo }\end{array}$ & $\begin{array}{c}\text { Amostras de } \\
\text { Laboratório }\end{array}$ \\
\hline Mecânico & & & & $\checkmark$ \\
\hline Tração "gravatinha" & & $\checkmark$ & $\checkmark$ & \\
\hline Tração faixa larga & $\checkmark$ & & & $\checkmark$ \\
\hline Tração multiaxial & $\checkmark$ & $\checkmark$ & $\checkmark$ & $\checkmark$ \\
\hline Rasgo & & $\checkmark$ & $\checkmark$ & \\
\hline Punção & & & & \\
\hline Stress cracking & & n.a. & & \\
\hline Com ranhura & n.a. & n.a. & & \\
\hline Sem ranhura & n.a. & & & \\
\hline Hidráulico & & & & \\
\hline $\begin{array}{l}\text { Permissividade ao } \\
\text { Vapor }\end{array}$ & &
\end{tabular}




\subsubsection{Ensaios Mecânicos}

Os ensaios mecânicos realizados nas geomembranas foram:

- Ensaio de tração do tipo "gravatinha" (ASTM D 882 e D 6693) e faixa larga (ABNT NBR 12824)

- Ensaio de rasgo (ASTM D1004)

- Ensaio de punção (ASTM D4833)

- Ensaio de tração multiaxial (ASTM D 5617)

\subsubsection{Ensaio de Tração}

Devido ao tamanho das amostras, as geomembranas submetidas a carregamentos cíclicos em laboratório foram ensaiadas seguindo as normas ASTM D 882 e D 6693; enquanto nas geomembranas de campo foram realizados ensaios de tração em faixa larga (ABNT NBR 12824). Foram utilizados três corpos de prova em cada direção. As informações obtidas a partir deste ensaio foram: tensões de escoamento (PEAD) e ruptura e as deformações no escoamento ou ruptura.

Na Figura 43 é apresentada uma ilustração do ensaio de tração do tipo gravatinha e em faixa larga. 


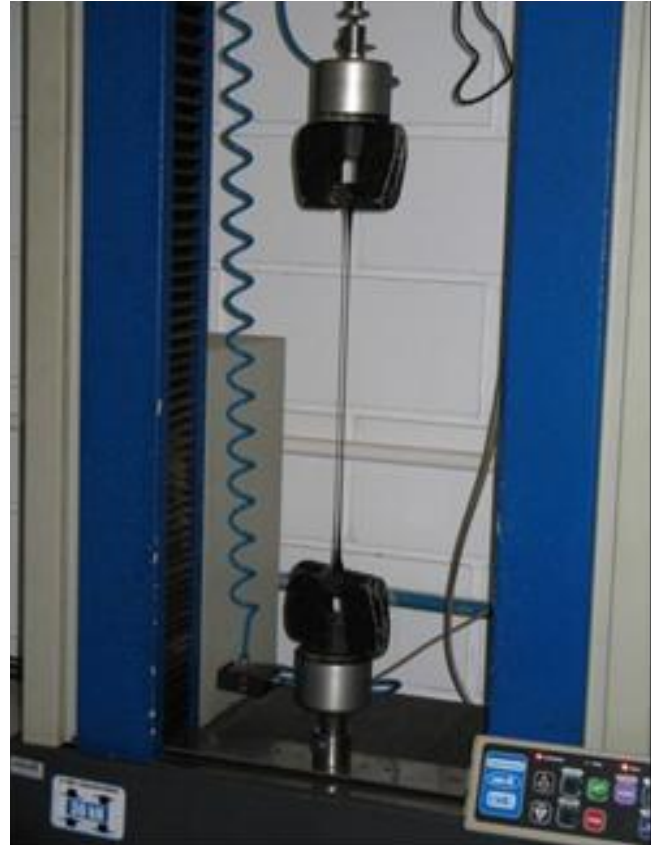

(a)

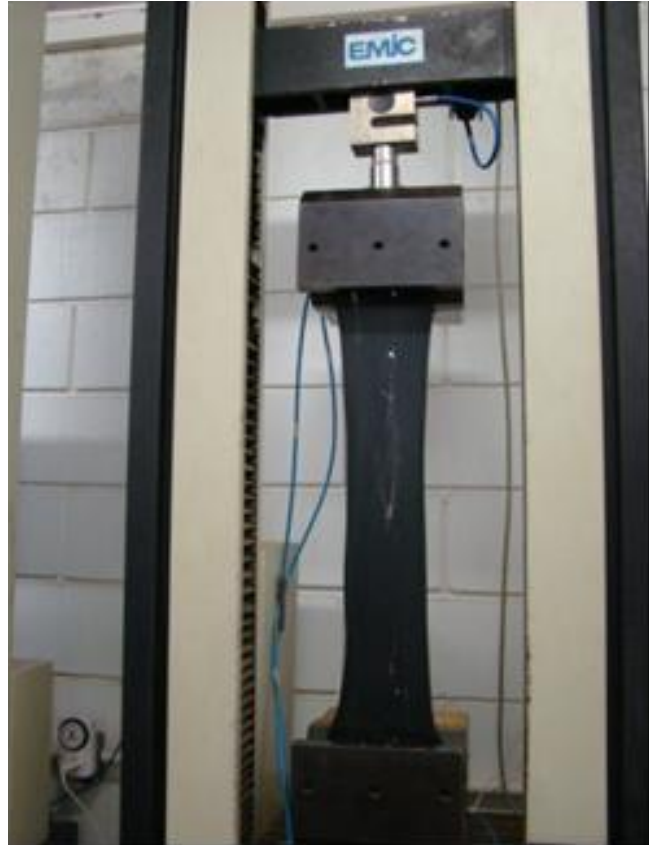

(b)

Figura 43. Ensaio do ensaio de tração: (a) normal; (b) faixa larga.

\subsubsection{Ensaio de Rasgo}

Os ensaios de rasgo foram realizados nas amostras de geomembranas submetidas a carregamentos cíclicos em laboratório. Foram realizados ensaios nas duas direções, sendo utilizados três corpos em cada direção. O ensaio fornece como resultado final a força necessária para iniciar o mecanismo de rasgo do corpo de prova. A Figura 44 ilustra o ensaio.
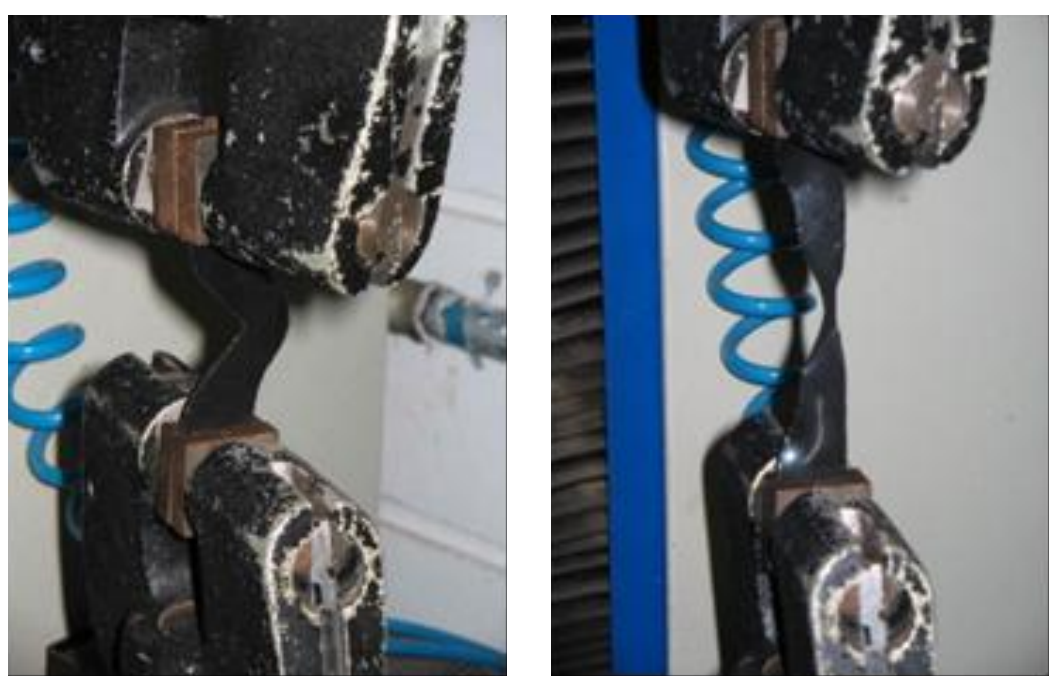

Figura 44. Ilustração do ensaio de rasgo em geomembrana de PEAD. 


\subsubsection{Ensaio de Punção}

Os ensaios de punção também foram realizados nas amostras de geomembranas submetidas a carregamentos cíclicos em laboratório. Foram ensaiados três corpos de prova para cada configuração de ensaio. O ensaio fornece como resultado final a força e deslocamento máximos para perfurar a geomembrana.

\subsubsection{Ensaio de Tração Multiaxial (estouro)}

Segundo Bueno e Vilar (2004), existem situações particulares nas quais os geossintéticos podem ser tracionados multidirecionalmente e, ao se deformar, adquirem a conformação de uma calota.

O ensaio de tração multiaxial tem como objetivo simular tal condição, que pode ocorrer em geomembranas utilizadas no sistema de impermeabilização basal. O procedimento do ensaio segue a norma da ASTM D5617 e consiste em aplicar uma pressão de água sobre uma amostra de geomembrana até que ocorra a ruptura. Durante o ensaio são medidas a pressão aplicada e a deflexão no ponto central da geomembrana.

A norma prevê um diâmetro mínimo de $450 \mathrm{~mm}$ para o corpo de prova. Além disto, a velocidade de aplicação da pressão deve ser controlada seguindo o valor de $20 \mathrm{~mm} / \mathrm{min}$. A Figura 45 apresenta uma ilustração do ensaio. 


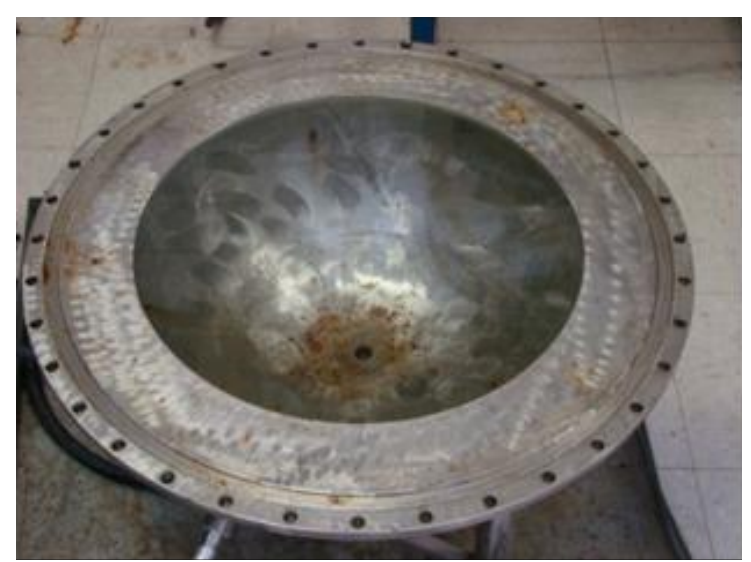

(a) parte inferior

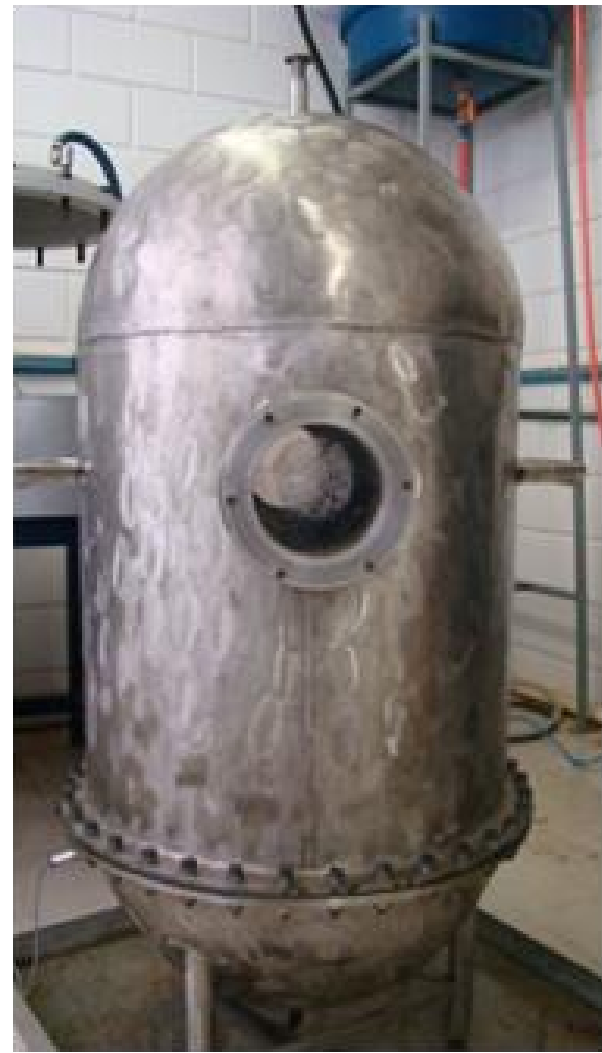

(b) vista geral do equipamento

Figura 45. Ilustração do ensaio de tração multiaxial.

O resultado do ensaio consiste numa curva pressão aplicada versus deflexão ou tensão versus deformação. Para o cálculo da tensão e deformação é considerado que a geomembrana assume uma forma esférica depois de deformada.

Segundo a norma ASTM D5617 e Koerner (1998), a geomembrana pode assumir a forma de arco ou de elipse, de acordo com as dimensões do corpo de prova e da deflexão da geomembrana ao longo do ensaio.

O cálculo da deformação da geomembrana é feito com base nas deflexões das amostras. Para deflexões menores do que o raio do corpo de prova $(\delta<\mathrm{L} / 2)$, a geomembrana assume a forma de arco; enquanto para deflexões maiores ou iguais ao raio do corpo de prova $(\delta \geq \mathrm{L} / 2)$, a geomembrana assume a forma de elipse. Assim a a deformação da geomembrana é calculada segundo as Equações 11 e 12. 


$$
\begin{gathered}
\varepsilon=\left\{\frac{\left[\arctan \left(\frac{4 \cdot L \cdot \delta}{L^{2}-4 \cdot \delta^{2}}\right)\right] \cdot\left(\frac{L^{2}+4 \cdot \delta}{4 \cdot L}\right)-L}{L}\right\} \times 100(\%) \\
\varepsilon=\left\{\frac{\text { para }(\delta<\mathrm{L} / 2),}{L}\right\} \times 100(\%) \text { para }(\delta \geq \mathrm{L} / 2),
\end{gathered}
$$

Onde:

$\varepsilon \rightarrow$ deformação da geomembrana

$\delta \rightarrow$ deflexão no centro da amostra

$\mathrm{L} \rightarrow$ diâmetro do corpo de prova

Para qualquer deflexão, a tensão atuante sobre a geomembrana é calculada pela Equação 13.

$$
\sigma=\frac{\left(L^{2}+4 \cdot \delta^{2}\right) \cdot p}{16 \cdot \delta \cdot L^{2} \cdot t}
$$

Onde:

$\sigma \rightarrow$ tensão de tração multiaxial

$\delta \rightarrow$ deflexão no centro da amostra

$\mathrm{L} \rightarrow$ diâmetro do corpo de prova

$\mathrm{P} \rightarrow$ pressão de ruptura

$\mathrm{t} \rightarrow$ espessura inicial da geomembrana 


\subsubsection{Ensaio de Fissuramento sob Tração (Stress cracking)}

Foram realizados dois tipos de ensaio de FST, ambos seguindo as prescrições recomendadas nas ASTM D 5397 e na GM 10:

- Método NCLT (Notched Constant Tensile Load Test): As cargas variaram entre 65 $\% 25 \%$ da tensão de tração da geomembrana virgem, e foram aplicadas nas geomembranas virgens e danificadas. Em média foram utilizados três corpos de prova para cada estágio de carga. Este método de ensaio foi aplicado para quantificação das geomembranas submetidas a danos de instalação em laboratório.

- Método SP - NCLT (Single Point-Notched Constant Tensile Load Test): Este método de ensaio utilizou apenas um estágio de carga, correspondente a $30 \%$ da tensão de tração da geomembrana virgem. Foram utilizadas em média três corpos de prova, sendo que o ensaio apresentou duas configurações. Na primeira, as geomembranas apresentaram a ranhura requerida pela norma. Na segunda configuração, as geomembranas não foram ranhuradas, tomando o dano existente como o agente catalisador do FST.

Utilizou-se o equipamento projetado e construído pelo Laboratório de Geossintéticos. A Figura 46 apresenta uma foto do equipamento. 


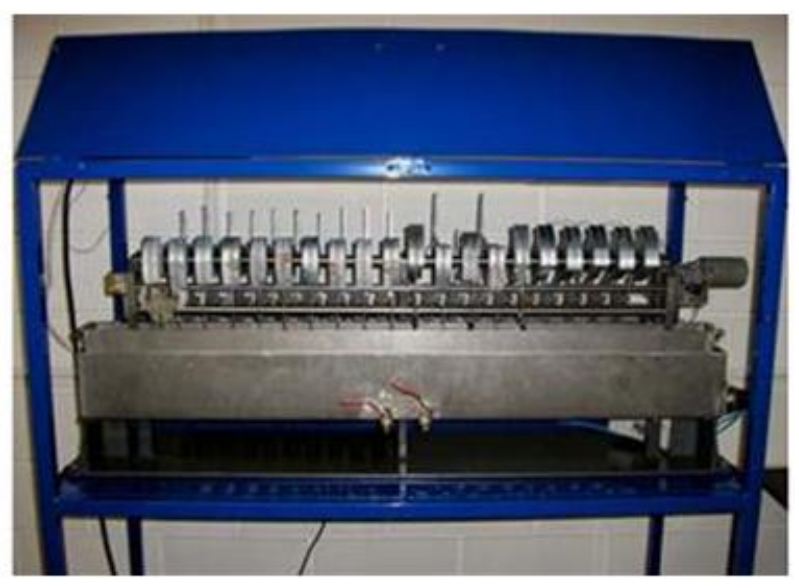

(a)

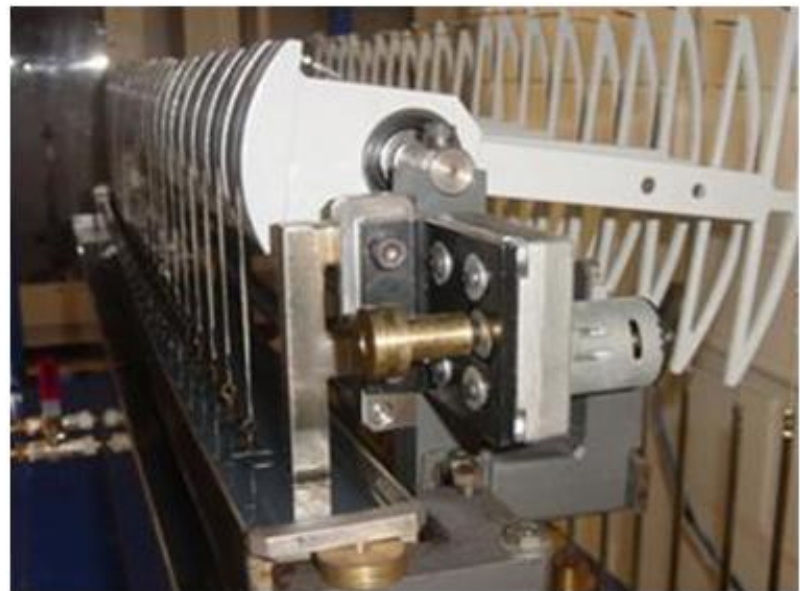

(b)

Figura 46. Vista do equipamento de FST: (a) vista frontal; (b) vista lateral do ensaio em andamento.

Os corpos de prova apresentam uma ranhura na região central, a qual corresponde a $20 \%$ da espessura da geomembrana. A Figura 47 mostra detalhes da ranhura e os moldes para corte do corpo de prova.

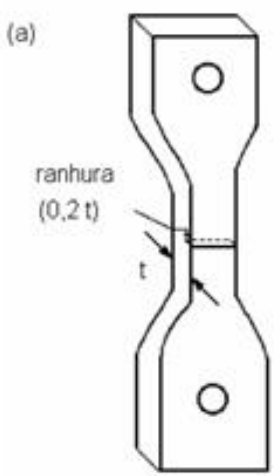

(a) (b)

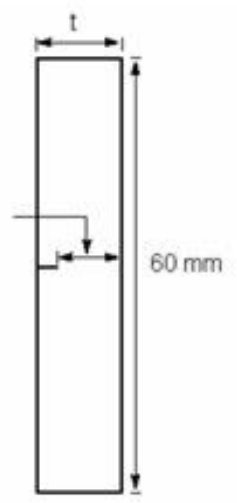

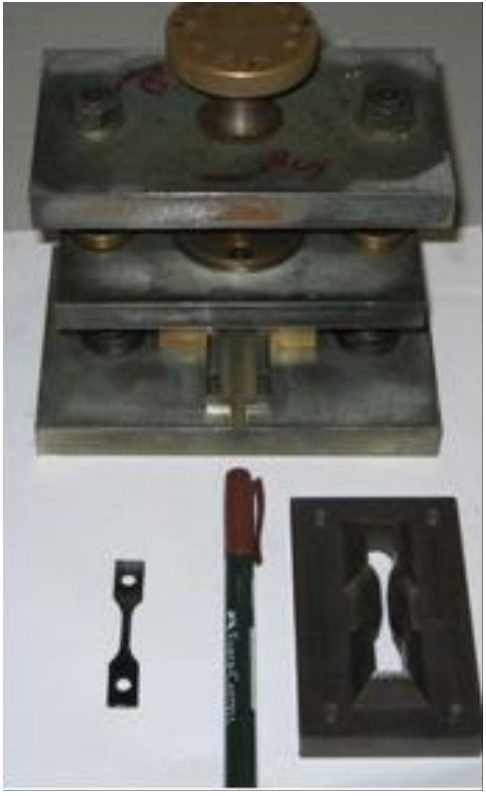

(b)

Figura 47. Ensaio de fissuramento sob tração (stress cracking): (a) detalhes da ranhura; (b) moldes para corte do corpo de prova. 


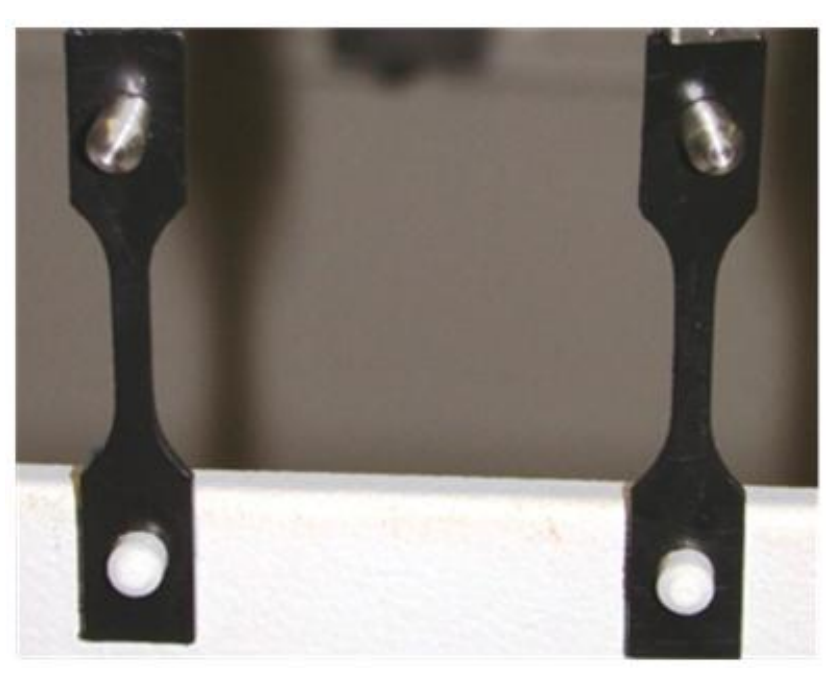

GM Virgem

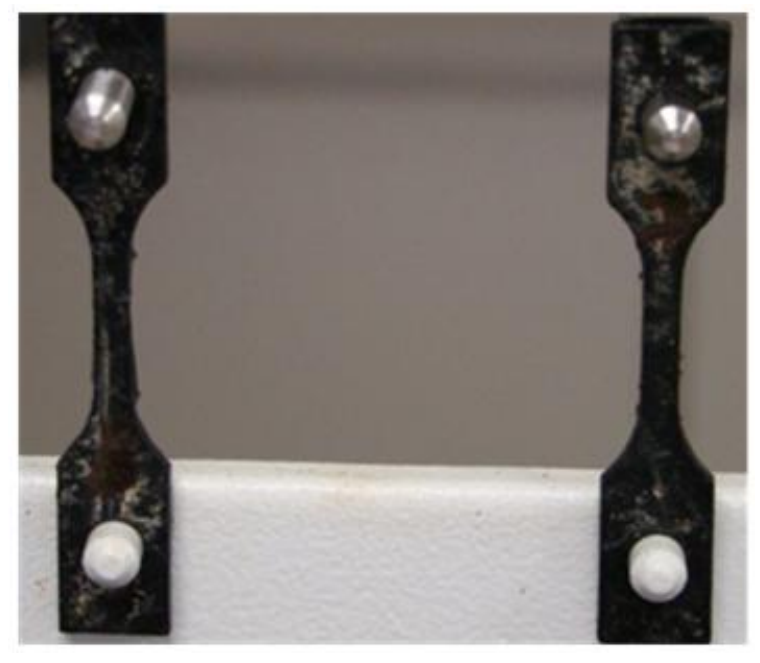

GM sem proteção

Figura 48. Ilustração de algumas configurações com corpo de prova sem ranhura.

A força aplicada em cada corpo de prova é calculada segundo a Equação 14.

$$
f_{\text {aplicada }}=\frac{A \cdot \sigma_{Y} \cdot w \cdot t_{L}}{M A}
$$

Onde:

- $\mathrm{f}_{\text {aplicada }}$ força aplicada ao corpo de prova;

- A: porcentagem da resistência ao escoamento;

- $\sigma_{\mathrm{Y}}$ : resistência ao escoamento do material;

- w: largura do pescoço do corpo de prova;

- $t_{\mathrm{L}}$ : espessura ligante do corpo de prova;

- MA: fator de multiplicação de carga. 


\subsubsection{Ensaio Hidráulico - Permeabilidade por Transmissividade ao Vapor d’Água}

O ensaio de permeabilidade foi realizado nas geomembranas submetidas a carregamentos cíclicos em laboratório. O princípio do ensaio consiste em colocar uma amostra de geomembrana sobre uma caneca de alumínio preenchida com água $(100 \%$ de umidade relativa), mantendo-a numa sala com temperatura controlada e menor umidade relativa. Devido a esta diferença de umidade, ocorre a passagem de vapor d'água através da geomembrana por difusão. A Figura 49 mostra uma visão geral do aparato.

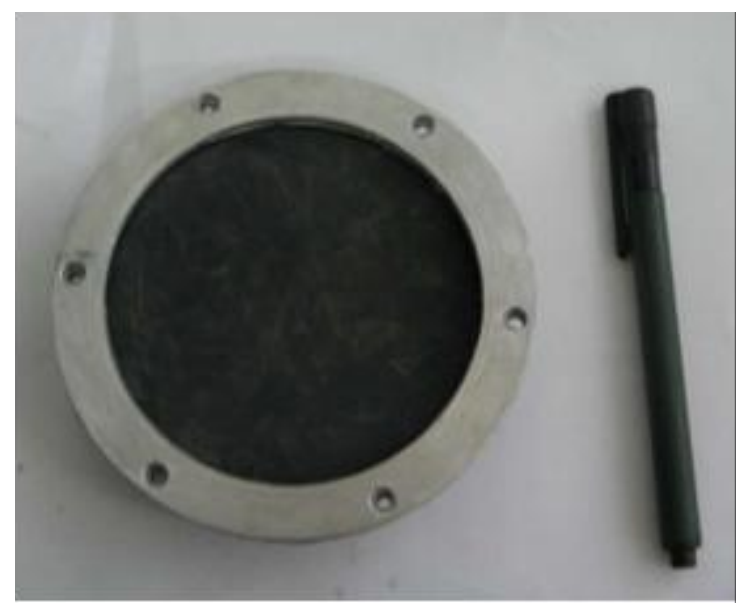

Figura 49. Ensaio de transmissividade ao vapor em geomembranas.

O resultado do ensaio resulta numa curva tempo (dias) versus perda de massa ( $\mathrm{g}$ ), de onde são calculadas a transmissividade ao vapor (WVT), a permeância e a permeabilidade (por difusão) da geomembrana. 


\section{CAPÍTULO 4. APRESENTAÇÃO E ANÁLISE DOS RESULTADOS}

\subsection{Ensaios de Caracterização dos Materiais}

\subsubsection{Geossintéticos}

Os resultados de caracterização das geomembranas são apresentados na Tabela 29; enquanto os resultados de caracterização dos geotêxteis são apresentados na Tabela 30. 
Tabela 29. Resultados dos ensaios de caracterização das geomembranas.

\begin{tabular}{|c|c|c|c|c|c|c|c|c|}
\hline \multirow{2}{*}{\multicolumn{2}{|c|}{ Ensaio }} & \multirow[b]{2}{*}{ Lote } & \multicolumn{5}{|c|}{ Geomembrana } & \multirow[b]{2}{*}{ Unidade } \\
\hline & & & $\begin{array}{c}\text { PEAD 1,5 } \\
\text { mm }\end{array}$ & $\begin{array}{c}\text { PEAD 2,0 } \\
\text { mm }\end{array}$ & $\begin{array}{l}\text { PELMD } \\
1,25 \mathrm{~mm}\end{array}$ & $\begin{array}{c}\text { PVC 1,0 } \\
\text { mm }\end{array}$ & PVC 2,0 mm & \\
\hline \multirow{2}{*}{\multicolumn{2}{|c|}{ Espessura }} & $\mathrm{A}$ & 1,52 & 1,95 & - & 1,01 & 1,92 & \multirow{2}{*}{$\mathrm{mm}$} \\
\hline & & $\mathrm{B}$ & 1,56 & 2,08 & 1,25 & 1,08 & 2,09 & \\
\hline \multirow{2}{*}{\multicolumn{2}{|c|}{ Densidade }} & $\mathrm{A}$ & 0,949 & 0,947 & - & 1,320 & 1,295 & \multirow{2}{*}{$\mathrm{g} / \mathrm{cm}^{3}$} \\
\hline & & $\mathrm{B}$ & 0,946 & 0,937 & 0,925 & 1,296 & 1,233 & \\
\hline \multirow{2}{*}{\multicolumn{2}{|c|}{$\begin{array}{c}\text { Permeabilidade ao } \\
\text { vapor } \\
\end{array}$}} & A & $2,72 \times 10-12$ & $1,75 \times 10-12$ & - & $1,21 \times 10-11$ & $1,13 \times 10-11$ & \multirow{2}{*}{$\mathrm{cm} / \mathrm{s}$} \\
\hline & & $\mathrm{B}$ & - & - & - & $1,34 \times 10-12$ & - & \\
\hline \multirow{4}{*}{\multicolumn{2}{|c|}{ Punção }} & \multirow{2}{*}{ A } & 709,8 & 744,0 & - & 314,8 & 559,6 & $\mathrm{~N}$ \\
\hline & & & 19,2 & 12,5 & - & 23,0 & 22,5 & $\mathrm{~mm}$ \\
\hline & & \multirow{2}{*}{ B } & 642 & 811 & 359 & 329 & 600 & $\mathrm{~N}$ \\
\hline & & & 21,2 & 12,0 & 13,21 & 26,9 & 19,6 & $\mathrm{~mm}$ \\
\hline \multirow{4}{*}{ Rasgo } & Long & \multirow{2}{*}{ A } & 242,7 & 289,2 & - & 44,4 & 79,3 & \multirow{2}{*}{$\mathrm{N}$} \\
\hline & Transv & & 247,6 & 294,0 & - & 53,7 & 90,4 & \\
\hline & Long & \multirow{2}{*}{ B } & 230,6 & 318,3 & 161 & 66,8 & 117,6 & \multirow{2}{*}{$\mathrm{N}$} \\
\hline & Transv & & 225,4 & 318,4 & 148 & 60,5 & 110,2 & \\
\hline \multirow{8}{*}{$\begin{array}{c}\text { Tração } \\
\text { Escoamento }\end{array}$} & \multirow{2}{*}{ Long } & \multirow{4}{*}{ A } & 32,5 & 36,3 & - & - & - & $\mathrm{N} / \mathrm{mm}$ \\
\hline & & & 15,5 & 16,4 & - & - & - & $\%$ \\
\hline & \multirow{2}{*}{ Transv } & & 34,8 & 38,6 & - & - & - & $\mathrm{N} / \mathrm{mm}$ \\
\hline & & & 14,25 & 15,55 & - & - & - & $\%$ \\
\hline & \multirow{2}{*}{ Long } & \multirow{4}{*}{ B } & 28,8 & 38,0 & 12,8 & - & - & $\mathrm{N} / \mathrm{mm}$ \\
\hline & & & 14,4 & 17,6 & 19,1 & - & - & $\%$ \\
\hline & \multirow{2}{*}{ Transv } & & 29,2 & 39,68 & 12,7 & - & - & $\mathrm{N} / \mathrm{mm}$ \\
\hline & & & 13,5 & 16,0 & 19,1 & - & - & $\%$ \\
\hline \multirow{8}{*}{$\begin{array}{l}\text { Tração } \\
\text { Ruptura }\end{array}$} & \multirow{2}{*}{ Long } & \multirow{4}{*}{ A } & 48,72 & 60,30 & - & 16,89 & 29,95 & $\mathrm{~N} / \mathrm{mm}$ \\
\hline & & & 790,70 & 766,90 & - & 394,20 & 474,50 & $\%$ \\
\hline & \multirow{2}{*}{ Transv } & & 47,29 & 57,19 & - & 13,83 & 27,07 & $\mathrm{~N} / \mathrm{mm}$ \\
\hline & & & 784,90 & 784,80 & - & 364,60 & 482,20 & $\%$ \\
\hline & Ion $\sigma$ & & 50,1 & 63,5 & 42,9 & 18,4 & 38,6 & $\mathrm{~N} / \mathrm{mm}$ \\
\hline & Loing & $B$ & 829 & 836 & 1080 & 422 & 494 & $\%$ \\
\hline & & $\mathrm{D}$ & 44,2 & 63,9 & 41,9 & 15,9 & 37,2 & $\mathrm{~N} / \mathrm{mm}$ \\
\hline & Iransv & & 818 & 887 & 1017 & 401 & 489 & $\%$ \\
\hline
\end{tabular}


Tabela 30. Resultados dos ensaios de caracterização dos geotêxteis.

\begin{tabular}{|c|c|c|c|c|c|c|c|c|c|}
\hline & & & & & Ge & xtil & & & \\
\hline & & Lote & $\begin{array}{c}\text { PET } \\
150\end{array}$ & $\begin{array}{c}\text { PET } \\
300\end{array}$ & $\begin{array}{c}\text { PET } \\
400\end{array}$ & $\begin{array}{c}\text { PET } \\
600\end{array}$ & PP 400 & PP 600 & Unidade \\
\hline Grar & turo & $\mathrm{A}$ & 168 & 293 & 353 & 576 & - & 593 & $\mathrm{~g} / \mathrm{m}^{2}$ \\
\hline Urat & tura & $\mathrm{B}$ & 143 & 286 & 342 & 582 & 415 & 538 & $\mathrm{~g} / \mathrm{m}^{2}$ \\
\hline & & & 0,98 & 1,82 & 2,67 & 3,79 & - & 5,06 & $\mathrm{kN}$ \\
\hline & & A & 51,37 & 58,85 & 50,67 & 58,05 & - & 56,45 & $\mathrm{~mm}$ \\
\hline & & $\mathrm{P}$ & 0,22 & 0,43 & 0,55 & 0,94 & 0,95 & 1,20 & $\mathrm{kN}$ \\
\hline & & B & 14,2 & 15,6 & 15,5 & 16,2 & 18,6 & 22.0 & $\mathrm{~mm}$ \\
\hline & Long & & 195 & 364 & 480 & 621 & - & 730 & $\mathrm{~N}$ \\
\hline $\operatorname{Ras} \sigma 0$ & Transv & A & 184 & 235 & 271 & 488 & - & 451 & $\mathrm{~N}$ \\
\hline & Long & P & - & - & - & - & - & - & $\mathrm{N}$ \\
\hline & Transv & B & - & - & - & - & - & - & $\mathrm{N}$ \\
\hline & & & 7,1 & 9,9 & 10,9 & 21,9 & - & 21,9 & $\mathrm{~N} / \mathrm{mm}$ \\
\hline & Long & & 69 & 93 & 74 & 78 & - & 82 & $\%$ \\
\hline & Tron & A & 6,8 & 13,2 & 21,6 & 26,7 & - & 37,2 & $\mathrm{~N} / \mathrm{mm}$ \\
\hline & 1 ransv & & 99 & 93 & 55 & 76 & - & 62 & $\%$ \\
\hline Tração & & & 4,7 & 12,1 & 10,9 & 21,2 & 25,8 & 27,9 & $\mathrm{~N} / \mathrm{mm}$ \\
\hline & Long & $\mathrm{B}$ & 47 & 67 & 51 & 57 & 80 & 83 & $\%$ \\
\hline & Troncu & B & 6,8 & 15,9 & 20,2 & 31,4 & 25,6 & 31,8 & $\mathrm{~N} / \mathrm{mm}$ \\
\hline & Transv & & 64 & 69 & 69 & 55 & 96 & 93 & $\%$ \\
\hline
\end{tabular}

\subsubsection{Solos e Agregados}

As características dos solos utilizados nos ensaios de laboratório (solo 1) e nos ensaios de campo (solo 1 e 2) são apresentadas na Tabela 31. A curva granulométrica é apresentada na Figura 50. 
Tabela 31. Características dos solos utilizados.

\begin{tabular}{ccc}
\hline Propriedade & Solo 1 & Solo 2 \\
\hline Classificação & SC (areia argilosa) & SW (areia bem graduada) \\
\hline $\begin{array}{c}\text { Massa específica dos sólidos, } \\
\rho_{\mathrm{s}}\end{array}$ & $2,690 \mathrm{~g} / \mathrm{cm}^{3}$ & $2,671 \mathrm{~g} / \mathrm{cm}^{3}$ \\
\hline $\begin{array}{c}\text { Proctor Normal } \\
\text { Peso específico seco } \\
\text { máximo }\left(\rho_{\text {dmáximo }}\right)\end{array}$ & $1,820 \mathrm{~g} / \mathrm{cm}^{3}$ & - \\
\hline Umidade ótima (wótima) & $14,5 \%$ & - \\
\hline $\begin{array}{c}\text { Condições da compactação de } \\
\text { campo }\end{array}$ & & - \\
\hline $\begin{array}{c}\text { Peso específico seco campo } \\
\left(\rho_{\text {dcampo }}\right)\end{array}$ & $95 \%$ & - \\
\hline Desvio de umidade $(\Delta \mathrm{w})$ & $+1,4 \%$ & - \\
\hline $\begin{array}{c}\text { Permeabilidade na umidade } \\
\text { ótima }(\mathrm{k} \text { wótima })\end{array}$ & $1,2 \times 10^{-7} \mathrm{~cm} / \mathrm{s}$ & - \\
\hline Limites de consistência & & - \\
\hline Limite de liquidez $(\mathrm{LL})$ & $38 \%$ & - \\
\hline Índice de Plasticidade $(\mathrm{IP})$ & $17 \%$ & - \\
\hline Índice de vazios máximo & - & 0,78 \\
\hline Índice de vazios mínimo & - & 0,52 \\
\hline
\end{tabular}

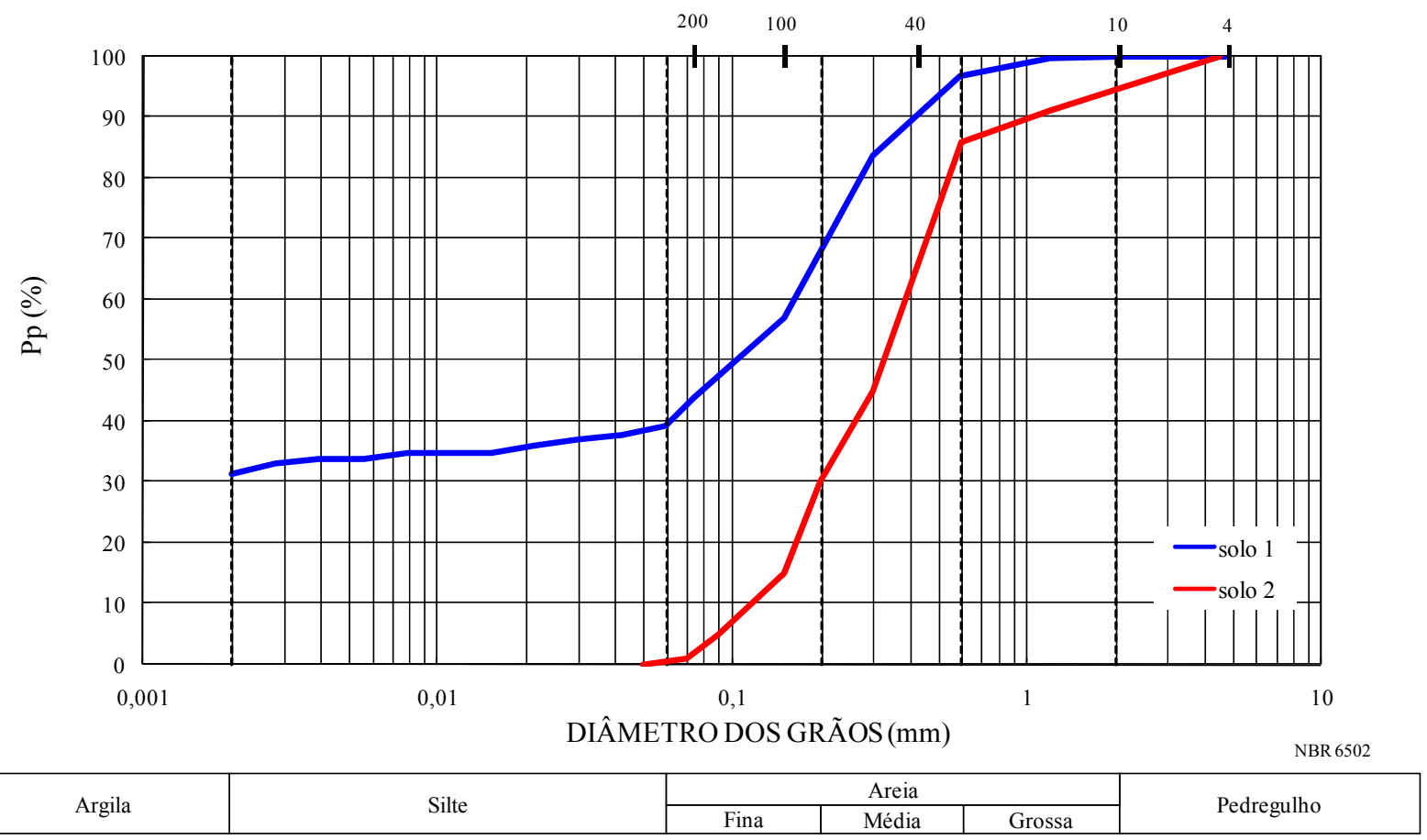

Figura 50. Curva granulométrica do solo. 
Foram utilizadas duas granulometrias de agregados na construção da camada de drenagem, cujas principais características são apresentadas na Tabela 32. O resultado dos ensaios de índice de forma é apresentado na Figura 51; enquanto a Figura 52 apresenta a curva granulométrica dos agregados.

Tabela 32. Características dos agregados.

\begin{tabular}{lcc}
\hline Propriedade & Brita 1 & Brita 3 \\
\hline Classificação & Pedregulho médio & Pedregulho grosso \\
\hline Faixa granulométrica & 10 a $27 \mathrm{~mm}$ & 15 a 110 mm \\
\hline $\mathrm{D}_{10}(\mathrm{~mm})$ & 11 & 25 \\
\hline $\mathrm{D}_{30}(\mathrm{~mm})$ & 13 & 29 \\
\hline $\mathrm{D}_{60}(\mathrm{~mm})$ & 15 & 38 \\
\hline Coeficiente de uniformidade, $\mathrm{C}_{\mathrm{u}}$ & 1,4 & 1,5 \\
\hline Coeficiente de curvatura, $\mathrm{C}_{\mathrm{c}}$ & 1,0 & 0,9 \\
\hline Classificação Unificada & GP & GP \\
\hline Índice de forma & Cúbico & Cúbico-lamelar \\
\hline
\end{tabular}

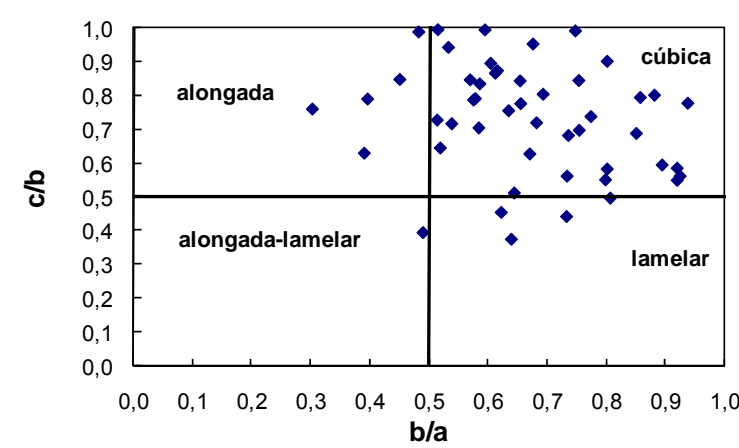

(a)

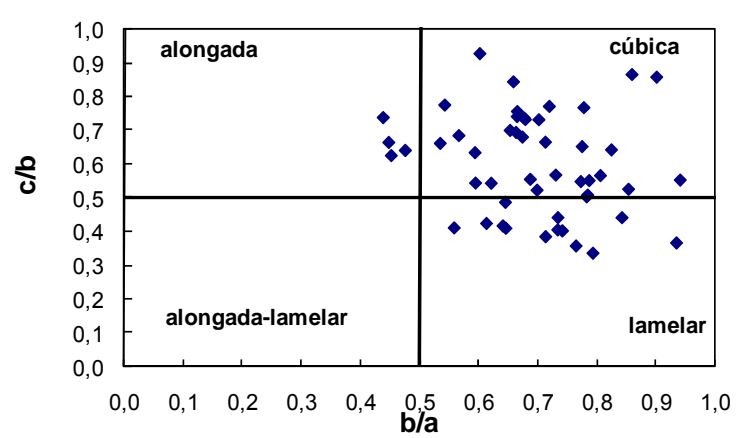

(b)

Figura 51. Resultado do ensaio de índice de forma: (a) brita 1; (b) brita 3. 


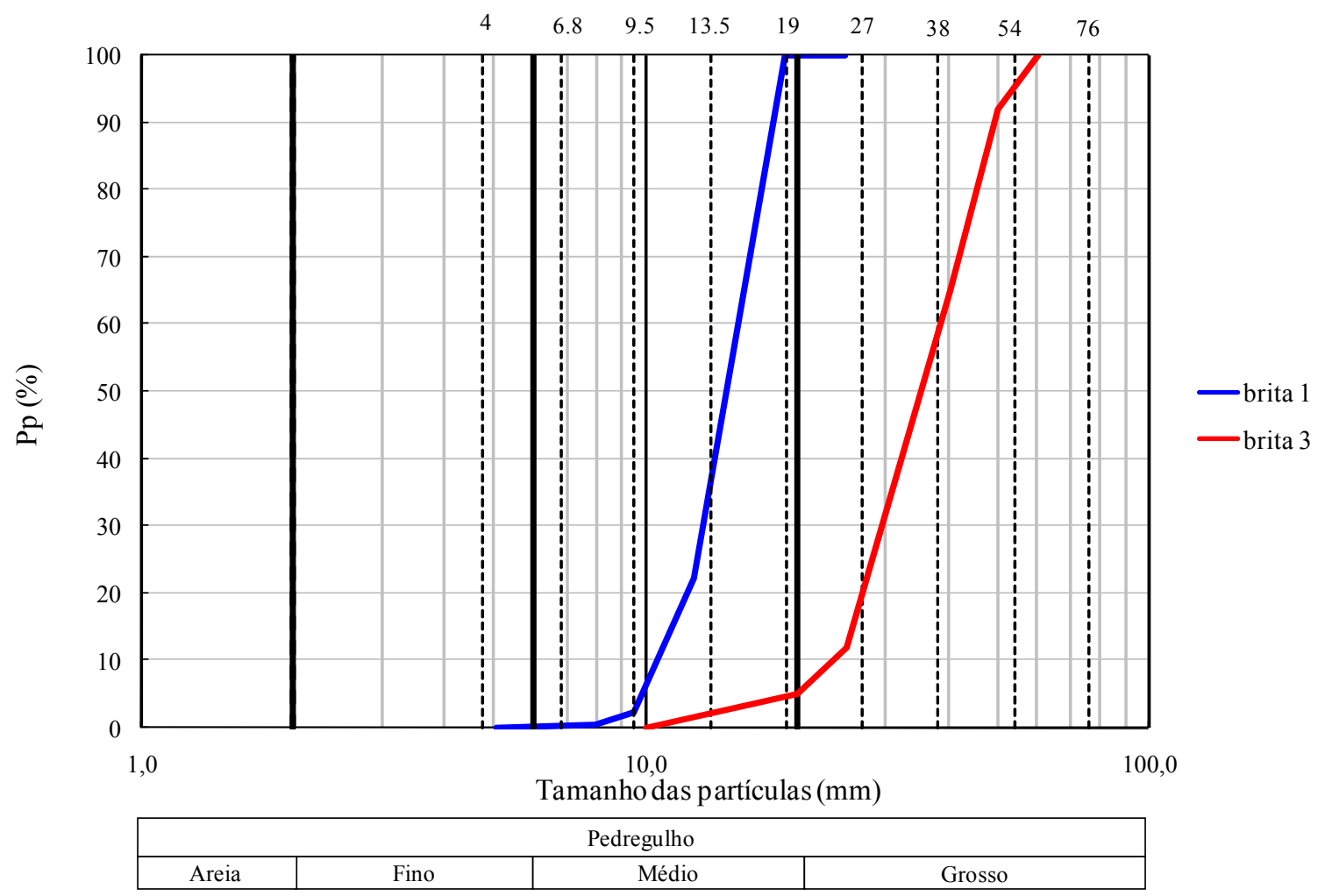

Figura 52. Curva granulométrica dos agregados.

\subsection{Ensaios de Laboratório}

\subsubsection{Ensaios Índices}

\subsubsection{Ensaios Estáticos}

As Figuras abaixo apresentam aos resultados dos ensaios estáticos realizados nas geomembranas de PVC (1,0 mm), PEAD (1,5 mm) e PELMD $(1,25 \mathrm{~mm})$, utilizando geotêxteis de PET e PP como elemento de proteção e em diferentes configurações. Tais curvas representam o comportamento típico de um ensaio de punção e não se referem aos valores médios dos resultados. Os valores médios dos resultados são apresentados na Tabela 33. 


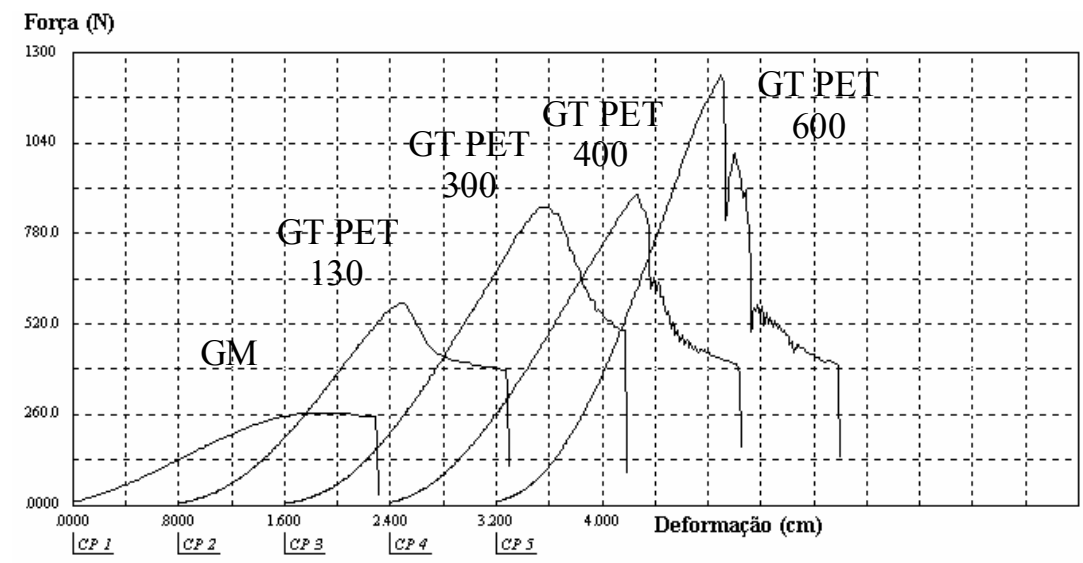

Figura 53. Curvas de punção - geomembrana de PVC, 1,0mm - GT/GM, GT PET.

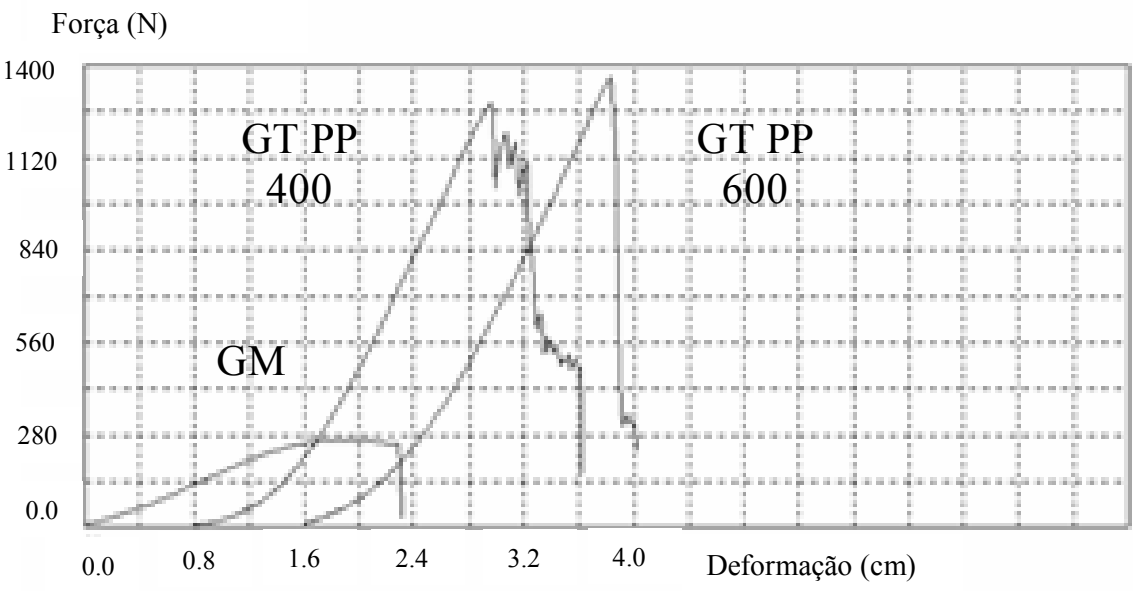

Figura 54. Curvas de punção - geomembrana de PVC, 1,0mm - GT/GM, GT PP.

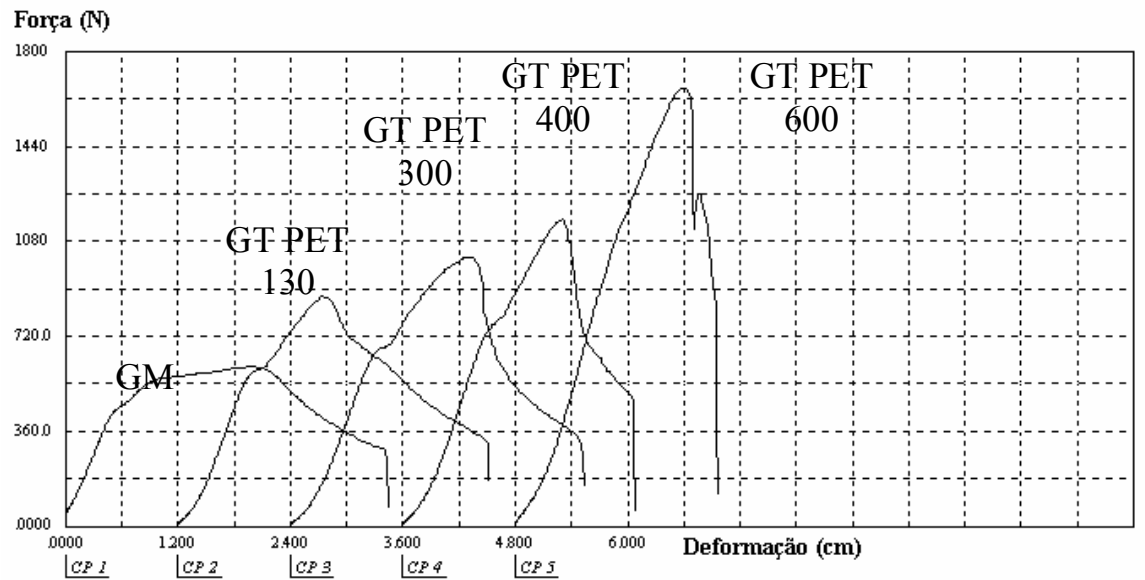

Figura 55. Curvas de punção - geomembrana de PEAD, 1,5 mm - GT/GM, GT PET. 


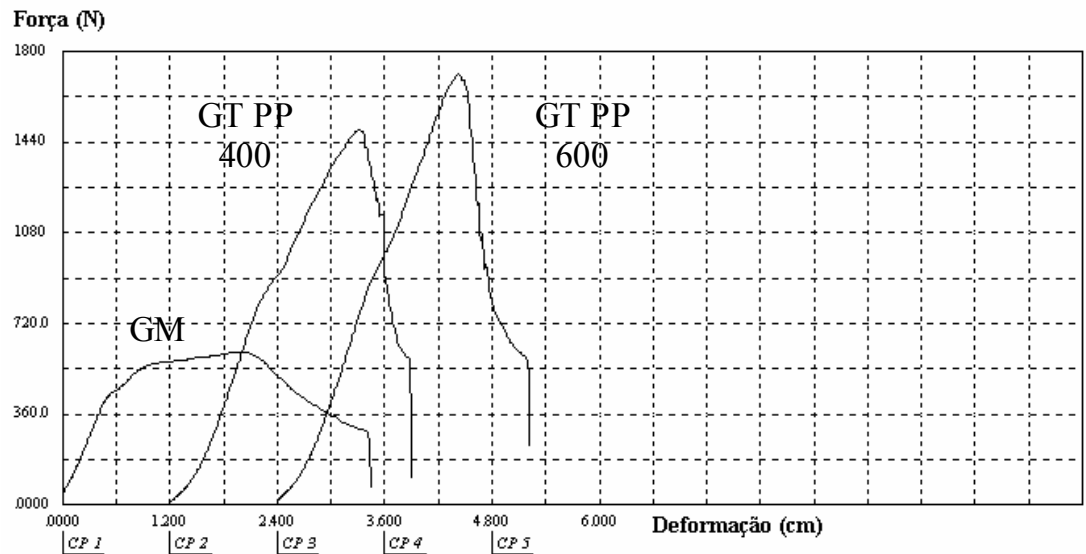

Figura 56. Curvas de punção - geomembrana de PEAD, 1,5 mm - GT/GM, GT PP.

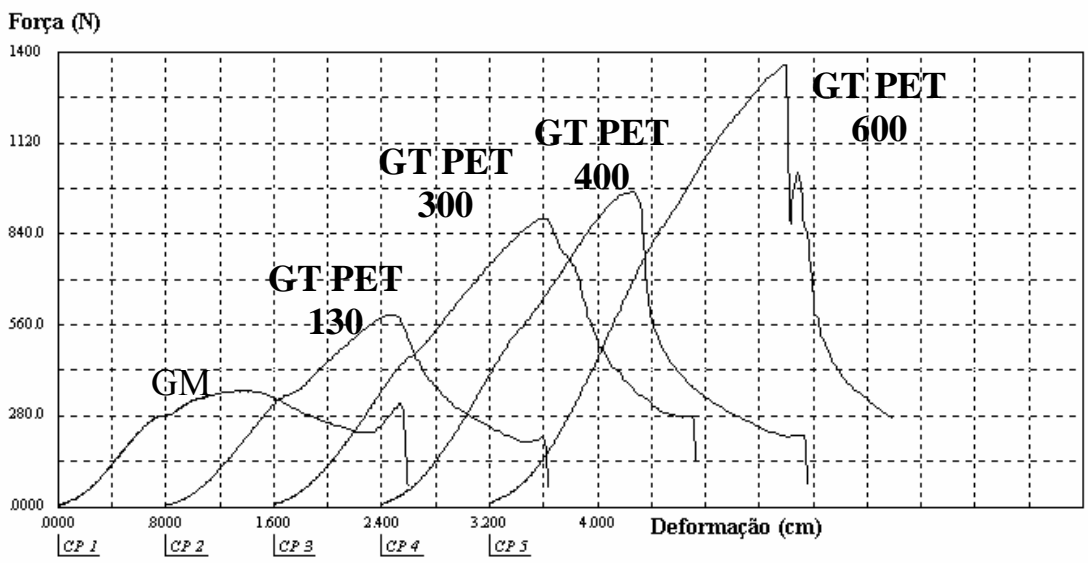

Figura 57. Curvas de punção - geomembrana de PELMD, 1,25 mm - GT/GM, GT PET.

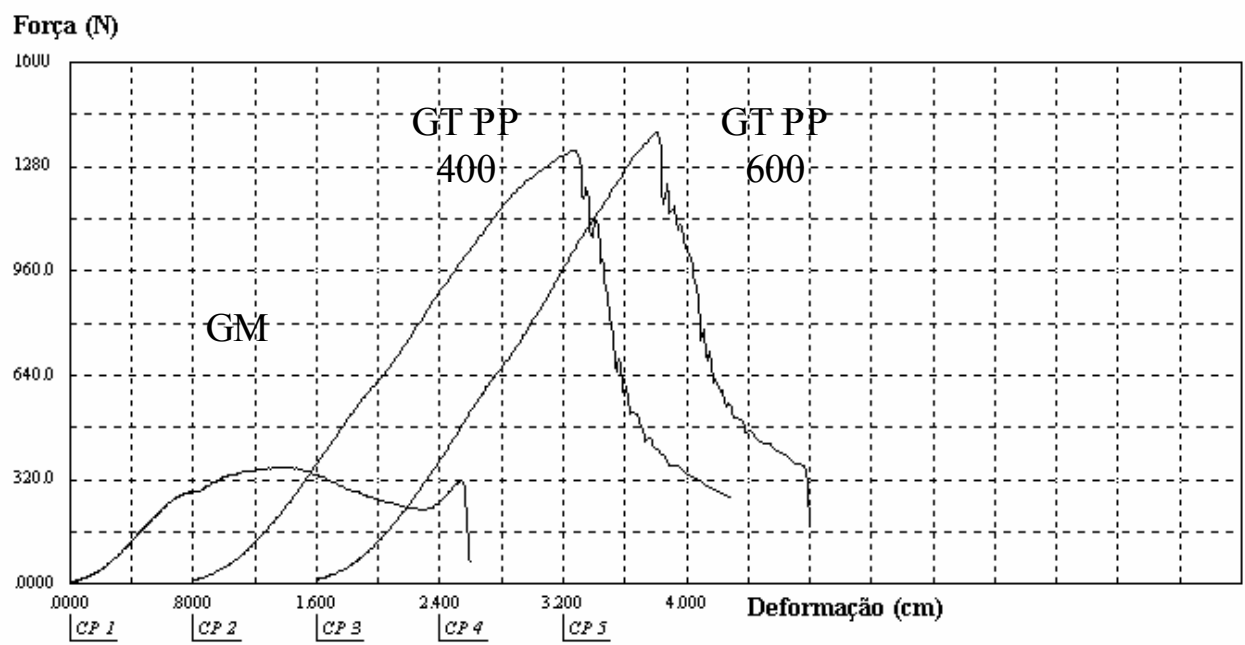

Figura 58. Curvas de punção - geomembrana de PELMD, 1,25 mm - GT/GM, GT PET. 
Tabela 33. Resumo dos resultados dos ensaios índice.

\begin{tabular}{|c|c|c|c|c|c|c|c|}
\hline \multirow{4}{*}{ Geomembrana } & \multirow{4}{*}{ Tipo de Geotêxtil } & \multicolumn{6}{|c|}{ Disposição do Geotêxtil } \\
\hline & & \multicolumn{2}{|c|}{$G T / G M$} & \multicolumn{2}{|c|}{$G M / G T$} & \multicolumn{2}{|c|}{$G T / G M / G T$} \\
\hline & & $\mathrm{Fp}$ & $\delta$ & $\mathrm{Fp}$ & $\varepsilon$ & $\mathrm{Fp}$ & $\varepsilon$ \\
\hline & & $(\mathrm{N})$ & $(\mathrm{mm})$ & $(\mathrm{N})$ & $(\mathrm{mm})$ & $(\mathrm{N})$ & $(\mathrm{mm})$ \\
\hline \multirow{7}{*}{ PVC 1,0 mm } & sem proteção & 329 & 27 & 329 & 27 & 329 & 27 \\
\hline & PET 130 & 515 & 17 & 541 & 19 & 729 & 20 \\
\hline & PET 300 & 844 & 23 & 701 & 21 & 1040 & 20 \\
\hline & PET 400 & 869 & 18 & - & - & - & - \\
\hline & PET 600 & 1249 & 19 & 1201 & 17 & 2111 & 25 \\
\hline & PP 400 & 1221 & 19 & 1226 & 22 & 1888 & 24 \\
\hline & PP 600 & 1413 & 21 & 1381 & 23 & 2077 & 22 \\
\hline \multirow{7}{*}{ PEAD $1,5 \mathrm{~mm}$} & sem proteção & 652 & 21 & 652 & 21 & 652 & 21 \\
\hline & PET 130 & 884 & 16 & 855 & 19 & 1047 & 18 \\
\hline & PET 300 & 1016 & 18 & 974 & 20 & 1318 & 20 \\
\hline & PET 400 & 1157 & 18 & - & - & - & - \\
\hline & PET 600 & 1669 & 19 & 1515 & 20 & 2230 & 21 \\
\hline & PP 400 & 1476 & 20 & 1370 & 24 & 2008 & 22 \\
\hline & PP 600 & 1712 & 22 & 1639 & 26 & - & - \\
\hline \multirow{7}{*}{ PELMD 1,25 mm } & sem proteção & 336 & 13 & 336 & 13 & 336 & 13 \\
\hline & PET 130 & 585 & 17 & 580 & 18 & 882 & 18 \\
\hline & PET 300 & 877 & 21 & 864 & 21 & 1134 & 22 \\
\hline & PET 400 & 970 & 19 & - & - & - & - \\
\hline & PET 600 & 1357 & 22 & 1202 & 19 & 2218 & 20 \\
\hline & PP 400 & 1221 & 24 & 1265 & 22 & 2020 & 22 \\
\hline & PP 600 & 1382 & 25 & 1307 & 25 & 2367 & 25 \\
\hline
\end{tabular}

* Valores médios 
Nos ensaios realizados na geomembrana de PVC sem proteção foi obtida uma força de punção de 329 N. Nos ensaios com geotêxteis de PET foram obtidos valores de 515, 844, 869 e $1249 \mathrm{~N}$ para as gramaturas de 130, 300, 400 e $600 \mathrm{~g} / \mathrm{m}^{2}$, respectivamente. A relação entre a força de punção do conjunto geomembrana mais geotêxtil e a força de punção da geomembrana foi de $1,6,2,6,2,6$ e 3,8 para as respectivas gramaturas citadas acima. Nos ensaios realizados com geotêxtil de PP, os valores obtidos foram de 1221 (relação de 3,7) e $1413 \mathrm{~N}(4,3)$ para as gramaturas de 400 e $600 \mathrm{~g} / \mathrm{m}^{2}$, respectivamente.

O valor da força de punção obtido na geomembrana de PEAD sem proteção foi de 652 N. Nos ensaios com geotêxteis de PET foram obtidos valores de $884(1,4), 1016(1,6), 1157$ $(1,8)$ e $1669 \mathrm{~N}(2,6)$ para as gramaturas de $130,300,400$ e $600 \mathrm{~g} / \mathrm{m}^{2}$, respectivamente. Nos ensaios realizados com geotêxtil de PP, os valores obtidos foram de $1476(2,3)$ e $1712 \mathrm{~N}$ $(2,6)$, para as gramaturas de 400 e $600 \mathrm{~g} / \mathrm{m}^{2}$.

O valor da força de punção obtida na geomembrana de PELMD sem qualquer proteção foi de 336 N. Nos ensaios com geotêxteis de PET foram obtidos valores de $584(1,7), 877$ $(2,6), 970(2,9)$ e $1357 \mathrm{~N}(4,0)$ para as gramaturas de 130, 300, 400 e $600 \mathrm{~g} / \mathrm{m}^{2}$, respectivamente. Nos ensaios realizados com geotêxtil de PP, os valores obtidos foram de $1221(3,6)$ e $1382 \mathrm{~N}(4,1)$, para as gramaturas de 400 e $600 \mathrm{~g} / \mathrm{m}^{2}$.

As Figuras abaixo mostram o efeito da gramatura do geotêxtil no acréscimo de resistência à punção $(\Delta \mathrm{Fp})$ para diferentes geomembranas e geotêxteis. Nestas figuras, $\Delta \mathrm{Fp}$ corresponde a razão entre a força de punção do conjunto geotêxtil/geomembrana e a força de punção da geomembrana sem elemento de proteção, expressa em porcentagem. 


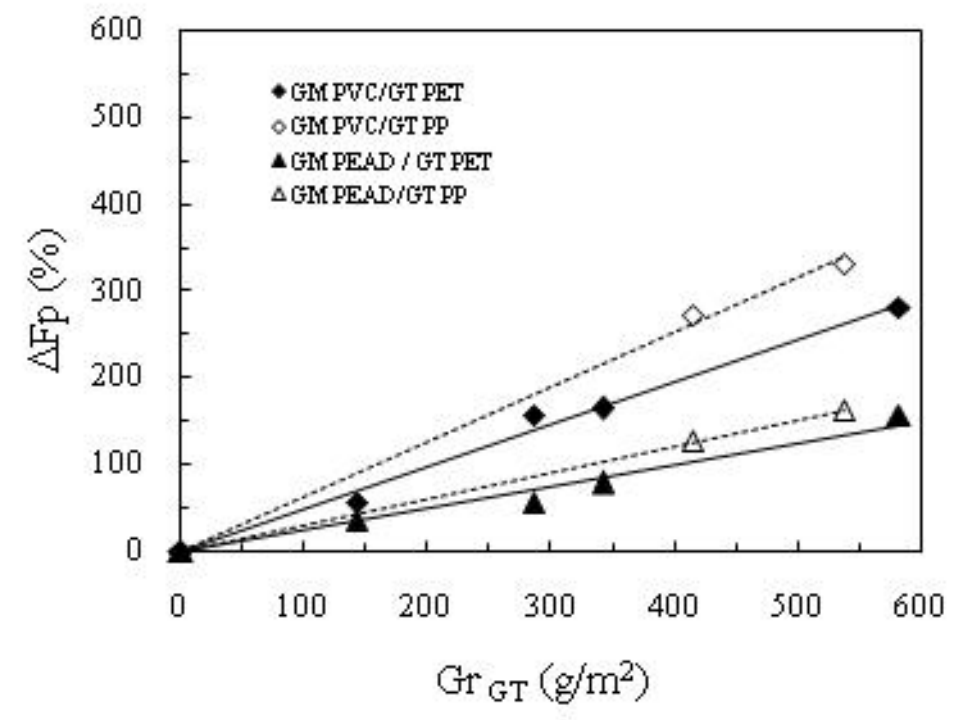

Figura 59. Efeito da gramatura na resistência à punção - GT sobre GM.

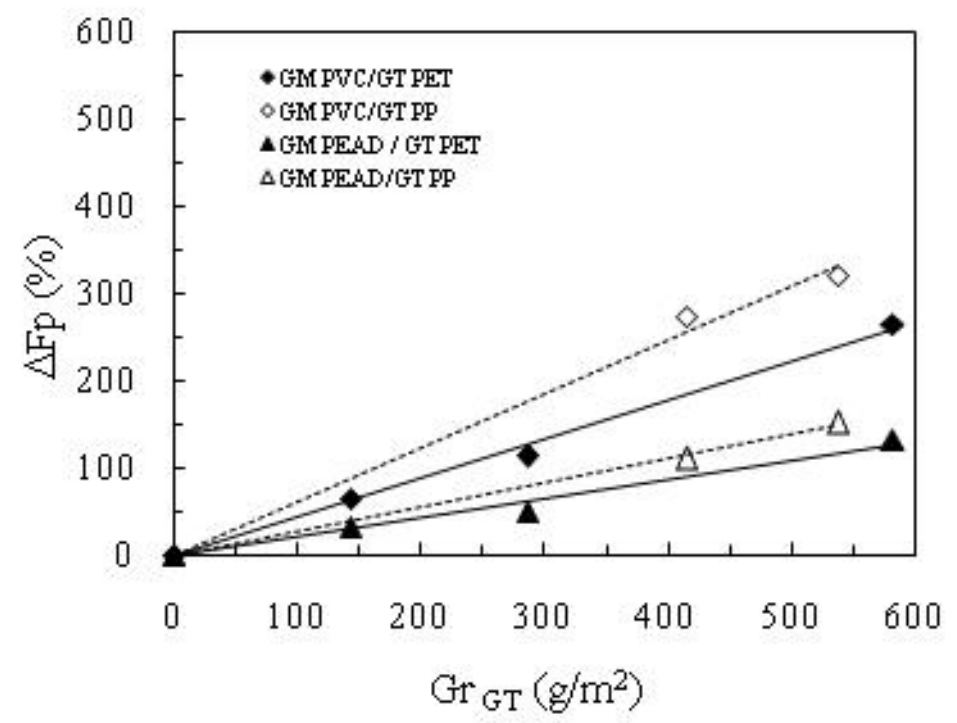

Figura 60. Efeito da gramatura na resistência à punção - GM sobre GT. 


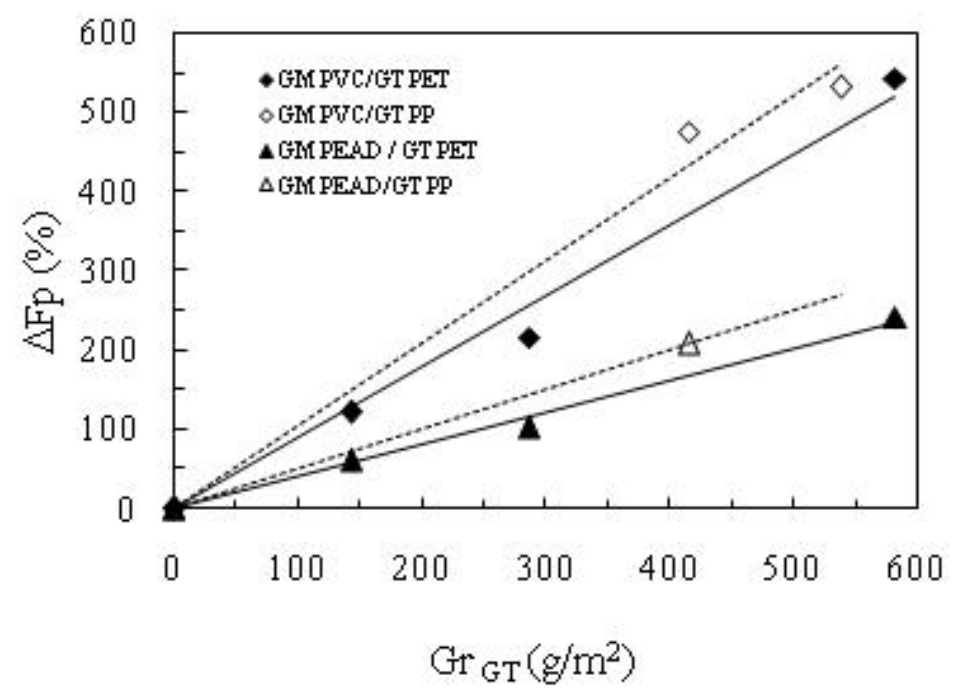

Figura 61. Efeito da gramatura na resistência à punção - GT/GM/GT.

Observa-se, em todas as configurações, que a resistência à punção das geomembranas é proporcional a gramatura do geotêxtil. Além disto, as curvas apresentadas mostram que as geomembranas de PVC foram mais sensíveis à presença de geotêxtil do que as geomembranas de PEAD, pois o aumento da força de punção nas geomembranas de PVC foi cerca de $100 \%$ maior do que o aumento obtido na geomembrana de PEAD. Somente nos ensaios com geotêxteis de baixa gramatura $\left(130 \mathrm{~g} / \mathrm{m}^{2}\right)$ o aumento foi de menor magnitude, em torno de $50 \%$.

Os resultados também mostram que os geotêxteis de polipropileno (PP) introduziram maiores ganhos de resistência à punção do que os geotêxteis de poliéster (PET), o que indica que a gramatura do geotêxtil não é única característica responsável pelo seu desempenho como proteção.

A Figura 62 apresenta uma análise do desempenho de geotêxteis correlacionando as propriedades de gramatura $(\mathrm{Gr})$, tensão de tração do geotêxtil $\left(\mathrm{F}_{\mathrm{yGT}}\right)$ e o aumento da força de punção do conjunto $(\Delta \mathrm{Fp})$. 


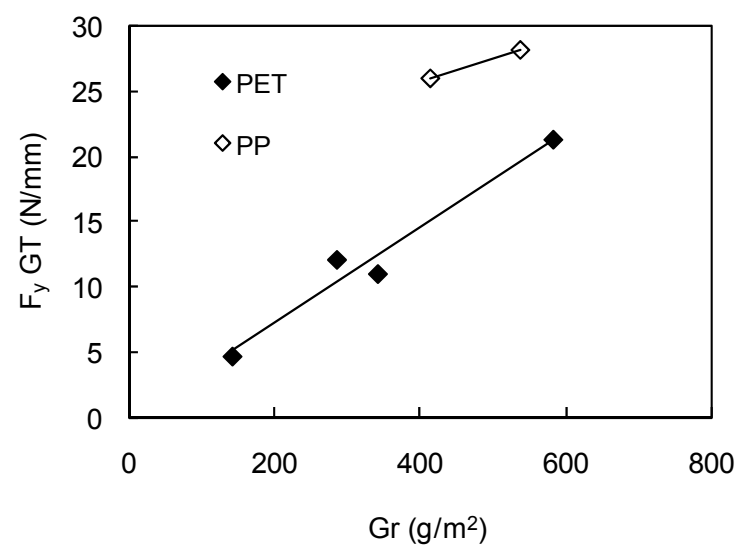

(a)

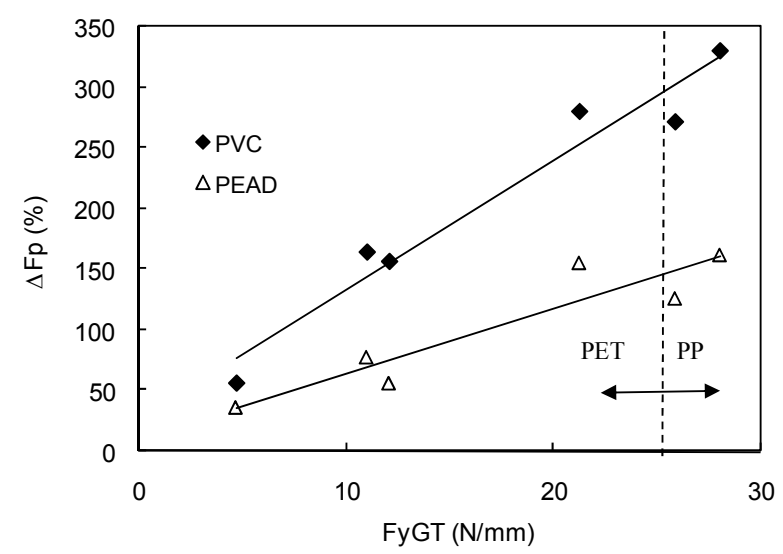

(b)

Figura 62. Influência das características do geotêxtil.

Os resultados apresentados na Figura 62a mostram que a resistência à tração do geotêxtil é proporcional a sua gramatura. Além disto, pode-se observar que os geotêxteis de polipropileno (PP) forneceram maiores valores de resistência à tração do que os de poliéster (PET).

Ao se analisar a (Figura 62b), constatou-se que a resistência à punção do conjunto geotêxtil/geomembrana também é proporcional à resistência a tração do conjunto. No entanto, observa-se que os geotêxteis de polipropileno (PP) forneceram maiores valores de acréscimo de resistência do que os geotêxteis de poliéster (PET). Tais resultados indicam que a resistência à tração constitui um importante parâmetro na avaliação do desempenho de 
geotêxtil, uma vez que este parâmetro expressa a gramatura e variação do tipo de geotêxtil em termos de acréscimo de resistência à punção para o conjunto geotêxtil/geomembrana.

A princípio, percebem-se duas características importantes que influenciam no desempenho de geotêxteis como elemento de proteção: a resistência à tração da geomembrana e a resistência à tração do geotêxtil. Atribuindo um fator adimensional $\delta$, o qual representa a relação entre a resistência à tração de ruptura $\left(\mathbf{F}_{\mathbf{Y G M}}\right)$ da geomembrana e a relação entre a força de tração de ruptura do geotêxtil $\left(\mathbf{F}_{\mathbf{t}} \mathbf{G T}\right)$, pôde-se realizar uma análise do acréscimo de resistência a punção $(\Delta \mathrm{Fp})$ em função deste fator. A Figura 63 ilustra a correlação proposta.

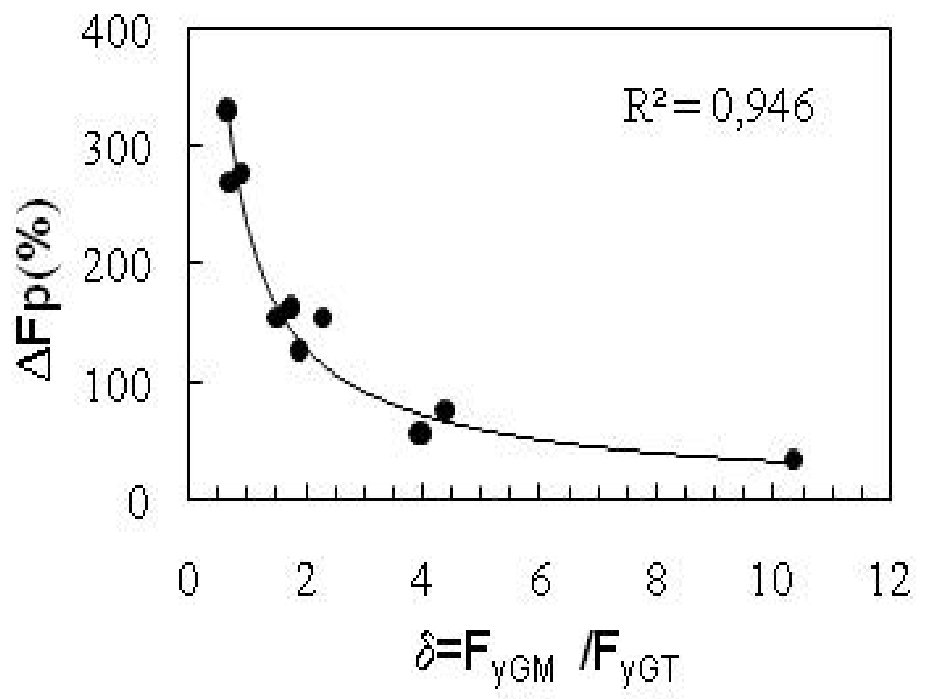

Figura 63. Influência das características de tração da geomembrana e do geotêxtil no aumento na força de punção.

Observa-se que o fator $\delta$ apresentou uma boa correlação com os resultados dos ensaios. Verificou-se, por exemplo, que valores mais baixos de $\delta$ geram elevados valores de acréscimo de resistência à punção. Além disto, observa-se que o acréscimo de resistência foi bastante influenciado pelo aumento da resistência à tração do geotêxtil. Tal situação representa o comportamento típico verificado nas geomembranas de PVC (baixos valores de resistência à tração). 
Em contrapartida, para elevados valores de $\delta$ foram gerados baixos valores de acréscimo de resistência à punção. Observou-se ainda que a resistência à punção é pouco influenciada pelo aumento da resistência a tração do geotêxtil. Este comportamento foi constatado nas geomembranas de PEAD.

A Figura 64 ilustra o efeito do aumento da espessura da geomembrana (e) na força de punção (Fp) do conjunto GT/GM realizados nas geomembranas de PVC e PEAD, utilizandose geotêxteis de PET $300 \mathrm{~g} / \mathrm{m}^{2}$.

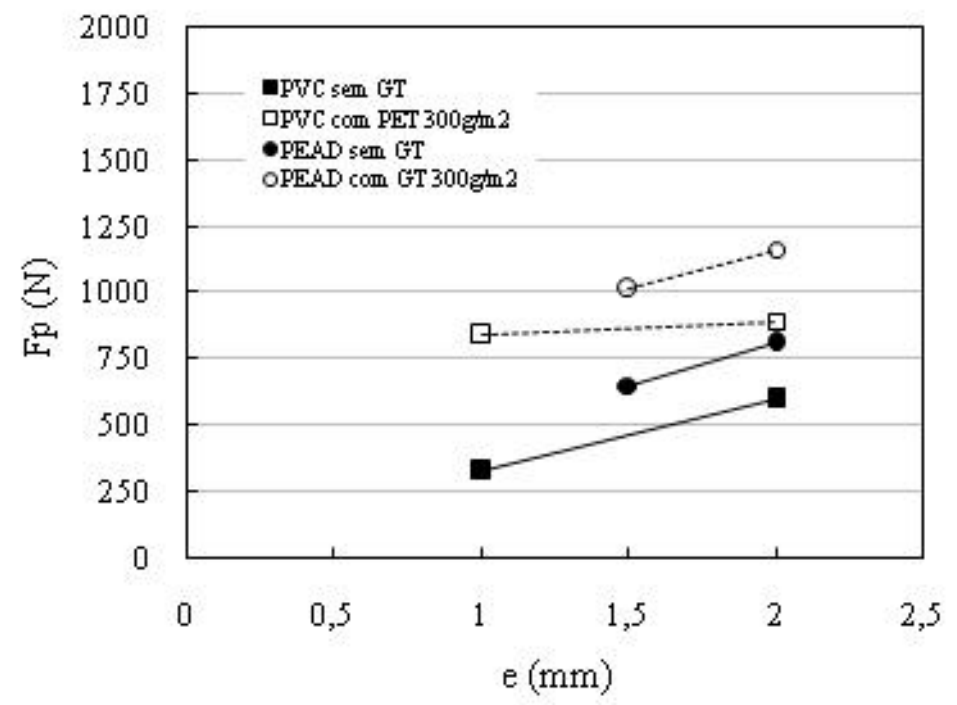

Figura 64. Influência da espessura - sistema GT/GM, GT PET 300 g/m².

No ensaio realizado com geomembrana de PVC de 1,0 mm sem proteção foi obtida a força de punção de $329 \mathrm{~N}$, valor que atinge $600 \mathrm{~N}$ para a geomembrana de 2,0 mm, um aumento de aproximadamente $80 \%$. No ensaio realizado com geomembrana de PEAD, obtiveram-se força de punção de $652 \mathrm{~N}$ e $811 \mathrm{~N}$ para as espessuras de 1,5 mm e 2,0 mm, respectivamente, num aumento de aproximadamente $25 \%$. Nota-se que o aumento de resistência foi proporcional ao aumento da espessura. 
Ao se analisar a introdução do geotêxtil na geomembrana de PVC, obteve-se uma resistência à punção de $844 \mathrm{~N}(\Delta \mathrm{Fp} \cong 160 \%)$ na geomembrana de $1,0 \mathrm{~mm}$; enquanto na geomembrana de $2,0 \mathrm{~mm}$, o valor obtido foi de $1000 \mathrm{~N}(\Delta \mathrm{Fp} \cong 66 \%)$. Na geomembrana de PEAD com proteção de GT PET $300 \mathrm{~g} / \mathrm{m}^{2}$ foram obtidas resistências à punção de $1016 \mathrm{~N}$ $(\Delta \mathrm{Fp} \cong 60 \%)$ e $1165 \mathrm{~N}(\Delta \mathrm{Fp} \cong 45 \%)$ para geomembranas de $1,5 \mathrm{~mm}$ e $2,0 \mathrm{~mm}$, respectivamente. Em geral, verifica-se que quanto maior a espessura da geomembrana (e), menor o acréscimo de resistência à punção com a introdução do geotêxtil $(\Delta \mathbf{F p})$, comportamento este mais evidenciado na geomembrana de PVC.

A Figura 65a correlaciona a força de tração e a espessura das geomembranas de PVC e PEAD, enquanto a Figura 65b mostra a correlação entre a espessura da geomembrana e o parâmetro $\delta$.

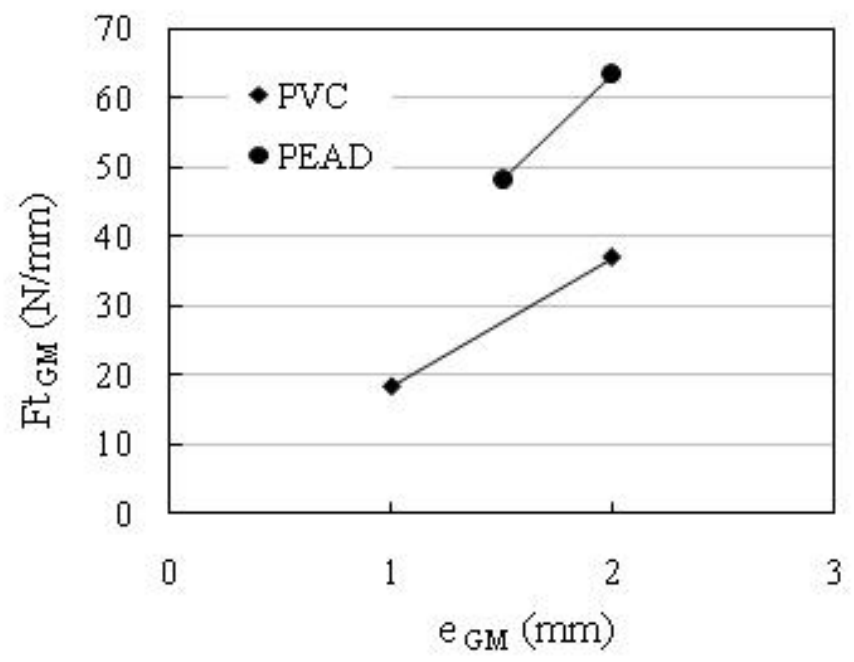

(a) 


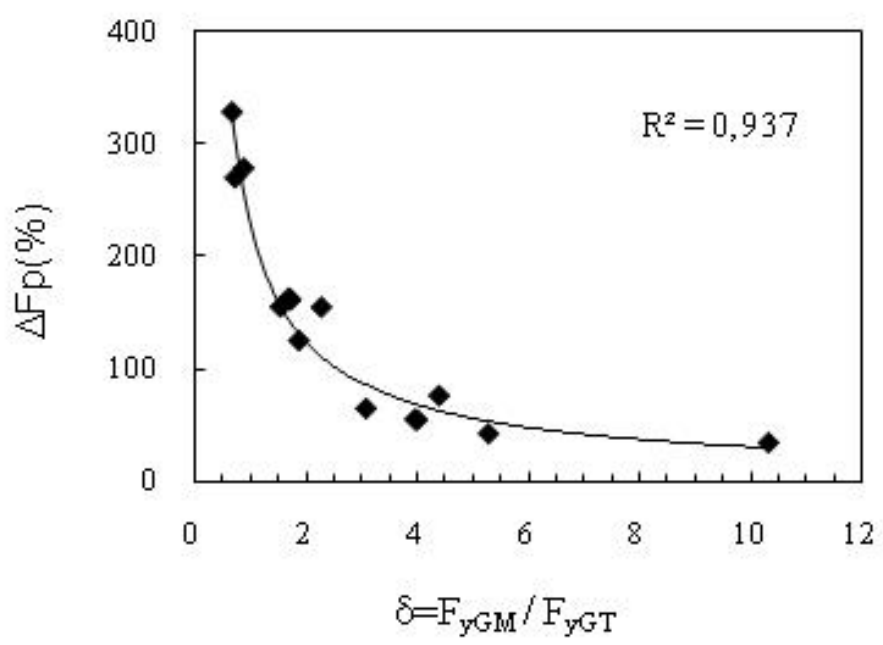

(b)

Figura 65. Influência da espessura - sistema GT/GM, GT PET $300 \mathrm{~g} / \mathrm{m}^{2}$.

Analisando-se as propriedades de tração das geomembranas (Figura 65a), verifica-se que a resistência à tração da geomembrana é diretamente proporcional a espessura da geomembrana. Deste modo, verifica-se que a espessura da geomembrana está diretamente relacionada ao parâmetro $\delta$ e, conseqüentemente ao valor de $\Delta \mathbf{F p}$.

No caso das geomembranas de PVC com geotêxtil, ao se aumentar a espessura de 1,0 $\mathrm{mm}$ para 2,0 $\mathrm{mm}$ obteve-se um aumento de $\delta$ de 1,5 para 3,1 . Concomitantemente, o acréscimo de resistência à punção com a introdução do geotêxtil passou de $160 \%$ para $65 \%$. Nas geomembranas de PEAD, o valor, o valor de $\delta$ aumentou de 4,0 para 5,3 ao se aumentar a espessura de $1,5 \mathrm{~mm}$ para $2,0 \mathrm{~mm}$; enquanto o valor de $\Delta \mathrm{Fp}$ passou de $60 \%$ para $45 \%$.

A Figura 65b corrobora a constatação acima. Observa-se, nas geomembranas de PVC, uma elevada redução no valor do $\Delta \mathrm{Fp}$ com o aumento da espessura; enquanto as geomembranas de PEAD apresentaram uma menor redução no valor de $\Delta \mathrm{Fp}$.

Em síntese, os resultados apresentados indicam que a variação da composição polimérica e da espessura da geomembrana pode ser expressa em termos de resistência à tração na ruptura $\left(\mathbf{F}_{\mathbf{y G M}}\right)$ no comportamento de geotêxteis como elemento de proteção. Além 
disto, verifica-se que a variação do tipo e da gramatura do geotêxtil pode ser expressa em termos de sua resistência à tração $\left(\mathbf{F}_{\mathbf{y G T}}\right)$.

A Figura 66 apresenta os resultados dos ensaios realizados com geomembranas de PVC e PEAD com geotêxteis de PET e PP, dispostos em diferentes configurações: geotêxtil sobre geomembrana (GT/GM), geomembrana sobre geotêxtil (GM/GT) e geotêxtil / geomembrana / geotêxtil (GT/GM/GT), respectivamente. Tais resultados são expressos em função do parâmetro $\delta$ versus acréscimo de resistência à punção $(\Delta \mathrm{Fp})$. As curvas forças versus deslocamento seguem as feições típicas mostradas nas Figuras 54 a 59 e também serão omitidas na discussão que se segue.

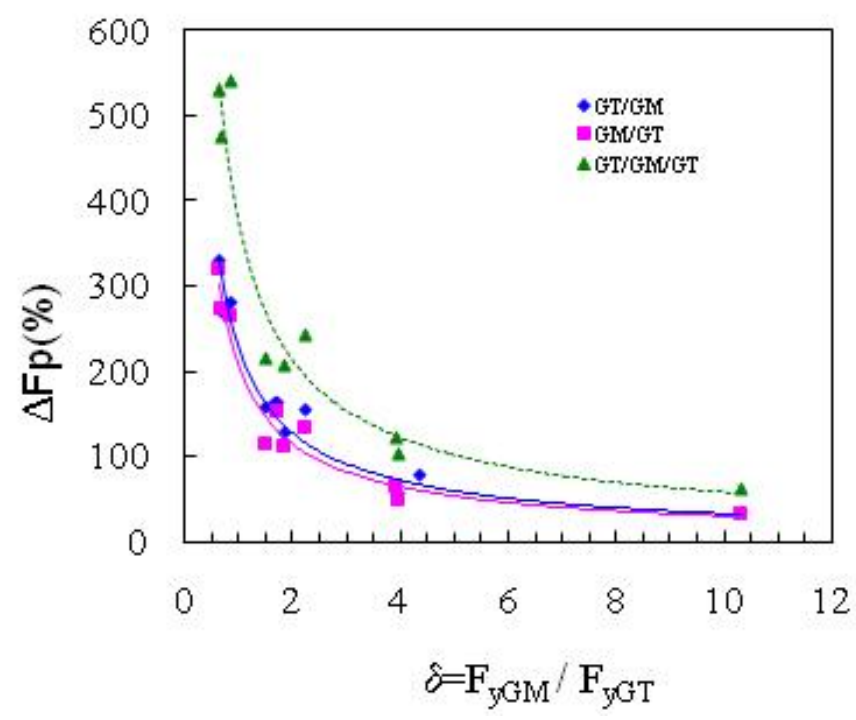

Figura 66. Efeito da disposição dos geotêxteis na resistência à punção do sistema.

Os resultados mostram que todas as formas de disposição contribuíram para aumentar a força de punção para a geomembrana. Verificou-se, nos diferentes tipos de geomembranas geotêxteis utilizados, que o sistema geotêxtil sobre geomembrana (GT/GM) apresentou força de punção ligeiramente maior do que o sistema geomembrana sobre geotêxtil (GM/GT). 
Conforme se esperava o sistema duplo de geotêxteis (GT/GM/GT) apresentou o melhor desempenho com elevados valores de força de punção.

$\mathrm{Na}$ Figuras abaixo são apresentados os resultados dos ensaios realizados apoiados sobre uma base de solo argiloso compactado com GC 95\% $\left(\rho_{d}=1,729 \mathrm{~g} / \mathrm{m}^{3}\right)$ e desvio de umidade $(\Delta \mathrm{w})$ de 2,0\%. Tais resultados se referem ao sistema GT/GM, com geotêxtil de PET $300 \mathrm{~g} / \mathrm{m}^{2}$

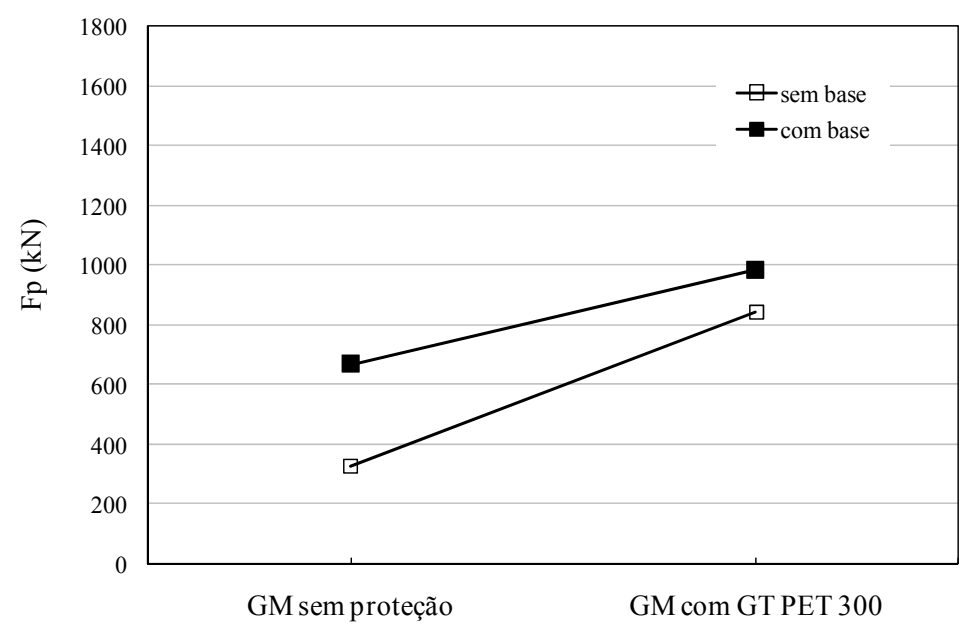

Figura 67. Análise do efeito da introdução de base de solo compactado: GMs de PVC.

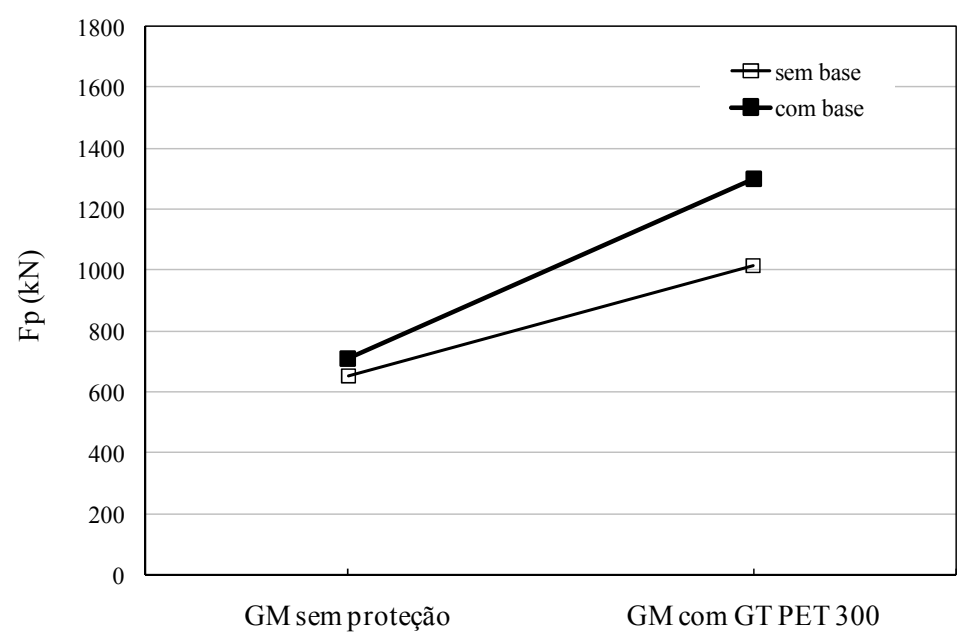

Figura 68. Análise do efeito da introdução de base de solo compactado: GMs de PEAD. 


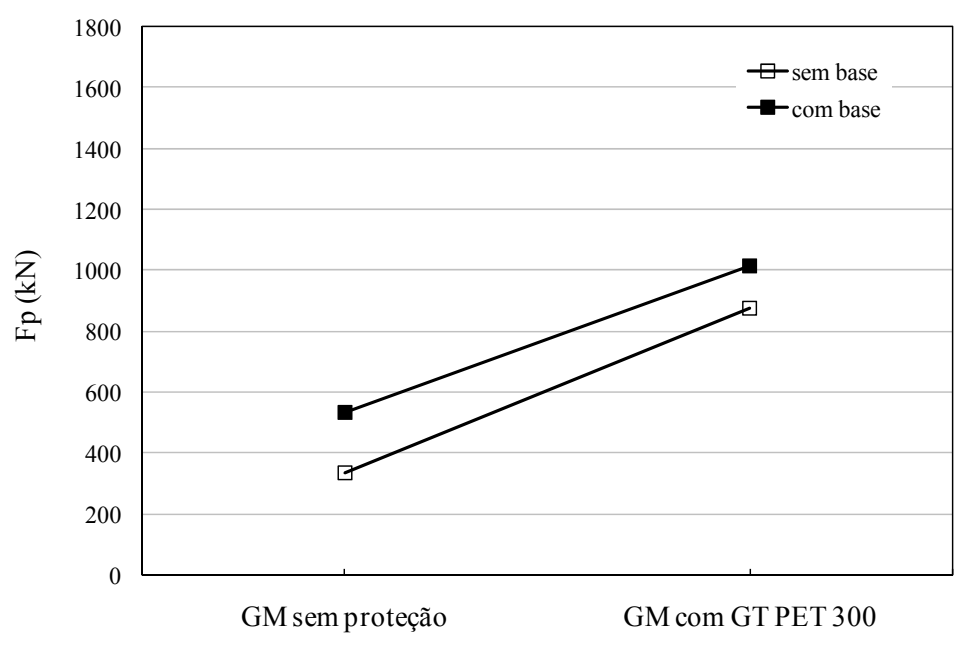

Figura 69. Análise do efeito da introdução de base de solo compactado: GMs de PELMD.

As geomembranas de PVC sem proteção mostraram um aumento de $100 \%$ na força de punção $(\Delta \mathrm{Fp})$ pela presença da base de solo compactado. Com a introdução do geotêxtil de PET $300 \mathrm{~g} / \mathrm{m}^{2}$, obteve-se um acréscimo de $\Delta \mathrm{Fp}$ em torno de $160 \%$ nos ensaios realizados sem base de solo compactado e, $47 \%$ nos ensaios realizados com base de solo compactado.

As geomembranas de PEAD sem proteção apresentaram um aumento de apenas 10\% na força de punção devido à base de solo compactado. Com a introdução de geotêxtil de PET, obteve-se um acréscimo de $\Delta \mathrm{Fp}$ em torno de $56 \%$ nos ensaios realizados sem base de solo compactado e, $83 \%$ nos ensaios realizados com base de solo compactado.

As geomembranas de PELMD sem proteção apresentaram um aumento de aproximadamente $60 \%$ na força de punção devido à base de solo compactado. Com a introdução de geotêxtil de PET, ao acréscimo de $\Delta \mathrm{Fp}$ obtido nos ensaios sem base de solo compactado foi de $160 \%$; enquanto nos ensaios com base de solo compactado o acréscimo foi $90 \%$. 


\subsubsection{Ensaios Dinâmicos}

As Figuras abaixo mostram os resultados dos ensaios dinâmicos (queda do cone) realizados nas geomembranas de PVC $(1,0 \mathrm{~mm})$, PEAD $(1,5 \mathrm{~mm})$ e PELMD $(1,25 \mathrm{~mm})$, respectivamente, com geotêxteis de PET e PP como elemento de proteção, referentes ao sistema GTGM. Nestas figuras $\phi_{\mathbf{p}}$ e $\mathbf{G r}$ representam o diâmetro de perfuração na geomembrana e a gramatura do geotêxtil empregado, respectivamente.

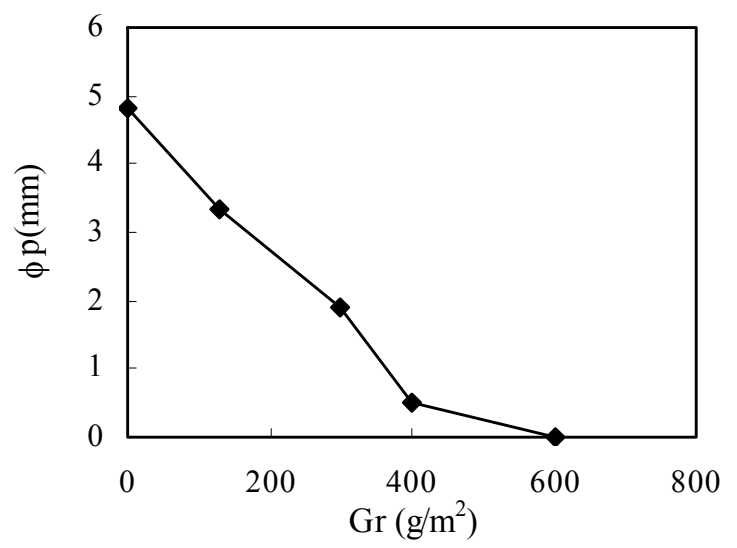

GT PET

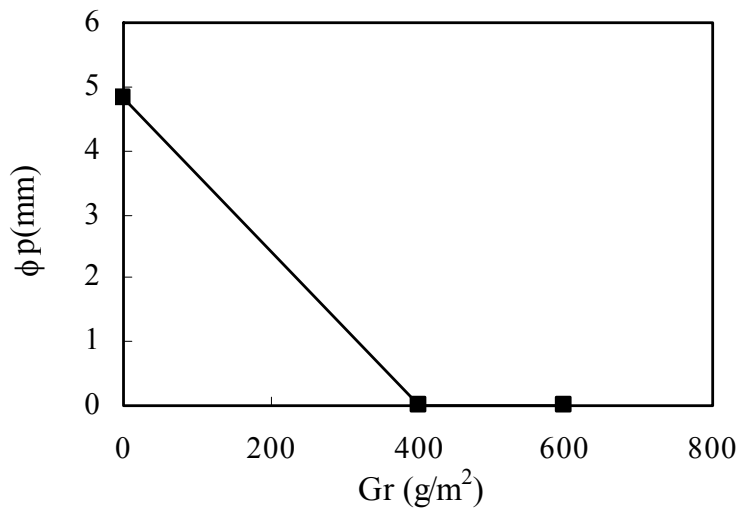

GT PP

Figura 70. Resultados obtidos no ensaio de punção dinâmica - geomembrana de PVC, 1,0 mm - GT/GM.

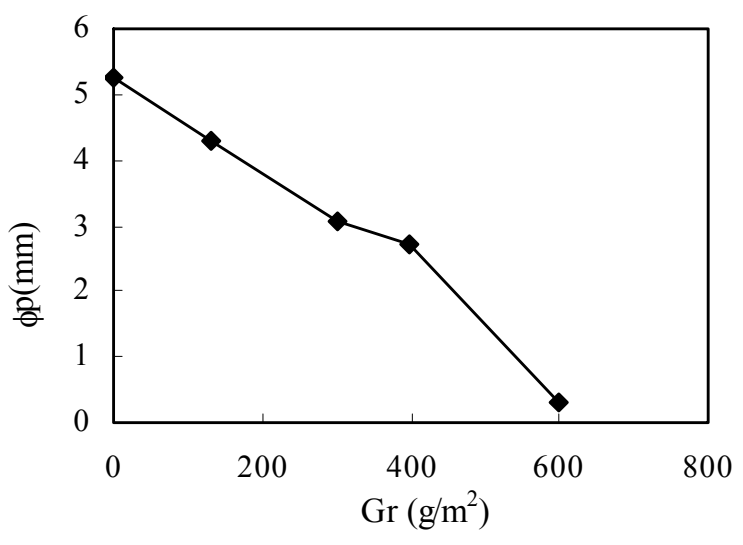

GT PET

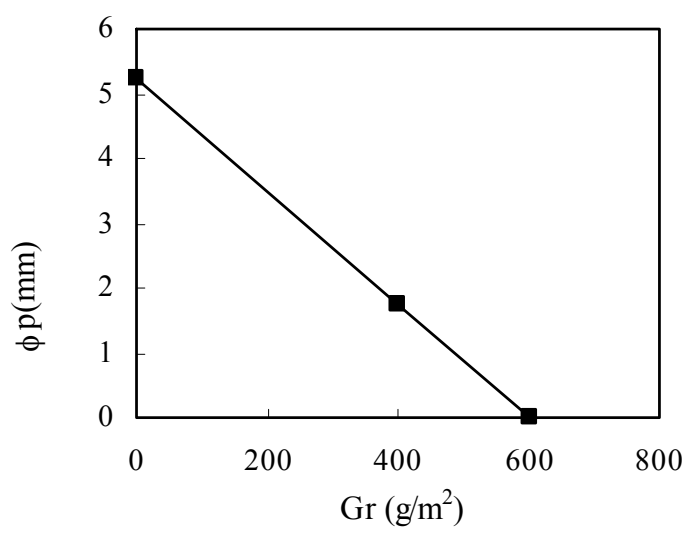

GT PP

Figura 71. Resultados obtidos no ensaio de punção dinâmica - geomembrana de PEAD, 1,5 $\mathrm{mm}-\mathrm{GT} / \mathrm{GM}$. 


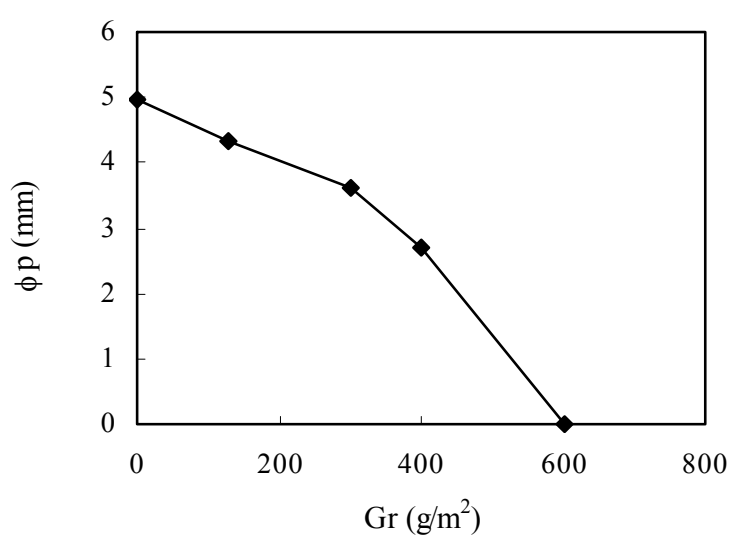

GT PET

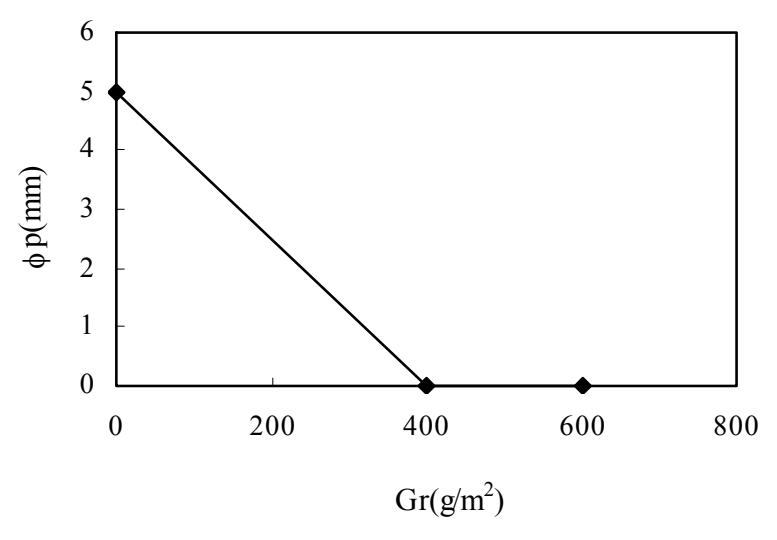

GT PP

Figura 72. Resultados obtidos no ensaio de punção dinâmica - geomembrana de PELMD, 1,25 $\mathrm{mm}-\mathrm{GT} / \mathrm{GM}$.

Os resultados apresentados mostram que todas as geomembranas sem proteção apresentaram um diâmetro de perfuração da ordem de $5 \mathrm{~mm}$. Constatou-se que a introdução do geotêxtil diminuiu o diâmetro de perfuração em todas as geomembranas. Também se constatou que quanto maior a gramatura do geotêxtil, menor o diâmetro de perfuração na geomembrana.

Verificou-se que apenas os ensaios realizados com geotêxtil de PET de gramatura de $600 \mathrm{~g} / \mathrm{m}^{2}$ não apresentaram furos nas geomembranas de PVC e PELMD. No caso da geomembrana de PEAD, nenhum geotêxtil de PET foi capaz de garantir a integridade da geomembrana. A mesma tendência de diminuição do diâmetro de perfuração com o aumento da gramatura foi observado com os geotêxteis de PP.

Na Figura 73 são apresentados os gráficos comparativos dos ensaios dinâmicos realizados com geomembrana de PVC (1,0mm) e PEAD (1,5mm), respectivamente, e geotêxteis de PET e PP com diferentes gramaturas. Nesta figuras, $\Delta \phi_{\mathbf{p}}$ corresponde à relação entre o diâmetro perfurado no conjunto geotêxtil/geomembrana e o diâmetro perfurado na geomembrana e, Gr corresponde à gramatura do geotêxtil utilizado. 


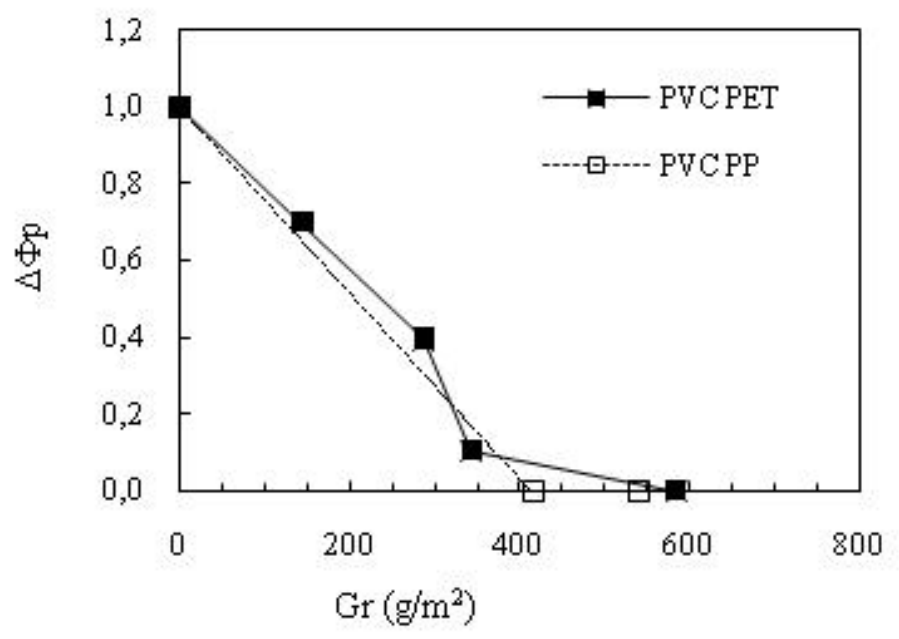

(a)

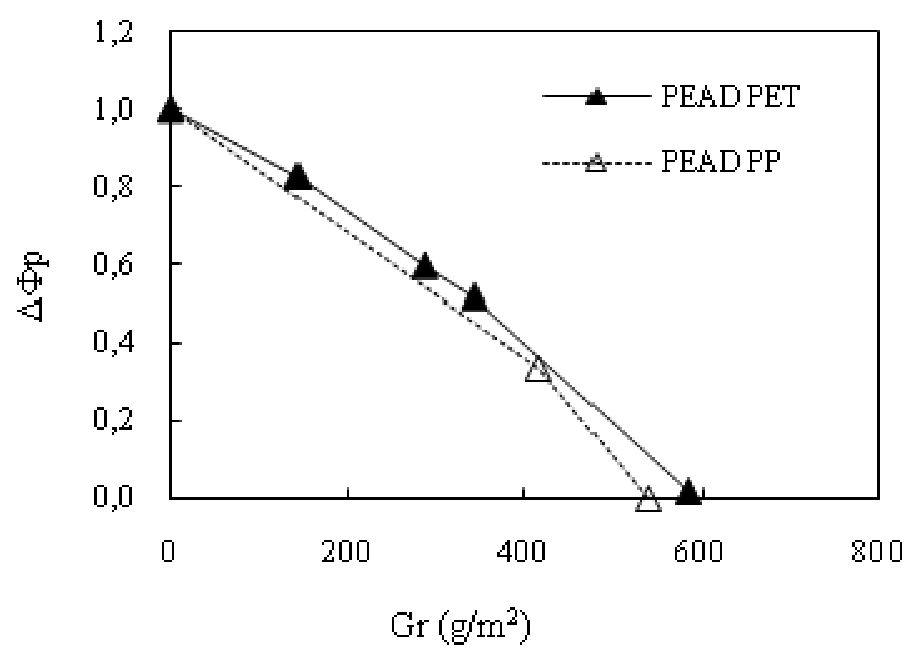

(b)

Figura 73. Efeito do polímero nas geomembranas de PVC (1,0mm) e PEAD (1,5mm).

Analisando-se a Figura 73a, verificou-se, no caso da geomembrana de PVC, que o geotêxtil de PP $400 \mathrm{~g} / \mathrm{m}^{2}$ apresentou melhor desempenho do que o geotêxtil de PET de mesma gramatura, não sendo constatado nenhum furo na geomembrana. Ao se comparar a gramatura de $600 \mathrm{~g} / \mathrm{m}^{2}$, ambas as variações de geotêxteis foram capazes de prevenir furos na geomembrana.

Para a geomembrana de PEAD, verificou-se que os geotêxteis de PP apresentaram melhor desempenho do que os geotêxteis de PET para ambas as gramaturas, constatando-se 
menores diâmetros de perfuração. No entanto, salienta-se a existência de furos, excetuando-se as configurações com PET e PP de $600 \mathrm{~g} / \mathrm{m}^{2}$.

Na Figura 74, Figura 75 e Figura 76 são apresentados os resultados dos ensaios realizados com geomembranas de PVC (1,0mm), PEAD (1,5mm) e PELMD (1,25mm) e geotêxteis de PET e PP dispostos em diferentes configurações: GT/GM, GM/GT e GT/GM/GT.

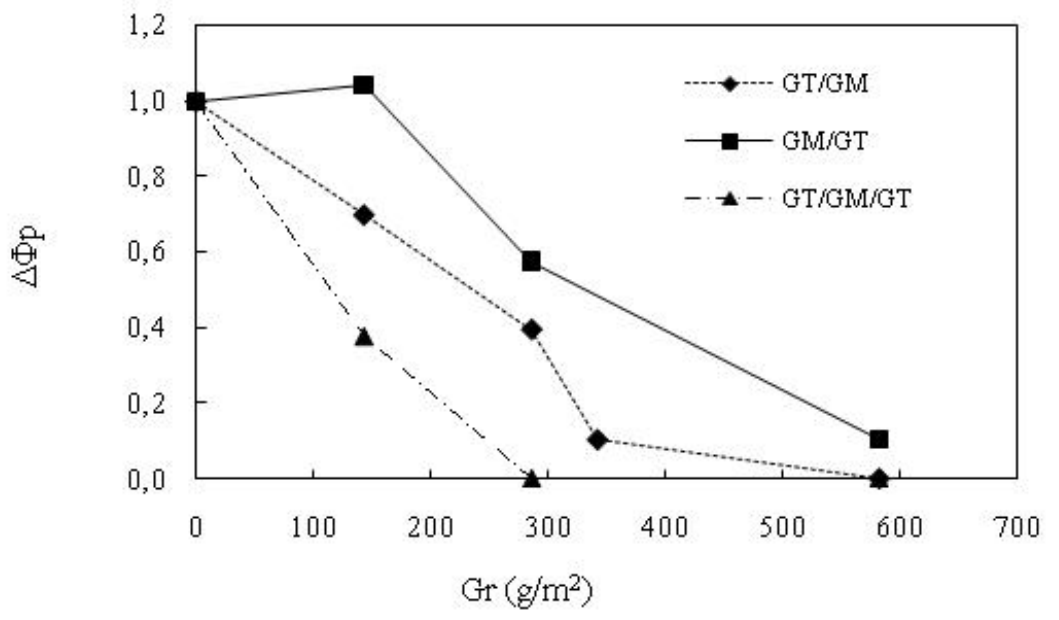

(a) PET

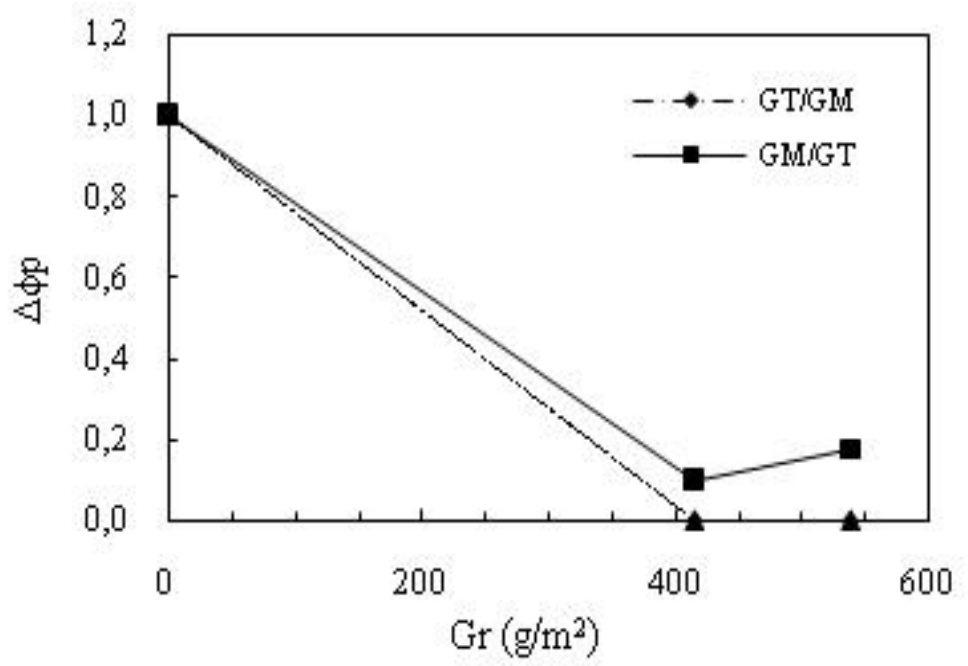

(b) PP

Figura 74. Análise dos ensaios realizados com geomembrana de PVC, 1,0mm: efeito da disposição. 


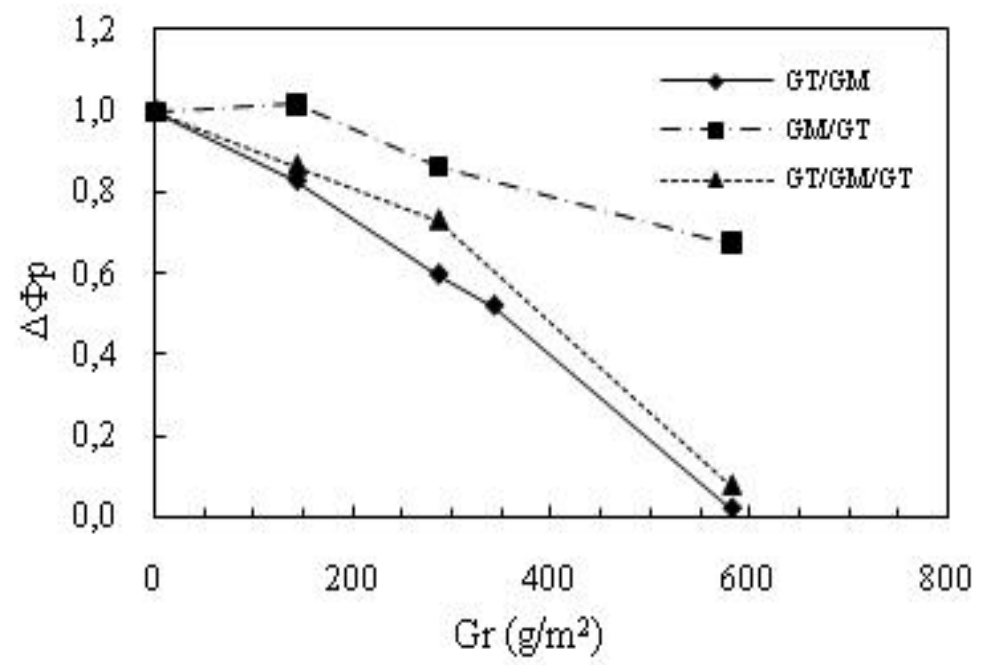

(a) PET

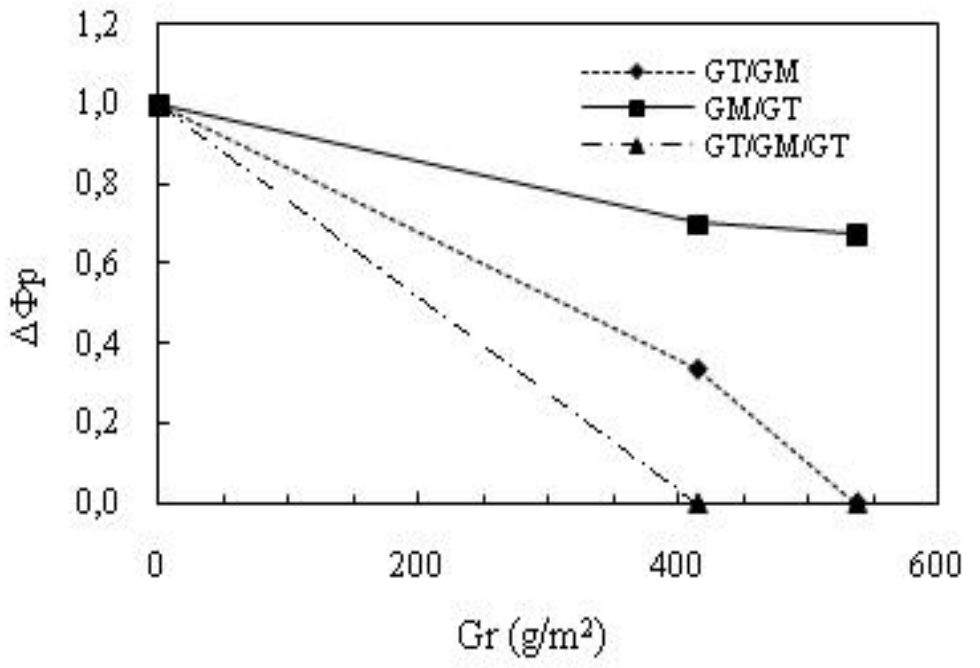

(b) PP

Figura 75. Análise dos ensaios realizados com geomembrana de PEAD, 1,5mm: efeito da disposição. 


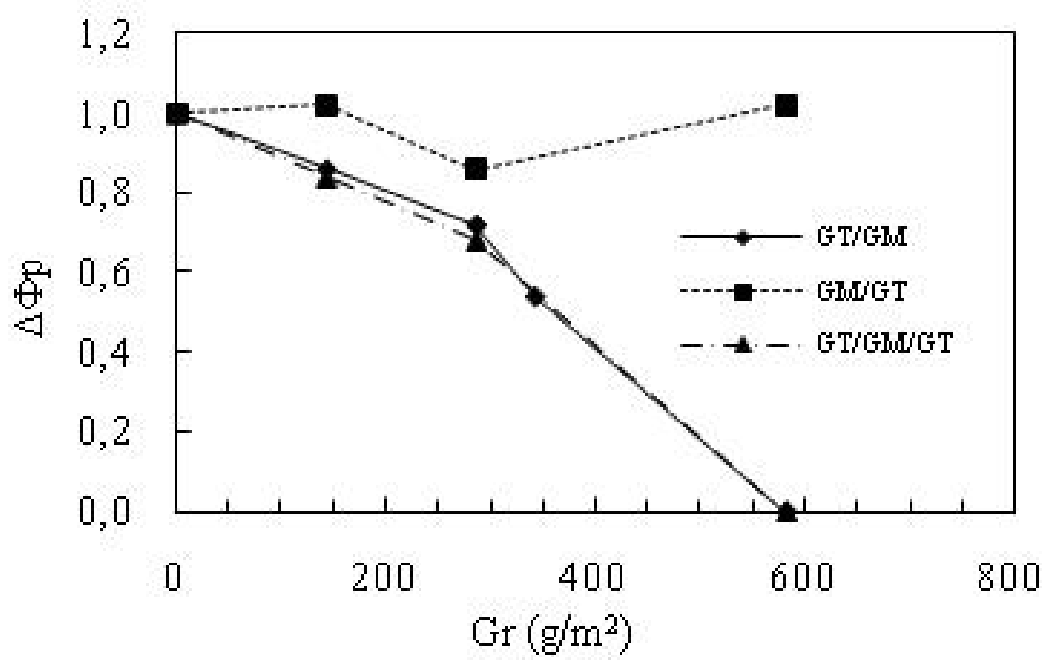

(a) PET

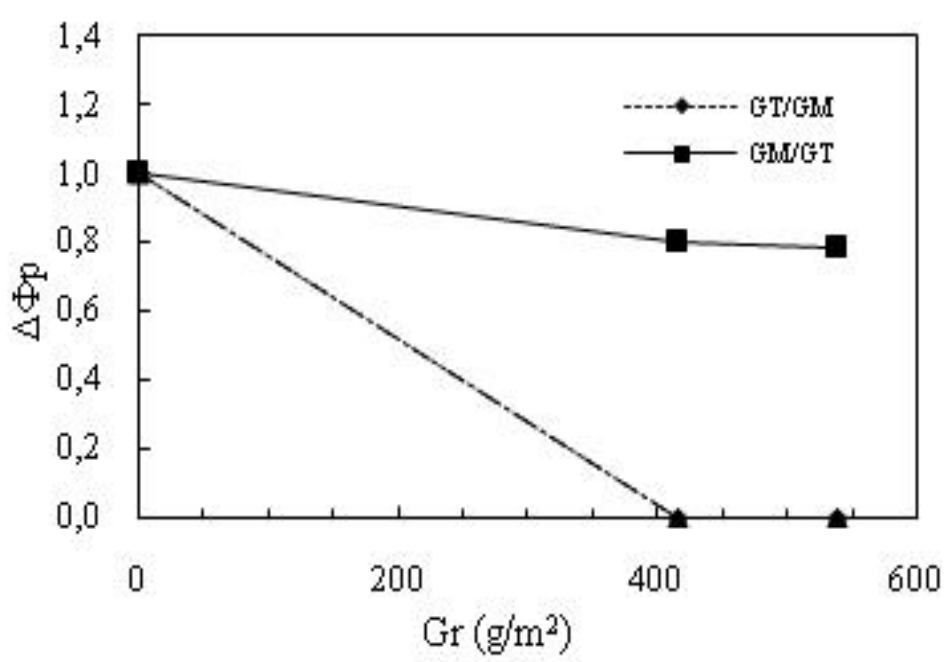

(b) PP

Figura 76. Análise dos ensaios realizados com geomembrana de PELMD, 1,25mm: efeito da disposição.

Em geral, os resultados mostram que os sistemas GT/GM e GT/GM/GT apresentaram menores diâmetros de perfuração na geomembrana. Apesar do sistema GM/GT ter diminuído os diâmetros de perfuração, em nenhuma situação foi capaz de impedir furos na geomembrana.

Observou-se nas geomembranas de PVC que o sistema composto GT/GM/GT foi o que apresentou melhor desempenho nos ensaios realizados com geotêxtil de PET. Nos ensaios realizados com geotêxtil de PP, ambos os sistemas GT/GM e GT/GM/GT apresentaram comportamento similar. 
No caso das geomembranas de PEAD e PELMD, notou-se que os sistemas GT/GM e GT/GM/GT apresentaram desempenho semelhante. Observou-se também que a geomembrana de PEAD parece ser mais sensível a este tipo de solicitação, sendo constatada a presença de furos mesmo nas geomembranas protegidas com geotêxtil e com sistema duplo de proteção.

Na Figura 77 é apresentado um gráfico comparativo do diâmetro de perfuração para geomembranas de PVC $(1,0 \mathrm{~mm})$ e PEAD $(1,5 \mathrm{~mm})$ com geotêxteis de PET $\left(300 \mathrm{~g} / \mathrm{m}^{2}\right)$, apoiados sob uma base de solo argiloso compactado com GC $95 \%\left(\gamma_{d}=1,510 \mathrm{~g} / \mathrm{m}^{3}\right)$ e umidade ótima $(\mathrm{w}=15,0 \%)$.

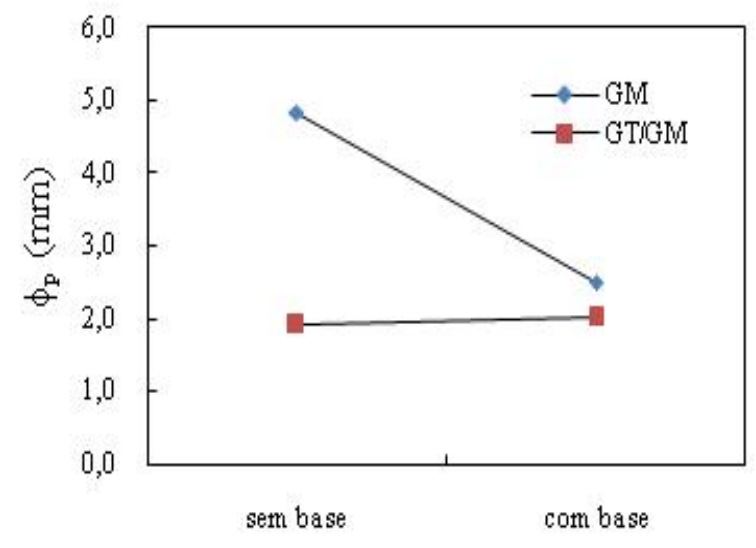

(a) PVC

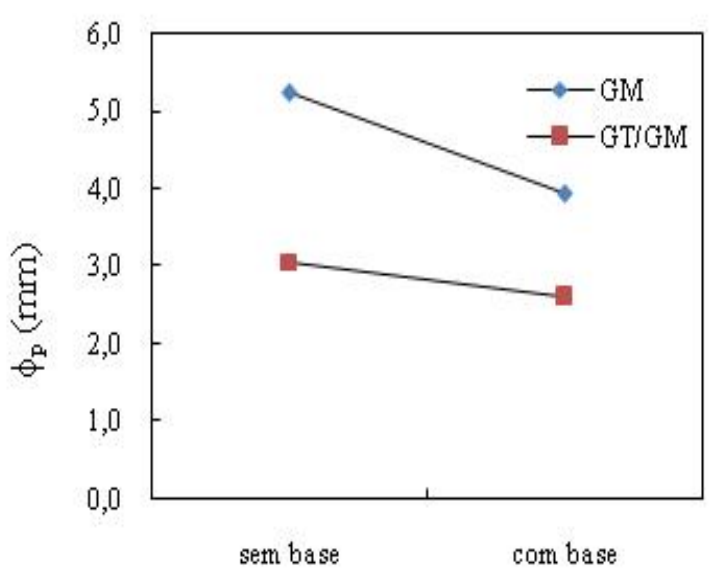

(b) PEAD

Figura 77. Influência da camada de solo compactado - GT PET $300 \mathrm{~g} / \mathrm{m}^{2}$.

Na geomembrana de PVC sem proteção, a introdução da base de solo compactado diminuiu o diâmetro de perfuração em torno de 50\%. Na geomembrana com GT PET $300 \mathrm{~g} / \mathrm{m}^{2}$, o diâmetro de perfuração se manteve o mesmo ao se introduzir a base de solo compactado.

No caso da geomembrana de PEAD também foi verificada uma diminuição no diâmetro de perfuração com a introdução da base de solo compactado nos ensaios com e sem proteção. Constata-se, desta forma, que a introdução de uma base de solo compactado não influenciou no comportamento dinâmico em ensaios realizados com geotêxteis. 


\subsubsection{Ensaios de Desempenho: Danos de Instalação}

\subsubsection{Geomembranas de PEAD}

A Figura 78 mostra a superfície das geomembranas de PEAD de 1,5 mm antes e após submetida a carregamento dinâmico e sob diferentes solicitações.

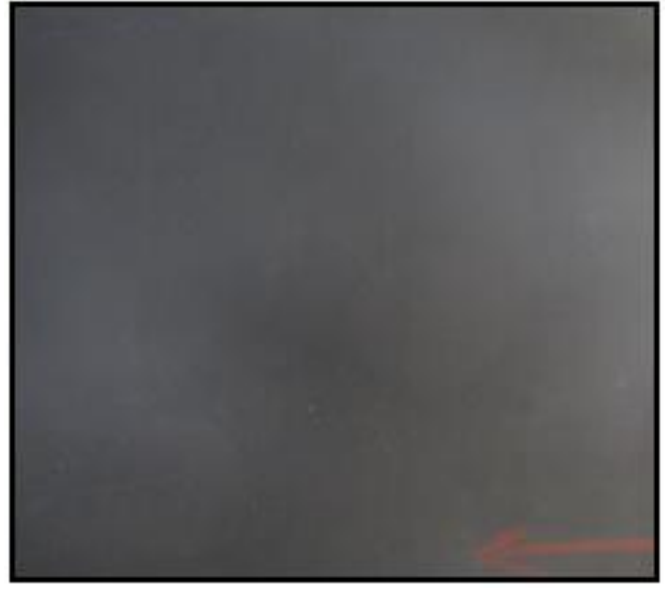

(a) GM virgem

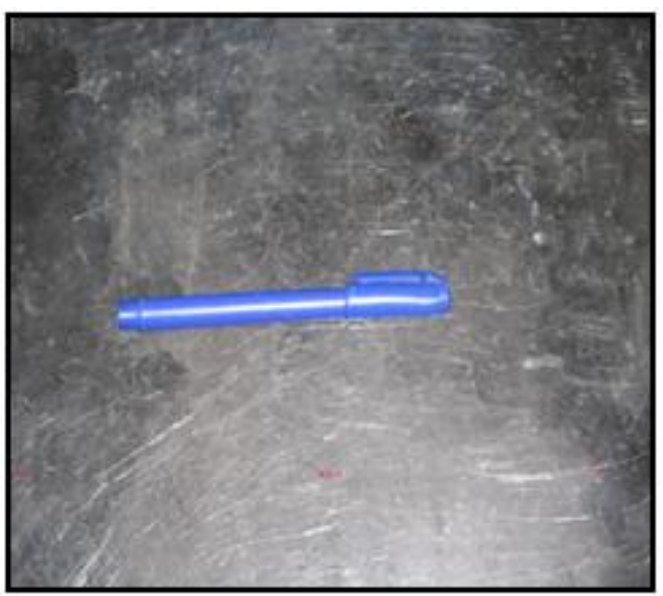

(c) GM sem proteção $400 \mathrm{kPa}, 200$ ciclos

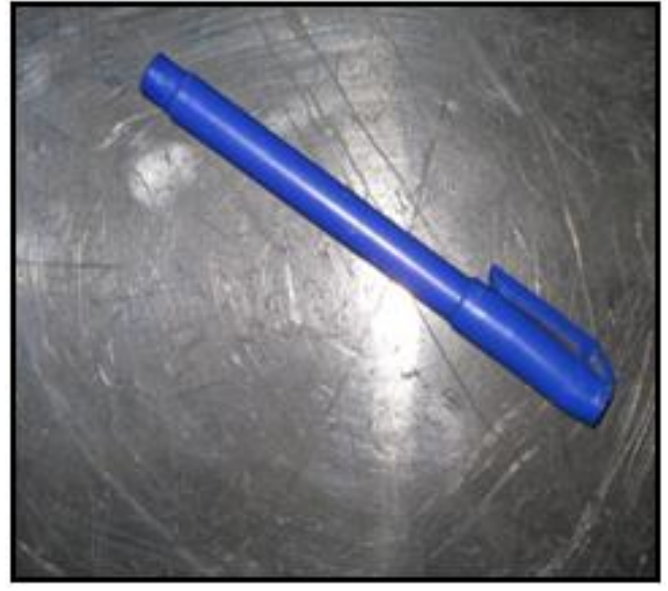

(b) GM sem proteção $200 \mathrm{kPa}, 200$ ciclos

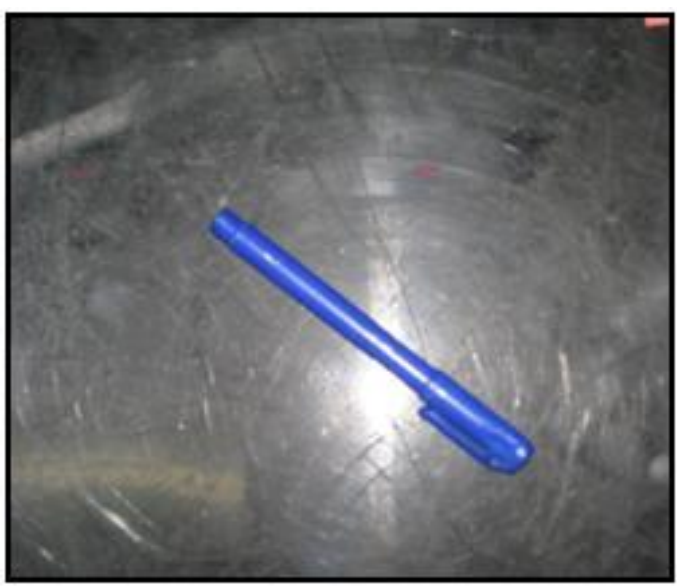

(d) GM com GTPET $600200 \mathrm{kPa}, 1000$ ciclos

Figura 78. Vista da superfície da geomembrana de PEAD (1,5 mm).

Em todas as configurações foram verificados arranhões nas superfícies das geomembranas depois de submetidas ao carregamento dinâmico. Até mesmo nos ensaios com geotêxtil de proteção foram verificados os mesmos danos, porém em menor quantidade. 
Também não foram observados furos, indentações ou rasgos visíveis nas geomembranas devido a esta solicitação.

As Figuras abaixo apresentam os resultados dos ensaios mecânicos (punção, tração e rasgo) realizados na geomembrana de PEAD $(1,5 \mathrm{~mm})$ sem proteção, depois de submetidas ao carregamento dinâmico. Os ensaios incluem as geomembranas virgens e as geomembranas após ensaio de danos, sob diferentes cargas e número de ciclos. A Tabela 34 e a Tabela 35 apresentam o sumário dos resultados dos ensaios.

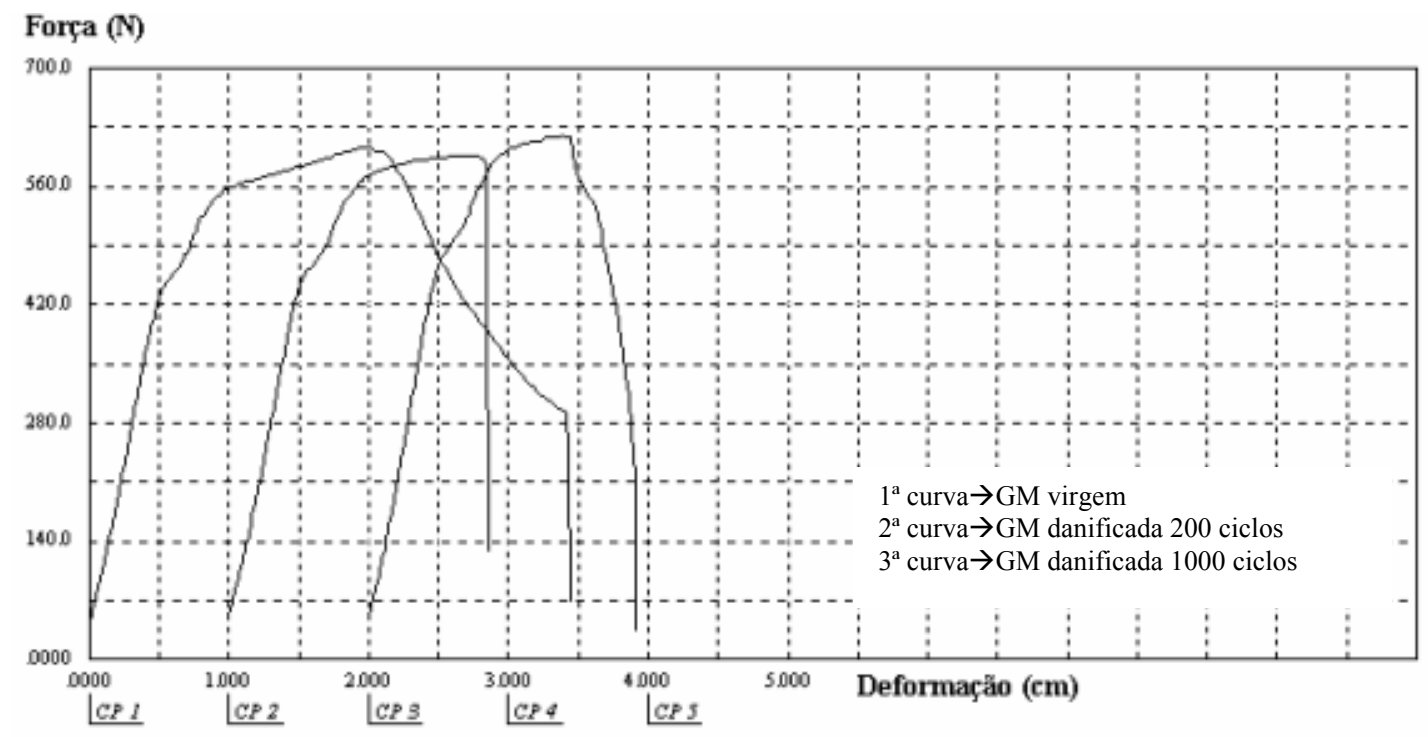

Figura 79. Curvas obtidas nos ensaios de punção para geomembrana de PEAD - carga de 200 $\mathrm{kPa}$. 


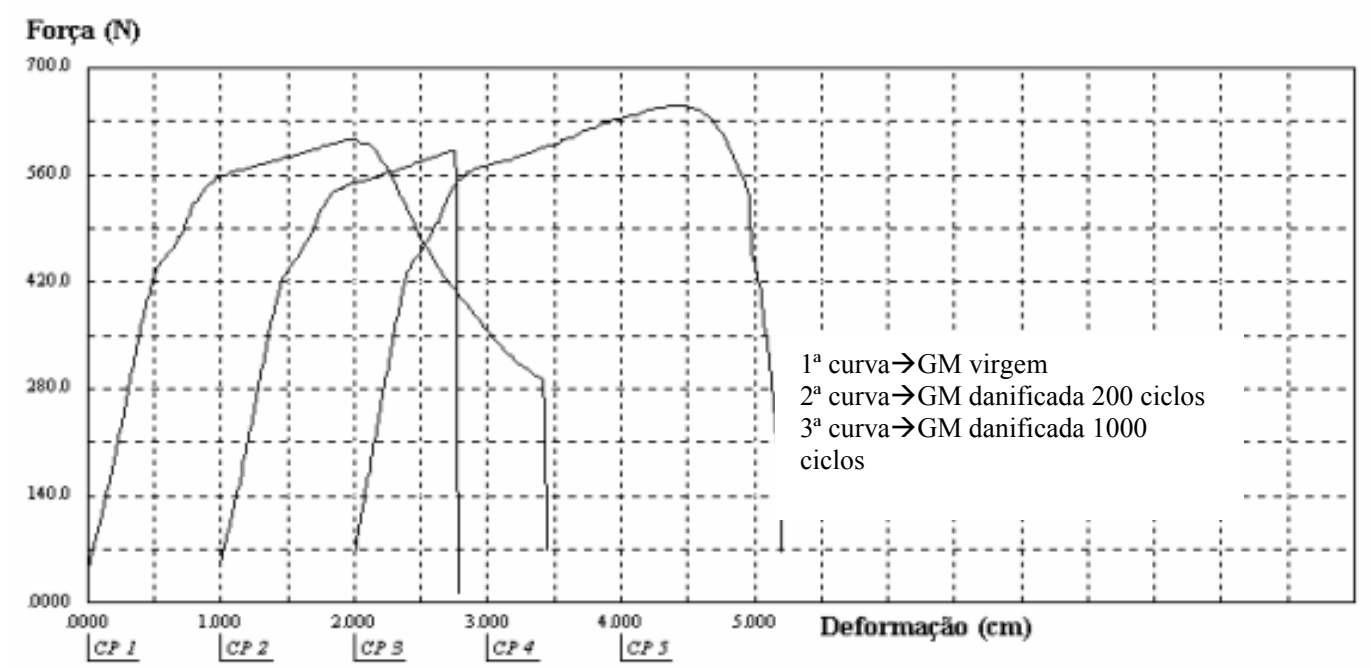

Figura 80. Curvas obtidas nos ensaios de punção para geomembrana de PEAD - carga de 400 $\mathrm{kPa}$.

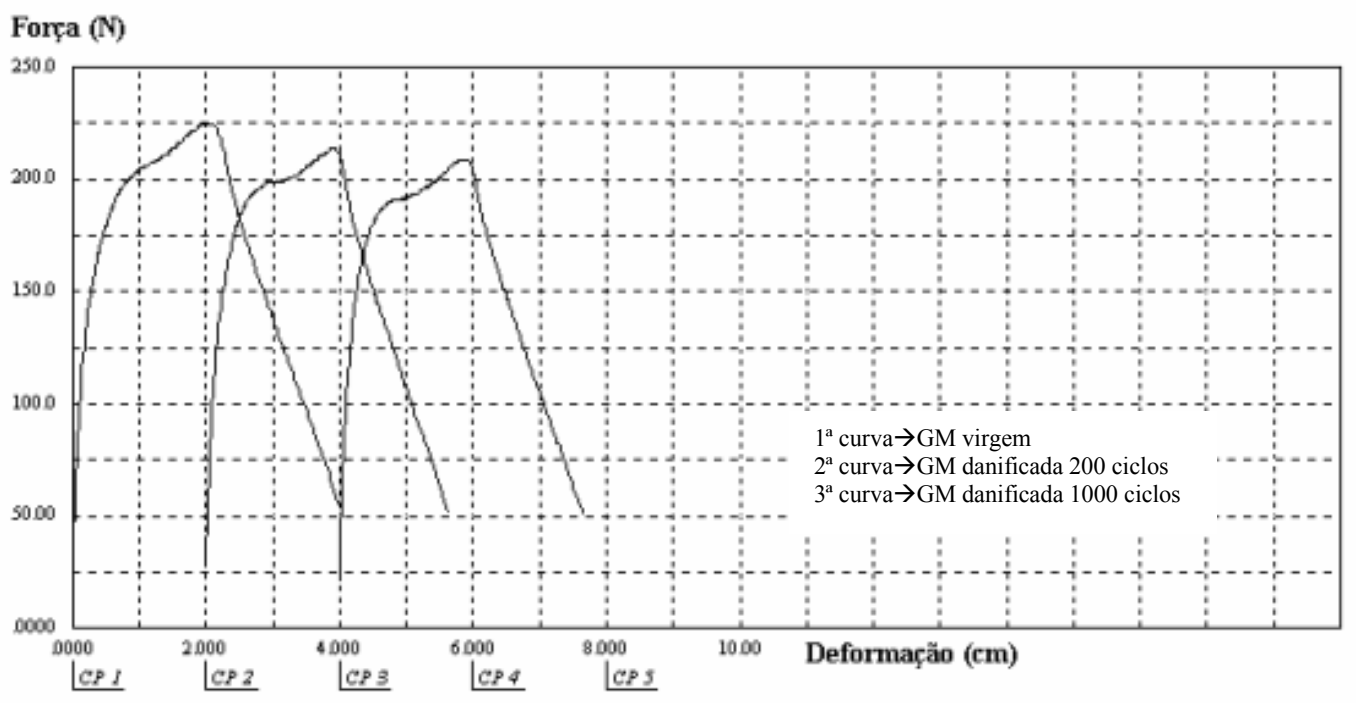

Figura 81. Curvas obtidas nos ensaios de rasgo para geomembrana de PEAD - carga de 200 $\mathrm{kPa}$. 


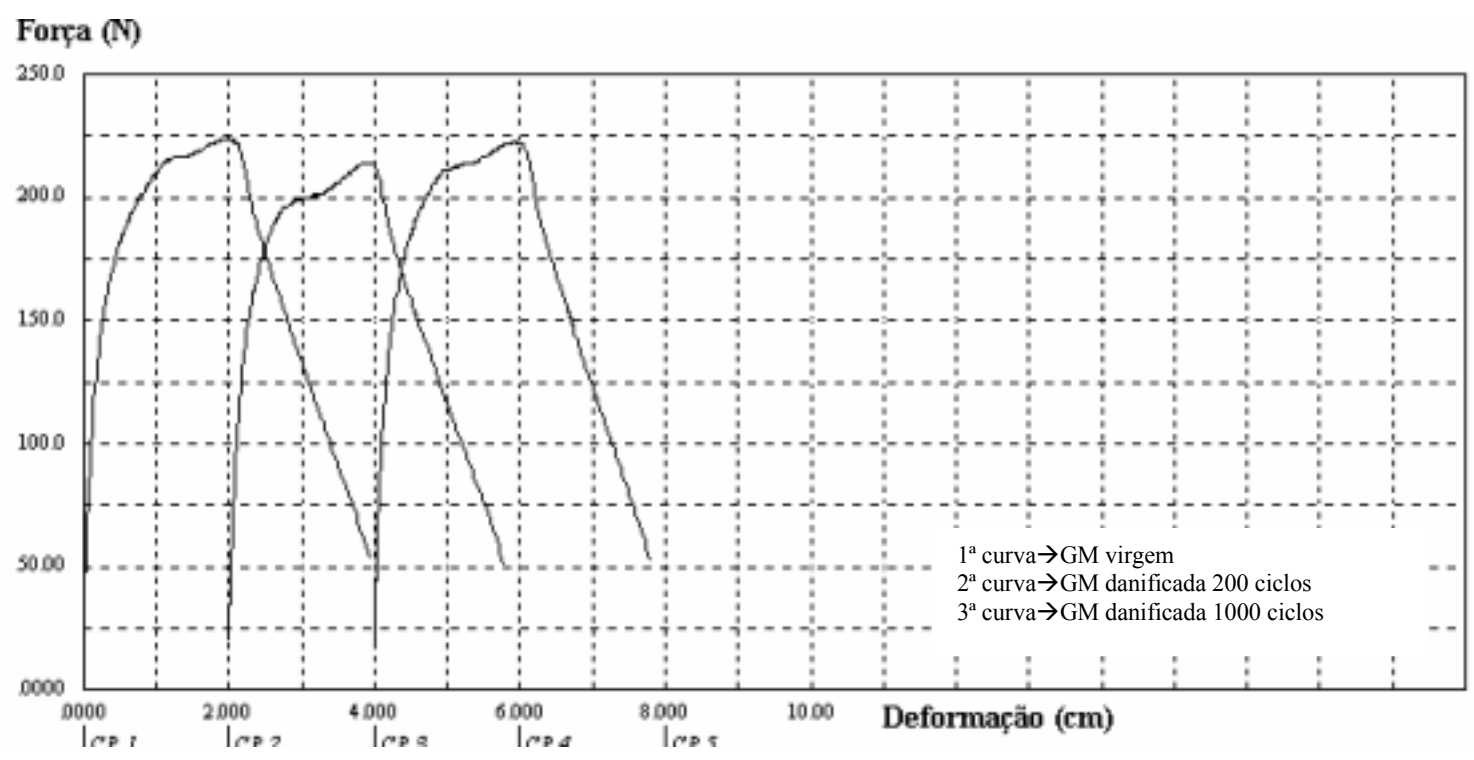

Figura 82. Curvas obtidas nos ensaios de rasgo para geomembrana de PEAD - carga de 400 $\mathrm{kPa}$.

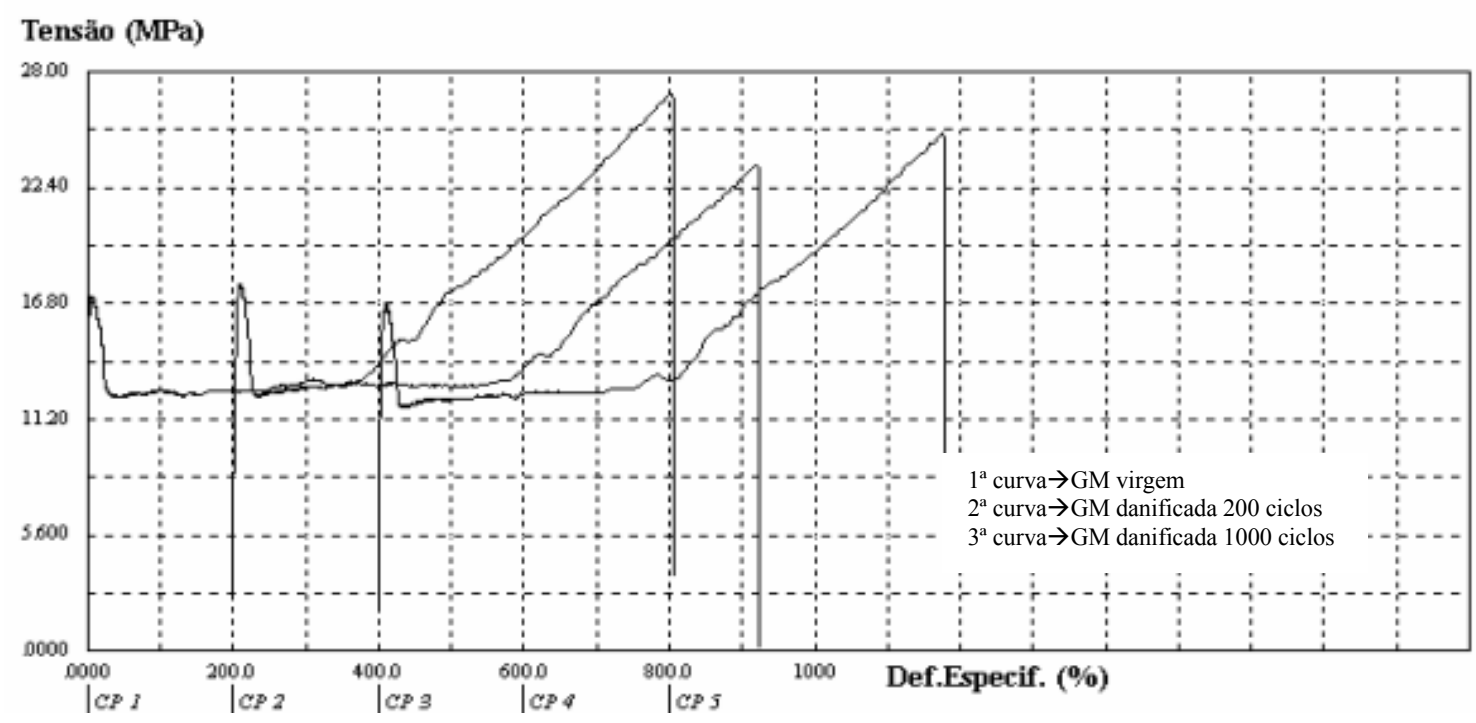

Figura 83. Curvas obtidas nos ensaios de tração para geomembrana de PEAD - carga de 200 $\mathrm{kPa}$. 


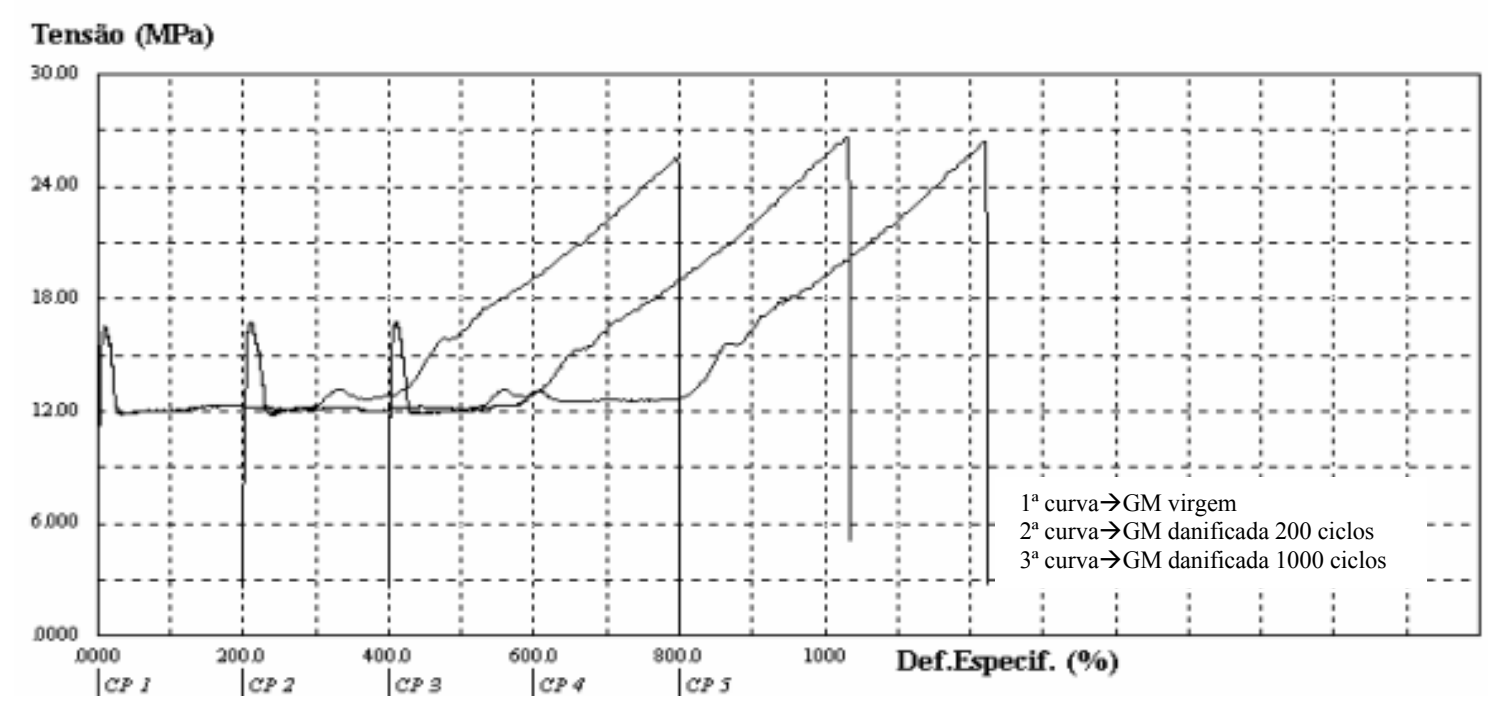

Figura 84. Curvas obtidas nos ensaios de tração para geomembrana de PEAD - carga de 400 $\mathrm{kPa}$.

Tabela 34. Resultados dos ensaios mecânicos pós-dano - GM PEAD (1,5 mm) sem proteção.

\begin{tabular}{cccccccccc}
\hline \multirow{2}{*}{ Condição } & \multirow{2}{*}{ Tensão } & \multirow{2}{*}{ Ciclos } & \multicolumn{4}{c}{ Punção } & \multicolumn{4}{c}{ Rasgo } \\
\cline { 4 - 10 } & & $\mathbf{F}$ & $\Delta \mathbf{F}$ & $\delta$ & $\Delta \delta$ & $\mathbf{F}$ & $\Delta \mathbf{F}$ \\
& - & & - & $\mathbf{6 3 3}$ & & $\mathbf{2 1}$ & & $\mathbf{2 3 6}$ & \\
\hline GM virgem & 200 & 200 & $\mathbf{6 1 1}$ & 0,97 & $\mathbf{1 9}$ & 0,90 & $\mathbf{2 1 8}$ & 0,92 \\
\hline GM sem proteção & & & & & & & & \\
\cline { 2 - 9 } & 200 & 1000 & $\mathbf{6 2 7}$ & 0,99 & $\mathbf{1 7}$ & 0,81 & $\mathbf{2 0 9}$ & 0,89 \\
\hline GM danificada sem proteção & 400 & 200 & $\mathbf{6 0 0}$ & 0,94 & $\mathbf{1 9}$ & 0,90 & $\mathbf{2 3 5}$ & 1,00 \\
& & & & & & & & \\
\cline { 2 - 9 } & 400 & 1000 & $\mathbf{6 5 0}$ & 1,03 & $\mathbf{2 4}$ & 1,14 & $\mathbf{2 2 1}$ & 0,94 \\
\hline
\end{tabular}

Legenda: $\Delta \rightarrow$ relação entre a Propriedade da geomembrana danificada e a Propriedade da geomembrana virgem.

Tabela 35. Resultados dos ensaios mecânicos pós-dano - GM PEAD (1,5 mm) sem proteção.

\begin{tabular}{|c|c|c|c|c|c|c|c|c|c|c|}
\hline \multirow{4}{*}{ Condição } & \multirow{3}{*}{ Tensão } & \multirow{4}{*}{ Ciclos } & \multicolumn{8}{|c|}{ Tração } \\
\hline & & & \multicolumn{4}{|c|}{ Escoamento } & \multicolumn{4}{|c|}{ Ruptura } \\
\hline & & & $\sigma$ & $\Delta \sigma$ & $\varepsilon$ & $\Delta \varepsilon$ & $\sigma$ & $\Delta \sigma$ & $\varepsilon$ & $\Delta \varepsilon$ \\
\hline & (kPa) & & MPa & & $\%$ & & MPa & & $\%$ & \\
\hline GM virgem & - & - & 19 & & 17 & & 34 & & 840 & \\
\hline \multirow[t]{2}{*}{ GM sem proteção } & 200 & 200 & 17 & 0,90 & 15 & 0,88 & 24 & 0,71 & 721 & 0,86 \\
\hline & 200 & 1000 & 15 & 0,79 & 14 & 0,82 & 26 & 0,76 & 782 & 0,93 \\
\hline \multirow[t]{2}{*}{ GM danificada sem proteção } & 400 & 200 & 18 & 0,94 & 15 & 0,88 & 26 & 0,76 & 772 & 0,92 \\
\hline & 400 & 1000 & 16 & 0,84 & 14 & 0,82 & 26 & 0,76 & 815 & 0,97 \\
\hline
\end{tabular}


As geomembranas danificadas apresentaram uma redução na força e deslocamento de punção cerca de 5\% e 10\%, respectivamente, em relação às geomembranas virgens. A força ao rasgo nas geomembranas danificadas foi reduzida em torno $10 \%$ em relação à geomembrana virgem.

Os valores da tensão e deformação de tração nas geomembranas danificadas também foram menores do que na geomembrana virgem. Em termos de escoamento, as tensões nas geomembranas danificadas apresentaram uma redução em torno de 10 a $15 \%$ em relação às geomembranas virgens. Os deslocamentos no escoamento na geomembrana danificada apresentaram uma redução de $12 \%$ aproximadamente em relação à geomembrana virgem. Em termos de ruptura, verificou-se que a tensão de ruptura na geomembrana danificada apresentou uma redução de cerca de $30 \%$ em relação à geomembrana virgem, enquanto os deslocamentos na ruptura apresentaram uma redução de $10 \%$.

Os resultados apresentados mostram uma pequena variação das propriedades mecânicas das geomembranas de PEAD submetidas a carregamentos cíclicos. A maior variação encontrada foi em termos de tensão de ruptura. Os resultados também indicam que a magnitude da carga e o número de ciclos aplicados não influenciaram nas propriedades mecânicas das geomembranas de PEAD.

As Figuras abaixo apresentam os resultados dos ensaios realizados nas geomembranas de PEAD submetidas a carregamentos cíclicos com proteção de geotêxtil de PET. Os ensaios se referem à carga de $200 \mathrm{kPa}$ com 1.000 ciclos. 


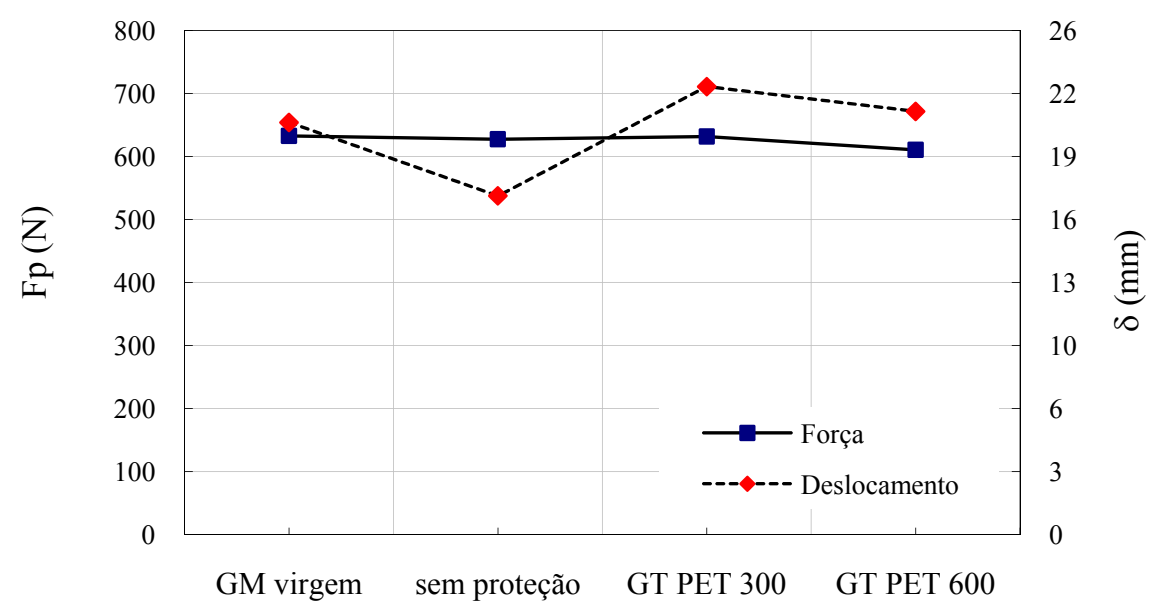

Tipo de Proteção

Figura 85. Resultados dos ensaios de punção realizados nas geomembranas de PEAD com proteção: ensaios cíclicos.

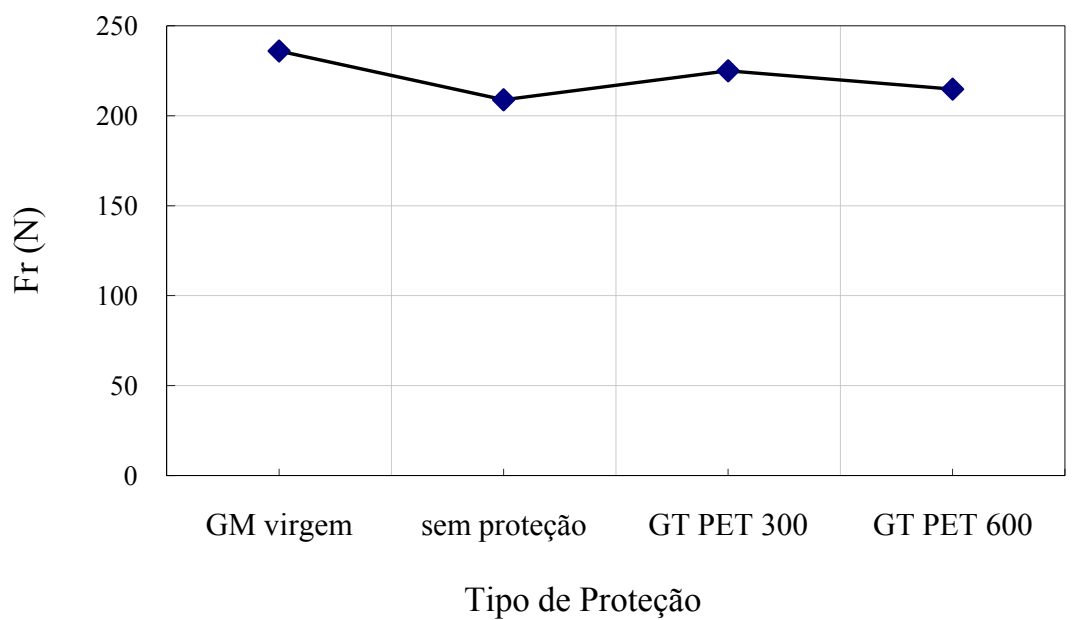

Figura 86. Resultados dos ensaios de rasgo realizados nas geomembranas de PEAD com proteção: ensaios cíclicos. 


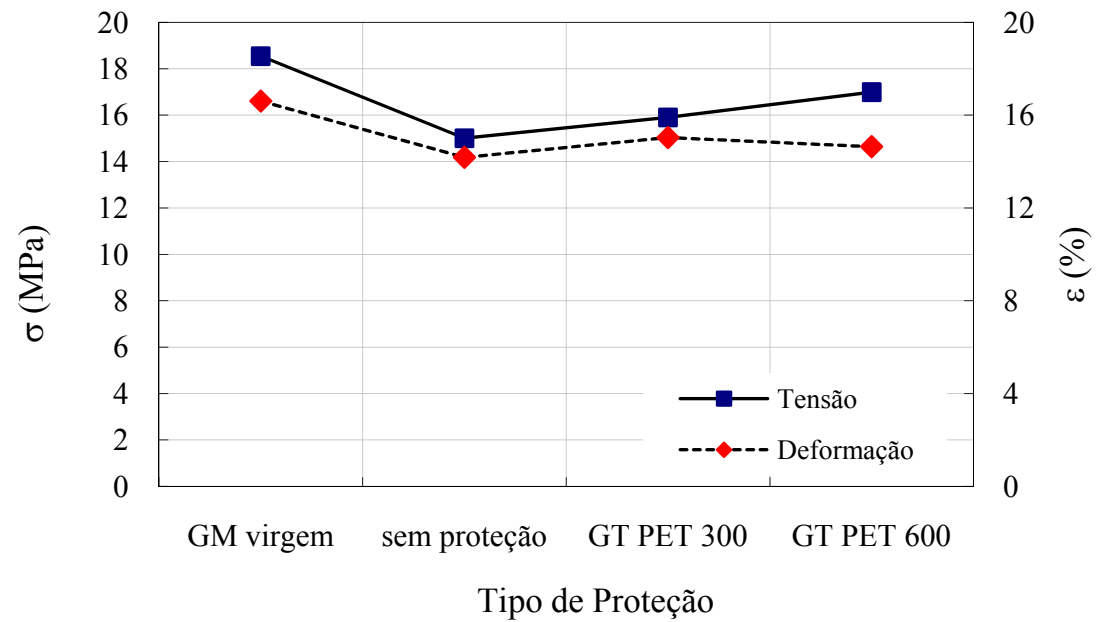

Figura 87. Resultados dos ensaios de tração realizados nas geomembranas de PEAD com proteção: ensaios cíclicos / valores no escoamento.

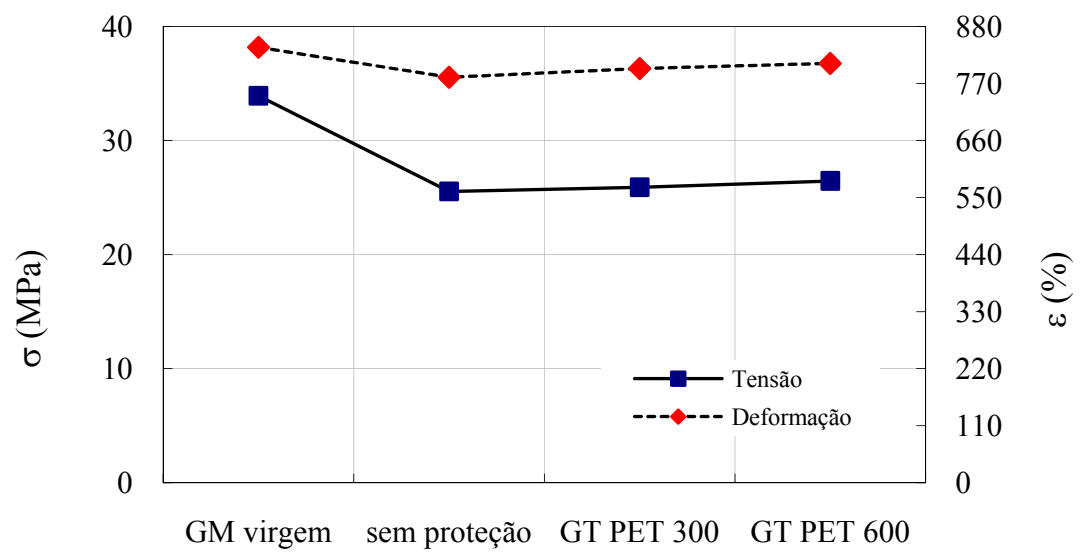

Tipo de Proteção

Figura 88. Resultados dos ensaios de tração realizados nas geomembranas de PEAD com proteção: ensaios cíclicos / valores na ruptura.

Ao contrário do que se esperava a introdução do geotêxtil não forneceu um aumento expressivo nas propriedades mecânicas das geomembranas de PEAD, tais como força de punção, rasgo e tensão de tração, em relação às geomembranas danificadas sem proteção. 
A Figura 89 apresenta os resultados dos ensaios de stress cracking realizados nas geomembranas de PEAD em condição virgem e depois de submetidas a carregamentos cíclicos em diferentes condições. Na Tabela 36 são apresentados os resultados dos ensaios.

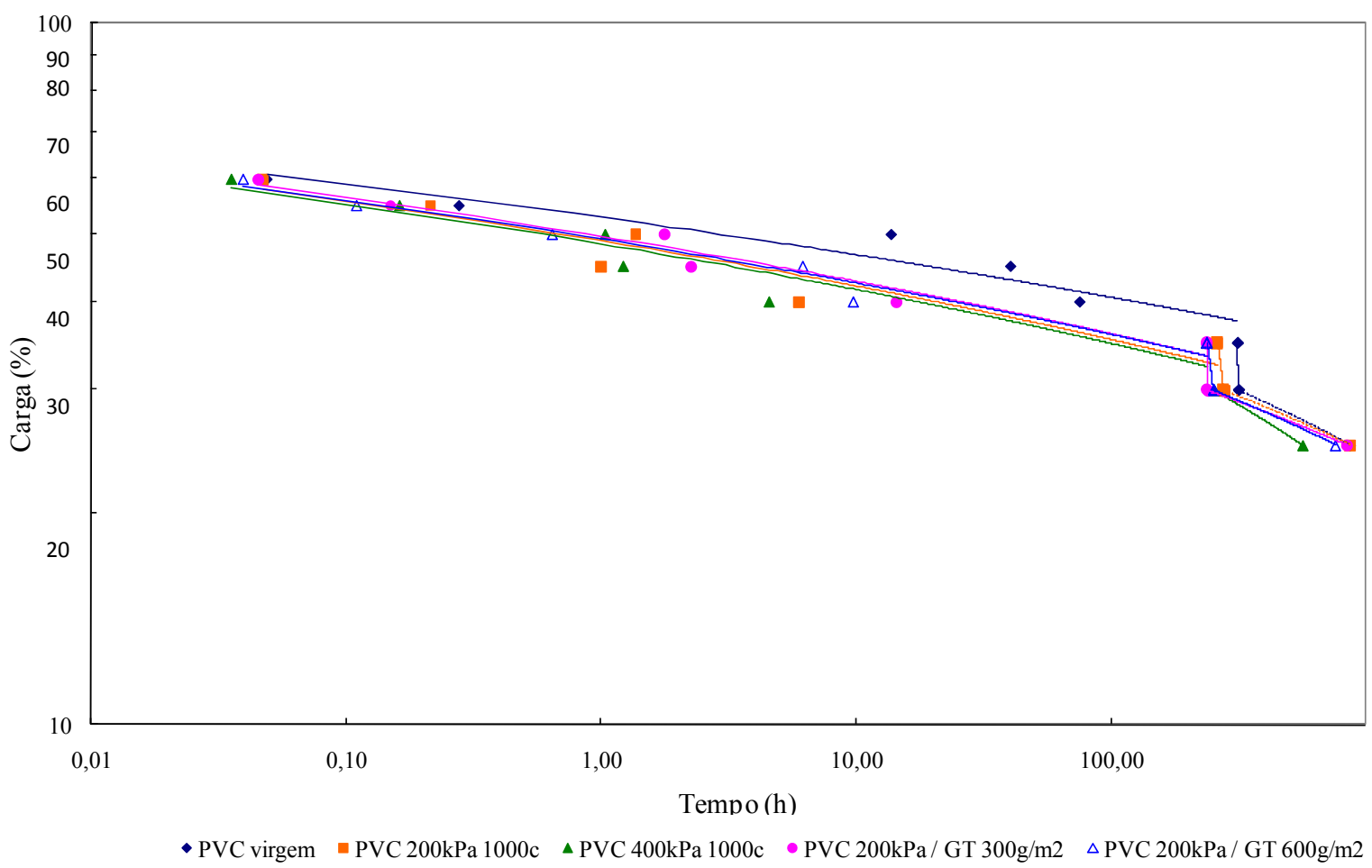

Figura 89. Curvas obtidas no ensaio de stress cracking: GM de PEAD 1,5 mm.

Tabela 36. Sumário dos resultados - stress cracking: geomembranas de PEAD, 1,5 mm de espessura.

\begin{tabular}{|c|c|c|c|c|c|c|c|c|c|c|c|}
\hline \multirow{3}{*}{\multicolumn{2}{|c|}{ Condição de Ensaio }} & \multicolumn{9}{|c|}{ T ruptura (horas) } & \multirow{3}{*}{$\begin{array}{c}T_{t_{t}} \\
\text { (horas) }\end{array}$} \\
\hline & & \multicolumn{9}{|c|}{ Carga (\%) } & \\
\hline & & 65 & 60 & 55 & 50 & 45 & 40 & 35 & 30 & 25 & \\
\hline GM virgem & & 0,09 & 0,05 & 0,28 & 13,71 & 40,25 & 75,17 & 313,03 & 316,17 & 870 & 316,17 \\
\hline $\begin{array}{c}\text { GM } \\
\text { danificada } \\
\text { sem proteção }\end{array}$ & $\begin{array}{c}200 \mathrm{kPa} \\
1000 \text { ciclos }\end{array}$ & 0,20 & 0,05 & 0,22 & 1,37 & 3,50 & 6,00 & 260,90 & 275,67 & 870 & 275,67 \\
\hline $\begin{array}{c}\text { GM } \\
\text { danificada } \\
\text { sem proteção }\end{array}$ & $\begin{array}{c}400 \mathrm{kPa} \\
1000 \text { ciclos }\end{array}$ & 0,05 & 0,04 & 0,16 & 1,03 & 1,22 & 4,54 & 237,02 & 252,17 & 562 & 252,17 \\
\hline $\begin{array}{c}\mathrm{GM} \\
\text { danificada } \\
\text { com GT } \\
300 \mathrm{~g} / \mathrm{m}^{2} \\
\end{array}$ & $\begin{array}{c}200 \mathrm{kPa} \\
1000 \text { ciclos }\end{array}$ & 0,07 & 0,05 & 0,15 & 1,77 & 2,25 & 14,4 & 236,9 & 235,65 & 837 & 235,65 \\
\hline $\begin{array}{c}\text { GM } \\
\text { danificada } \\
\text { com GT } \\
600 \mathrm{~g} / \mathrm{m}^{2}\end{array}$ & $\begin{array}{c}200 \mathrm{kPa} \\
1000 \text { ciclos }\end{array}$ & 0,12 & 0,04 & 0,11 & 0,64 & 6,2 & 9,71 & 236,90 & 252,17 & 760 & 252,17 \\
\hline
\end{tabular}


Verificou-se que todas as curvas apresentaram comportamento tipo degrau. O tempo de ruptura da geomembrana aumentou com a redução da carga aplicada até atingir a carga de $35 \%$. Ao se aplicar a carga de 30\%, constatou-se uma queda brusca da curva, formando-se o segundo trecho linear (degrau). Neste trecho, observa-se um pequeno aumento do tempo de ruptura com a diminuição da carga. A partir deste ponto, tem-se o terceiro trecho, onde baixos valores de carga forneceram elevados tempos de ruptura.

Comparando-se as geomembranas virgem e danificada, observa-se que para cargas mais altas, entre $65 \%$ e $55 \%$, o tempo de ruptura das geomembranas danificadas com e sem proteção de geotêxtil foi semelhante ao obtido nas geomembranas virgens. Entre as cargas de $50 \%$ e $40 \%$, observou-se que as geomembranas danificadas apresentaram uma redução do tempo de ruptura entre 80 a $90 \%$ em relação à geomembrana virgem. A partir da carga de $35 \%$, constatou-se que a redução do tempo de ruptura nas geomembranas danificadas foi de aproximadamente $20 \%$ em relação em relação às geomembranas virgens.

Os resultados mostraram uma redução do tempo de transição $\left(T_{t}\right)$ em torno de $20 \%$ nas geomembranas submetidas a carregamento cíclico. Observa-se ainda que a introdução do geotêxtil não aumentou o tempo de transição em relação à geomembrana danificada. No entanto, em todas as situações o tempo de transição foi superior ao valor mínimo recomendado de 100 horas, recomendado por Koerner et al.(1993).

\subsubsection{Geomembranas de PVC}

A Figura 91 mostra a superfície das geomembranas de PVC de 1,0 $\mathrm{mm}$ antes e após o carregamento dinâmico, sob diferentes solicitações. 


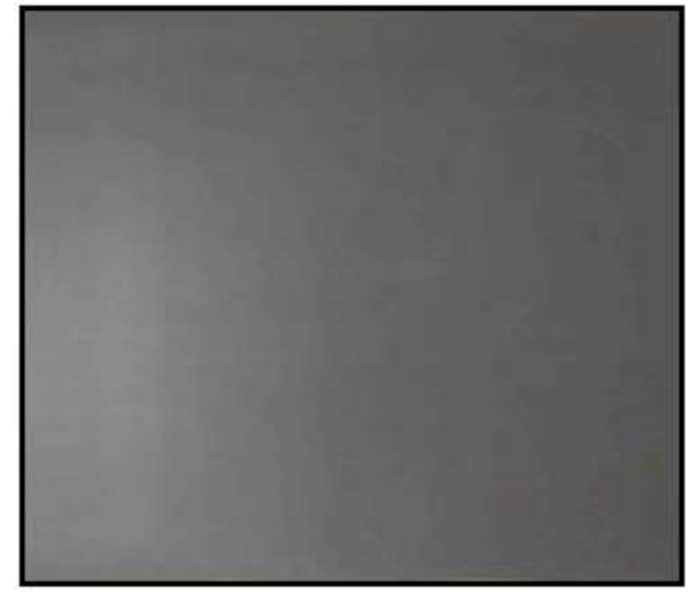

(a) GM virgem

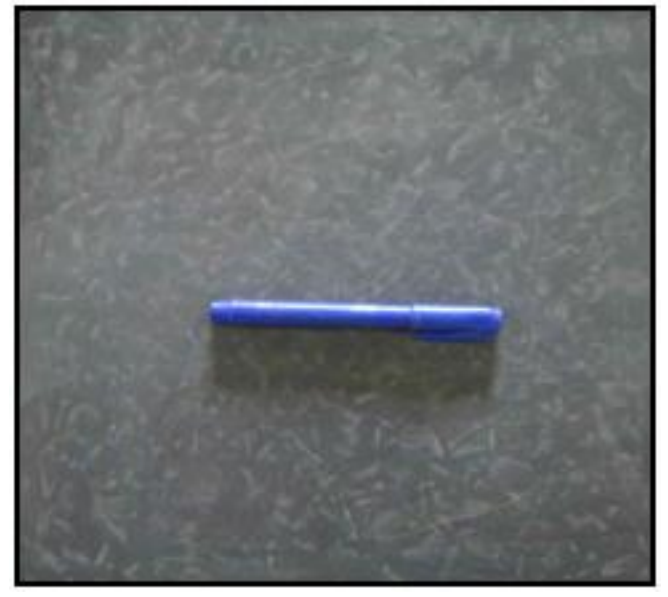

(c) GM sem proteção $400 \mathrm{kPa}, 1000$ ciclos

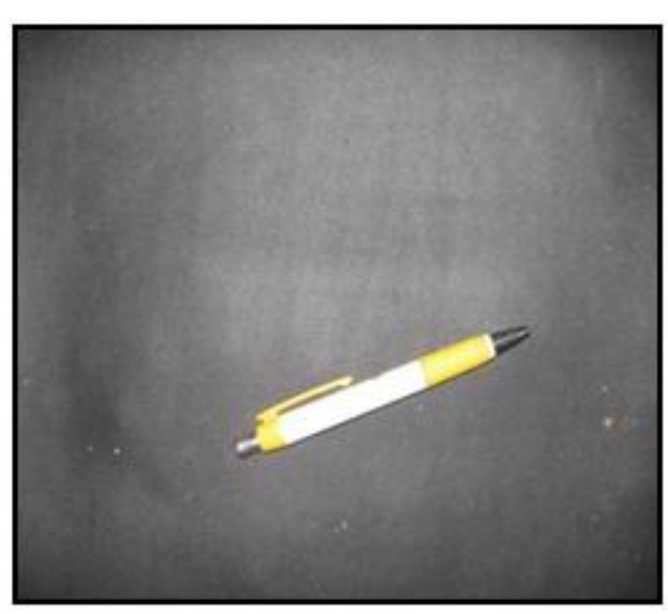

(e) GM com GT $600 \mathrm{~g} / \mathrm{m}^{2} 200 \mathrm{kPa}, 1000$ ciclos (b) GM sem proteção 200 kPa, 1000 ciclos

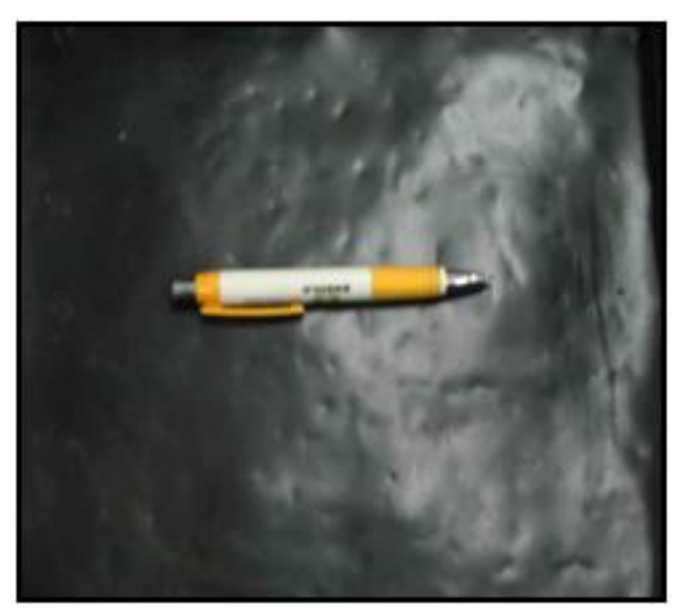

(d) GM com GT 300g/m² $200 \mathrm{kPa}, 1000$ ciclos
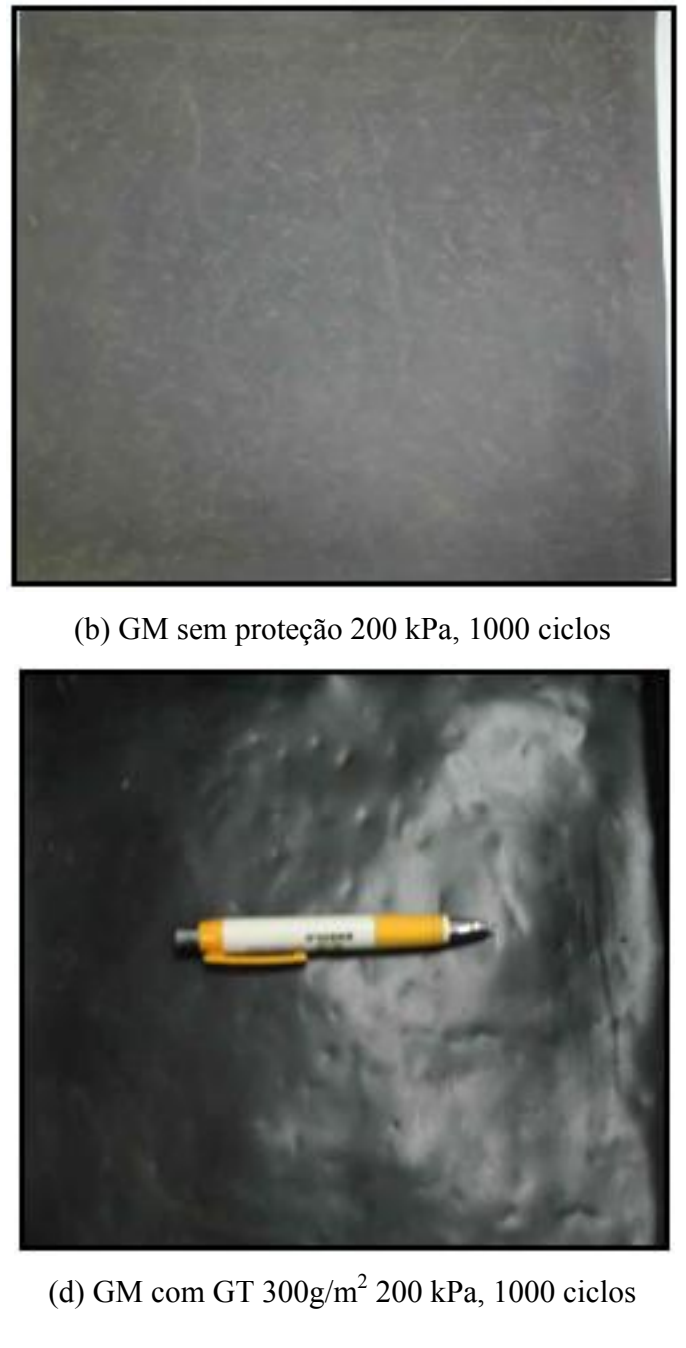
Observa-se que, após o carregamento dinâmico, a superfície da geomembrana apresentou-se totalmente marcada pela brita. As marcas foram mais evidenciadas nos ensaios com maior carga e maior número de ciclos.

Ao se introduzir o geotêxtil, verificou-se uma redução bastante significativa nas ondulações. No geotêxtil de gramatura de $600 \mathrm{~g} / \mathrm{m}^{2}$, nenhuma marca foi verificada na superfície após o carregamento.

Apesar dos efeitos verificados na superfície, em nenhuma solicitação constatou-se a presença de furos ou rasgos visíveis nas geomembranas de PVC.

As Figuras a seguir apresentam os resultados dos ensaios mecânicos (punção, tração e rasgo) realizados na geomembrana de PVC $(1,0 \mathrm{~mm})$ sem proteção, depois de submetidas ao carregamento dinâmico. Os ensaios incluem as geomembranas virgens e as geomembranas danificadas, sob diferentes cargas e número de ciclos. Na Tabela 37 é apresentado o sumário dos resultados dos ensaios.

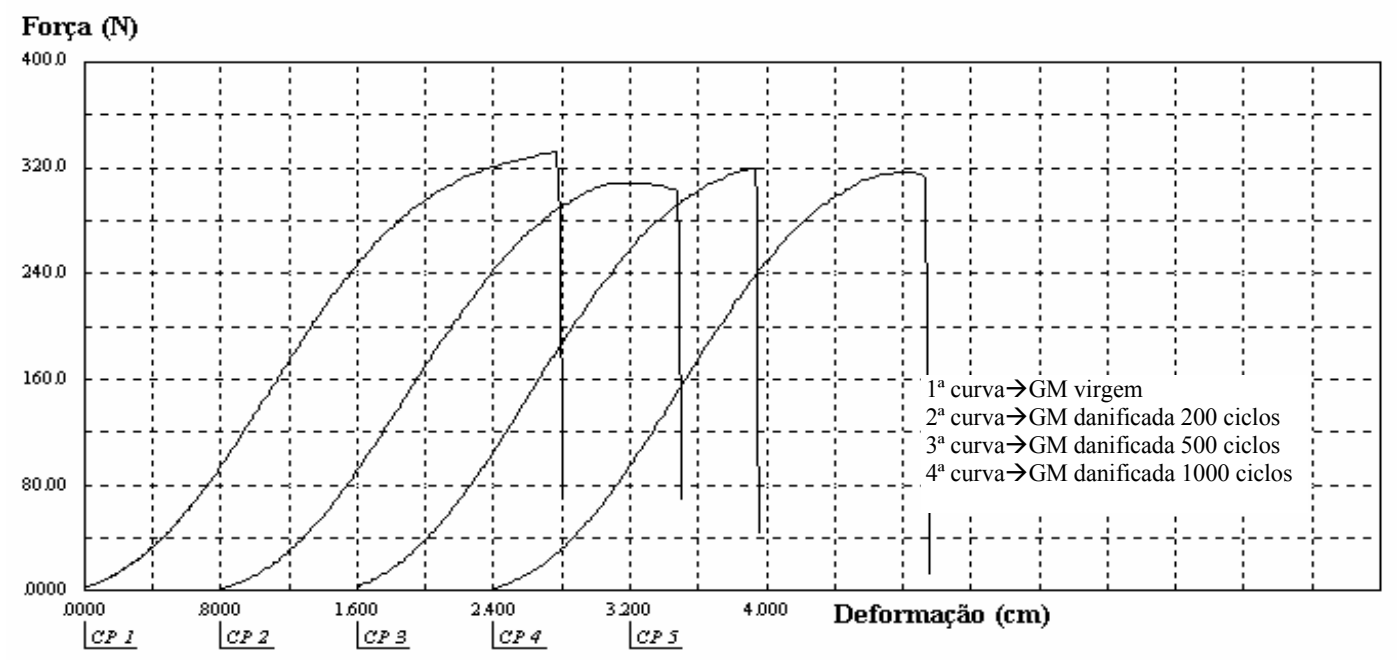

Figura 91. Curvas obtidas nos ensaios de punção para geomembrana de PVC - $200 \mathrm{kPa}$. 


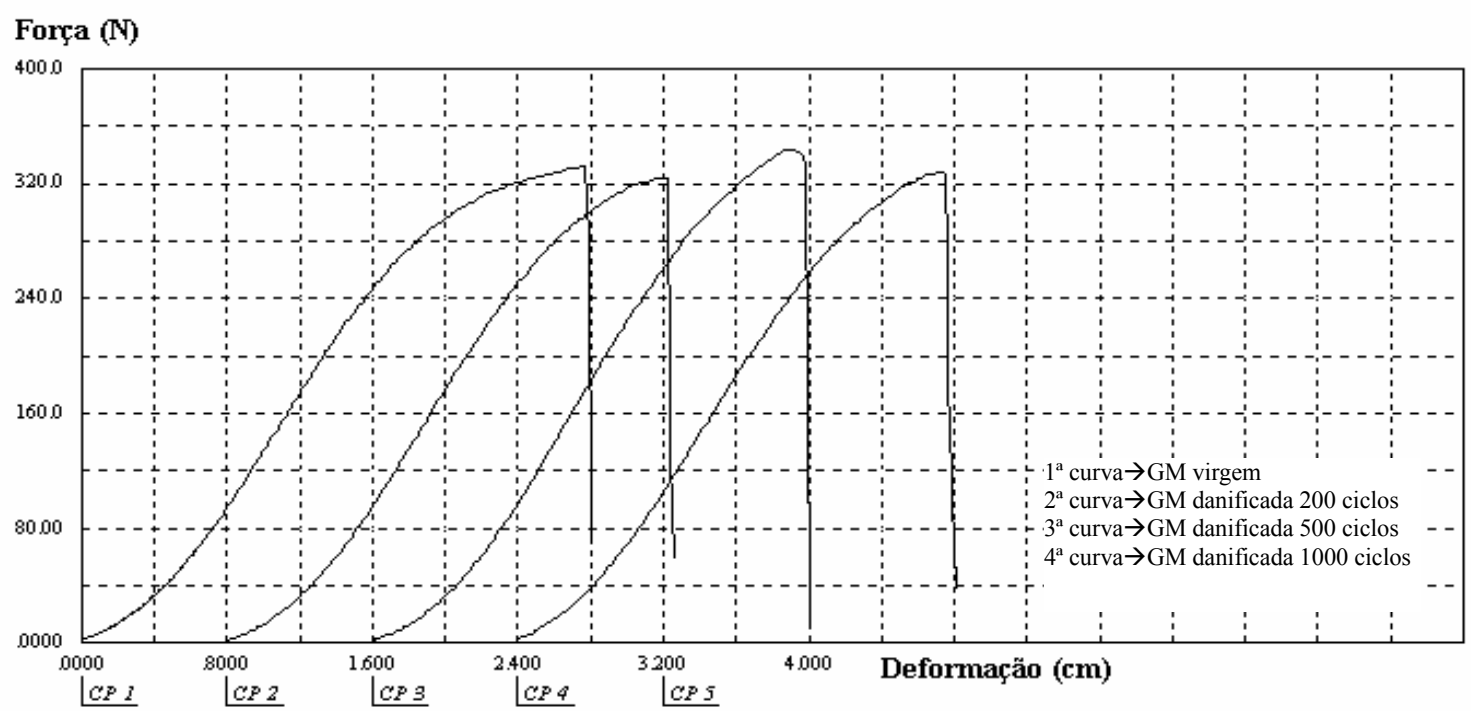

Figura 92. Curvas obtidas nos ensaios de punção para geomembrana de PVC $-400 \mathrm{kPa}$.

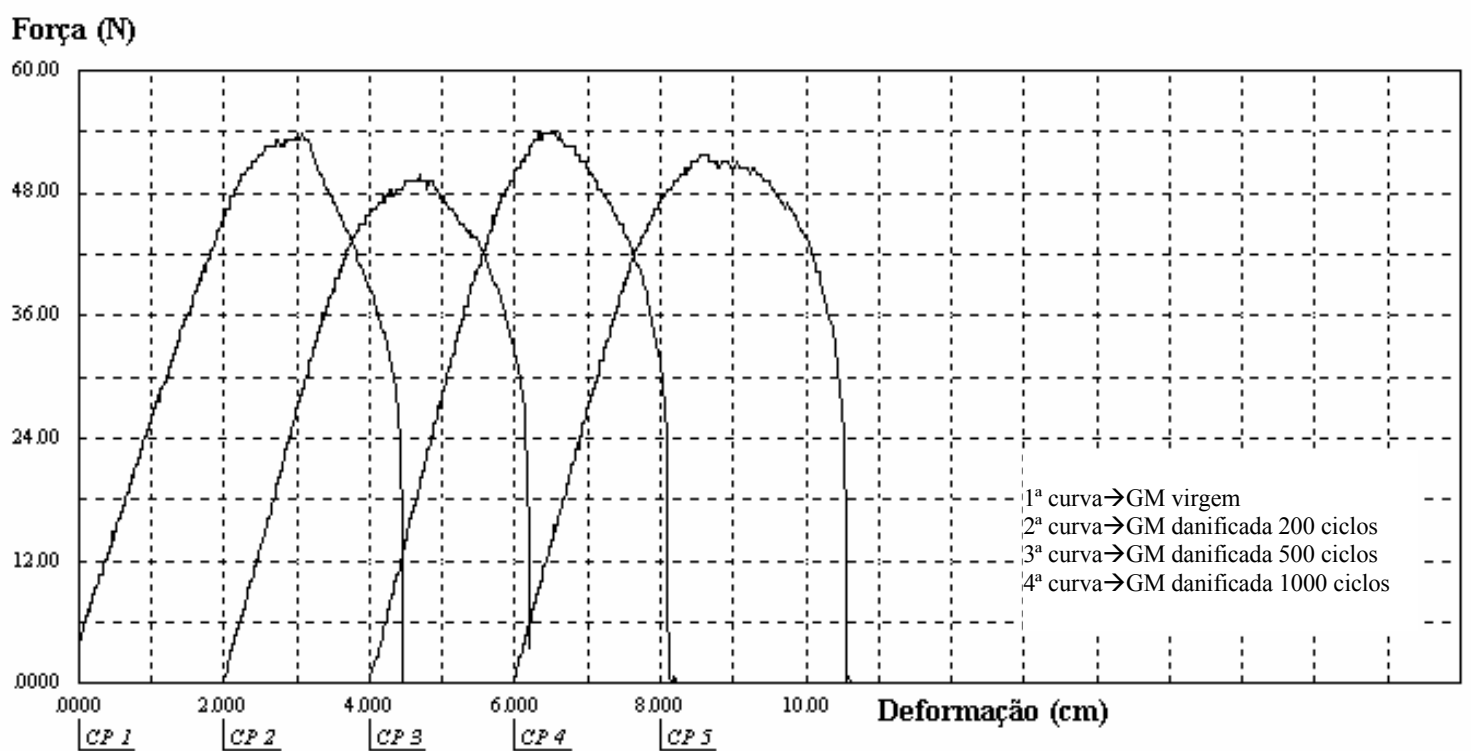

Figura 93. Curvas obtidas nos ensaios de rasgo para geomembrana de PVC - $200 \mathrm{kPa}$. 


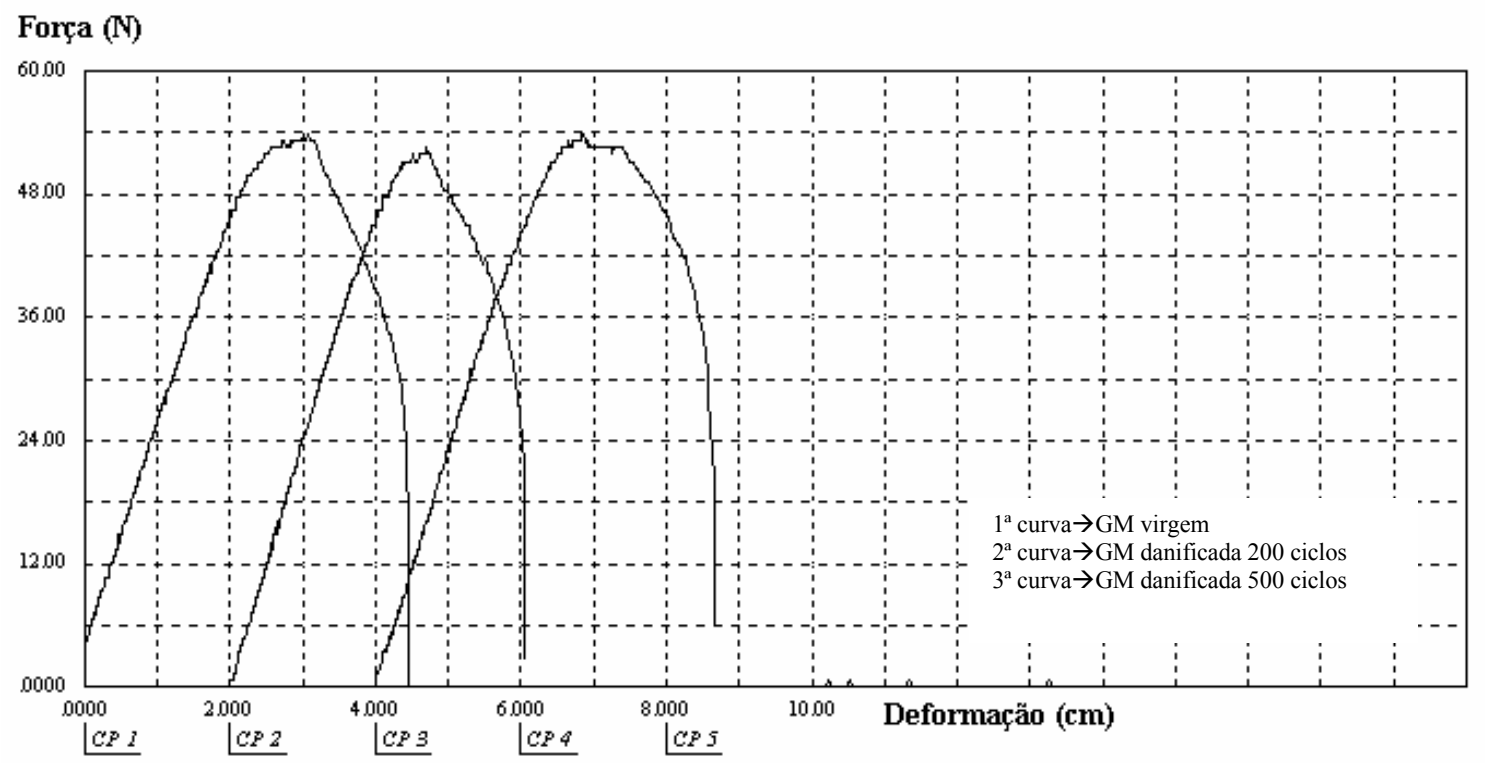

Figura 94. Curvas obtidas nos ensaios de rasgo para geomembrana de $\mathrm{PVC}-400 \mathrm{kPa}$.

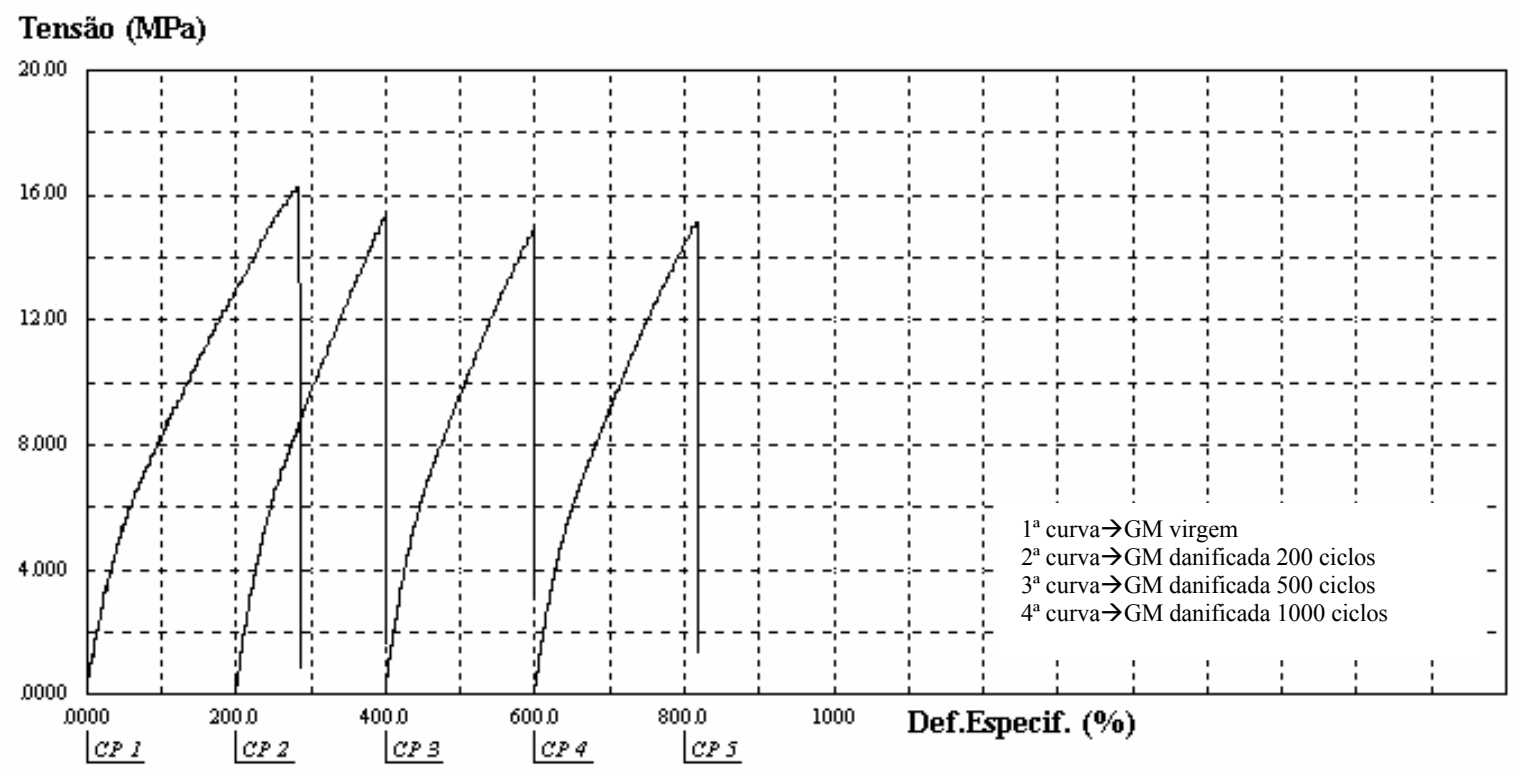

Figura 95. Curvas obtidas nos ensaios de tração para geomembrana de PVC $-200 \mathrm{kPa}$. 


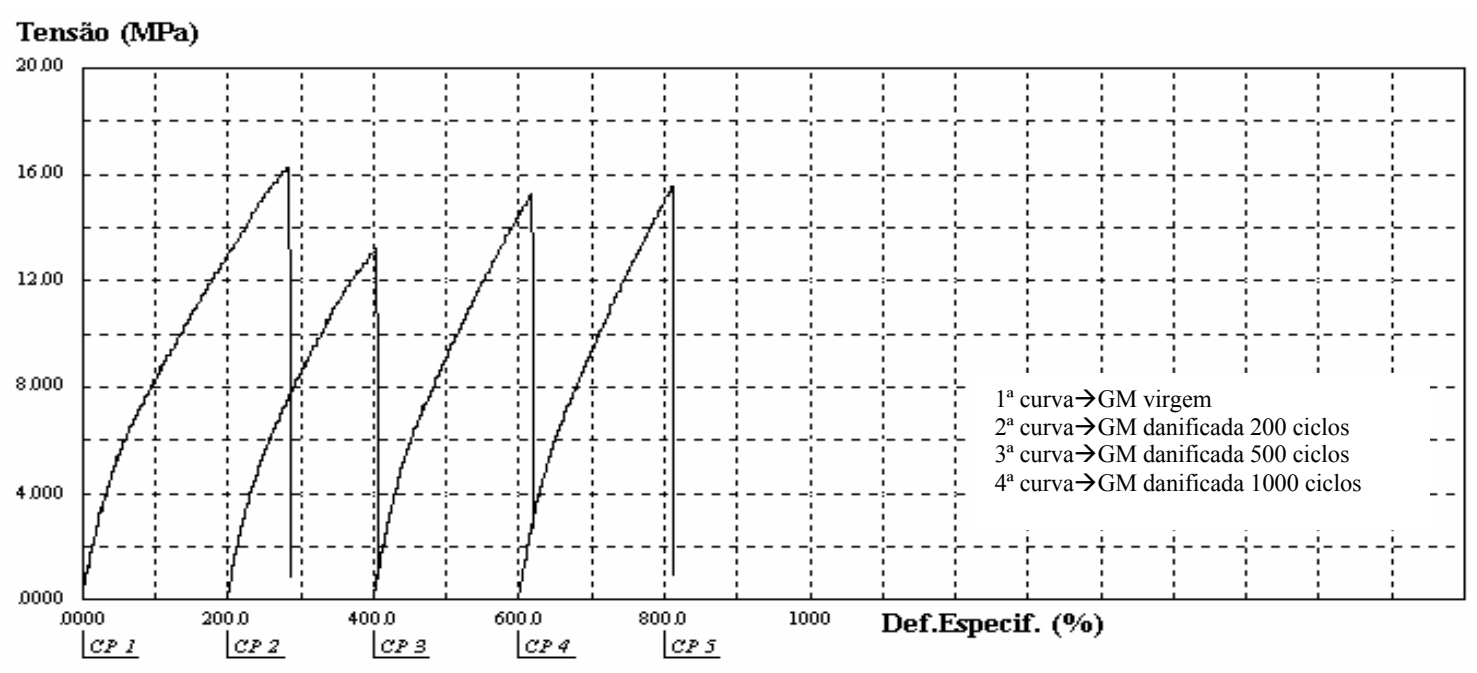

Figura 96. Curvas obtidas nos ensaios de tração para geomembrana de PVC - $400 \mathrm{kPa}$.

Tabela 37. Resultados dos ensaios mecânicos pós-dano - GM PVC (1,0 mm) sem proteção.

\begin{tabular}{|c|c|c|c|c|c|c|c|c|c|c|c|c|}
\hline \multirow{3}{*}{ Condição } & \multirow[t]{2}{*}{ Tensão } & \multirow{3}{*}{ Ciclos } & \multicolumn{4}{|c|}{ Punção } & \multicolumn{2}{|c|}{ Rasgo } & \multicolumn{4}{|c|}{$\begin{array}{c}\text { Tração } \\
\text { Ruptura } \\
\end{array}$} \\
\hline & & & $\mathbf{F}$ & $\Delta \mathbf{F}$ & $\delta$ & $\Delta \delta$ & $\mathbf{F}$ & $\Delta \mathbf{F}$ & $\sigma$ & $\Delta \sigma$ & $\varepsilon$ & $\Delta \varepsilon$ \\
\hline & (kPa) & & $\mathbf{N}$ & & $\mathbf{m m}$ & & $\mathbf{N}$ & & MPa & & $\%$ & \\
\hline $\begin{array}{c}\mathrm{GM} \\
\text { virgem }\end{array}$ & - & - & 330 & & 27 & & 67 & & 18 & & 422 & \\
\hline \multirow{3}{*}{$\begin{array}{l}\text { GM sem } \\
\text { proteção }\end{array}$} & 200 & 200 & 309 & 0,94 & 24 & 0,89 & 50 & 0,75 & 16 & 0,89 & 207 & 0,49 \\
\hline & 200 & 500 & 319 & 0,97 & 24 & 0,89 & 54 & 0,80 & 15 & 0,83 & 196 & 0,47 \\
\hline & 200 & 1000 & 317 & 0,96 & 24 & 0,89 & 53 & 0,79 & 15 & 0,83 & 209 & 0,50 \\
\hline \multirow{3}{*}{$\begin{array}{c}\text { GM } \\
\text { danificada } \\
\text { sem } \\
\text { proteção }\end{array}$} & 400 & 200 & 325 & 0,98 & 24 & 0,89 & 53 & 0,79 & 14 & 0,78 & 209 & 0,50 \\
\hline & & & 342 & 1,04 & 24 & 0,89 & 53 & 0,79 & 15 & 0,83 & 215 & 0,51 \\
\hline & 400 & 1000 & 328 & 0,99 & 23 & 0,86 & 53 & 0,79 & 16 & 0,89 & 214 & 0,51 \\
\hline
\end{tabular}

Legenda: $\Delta \rightarrow$ relação entre a Propriedade da geomembrana danificada e a Propriedade da geomembrana virgem.

As geomembranas danificadas de PVC apresentaram uma redução na força e deslocamento de punção entre $5 \%$ e $10 \%$, respectivamente, em relação às geomembranas virgens. A força ao rasgo nas geomembranas danificadas foi reduzida em torno de $10 \%$ em relação à geomembrana virgem. A força ao rasgo nas geomembranas danificadas apresentou uma redução de cerca de $20 \%$. A tensão de ruptura na geomembrana danificada apresentou uma pequena redução, em torno de 10 a 15\%, em relação à geomembrana virgem. $\mathrm{O}$ efeito 
mais evidente foi verificado nos valores dos deslocamentos na ruptura, constatando-se uma diminuição de 50\% em relação à geomembrana virgem.

Os resultados também indicam que a magnitude da carga e o número de ciclos aplicados não influenciaram nas propriedades mecânicas das geomembranas de PVC.

As Figuras abaixo apresentam os resultados dos ensaios realizados nas geomembranas PVC submetidas a carregamentos cíclicos com proteção de geotêxtil de PET. Tais resultados também se referem à carga de $200 \mathrm{kPa}$ com 1.000 ciclos.

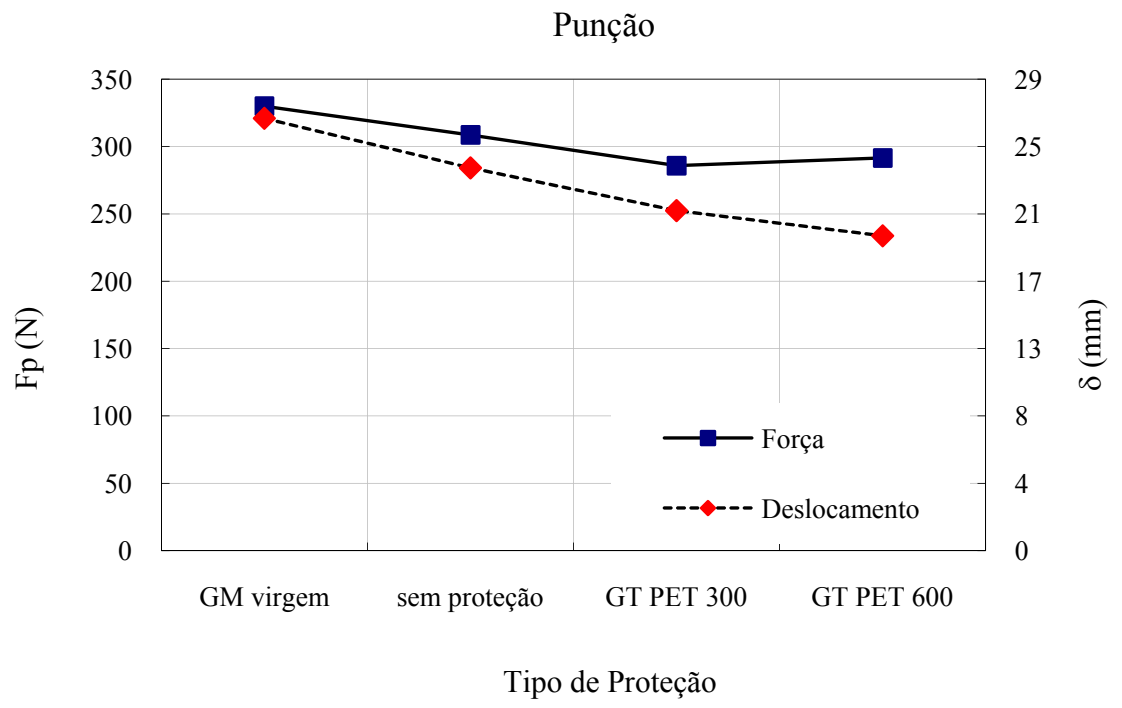

Figura 97. Resultados dos ensaios de punção realizados nas geomembranas de PVC: ensaios cíclicos. 


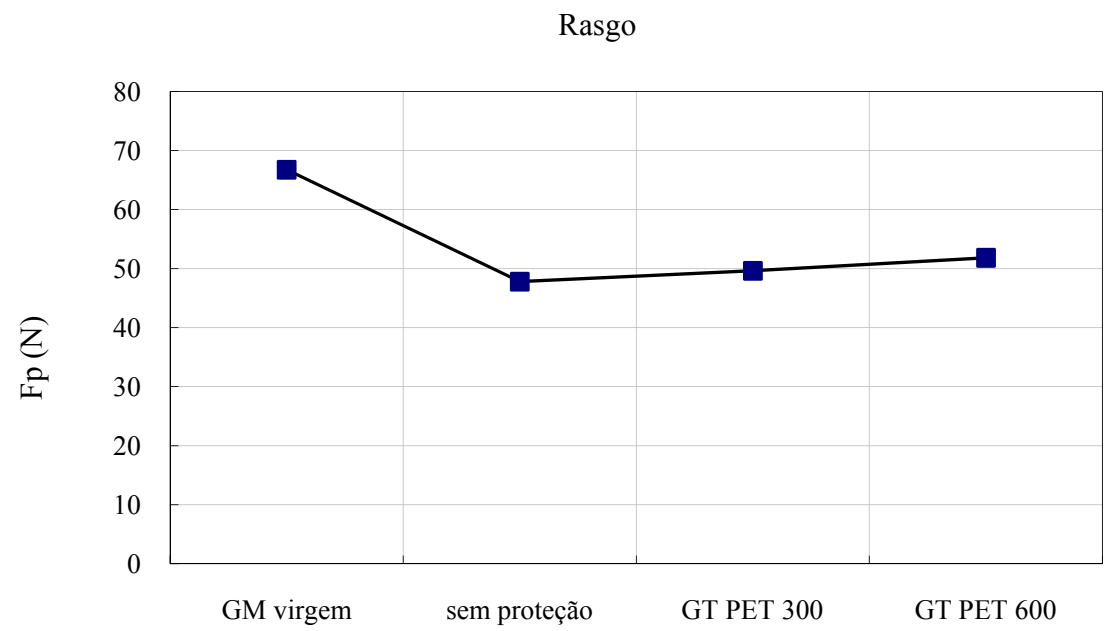

Tipo de Proteção

Figura 98. Resultados dos ensaios de rasgo realizados nas geomembranas de PVC: ensaios cíclicos.

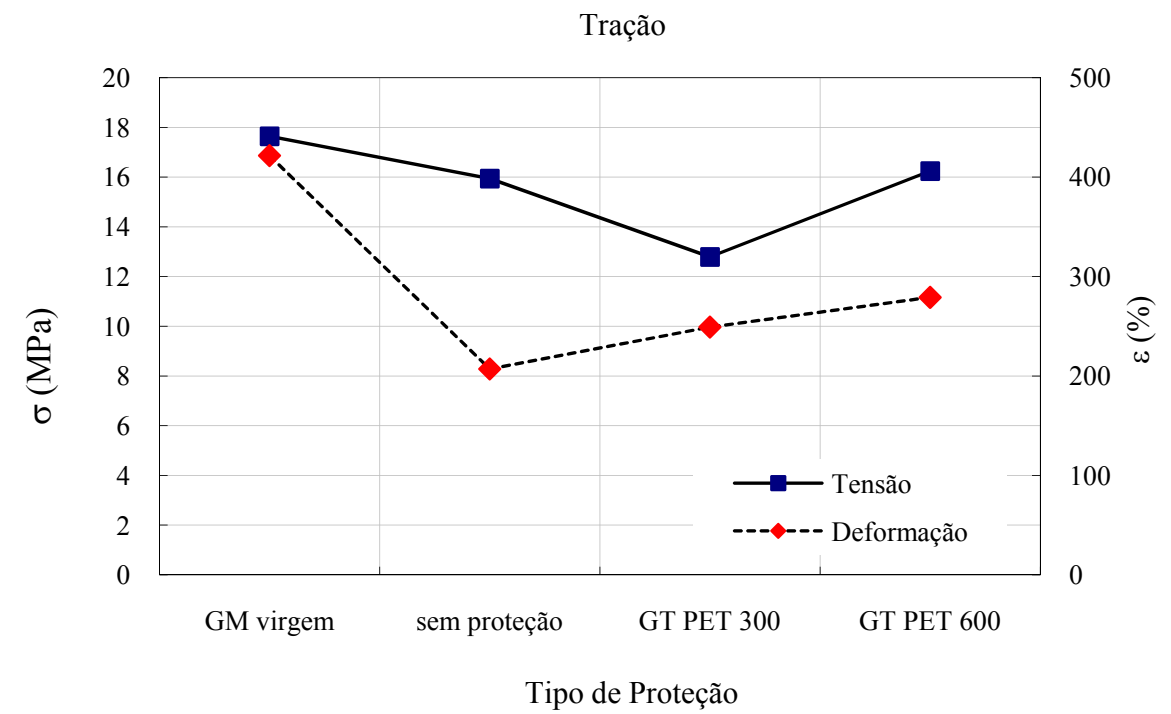

Figura 99. Resultados dos ensaios de tração realizados nas geomembranas de PVC: ensaios cíclicos.

Os resultados mostram que a introdução do geotêxtil não aumentou os valores das propriedades mecânicas das geomembranas de PVC. Em algumas situações, tais como nos ensaios de punção, os valores chegam a ser ligeiramente menores do que na geomembrana sem proteção. No entanto, tal redução é pequena, da ordem de $10 \%$. A maior variação foi 
verificada em termos de deformação na ruptura. Constata-se um aumento da deformação com a introdução do geotêxtil e com o aumento de sua resistência à tração.

A Figura 100 apresenta os resultados dos ensaios de transmissividade ao vapor (WVT) realizados nas geomembranas de $\mathrm{PVC}$, sob diferentes condições. A Tabela 38 apresenta alguns valores de permeabilidade por difusão $\left(\mathrm{g} \cdot \mathrm{m}^{-2} \cdot \mathrm{dia}^{-1} \cdot \mathrm{mmHG}^{-1} \cdot \mathrm{cm}\right)$ e condutividade hidráulica (cm/s) recomendados por Koerner(1998) e Haxo Jr., H.E; Pierson, P. (1996).

Os valores de condutividade hidráulica obtidos nos ensaios de WVT variaram entre $1,3 \times 10^{-12} \mathrm{~cm} / \mathrm{s}$ e $2,4 \times 10^{-12} \mathrm{~cm} / \mathrm{s}$. A maior dispersão foi verificada na configuração com geomembrana danificada sem proteção e sob carga de $200 \mathrm{kPa}$ e 200 ciclos.

Verifica-se que os valores condutividade hidráulica encontrados nos ensaios com amostras de geomembranas danificadas estão dentro dos valores de condutividade hidráulica sugeridos para geomembranas virgens, o que indica que as propriedades hidráulicas das geomembranas não foram afetadas pelo carregamento cíclico. 


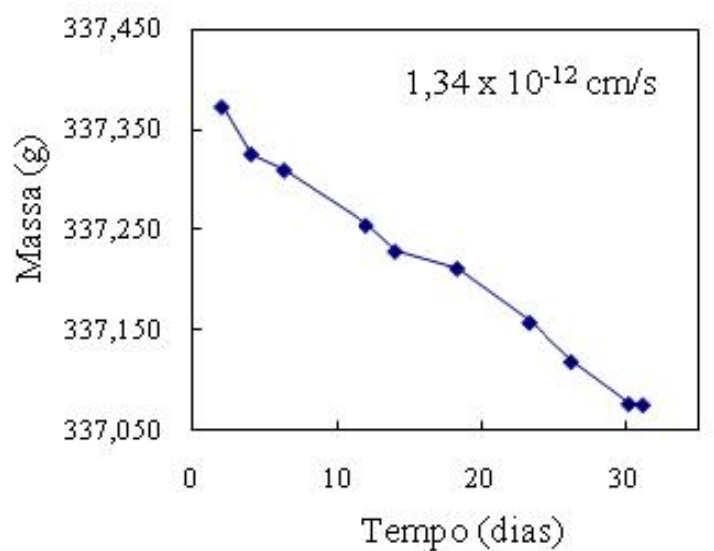

(a) GM virgem

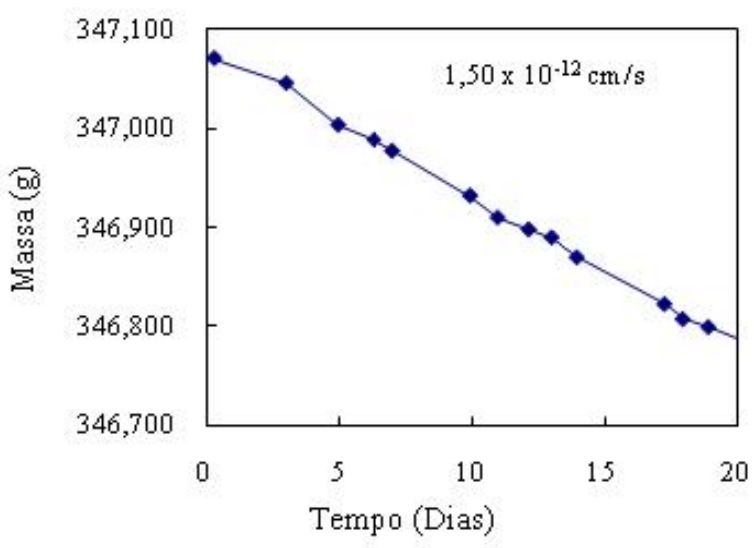

(c) GM danificada $200 \mathrm{kPa}-1000$ ciclos

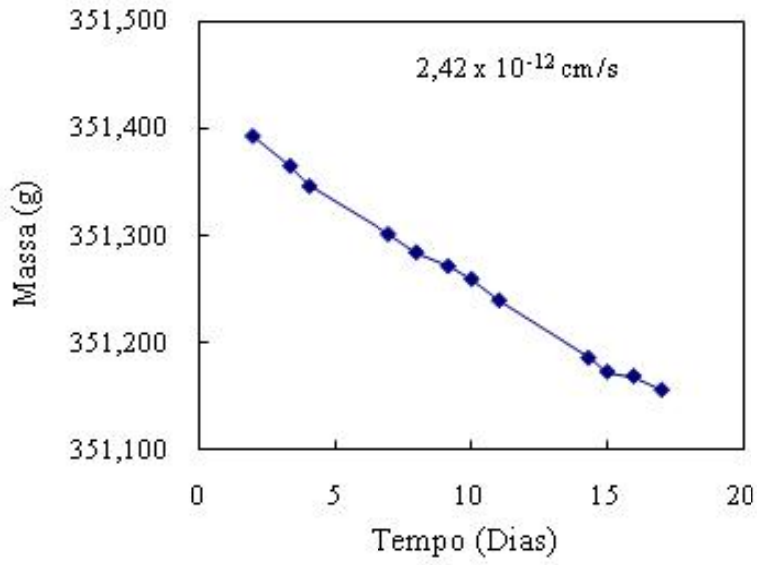

(e) GM danificada $400 \mathrm{kPa}-1000$ ciclos

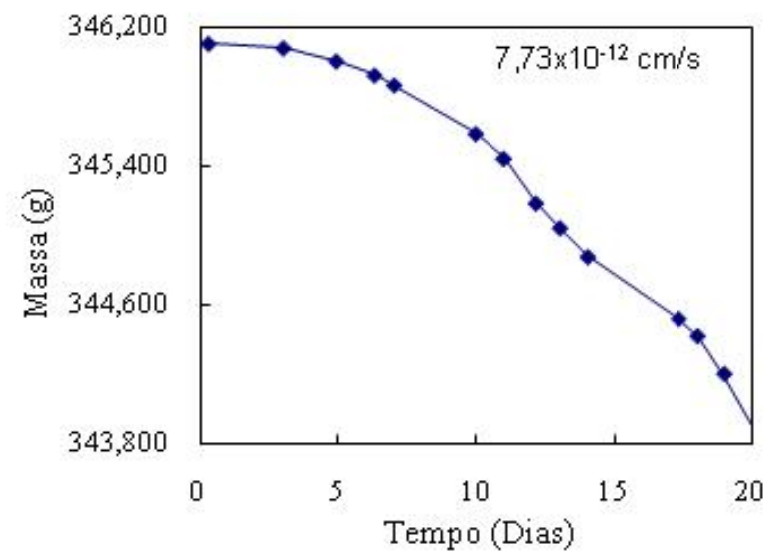

(b) GM danificada $200 \mathrm{kPa}-200$ ciclos

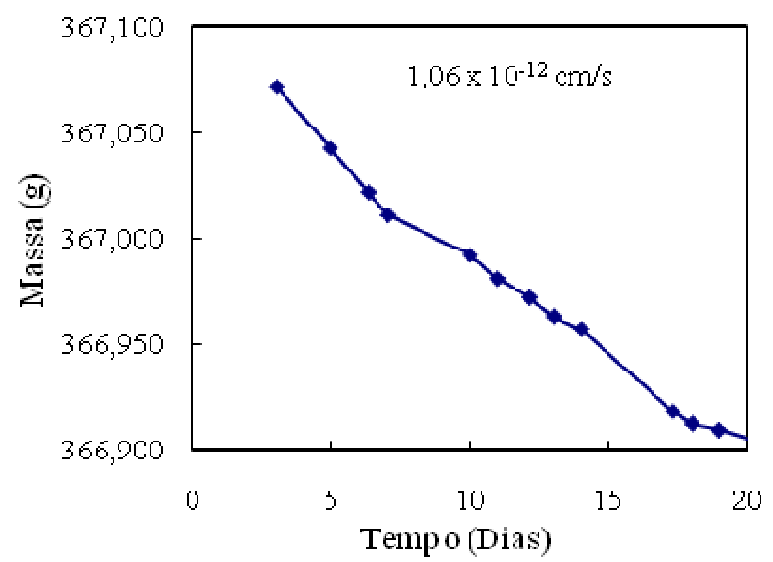

(d) GM danificada $400 \mathrm{kPa}-200$ ciclos

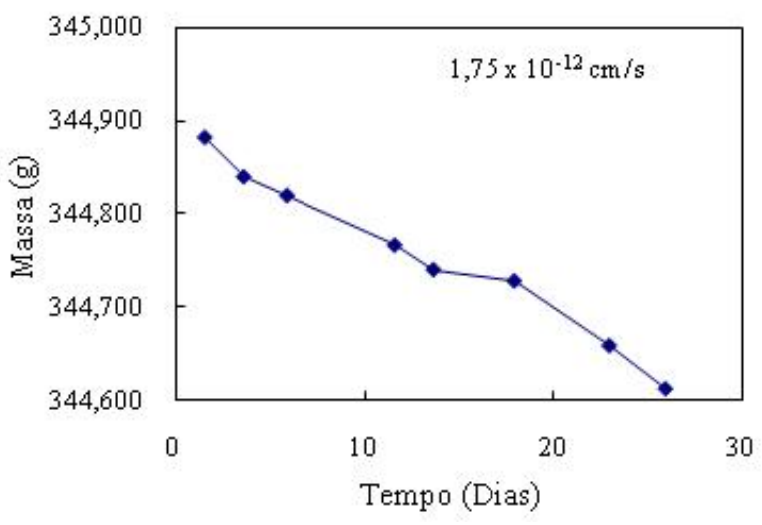

(f) GM danificada $200 \mathrm{kPa}, 200$ ciclos, GT $300 \mathrm{~g} / \mathrm{m}^{2}$

Figura 100. Resultados dos ensaios de transmissividade ao vapor (permeabilidade) em geomembranas de PVC. 
Tabela 38. Valores de permeabilidade recomendados.

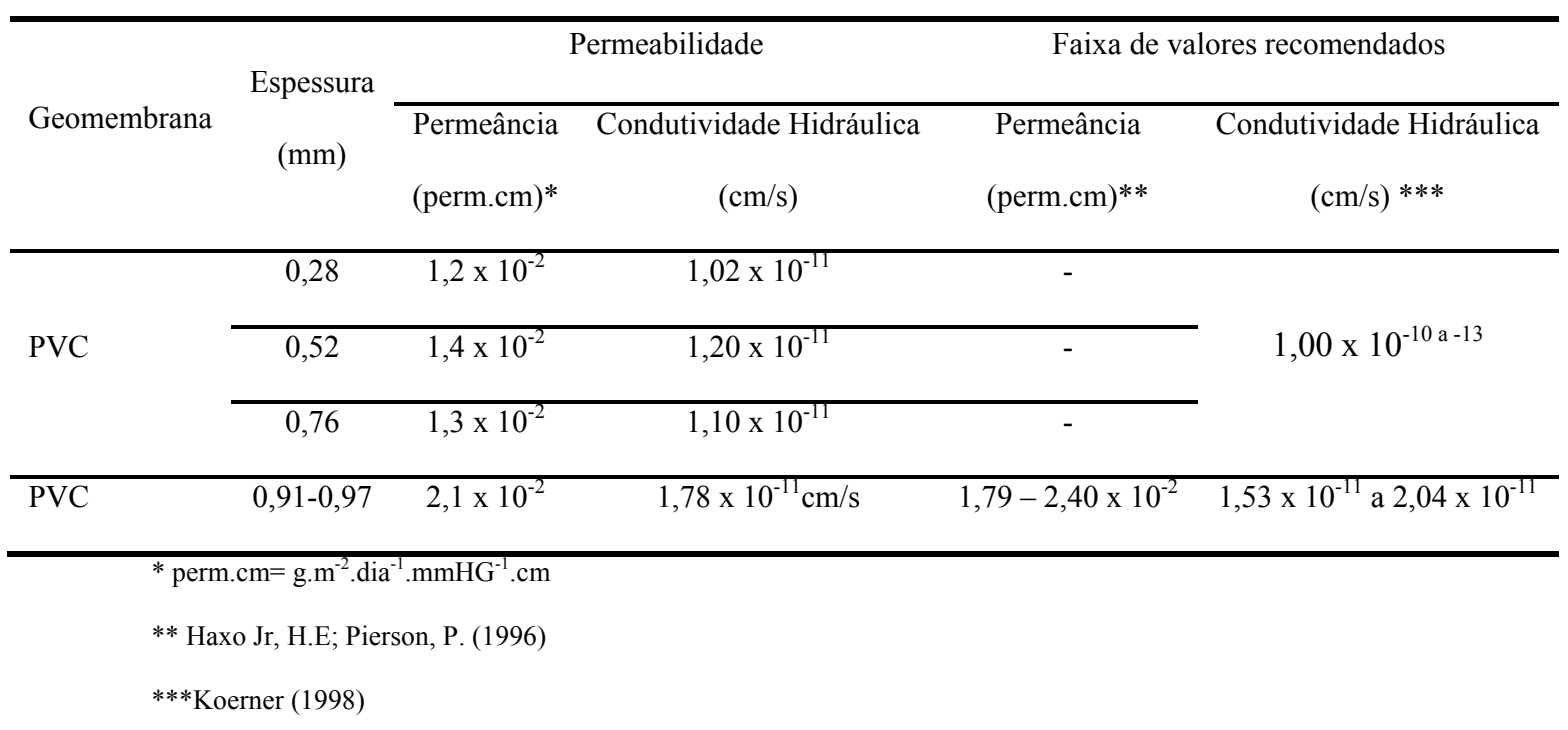

\subsection{Ensaios de Campo}

\subsubsection{Geomembranas de PEAD}

\subsubsection{Análise Visual}

As Figuras abaixo ilustram as superfícies das geomembranas de PEAD sob diferentes configurações, após retirada da camada de drenagem. Na Tabela 39 é apresentada uma síntese dos tipos de danos observados seguindo as recomendações propostas pelo CFG (2001). 


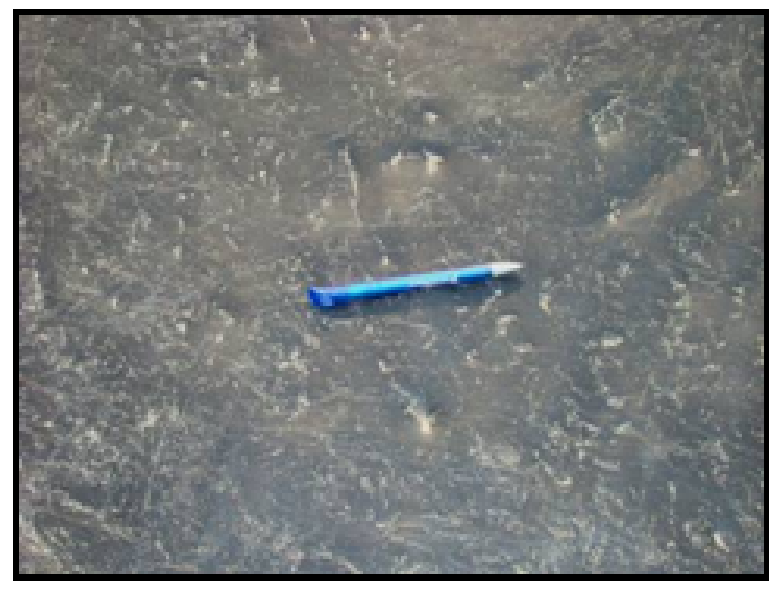

arranhões

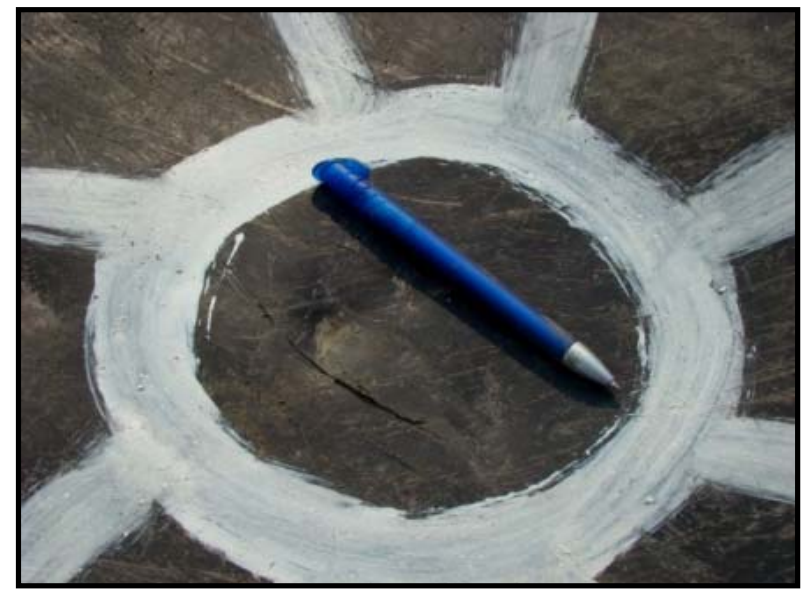

entalhe

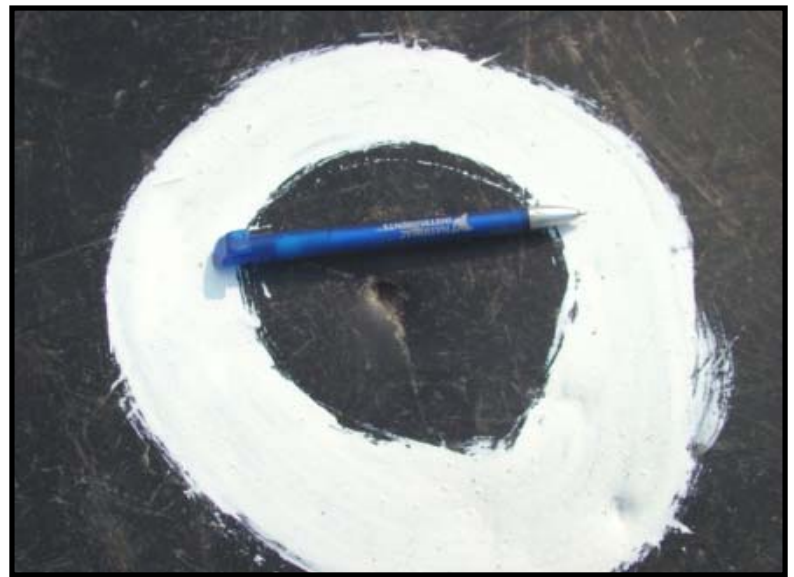

furos

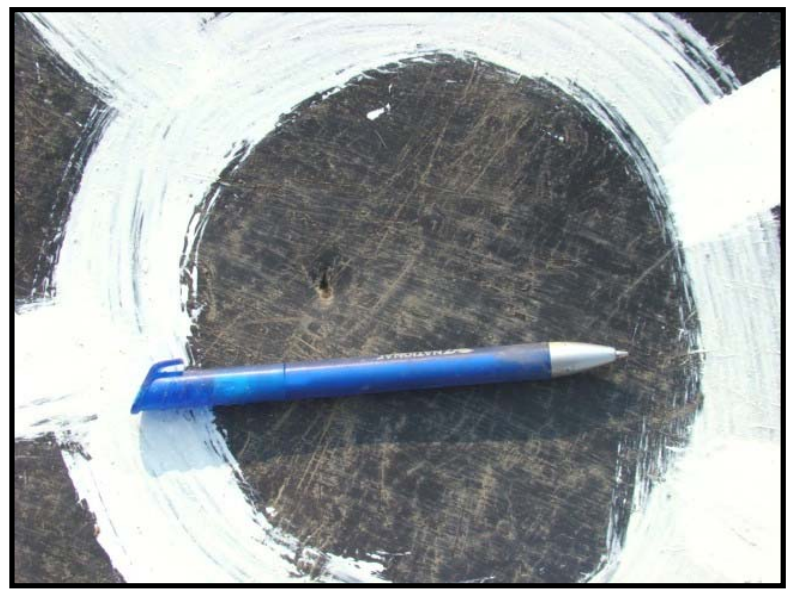

indentação

Figura 101. Danos visuais: GM de PEAD de 1,5 mm sem proteção e brita 3.

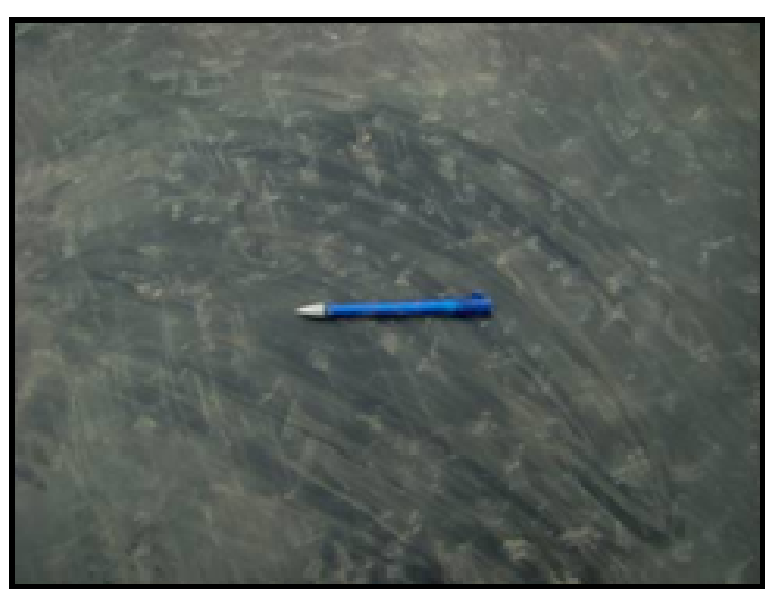

arranhões

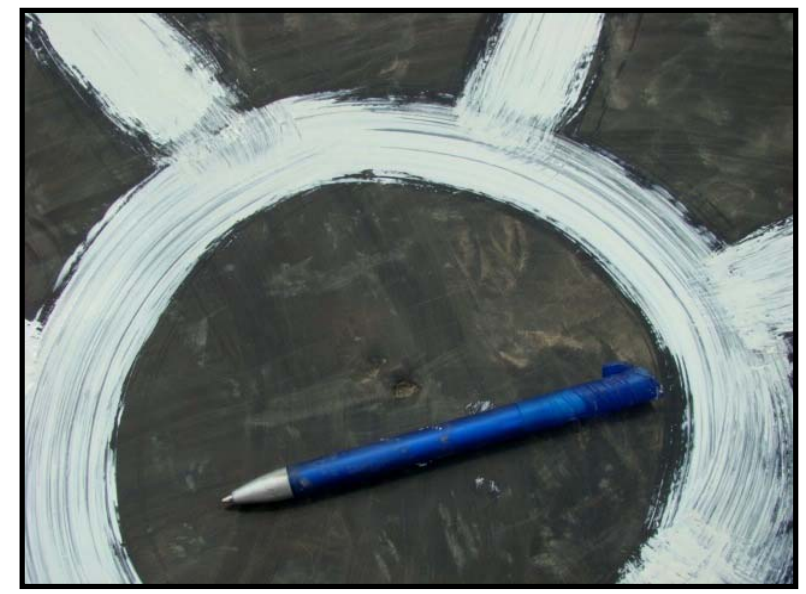

indentação

Figura 102. Danos visuais: GM de PEAD de 1,5 mm com GT PET $300 \mathrm{~g} / \mathrm{m}^{2}$ e brita 3 . 


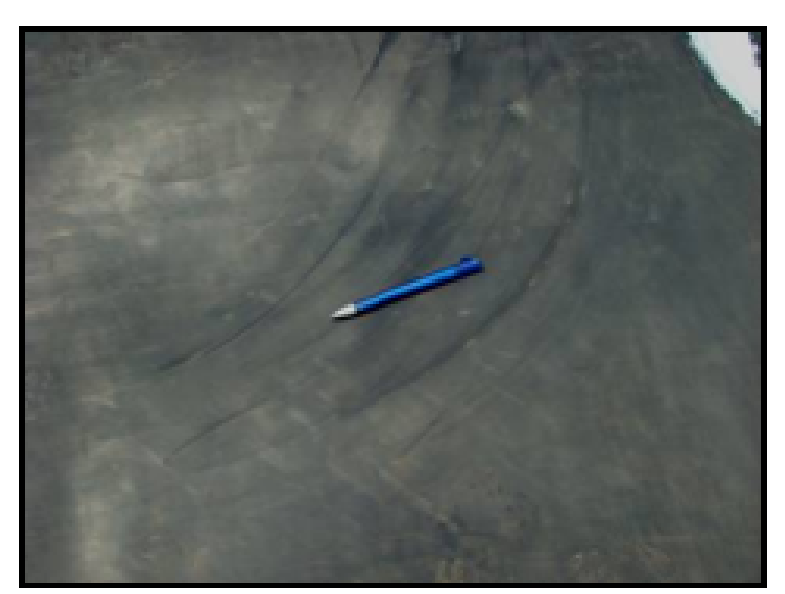

GM

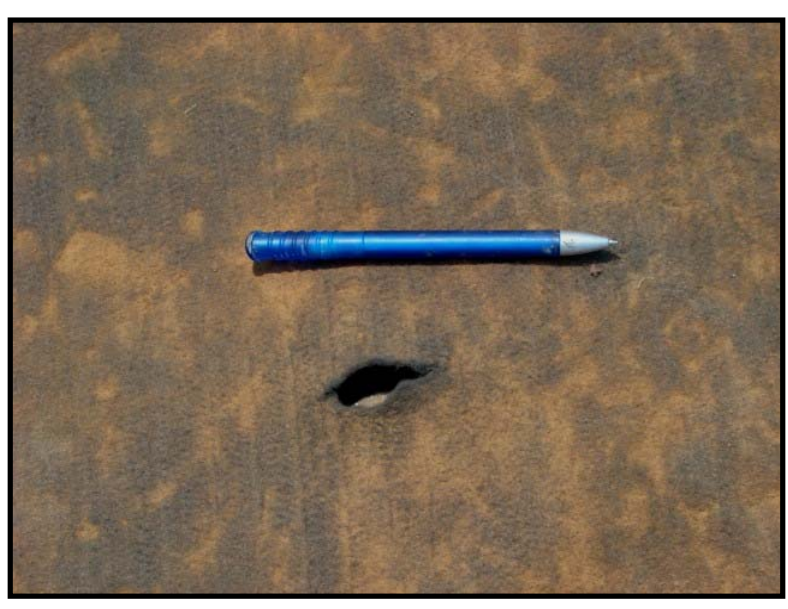

GT com furo

Figura 103. Danos visuais: GM de PEAD de $1,5 \mathrm{~mm}$ com GT PET $600 \mathrm{~g} / \mathrm{m}^{2}$ e brita 3 .

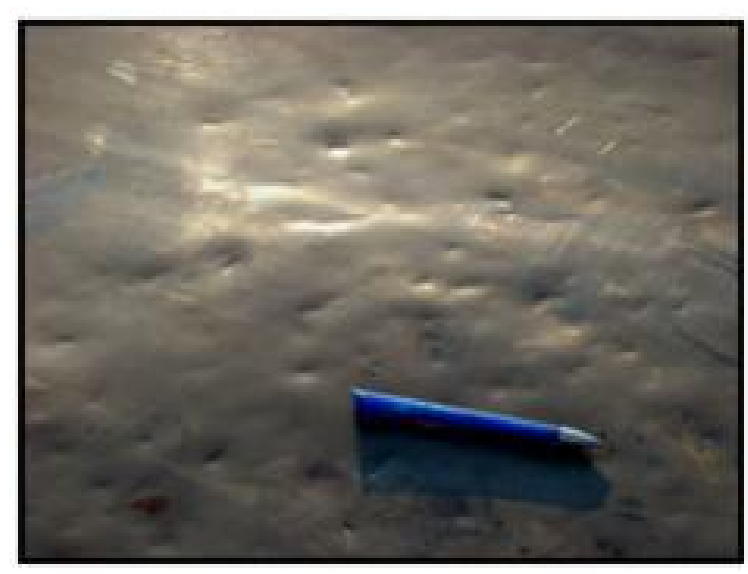

GM

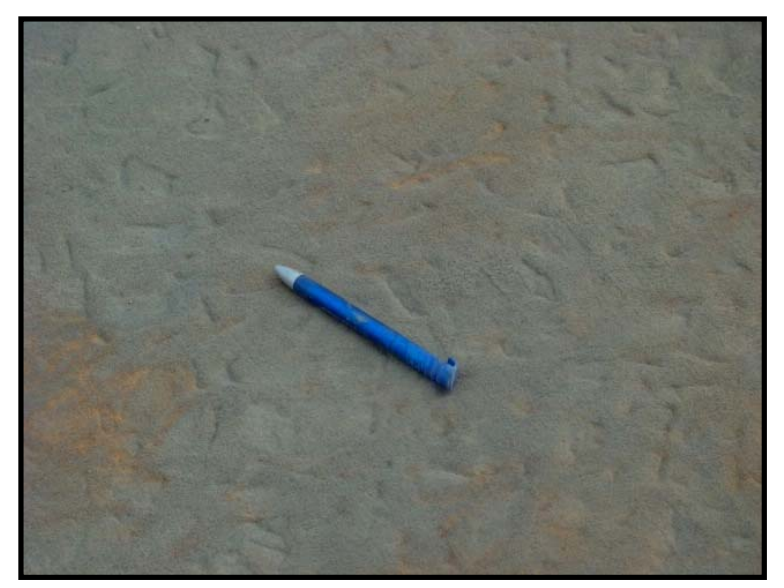

GT

Figura 104. Danos visuais: GM de PEAD de $1,5 \mathrm{~mm}$ com GT PP $600 \mathrm{~g} / \mathrm{m}^{2}$ e brita 3.

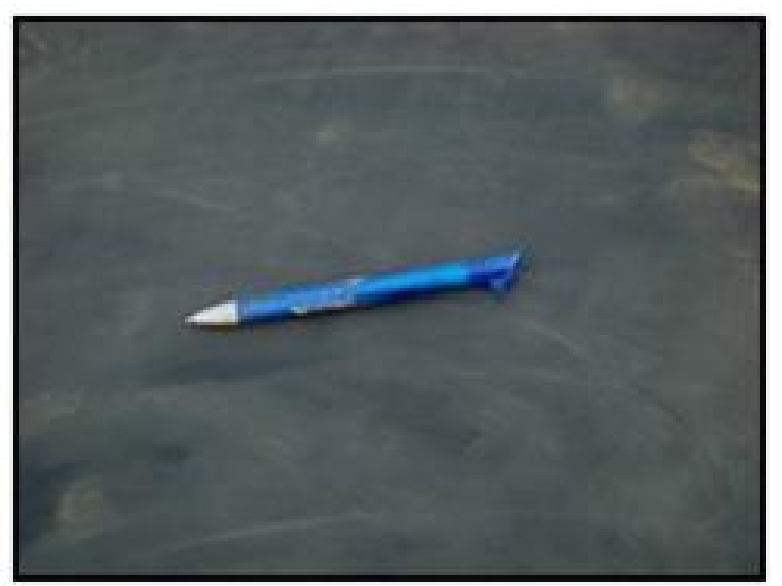

Figura 105. Danos visuais: GM de PEAD de $1,5 \mathrm{~mm}$ com GT PET $1200 \mathrm{~g} / \mathrm{m}^{2}$ e brita 3 . 


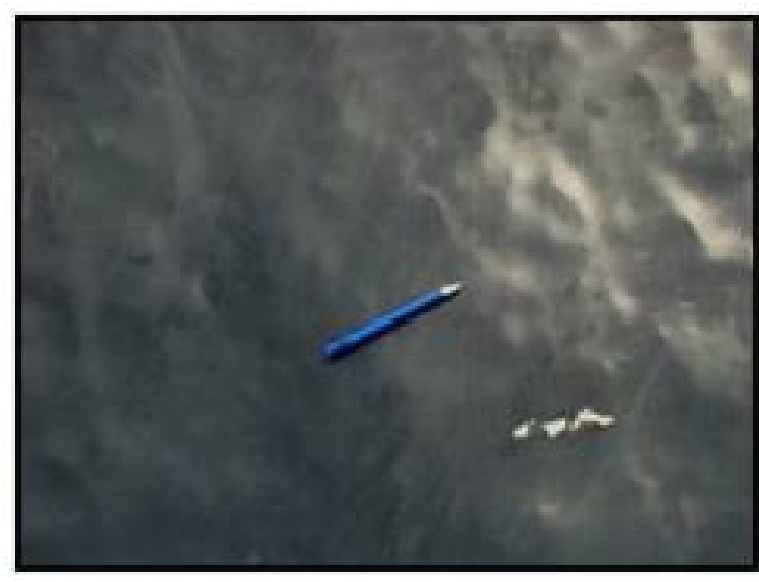

(a)

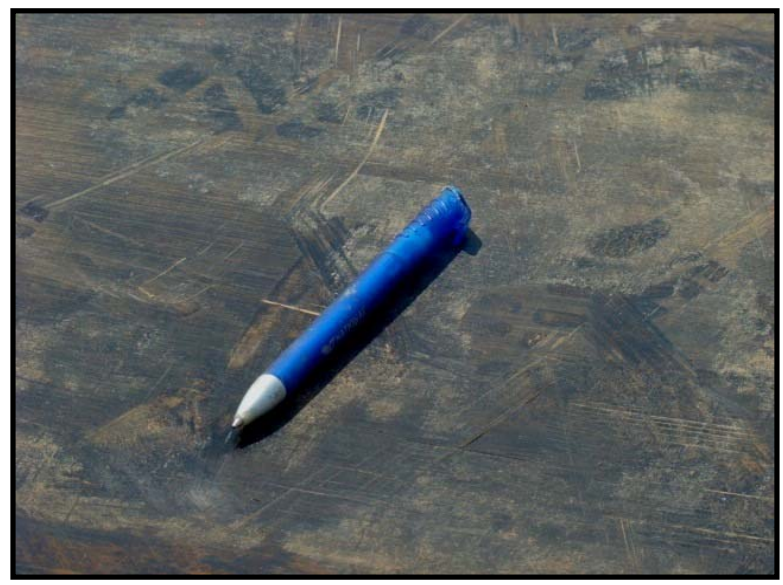

(b)

Figura 106. Danos visuais: GM de PEAD de 1,5 mm com camadas naturais e brita 3: (a) areia; (b) solo.

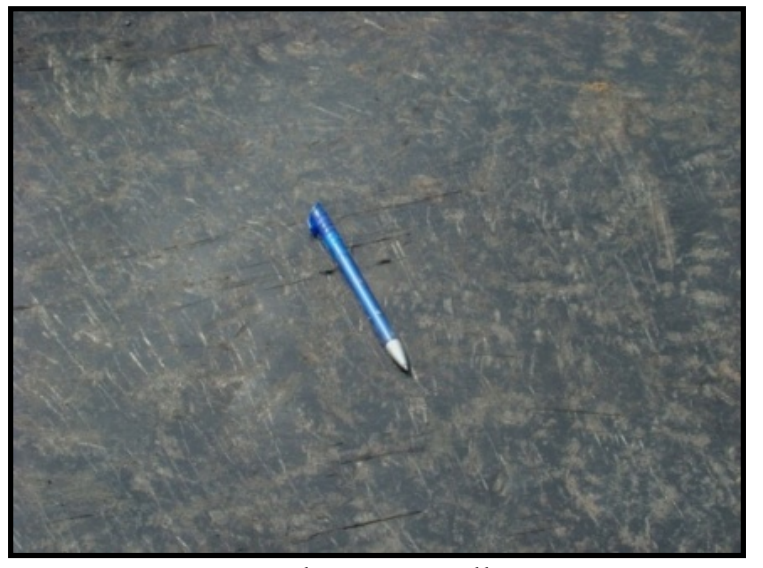

arranhões e entalhes

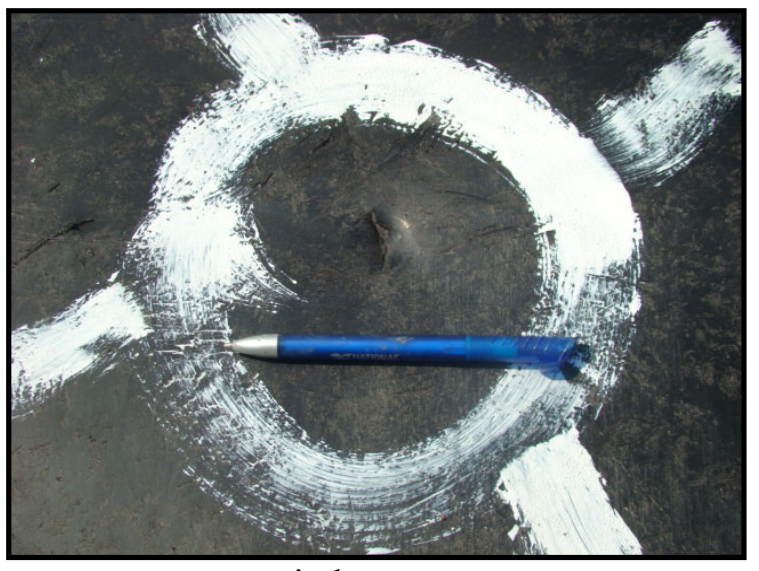

indentação

Figura 107. Danos visuais: GM de PEAD de 2,0 mm sem proteção e brita 3.

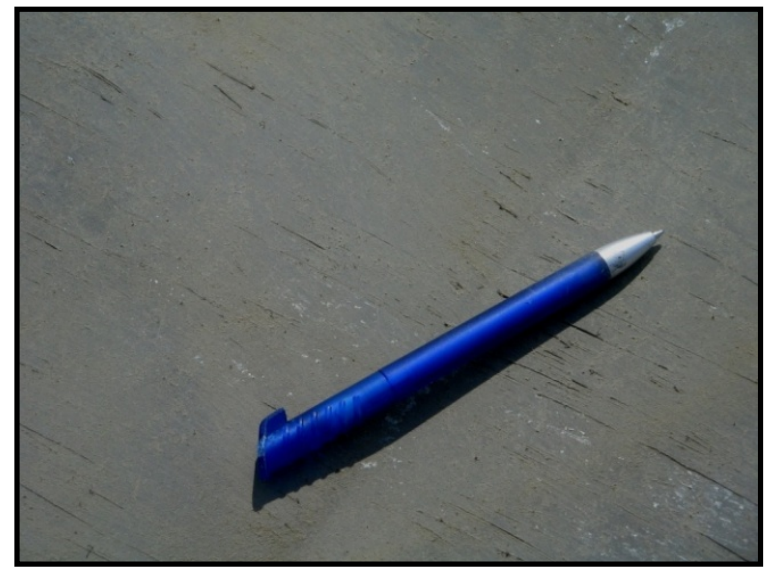

Figura 108. Danos visuais: GM de PEAD de 1,5 mm sem proteção e brita 1. 

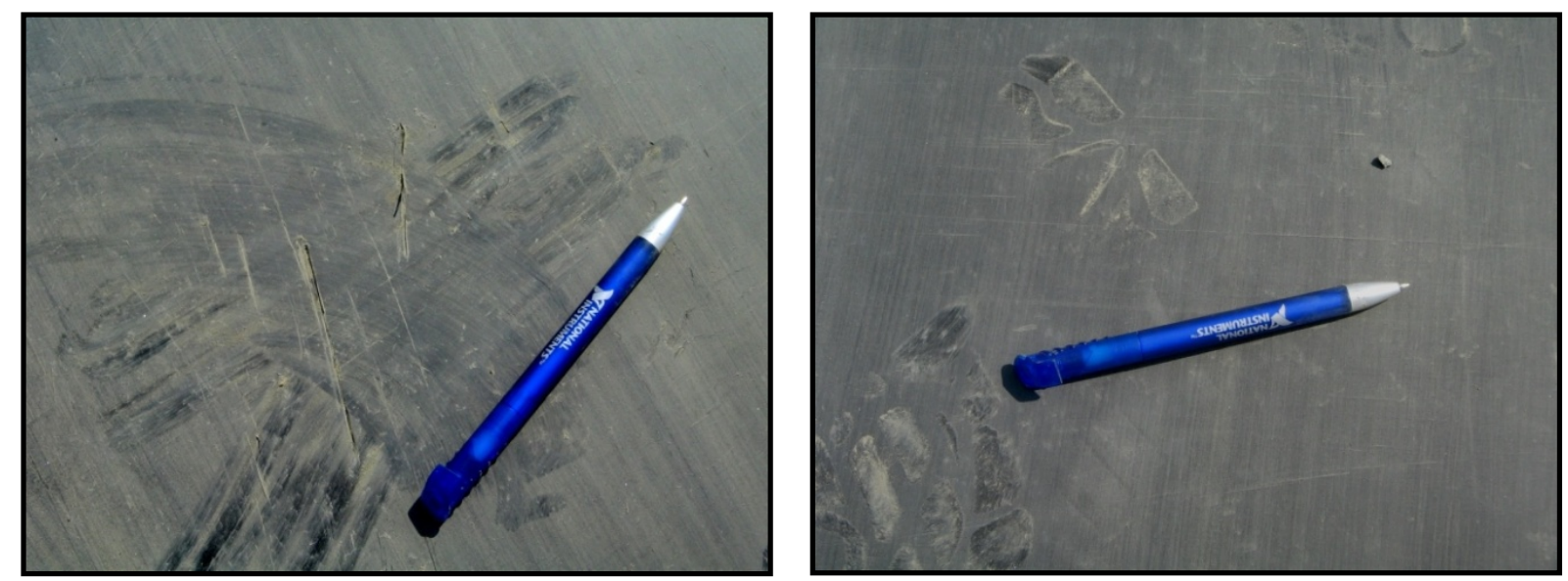

Figura 109. Danos visuais: GM de PEAD de $1,5 \mathrm{~mm}$ com GT PET $300 \mathrm{~g} / \mathrm{m}^{2}$ e brita 1.
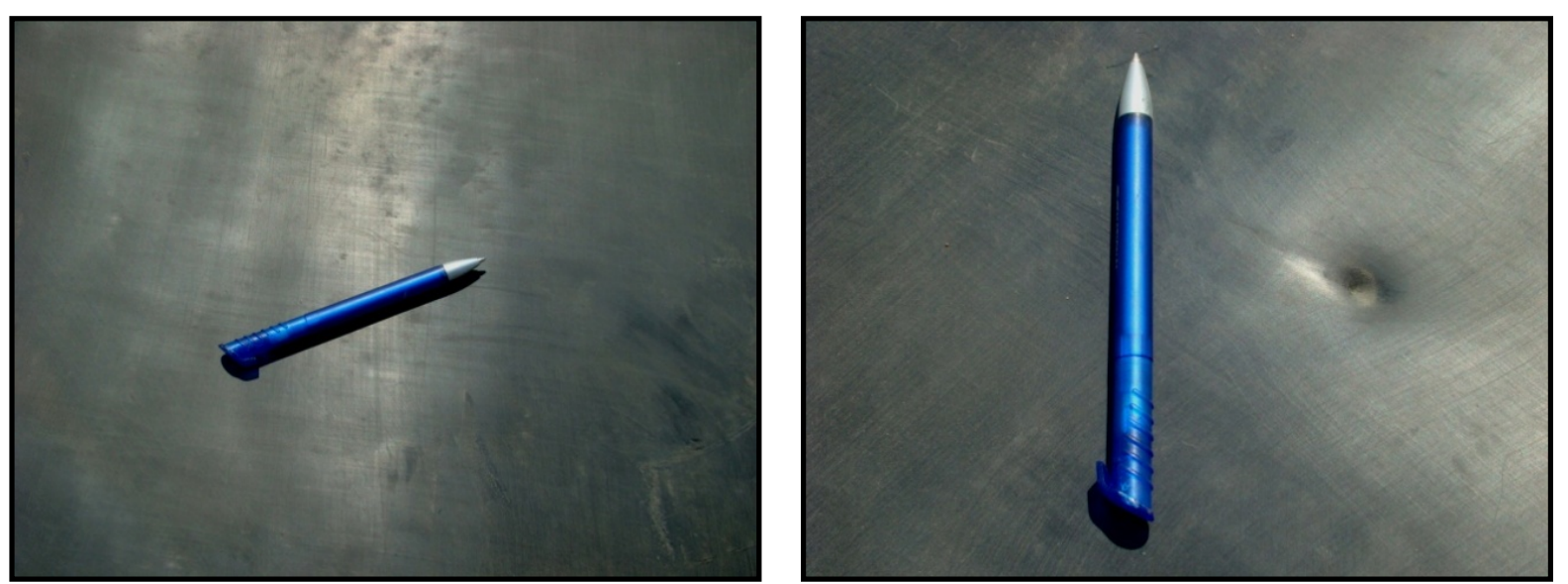

Figura 110. Danos visuais: GM de PEAD de $1,5 \mathrm{~mm}$ com GT PET $600 \mathrm{~g} / \mathrm{m}^{2}$ e brita 1 .
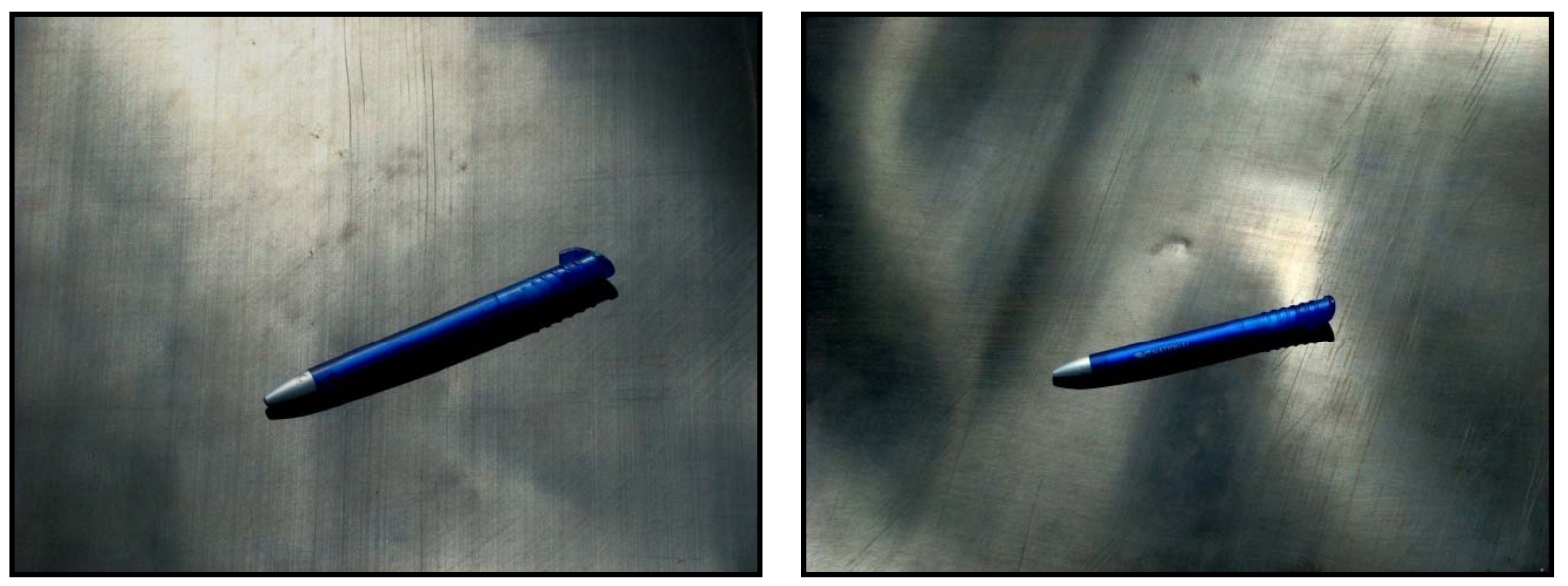

Figura 111. Danos visuais: GM de PEAD de $1,5 \mathrm{~mm}$ com GT PET $1200 \mathrm{~g} / \mathrm{m}^{2}$ e brita 1 . 


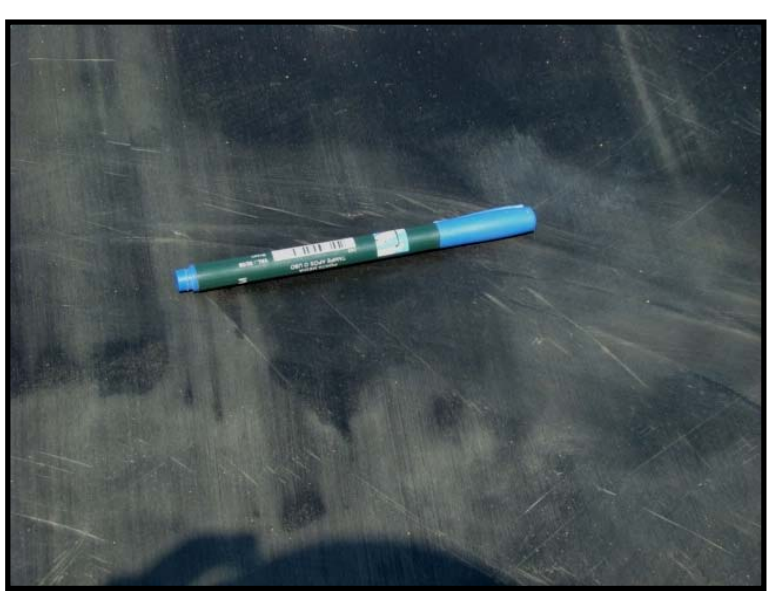

(a)

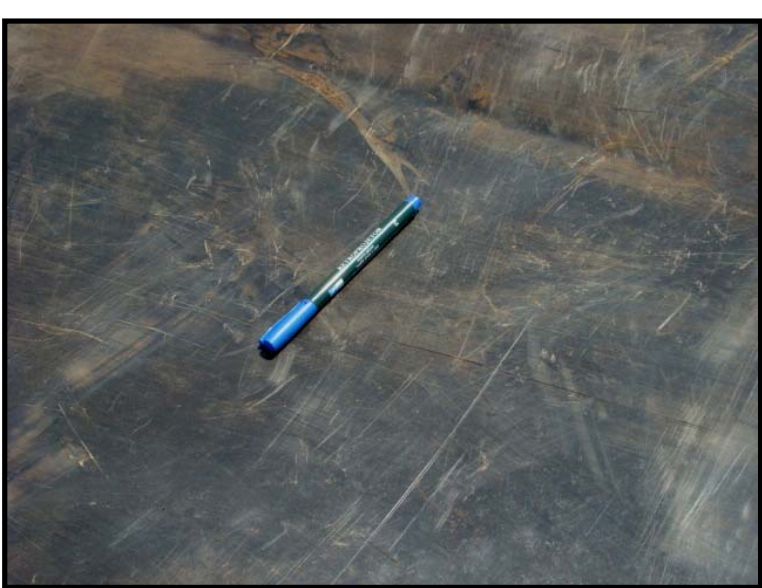

(b)

Figura 112. Danos visuais: GM de PEAD de 1,5 mm com camadas naturais e brita 1: (a) areia; (b) solo.

Tabela 39. Danos visuais observados nas geomembranas de PEAD.

\begin{tabular}{|c|c|c|c|c|c|c|c|c|}
\hline \multicolumn{3}{|c|}{ Configuração } & \multicolumn{5}{|c|}{ Tipo de Dano Visual } & \multirow{2}{*}{ Classe } \\
\hline GM & Proteção & Brita & Arranhão & Entalhe & Indentação & Deformação & Furos & \\
\hline \multirow{7}{*}{$\begin{array}{l}\text { PEAD } \\
1,5 \mathrm{~mm}\end{array}$} & - & \multirow{8}{*}{3} & muitos & vários & algumas & muitas & 2 & $\mathrm{I}$ \\
\hline & $\begin{array}{c}\text { GT PET } \\
300\end{array}$ & & bastante & - & algumas & muitas & - & II \\
\hline & $\begin{array}{c}\text { GT PET } \\
600 \\
\end{array}$ & & bastante & - & - & poucas & - & II \\
\hline & $\begin{array}{c}\text { GT PP } \\
600 \\
\end{array}$ & & poucos & - & - & muitas & - & II \\
\hline & $\begin{array}{c}\text { GT PET } \\
1200\end{array}$ & & - & - & - & - & - & III \\
\hline & Areia & & poucos & - & - & poucas & - & II \\
\hline & Solo & & poucos & - & - & poucas & - & II \\
\hline $\begin{array}{l}\text { PEAD } \\
2,0 \mathrm{~mm} \\
\end{array}$ & - & & muitos & - & várias & muitas & - & II \\
\hline \multirow{6}{*}{$\begin{array}{l}\text { PEAD } \\
1,5 \mathrm{~mm}\end{array}$} & - & \multirow{6}{*}{1} & muitos & - & - & poucas & 1 & $\mathrm{I}$ \\
\hline & $\begin{array}{c}\text { GT PET } \\
300 \\
\end{array}$ & & vários & - & - & poucas & - & II \\
\hline & $\begin{array}{c}\text { GT PET } \\
600\end{array}$ & & poucos & - & algumas & poucas & - & II \\
\hline & $\begin{array}{c}\text { GT PET } \\
1200\end{array}$ & & - & - & - & - & - & III \\
\hline & Areia & & poucos & - & - & - & - & II \\
\hline & Solo & & poucos & - & - & poucas & - & II \\
\hline
\end{tabular}

As geomembranas de PEAD sem proteção apresentaram todos os tipos de danos descritos pelo CFG (2001). Os arranhões e as deformações foram o tipo de dano mais recorrente. Também foi constatada a existência de alguns furos nas geomembranas de 1,5 
$\mathrm{mm}$. As geomembranas de 2,0 $\mathrm{mm}$ não apresentaram furos, no entanto, a presença dos outros tipos de danos foi intensa.

Nas configurações com elemento de proteção constatou-se uma redução dos danos visuais sobre a superfície da geomembrana, principalmente nos danos sob as formas de arranhões e entalhes. Em nenhuma configuração foi constatada a existência de furos nas geomembranas, apesar dos geotêxteis de PET $300 \mathrm{~g} / \mathrm{m}^{2}$ e PET $600 \mathrm{~g} / \mathrm{m}^{2}$ apresentaram furos sobre sua superfície.

Em termos de desempenho visual, as proteções com PET $1200 \mathrm{~g} / \mathrm{m}^{2}$ apresentaram melhor desempenho, sem provocar qualquer tipo de dano sobre a superfície da geomembrana. Apenas esta configuração se enquadrou na classe III proposta pelo CFG.

A proteção com geotêxtil de PP $600 \mathrm{~g} / \mathrm{m}^{2}$ também proporcionou um bom desempenho visual, com poucos arranhões sobre a superfície da geomembrana e sem perfurações no geotêxtil.

As camadas de proteção com areia e solo apresentaram melhor desempenho visual do que os geotêxteis com gramatura de 300 e $600 \mathrm{~g} / \mathrm{m}^{2}$, sendo observados apenas poucos arranhões e deformações.

\subsubsection{Ensaios Pós-Danos}

\subsection{Ensaio de Tração Faixa Larga}

As Figuras abaixo apresentam as curvas obtidas nos ensaios de tração em faixa larga nas geomembranas de PEAD, com diferentes camadas de proteção. A Figura 127 ilustra o mecanismo de ruptura verificado em algumas configurações. 


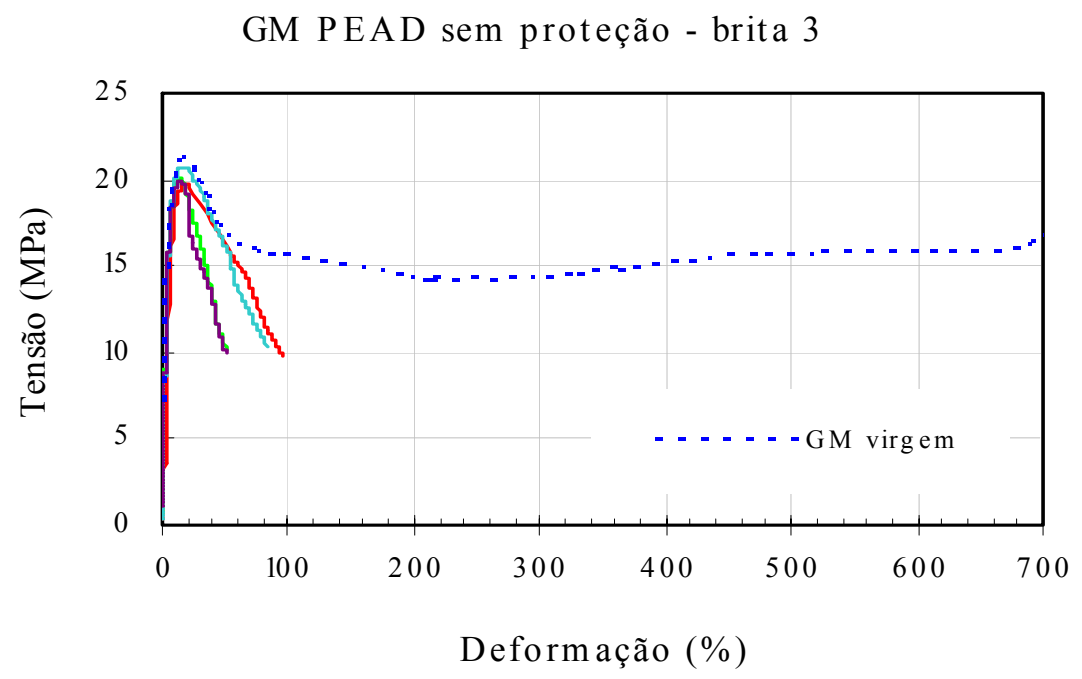

Figura 113. Resultados dos ensaios de tração em faixa larga: GM de PEAD de 1,5 mm sem proteção / brita 3 .

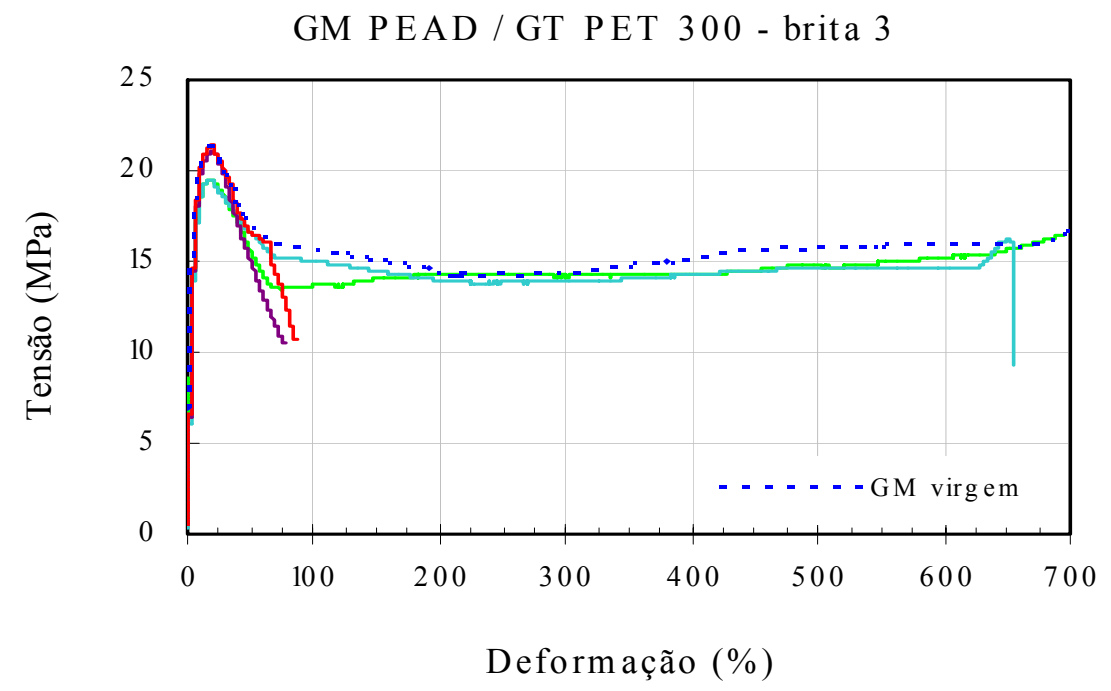

Figura 114. Resultados dos ensaios de tração em faixa larga - GM de PEAD e GT PET 300 $\mathrm{g} / \mathrm{m}^{2} /$ brita 3 . 


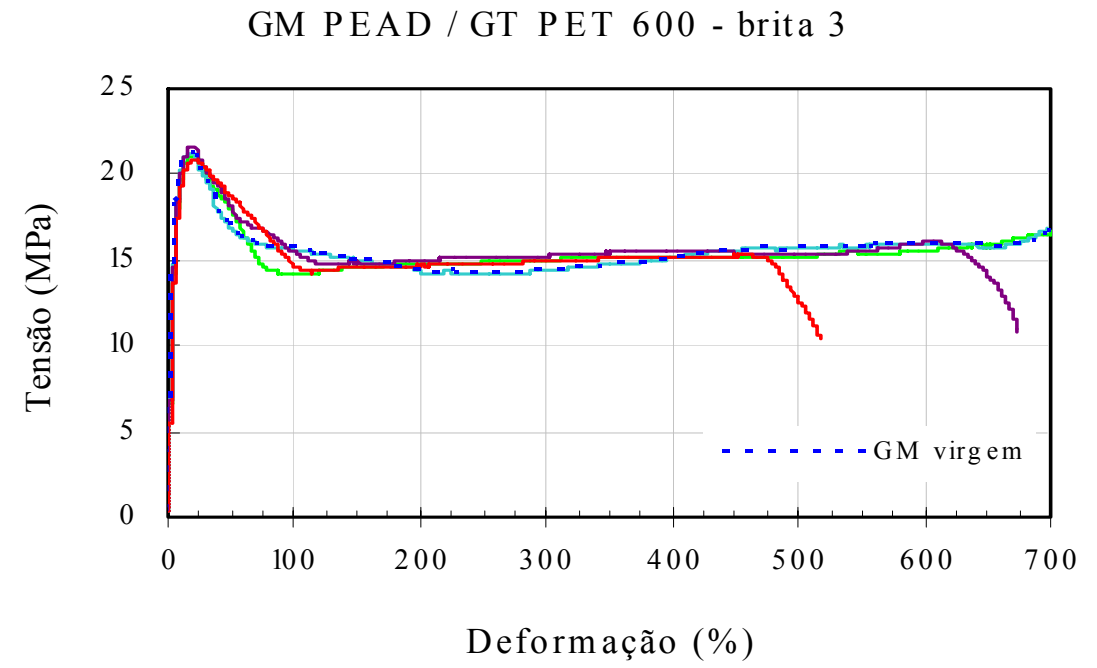

Figura 115. Resultados dos ensaios de tração em faixa larga - GM de PEAD e GT PET 600 $\mathrm{g} / \mathrm{m}^{2} /$ brita 3 .

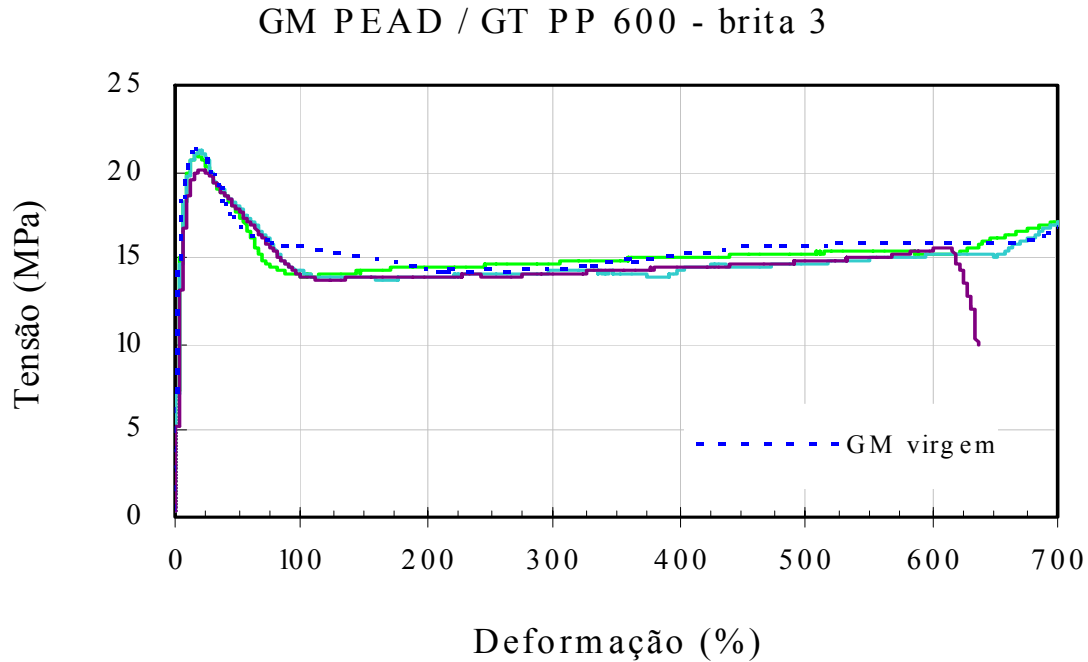

Figura 116. Resultados dos ensaios de tração em faixa larga - GM de PEAD e GT PP 600 $\mathrm{g} / \mathrm{m}^{2} /$ brita 3 . 
GM PEAD / GT PET 1200 - brita 3

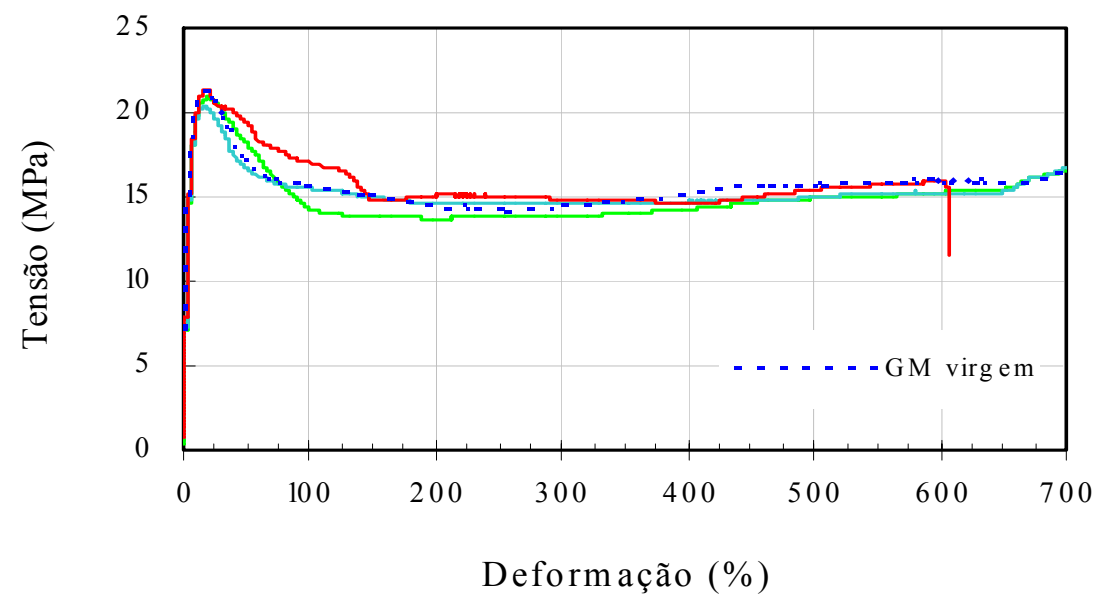

Figura 117. Resultados dos ensaios de tração em faixa larga - GM de PEAD e GT PET 1200 $\mathrm{g} / \mathrm{m}^{2} /$ brita 3 .

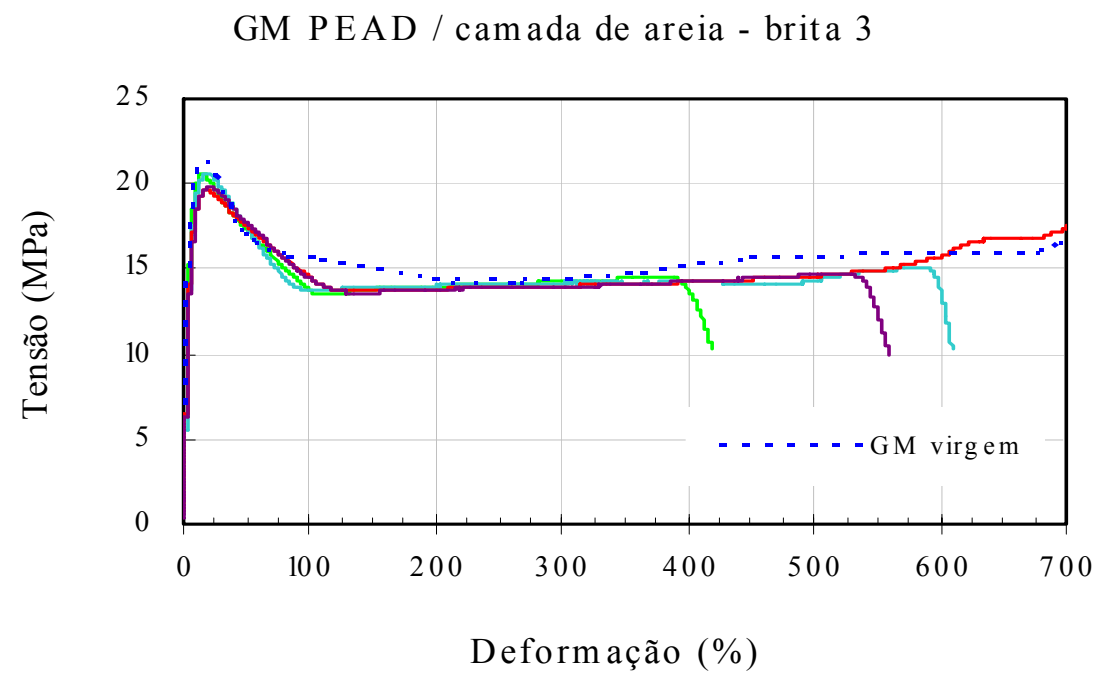

Figura 118. Resultados dos ensaios de tração em faixa larga - GM de PEAD e areia / brita 3. 
GM PEAD / camada de solo - brita 3

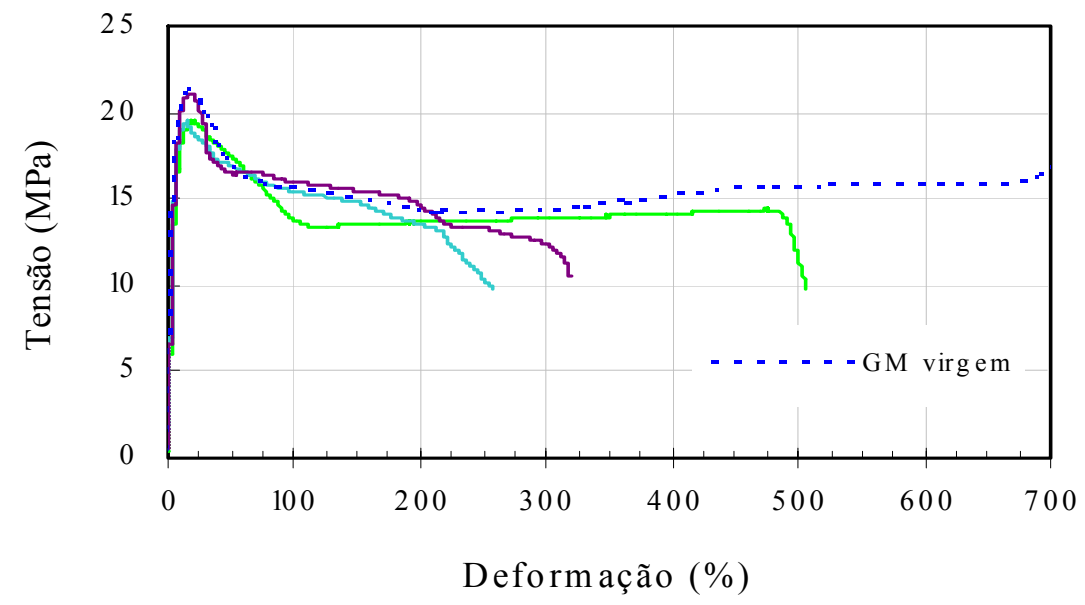

Figura 119. Resultados dos ensaios de tração em faixa larga - GM de PEAD e solo / brita 3.

GM PEAD $2.0 \mathrm{~mm}$ sem proteção

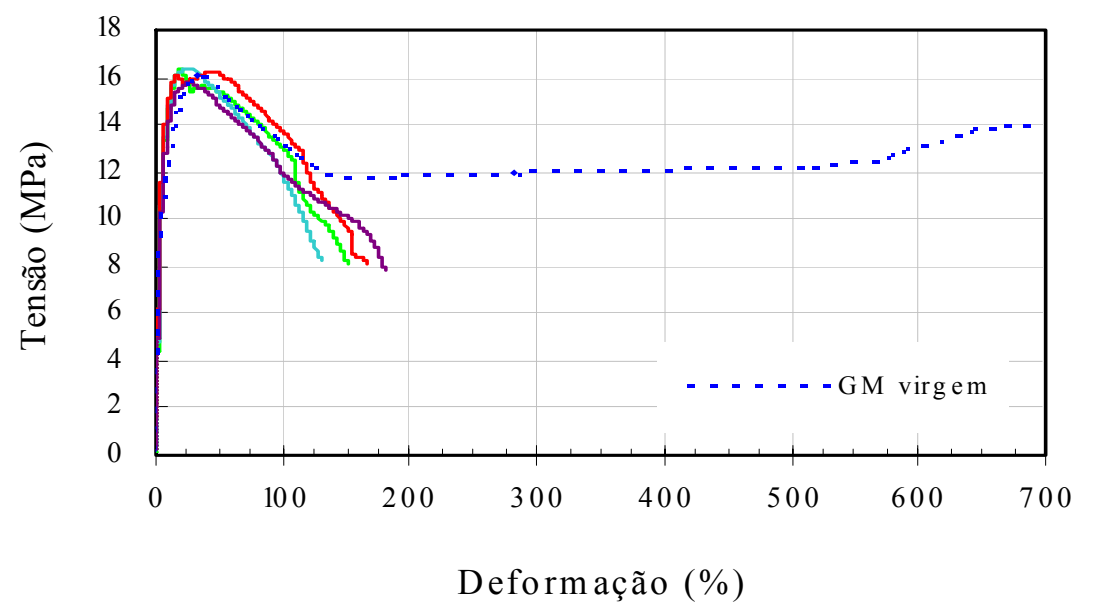

Figura 120. Resultados dos ensaios de tração em faixa larga - GM de PEAD de 2,0 mm sem proteção / brita 3 . 
GM PEAD sem protecão - brita 1

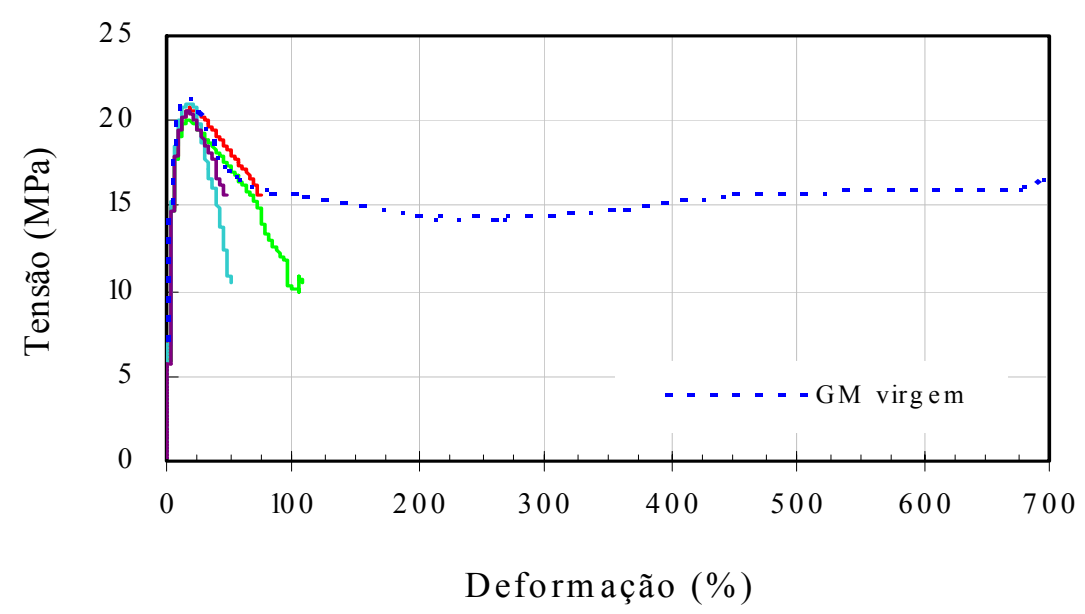

Figura 121. Resultados dos ensaios de tração em faixa larga - GM de PEAD de 1,5 mm sem proteção / brita 1.

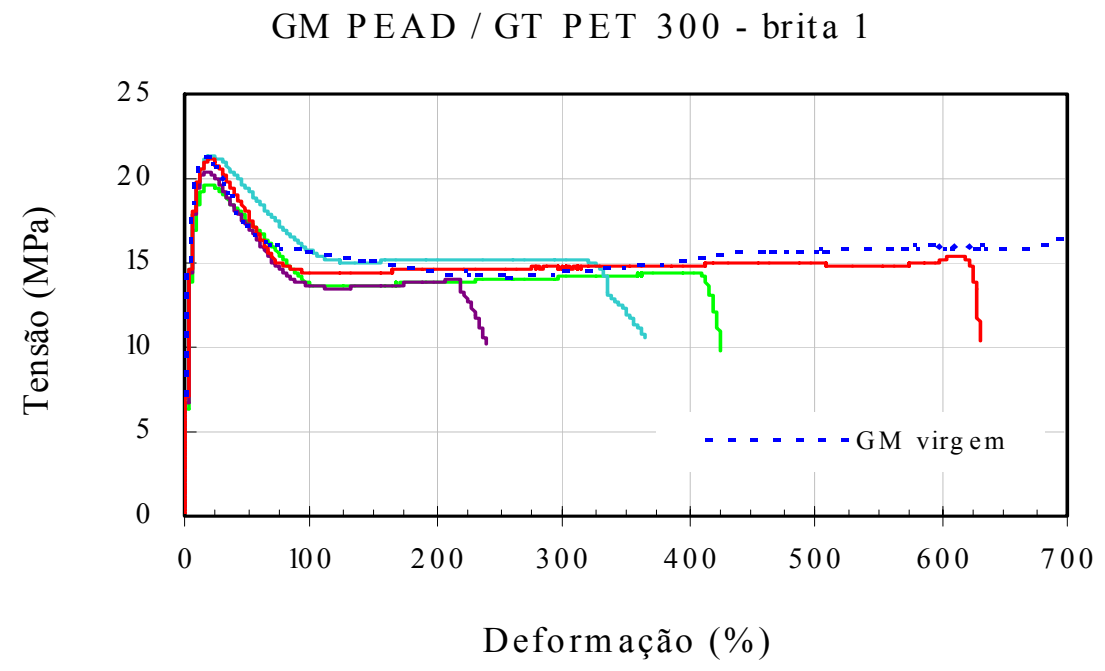

Figura 122. Resultados dos ensaios de tração em faixa larga - GM de PEAD e GT PET 300 $\mathrm{g} / \mathrm{m}^{2} /$ brita 1 . 


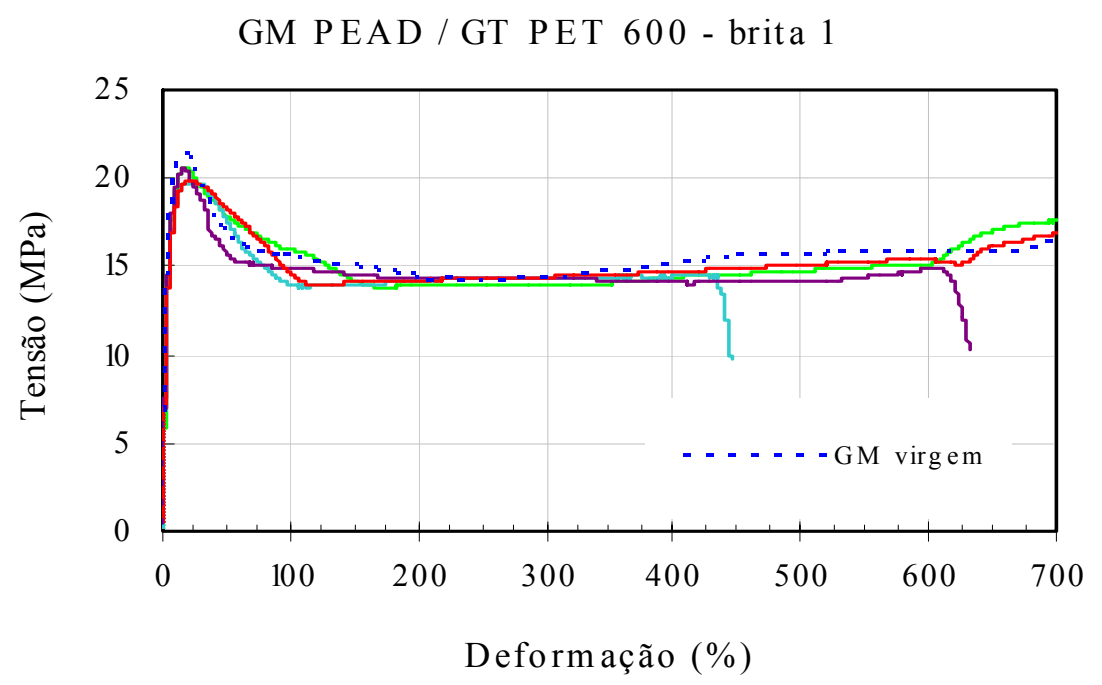

Figura 123. Resultados dos ensaios de tração em faixa larga - GM de PEAD e GT PET 600 $\mathrm{g} / \mathrm{m}^{2} /$ brita 1 .

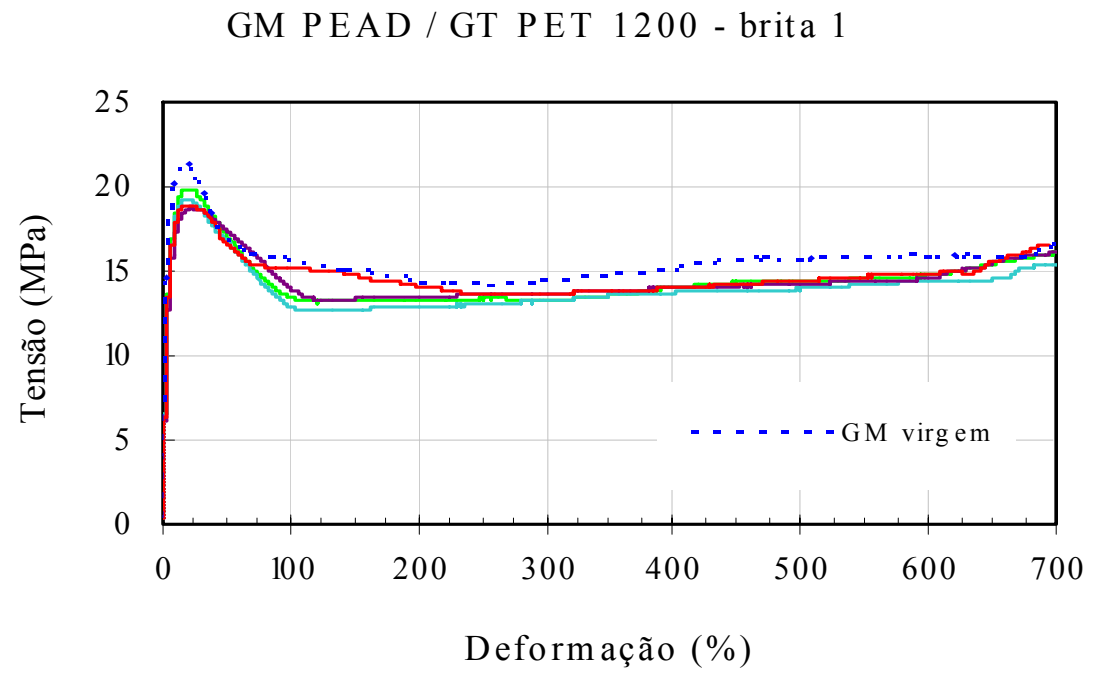

Figura 124. Resultados dos ensaios de tração em faixa larga - GM de PEAD e GT PET 1200 $\mathrm{g} / \mathrm{m}^{2} /$ brita 1 . 
GM PEAD / camada de areia - brita 1

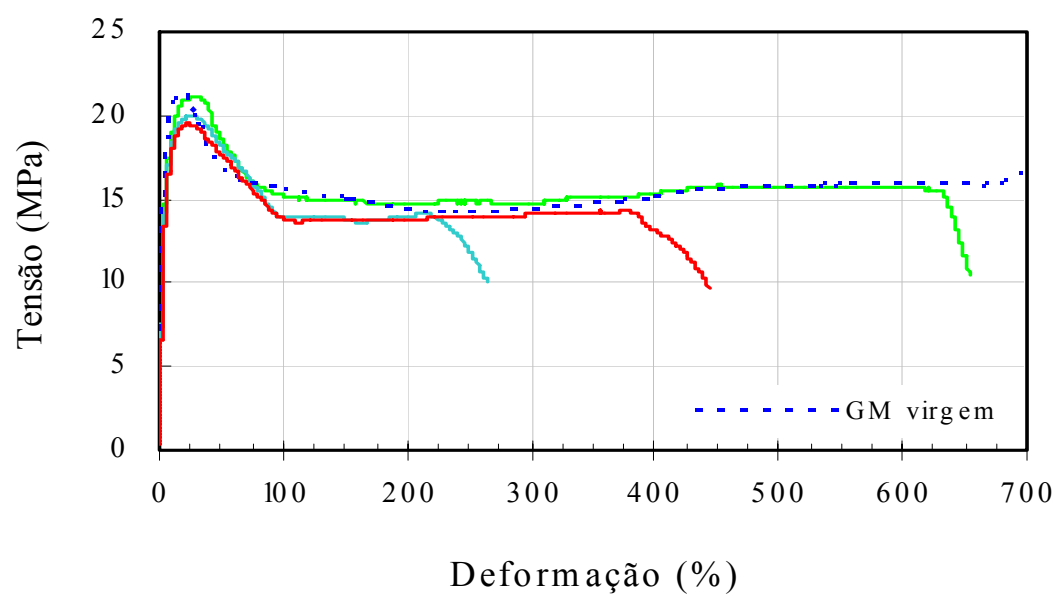

Figura 125. Resultados dos ensaios de tração em faixa larga - GM de PEAD e areia / brita 1.

GM PEAD / camada de solo

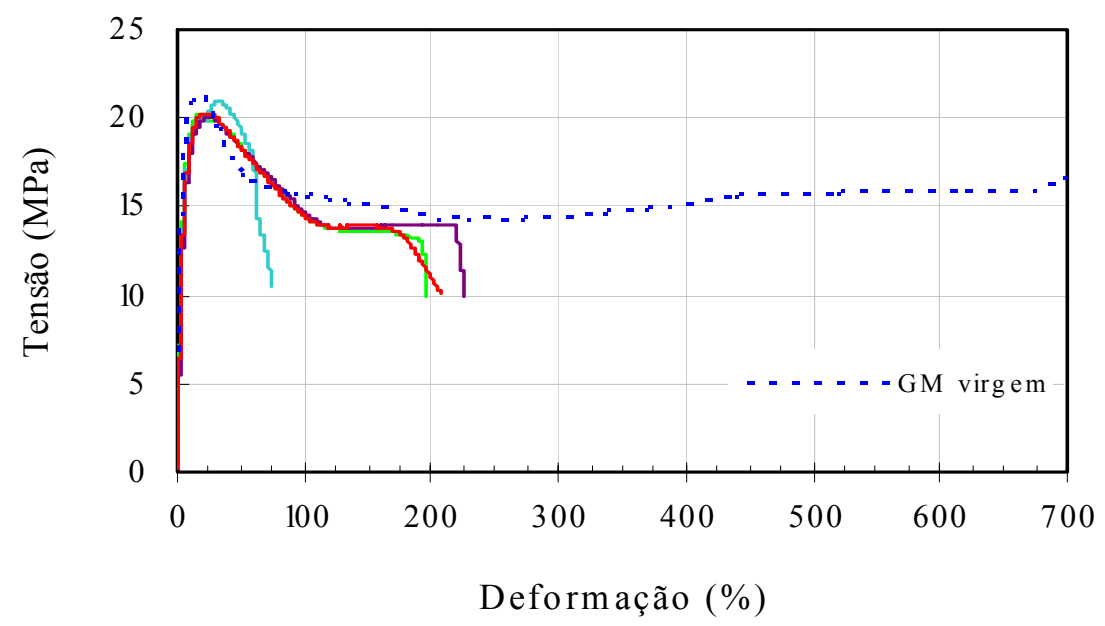

Figura 126. Resultados dos ensaios de tração em faixa larga - GM de PEAD e solo / brita 1. 


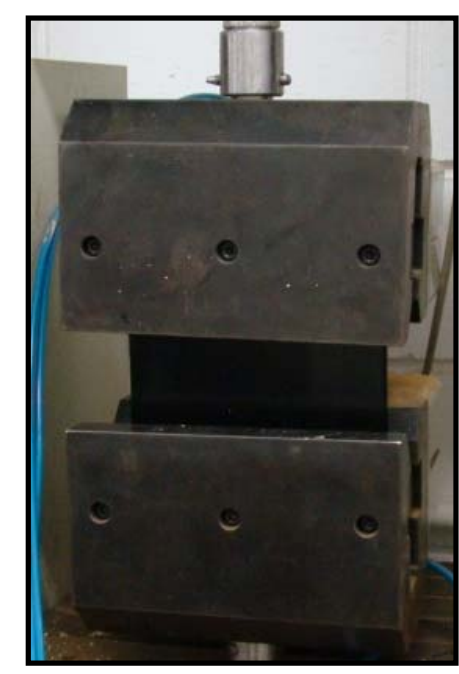

GM virgem - início do ensaio

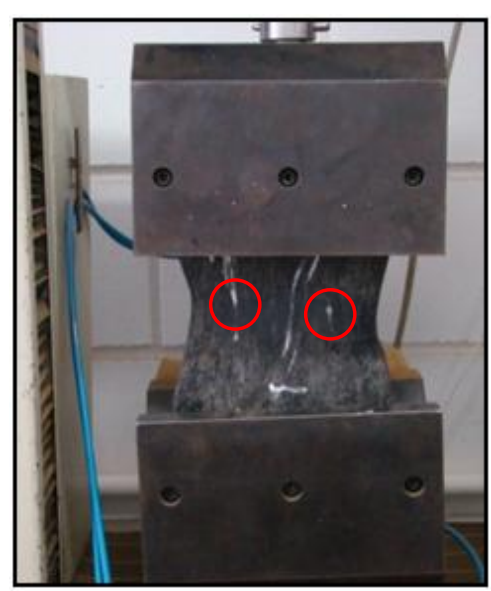

GM sem proteção - início do

rasgo

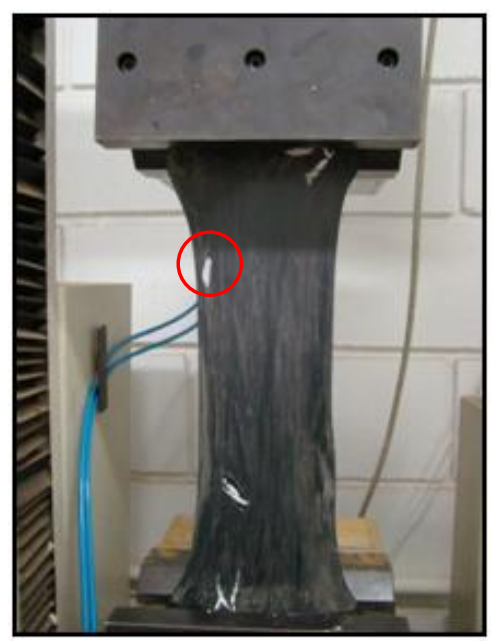

GT PET 300

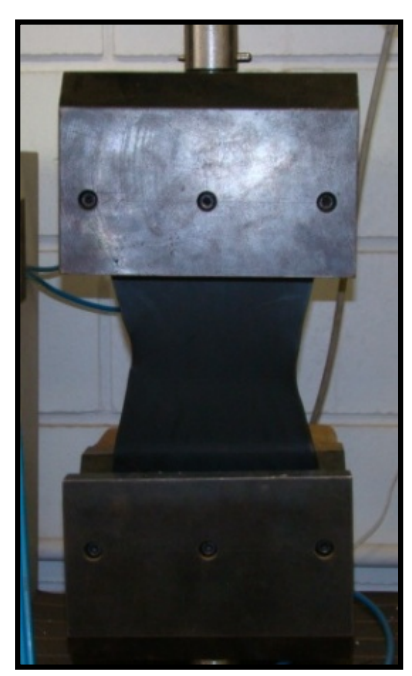

GM virgem

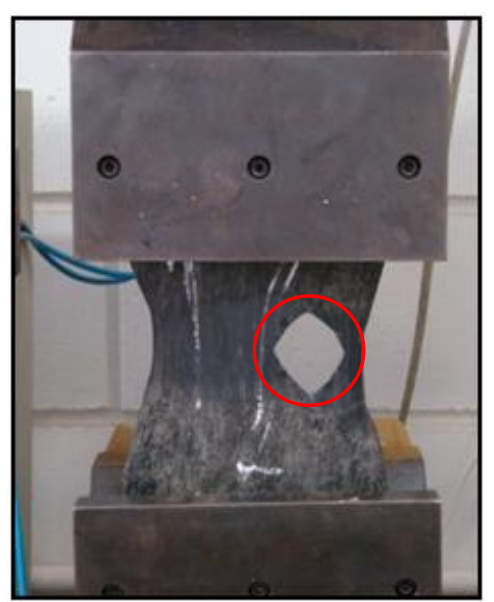

GM sem proteção propagação do rasgo

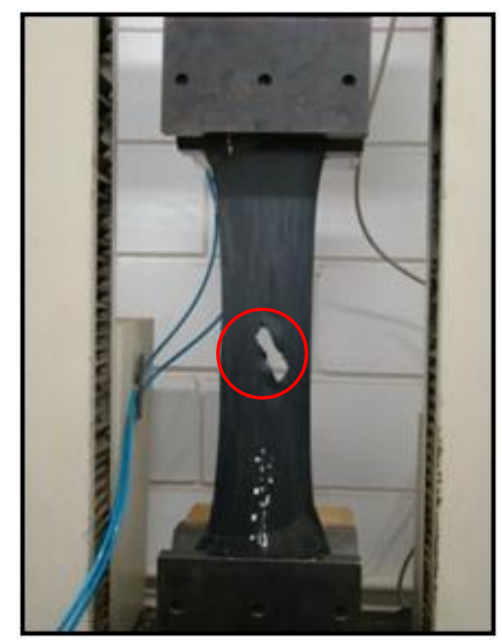

GT PET 600

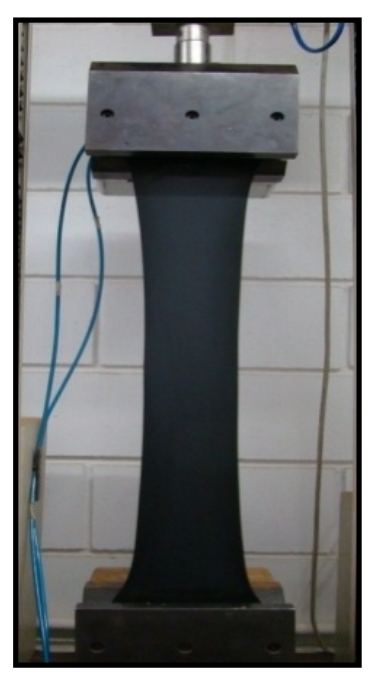

GM virgem - final do ensaio

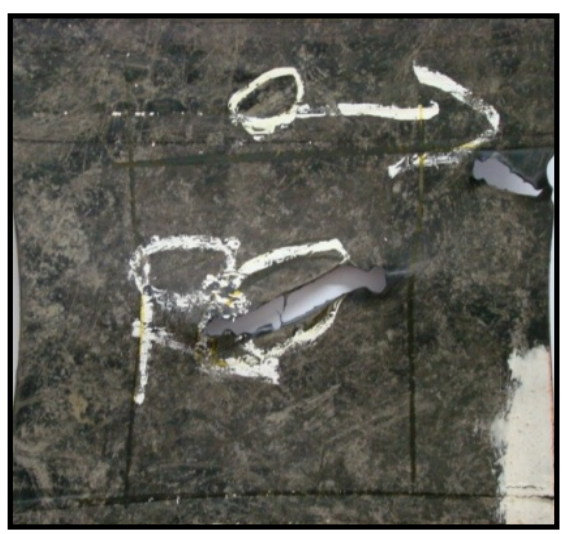

Detalhe ruptura no entalhe

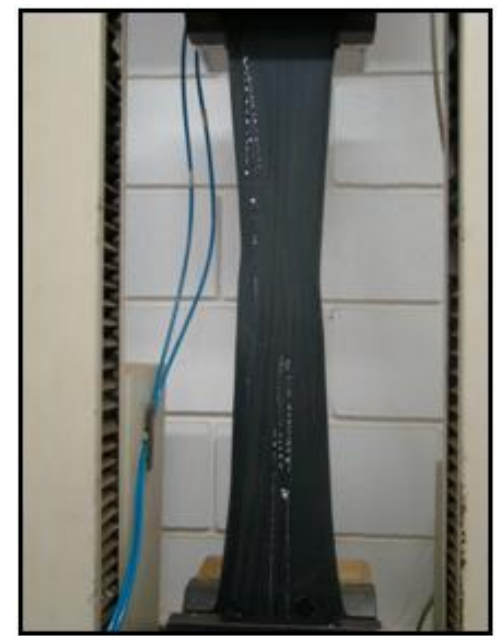

GT PET 1200

Figura 127 (Continua). Mecanismo de ruptura nos ensaios de tração em faixa larga - GM de PEAD. 


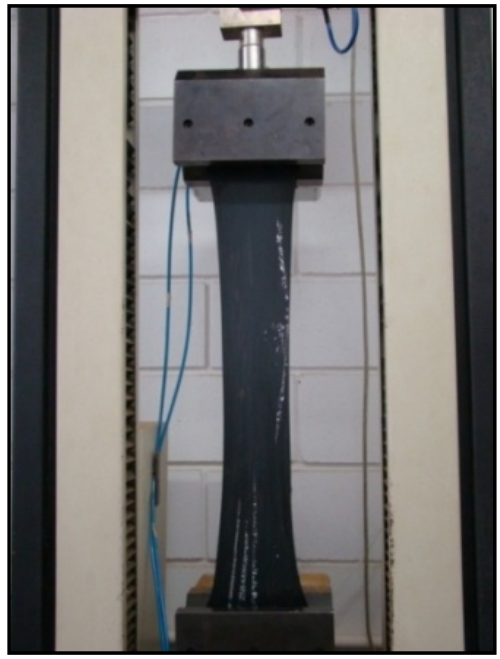

GT PP 600

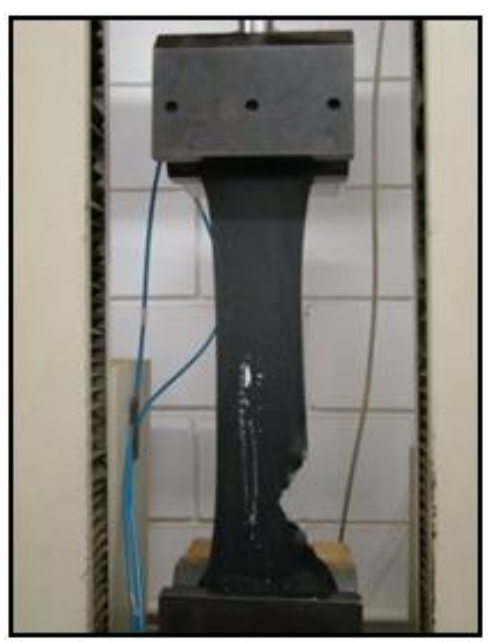

Camada de areia

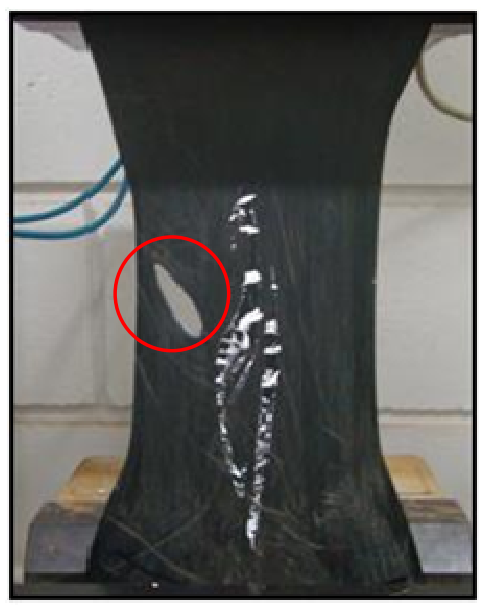

Camada de solo

Figura 127 (Final). Mecanismo de ruptura nos ensaios de tração em faixa larga - GM de PEAD.

O resultado típico do ensaio de tração em faixa larga em geomembranas de PEAD é caracterizado pelo alongamento da geomembrana com o acréscimo de tensão aplicada até que a geomembrana atinja um valor de pico (limite elástico). A partir deste ponto e continuando o alongamento da geomembrana, ocorre a estricção da seção transversal do corpo e conseqüente diminuição da tensão aplicada. Novamente, a tensão volta a crescer com o aumento do alongamento até que ocorra a ruptura. Neste caso, a ruptura é caracterizada por um corte instantâneo ao longo de toda a seção transversal da geomembrana.

Geralmente, a ruptura em geomembranas de PEAD ocorre para valores em torno de $1000 \%$. Devido à limitação do deslocamento da máquina (fim de curso), o corpo de prova atingiu deformações em torno de $800 \%$, valor este tomado com deformação de ruptura para fins de análise.

Diferente do observado nas geomembranas virgens, as amostras de geomembranas danificadas sem proteção romperam imediatamente após atingir o limite elástico, ou seja, com baixos valores de deformação e tensão. A ruptura do corpo de prova é caracterizada por um 
rasgo que se inicia na região mais danificada da geomembrana, localizada sobre os arranhões e entalhes, e se propaga ao longo do corpo de prova.

Com a introdução do elemento de proteção, verificou-se que a geomembrana alcançou maiores valores de alongamento antes de atingir a ruptura. Contudo, a ruptura também é caracterizada por um rasgo iniciado geralmente nos arranhões.

Mesmo nas configurações com poucos arranhões como, por exemplo, com proteção de areia, solo e PET 600, a ruptura da geomembrana foi caracterizada por um rasgo. Somente a proteção com PET $1200 \mathrm{~g} / \mathrm{m}^{2}$ e PP $600 \mathrm{~g} / \mathrm{m}^{2}$ que atingiu grandes valores de alongamento e apresentou modo de ruptura semelhante à da geomembrana virgem.

Apesar de algumas configurações apresentarem indentações, não se verificou o início da ruptura nestas regiões e sim nos arranhões e entalhes.

As Figuras abaixo apresentam os gráficos de tensão e deformação em termos de escoamento e ruptura respectivos aos ensaios realizados com geotêxteis. Nestas figuras $\alpha$ representa a relação entre a força de tração do geotêxtil $\left(F_{t} G T\right)$ e a força de tração da geomembrana, e $\beta$ representa a relação entre a propriedade da geomembrana danificada $\left(\mathrm{P}_{\mathrm{GM}}\right.$ danificada $)$ e propriedade da geomembrana virgem $\left(\mathrm{P}_{\mathrm{GM}}\right.$ virgem $)$ analisada. A Tabela 40 sintetiza os resultados de todas as configurações. 
GM PEAD $1.5 \mathrm{~mm}$ - Brita 3

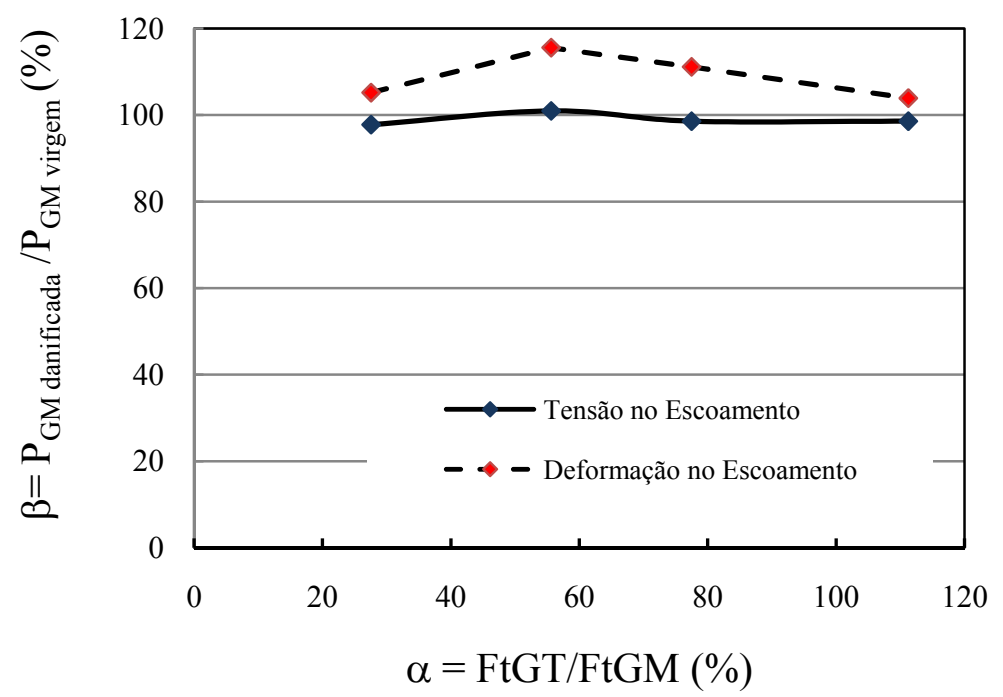

(a)

GM PEAD $1.5 \mathrm{~mm}$ - Brita 3

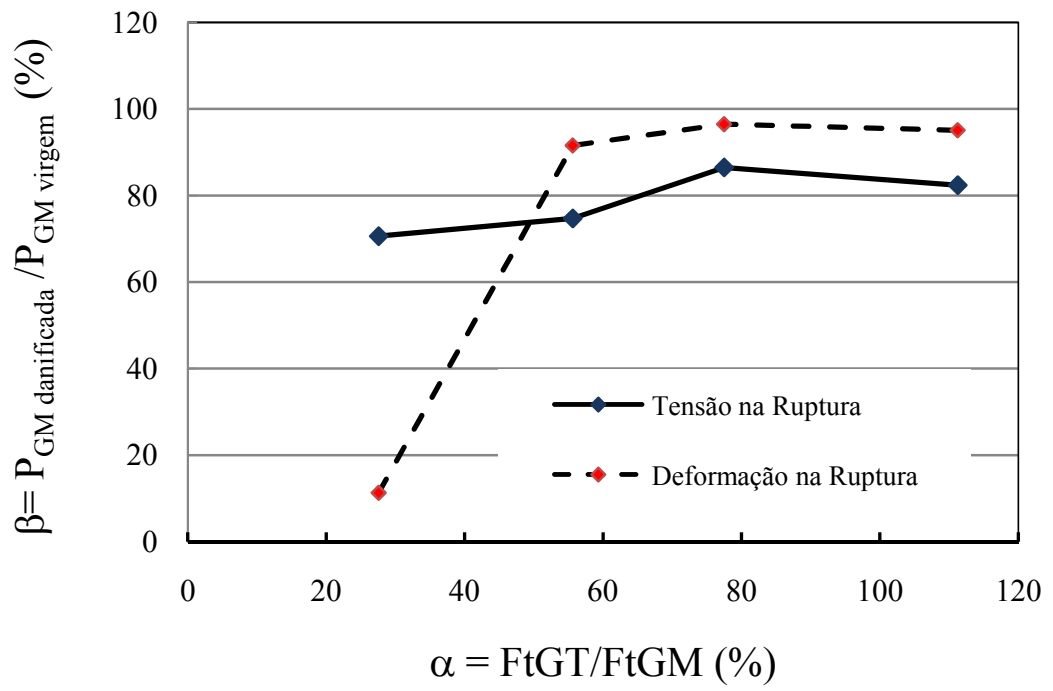

(b)

Figura 128. Resultados de tração em faixa larga - GM de PEAD e brita 3: (a) escoamento; (b) ruptura. 


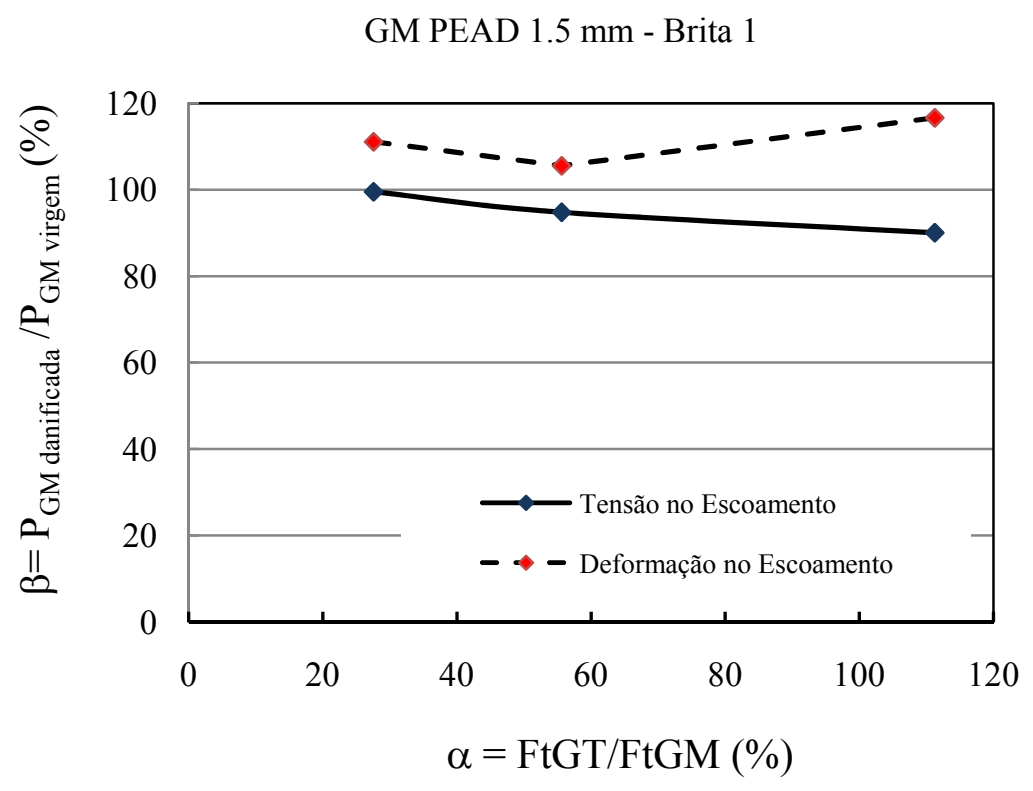

(a)

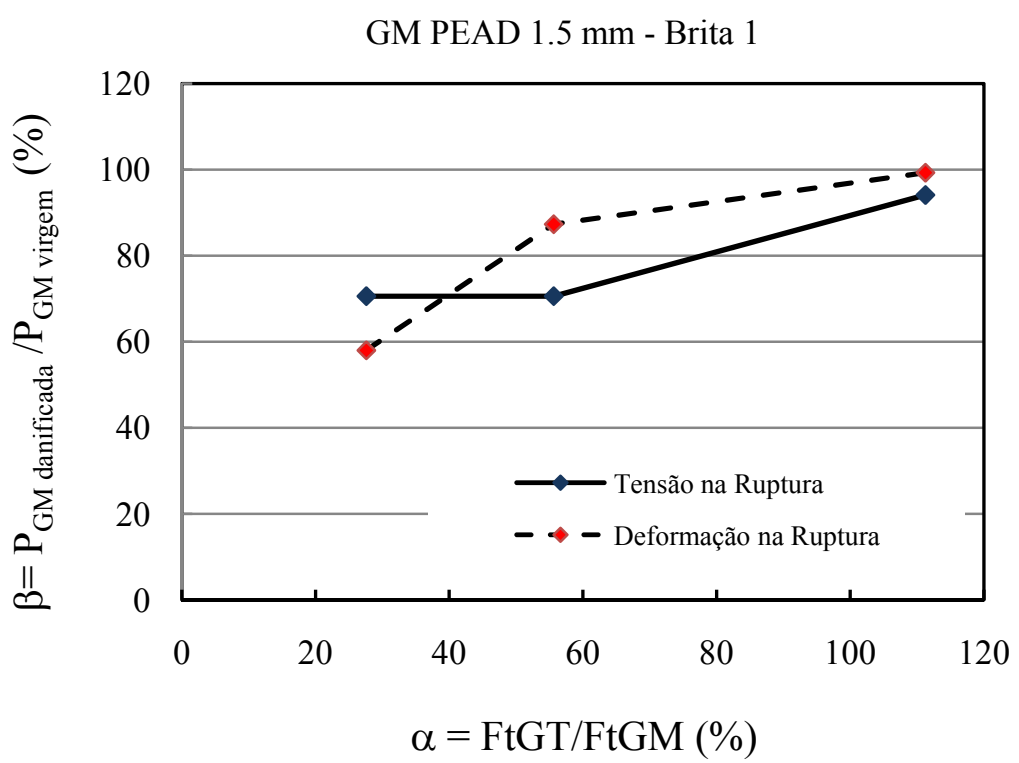

(b)

Figura 129. Resultados de tração em faixa larga - GM de PEAD e brita 1: (a) escoamento; (b) ruptura. 
Tabela 40. Resultados dos ensaios de tração faixa larga realizados nas geomembranas de PEAD.

\begin{tabular}{|c|c|c|c|c|c|c|}
\hline \multirow{2}{*}{\multicolumn{3}{|c|}{ Configuração de Ensaio }} & \multicolumn{2}{|c|}{ Escoamento } & \multicolumn{2}{|l|}{ Ruptura } \\
\hline & & & $\sigma$ & $\varepsilon$ & $\sigma$ & $\varepsilon$ \\
\hline GM & Proteção & Brita & (MPa) & $(\%)$ & (MPa) & \\
\hline GM virgem $1.5 \mathrm{~mm}$ & - & - & 21,1 & 18 & 16,9 & 710 \\
\hline GM virgem $2.0 \mathrm{~mm}$ & - & - & 15,3 & 36 & 13,7 & 703 \\
\hline \multirow{7}{*}{ GM danificada $1.5 \mathrm{~mm}$} & Sem proteção & \multirow{8}{*}{3} & 20,0 & 19 & 10,0 & 67 \\
\hline & GT PET 300 & & 20,6 & 19 & 10,1 & 80 \\
\hline & GT PET 600 & & 21,3 & 21 & 12,7 & 650 \\
\hline & GT PET 1200 & & 20,8 & 19 & 14,3 & 675 \\
\hline & GT PP 600 & & 20,8 & 20 & 14,7 & 685 \\
\hline & Areia & & 20,2 & 19 & 12,1 & 575 \\
\hline & Solo & & 20,0 & 17 & 10,0 & 270 \\
\hline GM danificada $2.0 \mathrm{~mm}$ & Sem proteção & & 16,2 & 25 & 8,1 & 160 \\
\hline \multirow{6}{*}{ GM danificada $1.5 \mathrm{~mm}$} & Sem proteção & \multirow{6}{*}{1} & 20,4 & 18 & 13,0 & 61 \\
\hline & GT PET 300 & & 21,0 & 20 & 10,4 & 412 \\
\hline & GT PET 600 & & 20,1 & 19 & 12,1 & 620 \\
\hline & GT PET 1200 & & 19,0 & 21 & 16,1 & 705 \\
\hline & Areia & & 19,8 & 22 & 10,0 & 454 \\
\hline & Solo & & 20,4 & 18 & 10,4 & 175 \\
\hline
\end{tabular}

As propriedades de tração em termos de escoamento não se modificaram em relação à geomembrana virgem. Somente foram verificadas alterações em termos de resistência a ruptura.

As configurações sem proteção apresentaram uma grande redução em termos de deformação na ruptura. Na configuração com brita 3, as geomembranas apresentaram uma redução em torno de $40 \%$ e $90 \%$ na tensão e deformação de ruptura, respectivamente, em relação aos valores da geomembrana virgem.

Com a introdução do elemento de proteção, constatou-se um aumento nos valores de tensão e deformação de ruptura. Em geral, as camadas de proteção com geotêxtil proporcionaram elevados valores de deformação das geomembranas $(\varepsilon \approx 700 \%)$. Excetua-se a configuração com geotêxtil de PET $300 \mathrm{~g} / \mathrm{m}^{2}$, que alcançou baixos valores de deformação na ruptura da geomembrana $(\varepsilon \approx 80 \%)$. Ressalta-se que esta configuração apresentou o pior 
desempenho no campo em termos de danos mecânicos visíveis. Em termos de tensão de ruptura, verificou-se um pequeno acréscimo dos valores com a introdução do geotêxtil.

Os resultados mostram que as geomembranas com proteção de areia também proporcionaram um acréscimo de tensão e deformação na ruptura em relação à geomembrana virgem. Apesar de apresentar poucos danos na superfície da geomembrana, a configuração com proteção de solo gerou baixos valores de tensão e deformação na geomembrana.

Na configuração com brita 1 , as geomembranas sem proteção apresentaram uma redução de $40 \%$ e $90 \%$, respectivos à tensão e deformação de ruptura. As geomembranas com camada de proteção apresentaram um aumento na deformação de ruptura, sendo que as configurações com PET $1200 \mathrm{~g} / \mathrm{m}^{2}$ e PET $600 \mathrm{~g} / \mathrm{m}^{2}$ apresentaram os maiores valores $(\varepsilon \approx$ $700 \%$ e $\varepsilon \approx 620 \%$, respectivamente. Ressalta-se que estas configurações também apresentaram melhor desempenho no campo em relação à presença e intensidade de danos visíveis. Adicionalmente, a configuração com geotêxtil de PET $300 \mathrm{~g} / \mathrm{m}^{2}$, com desempenho insatisfatório no campo, alcançou valores da ordem de $410 \%$ na geomembrana.

Ao contrário do comportamento verificado no campo, as configurações com areia como proteção apresentaram baixos valores de deformação na ruptura ( $\varepsilon=180 \%)$.

Os resultados dos ensaios de tração em faixa larga indicam que a tensão e deformação de ruptura variam com a resistência à tração do geotêxtil. Constatou-se que quanto maior a resistência à tração do geotêxtil, maior a deformação da geomembrana. No entanto, esta tendência foi evidenciada apenas nas configurações com brita 1. 


\subsection{Ensaio de Tração Multiaxial}

As Figuras a seguir apresentam as curvas e a análise dos resultados obtidos nos ensaios de tração multiaxial com geomembranas de PEAD. A Tabela 41 apresenta a síntese dos resultados.

Tabela 41. Resultados dos ensaios de tração multiaxial realizados nas geomembranas de PEAD.

\begin{tabular}{|c|c|c|c|c|c|c|}
\hline \multicolumn{3}{|c|}{ Configuração de Ensaio } & $\sigma \mathbf{r}$ & \multirow{2}{*}{$\Delta \sigma$} & \multirow{2}{*}{$\frac{\varepsilon r}{(\%)}$} & \multirow{2}{*}{$\Delta \varepsilon$} \\
\hline GM & Proteção & Brita & (MPa) & & & \\
\hline GM virgem & - & - & 25,6 & - & 62 & - \\
\hline \multirow{7}{*}{ GM danificada } & Sem proteção & \multirow{7}{*}{3} & 25,0 & 1,00 & 14 & 0,23 \\
\hline & GT PET 300 & & 25,9 & 1,01 & 16 & 0,26 \\
\hline & GT PET 600 & & 23,7 & 0,93 & 29 & 0,47 \\
\hline & GT PET 1200 & & 23,0 & 0,90 & 35 & 0,50 \\
\hline & GT PP 600 & & 23,0 & 0,90 & 31 & 0,57 \\
\hline & Areia & & 23,3 & 0,91 & 23 & 0,38 \\
\hline & Solo & & 20,6 & 0,80 & 30 & 0,48 \\
\hline \multirow{6}{*}{ GM danificada } & Sem proteção & \multirow{6}{*}{1} & 23,8 & 0,93 & 23 & 0,37 \\
\hline & GT PET 300 & & 22,9 & 0,90 & 24 & 0,40 \\
\hline & GT PET 600 & & 21,7 & 0,85 & 39 & 0,64 \\
\hline & GT PET 1200 & & 22,4 & 0,88 & 50 & 0,81 \\
\hline & Areia & & 24,4 & 0,95 & 21 & 0,34 \\
\hline & Solo & & 23,0 & 0,90 & 28 & 0,45 \\
\hline
\end{tabular}

* $\Delta \rightarrow$ razão entre a tensão $(\sigma)$ ou deformação $(\varepsilon)$ da geomembrana danificada em relação à geomembrana virgem.

GM PEAD virgem

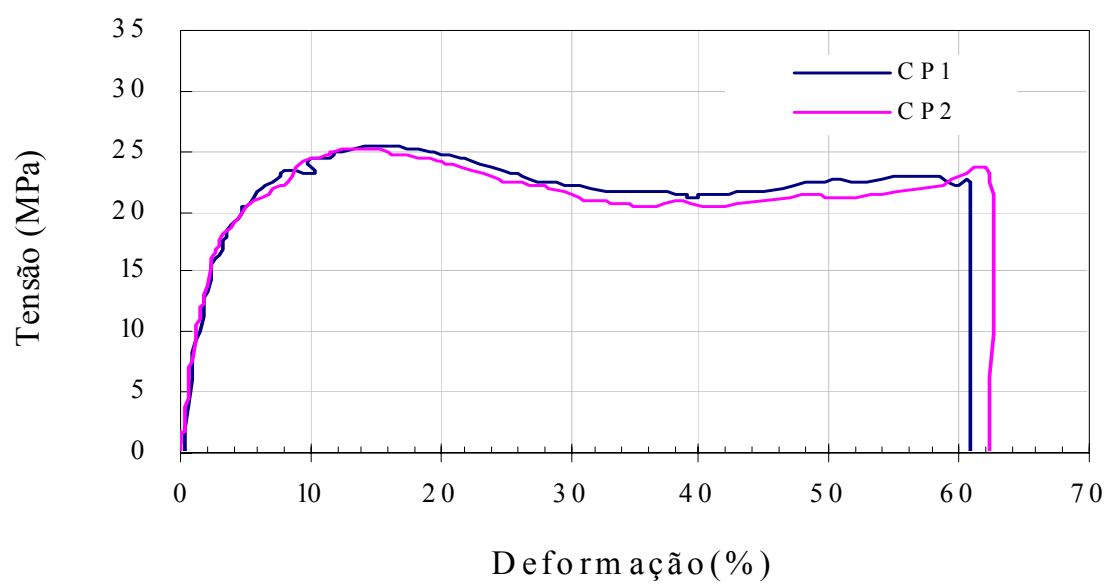

Figura 130. Resultados dos ensaios de tração multiaxial - GM de PEAD de 1,5 mm virgem. 


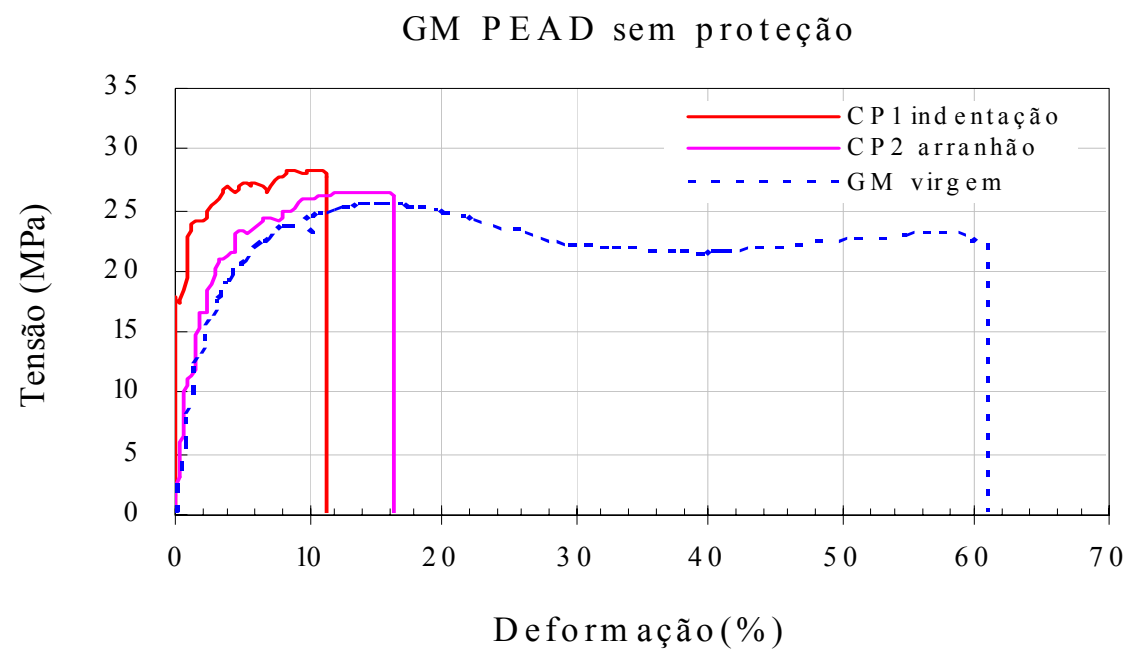

Figura 131. Resultados dos ensaios de tração multiaxial - GM de PEAD de $1,5 \mathrm{~mm}$ sem proteção / brita 3 .

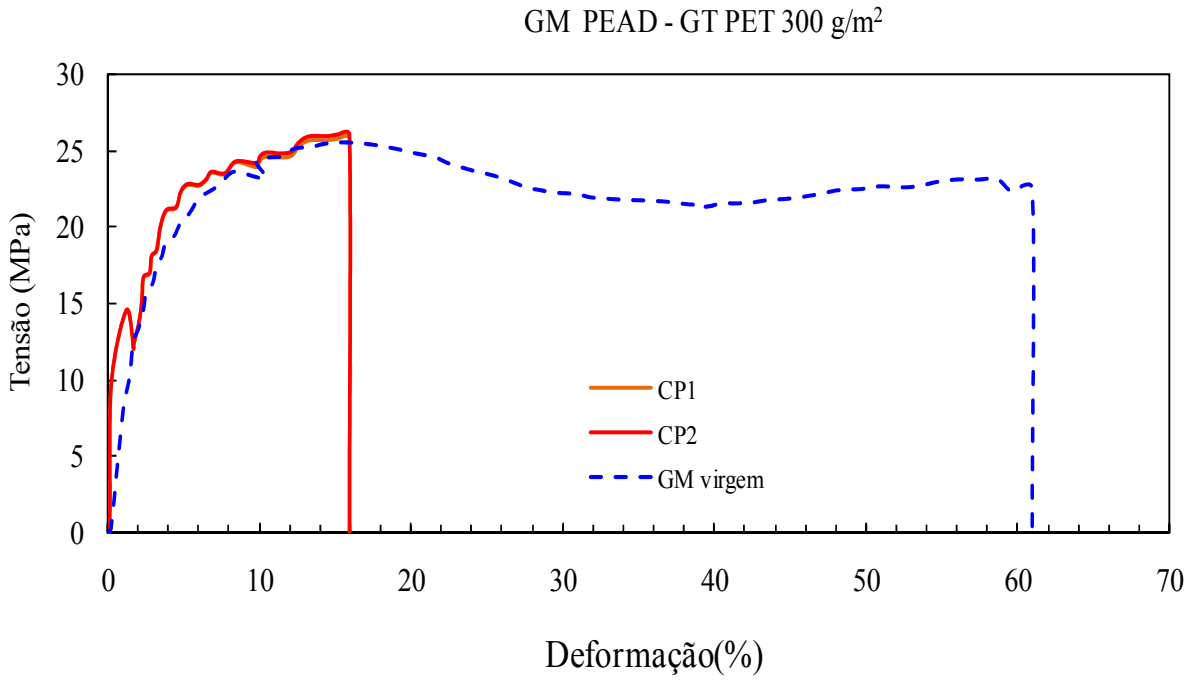

Figura 132. Resultados dos ensaios de tração multiaxial - GM de PEAD de 1,5 mm e GT PET $300 \mathrm{~g} / \mathrm{m}^{2} /$ brita 3 . 


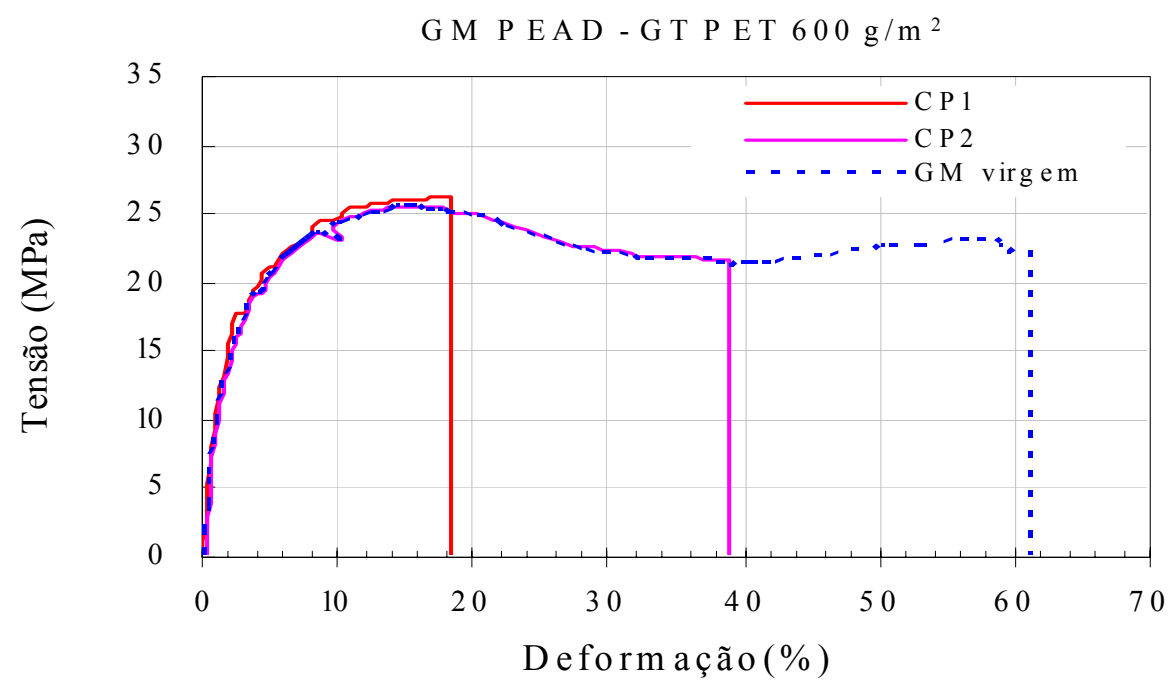

Figura 133. Resultados dos ensaios de tração multiaxial - GM de PEAD de 1,5 mm e GT PET $600 \mathrm{~g} / \mathrm{m}^{2} /$ brita 3 .

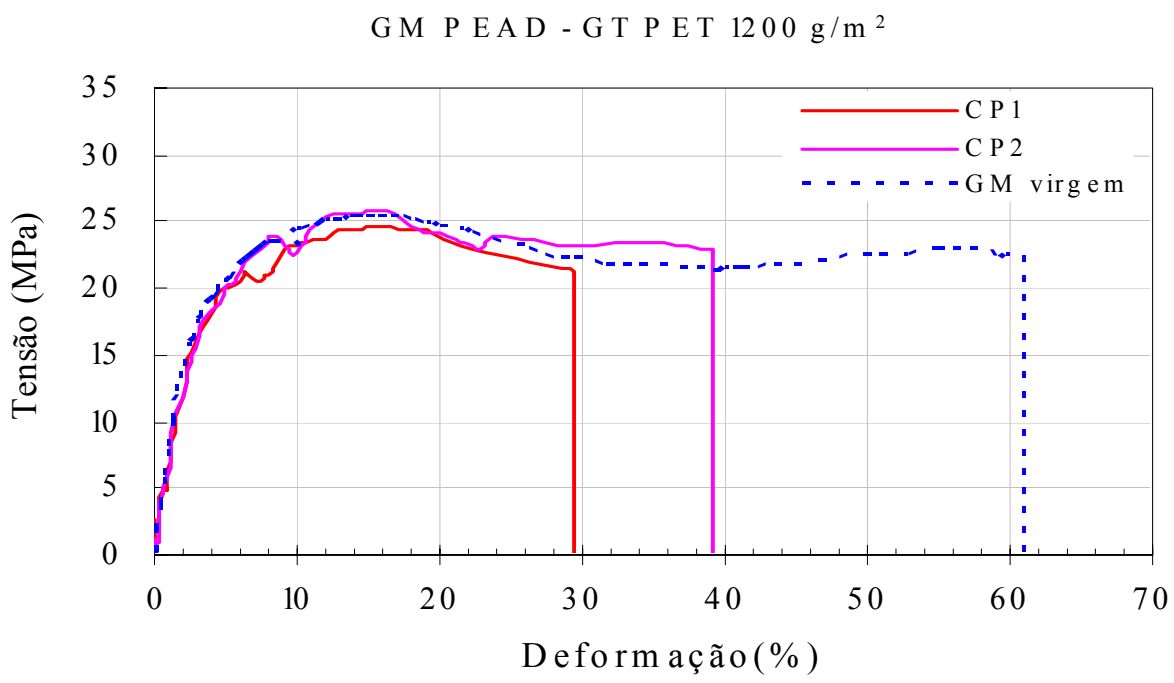

Figura 134. Resultados dos ensaios de tração multiaxial - GM de PEAD de 1,5 mm e GT PET $1200 \mathrm{~g} / \mathrm{m}^{2} /$ brita 3 . 


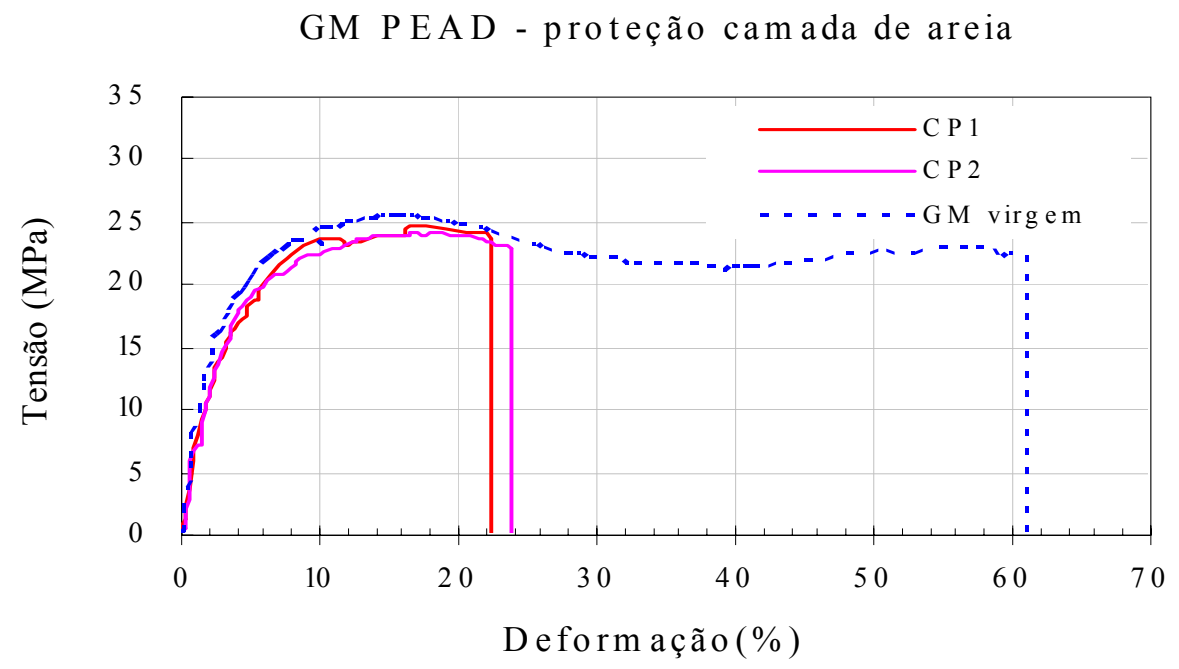

Figura 135. Resultados dos ensaios de tração multiaxial - GM de PEAD de 1,5 mm e camada de areia/ brita 3 .

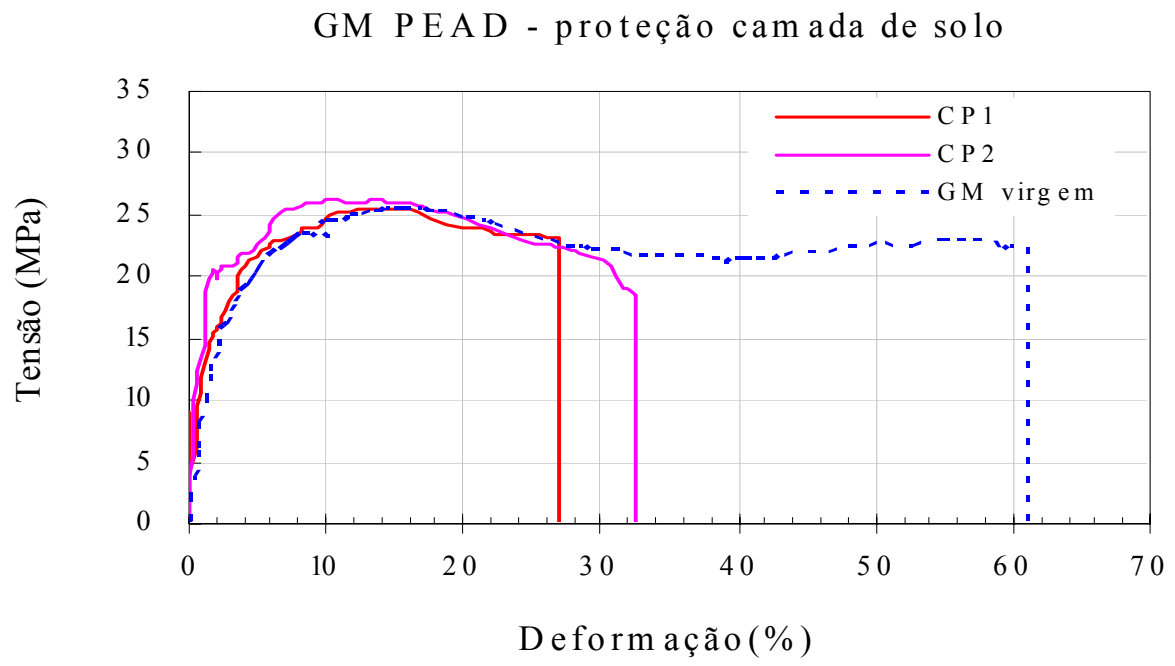

Figura 136. Resultados dos ensaios de tração multiaxial - GM de PEAD de 1,5 mm e camada de solo/ brita 3 . 


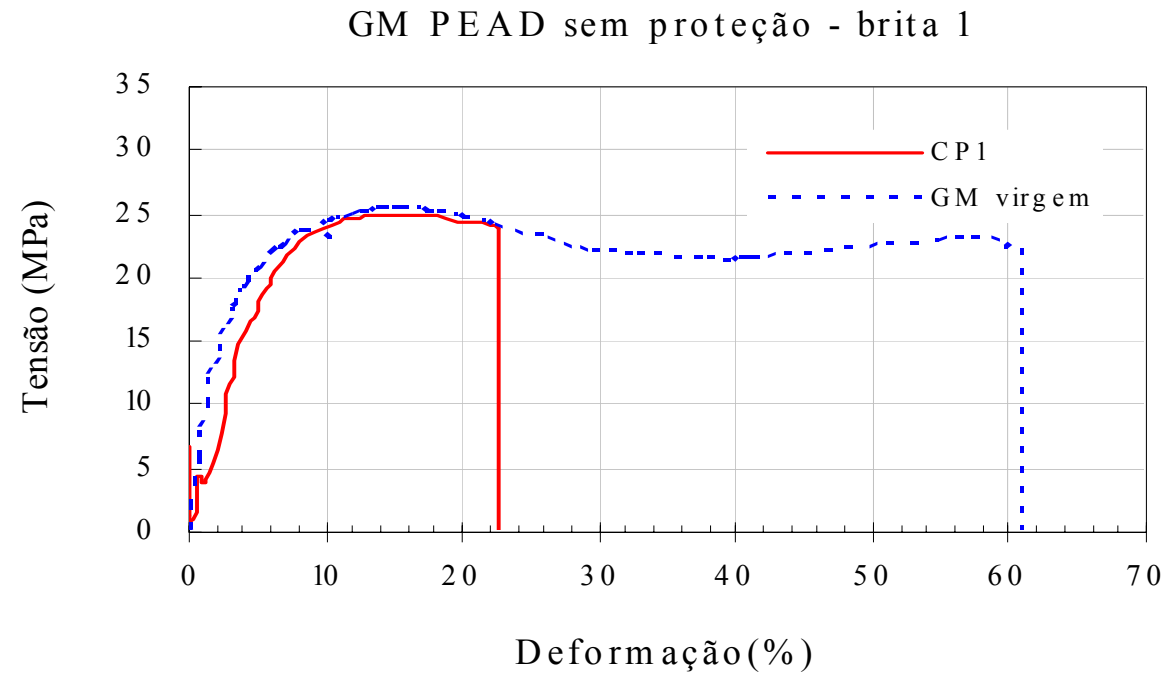

Figura 137. Resultados dos ensaios de tração multiaxial - GM de PEAD de 1,5 mm sem proteção / brita 1.

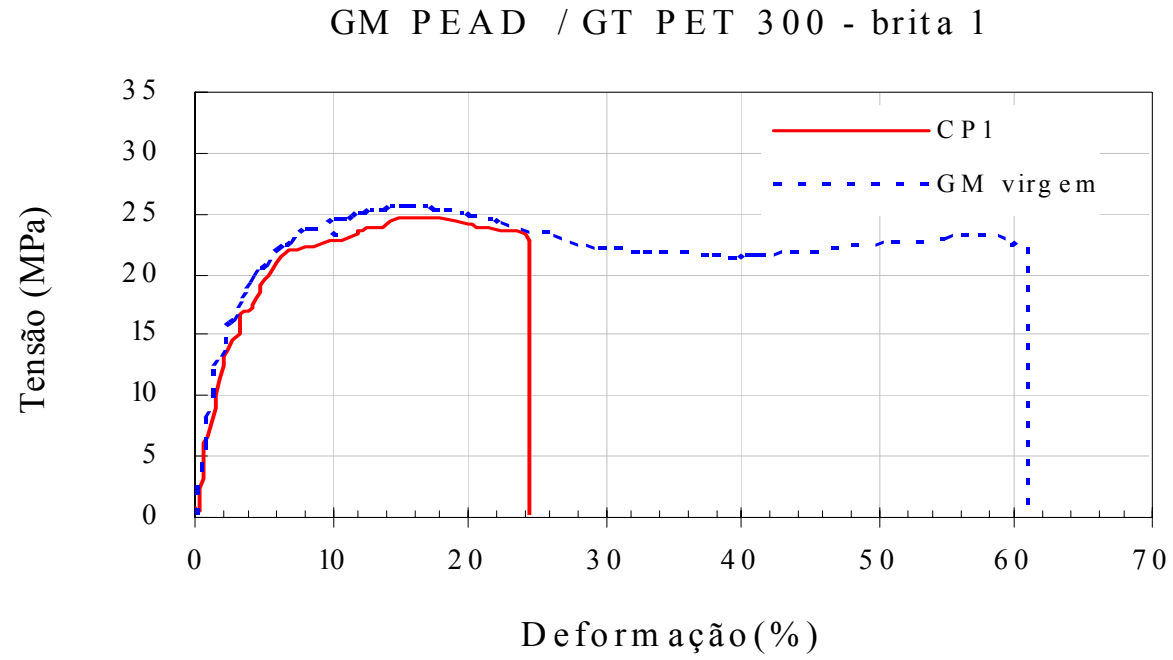

Figura 138. Resultados dos ensaios de tração multiaxial - GM de PEAD de 1,5 mm e GT PET $300 \mathrm{~g} / \mathrm{m}^{2} /$ brita 1 . 


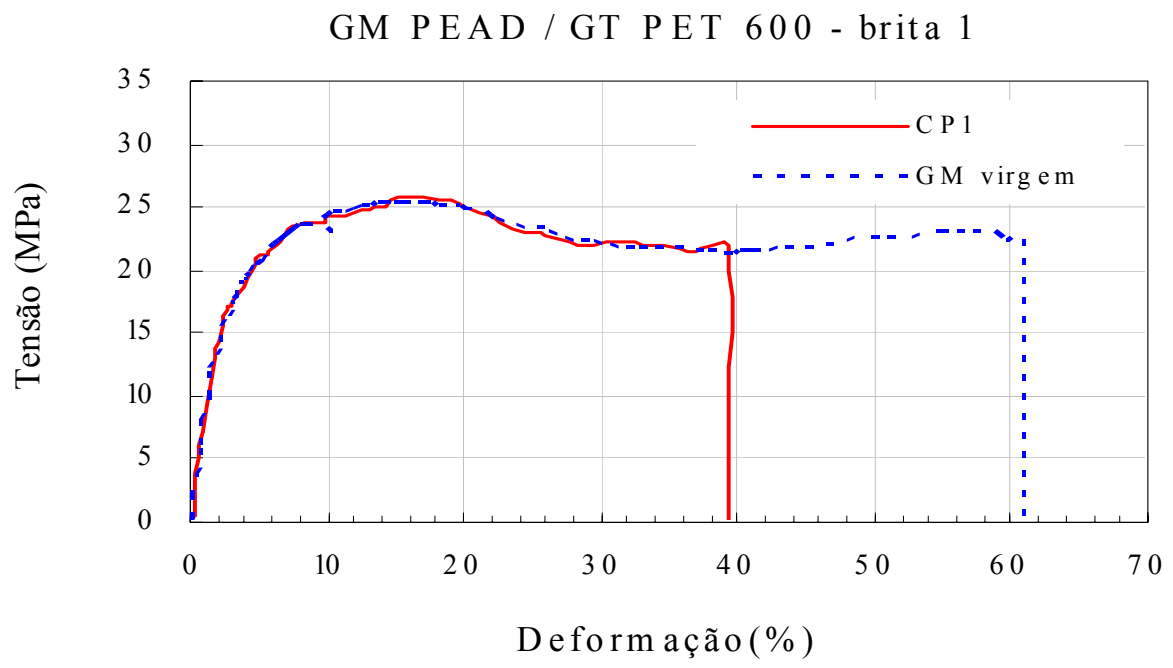

Figura 139. Resultados dos ensaios de tração multiaxial - GM de PEAD de 1,5 mm e GT PET $600 \mathrm{~g} / \mathrm{m}^{2} /$ brita 1 .

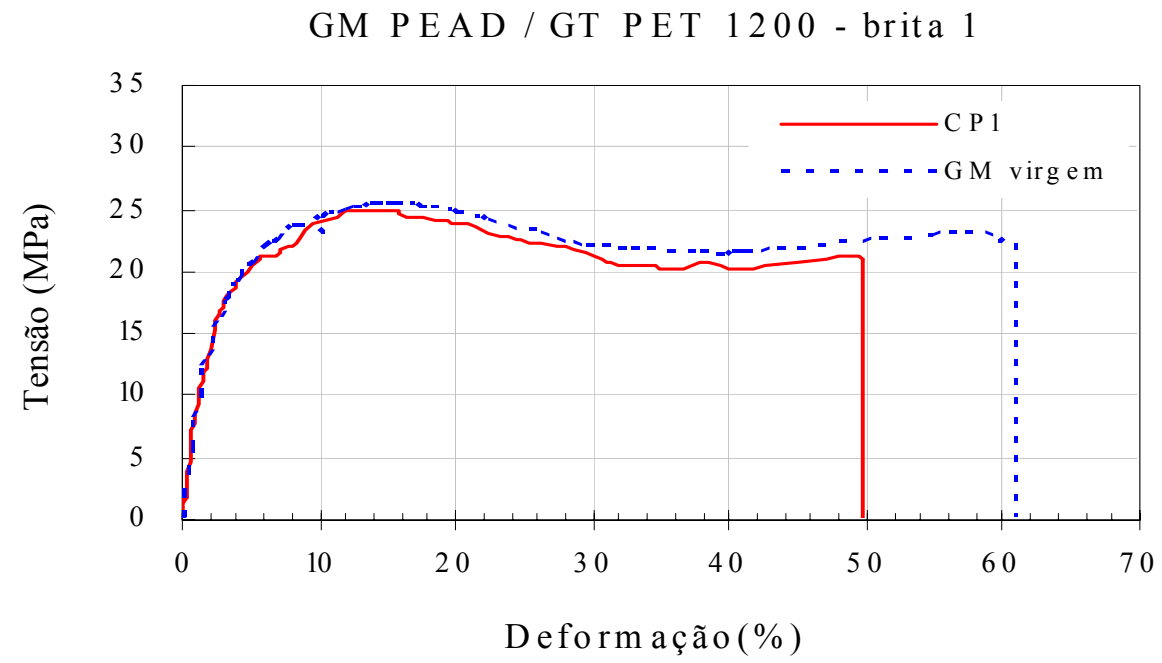

Figura 140. Resultados dos ensaios de tração multiaxial - GM de PEAD de 1,5 mm e GT PET $1200 \mathrm{~g} / \mathrm{m}^{2} /$ brita 1 . 


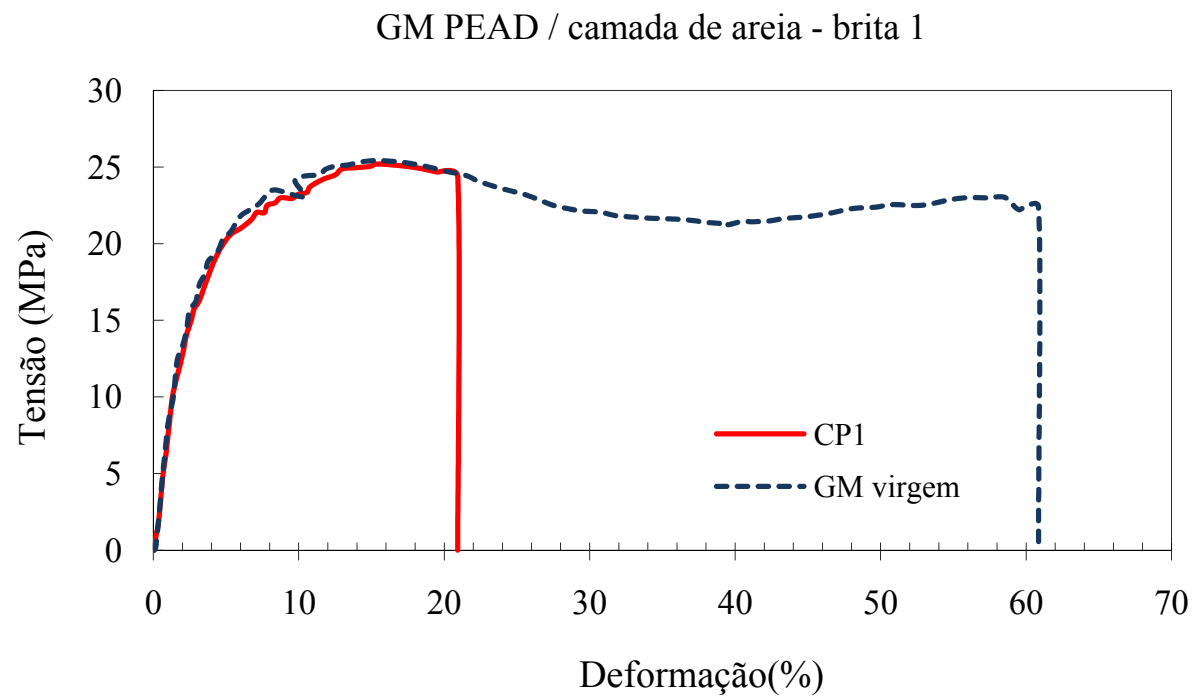

Figura 141. Resultados dos ensaios de tração multiaxial - GM de PEAD de 1,5 mm e camada de areia / brita 1.

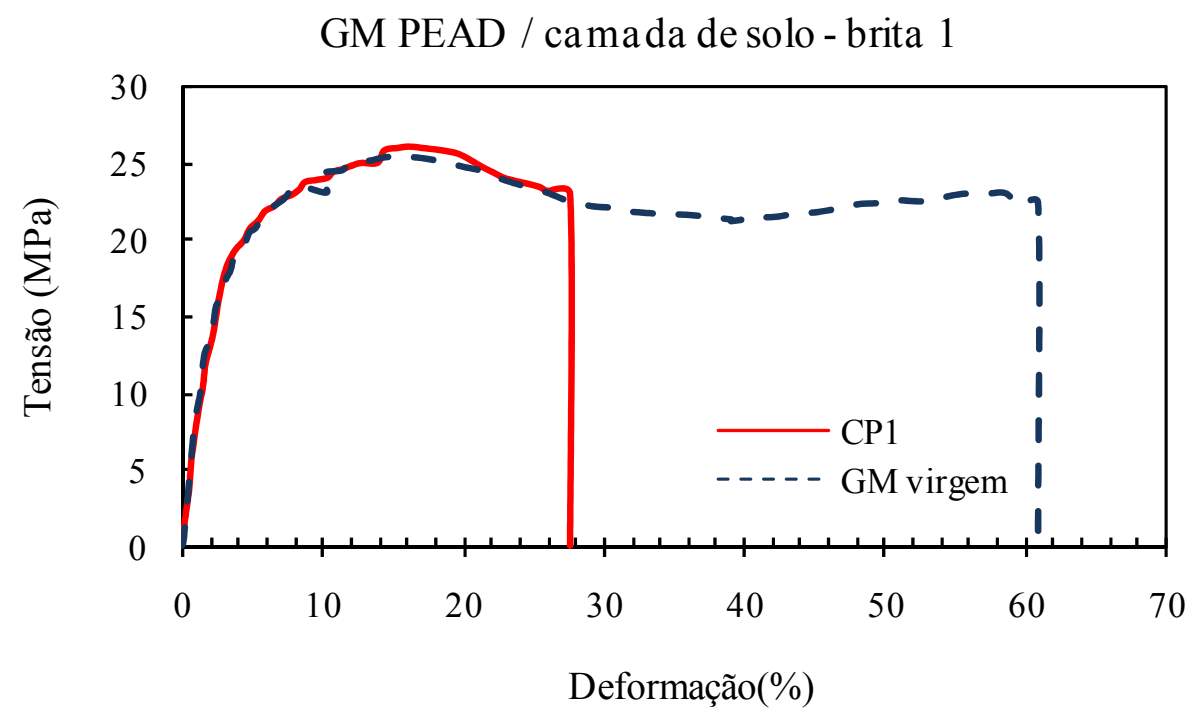

Figura 142. Resultados dos ensaios de tração multiaxial - GM de PEAD de 1,5 mm e camada de solo / brita 1 . 
GM PEAD 1.5 mm - Brita 3

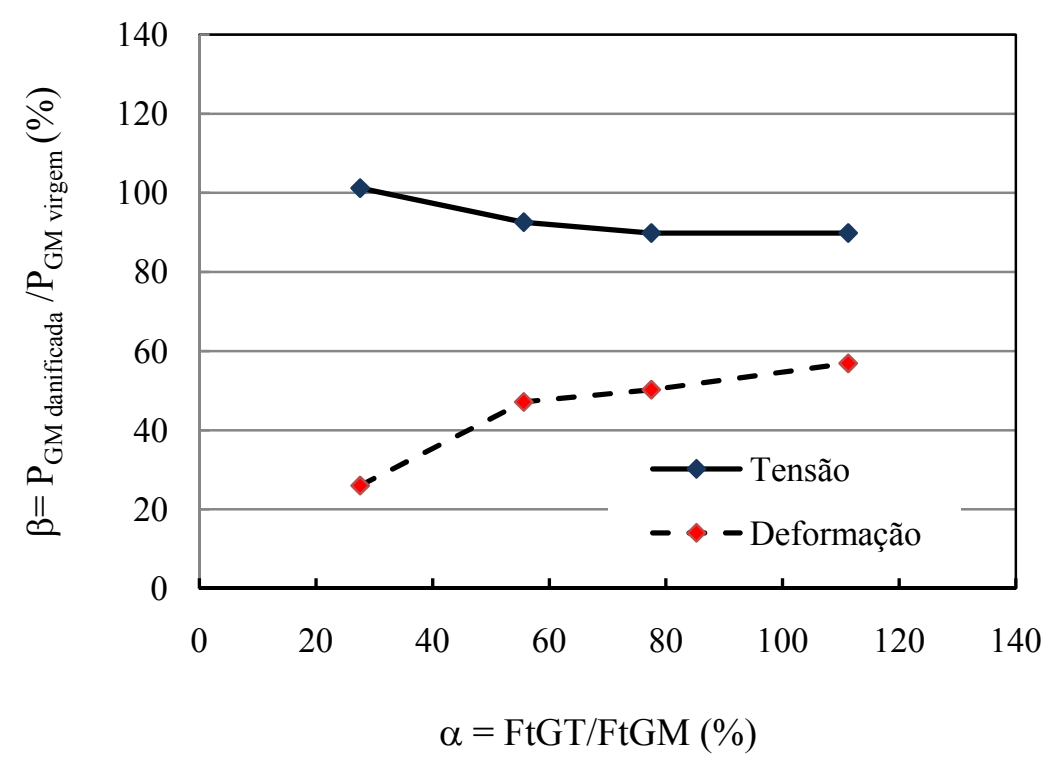

GM PEAD 1.5 mm - Brita 1

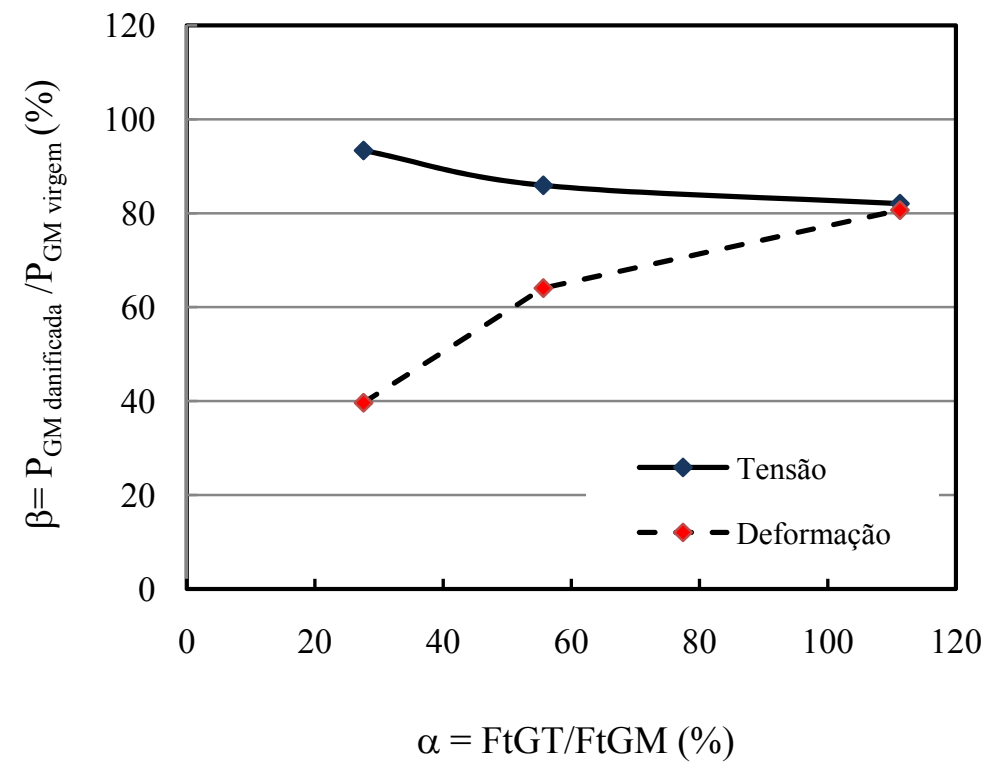

Figura 143. Resultados de tração multiaxial - GM de PEAD 1,5 mm.

Na configuração com geomembrana virgem, a tensão e deformação de ruptura foram de $25,6 \mathrm{MPa}$ e $62 \%$, respectivamente. Os valores de tensão de ruptura nas geomembranas danificadas apresentaram uma redução em relação à geomembrana virgem. No entanto, as 
maiores reduções são observadas em termos de deformação, constatando-se uma redução de $80 \%$ e $60 \%$ nos valores de deformação respectivos às configurações com brita 3 e brita 1 .

Com a introdução do elemento de proteção, verificou-se um aumento nos valores de deformação. No entanto, nenhuma configuração apresentou deformações de ruptura da mesma ordem de grandeza que a geomembrana virgem.

Em ambas as granulometrias, constatou-se uma variação significativa nos valores de deformação com o tipo de proteção utilizada. A configuração com geotêxtil de PET 1200 $\mathrm{g} / \mathrm{m}^{2}$ apresentou menor redução de deformação em relação à geomembrana virgem $(\Delta \varepsilon=0,57$ para a brita 3 e $\Delta \varepsilon=0,81$ para a brita 1$)$.

As configurações com solos também apresentaram uma elevada redução nos valores de deformação comparados à geomembrana virgem. No entanto, nas configurações com brita 3, os valores de deformação foram superiores a deformação de ruptura utilizando geotêxtil de PET $300 \mathrm{~g} / \mathrm{m}^{2}$. Nas configurações com brita 1, os valores de deformação foram da mesma ordem de grandeza.

Os resultados dos ensaios de tração multiaxial (Figura 143) também indicam uma correlação entre a resistência à tração do geotêxtil $\left(\mathrm{F}_{\mathrm{tGT}}\right)$ com a deformação na ruptura da geomembrana. Verifica-se que quanto maior a resistência a tração do geotêxtil, maior o valor de $\beta$, ou seja, menor a perda de deformação de ruptura na geomembrana danificada em relação à geomembrana virgem.

A Figura 144 e a Figura 145 ilustram o modo de ruptura das geomembranas de PEAD no ensaio de tração multiaxial. 


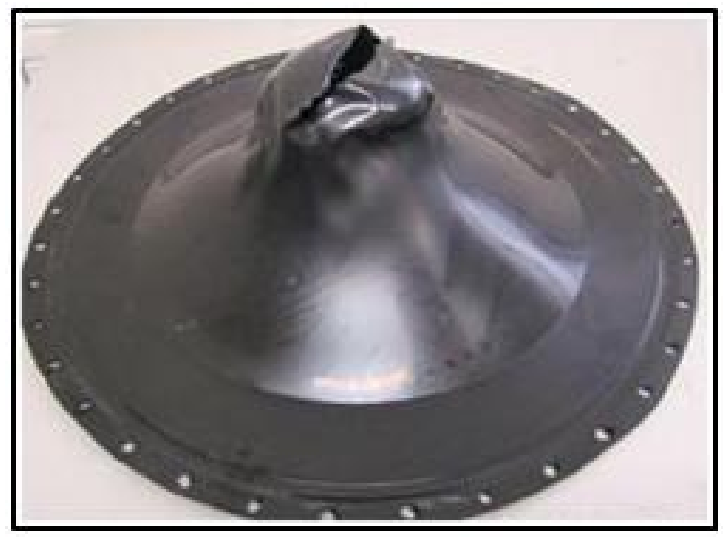

GM PEAD virgem

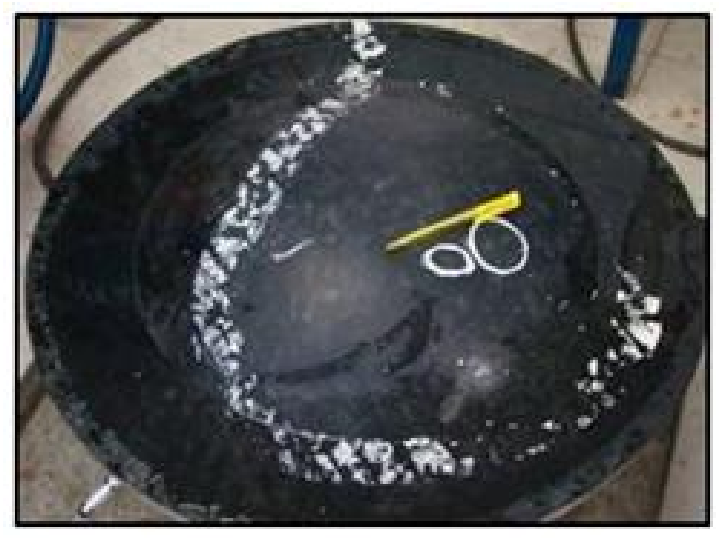

GM PEAD / GT PET 300 - CP arranhão

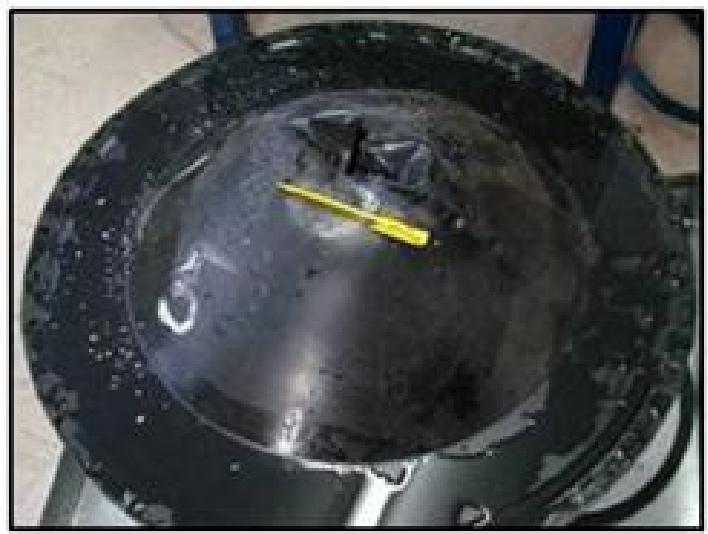

GM PEAD / GT PET 1200

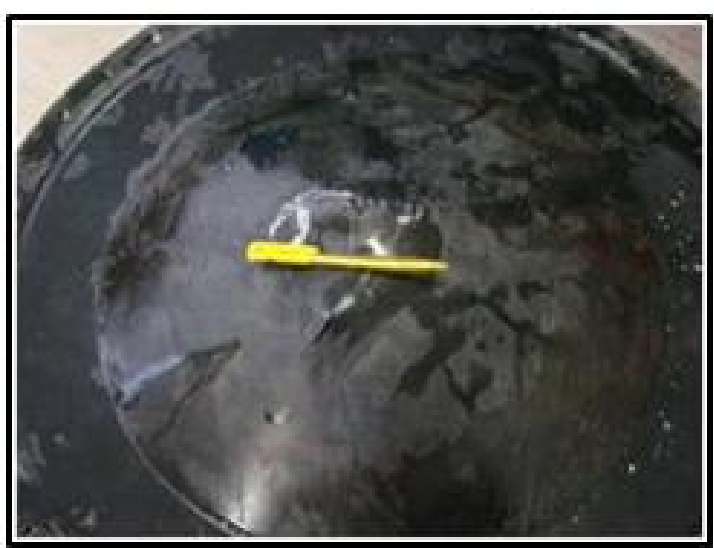

GM PEAD / areia

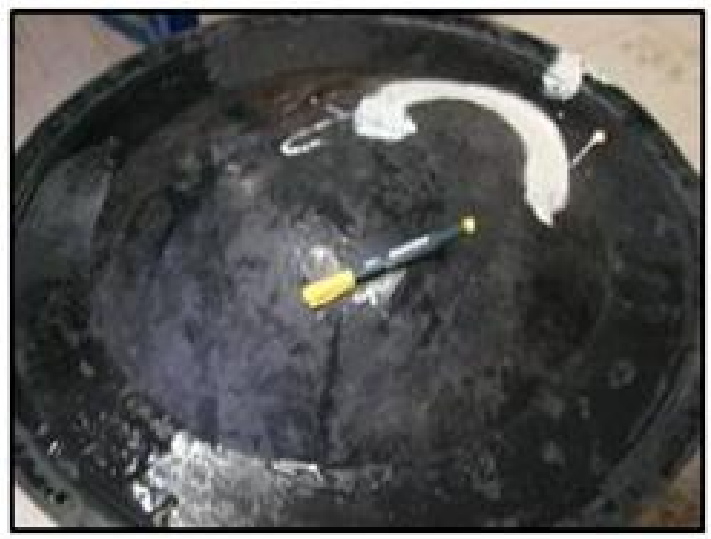

GM sem proteção

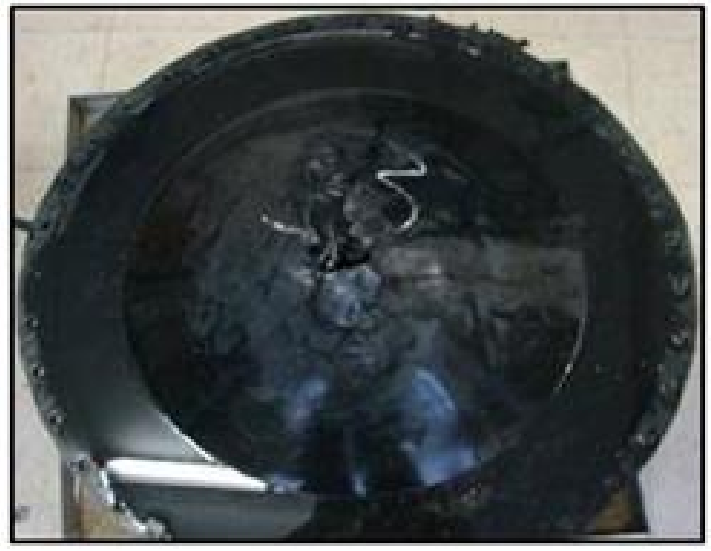

GM PEAD / GT PET 600

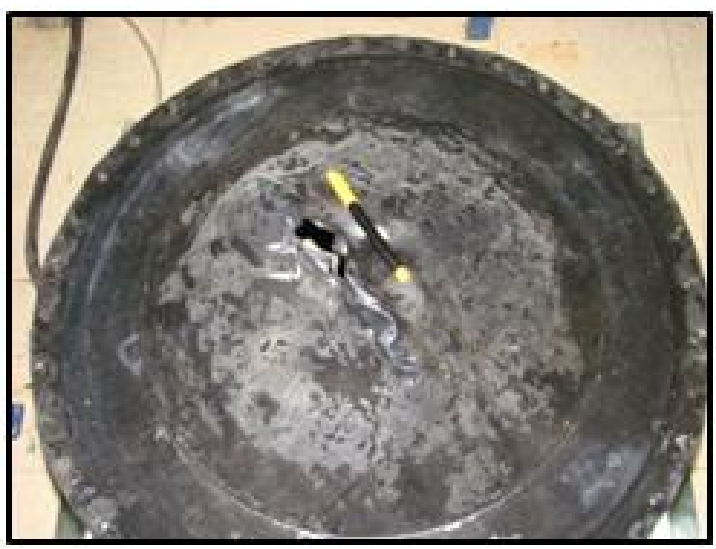

GM PEAD / GT PP 600

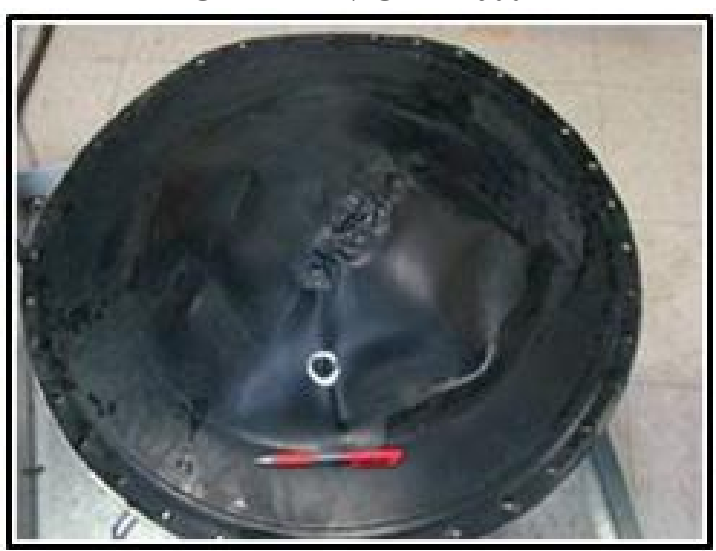

GM PEAD / solo

Figura 144. Modo de ruptura nos ensaios de tração multiaxial: GM PEAD 1,5 mm / brita3. 

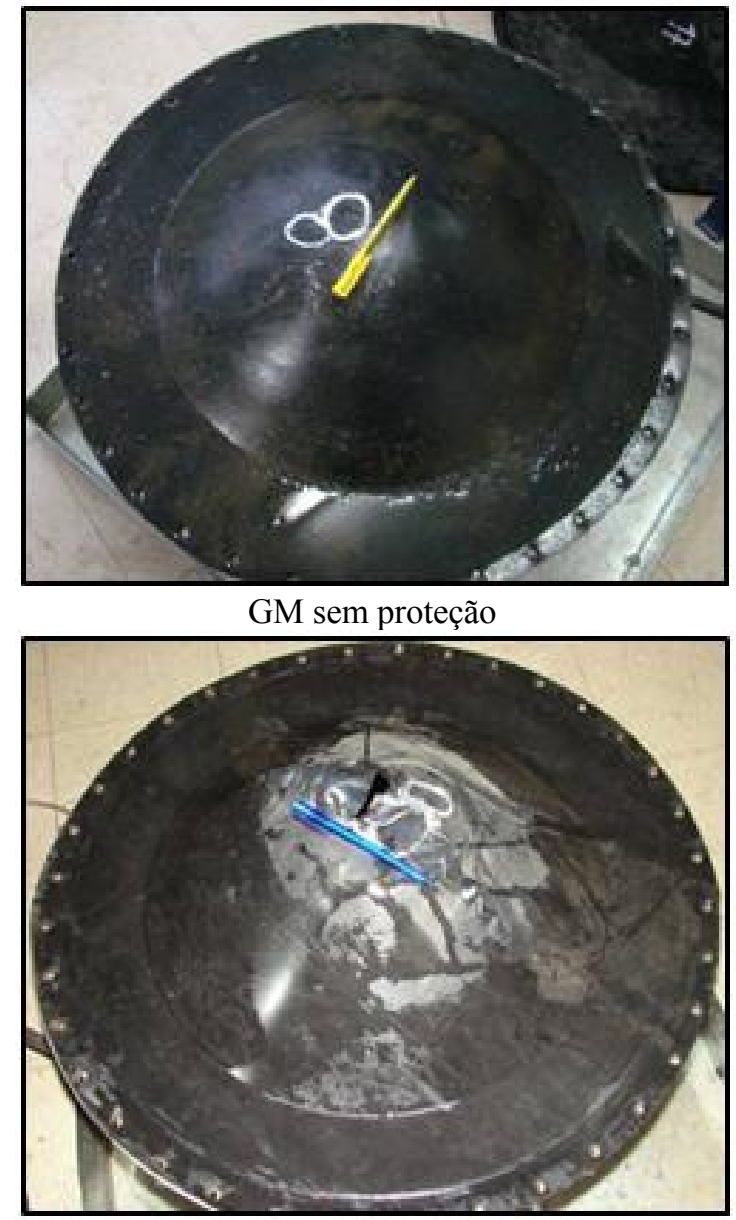

GM PEAD / GT PET 600

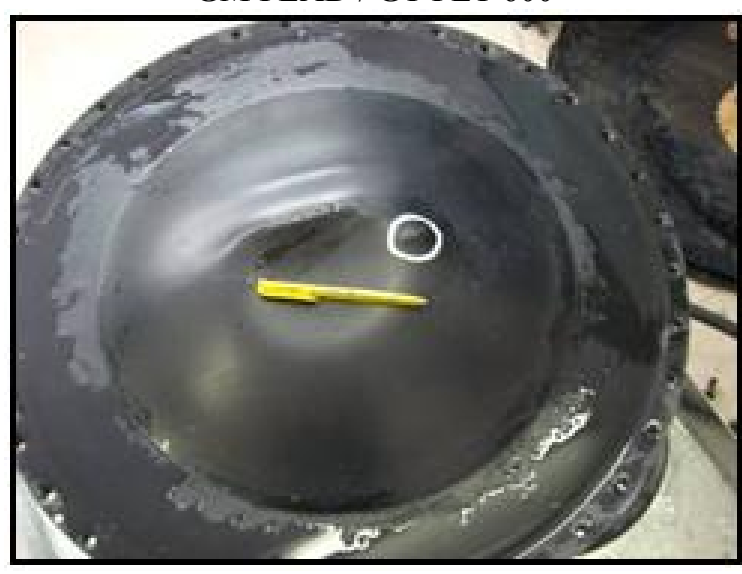

GM PEAD / areia

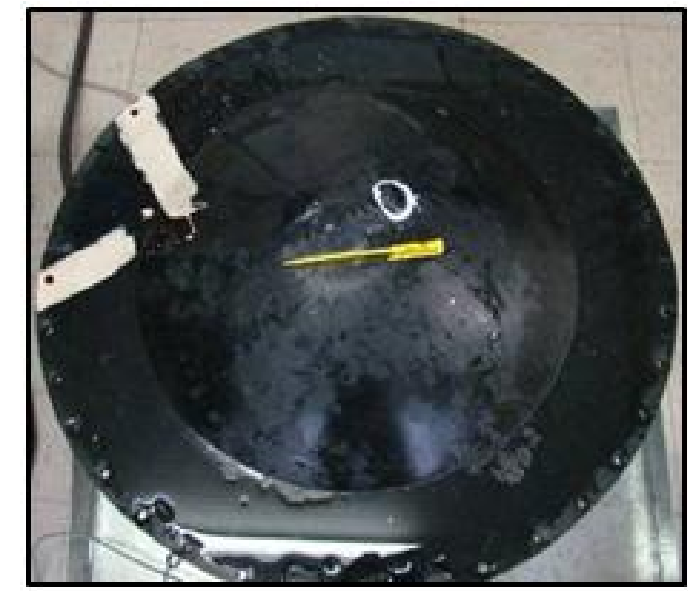

GM PEAD / GT PET 300

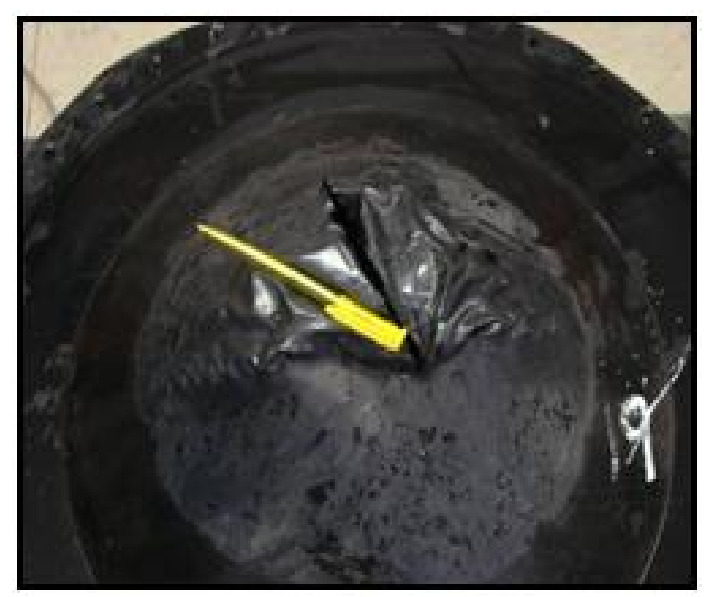

GM PEAD / GT PET 1200

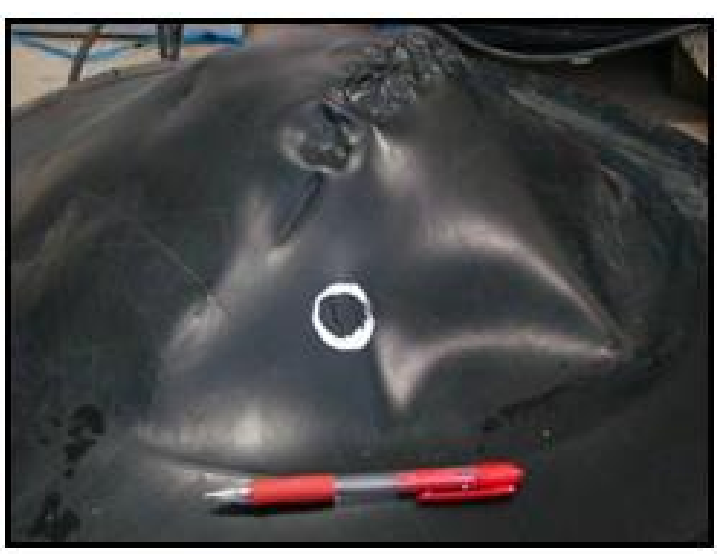

GM PEAD / solo

Figura 145. Modo de ruptura nos ensaios de tração multiaxial: GM PEAD 1,5 mm / brita1.

Observa-se que a geomembrana virgem se deforma assumindo uma forma esférica ou elíptica até atingir a ruptura, localizada no centro da amostra. Em geral, as geomembranas danificadas sem e com camada de proteção apresentaram comportamento diferente da 
geomembrana virgem. A ruptura nas geomembranas sem proteção foi caracterizada por pequenos cortes localizados em cima dos arranhões e fora do centro da amostra.

As configurações com brita 3 e geotêxteis de PP $600 \mathrm{~g} / \mathrm{m}^{2}$ e $1200 \mathrm{~g} / \mathrm{m}^{2}$ foram as que apresentaram comportamento mais próximo a geomembrana virgem, com ruptura localizada no centro da amostra e sob a forma de estouro. Nas configurações com brita 1, as configurações com geotêxteis de PET $600 \mathrm{~g} / \mathrm{m}^{2}$ e $1200 \mathrm{~g} / \mathrm{m}^{2}$ se assemelharam ao comportamento verificado nas geomembranas virgens. Em ambas as granulometrias, verificou-se que a ruptura nas geomembranas danificadas com proteção de areia e solo também foi localizada por pequenos cortes localizados em cima dos arranhões e fora do centro da amostra.

\subsection{Ensaio de Stress Cracking}

A Figura 146 apresenta os resultados dos ensaios de stress cracking (SP-NTCL) respectivos as amostras com ranhura (ASTM D5397) e sem ranhura na região central da geomembrana. Tais resultados se referem às geomembranas de PEAD de 1,5 $\mathrm{mm}$ com geotêxtil de proteção. A Tabela 42 apresenta os resultados de todas as configurações. 


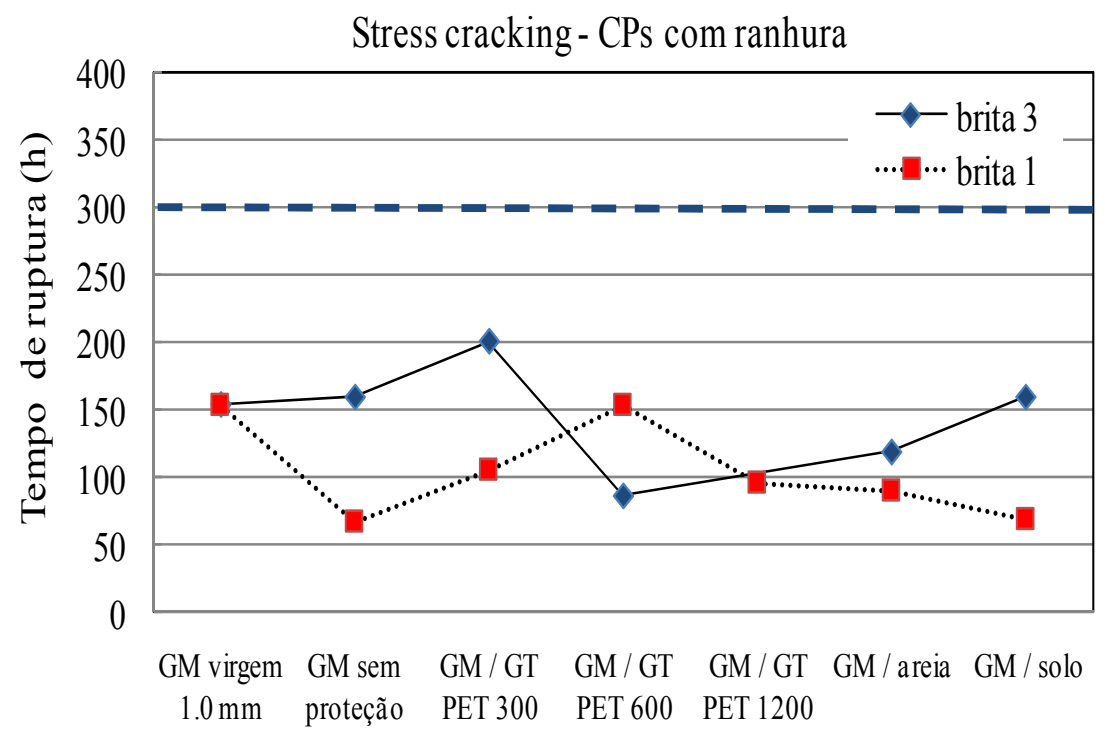

(a)

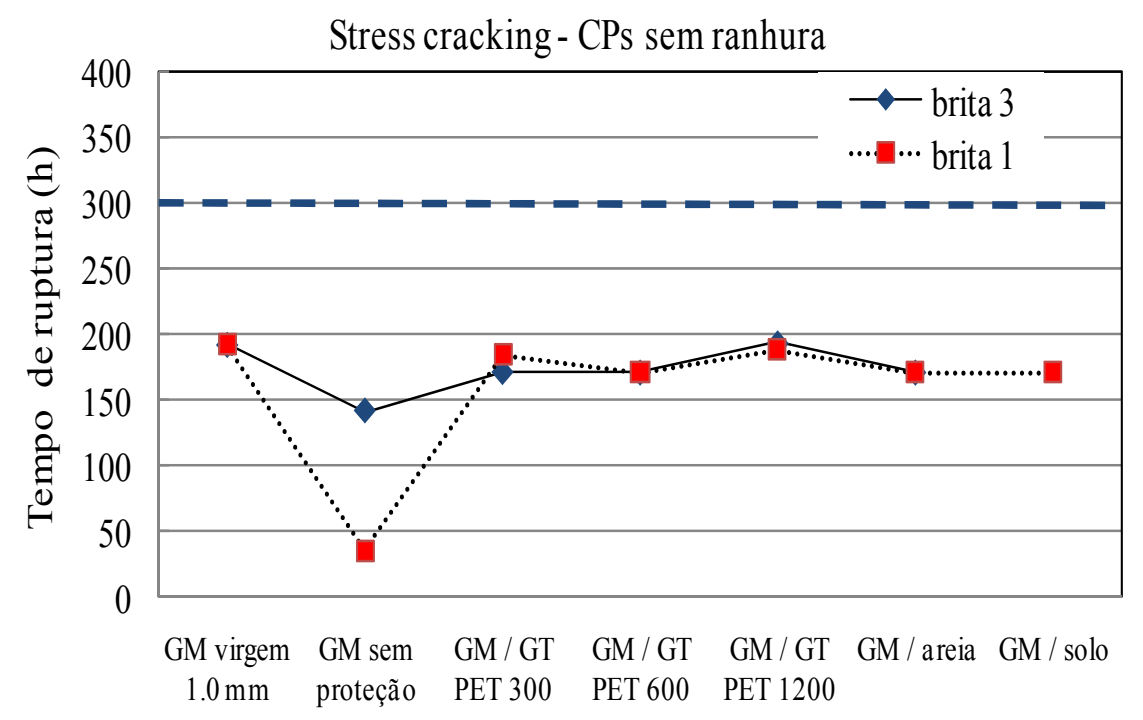

(b)

Figura 146. Resultados do ensaio de stress cracking: (a) CPs com ranhura; (b) CPs sem ranhura. 
Tabela 42. Síntese dos resultados de stress cracking em geomembranas de PEAD.

\begin{tabular}{|c|c|c|c|}
\hline \multirow{3}{*}{ Brita } & \multirow{3}{*}{ Configuração } & \multicolumn{2}{|c|}{ Carga $30 \%$} \\
\hline & & CP com ranhura & CP sem ranhura \\
\hline & & $\operatorname{Tr}(\mathbf{h})$ & $\operatorname{Tr}(\mathbf{h})$ \\
\hline- & GM virgem $1.0 \mathrm{~mm}$ & 153 & 192 \\
\hline- & GM virgem $2.0 \mathrm{~mm}$ & 131 & - \\
\hline \multirow{7}{*}{ Brita 3} & GM sem proteção & 158 & 141 \\
\hline & GM / GT PET 300 & 200 & 171 \\
\hline & GM / GT PET 600 & 86 & 171 \\
\hline & GM / GT PET 1200 & - & 193 \\
\hline & $\mathrm{GM} /$ areia & 118 & 171 \\
\hline & GM / solo & 158 & - \\
\hline & PEAD 2,00 s/p & 197 & - \\
\hline \multirow{6}{*}{ Brita 1} & GM sem proteção & 67 & 35 \\
\hline & GM / GT PET 300 & 105 & 185 \\
\hline & GM / GT PET 600 & 153 & 171 \\
\hline & GM / GT PET 1200 & 95 & 188 \\
\hline & $\mathrm{GM} /$ areia & 89 & 171 \\
\hline & GM / solo & 68 & 171 \\
\hline
\end{tabular}

Nos corpos de prova sem ranhura, o tempo de ruptura da geomembrana virgem foi de 192 horas. Obteve-se na geomembrana danificada sem proteção e com brita 3 um tempo de ruptura de 140 horas, o que representa uma redução de 30\% em relação ao tempo de ruptura da geomembrana virgem. Nas configurações com elemento de proteção, constata-se um aumento do tempo de ruptura, que atinge valores próximos ao da geomembrana virgem. Verificou-se também que o tempo de ruptura nas geomembranas danificadas não varia com o tipo de proteção utilizado.

Nas configurações com brita 1, o tempo de ruptura na geomembrana danificada sem proteção foi de $35 \mathrm{~h}$, representando uma redução de $80 \%$. Ao se introduzir a camada de proteção, o tempo de ruptura alcançou valores próximos ao tempo de ruptura da geomembrana virgem, não sendo constatada variação do tempo de ruptura com o tipo de proteção utilizado.

Desta forma, os resultados mostram que os danos decorrentes do processo de instalação somente alteraram a susceptibilidade da geomembrana ao fenômeno de stress cracking nas configurações sem proteção, principalmente nas configurações com brita de 
menor graduação (brita 1). As configurações com camada de proteção apresentaram o mesmo tempo de ruptura.

Os corpos de prova com ranhura apresentaram uma elevada dispersão nos resultados do ensaio. Ao contrário do observado nos corpos de prova sem ranhura, não se constatou nenhuma relação do tempo de ruptura com o tipo de proteção utilizado, principalmente nas configurações com brita 3. Observa-se, por exemplo, que o tempo de ruptura na geomembrana sem proteção foi semelhante ao da geomembrana virgem. Nas configurações com brita 1, observa-se que os resultados atingiram o comportamento esperado. O tempo de ruptura na geomembrana sem proteção foi menor do que na geomembrana virgem; enquanto nas camadas com proteção, constatou-se um aumento do tempo de ruptura.

Contudo, os ensaios realizados com ranhura no corpo de prova podem mascarar os resultados, assim como dificultar a interpretação de tais dados. Uma das questões consiste na intensificação dos danos existentes, uma vez que pode ocorrer a sobreposição da ranhura com o próprio dano, dificultando até mesmo a padronização da espessura ligada do corpo de prova. Ao contrário, nos ensaios sem ranhura, ocorre uma padronização mais adequada dos resultados, onde o próprio dano é considerado o agente catalisador do stress cracking.

\subsubsection{Influência das características dos agregados no desempenho do elemento de proteção.}

As Figuras a seguir ilustram os resultados dos ensaios de tração faixa larga, multiaxial e stress cracking utilizando britas de diferentes diâmetros. Nesta figuras, a brita 3 corresponde a de maior diâmetro e brita 1 a de menor diâmetro. 

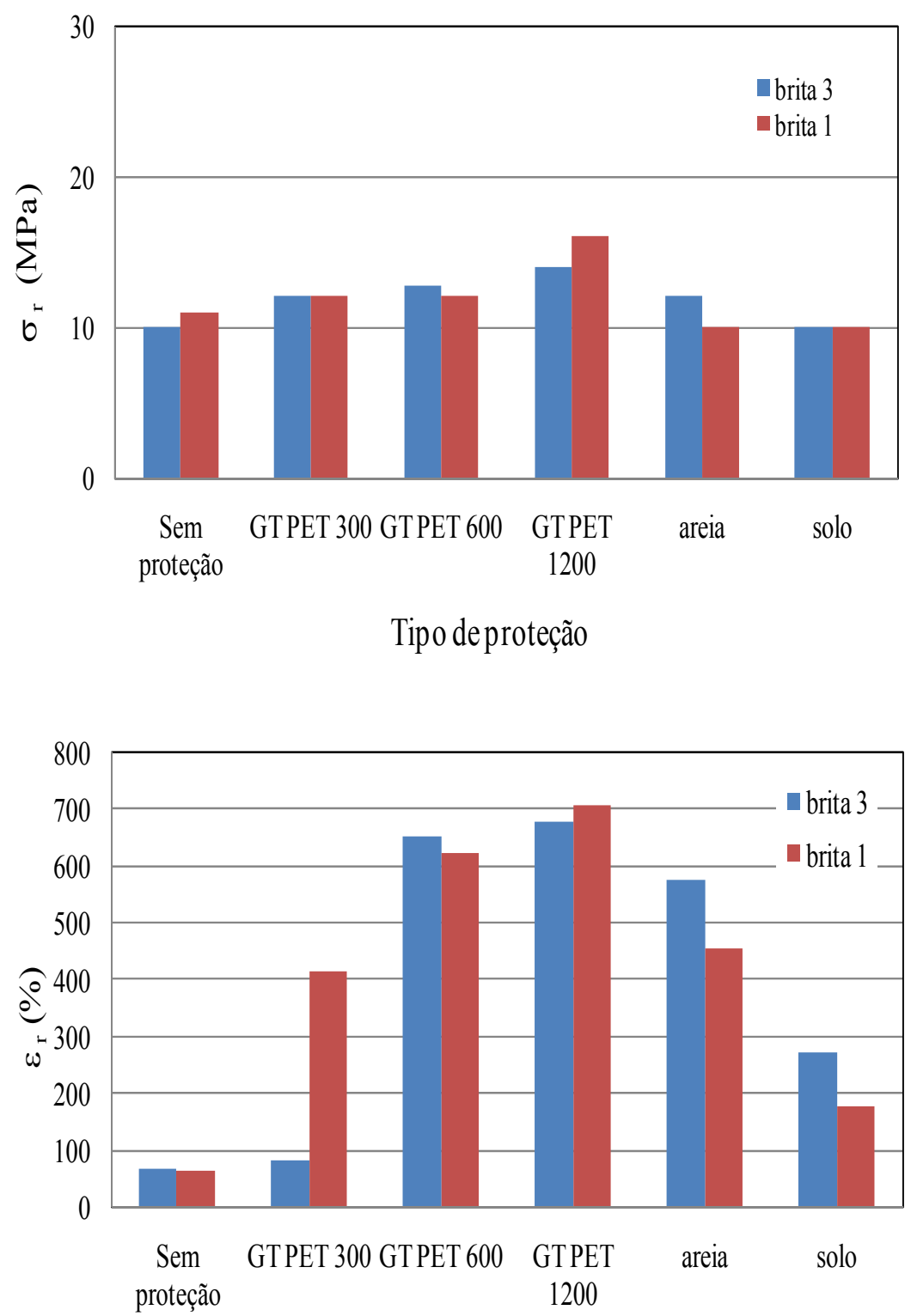

Tipo deproteção

Figura 147. Resultados dos ensaios de tração em faixa larga em função do diâmetro dos agregados: GM de PEAD. 


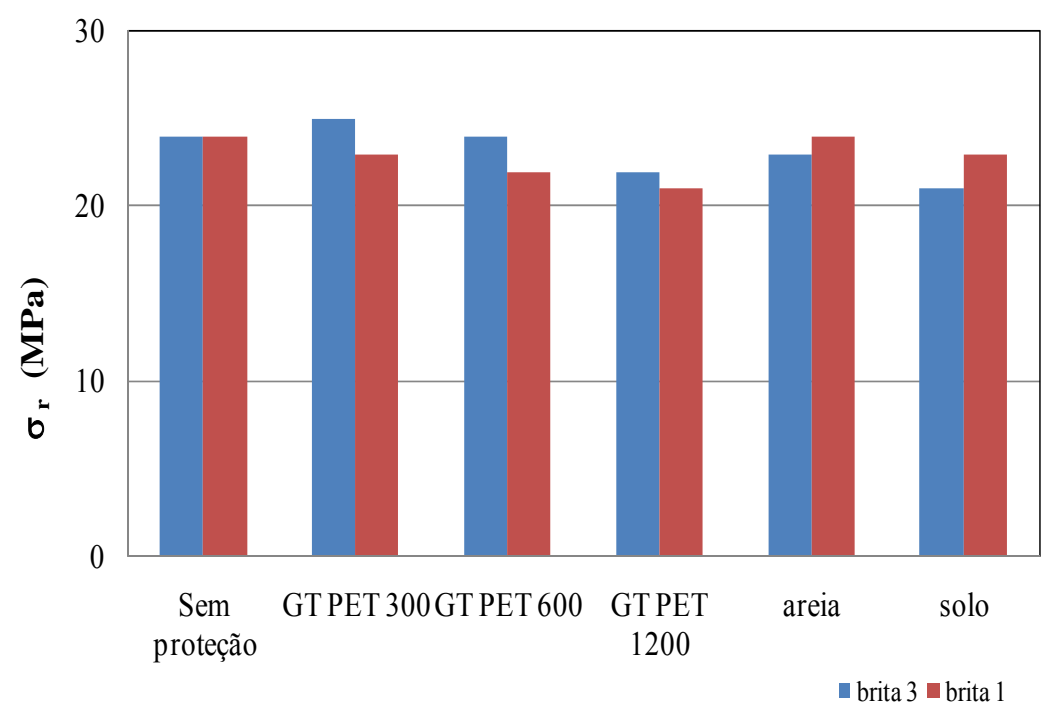

Tipo de proteção

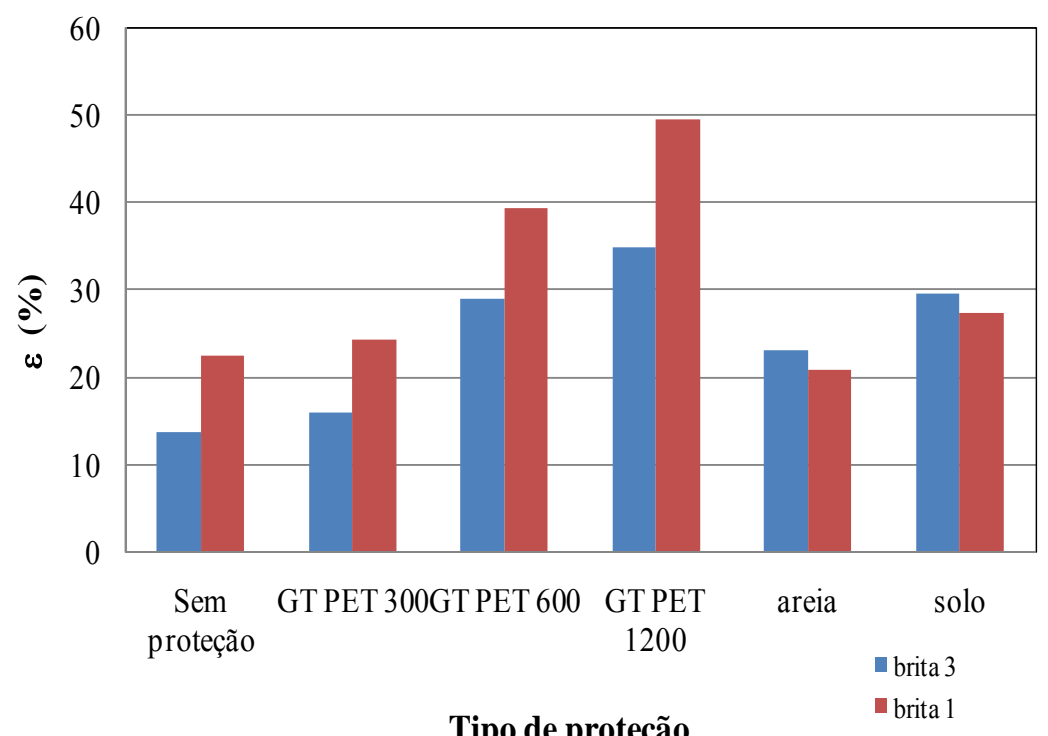

Figura 148. Resultados dos ensaios de tração multiaxial em função do diâmetro dos agregados:

GM de PEAD. 


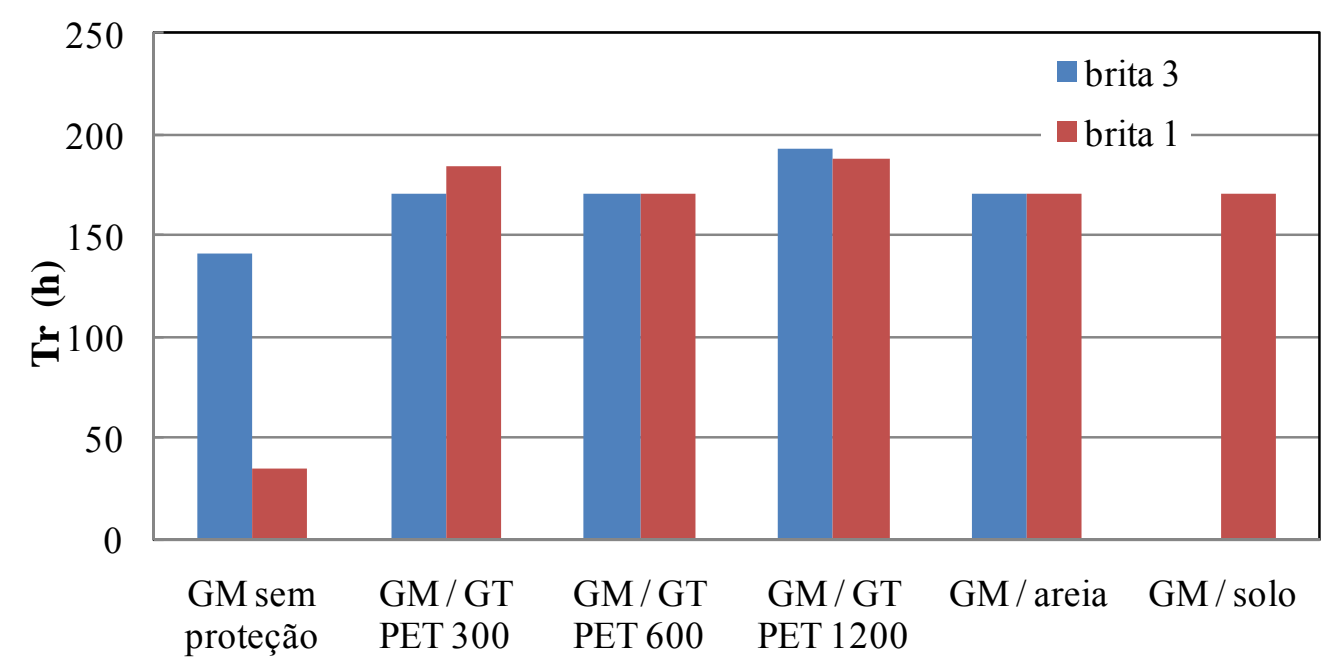

Tipo de proteção

Figura 149. Resultados dos ensaios de stress cracking em geomembranas de PEAD em função do diâmetro dos agregados: CP's sem ranhura.

Os resultados dos ensaios de tração em faixa larga indicaram que a variação da deformação com relação ao tamanho dos agregados é pequena. Nas configurações sem proteção, por exemplo, a deformação foi a mesma nos dois tipos de brita utilizados. A mesma constatação foi verificada nas configurações com geotêxteis como elemento de proteção. Excetua-se apenas o geotêxtil de PET $300 \mathrm{~g} / \mathrm{m}^{2}$, que apresentou valores de deformação de tração mais baixos na configuração com brita 3. Os resultados dos ensaios de tração multiaxial mostram que os valores de deformação foram menores nas configurações com brita 3, com e sem geotêxtil como elemento de proteção.

Em termos de resistência à tração, verificou-se que as maiores reduções de deformação foram verificadas nas configurações com brita de maior diâmetro. Estas constatações corroboram com os resultados retratados na literatura. Koerner et al. (1996) e Badu et al. (1998), por exemplo, relatam que a resistência a punção das geomembranas danificadas depende, dentre outros fatores, do diâmetro. Quanto maior o diâmetro das partículas, menor a 
área de contato entre os agregados e a geomembrana, gerando maiores valores de tensão e, consequentemente, maiores os danos à geomembrana.

Reddy et al (1996) também constatou que quanto maior o diâmetro do agregado , maiores as reduções nos valores de deformação de ruptura no ensaio de tração multiaxial. Nos ensaios de tração em faixa larga não foram verificadas alterações nas características de tração com relação ao diâmetro dos agregados.

Com relação ao ensaio de stress cracking, verificou-se que o tempo de ruptura ( $\mathrm{Tr}$ ) nas geomembranas sem proteção é menor nas configurações com brita 1. A redução do tempo de ruptura foi da ordem de 70\% em relação às configurações com brita 3. Nas configurações com camada de proteção, o tempo de ruptura independe das características da brita. Isto porque, conforme já mencionado, os danos existentes não foram capazes de acelerarem o processo de stress cracking. Ao contrário dos ensaios de tração, os agregados com menor diâmetro (brita 1) apresentaram maior susceptibilidade ao fenômeno de stress cracking, o que indica que os danos foram mais intensos.

Nas configurações com solos naturais verificou-se, em geral, que as características das geomembranas não se alteram com o diâmetro dos agregados.

\subsubsection{Geomembranas de PVC}

\subsubsection{Análise Visual}

As Figuras abaixo ilustram as superfícies das geomembranas de PVC sob diferentes configurações, após retirada da camada de drenagem. A Tabela 43 sintetiza os danos observados nas geomembranas de PVC seguindo o critério proposto pelo CFG (2001). 

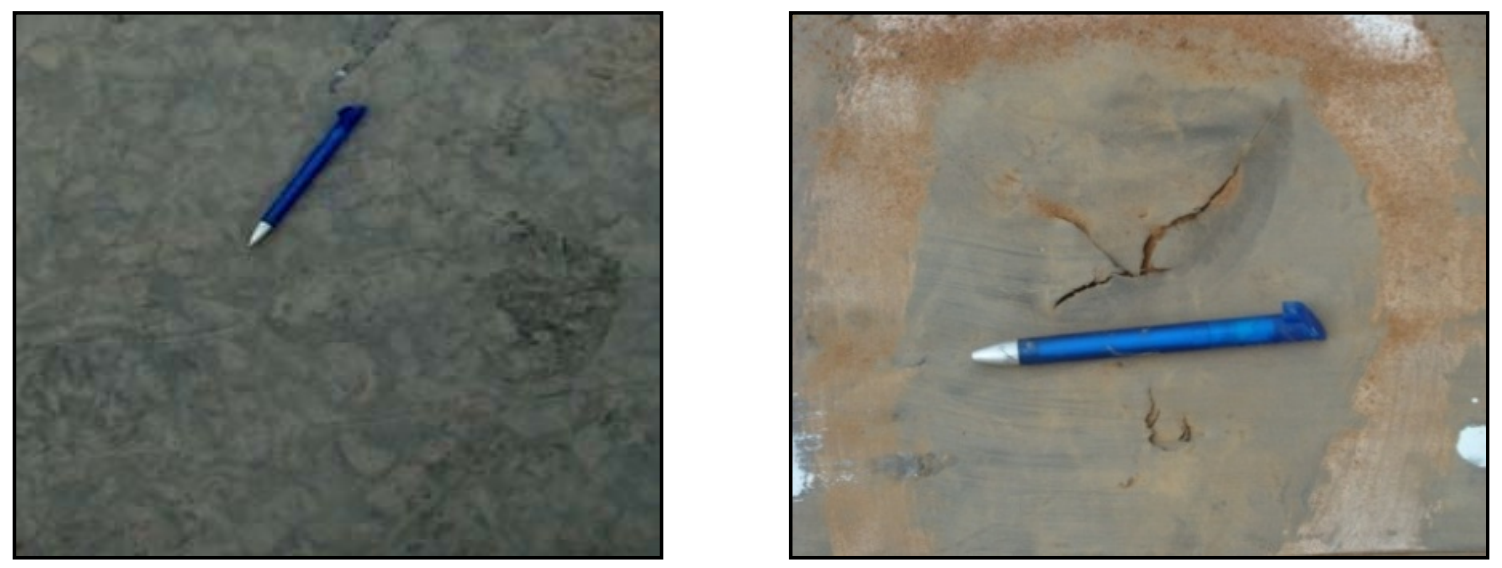

Figura 150. Danos visuais: GM de PVC de 1,0 $\mathrm{mm}$ sem proteção e brita 3.

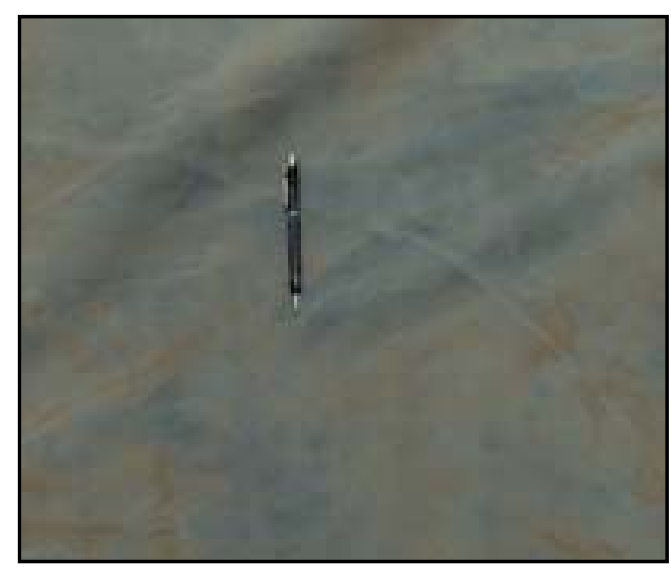

Superfície da GM

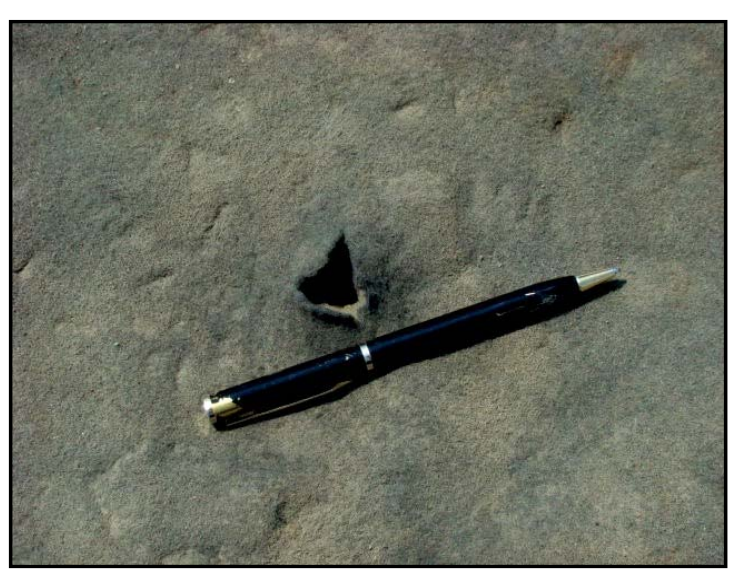

Rasgo no GT

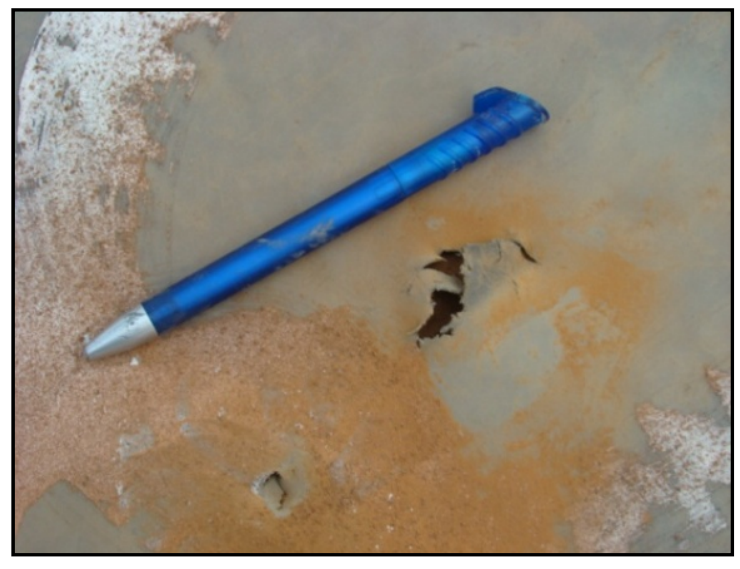

Rasgo na GM

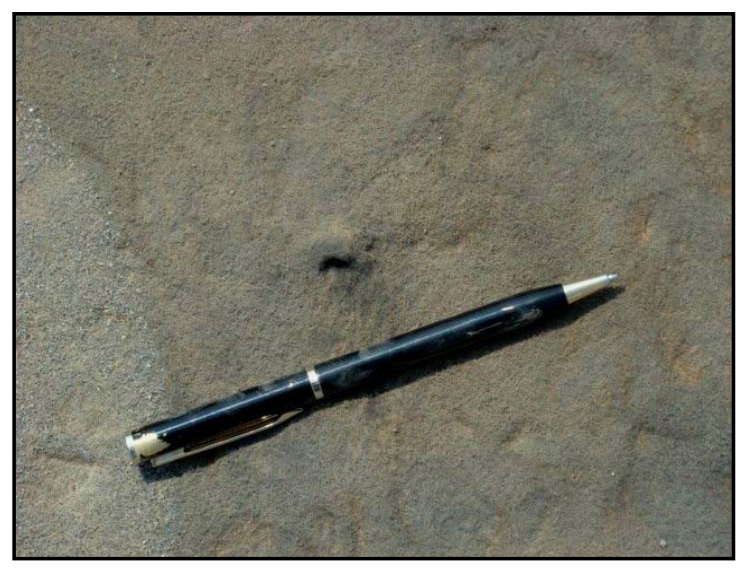

Rasgo no GT

Figura 151. Danos visuais: GM de PVC de 1,0 mm com GT PET $300 \mathrm{~g} / \mathrm{m}^{2}$ e brita 3. 

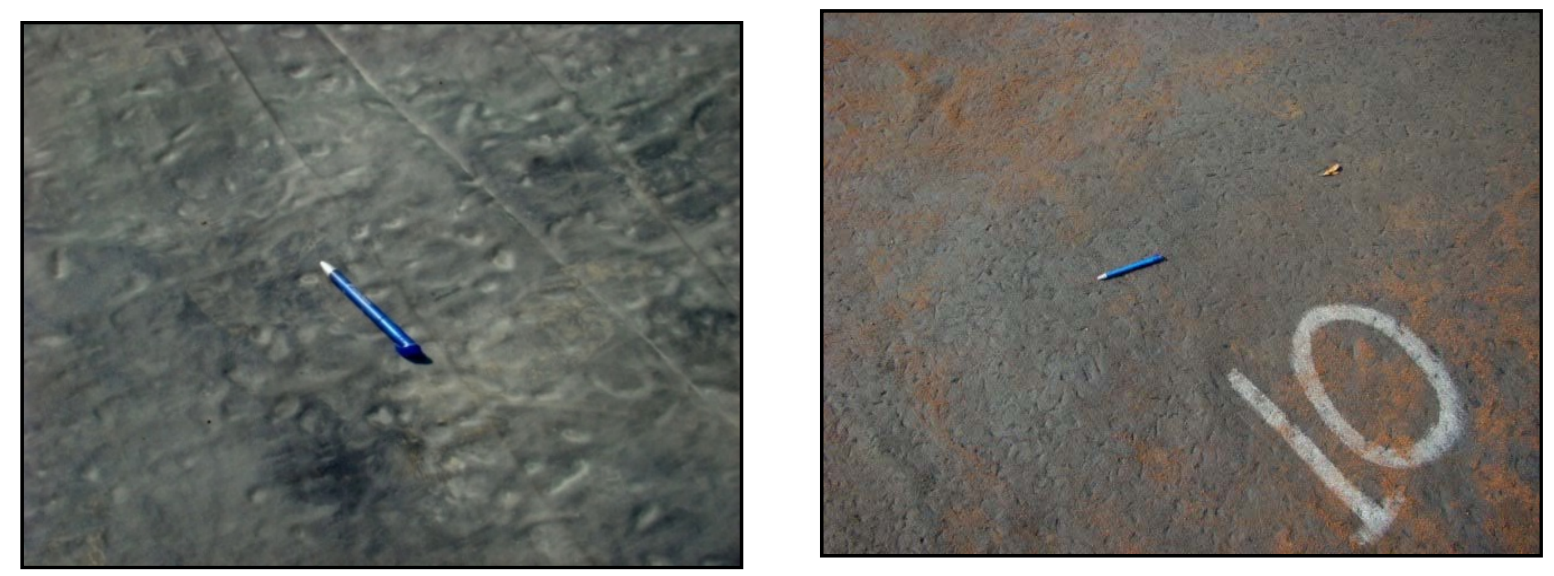

Figura 152. Danos visuais: GM de PVC de 1,0 mm com GT PET $600 \mathrm{~g} / \mathrm{m}^{2}$ e brita 3.

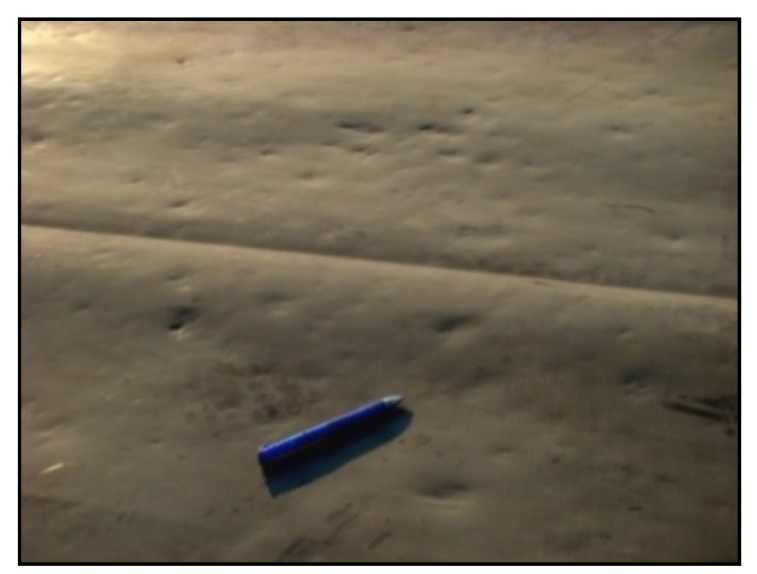

Superfície da GM

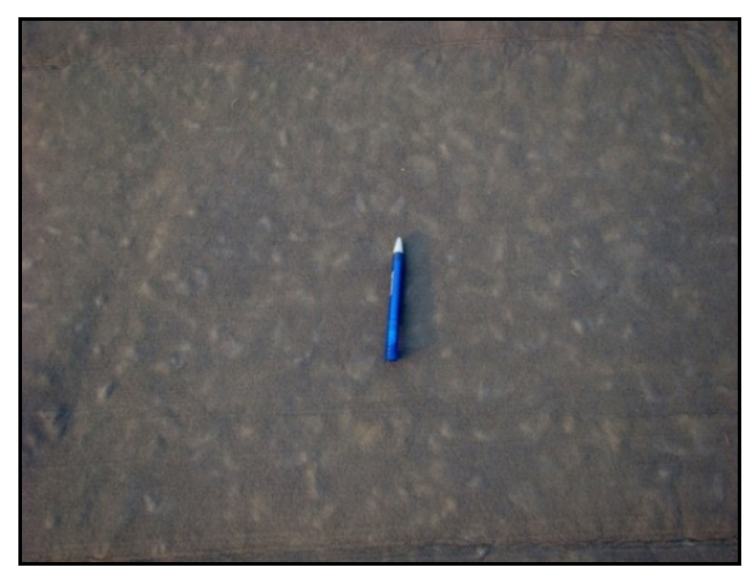

Superfície do GT

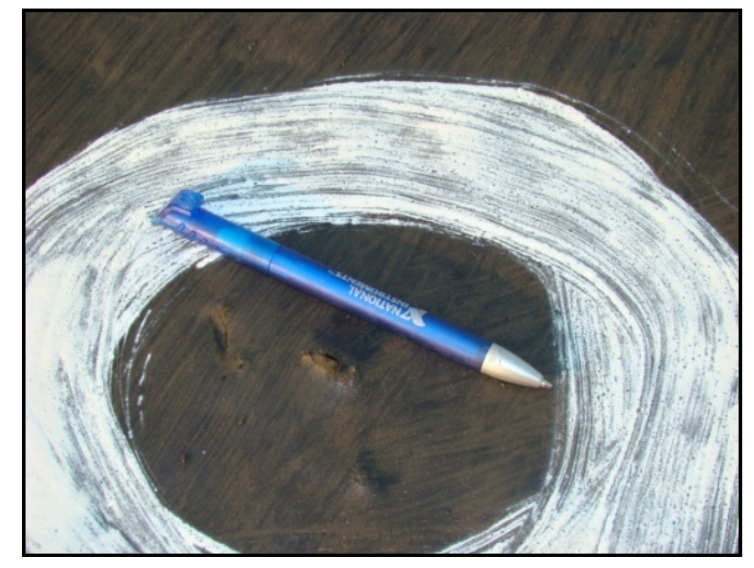

Rasgo na GM

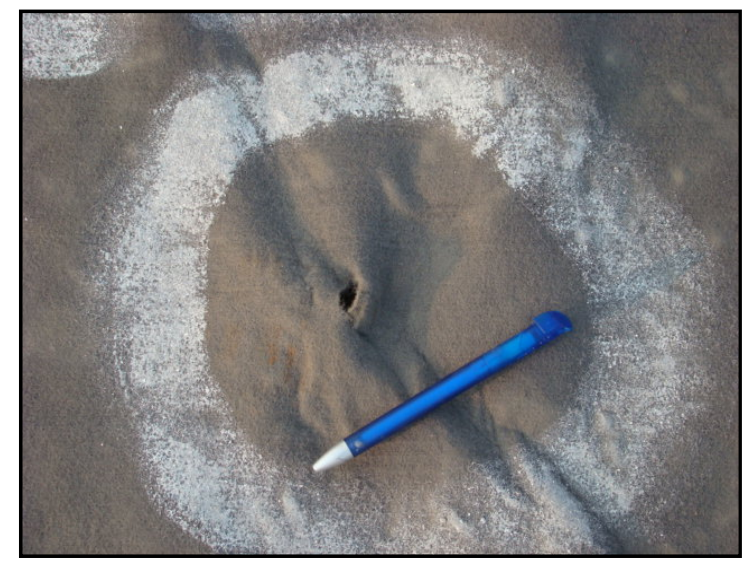

Furo no GT

Figura 153. Danos visuais: GM de PVC de 1,0 mm com GT PP $600 \mathrm{~g} / \mathrm{m}^{2}$ e brita 3. 


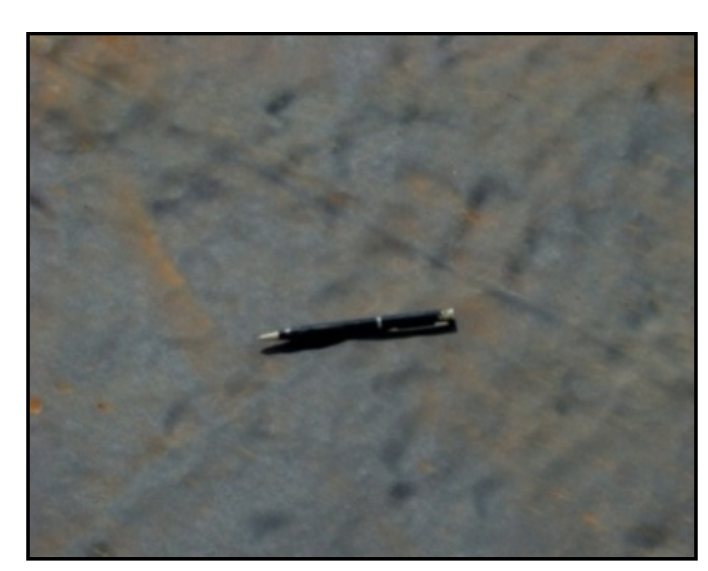

Superfície da GM

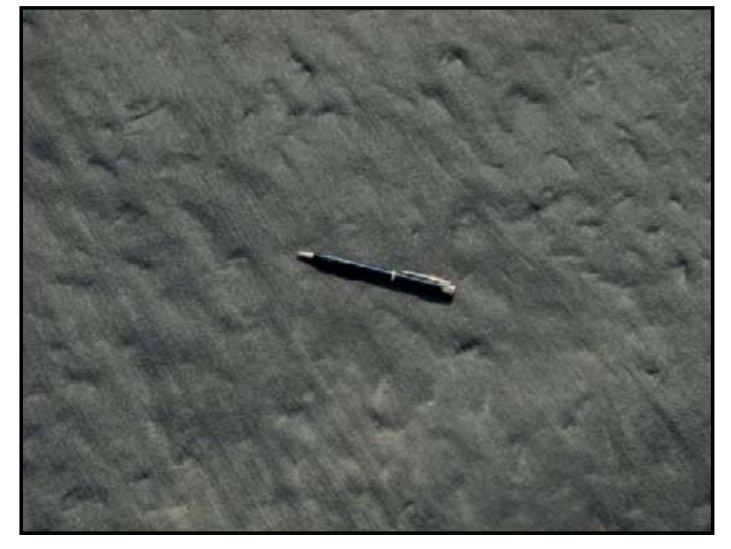

Superfície do GT

Figura 154. Danos visuais: GM de PVC de 1,0 mm com GT PET $1200 \mathrm{~g} / \mathrm{m}^{2}$ e brita 3.

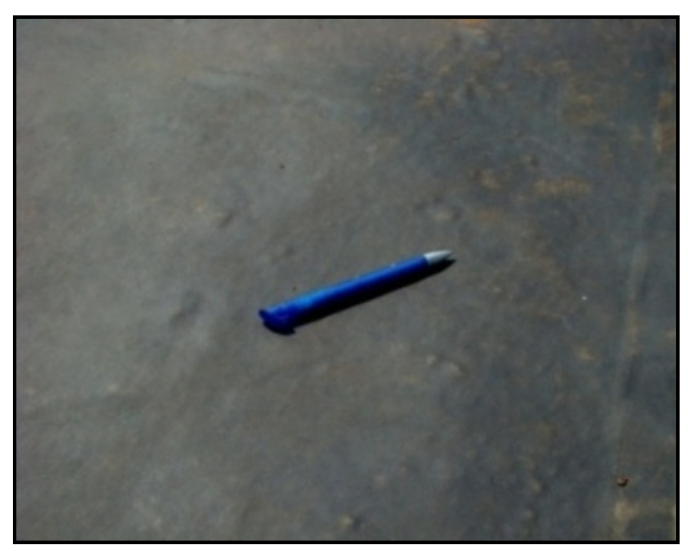

areia

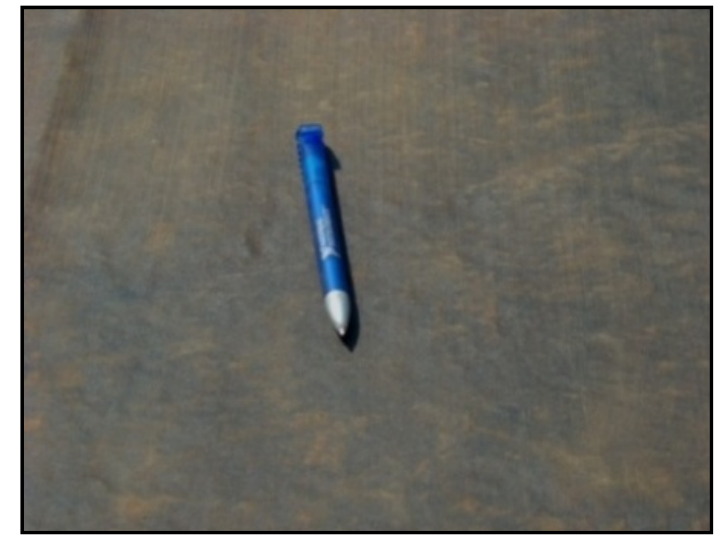

solo

Figura 155. Danos visuais: GM de PVC de 1,0 mm com camadas naturais e brita 3.
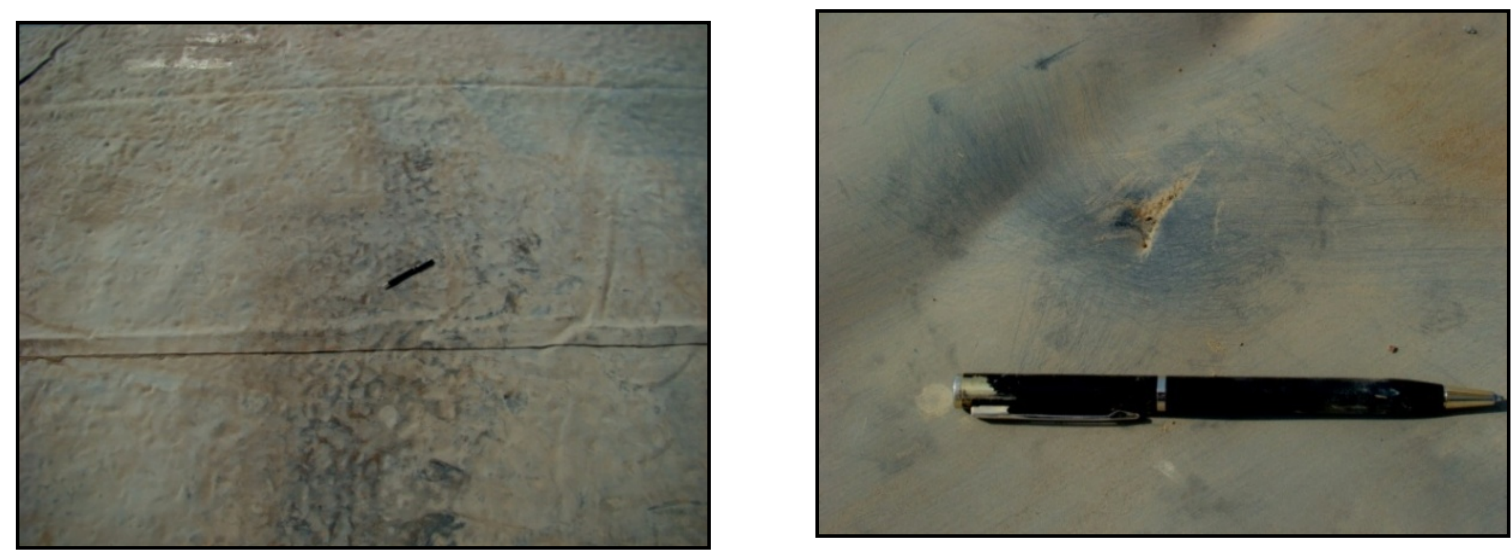

Figura 156. Danos visuais: GM de PVC de 2,0 mm sem proteção e brita 3. 


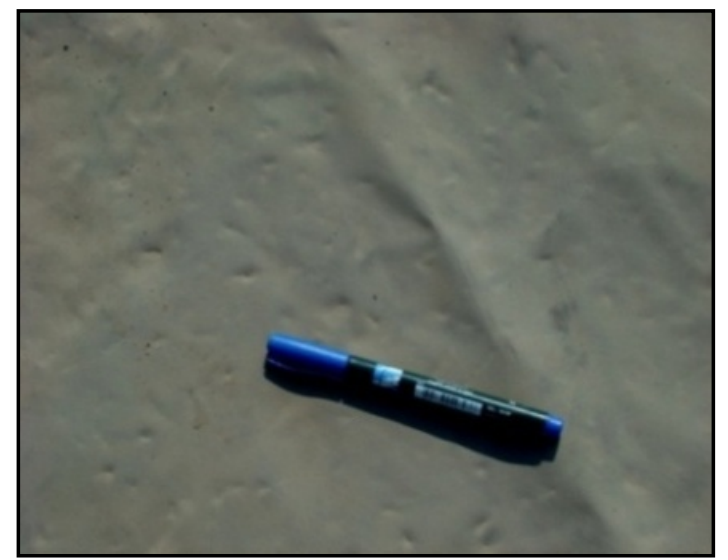

Figura 157. Danos visuais: GM de PVC de 1,0 mm sem proteção e brita 1.
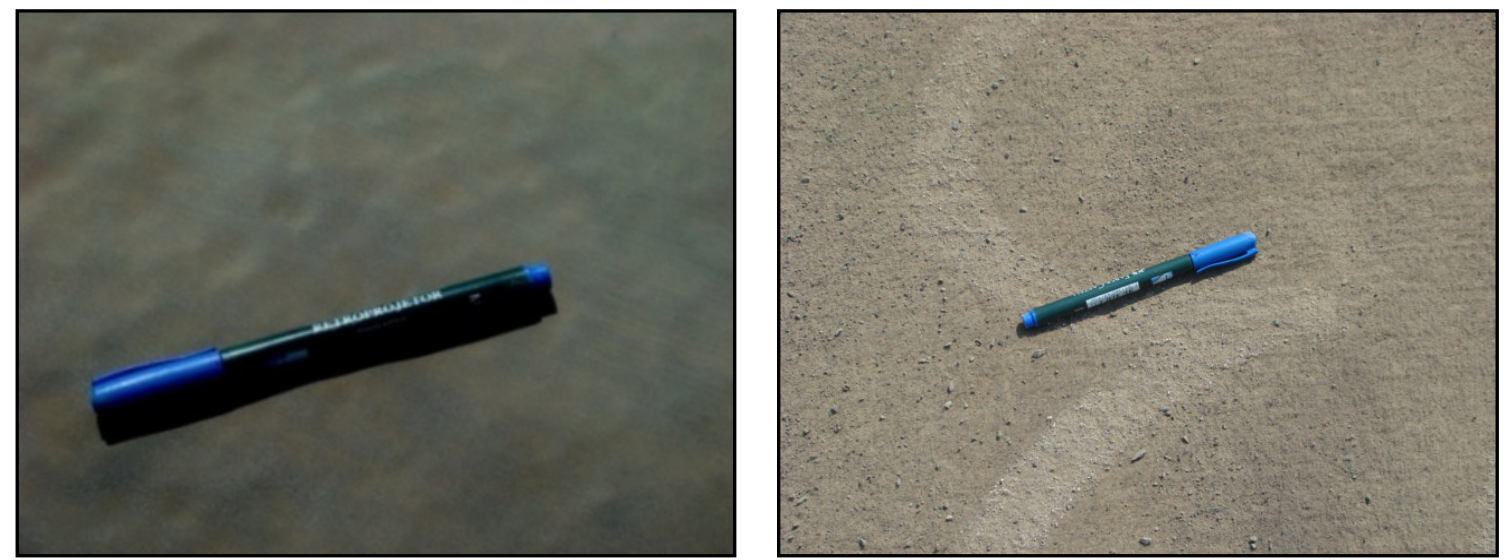

Figura 158. Danos visuais: GM de PVC de 1,0 mm com GT PET $600 \mathrm{~g} / \mathrm{m}^{2}$ e brita 1.
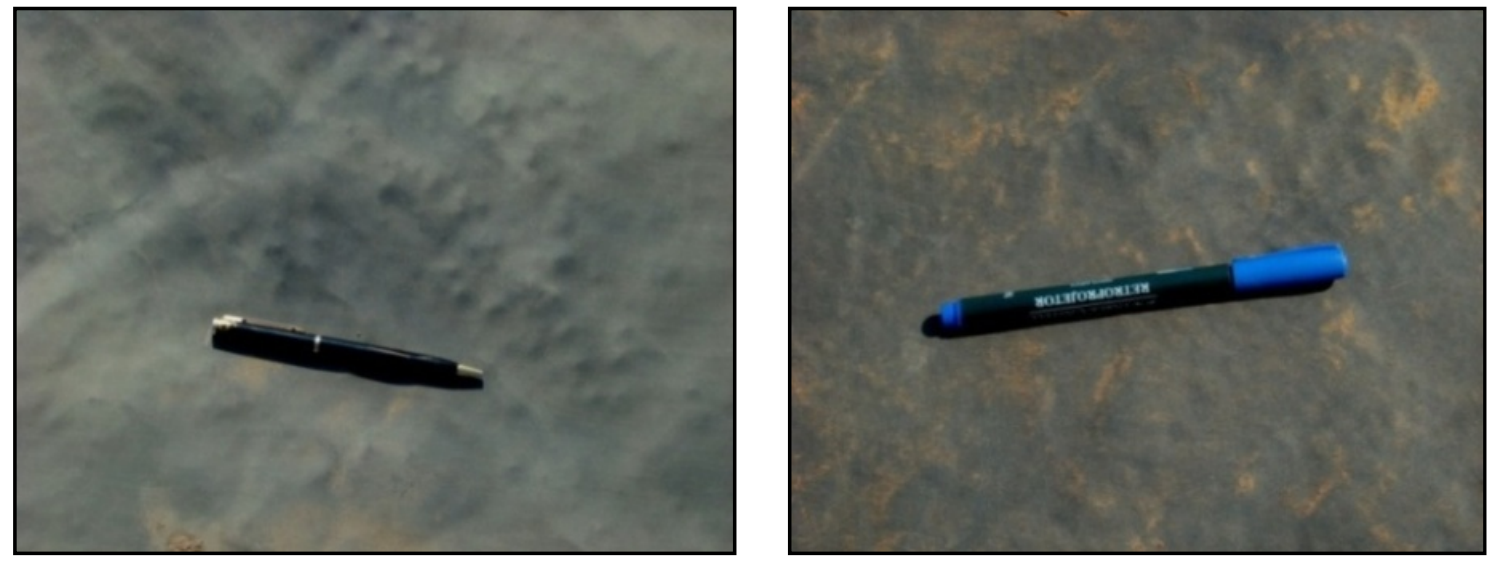

Figura 159. Danos visuais: GM de PVC de 1,0 mm com camadas naturais e brita 1: (a) areia; (b) solo. 


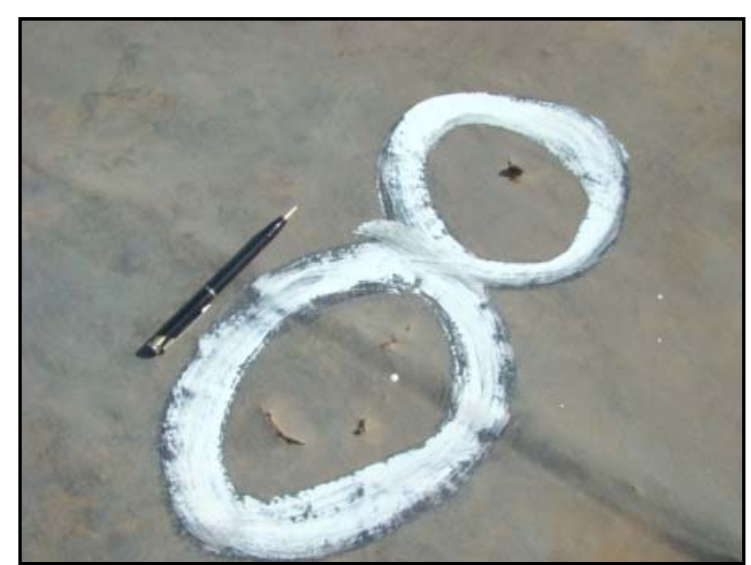

Superfície inferior (GM)

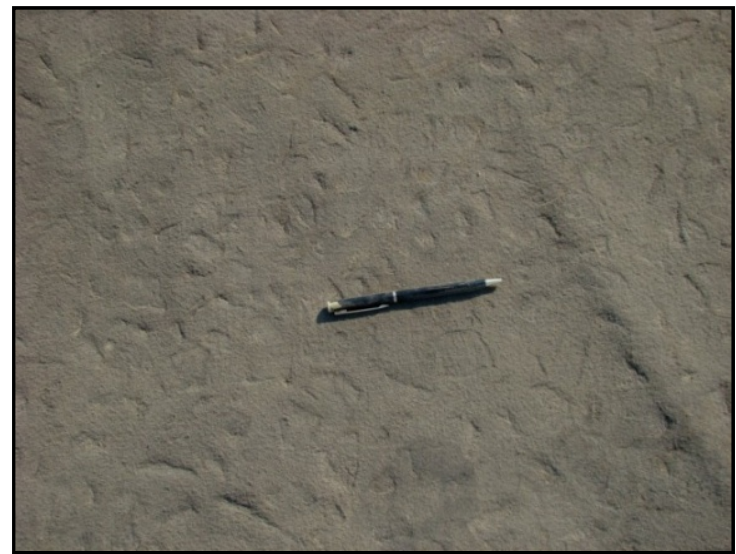

Superfície superior (GT)

Figura 160. Danos visuais: GM de PVC de 1,0 mm com geocomposto.

Tabela 43. Danos visuais observados nas geomembranas de PVC.

\begin{tabular}{|c|c|c|c|c|c|c|c|c|}
\hline \multicolumn{3}{|c|}{ Configuração } & \multicolumn{5}{|c|}{$\begin{array}{l}\text { Tipo de Dano Visual } \\
\end{array}$} & \multirow{2}{*}{ Classe } \\
\hline GM & Proteção & Brita & Arranhão & Entalhe & Indentação & Deformação & Furos & \\
\hline \multirow{7}{*}{$\begin{array}{l}\text { PVC } \\
1,0 \mathrm{~mm}\end{array}$} & - & \multirow{9}{*}{3} & - & - & - & muitas & 67 & $\mathrm{I}$ \\
\hline & $\begin{array}{c}\text { GT PET } \\
300 \\
\end{array}$ & & - & - & - & várias & 2 & I \\
\hline & $\begin{array}{c}\text { GT PET } \\
600 \\
\end{array}$ & & - & - & - & muitas & - & II \\
\hline & $\begin{array}{c}\text { GT PP } \\
600 \\
\end{array}$ & & - & - & - & poucas & 11 & I \\
\hline & $\begin{array}{c}\text { GT PET } \\
1200\end{array}$ & & - & - & - & várias & - & II \\
\hline & Areia & & - & - & - & várias & - & II \\
\hline & Solo & & - & - & - & várias & - & II \\
\hline $\begin{array}{c}\text { PVC } \\
2,0 \mathrm{~mm} \\
\end{array}$ & - & & - & - & - & muitas & 2 & I \\
\hline $\mathrm{GC}$ & - & & - & - & - & inúmeras & inúmeros & $\mathrm{I}$ \\
\hline \multirow{4}{*}{$\begin{array}{c}\text { PVC } \\
1,0 \mathrm{~mm}\end{array}$} & - & \multirow{4}{*}{1} & - & - & - & poucas & 5 & $\mathrm{I}$ \\
\hline & $\begin{array}{c}\text { GT PET } \\
600\end{array}$ & & - & - & - & poucas & - & II \\
\hline & Areia & & - & - & - & várias & - & II \\
\hline & Solo & & & - & - & várias & - & II \\
\hline
\end{tabular}

No caso das geomembranas de PVC somente foram verificados danos na forma de deformações e furos. Em se tratando de furos, pôde-se verificar que a incidência de furos foi bastante elevada nas geomembranas sem proteção. Foram verificados grandes rasgos, com extensão em torno de $10 \mathrm{~cm}$, e pequenos furos, muitos deles imperceptíveis a olho nu. A 
configuração com geomembrana de $2,0 \mathrm{~mm}$ também apresentou furos, embora em menor quantidade do que na geomembrana de $1,0 \mathrm{~mm}$.

Nas configurações com elemento de proteção constatou-se uma redução das deformações e dos furos sobre a superfície da geomembrana. Apenas os geotêxteis de PET $300 \mathrm{~g} / \mathrm{m}^{2}$ e PP $600 \mathrm{~g} / \mathrm{m}^{2}$ não foram capazes de proteger a geomembrana contra furos. Estes danos possivelmente estão associados aos movimentos operacionais dos maquinários, que podem ter gerado acréscimos de tensão localizada.

As camadas de proteção com areia e solo apresentaram um bom desempenho visual comparado às proteções com geotêxtil, apresentando poucas deformações e sem furos. Em contrapartida, o geocomposto utilizado apresentou um elevado número de furos.

\subsubsection{Ensaios Pós-Danos}

\subsection{Ensaio de Tração Faixa Larga}

As Figuras a seguir apresentam as curvas obtidas nos ensaios de tração em faixa larga nas geomembranas de PVC, com diferentes camadas de proteção. A Figura 173 ilustra o mecanismo de ruptura verificado em algumas configurações. 


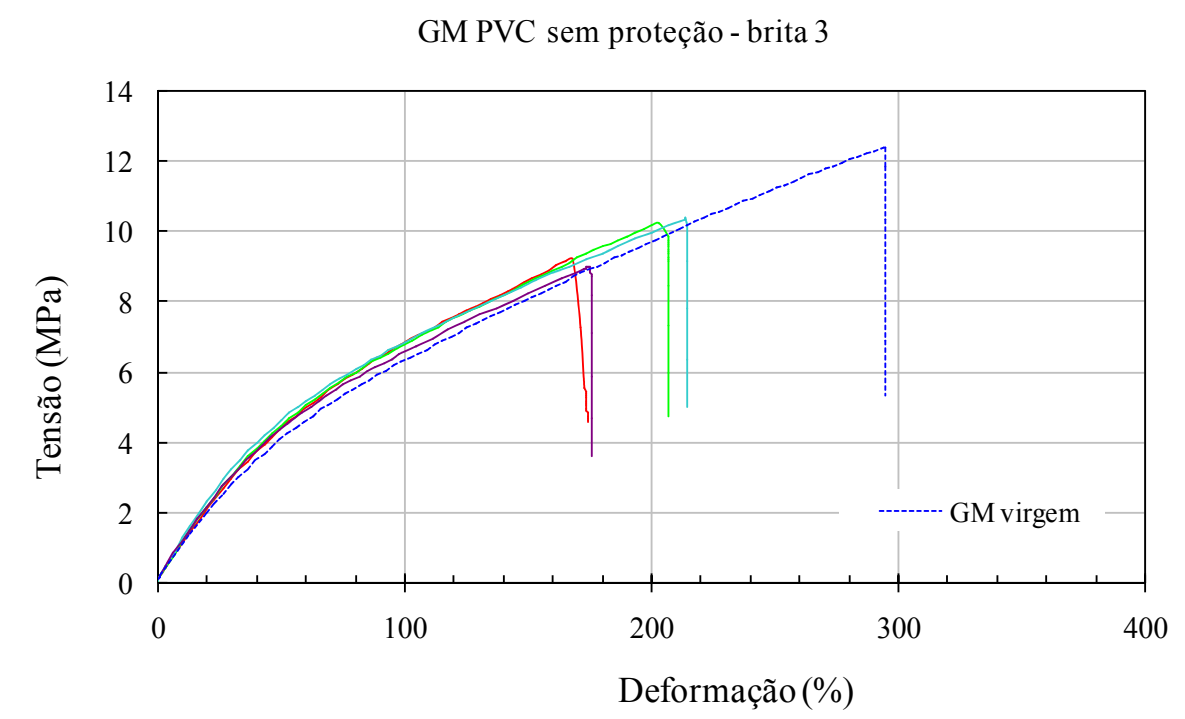

Figura 161. Resultados dos ensaios de tração em faixa larga: GM de PVC de 1,0 mm sem proteção / brita 3 .

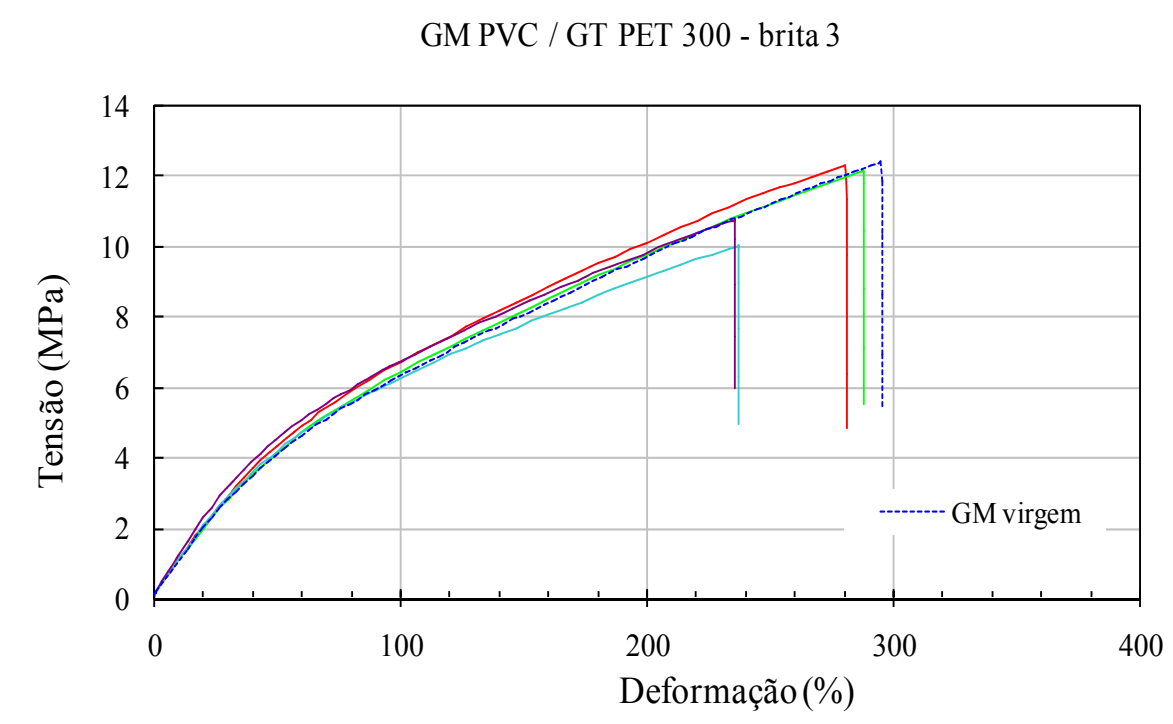

Figura 162. Resultados dos ensaios de tração em faixa larga - GM de PVC de 1,0 mm e GT PET 300 g/m² / brita 3 . 
GM PVC / GT PET 600 - brita 3

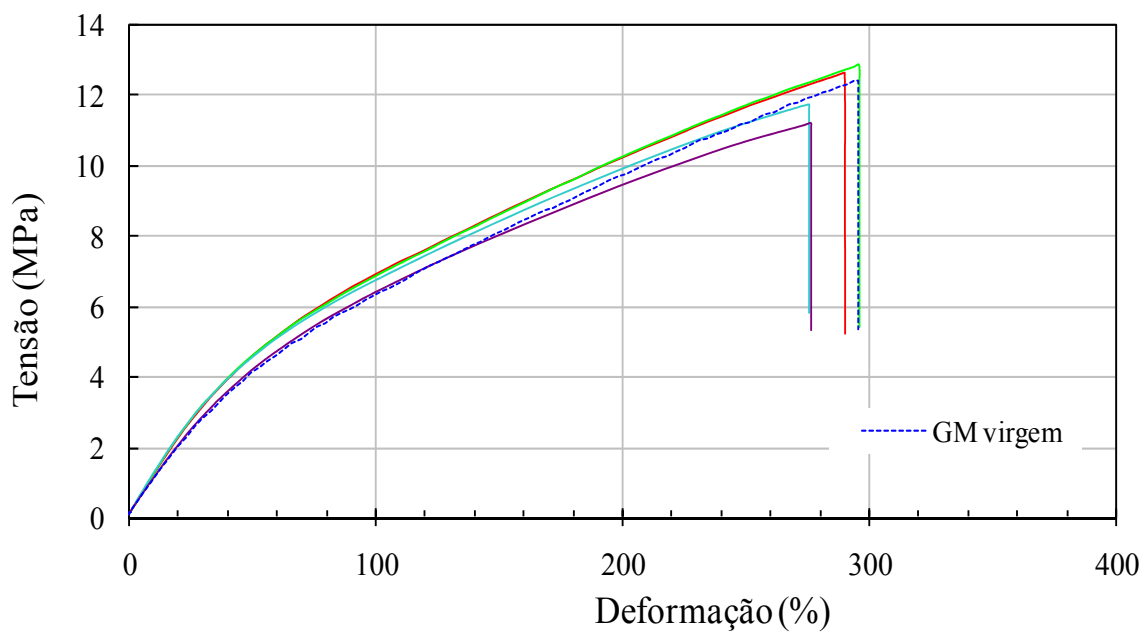

Figura 163. Resultados dos ensaios de tração em faixa larga - GM de PVC de 1,0 mm e GT PET $600 \mathrm{~g} / \mathrm{m}^{2} /$ brita 3 .

GM PVC / GT PP 600 - brita 3

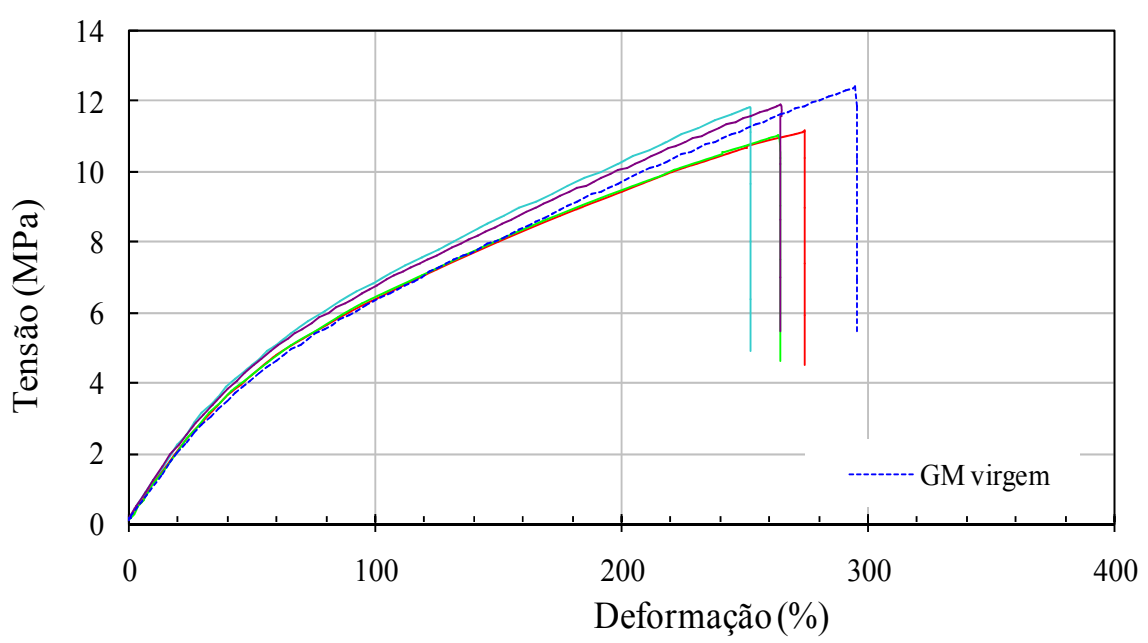

Figura 164. Resultados dos ensaios de tração em faixa larga - GM de PVC de 1,0 mm e GT PP $600 \mathrm{~g} / \mathrm{m}^{2} /$ brita 3 . 
GM PVC / GT PET 1200 - brita 3

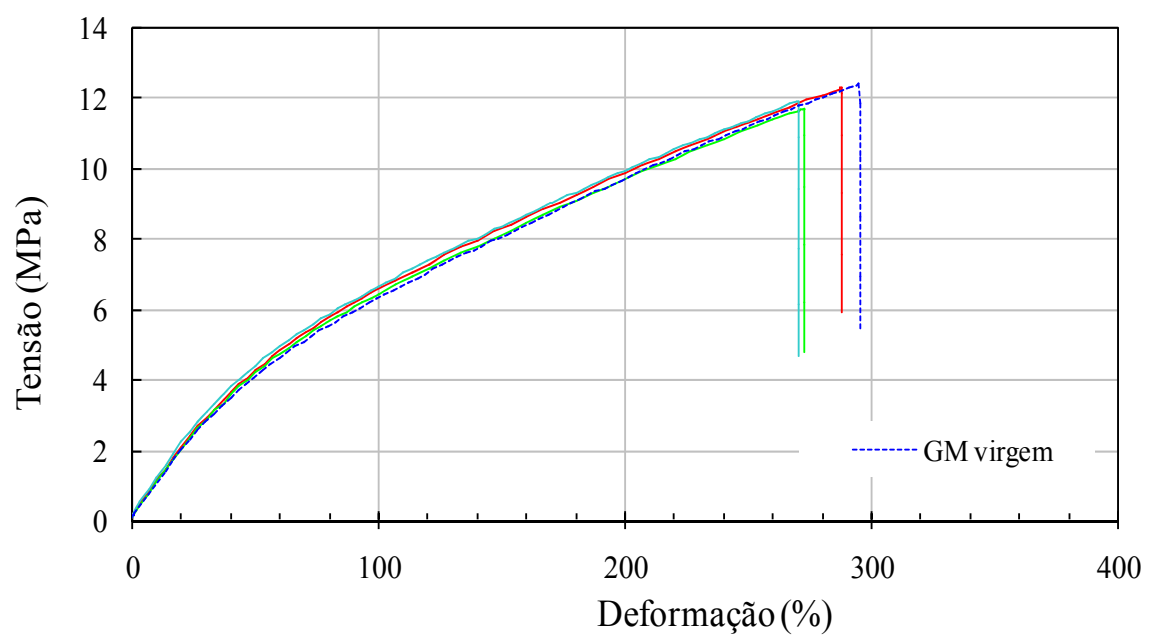

Figura 165. Resultados dos ensaios de tração em faixa larga - GM de PVC de 1,0 mm e GT PET $1200 \mathrm{~g} / \mathrm{m}^{2} /$ brita 3 .

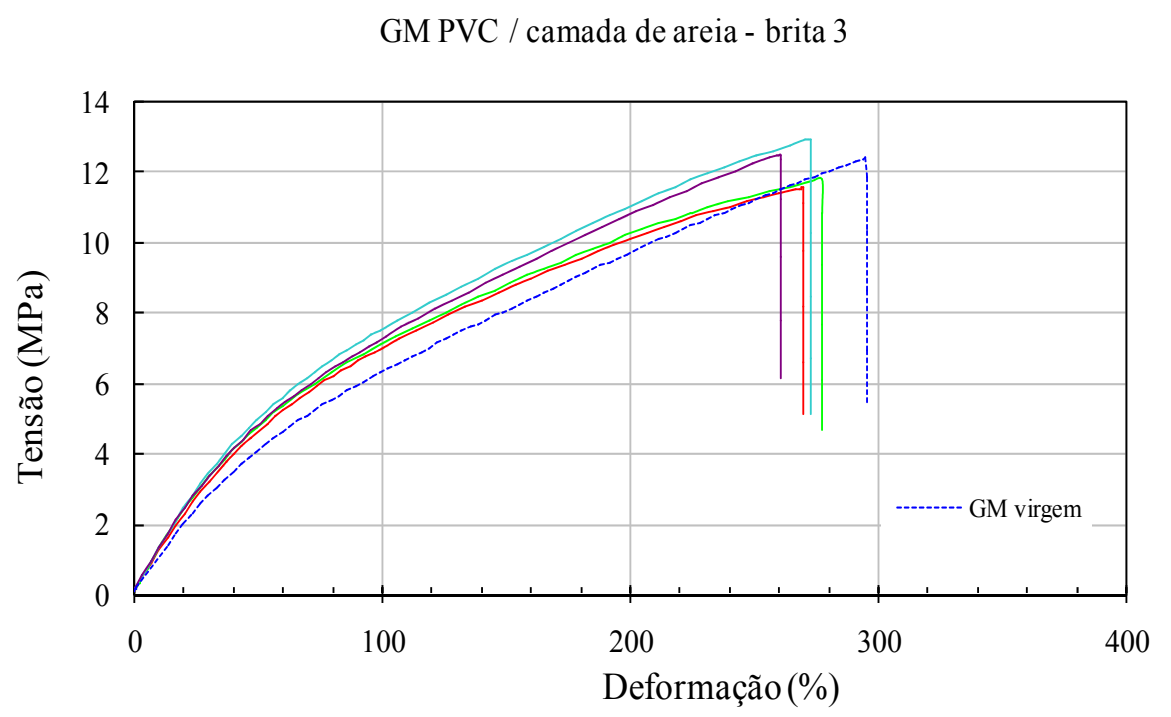

Figura 166. Resultados dos ensaios de tração em faixa larga - GM de PVC de 1,0 mm e camada de areia / brita 3 . 
GM PVC / camada de solo - brita 3

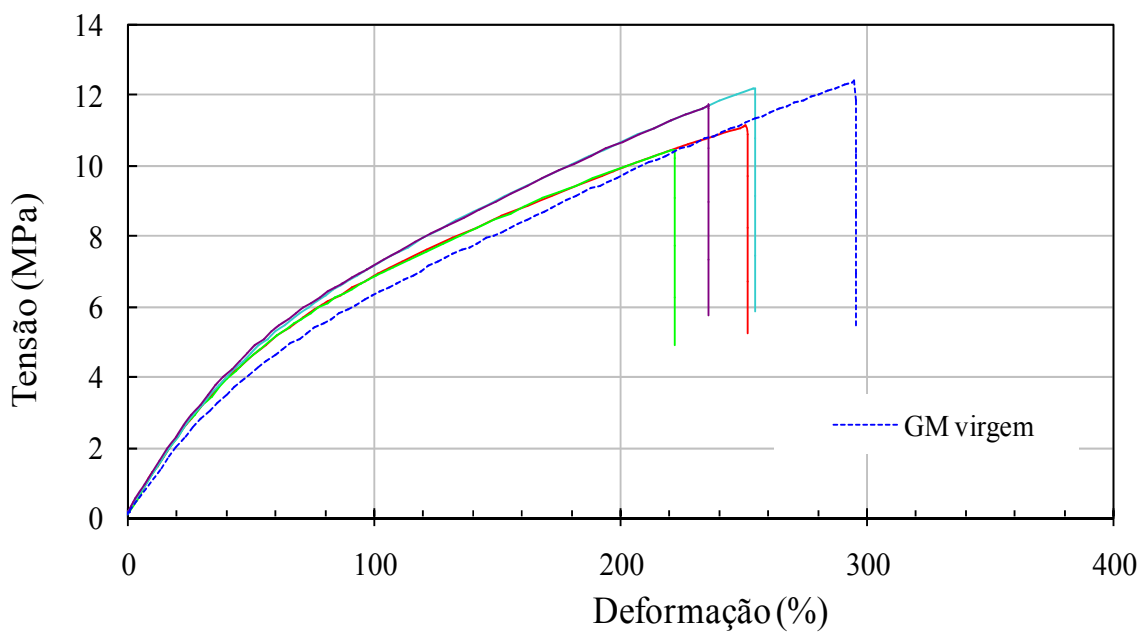

Figura 167. Resultados dos ensaios de tração em faixa larga - GM de PVC de 1,0 mm e camada de solo / brita 3 .

GM PVC $2.0 \mathrm{~mm}$ sem proteção - brita 3

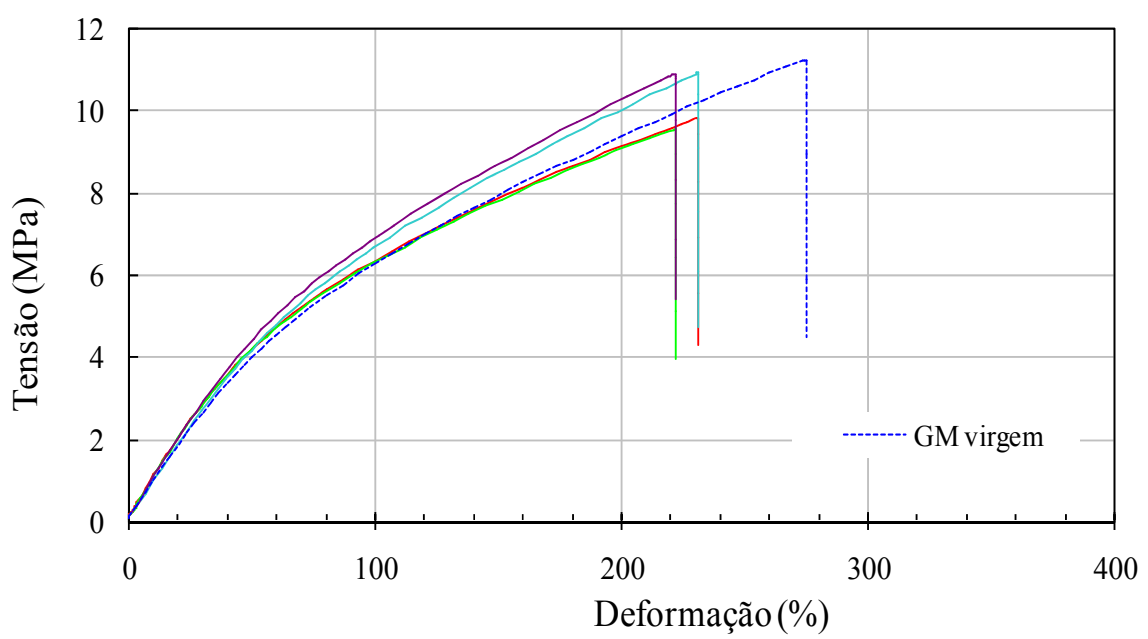

Figura 168. Resultados dos ensaios de tração em faixa larga: GM de PVC de 2,0 mm sem proteção / brita 3 . 


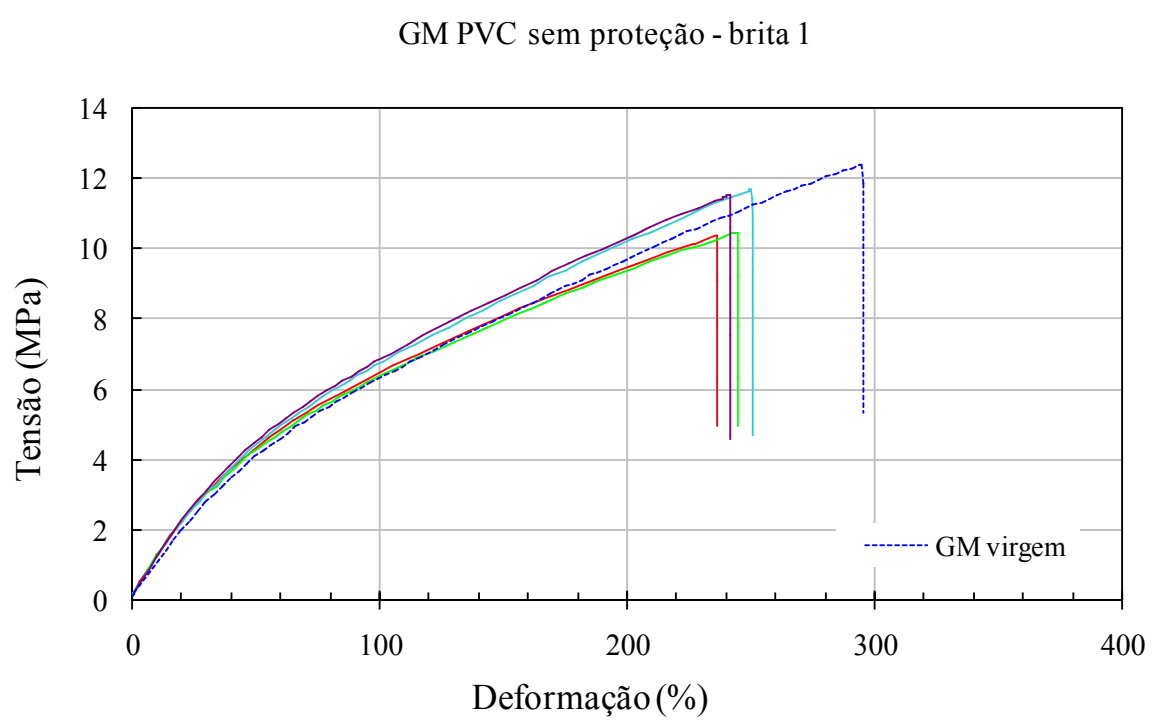

Figura 169. Resultados dos ensaios de tração em faixa larga - GM de PVC de 1,0 mm sem proteção/ brita 1 .

GM PVC / GT PET 600 - brita 1

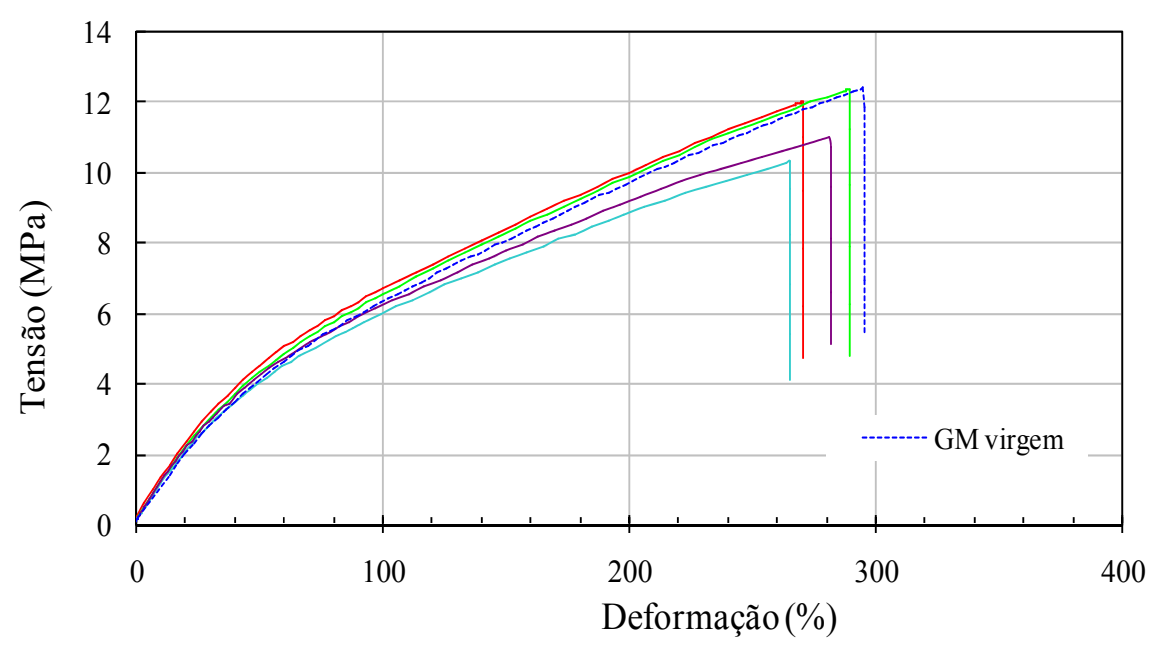

Figura 170. Resultados dos ensaios de tração em faixa larga - GM de PVC de 1,0 mm e GT PET $600 \mathrm{~g} / \mathrm{m}^{2} /$ brita 1. 
GM PVC / camada de areia - brita 1

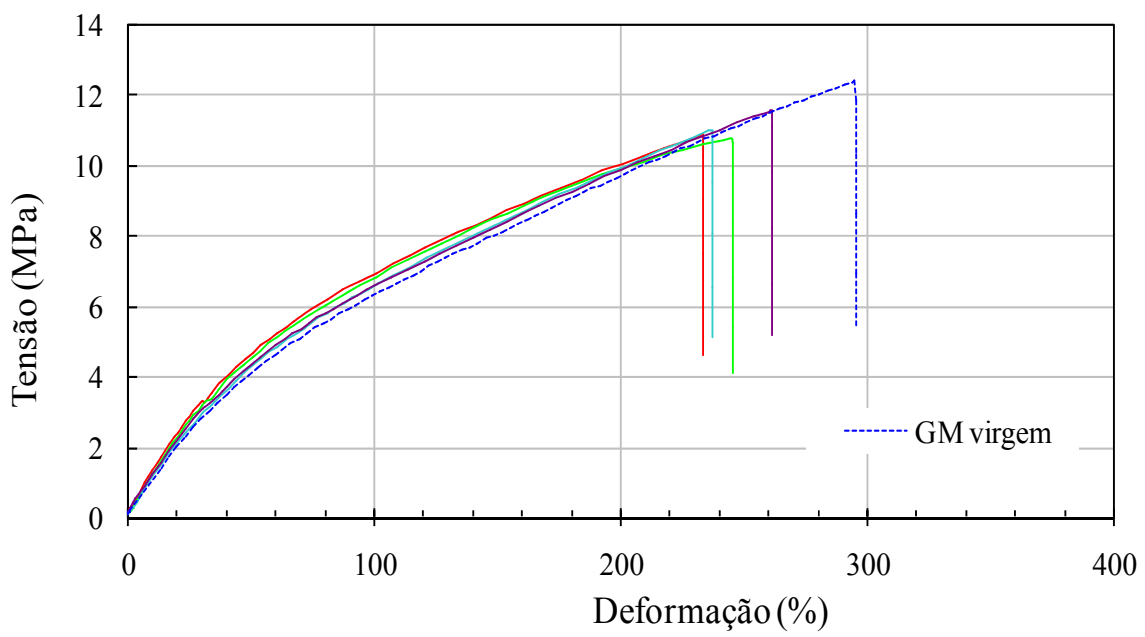

Figura 171. Resultados dos ensaios de tração em faixa larga - GM de PVC de 1,0 mm e areia / brita 1.

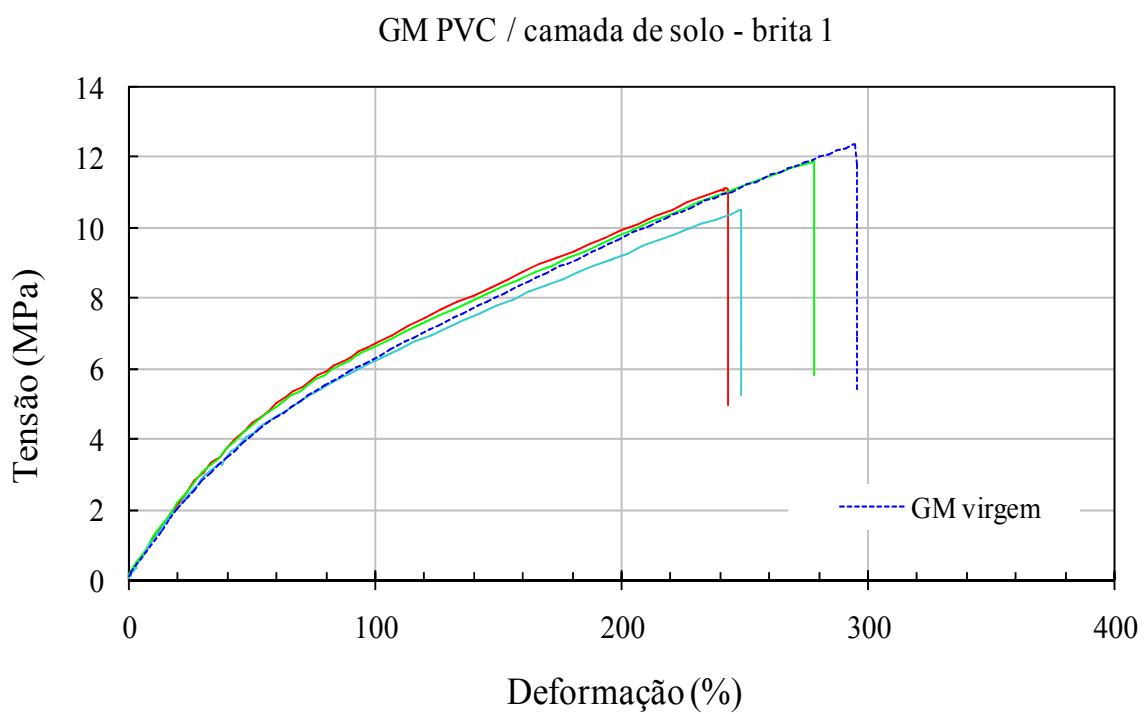

Figura 172. Resultados dos ensaios de tração em faixa larga - GM de PVC de 1,0 mm e solo / brita 1. 


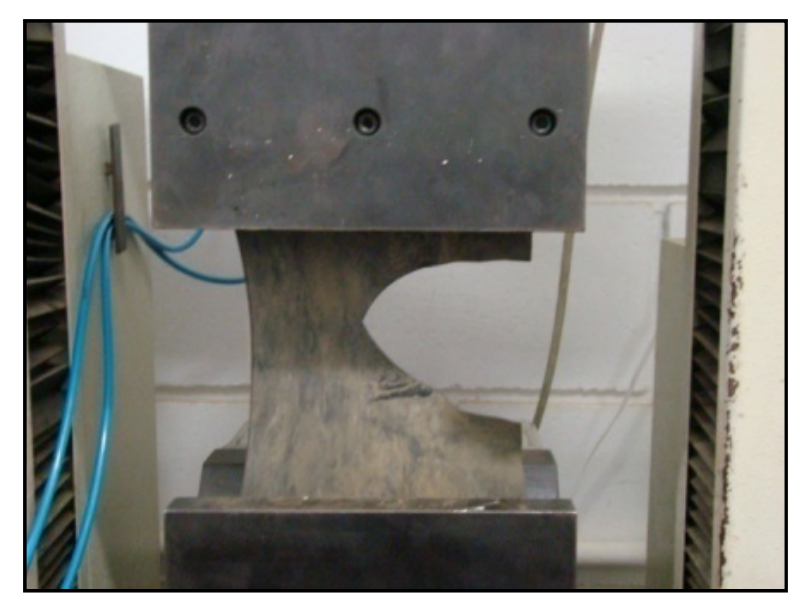

GM sem proteção

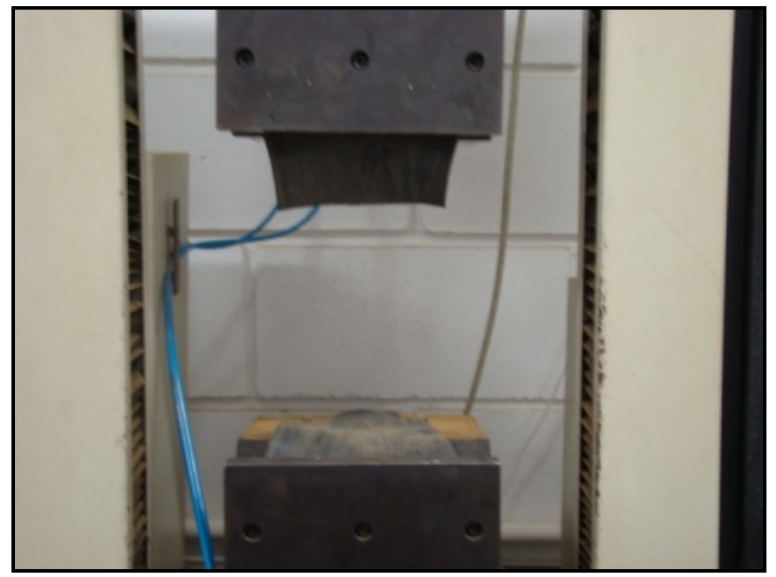

GT PET 600

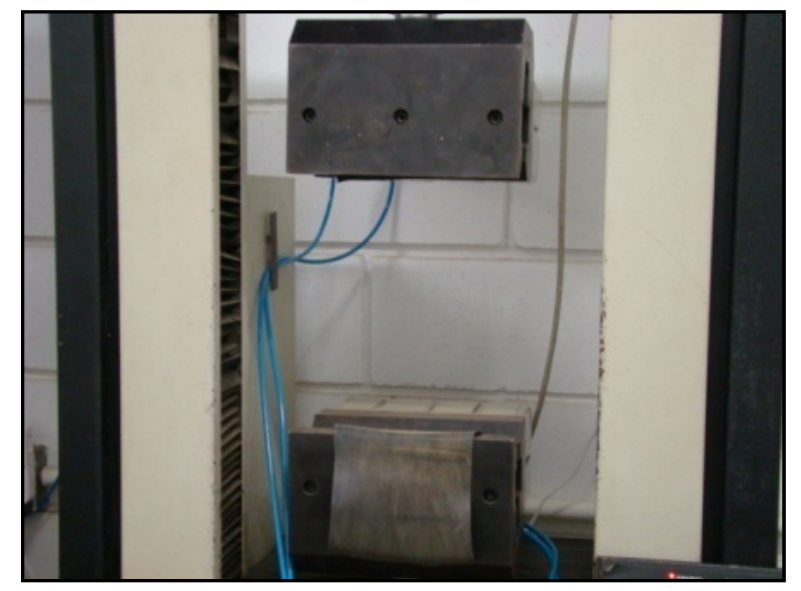

Camada de areia

Figura 173. Mecanismo de ruptura nos ensaios de tração em faixa larga - GM de PVC.

As geomembranas sem elemento de proteção romperam com valores de alongamento e tensão de tração mais baixos do que verificado nas geomembranas virgens. Ao se introduzir o elemento de proteção, constatou-se um aumento nos valores de tensão e alongamento de tração na geomembrana, com comportamento semelhante ao da geomembrana virgem.

Com relação ao modo de ruptura, verificou-se que as geomembranas sem proteção romperam por meio de um rasgo iniciado na região mais danificada. Ao contrário, nas geomembranas virgens a ruptura é caracterizada por um corte instantâneo ao longo de toda a 
largura do corpo de prova. Nas configurações com proteção, o modo de ruptura foi similar ao verificado nos ensaios de tração com geomembranas virgens.

A Figura 174 apresenta os gráficos de tensão e deformação respectivos aos ensaios realizados com geotêxtil como elemento de proteção. A Tabela 44 sintetiza os resultados de todas as configurações ensaiadas.

Os resultados dos ensaios de tração faixa larga mostram que as maiores reduções ocorreram nas geomembranas danificadas sem proteção. Constataram-se reduções em torno de $45 \%$ e $35 \%$ nas forças e deformação de ruptura, respectivamente, para a configuração com brita 3. Na configuração com brita 1 , a redução foi de aproximadamente $10 \%$ e $20 \%$ respectivos à força e deformação na ruptura.

Com a introdução do elemento de proteção, verificou-se um acréscimo da tensão de tração nas geomembranas danificadas atingindo, em todas as configurações, valores próximos à geomembrana virgem. As configurações com geotêxtil apresentaram uma redução de deformação inferior a 10\% comparada à geomembrana virgem, enquanto nas configurações com areia e solo apresentaram uma redução em torno de $15 \%$.

Observa-se também que a resistência à tração da geomembrana não é função das características de tração do geotêxtil. 
GM PVC $1.0 \mathrm{~mm}$ - Brita 3

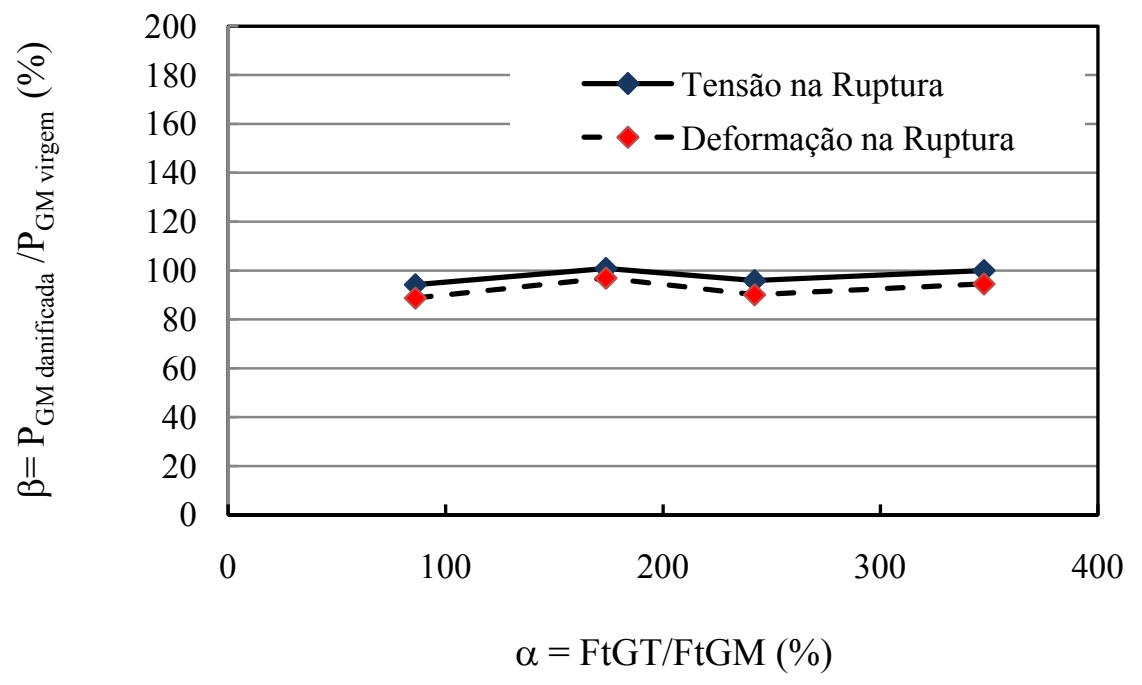

Figura 174. Resultados de tração em faixa larga - GM de PVC: (a) brita 3.

Tabela 44. Resultados dos ensaios de tração faixa larga realizados nas geomembranas de PVC.

\begin{tabular}{|c|c|c|c|c|c|c|}
\hline \multicolumn{3}{|c|}{ Configuração de Ensaio } & \multirow{2}{*}{$\frac{\sigma}{(\mathrm{MPa})}$} & \multirow[t]{2}{*}{$\Delta \sigma$} & \multirow{2}{*}{$\frac{\varepsilon}{(\%)}$} & \multirow[t]{2}{*}{$\Delta \varepsilon$} \\
\hline GM & Proteção & Brita & & & & \\
\hline GM virgem $1.0 \mathrm{~mm}$ & - & - & 11,9 & - & 293 & - \\
\hline GM virgem $2.0 \mathrm{~mm}$ & - & - & 10,7 & - & 275 & - \\
\hline \multirow{7}{*}{$\begin{array}{c}\text { GM danificada } 1.0 \\
\mathrm{~mm}\end{array}$} & $\begin{array}{c}\text { Sem } \\
\text { proteção }\end{array}$ & \multirow{8}{*}{3} & 6,5 & 0,55 & 193 & 0,66 \\
\hline & $\begin{array}{l}\text { GT PET } \\
300\end{array}$ & & 11,3 & 0,95 & 260 & 0,89 \\
\hline & $\begin{array}{l}\text { GT PET } \\
600\end{array}$ & & 12,1 & 1,02 & 284 & 0,97 \\
\hline & $\begin{array}{c}\text { GT PET } \\
1200 \\
\end{array}$ & & 11,5 & 1,01 & 277 & 0,95 \\
\hline & GT PP 600 & & 12,0 & 0,97 & 264 & 0,90 \\
\hline & Areia & & 12,2 & 1,03 & 270 & 0,92 \\
\hline & Solo & & 11,4 & 0,96 & 250 & 0,85 \\
\hline $\begin{array}{l}\text { GM danificada } 2.0 \\
\text { mm }\end{array}$ & $\begin{array}{c}\text { Sem } \\
\text { proteção }\end{array}$ & & 10,6 & 0,99 & 226 & 0,82 \\
\hline \multirow{4}{*}{ GM danificada } & $\begin{array}{c}\text { Sem } \\
\text { proteção }\end{array}$ & \multirow{4}{*}{1} & 11,0 & 0,92 & 243 & 0,83 \\
\hline & $\begin{array}{l}\text { GT PET } \\
600 \\
\end{array}$ & & 11,4 & 0,96 & 277 & 0,95 \\
\hline & Areia & & 11,1 & 0,93 & 244 & 0,83 \\
\hline & Solo & & 11,2 & 0,94 & 256 & 0,87 \\
\hline
\end{tabular}




\subsection{Ensaio de Tração Multiaxial}

As Figuras a seguir apresentam as curvas e a análise dos resultados obtidos nos ensaios de tração multiaxial com geomembranas de PVC. A Tabela 45 apresenta a síntese dos resultados.

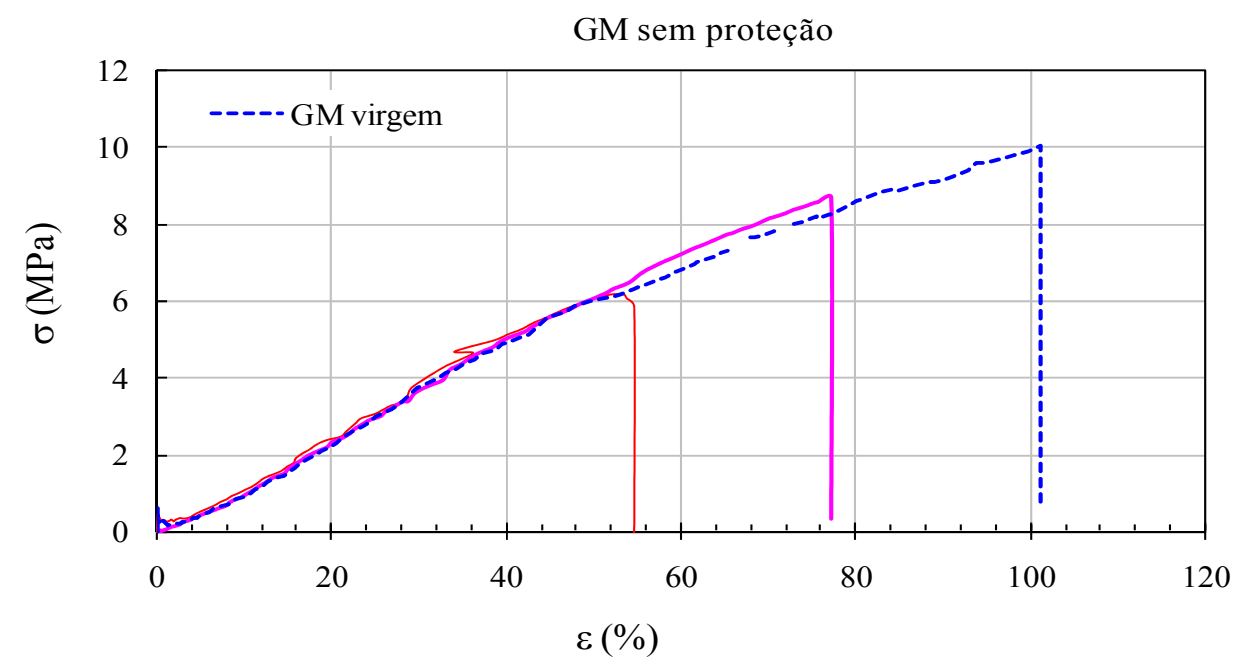

Figura 175. Resultados dos ensaios de tração multiaxial - GM de PVC de 1,0 mm sem proteção / brita 3 .

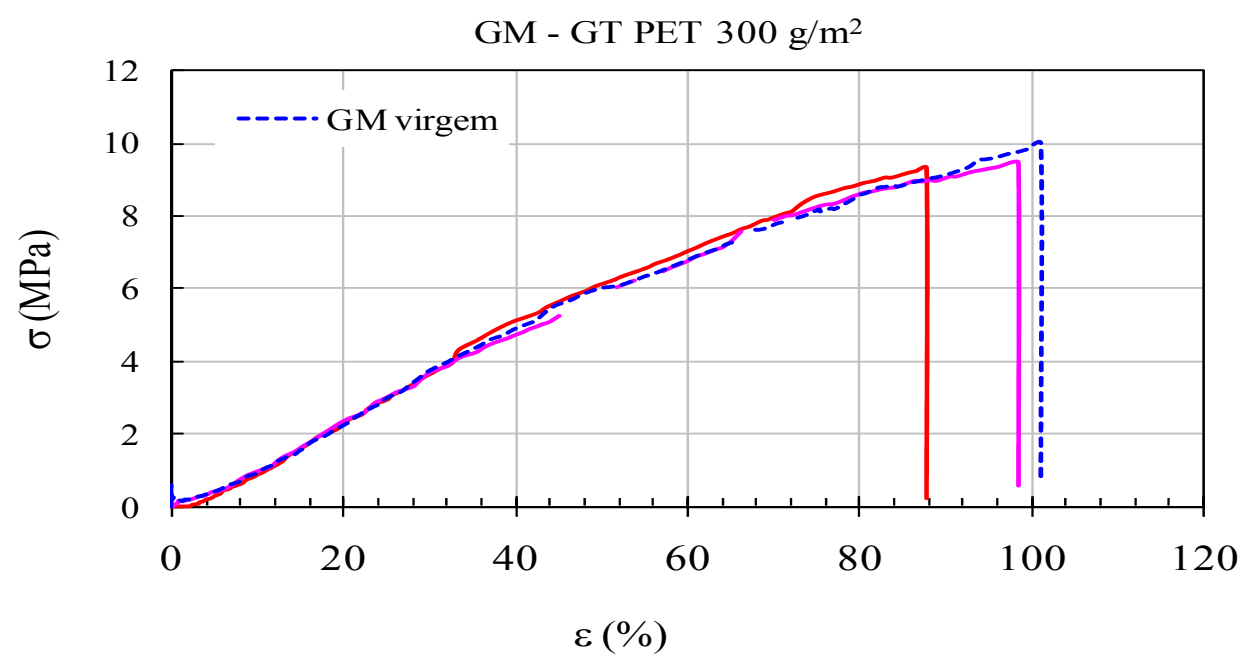

Figura 176. Resultados dos ensaios de tração multiaxial - GM de PVC de 1,0 mm e GT PET $300 \mathrm{~g} / \mathrm{m}^{2} /$ brita 3 . 


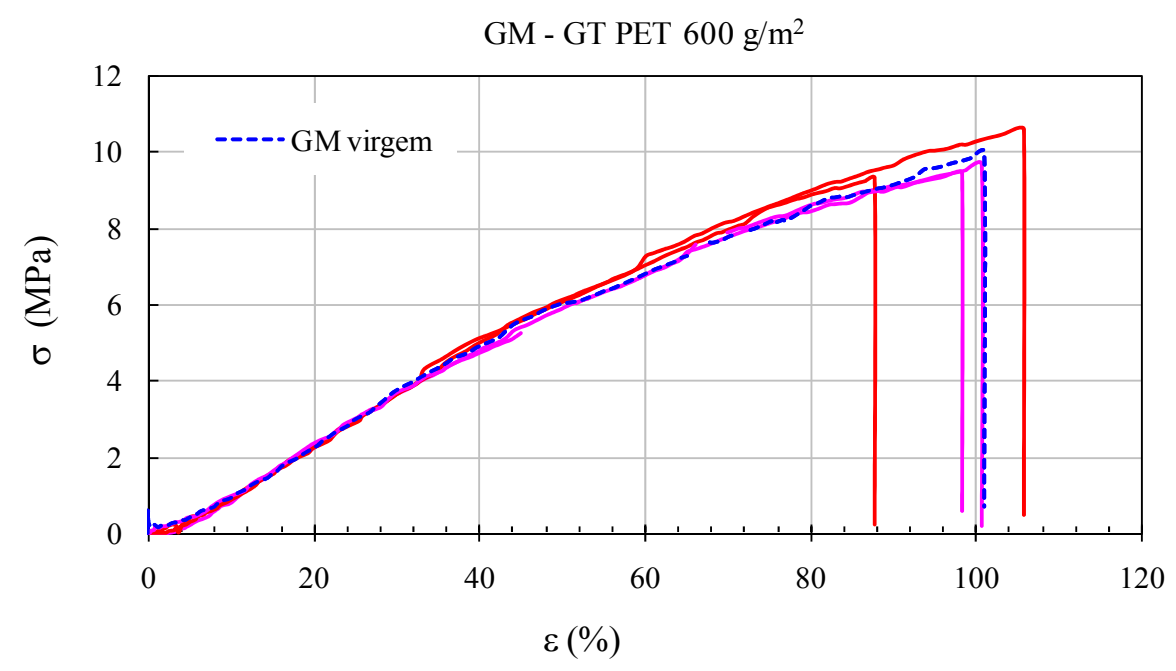

Figura 177. Resultados dos ensaios de tração multiaxial - GM de PVC de 1,0 mm e GT PET $600 \mathrm{~g} / \mathrm{m}^{2} /$ brita 3 .

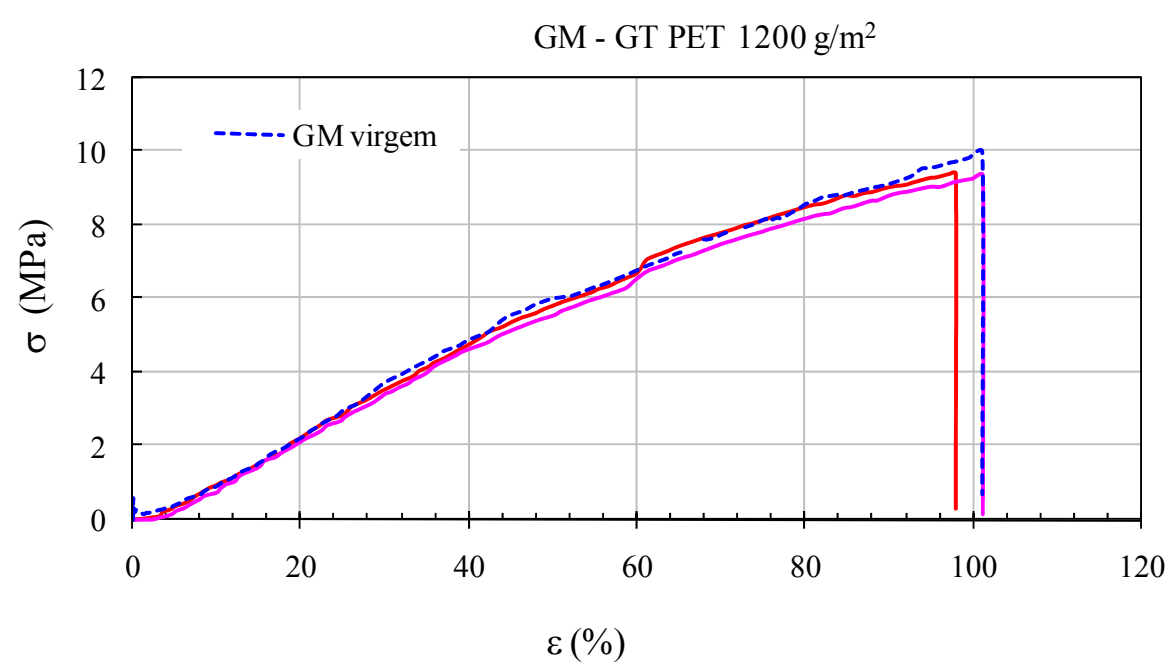

Figura 178. Resultados dos ensaios de tração multiaxial - GM de PVC de 1,0 mm e GT PET $1200 \mathrm{~g} / \mathrm{m}^{2} /$ brita 3 . 


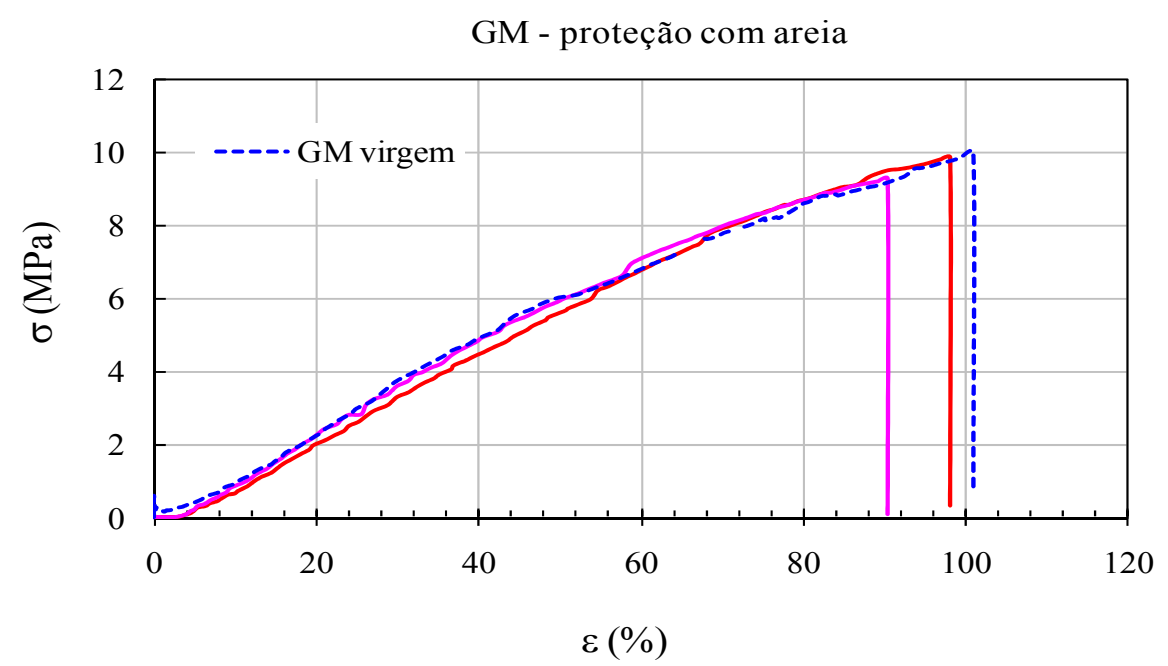

Figura 179. Resultados dos ensaios de tração multiaxial - GM de PVC de 1,0 mm e camada de areia / brita 3 .

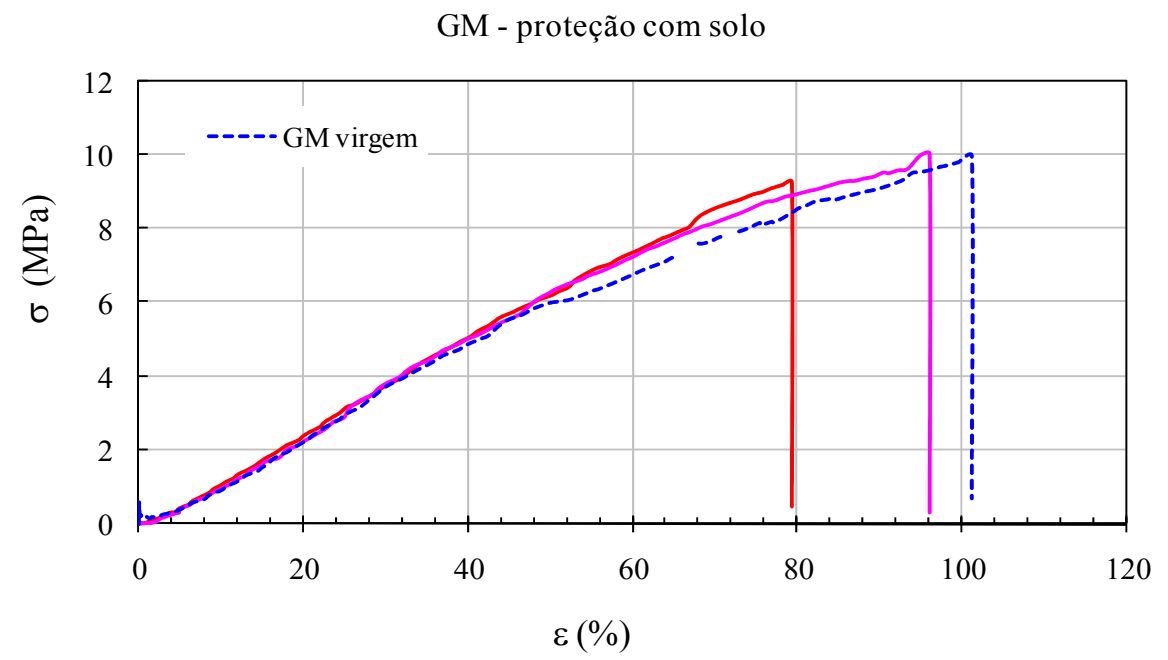

Figura 180. Resultados dos ensaios de tração multiaxial - GM de PVC de 1,0 mm e camada de solo / brita 3 . 
GM PVC 1.0 mm - Brita 3

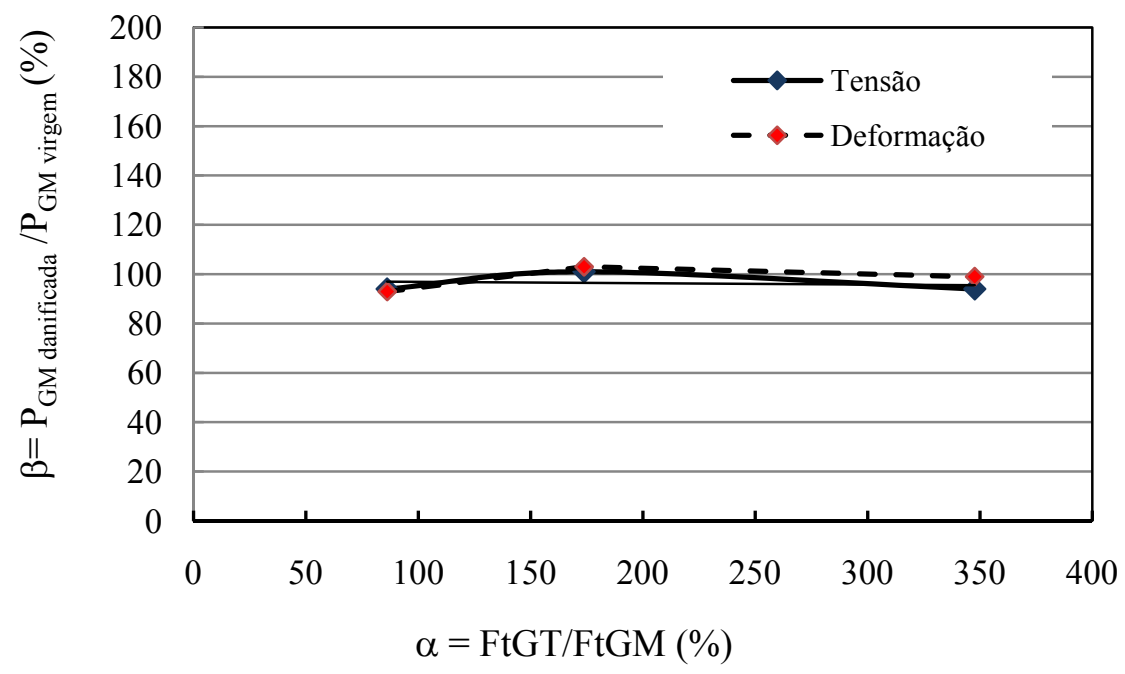

Figura 181. Análise ensaio de tração multiaxial - GM de PVC e brita 3.

Tabela 45. Resultados dos ensaios de tração multiaxial realizados nas geomembranas de PVC.

\begin{tabular}{|c|c|c|c|c|c|c|}
\hline \multicolumn{3}{|c|}{ Configuração de Ensaio } & \multirow{2}{*}{$\frac{\sigma}{(\mathbf{M P a})}$} & $\Delta \sigma$ & \multirow{2}{*}{$\frac{\varepsilon}{(\%)}$} & \multirow[t]{2}{*}{$\Delta \varepsilon$} \\
\hline GM & Proteção & Brita & & & & \\
\hline GM virgem $1.0 \mathrm{~mm}$ & - & - & 10,0 & - & 100 & - \\
\hline \multirow{6}{*}{$\begin{array}{l}\text { GM danificada } 1.0 \\
\mathrm{~mm}\end{array}$} & Sem proteção & \multirow{6}{*}{3} & 7,2 & 0,72 & 66 & 0,66 \\
\hline & GT PET 300 & & 9,4 & 0,94 & 93 & 0,93 \\
\hline & GT PET 600 & & 10,1 & 1,01 & 103 & 1,03 \\
\hline & GT PET 1200 & & 9,4 & 0,94 & 99 & 0,99 \\
\hline & Areia & & 9,5 & 0,95 & 94 & 0,94 \\
\hline & Solo & & 9,7 & 0,97 & 90 & 0,90 \\
\hline
\end{tabular}

Os resultados mostram que a geomembrana danificada sem proteção apresentou grande redução nos valores de tensão e deformação à tração, em torno de 30\%.

No caso das geomembranas com proteção, constata-se um aumento nos valores da tensão e deformação, que tendem ao valor da geomembrana virgem. De modo análogo ao verificado nos ensaios de tração em faixa larga, a variação das propriedades de tração multiaxial da geomembrana com o tipo de proteção empregado foi de pequena grandeza.

A Figura 182 ilustra o modo de ruptura observado nas geomembranas de PVC submetidas ao ensaio de tração multiaxial. 


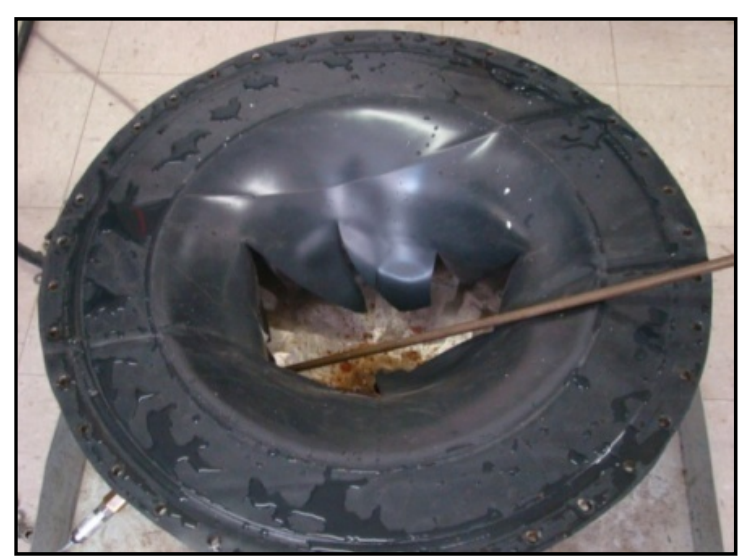

GM PVC virgem

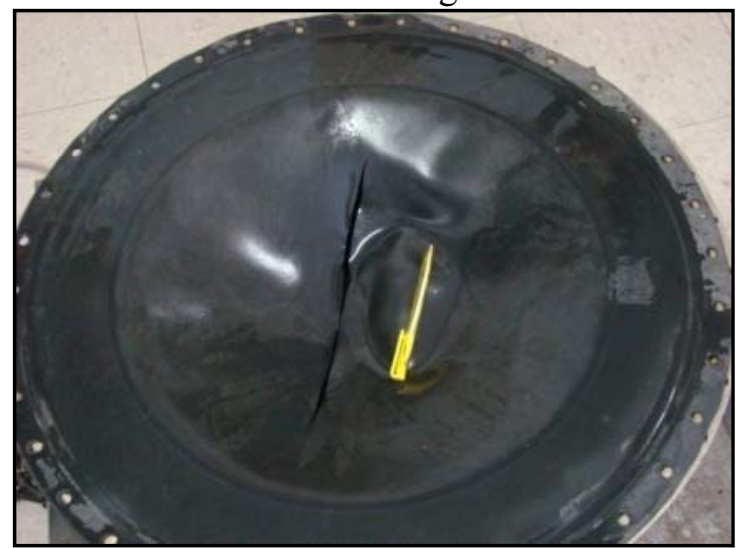

GM sem proteção - CP2

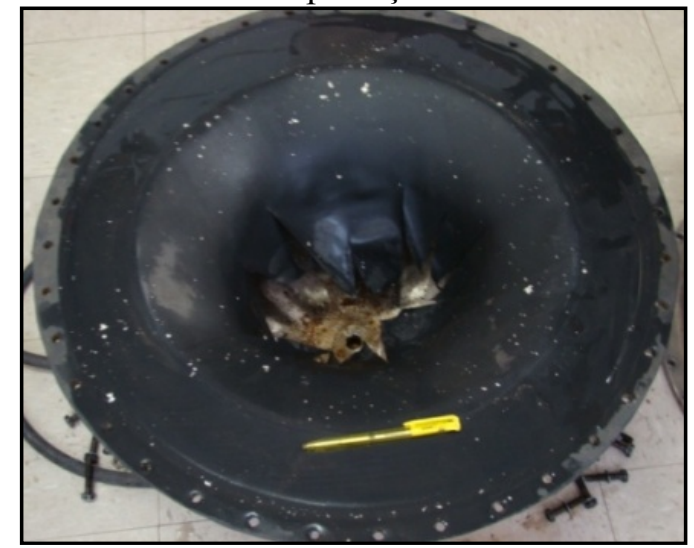

GM PEAD / GT PET 600

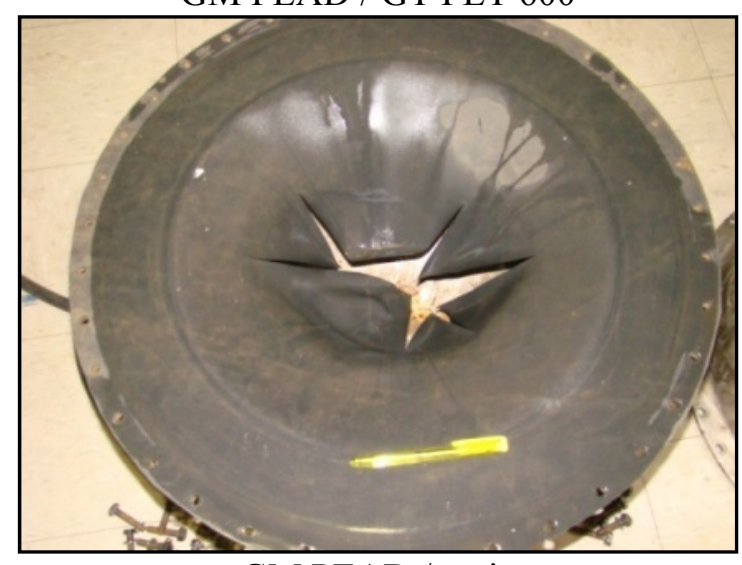

GM PEAD / areia

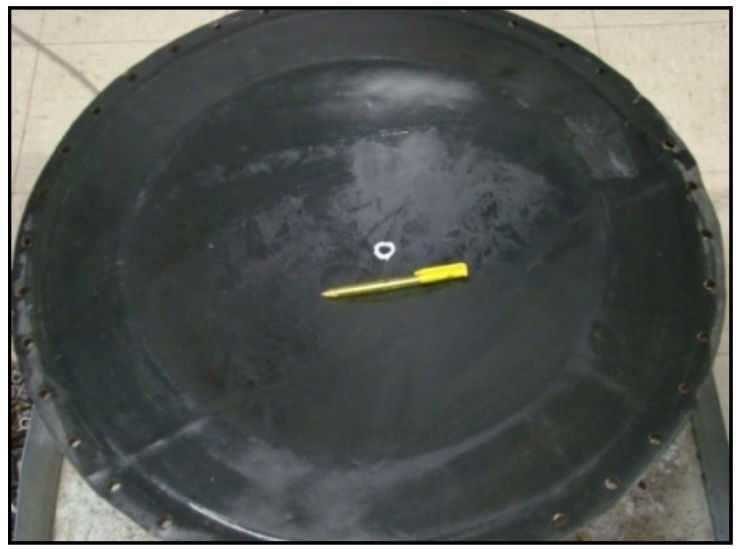

GM sem proteção - CP1

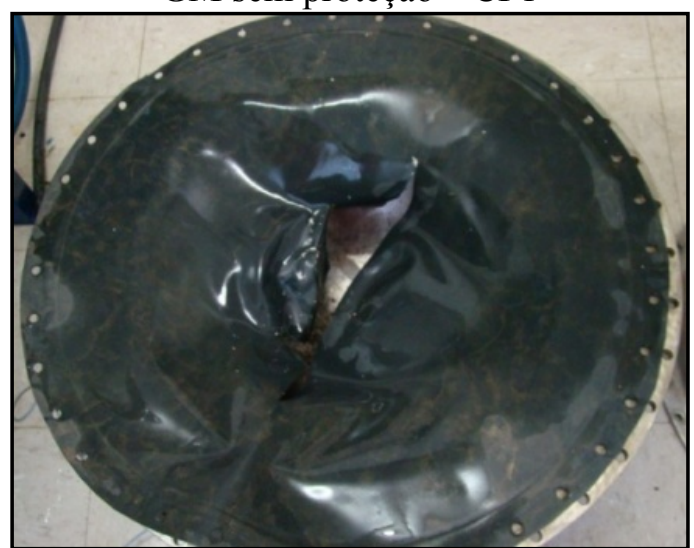

GM PVC / GT PET 300

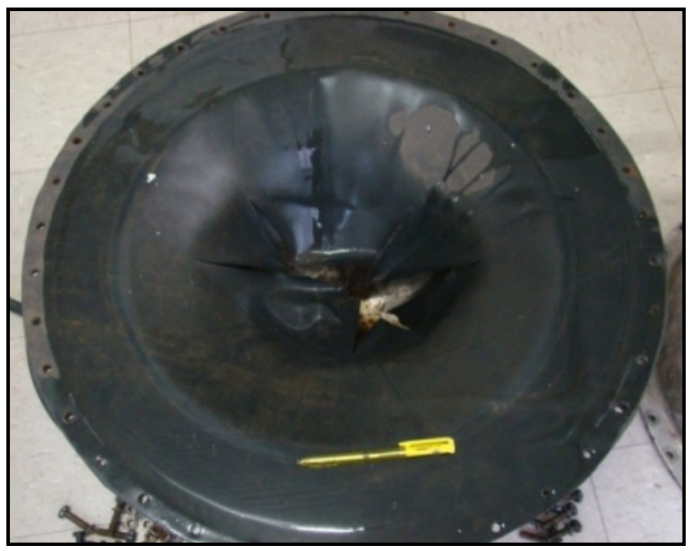

GM PEAD / GT PET 1200

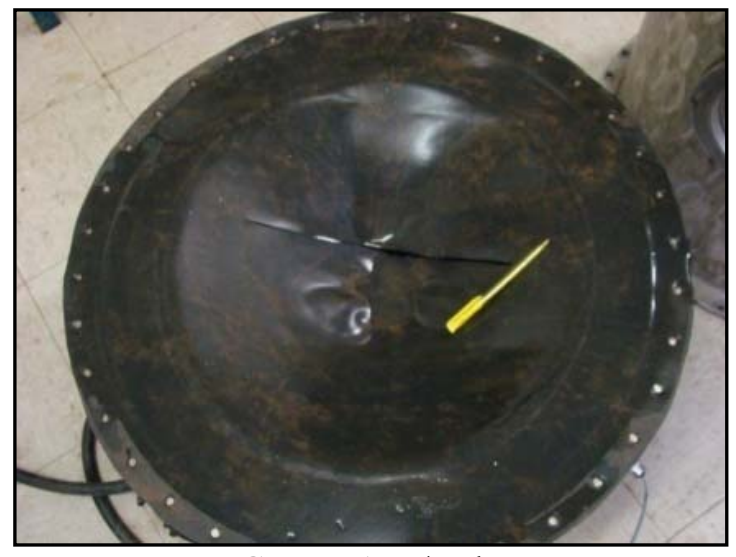

GM PEAD / solo

Figura 182. Modo de ruptura nos ensaios de tração multiaxial: GM PVC 1,0 mm / brita3. 
Verifica-se que a geomembrana virgem rompeu no centro da amostra (topo da abóbada) como um estouro. No entanto, a geomembrana danificada sem proteção apresentou sua ruptura caracterizada por um pequeno furo (primeiro corpo de prova) e um longo corte central (primeiro corpo de prova), ambos localizados no centro da amostra.

Em geral, as geomembranas danificadas com proteção apresentaram o modo de ruptura semelhante à geomembrana virgem. Excetuam-se as geomembranas com proteção de geotêxtil de PET $300 \mathrm{~g} / \mathrm{m}^{2}$ e com solo, as quais apresentaram a ruptura caracterizada por um longo corte central.

De acordo com o modo de ruptura observado e com o critério proposto por Badu et al. (1998), todas as configurações seriam capazes de garantir a integridade da geomembrana, incluindo a configuração sem elemento de proteção. Fato não constatado no campo, pois as configurações sem proteção e com PET $300 \mathrm{~g} / \mathrm{m}^{2}$ e PP $600 \mathrm{~g} / \mathrm{m}^{2}$ apresentaram furos.

No caso específico das geomembranas de PVC, que são flexíveis, os danos se distribuem praticamente ao longo de toda a sua superfície, isto é, são uniformes e não pontuais, como ocorrem nas geomembranas de PEAD. Desta forma, a ruptura ocorre sempre na região central devido à sobreposição do dano com a região onde as tensões são maiores.

\subsubsection{Influência das características dos agregados no desempenho do elemento de proteção.}

A Figura 183 abaixo mostra o resultado dos ensaios de tração em faixa larga em função das características dos agregados utilizados. 


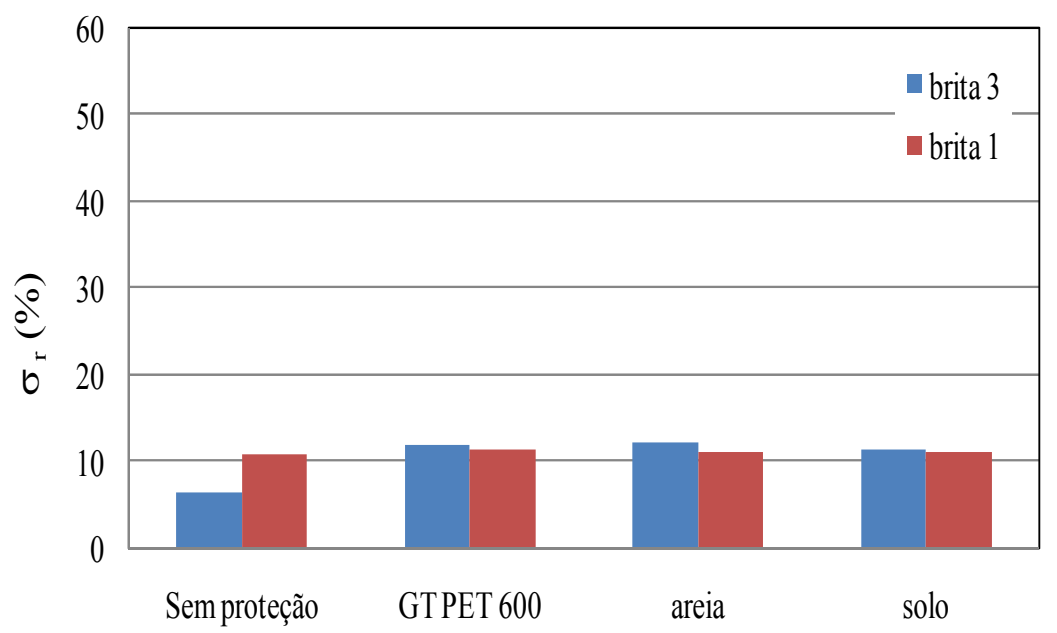

Tipo de proteção

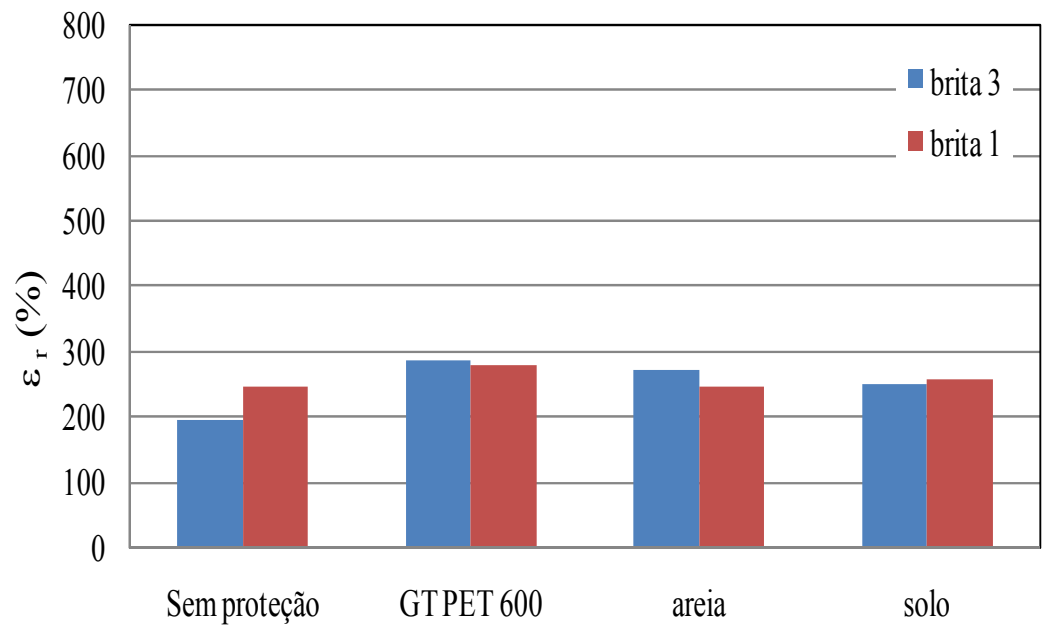

Tipo de proteção

Figura 183. Resultados dos ensaios de tração em faixa larga de GM de PVC (1,0mm) em função do diâmetro e formato dos agregados.

Os resultados dos ensaios de tração em faixa larga mostram que as propriedades de tração das geomembranas não variam com o tamanho e formato dos agregados. Apenas as geomembranas sem proteção que apresentaram decréscimos de resistência e deformação. Os valores de tensão e de deformação apresentaram uma redução de $30 \%$ e $40 \%$, respectivamente, comparados aos valores obtidos nas geomembranas virgens. 
No entanto, nas configurações com proteção não se verificou alteração nas propriedades de tração da geomembrana com o tamanho ou com a forma dos agregados.

\subsection{Avaliação do Desempenho dos Materiais de Proteção para Ensaios de Campo segundo o CFG (2001)}

Com base nos resultados dos ensaios pós-danos realizados nas geomembranas associados à análise visual, e seguindo a classificação proposta pelo CFG (2001), pôde-se avaliar o desempenho dos elementos de proteção utilizados.

Assim, propõe-se o seguinte critério de classificação das geomembranas submetidas aos ensaios de campo:

- Classe I $\rightarrow$ A geomembrana apresenta furos (1 ou vários).

- Classe II.1 $\rightarrow$ Geomembrana sem furos, mas com outros tipos de danos; os decréscimos de tensão $(\Delta \sigma)$ e deformação $(\Delta \varepsilon)$ de ruptura nos ensaios de tração em faixa larga são maiores que $25 \%$, e os decréscimos de deformação no ensaio multiaxial são maiores que $50 \%$.

- Classe II.2 $\rightarrow$ os decréscimos de tensão $(\Delta \sigma)$ e deformação $(\Delta \varepsilon)$ de ruptura nos ensaios de tração em faixa larga são menores ou iguais a $25 \%$, e os decréscimos de deformação no ensaio multiaxial são menores ou iguais a 50\%.

- Classe III $\rightarrow$ A geomembrana não apresenta nenhum tipo de dano

A Tabela 46 apresenta o desempenho dos elementos de proteção utilizados nas geomembranas de PEAD com base na classificação proposta. 
Tabela 46. Desempenho dos elementos de proteção utilizados nas geomembranas de PEAD.

\section{Elemento de Proteção Tipo de brita Classificação}

\begin{tabular}{|c|c|c|}
\hline GT PET $300 \mathrm{~g} / \mathrm{m}^{2}$ & \multirow{6}{*}{3} & II.1 \\
\hline GT PET $600 \mathrm{~g} / \mathrm{m}^{2}$ & & II. 2 \\
\hline GT PP $600 \mathrm{~g} / \mathrm{m}^{2}$ & & II. 2 \\
\hline GT PET $1200 \mathrm{~g} / \mathrm{m}^{2}$ & & III \\
\hline Areia & & II.1 \\
\hline Solo & & II.1 \\
\hline GT PET $300 \mathrm{~g} / \mathrm{m}^{2}$ & \multirow{5}{*}{1} & II.1 \\
\hline GT PET $600 \mathrm{~g} / \mathrm{m}^{2}$ & & II. 2 \\
\hline GT PET $1200 \mathrm{~g} / \mathrm{m}^{2}$ & & III \\
\hline Areia & & II. 1 \\
\hline Solo & & II.1 \\
\hline
\end{tabular}

Observa-se que o geotêxtil de PET $300 \mathrm{~g} / \mathrm{m}^{2}$, a camada de areia e de solo apresentaram o mesmo desempenho como elemento de proteção, enquadrando-se na categoria II.1. Apesar das configurações com proteção de areia e solo apresentarem poucos danos mecânicos visíveis, constatou-se uma elevada redução nas propriedades das geomembranas danificadas.

Verificou-se também que os geotêxteis de PET $600 \mathrm{~g} / \mathrm{m}^{2}$ e PP $600 \mathrm{~g} / \mathrm{m}^{2}$ se enquadram na categoria II.2, como desempenho semelhante, independente de suas características de tração.

E, por último, verificou-se que o geotêxtil de PET $1200 \mathrm{~g} / \mathrm{m}^{2}$ se enquadra na categoria III, sendo a única configuração onde as propriedades das geomembranas não são significativamente afetadas pelo dano de instalação, e sem a presença de danos mecânicos visíveis. 
A Tabela 47 apresenta o desempenho dos elementos de proteção utilizados nas geomembranas de PVC seguindo também a classificação proposta.

Tabela 47. Desempenho dos elementos de proteção utilizados nas geomembranas de PVC.

\section{Elemento de Proteção Tipo de brita Classificação}

\begin{tabular}{|c|c|c|}
\hline GT PET $300 \mathrm{~g} / \mathrm{m}^{2}$ & \multirow{6}{*}{3} & $\mathrm{I}$ \\
\hline GT PET $600 \mathrm{~g} / \mathrm{m}^{2}$ & & II. 2 \\
\hline GT PP $600 \mathrm{~g} / \mathrm{m}^{2}$ & & $\mathrm{I}$ \\
\hline GT PET $1200 \mathrm{~g} / \mathrm{m}^{2}$ & & II. 2 \\
\hline Areia & & II. 2 \\
\hline Solo & & II. 2 \\
\hline GT PET $600 \mathrm{~g} / \mathrm{m}^{2}$ & \multirow{3}{*}{1} & II. 2 \\
\hline Areia & & II. 2 \\
\hline Solo & & II. 2 \\
\hline
\end{tabular}

Em geral, conforme já discutido anteriormente, os elementos de proteção utilizados nas geomembranas de PVC apresentaram o mesmo desempenho. Verifica-se que os elementos se encaixam na categoria II.2, com pouca ou nenhuma variação nas propriedades das geomembranas danificadas.

Verifica-se que os únicos elementos de proteção não capazes de prevenir furos nas geomembranas foram os geotêxteis de PET $300 \mathrm{~g} / \mathrm{m}^{2}$ e PP $600 \mathrm{~g} / \mathrm{m}^{2}$ (brita 3), enquadrando-se na categoria I. 


\subsection{Comparação entre os Resultados dos Ensaios de Laboratório e de Campo}

\subsubsection{Ensaios de Campo versus Ensaios Índice}

Os resultados dos ensaios índices mostraram que as geomembranas de PVC apresentaram um elevado aumento na força de punção com a introdução do geotêxtil. Verificou-se também que o desempenho dos geotêxteis foi mais bem caracterizado em termos de resistência à tração $\left(\mathrm{R}_{\mathrm{tGT}}\right)$ do que pela gramatura $(\mathrm{Gr})$. Os dados indicaram que quanto maior a resistência à tração do geotêxtil, maior a força de punção do conjunto geomembrana / geotêxtil.

Os resultados dos ensaios de tração realizados nas amostras de geomembranas danificadas no campo também mostraram que a introdução do geotêxtil como elemento de proteção aumenta a resistência da geomembrana contra danos de instalação. Verificou-se que as características de tração das geomembranas danificadas com camada de proteção se aproximaram das características da geomembrana virgem. No entanto, verificou-se que todos os geotêxteis apresentaram o mesmo desempenho em termos quantitativos, independente da resistência à tração.

Adicionalmente, os resultados dos ensaios índices realizados com geomembranas de PEAD mostraram o aumento da força de punção da geomembrana com a introdução do geotêxtil como elemento de proteção. Também se constatou que quanto maior a resistência à tração do geotêxtil, maior a força de punção do conjunto geomembrana / geotêxtil.

Ao se analisar as geomembranas de PEAD submetidas aos danos de instalação de campo, verificou-se que a introdução do elemento de proteção também aumenta a resistência da geomembrana. Observou-se uma redução dos danos mecânicos visíveis sobre a superfície das geomembranas, e um aumento das propriedades de tração em relação às geomembranas danificadas sem proteção. Nas configurações com brita de menor diâmetro verificou-se um 
aumento das propriedades de tração das geomembranas com o aumento da resistência à tração do geotêxtil. Contudo, nas configurações com brita de maior diâmetro, constatou-se que as propriedades de tração da geomembrana não se modificam com o aumento da resistência à tração do geotêxtil.

Ou seja, os resultados indicam que a avaliação dos elementos de proteção através de ensaios índices não se correlaciona com as características granulométricas dos agregados utilizados em campo.

\subsubsection{Ensaios de Campo versus Ensaios Cíclicos}

As Tabelas a seguir mostram uma comparação da análise visual das geomembranas de PEAD e PVC, respectivamente, submetidas a ensaios de danos de instalação provocados por carregamentos cíclicos em laboratório e em campo. Tais resultados se referem aos ensaios realizados com brita 1 .

Tabela 48. Comparação dos danos visuais observados nas geomembranas de PEAD.

\begin{tabular}{|c|c|c|c|c|c|c|}
\hline \multirow{2}{*}{ Configuração } & \multirow{2}{*}{ Ensaio } & \multicolumn{5}{|c|}{ Tipo de Dano } \\
\hline & & arranhão & entalhe & indentação & deformação & furo \\
\hline GM sem proteção- $200 \mathrm{kPa}-200$ ciclos & \multirow{6}{*}{ laboratório } & $\checkmark$ & - & - & - & - \\
\hline GM sem proteção- $200 \mathrm{kPa}-500$ ciclos & & $\checkmark$ & - & - & - & - \\
\hline GM sem proteção- $200 \mathrm{kPa}-1000$ ciclos & & $\checkmark$ & - & - & - & - \\
\hline GM sem proteção- $400 \mathrm{kPa}-200$ ciclos & & $\checkmark$ & - & - & - & - \\
\hline GM sem proteção- $400 \mathrm{kPa}-500$ ciclos & & $\checkmark$ & - & - & - & - \\
\hline GM sem proteção- $400 \mathrm{kPa}-1000$ ciclos & & $\checkmark$ & - & - & - & - \\
\hline GM sem proteção & campo & $\checkmark$ & - & - & $\checkmark$ & $\checkmark$ \\
\hline \multirow{2}{*}{ GM GT PET 300} & laboratório & $\checkmark$ & - & - & - & - \\
\hline & campo & $\checkmark$ & - & - & $\checkmark$ & - \\
\hline \multirow{2}{*}{ GM GT PET 600} & laboratório & $\checkmark$ & - & - & - & - \\
\hline & campo & $\checkmark$ & - & $\checkmark$ & $\checkmark$ & - \\
\hline
\end{tabular}


Tabela 49. Comparação dos danos visuais observados nas geomembranas de PVC.

\begin{tabular}{|c|c|c|c|c|c|c|}
\hline \multirow{2}{*}{ Configuração } & \multirow{2}{*}{ Ensaio } & \multicolumn{5}{|c|}{ Tipo de Dano } \\
\hline & & arranhão & entalhe & indentação & deformação & furo \\
\hline GM sem proteção- $200 \mathrm{kPa}-200$ ciclos & \multirow{6}{*}{ laboratório } & - & - & - & $\checkmark$ & - \\
\hline GM sem proteção- $200 \mathrm{kPa}-500$ ciclos & & - & - & - & $\checkmark$ & - \\
\hline GM sem proteção- $200 \mathrm{kPa}-1000$ ciclos & & - & - & - & $\checkmark$ & - \\
\hline GM sem proteção- $400 \mathrm{kPa}-200$ ciclos & & - & - & - & $\checkmark$ & - \\
\hline GM sem proteção- $400 \mathrm{kPa}-500$ ciclos & & - & - & - & $\checkmark$ & - \\
\hline GM sem proteção- $400 \mathrm{kPa}-1000$ ciclos & & - & - & - & $\checkmark$ & - \\
\hline GM sem proteção & campo & - & - & - & $\checkmark$ & $\checkmark$ \\
\hline \multirow{2}{*}{ GM GT PET 300} & laboratório & - & - & - & - & - \\
\hline & campo & - & - & - & $\checkmark$ & - \\
\hline \multirow{2}{*}{ GM GT PET 600} & laboratório & - & - & - & - & - \\
\hline & campo & - & - & - & $\checkmark$ & - \\
\hline
\end{tabular}

Comparando as geomembranas de PEAD, observa-se que os danos mecânicos foram mais intensos nos ensaios de campo. Enquanto nos ensaios de laboratório só foi verificada a presença de arranhões, no campo verificou-se a existência de outros tipos de danos como entalhes, indentações e furos. Além disto, a ocorrência dos arranhões foi maior nos ensaios de campo.

A análise visual também mostra que os elementos de proteção reduzem os danos, mas no campo, dependendo da configuração, não impedem o aparecimento de alguns danos considerados críticos como arranhões e indentações.

Os danos mecânicos nas amostras de geomembrana de PVC submetidas aos ensaios de instalação em campo também foram mais intensos do que as amostras de geomembranas submetidas campo aos ensaios de carregamento cíclico em laboratório. Observa-se que nenhuma amostra de geomembrana sem elemento de proteção apresentou furos nos ensaios de laboratório. Nas configurações com geotêxtil como elemento de proteção também não foram constatados furos e, a introdução deste reduziu as deformações na superfície das geomembranas. Ao contrário, nos ensaios de campo, constatou-se a presença de furos (rasgos) 
nas geomembranas sem proteção, e de deformações nos ensaios realizados com geotêxtil de PET 300 e $600 \mathrm{~g} / \mathrm{m}^{2}$.

Comparando-se os ensaios de danos de instalação em laboratório e no campo, verificou-se que o processo de execução apresenta o mesmo mecanismo, que consiste na aplicação sucessiva de vários carregamentos e descarregamentos sobre a geomembrana (carregamento cíclico). No entanto, ao analisar os detalhes executivos, verificam-se várias diferenças. No ensaio de carregamento cíclico em laboratório, a carga atuante variou de 200 a $400 \mathrm{kPa}$ e foram aplicados 1.000 ciclos $(1.000$ manobras de carregamento e descarregamento). Em contrapartida, no ensaio de campo, a carga atuante exercida pela área de contato do trator com a geomembrana foi de aproximadamente $60 \mathrm{kPa}$. Além disto, após o lançamento da brita, a camada de drenagem foi compactada com 8 passadas, sendo que cada passada corresponde a um movimento de avanço e recuo do trator.

Observa-se que o carregamento e o número de ciclos (passadas) no campo foram de menor intensidade do que no laboratório. No entanto, os danos no campo foram muito mais intensos. Cabe ressaltar que os ensaios de laboratório não simulam as manobras operacionais que ocorrem no campo como frenagem e movimentação giratória do trator. Tais manobras geram esforços adicionais, em especial esforços cisalhantes, e pelo constatado no campo, aumentam os danos à geomembrana.

Conclui-se que, em termos de análise visual, o tipo e a intensidade dos danos mecânicos verificados nos ensaios de carregamento cíclico não condizem com o comportamento verificado em campo.

Em termos quantitativos, verificou-se nos ensaios de laboratório (Figura 85) uma redução nos valores de tensão e deformação à tração na ruptura nas geomembranas de PEAD de $30 \%$ e $20 \%$, respectivamente, nas configurações sem elemento de proteção. Nos ensaios de campo a redução foi de $35 \%$ e $90 \%$ respectivos a tensão e a deformação de tração na ruptura. 
Os ensaios de laboratório indicaram que as propriedades das geomembranas não se alteram com a introdução do geotêxtil. Incluem-se nestas propriedades as forças de punção, de rasgo e a tensão e deformação à tração na ruptura. Entretanto, nos ensaios de campo verificou-se que a introdução do geotêxtil proporcionou elevado aumento de deformação à tração na ruptura.

Analisando-se as alterações das geomembrana de PVC em termos quantitativos, verificou-se nos ensaios de laboratório uma redução da tensão e deformação à tração na ruptura de $15 \%$ e $50 \%$, respectivamente, nas configurações sem elemento de proteção. Nos ensaios de campo a redução foi de $8 \%$ e $15 \%$ respectivos a tensão e deformação à tração na ruptura. Os ensaios de laboratório e de campo também indicam que deformação a tração na ruptura aumentou com a introdução do geotêxtil. No entanto, ao contrário do que se esperava, os menores decréscimos de deformação foram verificados nos ensaios de campo, onde os danos foram mais intensos.

\subsection{Comparação dos Resultados de Campo com os Dados e Métodos da Literatura}

4.5.1. Análise dos Danos de Instalação: Comparação com Reddy et al. (1996)

As Tabelas a seguir apresentam uma comparação entre os resultados dos ensaios de tração multiaxial e em faixa larga realizados nas geomembranas de PEAD e os dados relatados em Reddy et al. (1996), também referentes a danos de instalação.

Os geotêxteis comparados são não tecidos, agulhados e gramatura aproximada de 300 $\mathrm{g} / \mathrm{m}^{2}$. O pedregulho classificado como médio apresenta partículas com diâmetro entre 10 a 40 $\mathrm{mm}$, enquanto o pedregulho fino apresenta partículas com diâmetro entre 8 e $25 \mathrm{~mm}$, ambos com forma angular e com granulometria não uniforme. Estas características assemelham-se às características dos agregados utilizados nos ensaios de campo, respectivos a brita 3 e brita 1 . A maior variação refere-se à granulometria da brita 3 (20 a 100 mm). 
Tabela 50. Comparação dos Ensaios de Tração Multiaxial.

\begin{tabular}{|c|c|c|c|c|c|c|c|c|}
\hline \multirow{4}{*}{ Condição do Ensaio } & \multicolumn{8}{|c|}{ Ensaios de Tração Multiaxial } \\
\hline & \multicolumn{4}{|c|}{ Reddy et al. (1996) } & \multicolumn{4}{|c|}{ Ensaios de Campo } \\
\hline & $\sigma$ & & $\varepsilon$ & & $\sigma$ & & $\varepsilon$ & \\
\hline & (MPa) & $\Delta \sigma$ & $(\%)$ & $\Delta \varepsilon$ & (MPa) & $\Delta \sigma$ & $(\%)$ & $\Delta \varepsilon$ \\
\hline GM virgem & 15,1 & - & 25,3 & - & 25,6 & - & 62 & - \\
\hline Pedregulho médio, sem GT & 16,9 & 1,12 & 15,16 & 0,60 & 25,0 & 0,98 & 14 & 0,23 \\
\hline Pedregulho médio, com GT & 14,6 & 0,97 & 26,9 & 1,06 & 25,9 & 1,01 & 16 & 0,26 \\
\hline Pedregulho fino, sem GT & 15,7 & 1,04 & 18,3 & 0,72 & 23,8 & 0,93 & 23 & 0,37 \\
\hline Pedregulho fino, com GT & 14,7 & 0,97 & 29,2 & 1,15 & 23,9 & 0,93 & 24 & 0,40 \\
\hline
\end{tabular}

Tabela 51. Comparação dos Ensaios de Tração Faixa Larga.

\begin{tabular}{|c|c|c|c|c|c|c|c|c|}
\hline \multirow{3}{*}{ Condição do Ensaio } & \multicolumn{8}{|c|}{ Ensaios de Tração Faixa Larga } \\
\hline & \multicolumn{4}{|c|}{ Reddy et al. (1996) } & \multicolumn{4}{|c|}{ Ensaios de Campo } \\
\hline & $\begin{array}{c}\sigma_{\text {rup }} \\
(\mathrm{MPa})\end{array}$ & $\Delta \sigma$ & $\begin{array}{l}\varepsilon_{\text {rup }} \\
(\%)\end{array}$ & $\Delta \varepsilon$ & $\begin{array}{c}\sigma_{\text {rup }} \\
(\mathrm{MPa})\end{array}$ & $\Delta \sigma$ & $\begin{array}{l}\varepsilon_{\text {rup }} \\
(\%)\end{array}$ & $\Delta \varepsilon$ \\
\hline GM virgem & 21,3 & - & 1211 & - & 16,9 & - & 710 & - \\
\hline Pedregulho médio, sem GT & 12,2 & 0,57 & 464 & 0,38 & 10,0 & 0,59 & 67 & 0,09 \\
\hline Pedregulho médio, com GT & 19,1 & 0,90 & 1048 & 0,87 & 10,1 & 0,60 & 80 & 0,11 \\
\hline Pedregulho fino, sem GT & 12,5 & 0,59 & 505 & 0,42 & 13 & 0,77 & 61 & 0,09 \\
\hline Pedregulho fino, com GT & 15,8 & 0,74 & 1027 & 0,85 & 10,4 & 0,62 & 412 & 0,58 \\
\hline
\end{tabular}


Verifica-se nas configurações sem proteção, em ambos os trabalhos, uma redução significativa dos valores de deformação multiaxial, e dos valores de tensão e deformação na ruptura nos ensaios de tração faixa larga.

No entanto, a redução das características analisadas nas geomembranas danificadas foi mais intensa no trabalho de campo aqui apresentado. Observa-se, por exemplo, que as deformações obtidas no ensaio multiaxial apresentaram uma redução de 80 \% (brita 3) e 60 \% (brita 1) em relação à geomembrana virgem. No trabalho de Reddy et al. (1996), as deformações apresentaram uma redução de 40 \% (brita 3) e $30 \%$ (brita 1). Os resultados dos ensaios de tração em faixa larga das amostras de campo mostram uma redução na deformação de ruptura de $90 \%$ em relação à geomembrana virgem, para ambas as granulometrias, enquanto os resultados de Reddy et al. (1996) mostram uma redução de 60 \%.

Ao se analisar a introdução do geotêxtil no trabalho de Reddy et al. (1996), observa-se um elevado aumento nos valores de deformação de ruptura no ensaio multiaxial, e de tensão e deformação de ruptura no ensaio de tração em faixa larga, alcançando valores próximos as características da geomembrana virgem.

Ao contrário, nos resultados do ensaio de campo aqui apresentado, verificou-se que a introdução do geotêxtil de PET $300 \mathrm{~g} / \mathrm{m}^{2}$ não aumenta os valores das propriedades de tração das geomembranas danificadas com proteção em relação às geomembranas danificadas sem proteção.

Com base no resultados de seu trabalho, Reddy et al. (1996) afirmam que um geotêxtil não tecido de PET $300 \mathrm{~g} / \mathrm{m}^{2}$ é capaz de fornecer proteção suficiente contra danos de instalação, sem que hajam danos sob sua superfície e alterações em suas propriedades mecânicas de tração.

Entretanto, os resultados dos ensaios aqui apresentados mostram que o geotêxtil de PET $300 \mathrm{~g} / \mathrm{m}^{2}$ utilizado não apresentou desempenho satisfatório como elemento de proteção. 
Esta configuração apresentou o pior desempenho visual no campo, com uma grande concentração de danos sob a forma de arranhões e entalhes. Além disto, a configuração com geotêxtil de PET $300 \mathrm{~g} / \mathrm{m}^{2}$ também apresentou os maiores decréscimos das propriedades das geomembranas analisadas comparados aos demais geotêxteis.

Entretanto, ao se avaliar as propriedades dos geotêxteis de PET $300 \mathrm{~g} / \mathrm{m}^{2}$ utilizados por Reddy et al. (1996) e utilizados no trabalho de campo aqui proposto, percebe-se uma grande diferença nas propriedades de tração. Verifica-se que os geotêxteis fabricados por empresas americanas, como os utilizados por Reddy et al. (op citu), apresentam elevada resistência à tração $(\approx 19 \mathrm{kN} / \mathrm{m})$ comparado ao geotêxtil utilizado no trabalho $(\approx 11 \mathrm{kN} / \mathrm{m})$, possível razão para tal discrepância de comportamento.

\subsubsection{Metodologia proposta por Badu et al.(1998)}

Segundo o critério proposto proposto por Badu et al. (1998) para geomembranas de PEAD, o desempenho de elementos de proteção está associado com a localização da ruptura num ensaio de tração multiaxial. Neste critério, uma amostra de geomembrana virgem rompe no topo da abóbada (forma do corpo de prova deformado) porque este é o local onde as tensões são maiores. Se a geomembrana rompe em local diferente do topo da abóbada, isto indica que a amostra foi previamente "enfraquecida" no local onde a ruptura ocorre. Além disto, o critério considera que as características de tração das geomembranas não são significativamente afetadas pelos danos, e que as propriedades obtidas não fornecem informações precisas para correlacioná-las com os danos visíveis.

No entanto, os resultados dos ensaios de tração multiaxial realizados nas amostras de geomembranas de PEAD submetidas ao ensaio de campo mostraram uma elevada redução nos valores de deformação na ruptura em todas as configurações. Mas também não 
forneceram informações que pudessem correlacionar as características obtidas com os danos visíveis.

Contudo, o modo de ruptura forneceu um bom indicativo do desempenho dos materiais utilizados. Verificou-se, nas configurações sem elemento de proteção e com geotêxtil de PET $300 \mathrm{~g} / \mathrm{m}^{2}$, que a ruptura foi localizada em cima dos arranhões e entalhes, fora da região central e sem aparecimento de uma zona de escoamento na geomembrana.

As configurações com geotêxteis de PET de $600 \mathrm{~g} / \mathrm{m}^{2}$, apesar da existência de poucos arranhões, apresentaram a ruptura caracterizada no centro da amostra, semelhante à geomembrana virgem. As configurações com geotêxteis de PP de 600 g/m² e de PET de 1200 $\mathrm{g} / \mathrm{m}^{2}$, com bom desempenho visual no campo, também apresentaram o modo de ruptura semelhante ao da geomembrana virgem.

Ressalta-se que, apesar das configurações com areia e solo conterem poucos arranhões sobre sua superfície, estas tiveram sua ruptura caracterizada por pequenos furos ou cortes localizados fora da região central. Ou seja, estas configurações foram capazes de diminuir a quantidade dos danos, mas não a intensidade dos danos.

Os resultados dos ensaios indicaram que os arranhões e entalhes correspondem aos danos mais críticos, sendo os principais catalisadores da ruptura da geomembrana.

\subsubsection{Metodologia proposta baseada no desempenho a curto prazo (Narejo et al, 1996)}

Para correlacionar os dados experimentais obtidos nos ensaios de campo com a metodologia proposta por Narejo et al. (1996), calculou-se a pressão disponível para cada gramatura de geotêxtil utilizada segundo a Equação 15.

$$
p_{\text {disponível }}=450 \cdot \frac{M}{H^{2}}
$$


Sendo que $\mathbf{M}$ corresponde à gramatura do geotêxtil em $\mathbf{g} / \mathbf{m}^{2}$, e $\mathbf{H}$ corresponde à altura de penetração dos grãos em mm.

A altura de penetração $(H)$ foi admitida como metade do diâmetro máximo do agregado $\left(1 / 2 \mathrm{D}_{\text {máximo }}\right)$. Assim, $\mathrm{H}_{1}=14 \mathrm{~mm} \mathrm{e} \mathrm{H}_{3}=50 \mathrm{~mm}$, onde $\mathrm{H}_{1}$ corresponde à altura de penetração da brita 1 e $\mathrm{H}_{3}$ a altura de penetração da brita 3 .

Obtida a pressão disponível, foram aplicados fatores de correlação para as condições de campo (Equação 16).

$$
p^{\prime}=p_{\text {disponivel }}\left(\frac{1}{M F_{S} \times M F_{P D} \times M F_{R}}\right) \cdot\left(\frac{1}{F S_{C R} \times F S_{C B D}}\right)
$$

Sendo que:

- $P_{\text {disponível- }}$ pressão máxima obtida do ensaio de cone;

- $\quad \mathrm{P}^{\prime}$ admissível - pressão máxima admissível para condições específicas;

- $\mathrm{MF}_{\mathrm{S}}$ - fator modificado para o formato dos grãos;

- $\mathrm{MF}_{\mathrm{PD}}$ - fator modificado para a densidade;

- $\mathrm{MF}_{\mathrm{R}}$ - fator modificado para o arqueamento do solo;

- $\mathrm{FS}_{\mathrm{CR}}$ - fator parcial de fluência;

- $\mathrm{FS}_{\mathrm{CBD}}$ - fator parcial de degradação biológica e química.

Os valores dos fatores de correlação adotados são apresentados na Tabela 52, com base nos valores sugeridos por Narejo et al. (1996).

Tabela 52. Fatores de correlação utilizados para as condições do ensaio de campo.

\begin{tabular}{lccccc}
\hline Agregado & $\boldsymbol{M F}_{\boldsymbol{S}}$ & $\boldsymbol{M F}_{\boldsymbol{P D}}$ & $\boldsymbol{M F}_{\boldsymbol{R}}$ & $\boldsymbol{F S}_{\boldsymbol{C R}}$ & $\boldsymbol{F S}_{\boldsymbol{C B D}}$ \\
\hline Brita 1 & 1.0 & 0.50 & 1.0 & 1.0 & 1.0 \\
Brita 3 & 1.0 & 0.50 & 1.0 & 1.0 & 1.0 \\
\hline
\end{tabular}


A pressão disponível para geomembranas sem proteção foi estimada a partir dos dados experimentais retratados por Narejo et al (1996), correlacionando a altura dos cones com a pressão máxima obtida (pressão disponível). A Figura 184 apresenta a correlação adotada. Os valores das pressões disponíveis e admissíveis para todas as configurações são apresentados na Tabela 53.

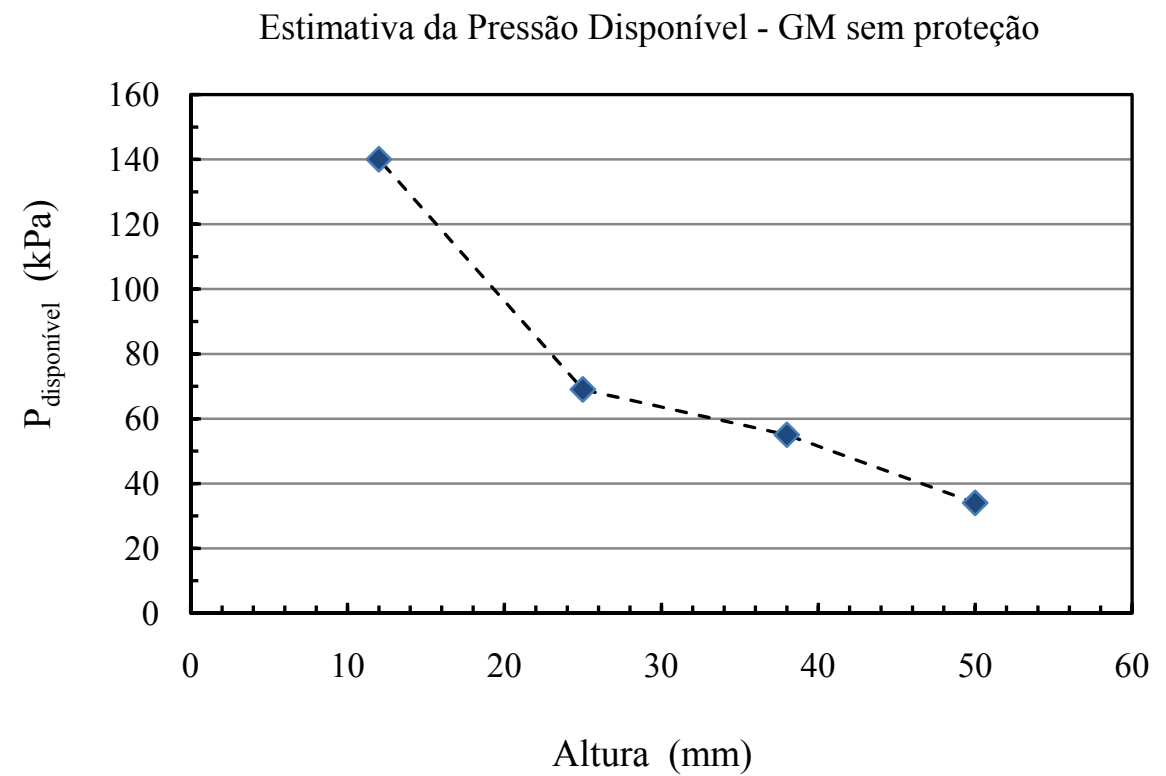

Figura 184. Estimativa da pressão disponível para geomembranas sem proteção (NAREJO et al, 1996).

Tabela 53. Cálculo da pressão admissível segundo a metodologia proposta por Narejo et al (1996).

\begin{tabular}{|c|c|c|c|c|c|c|c|}
\hline \multirow{3}{*}{$\begin{array}{c}\text { Geotêxtil } \\
\text { Gramatura } \\
\left(\mathrm{g} / \mathrm{m}^{2}\right)\end{array}$} & \multirow{2}{*}{\multicolumn{2}{|c|}{$\frac{\text { Ensaio dos Cones }}{\text { P disponível (kPa) }}$}} & \multirow{2}{*}{\multicolumn{2}{|c|}{$\frac{\text { Correlação com o campo }}{\text { P’ admissível (kPa) }}$}} & \multirow{3}{*}{$\begin{array}{c}\text { Pressão de Campo } \\
\text { (kPa) }\end{array}$} & \multirow{2}{*}{\multicolumn{2}{|c|}{ F.S.* }} \\
\hline & & & & & & & \\
\hline & $\mathbf{H}_{3}$ & $\mathrm{H}_{1}$ & $\mathbf{H}_{3}$ & $\mathbf{H}_{1}$ & & $\mathbf{H}_{3}$ & $\mathbf{H}_{1}$ \\
\hline Sem proteção & 34 & 122 & 24 & 61 & $\approx 60$ & 0,4 & 1,0 \\
\hline PET 300 & 53 & 673 & 105 & 1345 & $\approx 60$ & 1,8 & 22 \\
\hline PET 600 & 104 & $1322 * *$ & 207 & 2645 & $\approx 60$ & 3,5 & 44 \\
\hline PP 600 & 107 & $1361 * *$ & 213 & 2723 & $\approx 60$ & 3,6 & 45 \\
\hline PET 1200 & 207 & $2640 * *$ & 414 & 5281 & $\approx 60$ & 6,9 & 88 \\
\hline
\end{tabular}

* F.S. $\rightarrow$ fator de segurança (relação entre a pressão admissível e a pressão atuante)

** Obs.: nenhuma pressão maior que $1100 \mathrm{kPa}$ foi reportada nos ensaios de cones devido a limitação do equipamento. 
Segundo a metodologia proposta por Narejo et al. (1996), a configuração com geomembrana sem proteção e brita 3 não seria capaz de prevenir furos nas geomembranas, fato realmente verificado no ensaio de campo. Na configuração com brita 1, a pressão admissível é igual à pressão atuante. Entretanto, as geomembranas apresentaram furos, arranhões e entalhes sob sua superfície, além da elevada perda das suas características de tração.

A introdução de um geotêxtil de PET $300 \mathrm{~g} / \mathrm{m}^{2}$ gera uma pressão admissível de 105 $\mathrm{kPa}(\mathrm{FS}=1,8)$ e $1345 \mathrm{kPa}(\mathrm{FS}=22)$, respectivos à configuração com brita 3 e 1 . Ou seja, este geotêxtil seria suficiente para suportar as condições de campo (pressão) nas configurações com brita 3, e estaria superdimensionado para as condições com brita 1.

No entanto, verificou-se a existência de inúmeros danos sob a forma de entalhes e arranhões na superfície das geomembranas utilizando o geotêxtil de PET $300 \mathrm{~g} / \mathrm{m}^{2}$. Além disto, conforme já discutido anteriormente, os resultados dos ensaios realizados nas amostras de campo mostram que as características de tração das geomembranas foram bastante alteradas nesta configuração. Verificou-se na configuração com brita 3, por exemplo, decréscimos de $40 \%$ e $90 \%$ na tensão e deformação de tração de ruptura no ensaio de faixa larga, respectivamente, e $75 \%$ na deformação de ruptura no ensaio de tração multiaxial em relação à geomembrana virgem. Na configuração com brita 1 , os decréscimos foram de aproximadamente $40 \%$ para tensão e deformação de tração de ruptura no ensaio de faixa larga, e $60 \%$ para a deformação de ruptura no ensaio de tração multiaxial. O modo de ruptura do ensaio de tração multiaxial também indicou que a geomembrana foi danificada, apresentando comportamento distinto da geomembrana virgem.

Os resultados dos ensaios de campo mostram que a influência do tamanho dos agregados difere da metodologia proposta. Observa-se que a diminuição do tamanho dos agregados não gerou um efeito tão acentuado quanto indicado pela metodologia proposta. 
Ao se analisar os demais geotêxteis, também se observa que a pressão admissível é maior do que a pressão aplicada no ensaio de campo. Com os geotêxteis de PET $600 \mathrm{~g} / \mathrm{m}^{2}$ e PP $600 \mathrm{~g} / \mathrm{m}^{2}$ observou-se um fator de segurança de 3,5 e 45, respectivos as configurações com brita 3 e 1. E, com o geotêxtil de PET $1200 \mathrm{~g} / \mathrm{m}^{2}$, verifica-se um fator de segurança de 7 e 88 para as configurações com brita 3 e 1 , respectivamente.

Entretanto, apesar dos elevados valores de pressão admissível, os resultados dos ensaios mostraram uma considerável perda de características de tração das geomembranas, principalmente em termos de deformação de ruptura no ensaio de tração multiaxial.

Adicionalmente, os ensaios de campo mostram que as características de tração da geomembrana praticamente não se alteraram com o aumento da gramatura do geotêxtil. Em termos quantitativos, todos os geotêxteis apresentaram o mesmo desempenho, em especial nas configurações com brita de maior diâmetro (brita 3).

Desta forma, verificou-se que a metodologia proposta por Narejo et al (1996) não conseguiu reproduzir adequadamente os desempenhos observados em campo. 


\section{CAPÍTULO 5. CONCLUSÃO}

Esta tese apresentou uma investigação sobre o desempenho de diferentes materiais de proteção para geomembranas de PEAD e de PVC. Para isto, o programa experimental foi conduzido através ensaios de laboratório e de campo.

Nos ensaios índice de laboratório foram realizados ensaios de punção estática e de punção dinâmica. As conclusões acerca dos resultados dos ensaios índice foram:

- A introdução do geotêxtil aumenta a resistência à punção, nos ensaios estáticos, e diminui o diâmetro de perfuração, nos ensaios dinâmicos, da geomembrana.

- A resistência à punção do sistema geomembrana / geotêxtil é função da resistência à tração do geotêxtil. Quanto maior a resistência a tração do geotêxtil, maior o acréscimo de resistência a punção para a geomembrana.

- A resistência à punção também depende da resistência à tração da geomembrana. Geomembranas com menores valores resistência à tração (PVC) apresentam um elevado acréscimo de resistência com a introdução do geotêxtil. Ao contrário, geomembranas com maiores valores de resistência à tração (PEAD) apresentam baixos acréscimos de resistência.

A resistência à punção da geomembrana é proporcional a sua espessura. No entanto, este efeito é pequeno comparado a introdução do geotêxtil.

- $\quad$ A introdução de uma base de solo compactado aumenta a resistência à punção da geomembrana sem proteção. Ao comparar as configurações com proteção, observa-se que 
o acréscimo de resistência é menor na configuração geomembrana / geotêxtil sem base de solo compactado. Este comportamento indica que, em campo, o acréscimo de resistência pode não ser tão evidente com a introdução do geotêxtil.

Nos ensaios de desempenho de laboratório foram realizados ensaios de carregamento cíclico em geomembranas. As conclusões desta etapa foram:

- $\quad$ Os danos mecânicos presentes na geomembrana após o carregamento cíclico não foram tão intensos. Não foram constatados furos em nenhuma configuração de ensaio, até mesmo nos ensaios com maior número de ciclos e maior carga aplicada.

- $\quad$ As propriedades mecânicas, hidráulicas e de stress cracking das geomembranas danificadas praticamente não foram alteradas pelo carregamento cíclico.

- $\quad$ A introdução do geotêxtil não aumentou as características mecânicas das geomembranas em relação à geomembrana danificada.

Nos ensaios de campo foram simulados os danos de instalação em geomembranas referentes à fase de instalação das geomembrana e construção da camada de drenagem. As conclusões desta etapa foram:

- As geomembranas sem proteção apresentaram diversos e inúmeros tipos de danos sobre sua superfície. Nas geomembranas de PEAD os danos se apresentaram na forma de furos, arranhões, entalhes, deformações e indentações; enquanto nas geomembranas de PVC os danos se apresentaram na forma de furos (rasgos) e deformações.

- Com a introdução do elemento de proteção diminuiu-se o tipo e a intensidade dos danos nas geomembranas. Em termos de análise visual, os melhores elementos de proteção para geomembranas de PEAD foram o geotêxtil de PET $1200 \mathrm{~g} / \mathrm{m}^{2}$ e PP $600 \mathrm{~g} / \mathrm{m}^{2}$, e as camadas de proteção com areia e solo.

- $\quad$ Em termos de análise quantitativa, verificou-se que as configurações sem elemento de proteção geraram elevados decréscimos nas propriedades das geomembranas de PEAD em termos de tensão e deformação de ruptura nos ensaios de tração faixa larga e multiaxial, e no tempo de ruptura no ensaio de stress cracking. 
- Com a introdução do elemento de proteção, verificou-se um acréscimo nas características mecânicas e no tempo de ruptura do ensaio de stress cracking das geomembrana de PEAD em relação às geomembranas danificadas sem proteção.

- $\quad$ Nas configurações com brita 3 e geomembranas de PEAD, verificou-se que as características mecânicas das geomembranas não foram influenciadas pela resistência à tração do geotêxtil. No entanto, nas configurações com brita 1, verificou-se que quanto maior a resistência à tração do geotêxtil, menor a redução das propriedades analisadas da geomembrana.

Os elementos de proteção com solos naturais também apresentaram visualmente um bom desempenho com relação à redução da ocorrência de danos em geomembranas de PEAD. Contudo, os resultados dos ensaios indicam que tais configurações apresentaram elevados decréscimos de deformação.

- No caso das geomembranas de PVC, as configurações que apresentaram melhor desempenho em termos visuais foram com geotêxtil PET $1200 \mathrm{~g} / \mathrm{m}^{2}$, camada de areia e de solo.

- Com relação às propriedades das geomembranas danificadas, verificou-se que as geomembranas de PVC apresentaram uma redução significativa em termos de tensão e deformação de ruptura nos ensaios de tração faixa larga e multiaxial.

- Com a introdução do elemento de proteção, verificou-se um acréscimo nas características mecânicas das geomembrana de PVC, que tendem para o valor da geomembrana virgem em todas as configurações. Além disto, as características mecânicas das geomembranas não foram influenciadas pela resistência à tração do geotêxtil.

- $\quad$ O modo de ruptura das geomembranas de PVC nos ensaios multiaxiais não foi indicativo do desempenho dos elementos de proteção.

Comparando-se os ensaios de laboratório e os ensaios de campo, foram observadas as seguintes conclusões:

- $\quad$ Os resultados dos ensaios de tração em geomembrana de PEAD submetidas a carregamento de campo indicam uma boa correlação com os ensaios índices somente nas configurações com brita de pequeno diâmetro.

- Nas configurações com geomembrana de PVC, os ensaios de campo também 
contradizem com os resultados dos ensaios índice. Verificou-se que os as características mecânicas das geomembranas danificadas em campo não variaram com a resistência à tração do geotêxtil.

- Verificou-se que os danos de instalação no campo foram mais intensos do que nos ensaios de carregamento cíclico tanto nas geomembranas de PEAD quanto de PVC. Além disto, a introdução do elemento de proteção no campo minimiza, mas não impede o aparecimento de alguns tipos de danos no campo.

- Verificou-se também que as geomembranas danificadas de PEAD apresentaram maior decréscimo de suas propriedades mecânicas no campo. A introdução do elemento de proteção não alterou as propriedades das mecânicas das geomembranas danificadas sem proteção nos ensaios de laboratório. Por outro lado, nos ensaios de campo, proporcionou elevado aumento nas suas propriedades.

Os resultados dos ensaios pós-danos realizados nas geomembranas submetidas aos ensaios de campo permitiram avaliar o desempenho de diferentes elementos de proteção segundo o critério proposto pelo CFG. Foram verificadas as seguintes conclusões:

- $\quad$ Nas geomembranas de PEAD, verificou-se que s geotêxteis de PET $300 \mathrm{~g} / \mathrm{m}^{2}$, as camadas de areia e de solo se enquadram na mesma categoria, apresentando os maiores danos e os comportamentos semelhantes. Os geotêxteis de PET $600 \mathrm{~g} / \mathrm{m}^{2}$ e PP $600 \mathrm{~g} / \mathrm{m}^{2}$ apresentaram melhor desempenho do que os elementos citados anteriormente, com pequenos decréscimos nas características das geomembranas. O geotêxtil de PET $1200 \mathrm{~g} / \mathrm{m}^{2}$ apresentou o melhor desempenho, encaixando-se na categoria III do CFG, ou seja, sem ocorrência significativa de danos.

- $\quad$ Nas geomembranas de PVC, nenhuma configuração se encaixou na categoria III. Os elementos de proteção utilizados nas geomembranas de PVC apresentaram o mesmo desempenho. Verifica-se que os elementos se encaixam na categoria II.2, com pouca ou nenhuma variação nas propriedades das geomembranas danificadas.

- Verifica-se que os únicos elementos de proteção não capazes de prevenir furos nas geomembranas foram os geotêxteis de PET $300 \mathrm{~g} / \mathrm{m}^{2}$ e PP $600 \mathrm{~g} / \mathrm{m}^{2}$ (brita 3). 
Comparando os resultados dos ensaios de campo com os dados e/ou metodologias existentes na literatura, verificaram-se as seguintes conclusões:

- $\quad$ As reduções das características de tração das geomembranas danificadas foram mais intensas do que nos ensaios de campo retratados na literatura. Entretanto, esta discrepância pode ser atribuída aos maiores valores de resistência à tração encontrados nos geotêxteis utilizados por Reddy et al. (1996).

Segundo a metodologia proposta por Badu et al. (1998), verificou-se, nas configurações sem elemento de proteção e com geotêxtil de PET $300 \mathrm{~g} / \mathrm{m}^{2}$, que a ruptura foi localizada em cima dos arranhões e entalhes, fora da região central e sem aparecimento de uma zona de escoamento. Os demais geotêxteis apresentaram o mesmo comportamento com relação ao modo de ruptura.

As configurações com areia e solo tiveram sua ruptura caracterizada por pequenos furos ou cortes localizados fora da região central.

\subsection{Sugestão para Futuras Pesquisas}

Partindo dos resultados apresentados nesta Tese de Doutorado e nos estudos sobre camada de proteção para geomembranas relatados na literatura, sugere-se a investigação de geotêxteis de diferentes qualidades, variando-se os métodos de fabricação, tipo de fibra, etc.

Também seria interessante investigar o desempenho de geotêxteis através de ensaios de campo, porém com tensões mais elevadas (danos de operação). 

AGNELLI, J.A.M. (2000). Introdução a materiais poliméricos. Apostila - DEMA / UFSCar.

ASSOCIAÇÃO BRASILEIRA DE NORMAS TÉCNICAS - NBR 10004 (2004). Resíduos sólidos: Classificação. . NBR 12553 (2003). Geossintéticos - Terminologia. . NBR 12568 (2003). Geossintéticos - Determinação da massa por unidade de área. . NBR 12569 (1992). Geotêxteis - Determinação da espessura.

. NBR 12824 (1993). Geotêxteis - Determinação da resistência à tração nãoconfinada - Ensaio de tração de faixa larga.

. NBR 13359 (1995). Geotêxteis - Determinação da resistência ao puncionamento estático - Ensaio com pistão tipo CBR.

. NBR 14971 (1993). Geotêxteis e produtos correlatos - Determinação da resistência à perfuração dinâmica (queda de cone) - Método de ensaio

. NBR 6458 (1984). Grãos de pedregulhos retidos na peneira de $\mathbf{4 , 8} \mathbf{~ m m : ~}$

Determinação da massa específica . NBR 6459 (1984). Solo - Determinação do limite de liquidez . NBR 6508 (1984). Solo - Determinação da massa específica . NBR 7180 (1984). Solo - Determinação do limite de plasticidade . NBR 7181 (1986). Solo - Análise granulométrica . NBR 7182 (1986). Solo - Ensaio de compactação 
. NBR 8419 (1987). Apresentação de projetos de aterros sanitários de resíduos sólidos urbanos.

. NBR 12004 (1990). Solo - Determinação do índice de vazios máximo de solos não coesivos.

. NBR 12051 (1991). Solo - Determinação do índice de vazios mínimo de solos não coesivos.

. NBR 15226 (1991). Geossintéticos - Determinação do comportamento em deformação e na ruptura, por fluência sob tração não confinada

. NBR 15229 (2005). Geotêxteis e produtos correlatos - Determinação da abertura de filtração característica.

AMERICAN SOCIETY FOR TESTING AND MATERIALS - D792 (1991). Standard Test Methods for Specific Gravity and Density of Plastics by Displacement.

. D882 (1995a). Standard Test Method for Tensile Properties of Thin Plastic Sheeting.

. D883 (2000). Standard Terminology Relating to Plastics.

. D1004 (1994). Standard Test Method for Initial Tear Resistance of Plastic Film and Sheeting.

D1693 (1997). Standard Test Method for Environmental Stress-Cracking of Ethylene Plastics.

. D3776 (1996). Standard Test Methods for Mass Per Unit Area (Weight) of Fabric. . D3786 (1980a). Standard Test Method for Hydraulic Bursting Strength of Textile Fabrics-Diaphragm Bursting Strength Tester Method.

. D4533 (1991). Standard Test Method for Trapezoid Tearing Strength of Geotextiles.

. D4595 (1994). Standard Test Method for Tensile Properties of Geotextiles by the Wide-Width Strip Method.

D4632 (1996). Standard Test Method for Grab Breaking Load and Elongation of Geotextiles. 
. D4751 (1995). Standard Test Method for Determining Apparent Opening Size of a Geotextile.

. D4833 (1996). Standard Test Method for Index Puncture Resistance of Geotextiles, Geomembranes and Related Products.

. D 5101 (1996). Standard Test Method for Measuring the Soil-Geotextile System Clogging Potential by the Gradient Ratio.

. D5199 (1995). Measuring Nominal Thickness of Geotextiles and Geomembranes. . D5262 (1995). Standard Test Method for Evaluating the Unconfined Tension Creep Behavior of Geosynthetics.

.D5321 (1997). Standard Test Method for Determining the Coefficient of Soil and Geosynthetic or Geosynthetic and Geosynthetic Friction by the Direct Shear Method.

. D5397 (1995). Standard Test Method for Evaluation of Stress Crack Resistance of Polyolefin Geomembranes Using Notched Constant Tensile Load Test.

. D5494 (1993). Standard Test Method for the Determination of Pyramid Puncture Resistance of Unprotected and Protected Geomembranes

. D5514 (1994). Standard Test Method for Large Scale Hydrostatic Puncture Testing of Geosynthetics.

. D5617 (1999). Standard Test Method for Multi-Axial Tension Test for Geosynthetics.

. D5818 (1995). Standard Practice for Obtaining Samples of Geosynthetics from a Test Section for Assessment of Installation Damage.

. D6693 (2004). Standard Test Method for Determining Tensile Properties of Nonreinforced Polyethylene and Nonreinforced Flexible Polypropylene Geomembranes.

. D6747 (2004). Standard Guide for Selection of Techniques for Electrical Detection of Potential Leak Paths in Geomembranes. . E96 (1996). Standard Test Methods for Water Vapor Transmission of Materials. 
AZAMBUjA, E. (2003). Considerações sobre o Projeto e o Desempenho de Barreiras com Geomembranas nos Sistemas de Disposição de Resíduos Sólidos, In: $4^{\circ}$ Simpósio Brasileiro de Geossintéticos, Porto Alegre, Rio Grande do Sul, Brasil, p. 12.

BADU- TWEBEBOAH, K. et al. (1998). Evaluation of the Effectiveness of HDPE Geomembrane Liner Protection. 6th International Conference on Geosynthetics, Atlanta, Georgia, USA, pp. 279-284.

BATHIA, S.K.; SMITH, J.L. (1996). Geotextile characterization and pore-size distribution: Part 1. A review of manufacturing processes. Geosynthetics International, v. 3, n.1, p. 85-105.

BAM. (1999). Certification Guidelines for Plastic: Geomembranes Used to Line Landfills and Contaminated Sites.

BAM (1994). Guidelines for the Certification of Geomembranes as aComponent of Composite Liners for Municipal and Hazardous Waste Landfills and for Lining Contaminated Land.

BOUAZZA, A.; ZORNBERG, J.G.; ADAM, D. (2002). Geosynthetics in waste containment facilities: recent advances. Geosynthetics -7 th ICG. Delmas, Gourc \& Girard (eds.), Nice - França.

BUENO, B.S.; VILAR, O.M. (2004). Propriedades, Ensaios e Normas. Manual Brasileiro de Geossintéticos, Editora Edgard Blücher, pp. 27-62.

CFG (2001). Guide pour la réalisation de planches d'essais d'endommagement, Comité Français des Géosynthétiques, $\underline{\text { www.cfg.asso.fr, }} 16$ p.

CFGG (2003). Présentation de méthodes de détection et de localisation de défauts dans lés dispositifs d`etanchéité par géomembranes. Comité Français Géosynthétiques, France.

DANIEL, D.E. (1993). Geotechnical practice for waste disposal- London ; New YorkChapman \& Hall - 683p.

DANIEL, D.E.; KOERNER, R. M. (1995). Waste containment facilities Guidance for construction, quality assurance and quality control of liner and cover systems. American Society of Civil Engineering Press, New York.

FROBEL, R. \& RIGO, J-M. (1991). Puncture Testing. Geomembranes: Identification and Performance Testing. Edited by A. Rollin and J-M. Rigo, pp. 157-175. 
GALAGHER, E.M.; DARBYSHIRE, W.; WARWICK, R.G. (1999). Performance testing of geoprotectors: background, critique, development, and current UK practice. Geosynthetics International, vol. 4, n. 6, pp. 283-301.

GARTUNG, E. (1996). Landfill liners and covers. Geosynthetics: applications, design and construction, De Groot, Den Hoedt \& Termaat (eds.) - pp. 55 - 70.

GEROTO, R.E. (2008). Desempenho de Camadas de Proteção para Geomembranas. Dissertação de Mestrado. Escola de Engenharia de São Carlos / USP. São Carlos, SP, 188 páginas.

GIROUD; J.P.; BADU- TWENEBOAH, K., SODERMAN, K.L. (1995). Theoretical Analysis of geomembrana puncture. Geosynthetics International, vol. 2, n. 6, pp. 10191048.

GRI TEST METHOD GM10 (2002). Specification for the SCR of HDPE Geomembranes.

HSUAN, Y.G. (2000). Data Base of Field Incidents Used to Establish HDPE

Geomembrane Stress Crack Resistance Specifications. Geotextiles and Geomembranes n. 18 , pp. 1-22.

HAXO Jr., H.E.; PIERSON, P. (1996). Permeability Testing. Geosynthetics: applications, design and construction, De Groot, Den Hoedt \& Termaat (eds.) - pp. 219 - 240.

HSUAN, Y.G.; KOERNER, R.M. (1998). Antioxidant depletion lifetime in high density polyethylene geomembranes. Journal of Geotechnical and Geoenvironmental Engineering, ASCE, v. 119, n. 11, pp. 532-541.

ISO 10.722 (1998). Geotextile and geotextile - related products - Procedure for simulating damage during installation - Part 1: Installation in granular materials.

JONES, D.R.V.; SHERCLIFF, D.A.; DIXON, N. (2000). Difficulties associated with the specification of protection geotextiles using only unit weight. 2th European Geosynthetics Conference- Italian Geosynthetic Society.

KOERNER, R.M. (1998). Design with geosynthetics-4rd Edition- Prentice Hall.

KOERNER, R.M.; HSUAN, Y.G.; LORD, A.E.Jr. (1993). Stress cracking behavior of HDPE geomembranes and its prevention. Final Report to U.S. EPA Contract CR815692, Springfield, p. 94. 
KOERNER, R.M.; WILSON-FAHMY, R.F.; NAREJO, D. (1996). Puncture protection of geomembranes. Part 3: examples. Geosynthetics International, vol. 3, n. 5, pp. 655-675.

LENGEN, A.; SIEBKEN, J. (1996). Geomembrane in the United States: A brief discussion. Geosynthetics: applications, design and construction- De Groot, Den Hoedt \& Termaat (eds.)- pp. 697-704.

LAVOIE, F.L. (2006). Estudo do fissuramento sob tensão (stress cracking) em geomembranas de polietileno (PE) virgens e degradadas. Dissertação de mestrado. Escola de Engenharia de São Carlos / USP. São Carlos, SP, 157 páginas.

LODI, P. (2003). Aspectos de degradação de geomembranas poliméricas de polietileno de alta densidade (PEAD e policloreto de vinila (PVC). Tese de doutorado. Escola de Engenharia de São Carlos / USP. São Carlos, SP, 284 páginas.

LOPES (2006). Análise dos métodos de controlo de integridade de geomembranas de PEAD usadas em aterros de RSU. Revista Geotecnia, nº 106, pp. 107-131.

NAREJO, D. (1995). Three levels of geomembrane: puncture protection. Geosynthetics International, vol. 2, n. 4, pp. 765-769.

NAREJO, D.; KOERNER, R. M.; WILSON-FAHMY, R.F. (1996). Puncture protection of geomembranes. Part 2: experimental. Geosynthetics International, vol. 3, n. 5, pp. 629653.

PEGGS, I.D. (1988). Failure and remediation of a geomembrane lining system. Geotechnical Fabrics Report, 6(6), pp. 13-16.

PESQUISA NACIONAL DE SANEAMENTO BÁSICO - PNSB (2000). Comentários sobre os resultados apresentados no tema de Limpeza Urbana pelo Consultor J. $\mathbf{H}$. Penido Monteiro. J. H. Penido Monteiro, abril 2002.

REDDY, D.V.; BUTUL, B. (1999). A comprehensive literature review of liner failures and longevity. Center for Marine Structures and Geotechnique, Department of Ocean Engineering. Florida Atlantic University, 146 p.

REDDY, K.R.; BANDI, S.R.; ROHR, J.J.; FINY, M.; SIEBKEN, J. (1996). Field evaluation of protective covers for landfill geomembrana liners under construction loading. Geosynthetics International, vol. 3, n. 6, pp. 679-700. 
REDDY, K.R.; SAICHEK, R.E. (1998). A Rational Design for the Protection of Landfill Geomembrane Liners. 6th International Conference on Geosynthetics, Atlanta, Georgia, USA, pp. 289-294.

ROWE, 1998(1998). Geosynthetic and the Minimization of Contaminant Migration through Barrier Systems Beneath Solid Waste. 6th International Conference on Geosynthetics, Atlanta, Georgia, USA, pp. 279-284.

SEEGER, S.; MÜLLER, W. (1996). Requirements and testing of protective layer systems for geomembranas. Geotextiles and Geomembranes (14), pp. 365-376.

SNOW, M.; BISHOP, I.; KEENAN, R. (1999). Case history of geomembrane damage assessment. Proceedings of Geosynthetics’ 99, Boston, Massachusetts, pp. 635-644.

TOGNON (1999). Laboratory testing of geosynthetics used in landfill barrier systems. M.E.S c. thesis, Faculty of Engineering Science, University of Western Ontario, London, Ontario, Canadá.

TOGNON, A.R.; ROWE, R.K.; MOORE, I.D. (2000). Geomembrane strain observed in large-scale testing of protection layers. Journal of Geotechnical and Geoenvironmental Engineering, vol. 126, no 12, pp. 1194-1208.

VERTEMATTI, J.C. (2004). Manual Brasileiro de Geossintéticos. São Paulo, Editora Blücher.

VILAR, O. M. (2003). Geossintéticos em Aplicações Ambientais. IV Simpósio Brasileiro de Geossintéticos (Geossintéticos 2003), PUC, Porto Alegre (RS), 18 páginas (CD Rom).

WILSON-FAHMY, R.F.; NAREJO, D.; KOERNER, R. M. (1996). Puncture protection of geomembranes. Part 1: theory. Geosynthetics International, Vol. 3, No. 5, pp. 605-628.

ZANZINGER,H (1999). Efficiency of geosynthetic protection layers for geomembrana liners: performance in a large scale model test. Geosynthetics International, vol. 6, n. 4, pp. 303-317.

ZANZINGER, H; GARTUNG, E. (1998). A Rational Design for the Protection of Landfill Geomembrane Liners. 6th International Conference on Geosynthetics, Atlanta, Georgia, USA, pp. 285-288. 